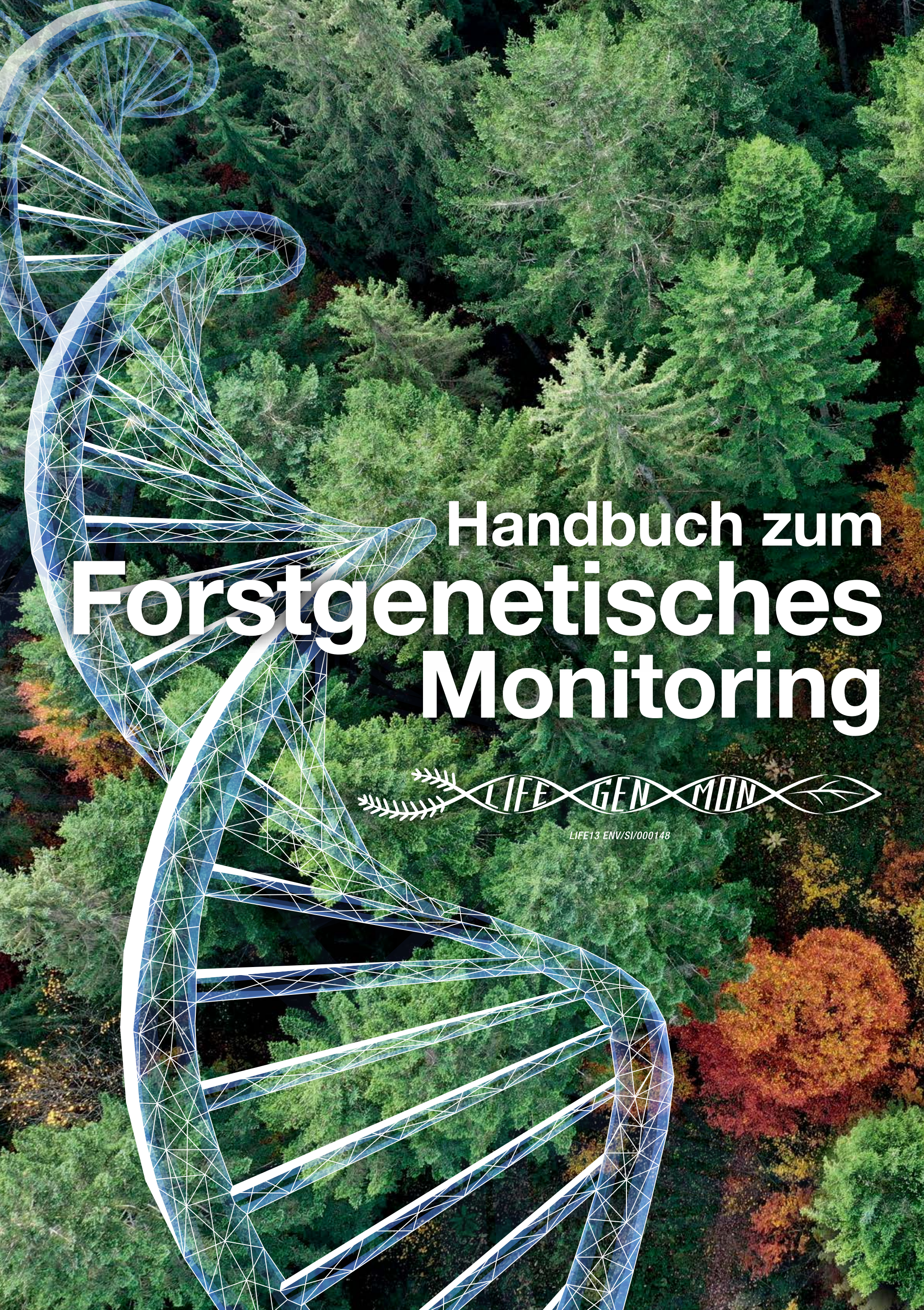





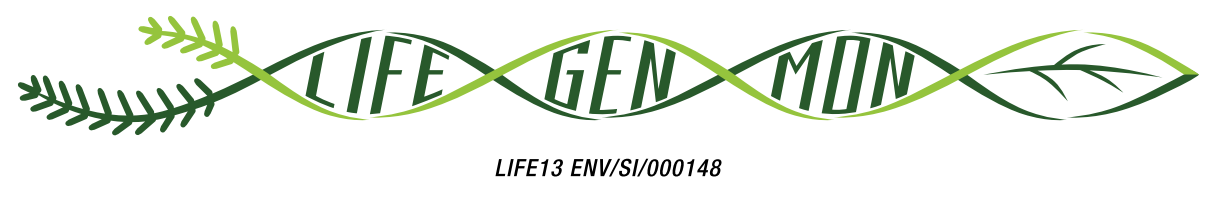

\section{Handbuch zum Forstgenetischen Monitoring}

\section{Editoren und Editorinnen}

Marko Bajc

Filippos A. Aravanopoulos

Marjana Westergren

Barbara Fussi

Darius Kavaliauskas

Paraskevi Alizoti

Fotios Kiourtsis

Hojka Kraigher 


\section{(2) \\ (13) Slovenica}

Studia Forestalia Slovenica, 172

ISSN 0353-6025

ISBN 978-961-6993-68-5 (PDF)

Herausgeber: Slowenisches Forstinstitut, Verlag Silva Slovenica, Ljubljana 2020

Titel: Handbuch zum forstgenetischen Monitoring

Editoren/Editorinnen: Marko Bajc, Filippos A. Aravanopoulos, Marjana Westergren, Barbara Fussi, Darius Kavaliauskas, Paraskevi Alizoti, Fotios Kiourtsis, Hojka Kraigher

Technische Editoren: Peter Železnik, Katja Kavčič Sonnenschein

Übersetzung: Ulrike Hagemann, Johanna von Versen (WALDKONZEPTE PartG)

Gestaltung: Boris Jurca, NEBIA, Slowenien

Ausgabe: elektronische Ausgabe

Preis: Kostenlos

Elektronische Ausgabe: http://dx.doi.org/10.20315/SFS.172

CIP - Kataložni zapis o publikaciji

Narodna in univerzitetna knjižnica, Ljubljana

ISBN 978-961-6993-68-5 (PDF)

COBISS.SI-ID 61212163 


\section{HINTERGRUNDINFORMATIONEN}

\section{GELÄNDEARBEITEN}

LABOR- UND DATENANALYSEN

KOSTEN DES FGM

8 ENTSCHEIDUNGSHILFE FÜR DIE AUSWAHL DES FGM-NIVEAUS

BAUMARTEN-LEITFÄDEN FÜR FORSTGENETISCHES MONITORING 


\section{LISTE DER MIDWIRKENDEN}

\section{EDITOREN UND EDITORINNEN}

Marko BAJC', Filippos A. ARAVANOPOULOS ${ }^{2}$, Marjana WESTERGREN', Barbara FUSSI ${ }^{3}$, Darius KAVALIAUSKAS ${ }^{3}$, Paraskevi ALIZOTI², Fotios KIOURTSIS ${ }^{4}$, Hojka KRAIGHER ${ }^{1}$

\section{AUTOREN UND AUTORINNEN}

Filippos A. ARAVANOPOULOS ${ }^{2}$, Marjana WESTERGREN ${ }^{1}$, Barbara FUSS ${ }^{3}$, Darius KAVALIAUSKAS ${ }^{3}$, Paraskevi ALIZOTI², Marko BAJC ${ }^{1}$, Fotios KIOURTSIS ${ }^{4}$, Monika KONNERT ${ }^{3}$, Evangelia V. AVRAMIDOU ${ }^{2,5}$, Dalibor BALLIAN ${ }^{1,6}$, Evangelos BARBAS ${ }^{2}$, Pavlos BEKIAROGLOU ${ }^{4}$, Sándor BORDÁCS ${ }^{7}$, Gregor BOŽlČ ${ }^{1}$, Philip BRAILEY-JONES ${ }^{1}$, Andrej BREZNIKAR ${ }^{8}$, Pavlos CHASILIDIS $^{4}$, Rok DAMJANIĆ ${ }^{1}$, Natalija DOVČ ${ }^{1}$, Anna-Maria FARSAKOGLOU ${ }^{2,9}$, Domen FINŽGAR ${ }^{1,10}$, Nikitas FRAGKISKAKIS ${ }^{4}$, loannis GANOPOULOS ${ }^{2,11}$, Berthold HEINZE'², Ermioni MALLIAROU², Georgios ROUSAKIS ${ }^{4}$, Chryse SARVANI ${ }^{4}$, Kristina SEVER ${ }^{8}$, Nataša ŠIBANC ${ }^{1}$, Nikolaos TOURVAS², Živan VESELIČ ${ }^{8}$, Zvonimir VUJNOVIĆ13 ${ }^{13}$ Peter ŽELEZNIK' ${ }^{1}$, Hojka KRAIGHER ${ }^{1}$

\section{WEITERE BEITRAGENDE}

Vlatko ANDONOVSKI ${ }^{14}$, Roland BAIER ${ }^{15}$, Mladen IVANKOVIĆ ${ }^{13}$, Davorin KAJBA ${ }^{16}$, Heino KONRAD ${ }^{12}$, Saša ORLOVIĆ ${ }^{17}$, Srđan STOJNIĆ17,

\section{EDITOR UND EDITORIN DER BOTANISCHEN ILLUSTRATIONEN}

Rok DAMJANIĆ ${ }^{1}$, Katja KAVČIČ SONNENSCHEIN ${ }^{1}$

\section{DANKSAGUNG}

Ricardo ALIA ${ }^{18}$, Tjaša BALOH ${ }^{1}$, Franc BATIČ ${ }^{19}$, Maria BELOVARSKA ${ }^{20}$, Michele BOZZANO ${ }^{9}$, Robert BRUS ${ }^{21}$, Bruno FADY ${ }^{22}$, Santiago C. GONZÁLESMARTÍNEZ $Z^{22}$, Tine GREBENC ${ }^{1}$, Melita HRENKO', Jason HUBERT ${ }^{23}$, Katja KAVČIČ-SONNENSCHEIN ${ }^{1}$, Alenka KORENJAK ${ }^{24}$, Ino-Basilia KOROMPOKI², Vasiliki-Maria KOTINA ${ }^{2}$, Tijana MARTINOVIĆ',25, Milan MATARUGA ${ }^{26}$, Tanja MRAK', László NAGY27, Despoina PAITARIDOU ${ }^{28}$, Marita PAPAGIANNI², Andrea R. PLUESS ${ }^{29}$, Boris RANTAŠA ${ }^{8}$, Mari RUSANEN ${ }^{30}$, Barbara ŠTUPAR', Urša VILHAR ${ }^{1}$, Ralph JENNER ${ }^{3}$, Susanne NOWAK ${ }^{3}$, Alwin Janßen ${ }^{3}$, Barbara Buchwinkler ${ }^{3}$, Mark Walter ${ }^{3}$, Gerti Haunedinger ${ }^{3}$, Karin Gruber ${ }^{3}$ 
Institute:

1. Slowenisches Forstinstitut (SFI), Slowenien

2. Aristoteles-Universität Thessaloniki (AUTH), Griechenland

3. Bayerisches Amt für Waldgenetik (AWG), Deutschland

4. Generaldirektion für Forst und Landwirtschaft, Dezentrale Verwaltung von Mazedonien-Thrakien, Griechenland

5. Institut für Mediterrane Waldökosysteme, ELGO DEMETER, Griechenland

6. Forstfakultät, Universität Sarajevo, Bosnien und Herzegowina

7. Szent-István-Universität, Budapest, Ungarn

8. Slowenische Forstverwaltung (SFS), Slowenien

9. Europäisches Programm für forstgenetische Ressourcen (EUFORGEN), Europäische Forstinstitut (EFI) (EFI), Spanien

10. Institut für Evolutionsbiologie, Universität von Edinburgh, Großbritannien

11. Institut für Pflanzenzüchtung und genetische Ressourcen, HAO ELGO DEMETER, Griechenland

12. Bundesforschungs- und Ausbildungszentrum für Wald, Naturgefahren und Landschaft (BFW), Österreich

13. Kroatisches Forstliches Forschungsinstitut (CFRI), Jastrebarsko, Kroatien

14. Forstfakultät, Ss. Cyril und Methodius Universität Skopje, Nord-Mazedonien

15. Nationalpark Berchtesgaden, Doktorberg 6, Berchtesgaden, 83471, Deutschland

16. Forstfakultät, Universität Zagreb, Kroatien

17. Institut für Auwaldforstwirtschaft und Umwelt (ILFE), Novi Sad, Serbien

18. Zentrum für Forstforschung, INIA, Spanien

19. Institut für Agrarwissenschaften, Biotechnologische Fakultät, Universität Ljubljana, Slowenien

20. Ausführende Forstagentur, Ministerium für Landwirtschaft und Ernährung, Sofia, Bulgarien

21. Ministerium für Forstwirtschaft und erneuerbare Waldressourcen, Biotechnische Fakultät, Universität Ljubljana, Slowenien

22. Nationales französisches Forschungsinstitut für Landwirtschaft, Ernährung und Umwelt (INRAe), Frankreich

23. Schottische Forstbehörde, Großbritannien

24. Ministerium für Landwirtschaft, Forst und Ernährung, Slowenien

25. Insitut für Umwelt-Mikrobiologie, Tschechische Akademie der Wissenschaften, Tschechische Republik

26. Forstfakultät, Universität Banja Luka, Rep. Srpska, BiH

27. Ungarisches Forstforschungsinsitut (ERTI), Ungarn

28. Griechisches Ministerium für Umwelt und Energie

29. Eidgenössische Forschungsanstalt für Wald, Schnee und Landschaft (WSL), Schweiz

30. Institut für natürliche Ressourcen (Luke), Finnland 
2.1 ANZAHL DER MONITORINGFLÄCHEN PRO BAUMART

\section{EINRICHTUNG UND INSTANDHALTUNG DER} MONITORINGFLÄCHEN

3.1 EINLEITUNG

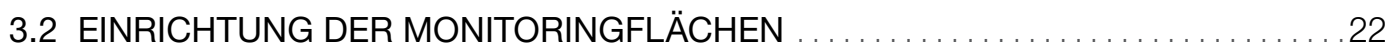

3.2.1 Bestandsbildende Baumarten . . . . . . . . . . . . . . . . . . . . . . . . . . . . . . . . 24

3.2.2 Nicht-bestandesbildende Arten. . . . . . . . . . . . . . . . . . . . . . . . . . . . . 26

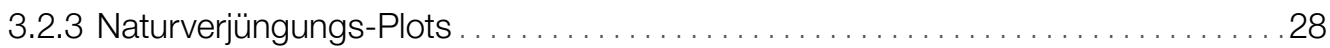

3.3 KENNZEICHNUNG, GEOREFERENZIERUNG, AUSSENAUFNAHMEN

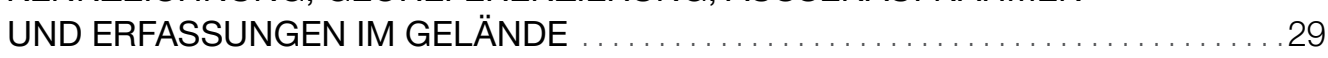

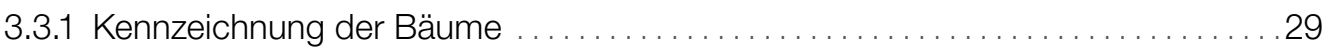

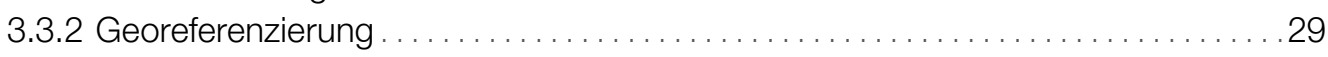

3.4 BESCHREIBUNG DER FGM-FLÄCHE (MITTELS STANDARDISIERTER

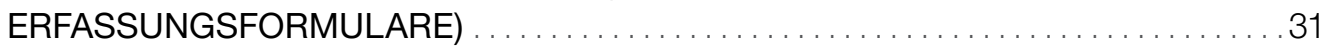

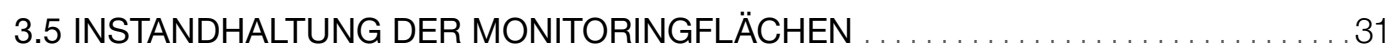

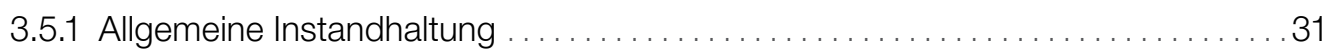

3.5.2 Ersatz von Beobachtungsbäumen..................................... 31

3.5.3 Längerfristige Instandhaltung der FGM-Fläche: . . . . . . . . . . . . . . . . . . 32

3.6 ERFASSUNG METEOROLOGISCHER DATEN $\ldots \ldots \ldots \ldots \ldots \ldots \ldots \ldots \ldots \ldots \ldots \ldots \ldots \ldots \ldots$

\section{INDIKATOREN, VERIFIKATOREN UND} HINTERGRUNDINFORMATIONEN

4.1 DEFINITION VON INDIKATOREN UND VERIFIKATOREN/ HINTERGRUNDINFORMATIONEN

4.2 AUSWAHL VON INDIKATOREN UND VERIFIKATOREN/

HINTERGRUNDINFORMATIONEN

4.3 BESCHREIBUNG DER INDIKATOREN UND VERIFIKATOREN/

HINTERGRUNDINFORMATIONEN 


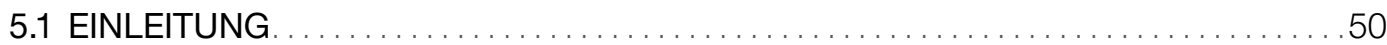

5.2 IM GELÄNDE ERFASSTE VERIFIKATOREN

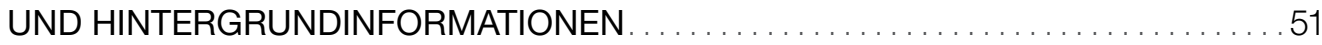

5.2 .1 Verifikator: Mortalität/ Überlebensrate. .............................. 52

5.2 .2 Verifikator: Abundanz der Naturverjüngung . . . . . . . . . . . . . . . . . . . 52

5.2.3 Hintergrundinformation: Durchmesserklassenverteilung . . . . . . . . . . . . 53

5.2.4 Hintergrundinformation: Höhenklassenverteilung ................... 53

5.3 PHÄNOLOGISCHE BEOBACHTUNGEN . . . . . . . . . . . . . . . . . . . . . . . . 54

5.3 .1 Einführung in die Phänologie . ................................. 54

5.3.2 Phänologische Verifikatoren und Hintergrundinformationen . . . . . . . . . . . . . . . . 54

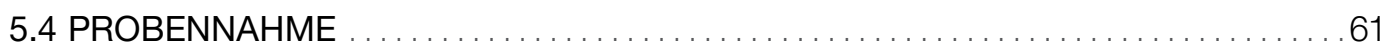

5.3.1 Probenahmeverfahren für die DNA-Analyse . . . . . . . . . . . . . . . . . . . . . . 61

LABOR- UND DATENANALYSEN

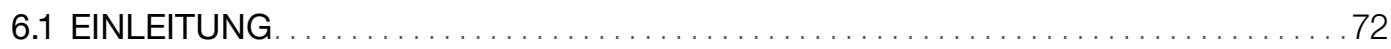

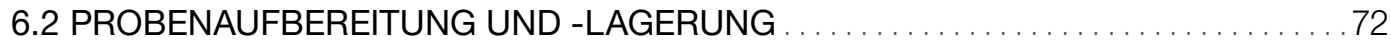

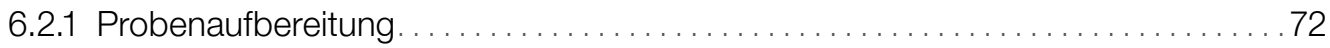

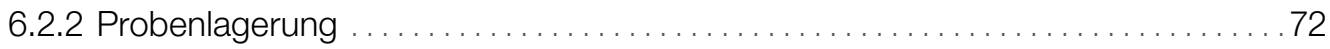

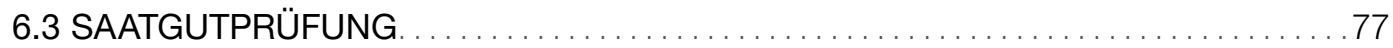

6.3.1 Gewinnung von Abies alba-Saatgut für die Saatgutprüfung . . . . . . . . 78

6.3.2 Vorbereitung von Fagus sylvatica- und Abies alba/A. borisii-regis-

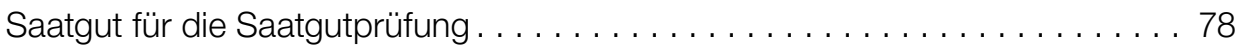

6.3.3 Biochemischer Test auf Lebensfähigkeit -

Der topografische Tetrazolium-Test (TT) . ......................... 83

6.4 DNA-ANALYSEN . . . . . . . . . . . . . . . . . . . . . . . . . . . . . . . . . . 86

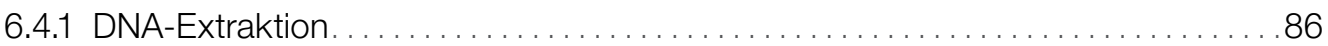

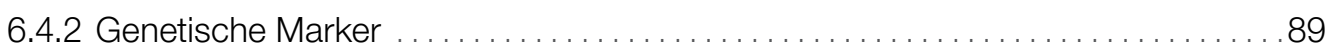

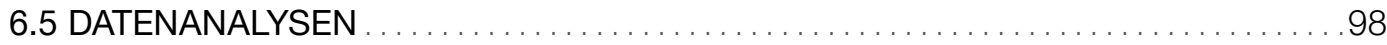

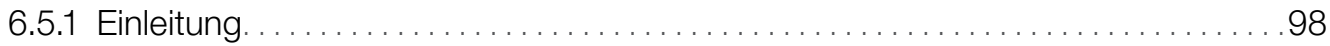

6.5.2 Datenbank ................................................. 98

6.5.3 Auswertung der im Bestand erhobenen Daten ....................... 100

6.5.4 Auswertung molekularer Daten ................................. 107

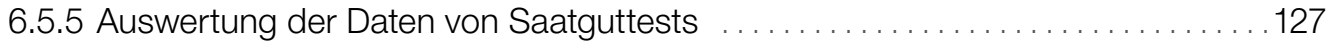

6.5.6 Schlüsselverifikatoren ...................................... 128

6.5.7 Interpretation von Werten: schrittweise Reaktion
auf Veränderungen innerhalb von 10 Jahren .......................... 129

KOSTEN DES FGM

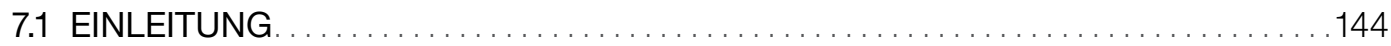

7.2 KOSTENSCHÄTZUNG . . . . . . . . . . . . . . . . . . . . . . . . . . . . . . 144

7.2.1 Annahmen zur Kostenschätzung . . . . . . . . . . . . . . . . . . . . . . . . . . . . 144

7.2 .2 Kostenschätzung ............................................ 147

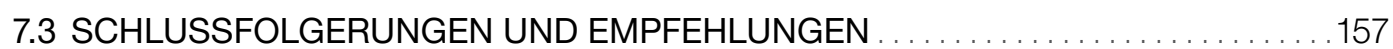


ENTSCHEIDUNGSHILFE FÜR DIE AUSWAHL DES FGMNIVEAUS

8.1 EINFÜHRUNG UND ZIELSTELLUNG $\ldots \ldots \ldots \ldots \ldots \ldots \ldots \ldots \ldots \ldots \ldots \ldots \ldots \ldots \ldots$

8.2 FRAGEN, DIE MITTELS FGM BEANTWORTET WERDEN KÖNNEN . . . . . . . . 162

8.3 KOSTEN DES FORSTGENETISCHEN MONITORINGS . . . . . . . . . . 163

8.4 INFORMATIONSWERT DER FGM-VERIFIKATOREN . . . . . . . . . . . . . . 166

8.5 FGM-INDIZIERTE BEWIRTSCHAFTUNGSMASSNAHMEN . . . . . . . . 166

8.6 BOTSCHAFTEN FÜR POLITISCHE ENTSCHEIDUNGSTRÄGER . . . . . . . . . . 166

\section{BAUMARTEN-LEITFÄDEN FÜR FORSTGENETISCHES} MONITORING

9.1 EINLEITUNG

9.2 LEITFADEN FÜR DAS GENETISCHE MONITORING DER

9.2.1 Weißtanne (Abies alba Mill.) and

König-Boris-Tanne (Abies borisii-regis Mattf.).

9.2.2 Rotbuche (Fagus sylvatica L.)

9.2.3 Gemeinen Esche (Fraxinus excelsior L.)

9.2.4 Europäischen Schwarzkiefer (Pinus nigra J. F. Arnold)

9.2.5 Schwarz-Pappel (Populus nigra L.)

9.2.6 Vogelkirsche (Prunus avium (L.) L.)

9.2.7 Stieleiche (Quercus robur L.) and

Traubeneiche (Quercus petraea (Matt.) Liebl.) 


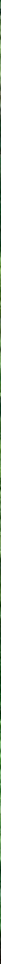

\section{VORWORT}

Das Handbuch zum forstgenetischen Monitoring ist das wichtigse Ergebnis des LIFEGENMON-Projekts. Ein Konsortium von Wissenschaftlerlnnen und Forstpraktikerlnnenn, das von sechs Organisationen geleitet wurde und an dem mehr als 50 Forscherlnnen aus Mittel- und Südosteuropa beteiligt waren, trug zu diesem Projekt bei. Es unterstützt den Schutz der genetischen Ressourcen des Waldes, die Widerstandsfähigkeit der Waldökosysteme, eine nachhaltige Waldbewirtschaftung, die Überwachung des Klimawandels und damit verbundene politische Prozesse. Dieses Handbuch basiert auf vorhandenem wissenschaftlichem Wissen und im Rahmen des LIFEGENMON-Projekts generiertes und getestetes Wissen, und enthält spezifische wissenschaftliche Verfahren für die Umsetzung von FGM in ganz Europa sowie praxisorientierte politische Empfehlungen. Die integrierte Entscheidungshilfe kann angewendet werden, um auf der Grundlage der nationalen Bedürfnisse und Mittel zu entscheiden, auf welcher Ebene FGM umgesetzt werden soll, und um die internationalen Bemühungen zur Umsetzung von FGM zu unterstützen.

Das LIFEGENMON-Konsortium hat sich mit den oben genannten Komponenten befasst und ist bestrebt, den künftigen Erhalt des Waldes auf verschiedenen Ebenen zu beeinflussen, von den Genen bis zum Ökosystem, von lokal bis global. Ziel dieses Handbuchs ist es, die Implementierung von FGM in der Forstpraxis zu unterstützen und das Verständnis für die Bedeutung von FGM für die multifunktionale Waldbewirtschaftung zu verbessern. 


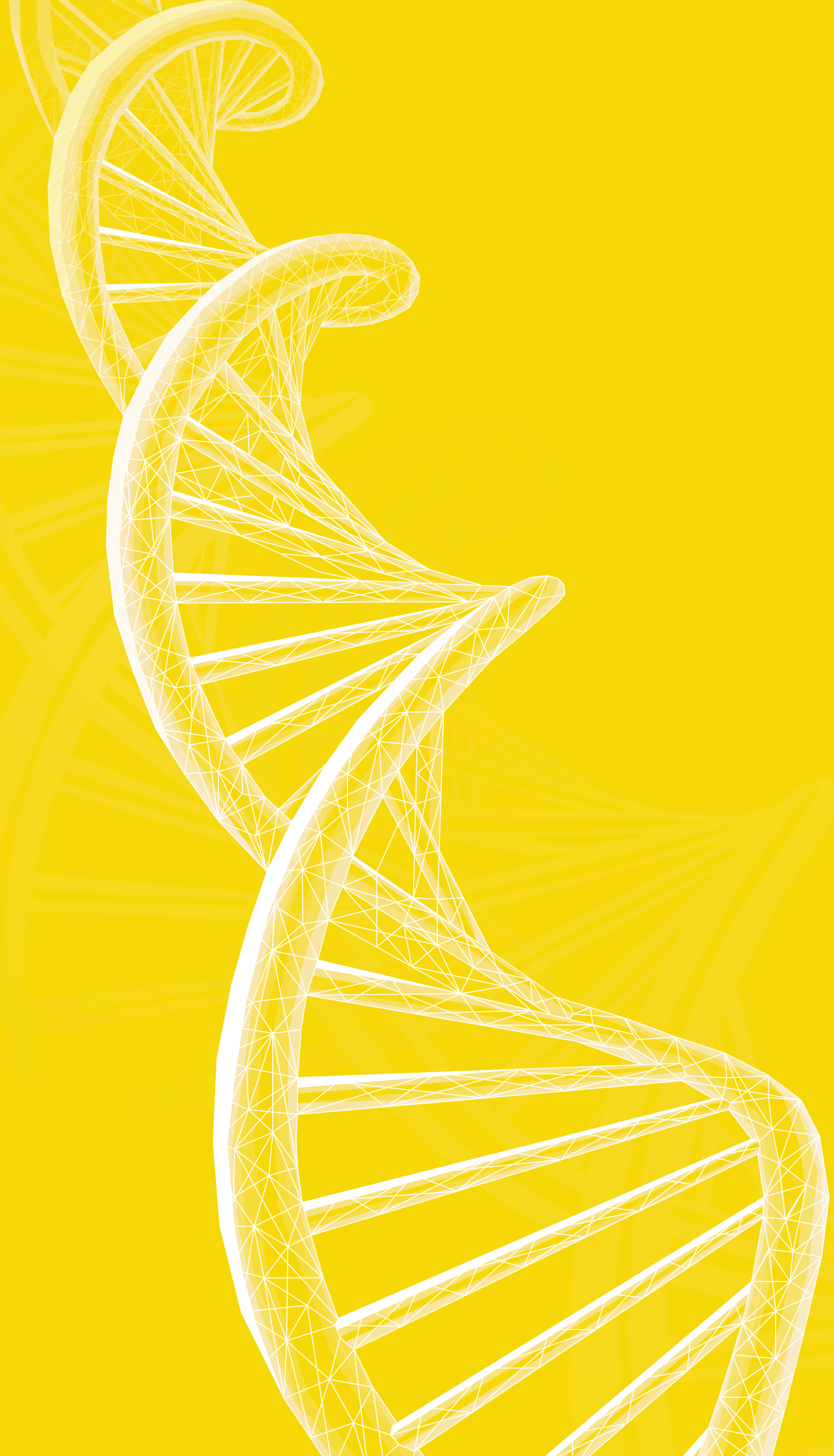




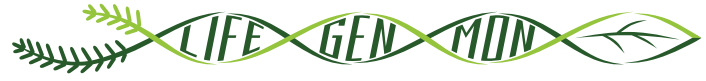 \\ LIFE13 ENV/S/ $/ 000148$}

\section{Handbuch zum Forstgenetisches Monitoring}
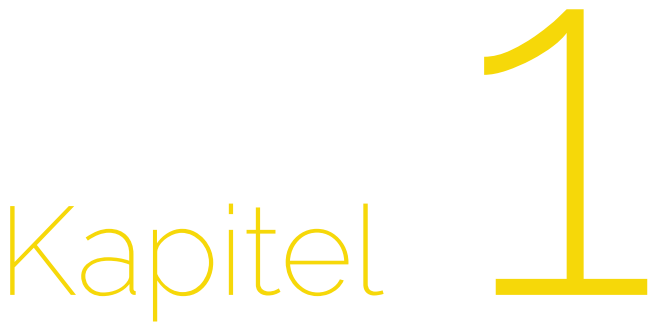

\section{EINLEITUNG}

Filippos A. ARAVANOPOULOS ${ }^{1}$, Marko BAJC², Barbara FUSSI ${ }^{3}$, Hojka KRAIGHER ${ }^{2}$

Zitat: Aaravanopoulos et al. (2020) Einleitung. In: Bajc et al. (Ed.) Handbuch zum forstgenetischen Monitoring. Slowenisches Forstinstitut: Verlag Silva Slovenica, Ljubljana, S. 11-14. http://dx.doi.org/10.20315/SFS.176

1. Aristoteles-Universität Thessaloniki (AUTh), Griechenland

2. Slowenisches Forstinstitut (SFI), Slowenien

3. Bayerisches Amt für Waldgenetik (AWG), Deutschland 
Aaravanopoulos et al. (2020) Introduction. In: Bajc et al. (eds) Manual for Forest Genetic Monitoring. Slovenian Forestry Institute: Silva Slovenica Publishing Centre, Ljubljana, pp 9-12. http://dx.doi.org/10.20315/SFS.167

Der rasch fortschreitende Klimawandel stellt für langlebige Waldbäume, für Waldökosysteme und deren Biodiversität eine zunehmende Bedrohung dar. Die genetische Diversität ist die ultimative Quelle biologischer Vielfalt und damit essentiell für die Vitalität von Wäldern und deren Anpassung an den Klimawandel. Sie ist außerdem Grundlage für die Widerstandsfähigkeit von Wäldern gegenüber anderen Stressfaktoren, wie z. B. Schädlingen und Krankheiten.

Das Übereinkommen über die biologische Vielfalt (Convention on Biological Diversity; CBD) ist das seit 1992 umfassendste internationale Abkommen mit dem Ziel der weltweiten Erhaltung der biologischen und genetischen Vielfalt. Artikel 7 der CBD fordert explizit Maßnahmen zum „Monitoring von Elementen der biologischen Vielfalt mit Hilfe von Probenahmen und anderen Verfahren" (CBD, 1993). Die Notwendigkeit des Monitorings der biologischen Vielfalt führte zur Entwicklung globaler Biodiversitätsindikatoren (Graudal et al. 2015), die sich auch in den anschließend formulierten Aichi-Biodiversitätszielen widerspiegeln (Aichi Biodiversity Targets; $\mathrm{CBD}, 2010)$. Weitere internationale und regionale Prozesse haben die Festlegung von Kriterien und Indikatoren für die Bewertung der genetischen Vielfalt und forstlicher Genressourcen (FGR) gefordert (z. B. der Forest EuropeProzess, die EU-Forststrategie, das EU-Programm zur Entwicklung des Ländlichen Raumes, die EU-Richtlinie über pflanzliches Vermehrungsgut und die EU-Verordnung über invasive gebietsfremde Arten) (siehe Bouillon et al., 2014)).

Genetische Aspekte sollten daher bei der Beobachtung der Auswirkungen des Klimawandels auf Waldökosysteme ebenso berücksichtigt werden wie bei der Bewirtschaftung bestehender und der Etablierung neuer Wälder, insbesondere jedoch bei der Auswahl und Produktion von Saatgut und anderem Vermehrungsmaterial zum Zweck der Wiederaufforstung und Renaturierung (ebd.).

Es ist das Ziel des forstgenetischen Monitorings (FGM), den aktuellen Zustand der genetischen Ressourcen zu erfassen und relevante Entwicklungen im Zeitverlauf zu quantifizieren, um das langfristige adaptive evolutionäre Potenzial zu erhalten. Durch die Beobachtung zeitlicher Veränderungen in Populationen können kausale Faktoren abgeleitet und deren relative Bedeutung bewertet werden. Das FGM ist daher ein prognostisches Werkzeug und bildet eine Methode zur Aufrechterhaltung von Prozessen, die die genetische Diversität in natürlichen Populationen sichern (Aravanopoulos 2011). Es kann frühzeitig eine potenziell nachteilige Entwicklung der Anpassungsfähigkeit von Wäldern identifizieren, bevor diese auf höheren Biodiversitätsebenen (z. B. Arten- oder Ökosystemdiversität) sichtbar werden, und somit die Nachhaltigkeit von Waldbewirtschaftungsmaßnahmen verbessern und zukünftige Forschungsaktivitäten steuern.

Die beim FGM zu berücksichtigenden grundlegenden Prinzipien wurden vom Europäischen Programm für forstgenetische Ressourcen (European Forest Genetic Resources Programme; EUFORGEN) festgelegt (Aravanopoulos et al. 2015). Dieses trägt kontinuierlich zur paneuropäischen Strategie für die Erhaltung von FGR bei (De Vries et al. 2014) und unterstützt die Umsetzung eines paneuropäischen FGM-Programms als eines der operativen Ziele des Aktionsplans für Phase VI (2020-2024) (EUFORGEN 2019).

Eine primäre Voraussetzung für die Umsetzung des FGM ist die Abgrenzung von Monitoring-Regionen, d. h. von Regionen, in denen forstgenetisches Monitoring durchgeführt werden sollte, um maximale Wirkung zu erzielen. Dies wurde durch einen kombinierten daten- und expertenbasierten Ansatz vorangetrieben und im LIFEGENMON-Projekt (LIFE ENV/SI/000148; 2014-2020; http://www.lifegenmon.si/) entlang eines Transekts

\footnotetext{
Die Ernährungs- und Landwirtschaftsorganisation der Vereinten Nationen (Food and Agriculture Organisation of the United Nations; FAO) stellt fest, dass „forstgenetische Ressourcen (FGR) das vererbbare genetische Material sind, welches innerhalb und zwischen Baum- und anderen holzigen Pflanzenarten erhalten wird ... und die von tatsächlichem oder potenziellem wirtschaftlichen, ökologischen, wissenschaftlichen oder gesellschaftlichen Wert sind. Sie sind entscheidend für die Anpassung und den Schutz unserer Ökosysteme, Landschaften und Produktionssysteme, unterliegen jedoch zunehmendem Druck und einer nicht nachhaltigen Nutzung" (übersetzt aus dem Englischen; http://www.fao.org/ forest-genetic-resources/background/en/).
} 
durchgeführt, der von den Bayerischen Alpen in Deutschland bis zum Olymp in Griechenland reicht und insgesamt neun Länder sowie sieben Baumarten bzw. Artengruppen mit unterschiedlicher Biologie und Verbreitung umfasst.

Das im LIFEGENMON-Projekt entwickelte forstgenetische Monitoring arbeitet mit einem wissenschaftlich fundierten System, das ein Minimum an konzeptionellen Ansätzen und Parametern berücksichtigt, die ein Maximum genetischer Informationen erbringen (Aravanopoulos 2016, Fussi 2016). Diese werden durch die Verwendung von Indikatoren und Verifikatoren konkretisiert. Ein Indikator bezieht sich auf einen Ökosystemaren Bestandteil oder Prozess, aus dem auf die Nachhaltigkeit der entsprechenden Ressource geschlossen werden kann (Aravanopoulos et al. 2015).

Ein Indikator wird in der Regel auf einer zeitlichen Basis erfasst, um eine Zielerreichung oder Veränderung in Bezug auf das zugehörige Kriterium abzubilden. Er muss direkt messbar sein, und die zur Messung eines Indikators eingesetzte Metrik wird als Verifikator bezeichnet. Dementsprechend handelt es sich bei Verifikatoren um Daten, mit denen die Spezifizität eines Indikators verbessert oder dessen Bewertung erleichtert wird. Damit ist ein Verifikator praktisch ein Maß für einen Indikator (Aravanopoulos et al. 2015). Das vorliegende Handbuch schlägt vor, dass FGM für die drei Indikatoren "Selektion", "genetische Variation" und "Genfluss/ Paarungssystem“ anhand von insgesamt 15 Verifikatoren durchzuführen. Der Indikator „Selektion“ wird durch demografische Verifikatoren bewertet, die sich auf vor Ort im Bestand erhobene Daten beziehen. Informationen zur "genetischen Variation“ werden mit Hilfe genetischer Marker an Proben von Altbäumen und Verjüngung gewonnen. Auch der "Genfluss“ wird anhand von genetischen Markern beurteilt und zwar durch die Beprobung von Saatgut, das offen bestäubte Pflanzenfamilien darstellt.

Es werden drei Optionen bzw. Niveaus für das forstgenetische Monitoring vorgeschlagen: Basis, Standard und Intensiv. Die erste Option (Basisniveau) verwendet demografische Daten zur Bewertung des Indikators „Selektion“. Die zweite (Standardniveau) nutzt demografische und genetische Daten, um zusätzlich zur Selektion auch die genetische Variation zu beurteilen. Die dritte Option (Intensivniveau) verwendet schließlich ergänzend Daten offen bestäubter Pflanzenfamilien (Saatgut), um die Selektion und genetische Variation, den Genfluss und die Paarungssysteme genauer zu bewerten (Aravanopoulos et al. 2015).

Aus den folgenden vier Gründen gibt es zunehmend internationale Bemühungen, um langfristige politische Verpflichtungen für die Umsetzung des FGM zu erwirken: (a) Machbarkeitsstudien haben gezeigt, dass FGM erfolgreich eingesetzt werden kann; (b) FGM kann wertvolle Einblicke in den zukünftigen Zustand der genetischen Vielfalt und des Überlebens von Populationen liefern, insbesondere da etliche genetisch bedeutsame Waldbaumpopulationen (z.B. marginale, seltene oder gefährdete) unterhalb einer kritischen effektiven Populationsgröße liegen; (c) FGM ist ein langwieriger Prozess und erfordert regelmäßige Auswertungen, um wichtige Signale zuverlässig erkennen und interpretieren zu können; und (d) die Kostenspanne des FGM reicht von gering (Basisniveau) bis hoch (Intensivniveau).

Im Rahmen des LIFEGENMON-Projekts wurden dieses FGM-Handbuch und die darin enthaltenen Baumarten-Leitfäden entwickelt - mit denen verschiedene Monitoringintensitäten auf unterschiedlichen Kostenniveaus umgesetzt werden können. Die Entscheidungshilfe (Decision Support System; DSS) wurde entwickelt, um politische Entscheidungsträger bei der Auswahl des optimalen FGM-Niveaus unter Berücksichtigung von Kosten und Nutzen zu unterstützen. Zusätzlich liefert das DSS Empfehlungen für die Umsetzung von Maßnahmen zur Erhaltung und nachhaltigen Nutzung von FGR unter sich verändernden klimatischen Bedingungen.

Das im LIFEGENMON-Projekt implementierte FGM-System basiert auf soliden theoretischen Prinzipien des genetischen Monitorings. Die Autoren dieses Dokuments erkennen dennoch an, dass nicht alle Aspekte des FGM während der Projektlaufzeit umfänglich getestet werden konnten. Als langfristiges Vorhaben kann das FGM sein volles Potenzial erst dann erreichen, wenn eine ausreichende Anzahl zeitlicher Erhebungen durchgeführt worden ist. Wie jedes analytische System ist auch das vorgeschlagene FGM-System kontinuierlich zu evaluieren, um zu überprüfen, ob die angestrebten Monitoringziele erreicht werden, und das System ggf. zu verbessern oder neu zu konzipieren (Fussi et al. 2016). 
Zukünftig wird sich das FGM wahrscheinlich vom genetischen zum genomischen Monitoring weiterentwickeln. Dadurch werden die Schätzungen der genetischen Diversität von Populationen und des adaptiven genetischen Potenzials vermutlich präziser. Da die epigenetische Variation offenbar viele der an der lokalen Anpassung beteiligten phänotypischen Merkmale beeinflusst, könnte epigenomisches Monitoring zukünftig eine weitere Option darstellen. Auf einer übergeordneten Ebene wird das FGM in Zukunft zweifellos von der Integration von Daten profitieren, die nicht nur aus der Beobachtung genetischer Parameter stammen, sondern auch klimatische, edaphische, physiologische und populationsbezogene Parameter betreffen. Diesbezüglich werden innovative GIS-, Fernerkundungs- und Data-Mining-Technologien von großer Bedeutung für das FGM sein.

Dieses Handbuch stell die Grundlagen und die Anwendung des FGM auf den oben genannten Niveaus detailliert vor. Es wurde mit dem Anspruch verfasst, ein primäres Referenzdokument für die Anwendung des forstgenetischen Monitorings in europäischen Wäldern und darüber hinaus zu sein, und die Voraussetzungen für eine vollständige Implementierung des FGM als Beitrag zur Erhaltung forstgenetischer Ressourcen und der nachhaltigen Bewirtschaftung von Wäldern zu schaffen.

\section{Quellen}

Aravanopoulos FA (2011) Genetic monitoring in natural perennial plant populations. Botany 89:75-81. https://doi. org/10.1139/b10-087

Aravanopoulos FA (2016) Conservation and monitoring of tree genetic resources in temperate forests. Current Forestry Reports 2:119-129. https://doi.org/10.1007/s40725-016-0038-8

Aravanopoulos FA, Tollefsrud MM, Graudal L, Koskela J, Katzel R, Soto A, Nagy L, Pilipovic A, Zhelev P, Bozic G \& Bozzano M (2015) Development of genetic monitoring methods for genetic conservation units of forest trees in Europe. European Forest Genetic Resources Programme (EUFORGEN), Bioversity International, Rome, Italy, 62 pp.

Bouillon P, Hubert J, Bakkebo Fjellstad K, Rusanen M, Zavrl Bogataj A, Olrik DC, Bordács S, Longauer R, Paitaridou D, Koiv K, Koskela J, Orlovic S, Black-Samuelsson S, Wolter F (2015) The implications of global, European and national policies for the conservation and use of forest genetic resources in Europe. European Forest Genetic Resources Programme (EUFORGEN), Bioversity International, Rome, Italy, 42 pp.

Convention on Biological Diversity (2010) Strategic Plan for Biodiversity 2011-2020,including Aichi Biodiversity Targets. https://www.cbd.int/sp/ Accessed 03 December 2020

de Vries SMG, Alan M, Bozzano M, Buriánek V, Collin E, Cottrell J, Ivankovic M, Kelleher C, Koskela J, Rotach P, Vietto L, Yrjänä L (2015) Pan-European strategy for genetic conservation of forest trees and establishment of a core network of dynamic conservation units. European Forest Genetic Resources Programme (EUFORGEN), Bioversity International, Rome, Italy, $40 \mathrm{pp}$.

EUFORGEN (2019) Strategic objectives and implementation plan for Phase VI (2020-2024). http://www.euforgen.org/ fileadmin/templates/euforgen.org/upload/Documents/EUFORGEN_PhaseVI_Objectives_and_Plan.pdf Accessed 08 December 2020

Food and Agriculture Organisation of the United Nations. Forest Genetic Resources. http://www.fao.org/forest-geneticresources/background/en/ Accessed 03 December 2020

Fussi B, Westergren M, Aravanopoulos F, Baier R, Kavaliauskas D, Finzgar D, Alizoti P, Bozic, G, Avramidoul E, Konnert M, Kraigher H (2016) Forest genetic monitoring: an overview of concepts and definitions. Environmental Monitoring and Assessment 188(8):493. https://doi.org/10.1007/s10661-016-5489-7

Graudal L, Aravanopoulos FA, Bennadji Z, Changtragoon S, Fady B, Kjaer ED, Loo J, Ramamonjisoa L, Vendramin GG (2014) Global to local genetic diversity indicators of evolutionary potential in tree species within and outside forests. For Ecol Manag 333:35-51. https://doi.org/10.1016/j.foreco.2014.05.002 



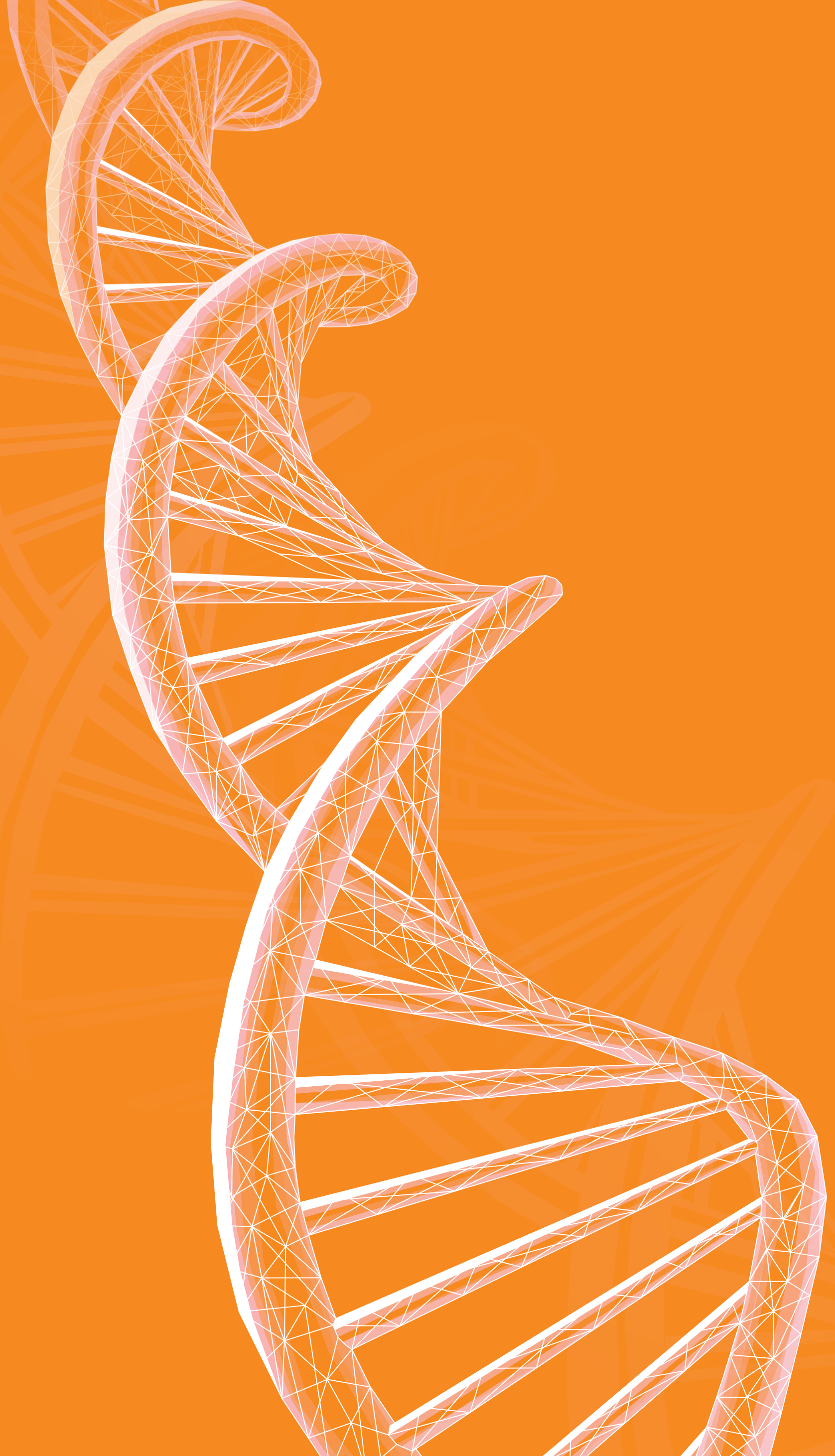




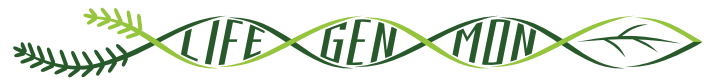 \\ LIFE13 ENV/S/ $/ 000148$}

\section{Handbuch zum Forstgenetisches Monitoring}
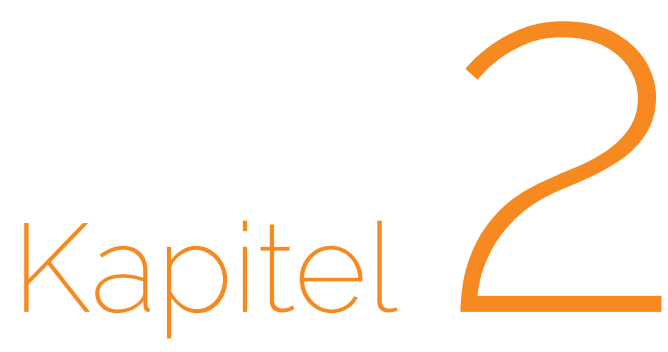

\section{AUSWAHL DER MONITORINGFLÄCHEN}

Hojka KRAIGHER', Marjana WESTERGREN ${ }^{1}$, Filippos A. ARAVANOPOULOS², Barbara FUSSI ${ }^{3}$, Marko BAJC', Dalibor BALLIAN ${ }^{114}$, Gregor BOŽIČ ${ }^{1}$, Domen FINŽGAR ${ }^{1,5}$, Darius KAVALIAUSKAS ${ }^{3}$, Fotios KIOURTSIS ${ }^{6}$, Monika KONNERT ${ }^{3}$, Živan VESELIČ7

Zitat: Kraigher et al. (2020) Auswahl der Monitoringflächen. In: Bajc et al. (Ed.) Handbuch zum forstgenetischen Monitoring. Slowenisches Forstinstitut: Verlag Silva Slovenica, Ljubljana, S. 17-19. http://dx.doi.org/10.20315/SFS.176

Institut:

1. Slowenisches Forstinstitut (SFI), Slowenien

2. Aristoteles-Universität Thessaloniki (AUTh), Griechenland

3. Bayerisches Amt für Waldgenetik (AWG), Deutschland

4. Forstfakultät, Universität Sarajevo, Bosnien und Herzegowina

5. Institut für Evolutionäre Biologie, Universität von Edinburgh, Großbritannien

6. Generaldirektion für Forst und Landwirtschaft, Dezentrale Verwaltung von MazedonienThrakien, Griechenland

7. Slowenische Forstverwaltung (SFS), Slowenien 


\subsection{ANZAHL DER MONITORINGFLÄCHEN PRO BAUMART}

Es wird empfohlen, pro Monitoring-Region mindestens eine (1) Fläche für das forstgenetische Monitoring (FGM) einzurichten, wobei die Monitoring-Regionen je Art oder Artenzusammensetzung abgegrenzt werden (siehe Anhang 10.1: Beschreibung der Abgrenzung und Karten der Monitoring-Regionen). Wenn Nachbarländer gemeinsame Monitoring-Regionen haben, kann durch internationale Zusammenarbeit die Gesamtzahl der FGM-Flächen über die Ländergrenzen hinweg soweit reduziert werden, dass jede Monitoring-Region durch eine FGM-Fläche repräsentiert wird.

Die Monitoring-Regionen sollten auf Grundlage folgender Kriterien ausgewiesen werden:

1. repräsentative Abdeckung der Vegetationszonen (siehe Anhang 10.1);

2. Erfassung beschriebener (Unter-)Arten oder Ökotypen unter Einbeziehung von unbedeutenden oder peripheren Populationen und unter Berücksichtigung von sowohl geographischen (Breiten-, Längengrad) und ökologischen Verbreitungsgrenzen im gesamten Verbreitungsgebiet der Art (Kerngebiet, Randbereiche),

3. Prüfung der Verteilung der EUFORGEN-Generhaltungseinheiten (EUFORGEN, http://portal.eufgis.org/), so dass jede genetische Monitoring-Region mindestens eine Generhaltungseinheit als genetische Monitoringeinheit umfasst, wenn die entsprechenden Voraussetzungen erfülltsind (siehe2.3Auswahlkriterienfür Monitoringflächen);

4. bestehende genetische Struktur und Variation auf Grundlage der Ergebnisse der Genmarker-Forschung,

5. Ergebnisse von Provenienzversuchen soweit verfügbar und relevant, und

6. Expertenwissen aus den einzelnen Ländern, zur Feinabstimmung der Lage der abgegrenzten Monitoring-Regionen hinsichtlich der repräsentierten Waldtypen, ihrer Vitalität, Biodiversität und ihres ökonomischen Wertes.

7. Für den Fall, dass nur unklare oder unvollständige Ergebnisse vorliegen, war die Meinung von Experten der final ausschlaggebende Faktor. Siehe Anhang 10.1 für die Monitoring-Regionen entlang des Transekts von Bayern nach Griechenland für Fagus sylvatica, Abies alba/A. borisii regis, Fraxinus excelsior, Populus nigra, Pinus nigra, Prunus avium und Quercus robur/Q. petraea.

\subsection{ANZAHL DER PROBEBÄUME PRO MONITORINGFLÄCHE}

Pro Fläche müssen für das FGM mindestens fünfzig (50) sich fortpflanzende Altbäume ausgewählt werden. In seltenen Fällen und nur bei einzelbaumweise eingemischten, verstreuten Baumarten, kann die Anzahl auf 30 Bäume reduziert werden (siehe Kapitel 3: Anlage und Instandhaltung der Monitoringflächen).

\subsection{KRITERIEN FÜR DIE AUSWAHL DER MONITORINGFLÄCHEN}

Die Kriterien 1 bis 4 basieren aufdenEUFGIS-Mindestanforderungen fürdynamischeErhaltungseinheiten von Waldbäumen (siehe http://portal.eufgis.org/fileadmin/templates/eufgis.org/documents/EUFGIS_Minimum_requirements.pdf)

1. Die Erhaltungseinheiten sollten einen ausgewiesenen Status haben (z.B. Generhaltungsobjekt, zertifizierter Saatgutbestand, Schutzgebiet etc.);

2. Das ausgewiesene Management für das Gebiet kann "Naturschutz", "multifunktionale Forstwirtschaft" oder andere Formen der Bewirtschaftung sein, solange sie die langfristige Lebensfähigkeit der Zielbaumpopulation erhält. Jede Art von Kahlschlag bei der aktuellen und zukünftigen Bewirtschaftung muss unbedingt ausgeschlossen werden, um nicht das von den Umweltveränderungen ausgehende Signal für mikroevolutionäre Prozesse zu überlagern.

3. Die Mindestgröße und -form der FGM-Fläche hängt von der Biologie der Zielbaumarten ab (siehe Kapitel 3: Anlage und Instandhaltung der Versuchsflächen), muss aber in jedem Fall innerhalb einer lebensfähigen Population 
eingerichtet werden (d.h. mindestens 50 sich fortpflanzende Bäume; in besonderen Fällen, wie z.B. beim Monitoring der Stabilisierung einer gefährdeten Population, ist eine geringere Anzahl fortpflanzungsfähiger Bäume akzeptabel).

4. Mindestens eine Baumart im Bestand sollte als Zielart für das FGM bestimmt werden. Wenn der Fokus des FGM auf der Hybridisierung liegt, muss das Gebiet, in dem sich die Monitoringfläche befindet, eine ausreichende Anzahl vermeintlicher Hybriden enthalten. Die Anlage von "Schwesterflächen" auch für artenreine Individuen in derselben Monitoring-Region ist in diesem Fall empfehlenswert.

5. Folgende Bestandesmerkmale sind für das FGM von besonderer Bedeutung, da sie Grundlage für die Bewertung der ökologischen Anpassung der Population an den Standort sind: sich fortpflanzende Altbäume, Vorhandensein und Überleben von Naturverjüngung (falls aufgrund des Alters des Waldbestandes zu erwarten), sexuelle und/oder vegetative Fortpflanzung.

6. Verfügbarkeit von genetischen Daten im gleichen oder einem nahegelegenen Bestand. Je nach genetischer Variation im Bestand kann dieser für das genetische Monitoring geeignet sein oder ausscheiden.

7. Vermeidung von Steillagen oder anderen topographischen Merkmalen, die den Genfluss innerhalb der Monitoringfläche beeinflussen könnten. Dieses Kriterium gilt nicht für Populationen am oberen Rand der Baumgrenze oder andere Sonderfälle, in denen eine starke Neigung des Geländes unvermeidbar ist.

8. Alle vorgenommenen rechtlichen, administrativen und waldbaulichen Veränderungen müssen dokumentiert werden.

\section{Weitere Überlegungen und Empfehlungen (keine Ausschlusskriterien)}

9. Vorrang sollte den Flächen eingeräumt werden, deren Bestandesgeschichte (z.B. Herkunft des Genmaterials, Zeitspanne seit dem letzten Kahlschlag, Durchforstungsintervalle etc.) bekannt ist und für die hochauflösende Bestandesdaten, insbesondere Zeitreihen und genaue Flächendokumentation, bereits vorhanden sind. Zum Beispiel ist es wichtig, die Hintergrunddaten für Generhaltungsobjekte (GOs), Versuchsflächen, waldwachstumskundliche Dauerbeobachtungsflächen, zertifizierte Saatgutbestände, Aufnahmepunkte der nationalen Waldinventuren, ICP-Forest-Flächen, etc. bei der Auswahl der Monitoringflächen und Auswertung der Monitoringergebnisse zu berücksichtigen - insbesondere bei der Auswahl der Monitoringflächen und der Interpretation der Ergebnisse. Solche Hintergrunddaten können zum Beispiel sein:

- Klima- / Umweltdaten

- Bodendaten

- Vegetationsdaten

- Daten über vorangegangene Fruktifikationsereignisse und das Vorhandensein von Naturverjüngung

10. Entfernung der betreuenden Institution von der Monitoringfläche. Wenn verschiedene Monitoringflächen in Frage kommen, die alle o.g. Anforderungen erfüllen, sollte die der betreuenden Institution am nächsten gelegene Fläche den Vorrang erhalten, da die Fahrtkosten für weiter entfernte Monitoringflächen die Gesamtkosten für das FGM erheblich erhöhen können (siehe Kapitel 7: Kosten des FGM).

11. Gute Erreichbarkeit der Monitoringfläche (z.B. Straße, Fußweg, keine Felsbrocken im Weg etc.). Wo immer möglich, sollten gut erreichbare Flächen für das FGM ausgewählt werden, da dies sowohl den Arbeitsaufwand im Wald als auch die Gesamtkosten für das FGM erheblich reduziert.

12. FGM-Flächen können als "Forschungsschwerpunkte" gefördert und in andere Monitoringprogramme und Forschungsprojekte integriert werden: nationale Inventuren, ICP Forest, Monitoringflächen für Treibhausgasaustausch, Waldbodenbiodiversitätsforschung und -monitoring, etc. Ein solcher Ansatz würde die langfristige Fortsetzung der Monitoringaktivitäten auf den FGM-Flächen erleichtern, zur langfristigen Finanzierung beitragen und die Verfügbarkeit verschiedener Daten für die FGM-Flächen verbessern. 


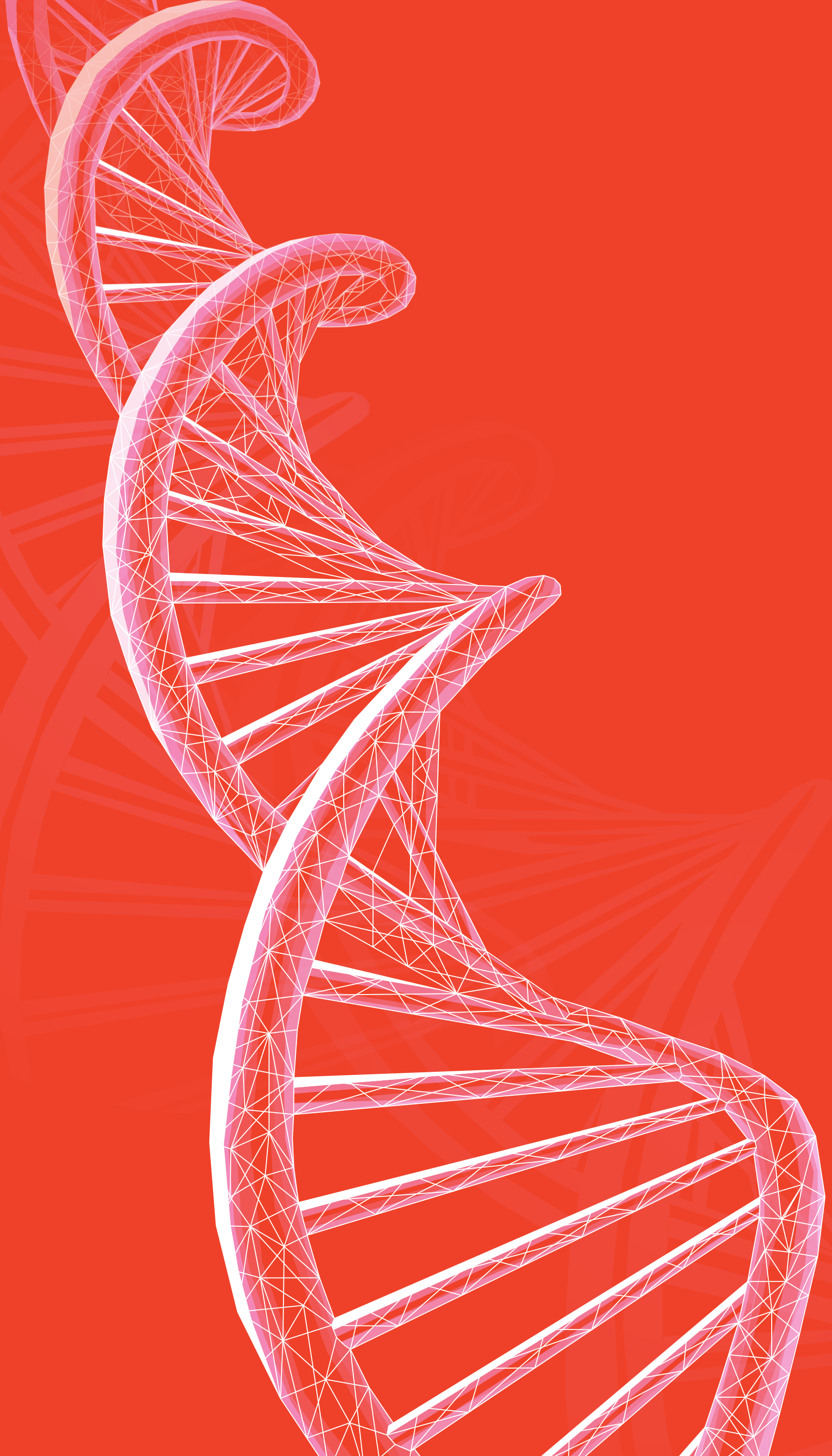




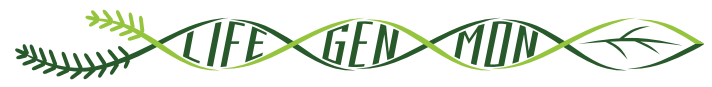 \\ LIFE13 ENV/S/ $/ 000148$}

\section{Handbuch zum Forstgenetisches Monitoring}

\section{Chapter}

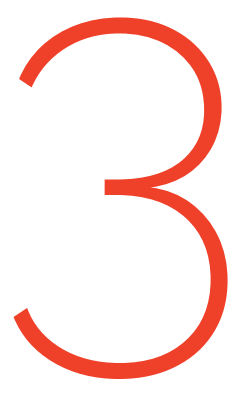

\section{EINRICHTUNG UND INSTANDHALTUNG DER MONITORINGFLÄCHEN}

Natalija DOVČ ${ }^{1}$, Darius KAVALIAUSKAS², Rok DAMJANIĆ'1,

Filippos A. ARAVANOPOULOS ${ }^{3}$, Barbara FUSSI', Marko BAJC',

Paraskevi ALIZOTI ${ }^{3}$, Domen FINŽGAR ${ }^{1,11}$, Evangelia V. AVRAMIDOU ${ }^{3,7}$,

Dalibor BALLIAN ${ }^{1,5}$, Evangelos BARBAS ${ }^{3}$, Pavlos BEKIAROGLOU ${ }^{6}$,

Sándor BORDÁCS ${ }^{8}$, Gregor BOŽIČ' ${ }^{1}$, Andrej BREZNIKAR ${ }^{4}$, Pavlos

CHASILIDIS $^{6}$, Anna-Maria FARSAKOGLOU ${ }^{3,10}$, Nikitas FRAGKISKAKIS ${ }^{6}$,

Ioannis GANOPOULOS ${ }^{3,9}$, Fotios KIOURTSIS ${ }^{6}$, Monika KONNERT²,

Ermioni MALLIAROU ${ }^{3}$, Georgios ROUSAKIS ${ }^{6}$, Chryse SARVANI ${ }^{6}$, Kristina SEVER ${ }^{4}$,

Nikolaos TOURVAS ${ }^{3}$, Marjana WESTERGREN ${ }^{1}$, Hojka KRAIGHER ${ }^{1}$

Zitat: Dovč et al. (2020) Einrichtung und Instandhaltung der Monitoringflächen. In: Bajc et al. (Ed.) Handbuch zum forstgenetischen Monitoring. Slowenisches Forstinstitut: Verlag Silva Slovenica, Ljubljana, S. 21-32. http://dx.doi.org/10.20315/SFS.176

Institut:

1. Slowenisches Forstinstitut (SFI), Slowenien

2. Bayerisches Amt für Waldgenetik (AWG), Deutschland

3. Aristoteles-Universität Thessaloniki (AUTh), Griechenland

4. Slovenische Forestverwaltung (SFS), Slowenien

5. Forstfakultät, Universität Sarajevo, Bosnien und Herzegovina

6. Generaldirektion für Forst und Landwirtschaft, Dezentrale Verwaltung von MazedonienThrakien, Griechenland

7. Institut für Mediterrane Waldökosysteme, ELGO DEMETER, Griechenland

8. Semmelweis Universität für Medizin, Budapest, Ungarn

9. Institut für Pflanzenzüchtung und genetische Ressourcen, HAO ELGO DEMETER, Griechenland

10. Europäisches Programm für forstgenetische Ressourcen (EUFORGEN), Europäische Forstinstitut (EFI) (EFI), Spanien

11. Institut für Evolutionäre Biologie, Universität von Edinburgh, Großbritannien 


\subsection{EINLEITUNG}

Die forstgenetische Monitoring(FGM-)fläche ist die Grundeinheit, auf der das genetische Monitoring durchgeführt wird; sie ist die Grundlage für alle weiteren Arbeiten. Es ist daher von übergeordneter Bedeutung, die Anweisungen für die Einrichtung und Instandhaltung der Monitoringfläche zu befolgen.

\subsection{EINRICHTUNG DER MONITORINGFLÄCHEN}

wenn ein Standort (d.h. ein Waldbestand) für FGM ausgewiesen wird, ist ein Teil davon für die Einrichtung einer FGM-Fläche auszuwählen (Abbildung 3.1). Für die bestandesbildenden Arten wird der Standort der FGM-Fläche zufällig ausgewählt, während für nicht-bestandesbildende Baumarten eine Voruntersuchung des ausgewählten Bestandes erforderlich ist.

Im Idealfall sollte die Monitoringfläche bei möglichst geringen Einrichtungskosten die nachfolgenden Arbeitsschritte ermöglichen, ohne die Zielgrößen des FGM zu beeinträchtigen. Bereiche mit eingeschränkter Sicht (z.B. dichtem Unterwuchs oder hoher Verjüngung) oder erschwerte Arbeitsbedingungen (z.B. lange Anfahrtswege zur Monitoringfläche oder felsiges Gelände) sollten nach Möglichkeit vermieden werden.

Erforderliche Ausrüstung:

- ein Gerät zur Entfernungsmessung (empfehlenswert ist ein Fernglas mit Entfernungsmesser)

- ein Kompass

- Farbe und Pinsel oder Farbspray zur dauerhaften Kennzeichnung der Bäume

- ein ausreichend präzises GPS-Gerät, welches das Speichern von Baumkoordinaten ermöglicht

BHD- und Höhenmessungen, die zur Berechnung der Hintergrundinformationen Durchmesser-(BHD) und Höhenklassenverteilung verwendet werden, können bereits während der Einrichtung der Monitoringflächen durchgeführt werden (siehe Kapitel 4 und 5 für Details). Daher ist zusätzliche Ausrüstung erforderlich:

- Kluppe oder Durchmessermaßband

- Neigungsmesser (vorzugsweise ein Laser-Neigungsmesser)

Eine FGM-Fläche für einhäusige Arten besteht aus 50 nicht verwandten, fortpflanzungsfähigen Bäumen und einem Mindestabstand von $30 \mathrm{~m}$ zwischen zwei beliebigen Bäumen. Für zweihäusige oder funktionell zweihäusige Arten müssen 25 weibliche und 25 männliche erwachsene fortpflanzungsfähige Bäume mit dem gleichen Mindestabstand wie für die einhäusigen Arten ausgewählt werden. Wenn ein Baum blüht, wird er als fortpflanzungsfähiger Baum angesehen. Daher ist der Frühling die beste Zeit für die Einrichtung einer FGM-Fläche und die Auswahl der Bäume, weil zu dieser Zeit potenzielle Bäume blühen. z.B. blühende Kirschbäume sind von weitem zu sehen. Falls die Einrichtung der Monitoringflächen im Frühjahr nicht möglich ist, können BHD und KRAFTsche Klasse als Anhaltspunkt zur Erkennung eines fortpflanzungsfähigen Baumes genutzt werden. Die Verwendung des BHD als Indikator zur Erkennung eines blühenden Baumes sollte sich auf die örtlichen Rahmenbedingungen und das Fachwissen des Försters vor Ort stützen. Für zweihäusige oder funktionell zweihäusige Arten müssen während der Blütezeit die Bäume ausgewählt werden, um das Geschlecht der Bäume eindeutig feststellen zu können.

Für Baumarten, bei denen Klone und Hybride zwischen der autochthonen Zielart und allochthonen Arten vorkommen, müssen die ausgewählten Bäume zunächst hinsichtlich Klonalität oder Hybridisierung genotypisiert werden. Stellt sich heraus, dass die Zahl der nicht miteinander verwandten, fortpflanzungsfähigen Bäume aufgrund der Auswahl von Klonen oder Hybriden bei der Einrichtung der Monitoringfläche weniger als 50 beträgt, müssen nochmal 50 Bäume ausgewählt und genotypisiert werden. Danach werden 50 Individuen, die nicht Hybride oder Klone sind, zufällig für das FGM ausgewählt. Falls die Analyse der ersten 50 Bäume einen sehr hohen Hybridanteil zeigt, sollte ein anderer Bestand gewählt werden (ausser das erklärte Ziel ist es, einen Hybridbestand zu beobachten). 
Da sich die Baumarten hinsichtlich ihrer Verteilung im Bestand unterscheiden, werden die Anweisungen für die Einrichtung der Monitoringflächen für bestandsbildende und nicht-bestandesbildende Baumarten in zwei Verfahren unterteilt: (i) Auswahl des Mittelpunkts der Monitoringfläche bei bestandsbildenden Arten bzw.

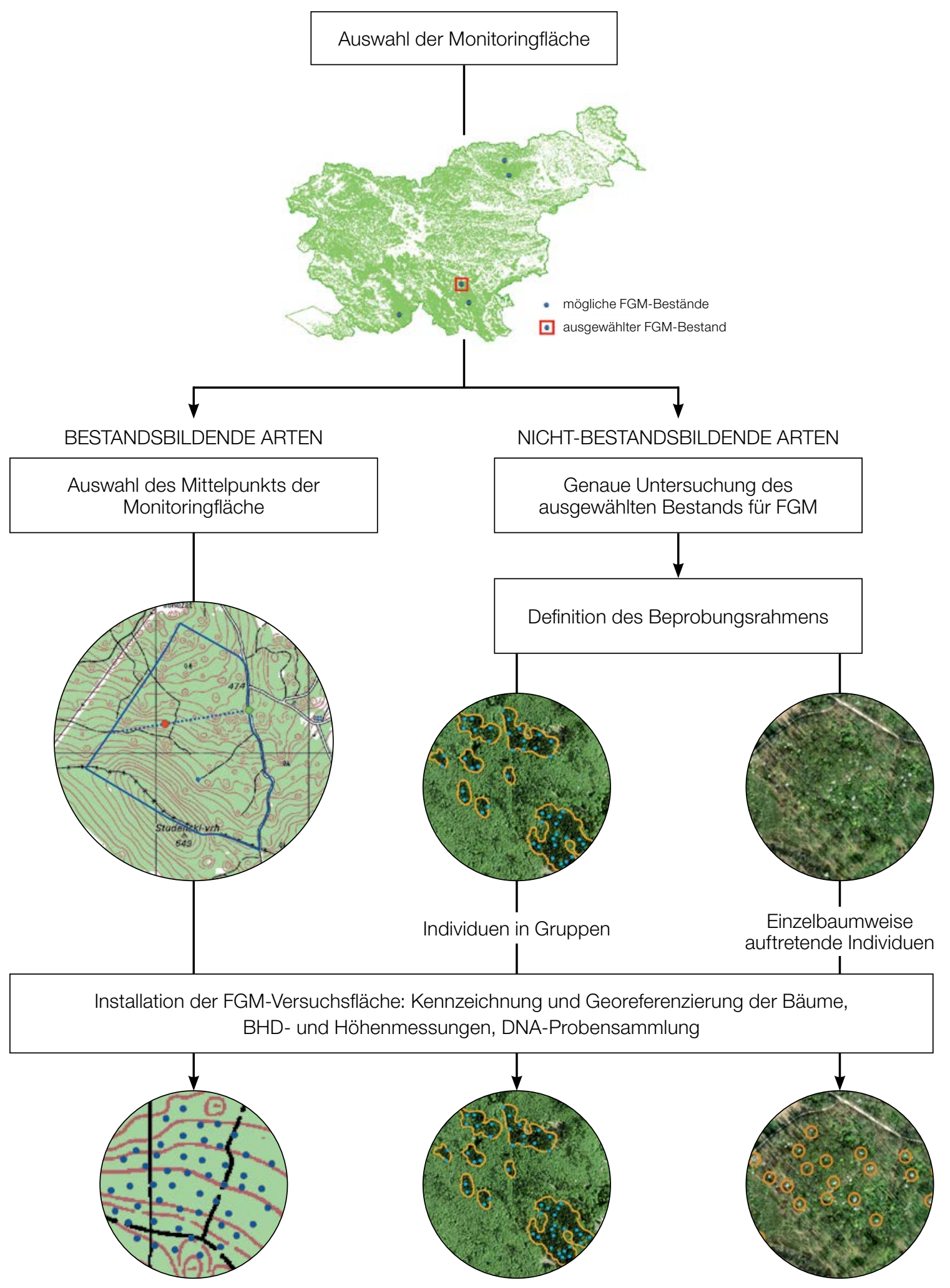

Abbildung 3.1: Ablaufschema für die Einrichtung der Monitoringfläche, getrennt nach bestandsbildenden und nichtbestandesbildende Baumarten. Für letztere ist eine Anpassung des Designs an die Biologie sowie die Verteilung der Baumart erforderlich. Beispiele für Esche, Kirsche und Pappel werden im Kapitel 9: Leitfäden vorgestellt. 
Festlegung des Beprobungsrahmens für nicht-bestandesbildende Baumarten und (ii) die Einrichtung der Monitoringfläche. Die Anweisungen für nicht-bestandesbildende Baumarten umfassen je nach Populationsdichte zwei verschiedene Ansätze. Neben den Vorgaben für zwei Baumartentypen wird in diesem Kapitel auch die Vorgehensweise für die Einrichtung von Naturverjüngungs (NV) - Plots beschrieben.

\subsubsection{Bestandsbildende Baumarten}

\subsubsection{Auswahl des Mittelpunkts der FGM-Fläche}

Wenn ein Standort (z.B. ein Waldbestand) für die Durchführung von FGM geprüft und als geeignet befunden ist, wird nach dem Zufallsprinzip ein Mittelpunkt für die FGM-Fläche ausgewählt. Die zufällige Auswahl mithilfe einer GIS-basierten Karte (erstellt z.B. mit ArcGis Map, Qgis) kommt hier deswegen zur Anwendung, weil sie die einzige statistisch sichere Option darstellt.

Das allgemeine Verfahren für die zufällige Auswahl des Mittelpunkts der FGM-Fläche (Abbildung 3.2.) besteht aus folgenden Schritten:

- Zufällige Auswahl eines Punktes (grüner Punkt) entlang einer an der Bestandesgrenze verlaufenden Forststraße oder eines Waldweges auf einer Karte,

- Einzeichnen einer annähernd senkrecht zur Straße verlaufenden Linie an diesem zufällig entlang der Straße ausgewählten Punkt;

- zufällige Auswahl eines Punktes auf der Linie (roter Punkt) - dieser Punkt stellt den Mittelpunkt der FGM-Fläche dar.

Der Mindestabstand zwischen einem Punkt und der Bestandesgrenze beträgt etwa $150 \mathrm{~m}$. Wenn der ausgewählte Mittelpunkt dieses Kriterium nicht erfüllt, muss nach dem oben beschriebenen Verfahren ein neuer Punkt ausgewählt werden.

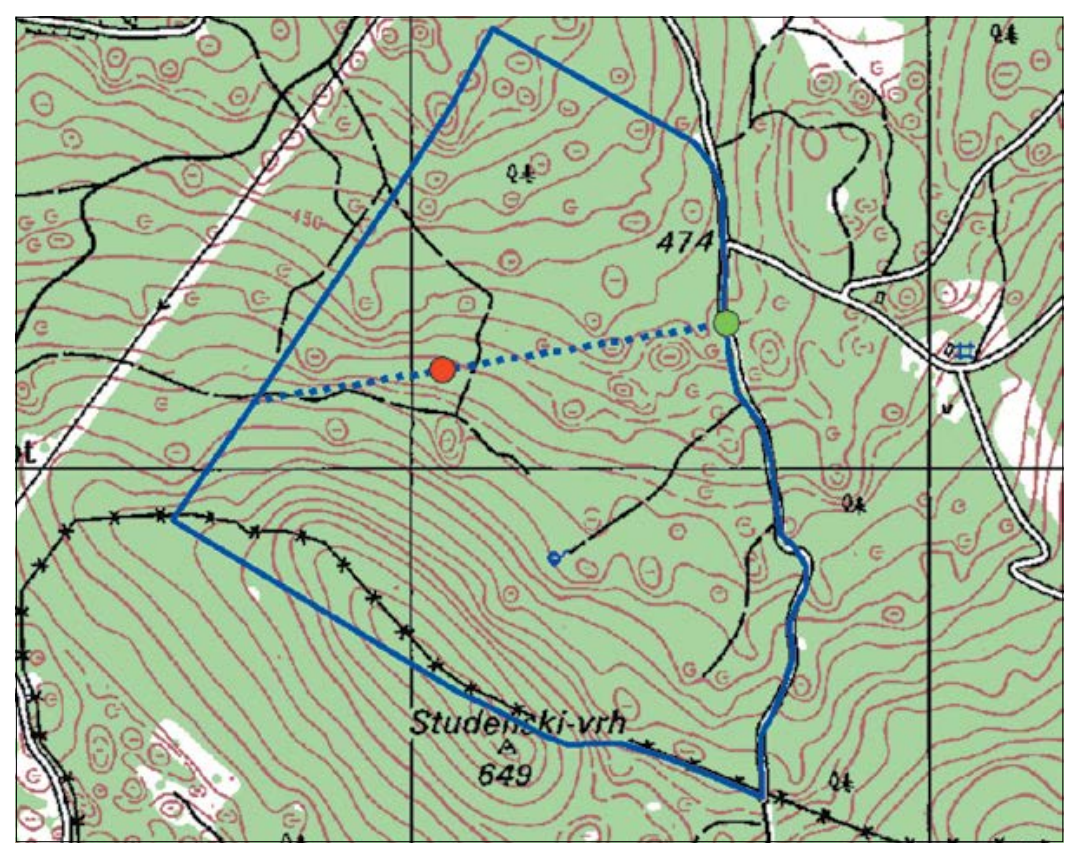

Abbildung 3.2: Zufallsauswahl des Mittelpunkts der FGM-Fläche

Es besteht die Möglichkeit, dass der ausgewählte Zufallspunkt, der den Mittelpunkt einer FGM-Fläche darstellt, in ein Gebiet fällt, in dem sowohl die Einrichtung einer FGM-Fläche als auch das weitere Monitoring schwierig zu realisieren wäre (z.B. aufgrund schlechter Sichtverhältnisse). Es wird daher empfohlen, nach dem gleichen 
Schema ein oder zwei Reservepunkte auszuwählen, auf die für den Fall einer Ablehnung des ersten ausgewählten Punktes zurückgegriffen werden kann.

Anstelle des oben beschriebenen Verfahrens können auch GIS-Werkzeuge zur Erstellung von Zufallspunkten verwendet werden.

Für die Nutzung im Gelände sollten die Koordinaten der ausgewählten Punkte in einem GPS-Gerät gespeichert werden.

\subsubsection{Einrichtung der Monitoringfläche im Gelände}

Vor Ort im Bestand wird der der gespeicherten GPS-Koordinate am nächsten stehende, fortpflanzungsfähige Baum als zentraler Beobachtungsbaum der Monitoringfläche bestimmt und mit der Nummer 1 gekennzeichnet. Weitere Altbäume werden in konzentrischen Kreisen mit einem um jeweils $30 \mathrm{~m}$ zunehmenden Radius um den zuvor bestimmten zentralen Beobachtungsbaum ausgewählt (Abbildung 3.3). Der erste Baum in jedem Kreis sollte nach dem Zufallsprinzip ausgewählt werden (in Abbildung 3.3 rot markiert), was auf verschiedene Weise erfolgen kann: durch Verwendung eines zufälligen Azimuts, der vom zentralen Beobachtungsbaum aus eingemessen wird (Tabelle 3.1), durch Folgen der Richtung des Sekundenzeigers auf einer analogen Uhr oder durch jede andere Vorgehensweise, die eine objektive Auswahl ermöglicht. Die anderen Bäume in jedem Kreis werden durch einen entsprechend größeren Azimut ausgewählt, um einen Mindestabstand von $30 \mathrm{~m}$ zwischen zwei beliebigen Bäumen zu gewährleisten:

$$
\begin{array}{ll}
- & +60^{\circ} \mathrm{im} \text { ersten Kreis (maximal } 6 \text { Bäume) } \\
\text { - } & +30^{\circ} \mathrm{im} \text { zweiten Kreis (maximal } 12 \text { Bäume) } \\
\text { - } \quad & +20^{\circ} \mathrm{im} \text { dritten Kreis (maximal } 18 \text { Bäume) } \\
\hline & +15^{\circ} \mathrm{im} \text { vierten Kreis (maximal } 24 \text { Bäume) }
\end{array}
$$

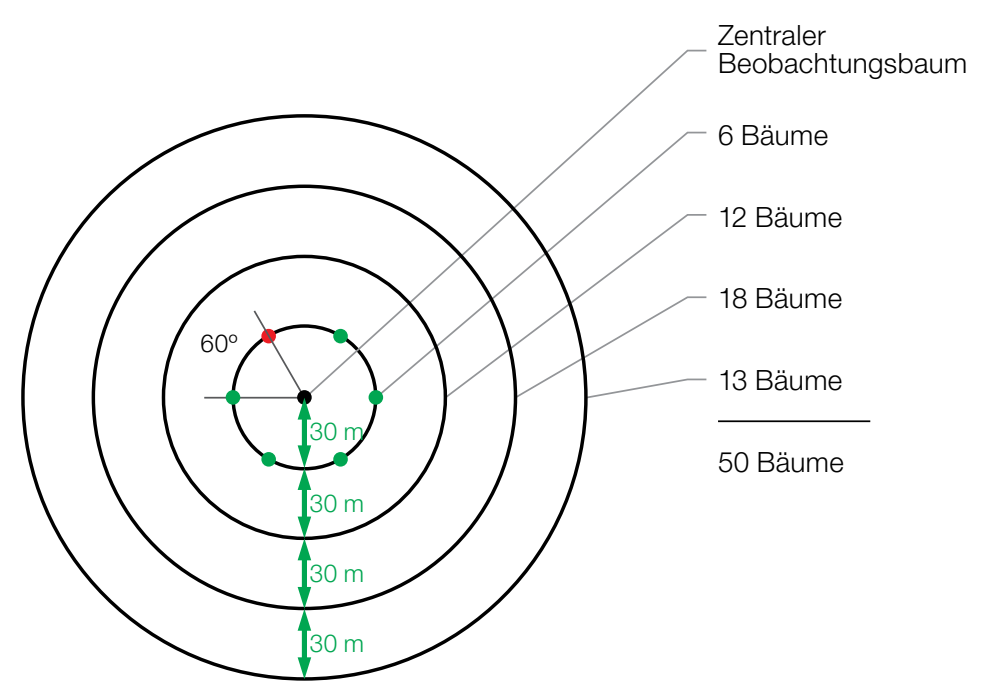

Abbildung 3.3: Schematische Darstellung einer FGM-Fläche für bestandsbildende Arten; Auswahl von Bäumen in konzentrischen Kreisen mit einem um jeweils $30 \mathrm{~m}$ zunehmenden Radius um den zuvor ausgewählten zentralen Beobachtungsbaum.

Wenn es nicht möglich ist, in jedem der drei inneren Kreise die entsprechende Anzahl von Bäumen zu finden, werden zusätzliche Bäume auf dem äußersten Kreis ausgewählt, um die erforderliche Anzahl von 50 Bäumen zu erreichen. 
Tabelle 3.1: Zufällige Azimute [Grad], die für die Auswahl des jeweils ersten Baumes im Kreis verwendet werden können.

\begin{tabular}{rrrrrrrrrrr}
\hline 108 & 15 & 186 & 35 & 178 & 29 & 305 & 351 & 44 & 150 \\
\hline 232 & 23 & 160 & 141 & 112 & 292 & 216 & 83 & 245 & 214 \\
\hline 63 & 65 & 345 & 234 & 95 & 78 & 279 & 323 & 40 & 236 \\
\hline 201 & 313 & 275 & 144 & 182 & 68 & 268 & 289 & 185 & 92 \\
\hline 356 & 177 & 93 & 1 & 145 & 198 & 287 & 251 & 224 & 142 \\
\hline
\end{tabular}

Bei der Auswahl der anderen Bäume in jedem Kreis soll ein entsprechend vergrößerter Azimut in erster Linie dazu dienen, einen ungefähren Standort zu bestimmen und die Zahl der Bäume im jeweiligen Kreis zu erfassen. Manchmal würde das Ermitteln eines Baumes mit einem exakten Azimut zu einem deutlich größeren Abstand vom zentralen Beobachtungsbaum führen, was noch größere oder exzentrische Kreise bedeuten würde. Es gibt auch Fälle, in denen der zentrale Beobachtungsbaum aus verschiedenen Gründen nicht sichtbar ist: große Entfernungen, andere Bäume, die den zentralen Beobachtungsbaum verdecken oder das Geländerelief. In solchen Fällen basiert die Baumauswahl ausschließlich auf einem Mindestabstand von drei zuvor ausgewählten Bäumen, von denen einer auf demselben und zwei auf dem weiter innenliegenden Kreis liegen. Der Mindestabstand sollte knapp über $30 \mathrm{~m}$ betragen.

\subsubsection{Nicht-bestandesbildende Arten}

Aufgrund der großen Unterschiede in der räumlichen Verteilung und der Dichte von Populationen der nichtbestandesbildende Arten gibt es hier keinen universellen Ansatz für die Einrichtung von FGM-Flächen. Während einige Arten einzelbaumweise im Bestand vorkommen, wachsen andere dagegen in Gruppen unterschiedlicher Größe in gemischten Beständen oder in spezifischer Mischungsform. Das Verfahren zur Einrichtung der Monitoringflächen mit den allgemeinen Anforderungen von 50 nicht miteinander verwandten, fortpflanzungsfähigen Bäumen und einem Mindestabstand von $30 \mathrm{~m}$ zwischen den gewählten Bäumen muss daher von Fall zu Fall entsprechend angepasst werden. In besonderen Fällen sehr geringer Populationsdichten (z.B. gefährdete Populationen, Randpopulationen) kann die Anzahl der Bäume auf 30 reduziert werden.

Wenn ein Standort für die Durchführung von FGM bestätigt wird (Kapitel 2) müssen die Standorte, an denen die Art in ausreichender Dichte erscheint, um eine Beobachtungsfläche einzurichten, zusätzlich im Feld genauer erfasst werden. Es empfiehlt sich, bei dieser Erstaufnahme die zurückgelegte Strecke aufzuzeichnen oder die Positionen aller geeigneten Bäume und der NV-Plots mit einer Handy-App (z.B. Locus Map) oder einem GPS-Empfänger zu erfassen. Dies erleichtert die weitere Planung wesentlich, da so die Verteilung der Bäume im Bestand in einer GIS-Anwendung dargestellt werden kann und die zu untersuchenden Bäume auch im Büro ausgewählt werden können. Ist die Population der Zielart auf einem Orthophoto des Gebiets deutlich sichtbar und von anderen Arten zu unterscheiden, kann die visuelle Auswertung dieser Fotos anstelle zusätzlicher Untersuchungen im Gelände zum Einsatz kommen (Abbildung 3.4).

Wurden die Positionen der Bäume im Rahmen der Erstaufnahme im Gelände bereits erfasst, ist der Ablauf für die Einrichtung der Monitoringfläche folgendermaßen:

- Die gespeicherten Positionen aller Bäume werden als Punktlayer in einer GIS-Anwendung angelegt,

- 50 (mindestens 30) Punkte - die Bäume repräsentieren - mit einem Mindestabstand von 30 m untereinander werden nach dem Zufallsprinzip ausgewählt,

- während der Einrichtung der Monitoringflächen werden diese vorausgewählten Bäume im Gelände aufgesucht und markiert.

Die jeweilige Vorgehensweise für die Einrichtung von Monitoringflächen ohne Kenntnis der genauen Positionen der Beobachtungsbäume sind im Folgenden beschrieben: einerseits für die Baumarten, deren Populationen in der Fläche in Gruppen auftreten, andererseits für die Baumarten mit geringer Populationsdichte, bei denen die Baumindividuen vereinzelt auf größerer Fläche vorkommen. 

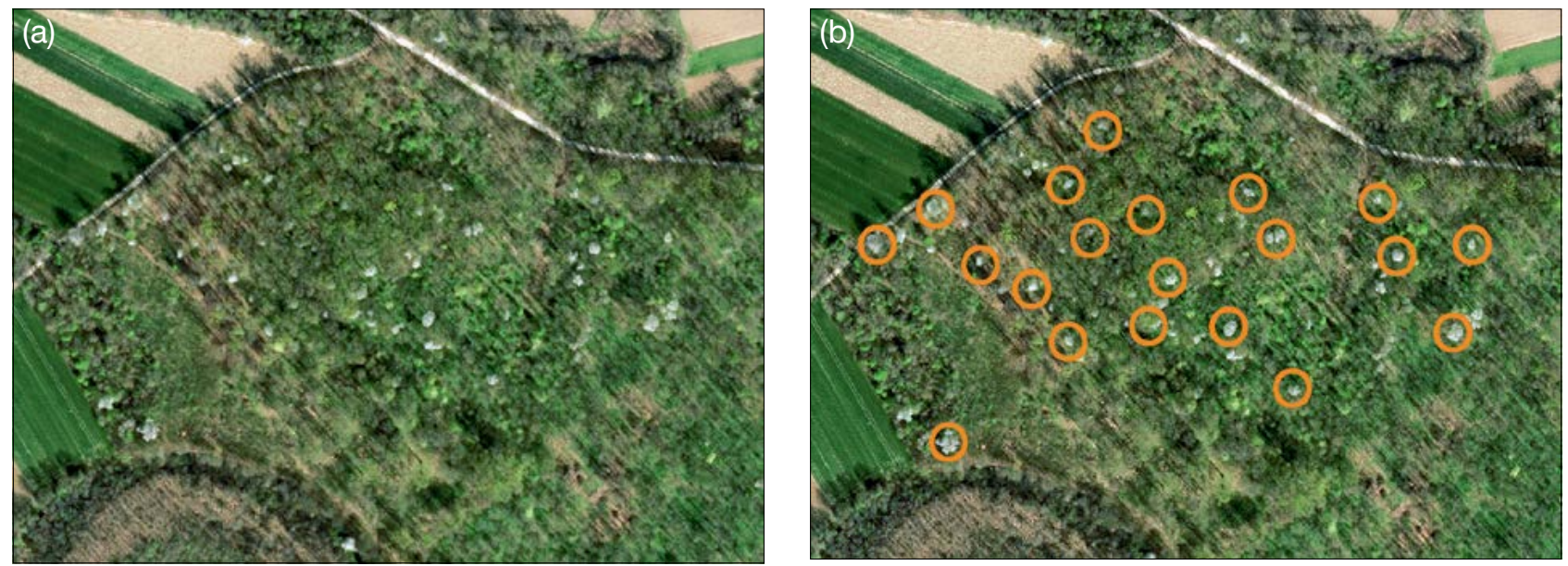

Abbildung 3.4: (a) Visuelle Auswertung eines Orthophotos der Monitoringflächeund (b) Auswahl der Beobachtungsbäume

\subsubsection{Beobachtungsbäume in Gruppen}

Treten die Zielbaumarten in der Fläche in Gruppen auf, sollten mehrere Monitoringplots - eines je Baumgruppe - die zusammen eine FGM-Fläche bilden, angelegt werden. Die Anzahl der Bäume pro Plot sollte hierbei proportional zur Größe der Gruppe sein, die Gesamtzahl derBäume auf der FGM-Fläche beträgtauch hier 50 Bäume. Die Baumgruppen müssen im selben Bestand liegen, damit die Umweltbedingungen und Artenzusammensetzung ähnlich sind.

\section{A. Festlegung des Beobachtungsrahmens}

Die Baumgruppen werden als Polygone auf der Karte verzeichnet, die alle zusammen einen Beobachtungsrahmen darstellen. Bäume innerhalb einer Baumgruppe sollten nach dem Zufallsprinzip ausgewählt werden. Der Ansatz, der eine zufällige Auswahl ermöglicht, besteht darin, in der GIS-Anwendung eine geeignete Anzahl von Zufallspunkten mit einem Mindestabstand von 35 m innerhalb jedes Polygons zu erzeugen (Abbildung 3.5). Durch die Verwendung eines erweiterten Abstands zwischen den Zufallspunkten soll ein Sicherheitspuffer für die reduzierte Genauigkeit von GPS-Geräten in Wäldern und die Entfernung des nächsten Baumes vom zufälligen GPS-Punkt geschaffen werden. Die Koordinaten der Zufallspunkte werden in einem GPS-Gerät gespeichert, welches im Gelände zum Einsatz kommt.

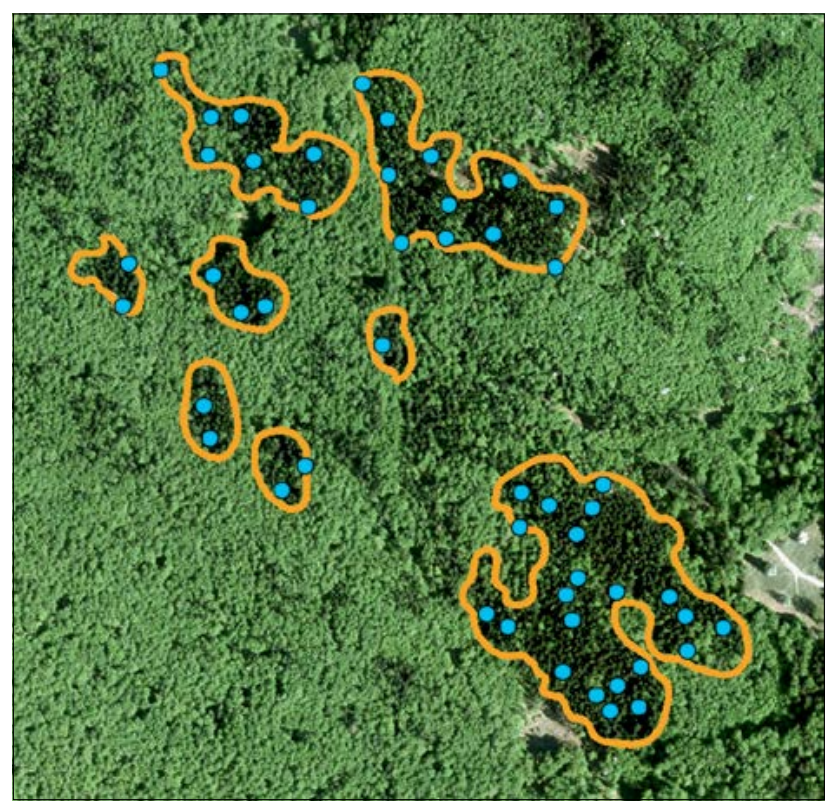

Abbildung 3.5: Darstellung mehrerer Baumgruppen (Polygone) mit Zufallspunkten, die die ungefähre Position der Beobachtungsbäume abbilden 


\section{B. Einrichtung der FGM-Fläche im Gelände}

Sobald die Koordinaten der ungefähren Position der Beobachtungsbäume bekannt sind, ist der Ablauf für die Einrichtung der Monitoringfläche folgendermaßen:

- Auffinden der gespeicherten GPS-Koordinaten im Bestand

- Auswahl und Kennzeichnung des der GPS-Position am nächsten gelegenen fortpflanzungsfähigen Baumes

Wenn die Populationsdichte für das oben beschriebene Vorgehen nicht ausreicht, kann innerhalb aller Gruppen der "Suche-und-Finde-Ansatz" genutzt werden (siehe 3.2.2.2).

\subsubsection{Vereinzelt vorkommende Baumindividuen ("Suche-und-Finde-Ansatz")}

In Fällen, in denen die Bäume einer Population in kleinen Gruppen von jeweils nur wenigen Individuen oder einzeln auftreten, kann eine Zufallsstichprobe mit den Anforderungen einer Mindestanzahl von fortpflanzungsfähigen Bäumen und einem Mindestabstand von $30 \mathrm{~m}$ zunehmend schwieriger werden. Das Auswahlgebiet könnte zu groß und damit unübersichtlich werden bzw. die Erstaufnahme von Fläche und Baumpositionen zu zeit- und arbeitsintensiv, insbesondere in unwegsamem Gelände. Es ist daher ratsam, ortskundige Förster zu Rate zu ziehen, die das Gebiet kennen und wissen, wo die Zielart mit höherer Wahrscheinlichkeit vorkommt.

\section{A. Festlegung des Beobachtungsrahmens}

Mit der Unterstützung eines ortskundigen Försters sollte eine Karte des Waldbestandes erstellt und die Bereiche gekennzeichnet werden, in denen die Zielart in höherer Dichte vorkommt. Entlang der nächstgelegenen Forststraße oder eines nahen Waldweges in diesem Gebiet werden ein oder mehrere Punkte ausgewählt, die, auf Grundlage der Ortskenntnis des ansässigen Försters, als Ausgangspunkte für die Suche nach Beobachtungsbäumen am geeignetsten sind. Die GPS-Koordinaten dieser Punkte werden in einem GPS-Gerät gespeichert, welches im Gelände zum Einsatz kommt.

\section{B. Einrichtung der FGM-Fläche im Gelände}

Die Suche nach Beobachtungsbäumen sollte ausgehend vom Waldweg beginnen und von dort aus in Richtung der Vorkommen mit einer höheren Dichte der Zielart vorrücken. Die Anwesenheit eines ortskundigen Försters wird das Auffinden geeigneter Bäume erleichtern. Am besten ist es, das Gebiet mithilfe eines GPS-Gerätes oder einer Handy-App mit Tracking-Funktion systematisch zu durchkämmen, um sicherzustellen, dass dasselbe Gebiet nicht wiederholt durchsucht bzw. übersehen wird. Alle fortpflanzungsfähigen Bäume mit dem erforderlichen Mindestabstand müssen ausgewählt werden. Wenn es nicht möglich ist, 50 fortpflanzungsfähige Bäume zu finden, sollten alle geeigneten Bäume, mindestens jedoch 30 (ausnahmsweise bei gefährdeten oder Randpopulationen), mit dem erforderlichen Mindestabstand von 30 m ausgewählt werden.

\subsubsection{Naturverjüngungs-Plots}

Innerhalb einer eingerichteten FGM-Fläche sollte eine größere Anzahl Naturverjüngungs (NV)-Plots eingerichtet werden, wenn möglich 20. Diese dienen verschiedenen Zwecken: DNA-Probennahme und Aufnahme der NV-Abundanz bzw. Mortalität. Die Einrichtung der NV-Plots sollte bei Fruktifikationsintervallen zwischen 3-12 Jahren (Tabelle 3.2) nach dem Auflaufen jedes starken oder extremen Fruktifikationsereignisses erfolgen. Tritt die Fruchtbildung jedes Jahr oder jedes zweite Jahr ein, sollten mit einem Abstand von jeweils etwa 5 Jahren nach einem starken Samenjahr NV-Plots angelegt werden. Bei der Planung der Einrichtung von NV-Plots muss die Keimruhe berücksichtigt werden: So überliegt z.B. Saatgut der Gemeinen Esche (Fraxinus excelsior) normalerweise zwei Winter, was bedeutet, dass sowohl Keimung als auch Einrichtung der NV-Plots zwei Jahre nach dem Fruktifikationsereignis stattfindet. 
Tabelle 3.2: Zeitleiste der Einrichtung von NV-Plots. Nach jedem erfassten Fruktifikationsereignis werden 20 neue NV-Plots angelegt. Im Idealfall werden zwei Fruktifikationsereignisse pro Dekade erfasst.

\begin{tabular}{|c|c|c|c|c|c|c|c|c|c|c|c|c|c|c|c|c|c|c|c|}
\hline Monitoringjahr & 1 & 2 & 3 & 4 & 5 & 6 & 7 & 8 & 9 & 10 & 11 & 121 & 13 & 1415 & 1516 & 17 & 1819 & 2021 & 2223 \\
\hline Fruktifikationsereignis & & $\bullet$ & & & & & $\bullet$ & & & & & & & $\cdot$ & & & $\bullet$ & & \\
\hline Einrichtung der NV-Plots & & & - & & & & & - & & & & & & & - & & & - & \\
\hline
\end{tabular}

\subsubsection{Definition des Beobachtungsrahmens}

Naturverjüngungscluster, die aus der Fruchtbildung des letzten Kalenderjahres (unter Berücksichtigung der Keimruhe) hervorgegangen sind, sollten im Gelände untersucht und ihre Positionen (GPS-Koordinaten, Nummer des Baumes, der dem Mittelpunkt des Verjüngungsclusters am nächsten ist) aufgenommen werden. Aus allen Verjüngungsclustern sollten nach dem Zufallsprinzip 20 für die Einrichtung von NV-Plots ausgewählt werden. Wenn es nur 20 oder weniger Verjüngungscluster gibt, sollten alle herangezogen werden. Es ist empfehlenswert, zusätzliche Informationen wie z.B. Entfernung (Anzahl Schritte) und Azimut vom nächstgelegenen markierten Altbaum aufzunehmen, um die NV-Plots leichter wiederfinden zu können.

\subsubsection{Einrichtung der Plots im Gelände}

Innerhalb jedes ausgewählten Naturverjüngungsclusters wird ein $1 \mathrm{~m}^{2}$ großer Plot angelegt und mit Metallstäben markiert. Die Metallstäbe werden an jeder Ecke des NV-Plots so tief wie möglich in den Boden eingeschlagen, um zu verhindern, dass sie von Tieren entfernt werden können. Die oberen Enden der Metallstäbe werden mit Signalfarbe markiert, um sie besser sichtbar zu machen.

\subsection{KENNZEICHNUNG, GEOREFERENZIERUNG, AUSSENAUFNAHMEN UND ERFASSUNGEN IM GELÄNDE}

\subsubsection{Kennzeichnung der Bäume}

Jeder ausgewählte Baum muss mit einer entsprechenden Nummer gekennzeichnet und mit einem Ring aus Dauermarkierfarbe um den Stamm herum versehen werden, um die Sichtbarkeit der Bäume aus allen Richtungen zu erleichtern. Der zentrale Beobachtungsbaum (Nummer 1) wird mit zwei oder mehr zusätzlichen Ringen markiert, um ihn von den anderen Bäumen unterscheiden zu können (Abbildung 3.6a). Es wird empfohlen, die Baumnummer auf die Seite des Baumes zu schreiben, die vom zentralen Beobachtungsbaum weg zeigt, da dies das Auffinden des zentralen Beobachtungsbaumes erleichtert, insbesondere von den äußeren Ringen der Monitoringfläche aus (Abbildung 3.6b). In manchen Fällen ist es hilfreich, die Bäume auf der straßenabgewandten Seite zu kennzeichnen, um Missverständnisse mit Erholungssuchenden zu vermeiden.

\subsubsection{Georeferenzierung}

Ausgewählte Bäume innerhalb der FGM-Fläche müssen georeferenziert werden, was bei der Einrichtung der Fläche erfolgen kann. Im Folgenden werden zwei Ansätze zur Georeferenzierung beschrieben.

Der einfachste Weg, Bäume zu georeferenzieren, ist, ihre Standposition mithilfe eines GPS-Empfängers aufzunehmen. Diese Methode ist jedoch nicht geeignet, wenn die Ziel- bzw. Messgenauigkeit des GPSEmpfängers nicht ausreicht. Die Abweichung von nicht-differentiellen GPS-Empfängern, wie sie im Allgemeinen von Förstern verwendet werden, kann in Altbeständen $15 \mathrm{~m}$ oder mehr betragen (Simwanda et al. 2011). Differentielle GPS-Geräte haben eine wesentlich bessere Ziel- und Messgenauigkeit (Zhang et al. 2014). 

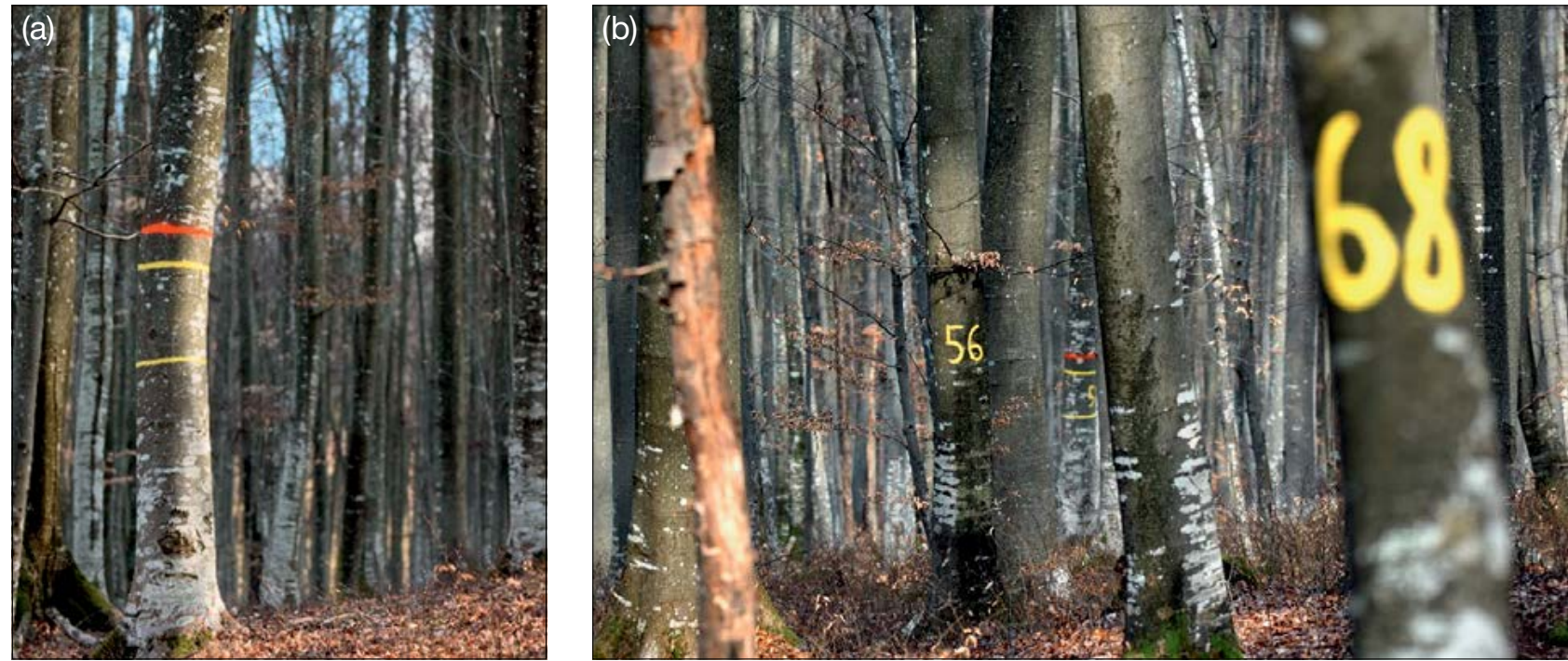

Abbildung 3.6: (a) Der zentrale Beobachtungsbaum auf der FGM-Fläche wird durch mehrere Ringe gekennzeichnet, um inn von den anderen Bäumen unterscheiden zu können; (b) die Baumnummern sind auf der vom zentralen Beobachtungsbaum abgewandten Seite angebracht.

Eine weitere Möglichkeit zur Georeferenzierung von Bäumen ist über die Messung der Entfernung und des Azimuts von einem Referenzpunkt. Zur Berechnung von Standpositionen einzelner Bäume kann der Georeferenzierungsrechner http://georeferencing.org/georefcalculator/gci3/source/gci3.html verwendet werden, wobei der 'Locality type' auf 'Distance at a heading' eingestellt sein muss. Dieses Werkzeug ermöglicht die Auswahl verschiedener Koordinatensysteme und Referenzpunkte. Der Nachteil bei der Nutzung eines Georeferenzierungsrechners ist, dass die Eingangsdaten für jeden Baum, wie z.B. die Koordinaten des Referenzpunktes, die Entfernung und der Azimut, einzeln eingegeben werden müssen.

Eine schnellere Möglichkeit ist die Verwendung eines Baum-Georeferenzierungsskripts (https:// github.com/roks531/Tree-georeferencing), welches mit einer einzigen Dateneingabe in Form einer Tabelle (im .txt- oder .csv-Format) die Koordinaten einzelner Bäume berechnet und im Rahmen der Projekte LIFEGENMON und LIFESYSTEMIC gemeinschaftlich entwickelt wurde. Das Skript verwendet Daten aus den projizierten Koordinatensystemen, z.B. UTM. Falls die Koordinaten des initialen Referenzpunktes in der Form LAT, LON (WGS84) vorliegen, müssen sie in ein metrisches Koordinatensystem konvertiert werden. Das Skript erfordert die Eingabe zweier separater Tabellen: Die erste enthält Daten zur Baum-Nummer, gemessene Entfernung zum Referenzpunkt in Metern, den Azimut (Gradabweichung von Norden) und die Nummer des Referenzpunktes, nach dem der Baum georeferenziert ist. Die zweite Tabelle enthält die Nummer der initialen Referenzpunkte (mindestens einer, es können mehrere sein) und seine $x$ - und y-Koordinaten. Es ist wichtig, dass die Benennung der Referenzpunkte in beiden Tabellen gleich ist.

Es wird empfohlen, so wenige Referenzpunkte wie möglich mit einer möglichst genau eingemessenen Position auszuwählen. Würde jeder Baum als Referenzpunkt für die Georeferenzierung des folgenden Baumes verwendet (z.B. Baum Nr. 1 ist der Referenzpunkt für die Georeferenzierung von Baum Nr. 2, Baum Nr. 2 ist der Referenzpunkt für die Georeferenzierung von Baum Nr. 3 usw.), würden sich Fehler systematisch fortpflanzen, und die Genauigkeit der Baumstandorte würde mit zunehmender aufeinanderfolgender Anzahl von georeferenzierten Bäumen abnehmen (Abdi et al. 2012). 


\subsection{BESCHREIBUNG DER FGM-FLÄCHE (MITTELS STANDARDISIERTER ERFASSUNGSFORMULARE)}

Nach der Einrichtung sollte die FGM-Fläche im Formular „FGM-Flächenbeschreibung“, das Teil dieses Handbuchs ist, detailliert beschrieben werden. Alle gesammelten Daten werden dann in einer Datenbank hinterlegt (siehe Kapitel 6.5.2.1). Das Formular besteht aus zwei Hauptteilen: (i) Daten zur Beschreibung der Monitoringfläche und (ii) Beschreibung und Qualität des aufstockenden Bestandes.

Die Beschreibung der Monitoringfläche enthält Daten zur exakten Lage, die Besitzverhältnisse, die Artenzusammensetzung des aufstockenden Bestandes, Merkmale der Region sowie Boden und Klima. Das waldbauliche System, die Ziele der Waldbewirtschaftung sowie der ausgewiesene Status werden ebenfalls aufgeführt.

Der Teil zur Beschreibung und Qualität des aufstockenden Bestandes ist so aufgebaut, dass für jeden Deskriptor eine der möglichen Antworten ausgewählt wird. In diesem Abschnitt des Formulars werden folgende Aspekte beschrieben: Gesundheitszustand des Waldes, ob der Wald bewirtschaftet wird oder nicht, forstliches Vermehrungsgut, Naturverjüngung, vertikale und horizontale Bestandesstruktur, Neigung, Qualität des aufstockenden Bestandes etc.

Das Formular befindet sich im Anhang 10.2: Formulare für die Außenaufnahmen.

\subsection{INSTANDHALTUNG DER MONITORINGFLÄCHEN}

\subsubsection{Allgemeine Instandhaltung}

Die Kennzeichnungen der Bäume und NV-Plots müssen regelmäßig (alle 2 Jahre) überprüft und bei Bedarf erneuert werden. Die für die Markierung der NV-Plots verwendeten Metallstäbe müssen nach Abschluss des NV-Abundanz-Monitorings entfernt werden.

\subsubsection{Ersatz von Beobachtungsbäumen}

Wenn ein Beobachtungsbaum stirbt oder im Zuge einer Bewirtschaftungsmaßnahme gefällt wird, muss er ersetzt werden. Hierbei sollte der dem abgestorbenen/ gefällten Baum am nächsten stehende geeignete Baum gewählt werden, wobei der Mindestabstand von 30 m zum nächsten Beobachtungsbaum erfüllt sein muss. Andernfalls ist ein Baum aus der Peripherie (bei bestandsbildenden Baumarten vorzugsweise im äußeren Kreis) der FGM-Fläche zu wählen.

Wird die Krone z.B. durch Windbruch, Eis- oder Schneebruch geschädigt, trägt aber weiterhin Früchte, verbleibt der Baum im Monitoringprogramm. Ist die Schädigung zu stark und eine Fruchtbildung nicht mehr zu erwarten, muss der Beobachtungsaum ersetzt werden.

Für Baumarten, bei denen aufgrund der Bestimmung der Klonalität oder Hybridisierung mittels Genotypisierung anfänglich mehr als 50 Individuen ausgewählt wurden, können aus diesen überzähligen Bäumen alle geeigneten Individuen als Ersatz für ausgefallene Probebäume verwendet werden. Wenn in der anfänglich größeren Anzahl potentieller Probebäume Klone identifiziert wurden, kann als Ersatz für den ausgefallenen Beobachtungsbaum sogar derselbe Genotyp verwendet werden.

Die Ursache für den Verlust eines Beobachtungsbaumes auf der FGM-Fläche ist zu ermitteln und in den Formularen sowie in der Datenbank zu dokumentieren.

Ersatzbäume müssen auf die gleiche Weise wie die ursprünglichen Bäume gekennzeichnet werden, jedoch mit fortlaufenden Nummern (51, 52, ...), um sie von den ersetzten Originalbäumen (nummeriert von 1 bis 50) unterscheiden zu können. 


\subsubsection{Längerfristige Instandhaltung der FGM-Fläche:}

Lücken in der Waldbedeckung können auch in naturnahen Waldbewirtschaftungssystemen auftreten. Im Falle der Entnahme einer größeren Anzahl von fortpflanzungsfähigen Bäumen auf der FGM-Fläche im Zuge forstlicher Bewirtschaftung (z.B. Femelschlag) sollte die Fläche weiterhin instandgehalten und die Erfassung von NV-Abundanz, Blüte, Fruchtbildung durchgeführt werden. In diesen Fällen muss die Anzahl der verbleibenden Bäume bei jeder Beobachtung dokumentiert werden.

Eine solche Situation, in der das FGM aufgrund einer reduzierten Anzahl fortpflanzungsfähiger Bäume stark eingeschränkt ist, kann mehrere Jahrzehnte andauern, bis genügend jüngere Bäume das Fortpflanzungsalter erreichen und die Mindestanforderungen für die Aufnahme ins FGM-Programm erfüllen. Der Prozess von Auswahl und Ersatz sollte über einen längeren Zeitraum erfolgen, damit die ausgewählten Ersatzbäume keinen systematischen Fehler in Richtung der am schnellsten wachsenden Individuen verursachen.

\subsection{ERFASSUNG METEOROLOGISCHER DATEN}

Heute ist der Klimawandel wahrscheinlich die größte direkte Bedrohung für die genetische Vielfalt und die Waldökosysteme. Indirekt verstärkt er auch die Gefährdung durch Krankheiten, Krankheitserreger, Insekten, Feuer und Extremwetterereignisse. Umweltfaktoren spielen eine wichtige Rolle für den Fortpflanzungserfolg, das Wachstum und die Überlebensfähigkeit von Bäumen. Beim forstgenetischen Monitoring (FGM) können viele Verifikatoren teilweise mit sich verändernden Umweltparametern, z.B. Temperatur und Niederschlag, erklärt werden. Um die Veränderungen der verschiedenen Verifikatoren zu erklären, empfiehlt es sich daher, direkt auf der FGM-Fläche meteorologische Messgeräte zu installieren. Das Internet der Dinge (IdD) entwickelt sich schnell, ebenso wie Datenlogger und verschiedene Umweltmessgeräte. Meteorologische Messgeräte sind heute billiger, einfacher zu installieren und ermöglichen eine einfache Datenfernerfassung. Die Daten werden über eine 2G/3G/4G-Verbindung oder ein lokales Wi-Fi-Netzwerk z.B. an eine Cloud-Datenbank oder einen FTP-Server übertragen, von wo aus sie für die weitere Analyse exportiert werden können.

Meteorologische Daten können auch von nahegelegenen Wetterstationen bezogen und extrapoliert werden. Dieser Ansatz ist jedoch nicht empfehlenswert an Orten mit räumlich sehr heterogenen Witterungsbedingungen oder Mikroklimata.

\section{Quellen}

Abdi E, Sisakht S R, Goushbor L, Soufi H (2012) Accuracy assessment of GPS and surveying technique in forest road mapping. Ann For Res 55:309-317

Simwanda M, Wing MG, Sessions J (2011) Evaluating global positioning system accuracy for forest biomass transportation tracking within varying forest canopy. West J Appl For 26:165-173. https://doi.org/10.1093/wjaf/26.4.165

Zhang H, Zheng J, Dorr G, Zhou H, Ge Y (2014) Testing of GPS accuracy for precision forestry applications. Arab J Sci Eng 39: 237 - 245. https://doi.org/10.1007/s13369-013-0861-1 



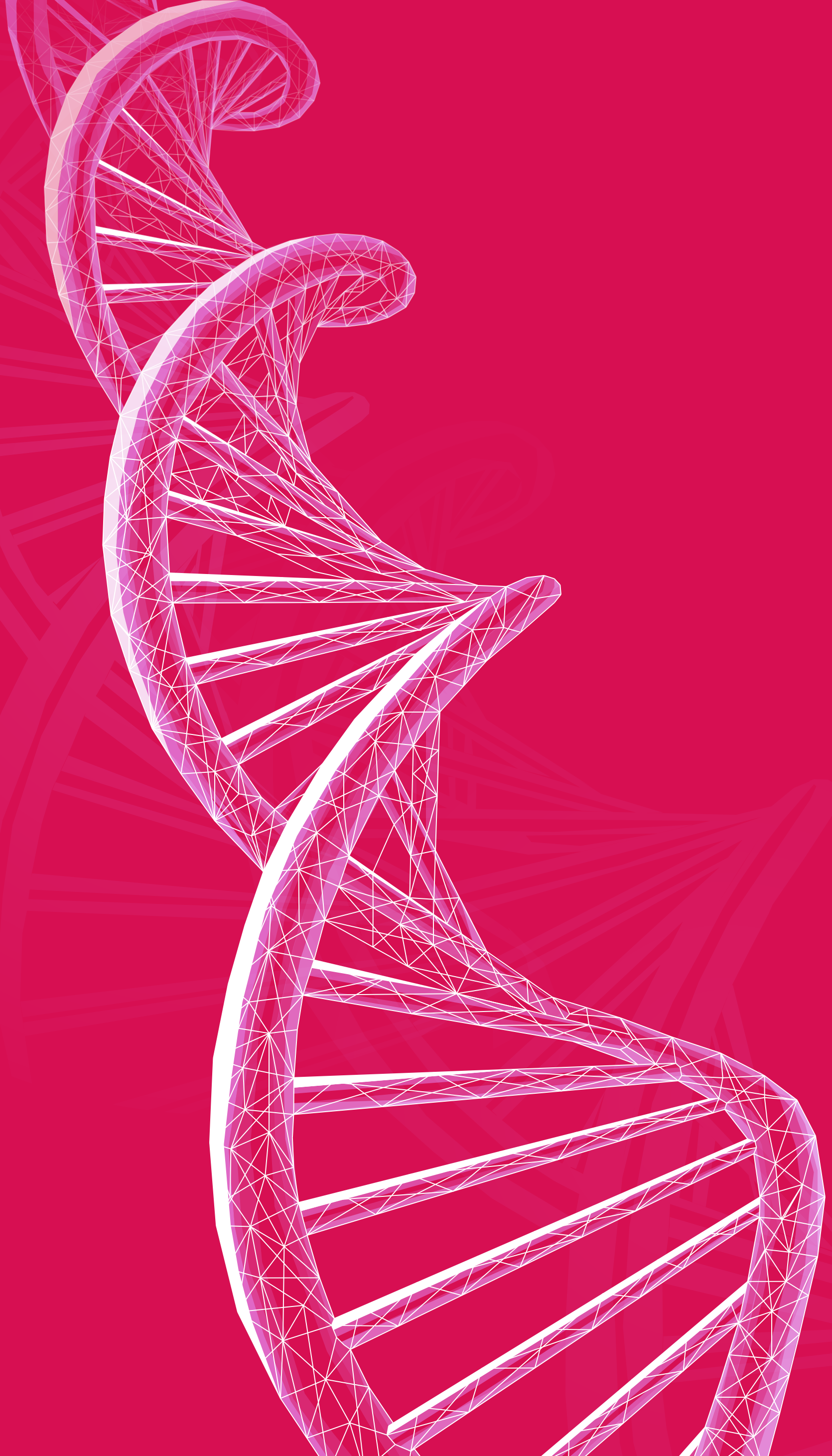




\section{wy \\ LIFE13 ENV/S//000148}

\section{Handbuch zum Forstgenetisches Monitoring}

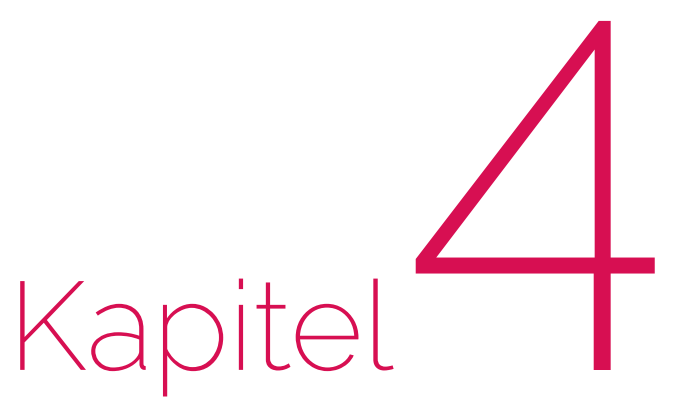

\section{INDIKATOREN, VERIFIKATOREN UND HINTERGRUNDINFORMATIONEN}

Filippos A. ARAVANOPOULOS 1 , Darius KAVALIAUSKAS², Barbara FUSSI², Marjana WESTERGREN ${ }^{3}$, Paraskevi ALIZOTI', Marko BAJC ${ }^{3}$, Nikolaos TOURVAS', Andrej BREZNIKAR ${ }^{4}$, Pavlos CHASILIDIS ${ }^{5}$, Rok DAMJANIĆ ${ }^{3}$, Natalija DOVČ ${ }^{3}$, Fotios KIOURTSIS ${ }^{5}$, Ermioni MALLIAROU'1 , Hojka KRAIGHER ${ }^{3}$

Zitat: Aravanopoulos et al. (2020) Indikatoren, Verifikatoren und Hintergrundinformationen. In: Bajc et al. (Ed.) Handbuch zum forstgenetischen Monitoring. Slowenisches Forstinstitut: Verlag Silva Slovenica, Ljubljana, S. 35-47. http://dx.doi.org/10.20315/SFS.176

Institut:

1. Aristoteles Universität von Thessaloniki (AUTh), Griechenland

2. Bayrisches Amt für Waldgenetik (AWG), Deutschland

3. Slowenisches Forstinstitut (SFI), Slowenien

4. Slowenische Staatsforsten, Slowenien

5. Dezentrale Verwaltung Mazedonien-Thrakien, Generaldirektion für Forst und Landwirtschaft, Griechenland 


\subsection{DEFINITION VON INDIKATOREN UND VERIFIKATOREN/ HINTERGRUNDINFORMATIONEN}

Genetisches Monitoring sollte auf einem soliden, wissenschaftlich fundierten System beruhen, welches ein Minimum an konzeptionellen Ansätzen und Parametern umfasst, die ein Maximum an genetischer Information extrahieren würden (Konnert et al. 2011, Aravanopoulos 2011, 2016). Diese werden durch die Verwendung von Kriterien, Indikatoren und Verifikatoren konkretisiert. Ein Kriterium ist ein Standard, nach dem eine bestimmte Größe bewertet wird, ohne ein direktes Erfolgsmaß zu sein (Boyle 2000, Aravanopoulos et al. 2015). Ein Kriterium wird daher normalerweise ein Ziel, eine Zielgröße oder eine umfassende Zielsetzung widerspiegeln, das bzw. die oft recht komplex und schwierig zu bewerten ist (Graudal et al. 2014, Aravanopoulos 2016). Ein Indikator bezieht sich auf einen ökosystemaren Bestandteil oder Prozess, der zur Ableitung von Attributen der Ressourcennachhaltigkeit verwendet wird (Boyle 2000, Aravanopoulos et al. 2015). Indikatoren werden per definitionem verwendet, um Entwicklungen zu erfassen, und sollten immer in Bezug auf ein bestimmtes Ziel definiert werden (Feld et al. 2009). Ein Indikator wird in der Regel mit einer zeitlichen Auflösung gemessen, die es ermöglicht, die Zielerreichung oder Veränderungen in Bezug auf das entsprechende Kriterium abzubilden. Indikatoren für biologische Vielfalt lassen sich in vier Kategorien einteilen: Zustand, Belastungen, Reaktion und Nutzen (Gradual et al. 2014, Sparks et al. 2011, UNEP/WCMC 2011). Die Indikatoren des forstgenetischen Monitorings (FGM) auf Populationsebene sind eindeutig Zustandsindikatoren, d.h. sie beziehen sich auf den Zustand und Status von Biodiversitätsaspekten (Gradual et al. 2014, Aravanopoulos 2016).

Indikatoren müssen direkt messbar sein, und die zur Messung eines Indikators verwendete Metrik wird als Verifikator bezeichnet. Verifikatoren erfordern deshalb die Erhebung parametrischer Daten, welche die Spezifizität eines Indikators verbessern oder dessen Bewertung erleichtern (Boyle 2000, Aravanopoulos et al. 2015). Damit ist ein Verifikator praktisch ein Maß für einen Indikator (Aravanopoulos et al. 2015).

In diesem Kontext bedient sich das FGM eines einzigen Kriteriums: dem Erhalt der genetischen Diversität und des adaptiven evolutionären Potenzials natürlicher Populationen, welches die Aufrechterhaltung evolutionärer Prozesse innerhalb von Waldbaumpopulationen in den Mittelpunkt stellt, um deren Potenzial für kontinuierliche Anpassung zu sichern (Aravanopoulos 2011, Namkoong et al. 1996). Die wissenschaftliche Grundlage für das forstgenetische Monitoring ist im genökologischen Ansatz zu finden: Die drei Faktoren natürliche Selektion, genetische Drift und Genfluss sind die auf der Mikroskala essentiellen Triebkräfte der Evolution. Die Auswirkungen der natürlichen Selektion können eine mit lokaler Anpassung verbundene Differenzierung bewirken, während die genetische Drift zu einer Differenzierung beitragen kann, die mit stochastischen Veränderungen und genetischer Erosion einhergeht. Dies wird durch die Wirkung des Genflusses relativiert, der zu einer genetischen Homogenisierung führen kann. Die Relevanz von Mutationen ist für relativ kurzfristige Prozesse zu vernachlässigen (Aravanopoulos 2011, 2016). Daher konzentriert sich das forstgenetische Monitoring auf die zeitliche Bewertung von drei Indikatoren: (1) die natürliche Selektion, (2) die genetische Variation an sich, wobei auch die genetische Drift mit einbezogen wird, und (3) der Genfluss / das Paarungssystem. Die Bewertung der einzelnen Indikatoren basiert auf einer Reihe von Verifikatoren, die nachfolgend vorgestellt werden. Die Anzahl der Verifikatoren pro Indikator reicht von dem, was als absolutes Minimum für die Bewertung eines Indikators angesehen wird (Schlüsselverifikator), bis zur umfassendsten (optimalen) Bewertung, bei der alle nachstehend aufgeführten Verifikatoren berücksichtigt werden.

Neben den Verifikatoren gibt es potentiell wichtige Zusatzinformationen, die - wenngleich sie es nicht wie ein Verifikator ermöglichen, den Zustand eines Indikators zu bewerten - dennoch helfen können, den Zustand eines forstgenetischen Monitoringbestandes einzuschätzen und den Wert eines Verifikators sowie dessen potentielle relative Veränderung zu interpretieren. Derartige allgemeinere Informationen werden unter dem Begriff „Hintergrundinformationen“ erläutert. 


\subsection{AUSWAHL VON INDIKATOREN UND VERIFIKATOREN/ HINTERGRUNDINFORMATIONEN}

Die Indikatoren und Verifikatoren für das in diesem Handbuch beschriebene FGM-Verfahren sind in der nachfolgenden Tabelle 4.1 aufgeführt. Die relevanten ausgewählten Verifikatoren und Hintergrundinformationen sind dabei direkt den ausgewählten Indikatoren zugeordnet.

Tabelle 4.1. Liste der Indikatoren und Verifikatoren/Hintergrundinformationen für das forstgenetische Monitoring auf drei Niveaus: Basis-, Standard- und Intensivniveau. X: Niveau, auf dem ein bestimmter Verifikator erfasst wird. V: Verifikator, Bl: Hintergrundinformation

\begin{tabular}{|c|c|c|c|c|c|}
\hline Indikator & Bezeichnung des Verifikators & Тур & Basis-niveau & $\begin{array}{l}\text { Standard- } \\
\text { niveau }\end{array}$ & Intensiv-niveau \\
\hline \multirow{13}{*}{ Selektion } & Mortalität / Überlebensrate & V & $x$ & $x$ & $x$ \\
\hline & Abundanz der Naturverjüngung (NV) & V & $x$ & $x$ & $x$ \\
\hline & Blüte & V & $x$ & $x$ & $x$ \\
\hline & Fruktifikation & V & $x$ & $x$ & $x$ \\
\hline & Anteil lebensfähiger Samen (\%) & V & & & $x$ \\
\hline & Keimprozent (\%) & V & & & $x$ \\
\hline & Eschentriebsterben & $\mathrm{Bl}$ & $x$ & $x$ & $x$ \\
\hline & Geschlechterverhältnis (zweihäusige Arten) & $\mathrm{Bl}$ & & $x$ & $x$ \\
\hline & Durchmesserklassenverteilung & $\mathrm{Bl}$ & & $x$ & $x$ \\
\hline & Höhenklassenverteilung & $\mathrm{Bl}$ & & $x$ & $x$ \\
\hline & Blühsynchronisation & $\mathrm{Bl}$ & & & $x$ \\
\hline & Austrieb & $\mathrm{Bl}$ & & $x$ & $x$ \\
\hline & Seneszenz & $\mathrm{Bl}$ & & $x$ & $x$ \\
\hline \multirow{9}{*}{$\begin{array}{c}\text { Genetische } \\
\text { Variation }\end{array}$} & Allelhäufigkeiten & V & & $x$ & $x$ \\
\hline & Latentes genetisches Potential & V & & $x$ & $x$ \\
\hline & Inzuchtkoeffizient & V & & $x$ & $x$ \\
\hline & Effektive Populationsgröße & V & & $x$ & $x$ \\
\hline & Allelische Vielfalt & V & & $x$ & $x$ \\
\hline & Kopplungsungleichgewicht & V & & $x$ & $x$ \\
\hline & Interspezifische Hybridisierung * & $\mathrm{Bl}$ & & $x$ & $x$ \\
\hline & Gametische Diversität & $\mathrm{Bl}$ & & $x$ & $x$ \\
\hline & F-basierter Ausreißertest & $\mathrm{Bl}$ & & $x$ & $x$ \\
\hline \multirow{5}{*}{$\begin{array}{l}\text { Genfluss / } \\
\text { Paarungs- } \\
\text { system }\end{array}$} & Genfluss & V & & & $x$ \\
\hline & Multilocus-Auskreuzungsrate der Population & V & & & $x$ \\
\hline & Tatsächliche Inzuchtrate & V & & & $x$ \\
\hline & Effektive Anzahl von Pollenspendern & $\mathrm{Bl}$ & & & $x$ \\
\hline & Biparentale Inzucht & $\mathrm{Bl}$ & & & $x$ \\
\hline
\end{tabular}

* Nur hybridisierende Arten

Die Auswahl der Indikatoren und Verifikatoren folgt den drei Niveaus des forstgenetischen Monitorings: Basis-, Standard- und Intensivniveau. Die Auswahl basiert auf: (1) der Prämisse einer möglichst umfassenden Bewertung eines Indikators unter Verwendung einer minimalen Anzahl von Verifikatoren (Aravanopoulos 2011, Aravanopoulos et al. 2015), (2) der Verfügbarkeit der Verifikatoren für eine Bewertung im zeitlichen Verlauf, und (3) dem Zeit- und Kostenaufwand für die Erfassung eines Verifikators (siehe Kapitel 7). Insgesamt gibt es 15 Verifikatoren: sechs Verifikatoren für die Selektion, sechs Verifikatoren für die genetische Variation und drei Verifikatoren für den 
Indikator "Genfluss/Paarungssystem“. Darüber hinaus gibt es acht Parameter, die als Hintergrundinformation benötigt werden: vier im Zusammenhang mit der Selektion, drei im Zusammenhang mit dem Genfluss/ Paarungssystem und einer im Zusammenhang mit der genetischen Variation. Von den 15 Verifikatoren beziehen sich vier auf quantitative Feldmessungen, neun werden von molekulargenetischen Markern abgeleitet, und zwei basieren auf Saatguttests. Die tatsächliche Anzahl der bewerteten Parameter für Hintergrundinformationen hängt von den Besonderheiten der jeweils erfassten Baumart ab, da nicht alle Parameter für alle Arten relevant sind. Die Hintergrundinformation „Geschlechterverhältnis“ wird beispielsweise nur für zweihäusige Arten bewertet.

\subsection{BESCHREIBUNG DER INDIKATOREN UND VERIFIKATOREN/ HINTERGRUNDINFORMATIONEN}

\section{Indikator I: SELEKTION}

Die Selektion ist ein Schlüsselindikator, da sie eine evolutionäre Kraft darstellt, die Allelhäufigkeiten schon über wenige Generationen hinweg verändern kann. Der Vorgang der Selektion erhöht die Anpassung einer Population an die aktuellen Umweltbedingungen bei gleichzeitig möglichem Verlust der genetischen Vielfalt. Daher ist die Bewertung der Selektion ein komplexer integraler Bestandteil des FGM, und stets im Kontext der anderen FGMIndikatoren durchzuführen.

\section{Verifikator: Mortalität / Überlebensrate}

Eine Veränderung des Trends in Bezug auf Mortalität oder Überleben (Mortalität $=1$ - Überlebensrate) über die durchschnittliche Erwartung hinaus deutet auf einen darunterliegenden Selektionsdruck hin, d.h. bei einer Erhöhung der Mortalitätsrate auf ein Absterben. Der Verifikator „Mortalität/Überlebensrate“ bezieht sich auf die Anzahl der Bäume, die im Vergleich zum Ausgangswert (und zur vorherigen Bewertung) abgestorben sind.

\section{Verifikator: Abundanz der Naturverjüngung (NV)}

Eineveränderte Abundanz der Naturverjüngung (NV) in einem Monitoringbestand kann auf einen darunterliegenden Selektionsdruck hindeuten, der zur Reduktion, zum Fehlen oder zum Absterben von Sämlingen und etablierter Jungpflanzen geführt hat. Die Abundanz der Naturverjüngung entspricht der Anzahl der Sämlinge pro Flächeneinheit. Sie wird durch das Zählen aller Pflanzen in 20 NV-Plots von je $1 \mathrm{~m}^{2}$ ab dem ersten Herbst nach dem Keimungsereignis bestimmt. Zusätzlich zur Gesamtzahl wird auch die Abundanz neu aufgelaufener NV und das Überleben etablierter NV innerhalb der NV-Plots bestimmt.

\section{Verifikator: Blüte}

Das Blühen - die Produktion von Blüten - ist ein interessanter Verifikator für das forstgenetische Monitoring. Das Ausbleiben der Blüte kann das panmiktische Gleichgewicht negativ beeinflussen (El-Kassaby et al. 1984, 1988), was zu nicht-zufälliger Kreuzbefruchtung und vermehrter Selbstbefruchtung führen kann (Bhumibhamon, 1978). Das Auftreten, die Häufigkeit und der Zeitpunkt der Blüte sind sehr klimasensitiv, was die Blühphänologie zu einem der variabelsten Pflanzenmerkmale macht (Chuine, 2010). Die Blühphänologie umfasst die Untersuchung der Entwicklungszeitpunkte der männlichen und weiblichen Blüten durch Erfassung der verschiedenen Phänophasen (Ducci et al. 2012). Die Blühphänologie ist ein entscheidender Faktor für die reproduktive Fitness der Bäume, da sie über den Genaustausch zwischen Genotypen die genetische Diversität der produzierten Samen und somit den Überlebenserfolg der daraus entstehenden Sämlinge bestimmt (Alizoti et al. 2010). 


\section{Verifikator: Fruktifikation}

Der Begriff der Fruktifikation bezeichnet die Produktion der Fortpflanzungsorgane und Früchte einer Pflanze (Merriam-Webster 2003). Die Fruktifikation ist die wichtigste Determinante für die Weitergabe der elterlichen genetischen Information an die Nachkommen. Sie ist ein zentraler Faktor für den Reproduktionserfolg von Genotypen und Populationen (Müller-Starck et al. 2005, Seifert und Müller-Starck 2009). Die Intensität und Periodizität einzelner Fruktifikationsjahre ist artspezifisch und variiert je nach Witterung, Ressourcenverfügbarkeit und genetischer Kontrolle (Mund et al. 2010 und darin enthaltene Referenzen). Daher findet bei einigen Waldbaumarten die Fruktifikation mit unterschiedlicher Intensität statt, so dass es Jahre mit vielen Früchten oder Zapfen und einige Jahre mit wenigen oder gar keinen gibt. Es ist wichtig zu wissen, dass sich infolge von genetischen und umweltbedingten Interaktionen Bäume einer Art oft über größere Flächen synchron fortpflanzen (Selas et al. 2002, Seifert und Müller-Starck 2009). Die Fruktifikation ist ein wichtiger Parameter bei der Interpretation von Werten der effektiven Populationsgröße.

\section{Verifikator: Anteil lebensfähiger Samen}

Eine Veränderung des Anteils lebensfähiger Samen deutet auf einen Selektionsdruck (im Falle einer Reduktion) oder eine Erholung (im Falle einer Erhöhung) hin. Sie ist auch ein wichtiger Parameter für die Interpretation von Werten der effektiven Populationsgröße. Die Schätzung des Anteils lebensfähiger Samen erfolgt für jeden Baum, an dem Früchte und/oder Samen beprobt wurden. Sie berücksichtigt die nach der Bestäubung abgestorbenen Samen und korreliert mit der Inzuchtrate. Die Schätzung basiert auf der in Prozent umgerechneten Anzahl lebensfähiger Samen in einer Zufallsstichprobe von 1000 Samen.

\section{Verifikator: Keimprozent}

Die Keimfähigkeit von Saatgut unter sich ändernden Umweltbedingungen beeinflusst sowohl die Verbreitung als auch die Häufigkeit von Arten. Selbst wenn Saatgut verfügbar ist, kann sich klimawandelbedingter Stress negativ auf die Keimung auswirken und zum Ausbleiben von Naturverjüngung führen (de Melo et al. 2015, Wang et al. 2016). Die Beurteilung der reproduktiven Fitness - einem Maß für die Fähigkeit eines Individuums, zu überleben und sich fortzupflanzen - kann im Rahmen des forstgenetischen Monitorings als Kombination des Anteils lebensfähiger Samen und des Keimprozents erfolgen (geschätzt auf Grundlage der Gesamtzahl beprobter Samen und der Gesamtzahl gekeimter lebensfähiger Samen) (Aravanopoulos 2011, Aravanopoulos et al. 2015, Aravanopoulos 2016). Ziel der Keimfähigkeitsprüfung nach den Regeln der ISTA (2020) ist die Bestimmung der maximalen Keimfähigkeit einer Saatgutpartie, die wiederum zum Vergleich der Qualität verschiedener Partien und zur Schätzung des tatsächlichen Pflanzwertes des Saatguts verwendet werden kann. Für die Prüfung der Lebensfähigkeit von Saatgut stehen zahlreiche verschiedene Methoden zur Verfügung. Die präziseste und zuverlässigste Methode ist der Keimtest (Rao et al. 2006). Die Keimung eines Samens in einem Labortest umfasst das Entstehen und die Entwicklung des Keimlings bis zu einem Stadium, in dem sein Erscheinungsbild und seine wesentlichen Strukturen anzeigen, ob der Keimling unter günstigen Bodenbedingungen zu einer normal entwickelten Pflanze heranwachsen kann oder nicht. Das Keimprozent gibt den Anteil der Samen an, die unter den artspezifischen Bedingungen und innerhalb des festgelegten Zeitraums als normal beurteilte Sämlinge hervorgebracht haben (ISTA 2020).

\section{Hintergrundinformation: Eschentriebsterben}

Das Eschentriebsterben wird nur beim FGM von Fraxinus sp. eingesetzt und dient dazu, den Schädigungsgrad durch den Pilz Hymenoscyphus fraxineus zu beurteilen, eine chronische Pilzerkrankung der Esche in Europa. 


\section{Hintergrundinformation: Geschlechterverhältnis (zweihäusige Arten)}

Das Geschlechterverhältnis bezieht sich auf die Erfassung des individuellen Geschlechts bei zweihäusigen Baumarten. Es ist eine wichtige Information, denn je gleichmäßiger das Verhältnis der verschiedenen Geschlechter ist, desto höher ist meist die effektive Populationsgröße.

\section{Hintergrundinformation: Durchmesserklassenverteilung}

Eine Veränderung der Durchmesserverteilung der Bäume in einem Monitoringbestand kann auf einen darunterliegenden Selektionsdruck hinweisen, d.h. auf das Absterben von Altbäumen oder Verjüngung.

\section{Hintergrundinformation: Höhenklassenverteilung}

Eine Veränderung der Höhenverteilung der Bäume in einem Monitoringbestand kann auf einen darunterliegenden Selektionsdruck hinweisen, d.h. einen Wachstumsstopp oder das Absterben von Altbäumen oder Verjüngung.

\section{Hintergrundinformation: Blühsynchronisation}

Die Blühsynchronisation, d.h. die gleichzeitige Reifung von weiblichen und männlichen Blüten, sorgt für die zeitliche Überlappung von weiblicher Blütenrezeptivität und Pollenabgabe und beeinflusst somit das panmiktische Gleichgewicht (El-Kassaby et al. 1984, 1988). Bei Vorliegen von Panmixie sollten alle männlichen und weiblichen Eltern mit gleicher Wahrscheinlichkeit an Paarungsereignissen teilnehmen und sich mit allen Individuen des anderen Geschlechts kreuzen. Fehlende Blühsynchronisation kann zu einer nicht-zufälligen Fremdbefruchtung, einem höheren Anteil hohler Samen und einer verstärkten Selbstbefruchtung führen (Bhumibhamon 1978).

\section{Hintergrundinformation: Austrieb}

Der Blattaustrieb umfasst den Zeitraum vom Ende der Knospenruhe bis zum Abschluss des Längenwachstums der Jungtriebe (Ende der Blattentfaltung). Er wird von mehreren Umweltfaktoren (Kältebedürfnis und Temperaturreize) beeinflusst, die v.a. für den Beginn des Prozesses notwendig sind, aber er unterliegt auch einer starken genetischen Kontrolle (Geburek 2004, Ducci et al. 2012). Informationen über den Zeitpunkt und die Dauer des Austriebs liefern wichtige Informationen über die Reaktion von Bäumen und Populationen auf sich ändernde Umweltbedingungen. Daten zu den phänologischen Phasen (d.h. den Phänophasen) des Austriebs sind für eine integrierte Bewertung verschiedener Aspekte innerhalb des FGM erforderlich. Die Fähigkeit einer Art, sich durch phänologische Verschiebungen langfristig an abiotische Umweltbedingungen anzupassen, kann als ein Indikator für ihre Vulnerabilität gegenüber zukünftigen Klimaveränderungen angesehen werden. Es ist das Hauptziel der Beobachtung des Austriebsverhaltens in FGM-Beständen, zusätzliche und ergänzende Informationen über die phänotypische Plastizität eines Waldes im Jahresverlauf zu liefern.

\section{Hintergrundinformation: Seneszenz}

Die Blattseneszenz ist die Gesamtheit degenerativer Ereignisse, welche die Stoffwechselaktivitäten verringern und den Tod von Zellen, Geweben und Blattorganen verursachen. Die Seneszenz wird durch zahlreiche umweltbedingte, physiologische und genetische Faktoren bedingt. Daten zum Zeitpunkt und der Dauer der Blattseneszenz liefern wichtige Informationen zum Verständnis des tatsächlichen Zustands der Bäume und Waldbaumpopulationen in einer sich verändernden Umwelt. 


\section{Indikator II: GENETISCHE VARIATION}

Genetische Variation ist Voraussetzung für zukünftige Anpassung und Evolution. Es wird vorgeschlagen, sie anhand der unten aufgeführten Parameter zu bewerten. Eine Veränderung - beispielsweise ein Rückgang in den Parametern, die genetische Variation abbilden, entspricht einer Reduktion der genetischen Vielfalt, die möglicherweise mit einer verringerten Anpassungsfähigkeit der Population einhergeht.

\section{Verifikator: Allelhäufigkeiten}

Eine Veränderung von Allelhäufigkeiten (AF) kann auf eine veränderte genetische Variation hinweisen. Der Nachweis veränderter Allelhäufigkeiten sowie zusätzlich der Verlust von Allelen sind Hinweise auf eine Veränderung der genetischen Vielfalt, die auf eine oder eine Kombination verschiedener evolutionärer Kräfte zurückzuführen ist, die im genökologischen System wirken. Sowohl Allelhäufigkeiten als auch Veränderungen der klinalen Variation von Populationen in deren gesamtem Verbreitungsgebiet können Anzeichen für adaptive Reaktionen auf Umweltveränderungen sein. Der Verifikator ist für sich allein genommen nicht aussagekräftig und sollte daher immer im Kontext mit anderen Verifikatoren des Indikators „Genetische Variation“ berücksichtigt werden.

\section{Verifikator: Allelische Vielfalt}

Der Allelreichtum (AR) entspricht der Gesamtzahl der Allele in einer Population für einen bestimmten Genort (Locus), gemittelt über alle Loci. Die allelische Vielfalt ist ein Schätzwert, der unter Einbeziehung des Stichprobenumfangs korrigiert wird (z.B. durch Verdünnung; sog. rarefaction). Er wird seltener als die Heterozygotie als Maß für die genetische Diversität verwendet, da es schwieriger ist, den stochastischen Prozess der genetischen Drift bei der Quantifizierung des Allelreichtums zu berücksichtigen. Dennoch wird die allelische Vielfalt als ein Parameter angesehen, der für die Generhaltung nützlicher ist als die Heterozygotie (Brown und Schoen 1992, Rajora und Mosseler 2001, Aravanopoulos 2011). Dieser Verifikator geht einher mit der Verwendung von genetischen Mikrosatelliten-Markern (SSR).

\section{Verifikator: Latentes genetisches Potential}

Das latente genetische Potenzial (LGP) ist ein wichtiger genetischer Parameter, der die Fähigkeit einer Population widerspiegelt, ihre Anpassungsfähigkeit im Hinblick auf die Vielzahl sich verändernder Umweltbedingungen zu erhalten (Stebbins und Hartl 1988, Bergmann et al. 1990). Eine populationsgenetische Analyse enthüllt ihr „wirksames genetisches Potential“ (d.h. den Teil ihrer genetischen Information, der das Überleben der Population unter den gegenwärtigen Bedingungen garantiert, was analog zur effektiven Anzahl der Allele ist), während der übrige Teil in diesem Zusammenhang derzeit „latent" ist. Dieser Teil der genetischen Vielfalt hängt mit seltenen Allelen in der Population zusammen, die dennoch eine bedeutende Rolle für die zukünftige Anpassung unter drastisch veränderten Umweltbedingungen spielen können, was insbesondere für Erhaltungsmaßnahmen von großer Bedeutung sein kann (Aravanopoulos 2011, 2016). Daher kann eine Veränderung, vor allem eine Verringerung des latenten genetischen Potenzials, auf eine Verringerung der gesamten Anpassungsfähigkeit der Population hindeuten. Das latente genetische Potenzial wird als Differenz der Gesamtanzahl und der effektiven Anzahl von Allelen summiert über alle Loci berechnet.

\section{Verifikator: Inzuchtkoeffizient}

Der Inzuchtkoeffizient $\left(F_{\mid S}\right)$ entspricht der Korrelation von sich vereinigenden Gameten relativ zu Gameten, die zufällig aus einer Teilpopulation gezogen wurden. Er beschreibt die Varianz innerhalb von Individuen relativ zu ihren Teilpopulationen. Der $F_{\text {IS }}$ hängt vom Verhältnis der beobachteten Heterozygoten zu dem unter dem HardyWeinberg-Gleichgewicht erwarteten Verhältnis ab, so dass er auch als die Reduktion der Heterozygotie eines Individuums im Vergleich zur Teilpopulation betrachtet werden kann (im Kontext mehrerer (Teil-)Populationen 
innerhalb einer Gesamt-(Meta-)Population). Eine Zunahme der Inzucht ist mit einer möglichen Verringerung der genetischen Vielfalt verbunden.

\section{Verifikator: Effektive Populationsgröße}

Die effektive Populationsgröße $\left(N_{e}\right)$ ist einer der wichtigsten (wenn nicht sogar der wichtigste) genetischen Parameter für das forstgenetische Monitoring, denn wenn sie gering ist, wird die genetische Drift deutlich wichtiger als die Selektion und spielt eine übergeordnete Rolle im Evolutionsprozess. Daher deutet eine Veränderung, insbesondere ein Absinken der effektiven Populationsgröße unter einen akzeptablen Schwellenwert, auf den Beginn der genetischen Drift (sowie auch der Inzucht) hin. Somit weist sie sowohl auf den Beginn zufälliger und stochastischer Prozesse in der Population als auch auf den Beginn der Inzucht und die mögliche Verringerung der genetischen Variation hin, wodurch insgesamt die zukünftige Anpassungsfähigkeit der Population in Frage gestellt wird. Die effektive Populationsgröße ist definiert als die Anzahl der Individuen, die mittels Kreuzung Gene für die nächste Generation beisteuern werden. Formeller ausgedrückt entspricht die effektive Populationsgröße einer tatsächlichen Population der Anzahl der Individuen in einer theoretisch idealen Population, die das gleiche Ausmaß an zufälliger genetischer Drift aufweist wie die tatsächliche Population. Es ist bekanntermaßen schwierig, die effektive Populationsgröße in natürlichen Populationen auf Grundlage demographischer Modelle abzuschätzen. Die derzeit am weitest verbreiteten Ansätze verwenden genetische Marker, die konservativer zu sein scheinen als demographische Modelle. In diesem Handbuch basiert die Schätzung der effektiven Populationsgröße auf genetischen Markern.

\section{Verifikator: Kopplungsungleichgewicht}

Das Kopplungsungleichgewicht (LD) ist die nicht-zufällige Assoziation von Allelen an verschiedenen Loci in jeder Population und tritt auf, wenn die Assoziation der verschiedenen Allele an einem Locus häufiger oder seltener ist als bei einer zufälligen (d.h. unabhängigen) Assoziation der Loci zu erwarten ist (Weir 1979). Das Kopplungsungleichgewicht kann sowohl durch evolutionäre Kräfte (siehe Hardy-Weinberg-Gleichgewicht oben) als auch durch demographische Eigenschaften (Populationsstruktur, asexuelle Reproduktion) beeinflusst werden. Ein Kopplungsungleichgewicht wird sich beispielsweise in kleinen Populationen, in Populationen unter dem Einfluss starker evolutionärer Kräfte oder im Fall von Beimischung manifestieren oder stärker hervortreten. Daher kann ein Kopplungsungleichgewicht ein starkes Anzeichen für zugrundeliegende genetische und demographische Prozesse in einer Population sein.

\section{Hintergrundinformation: Interspezifische Hybridisierung}

Die geschätzte interspezifische Hybridisierung ist ein wichtiger Parameter, wenn im Monitoringbestand oder dessen Umgebung sympatrische Populationen potenziell fremdbefruchtender Taxa existieren. Dies ist eine bei Waldbäumen nicht ungewöhnliche Situation, z.B. bei Tanne, Eiche, Esche, Pappel, usw. Die Abschätzung ist von größter Bedeutung, um das Erhaltungsziel in Bezug auf das betreffende Taxon zu beurteilen. Im Hinblick auf die Entwicklung der genetischen Vielfalt und Heterozygotie im Laufe der Zeit handelt es sich um ein sehr dynamisches Phänomen. Bei einer beobachteten Veränderung von Parametern der genetischen Vielfalt ist es deshalb wichtig zu wissen, ob die interspezifische Hybridisierung dabei eine Rolle gespielt hat. Interspezifische Hybridisierung wurde oft als Quelle für genetische und phänotypische Neuerungen und als Kraft der Evolution betrachtet (z.B. Leroy et al. 2017). Hybridisierung kann jedoch auch genetische Erosion verursachen, die Integrität von Arten beeinträchtigen und zum Aussterben von Arten führen (Soltis und Soltis 2009, Vit et al. 2014, Neale und Wheeler 2019). Erforderlich ist die Genotypisierung des mutmaßlichen Hybridschwarmes mit artspezifischen genetischen Markern unter Einbeziehung von Referenzproben der elterlichen Spezies in die Analyse. Im Idealfall sollte ein artspezifischer genetischer Marker der gleiche genetische Locus sein, der in der elterlichen Spezies 
vorhanden ist und in dem verschiedene Allele fixiert sind, die jedoch in der interspezifischen Hybridpopulation variabel sind. Die Hybridisierung wird prozentual berechnet als die Anzahl der Individuen, die artspezifische Allele beider Arten tragen, im Verhältnis zur Gesamtzahl. Basierend auf der Anzahl der Loci und Allele, die sich einer interspezifischen Schätzung unterziehen lassen, können weitere Informationen abgeleitet werden, wie z.B. die Häufigkeit von Rückkreuzungen oder höheren Filialgenerationen.

\section{Hintergrundinformation: Gametische Diversität}

Die gametische Diversität (hypothetische gametische Multilocus-Diversität; $V_{\text {gam }}$ ) definiert die tatsächliche oder potentielle Fähigkeit einer Population, sich durch Ausprägung verschiedener Allele an Umweltveränderungen anzupassen. Die gametische Diversität misst das Potenzial einer Population, genetisch diverse Gameten zu produzieren. Sie spiegelt einen Parameter der genetischen Variation wider, der unter sich verändernden Umweltbedingungen wichtig ist. Sie quantifiziert das Potenzial einer Population, genetisch unterschiedliche Gameten zu produzieren, die die nächste Generation bilden können (Müller-Starck 1995), und die Fähigkeit von Waldbaumpopulationen, genetische Variation zu erzeugen und damit die Anpassung an veränderte Umweltbedingungen zu erleichtern (Gregorius et al. 1986, Müller-Starck 1995). Daher kann eine Veränderung, insbesondere eine Reduktion der gametischen Diversität, aufeine Verringerung dergesamten Anpassungsfähigkeit der Population hindeuten. Die gametische Diversität $\bigvee_{\text {gam }}$ wird gemessen als die größtmögliche Anzahl verschiedener Allele, die maximale Anzahl möglicher Genotypen (als Einzelzählungen oder pro Locus), der Anteil der polymorphen Loci (P) und die durchschnittliche Anzahl von Allelen pro Locus. Sie wird als Gesamtheit der genannten Parameter bewertet.

\section{Hintergrundinformation: F-basierter Ausreißertest}

Die Identifikation von Ausreißer-Loci ist eine Analyse auf Populationsebene, bei der Schätzungen der populationsgenetischen Differenzierung verwendet werden, um Loci mit signifikant höherer oder niedrigerer genetischer Differenzierung zu erkennen als erwartet. Derartige Loci, die ein ungewöhnliches Variationsmuster aufweisen, unterliegen wahrscheinlich einer Selektion.

\section{Indikator III: GENFLUSS / PAARUNGSSYSTEM}

Der Indikator „Genfluss / Paarungssystem“ ermöglicht es, das Ausmaß des Genaustauschs zwischen Individuen und Populationen zu verfolgen, was für die künftige Anpassung und die Evolution von entscheidender Bedeutung ist. Es wird vorgeschlagen, inn anhand der unten aufgeführten Parameter zu bewerten.

\section{Verifikator: Genfluss (Nm)}

Als Genfluss wird der Genaustausch via Samen und Pollen zwischen Populationen bezeichnet, die sich in ihren genotypischen Häufigkeiten unterscheiden. Aus der Sicht der Erhaltungsgenetik, des forstgenetischen Monitorings und der forstlichen Züchtung kann der Genfluss entweder als vorteilhaft oder als schädlich angesehen werden (Burczyk et al. 2004). Er verursacht Veränderungen in der Zusammensetzung des Genpools (Allelhäufigkeiten) der Empfängerpopulation, indem Allele in ihren Genpool eingebracht werden. Die Integration neuer Allele durch den Genfluss erhöht die genetische Variabilität innerhalb der Population und ermöglicht Evolution und Merkmalskombinationen (Encyclopaedia Britannica 2019, Mallet 1999, Burczyk et al. 2004, Aravanopoulos 2011). Der Genfluss wird durch das Paarungssystem bestimmt, das die Rekombination und Vielfalt der Gene zwischen den Generationen vermittelt und das Ausmaß des Genaustauschs zwischen Individuen und Populationen bestimmt (Aravanopoulos 2011). Die Messung des Genflusses liefert indirekte Informationen über das Ausmaß der Migration zwischen Teilpopulationen. 


\section{Verifikator: Multilocus-Auskreuzungsrate der Population (tm)}

Das Paarungssystem ist einer der Schlüsselfaktoren für die genetische Struktur von Populationen (Hartl und Clark, 1989, Del Castillo und Trujillo 2008, Whitehead et al. 2018). Verschiedene Paarungssysteme beeinflussen das Niveau und die Dynamik der genetischen Vielfalt, die effektive Populationsgröße und die Differenzierung der Population, und können insgesamt die Widerstands- und Anpassungsfähigkeit einer Population verändern (Del Castillo und Trujillo 2008). Die Paarungssysteme von Pflanzen werden gewöhnlich durch das gemischte Paarungsmodell definiert, bei dem ein Teil der Samen und der daraus entstehenden Nachkommen auf einen unterschiedlich stark ausgeprägten Grad an Inzucht zurückzuführen ist, während der Rest aus zufälligen Auskreuzungen resultiert (Ritland 2002). Insbesondere die Auskreuzung fördert den Genfluss, homogenisiert die Populationen, erhöht die Heterozygotie und begünstigt das gametische Kopplungsungleichgewicht (Del Castillo und Trujillo 2008). Der Begriff der Auskreuzung bezieht sich auf die Verpaarung genetisch nicht verwandter Individuen und ist das Gegenteil von Inzucht (Aravanopoulos 2011). Die Multilocus-Auskreuzungsrate $\left(t_{m}\right)$ ist eine Schätzung des Anteils der ausgekreuzten Nachkommenschaft, die von der Gesamtpopulation produziert wird, wobei Auskreuzungsereignisse die Paarung zwischen verwandten und nicht verwandten Individuen einschließen. Eine Veränderung der Multilocus-Auskreuzungsrate, z.B. eine Zunahme, ist ein Hinweis auf die Stabilität oder sogar auf eine Steigerung der genetischen Multilocus-Variation; ein Ergebnis, das wahrscheinlich zu einer Erhaltung der Anpassungsfähigkeit der Population führen wird.

\section{Verifikator: Tatsächliche Inzuchtrate}

Die Schätzung der tatsächlichen Inzuchtrate (Einzellocus und Multilocus) basiert auf Saatgutdaten und genetischen Daten (Rajora et al. 2000, 2002; O' Connell et al. 2006). Auch dies ist ein wichtiger Parameter, da z.B. eine Erhöhung der Inzuchtrate zu einer Allelfixierung und zur Verminderung der genetischen Diversität einer Population führen kann. Die Schätzung von Inzuchtraten kann markerbasiert erfolgen. Da jedoch eine potenzielle Inzuchtdepression die Samenentwicklung und Keimung negativ beeinflussen kann, sind tatsächliche Inzuchtraten zuverlässiger. Die tatsächliche Inzuchtrate wird durch die Kombination von Inzuchtschätzungen (1 $-t_{m}$ ) aufgrund der Analyse des Paarungssystems und Inzuchtschätzungen auf der Basis von Samenmerkmalen berechnet. Sie ist das Verhältnis der: [Anzahl der hohlen Samen pro Frucht + (Anzahl der lebensfähigen Samen pro Frucht $\times$ Selbstbefruchtungsrate)] / [Anzahl der Inzucht-Samen pro Frucht + Anzahl der lebensfähigen Samen pro Frucht].

\section{Hintergrundinformation: Effektive Anzahl von Pollenspendern (Nep)}

Die effektive Anzahl von Pollenspendern ist die Anzahl der Pollenspender, die zu einer Samenfamilie beitragen. Die effektive Anzahl von Pollenspendern ist oft viel geringer als die absolute Zahl der beitragenden Pollenspender (Ritland, 1989, Smouse und Sork 2004, Sork und Smouse 2006). Ist die Zahl der Pollenspender klein, kann die Nachkommenschaft genetisch weniger vielfältig sein (Apsit et al. 2002). Informationen über die Wahrscheinlichkeit, dass Nachkommen denselben Vater teilen, können das Ausmaß der Diversität im Pollenspenderpool aufzeigen und ein Indikator für die effektive Anzahl von Pollenspendern $\left(\mathrm{N}_{\text {eр }}\right)$ für eine bestimmte Mutterpflanze sein (Ritland 1989). Bei auskreuzenden Arten kann die effektive Anzahl von Pollenspendern ein sensitiverer Indikator für die Paarung sein als die Auskreuzungsrate an sich. So kann z.B. nur ein einziger nicht verwandter Baum die Auskreuzung sicherstellen. Es ist daher sehr wichtig zu wissen, ob diese Auskreuzung wenige oder viele andere Bäume repräsentiert.

\section{Hintergrundinformation: Biparentale Inzucht}

Die Inzucht beeinflusst die Entwicklung vieler Pflanzen- und Tierpopulationen (Porcher und Lande 2016). Inzucht hat mehrere negative Folgen; so kann sie beispielsweise die effektive Populationsgröße (Paland und Schmid 2003, Tallmon et al. 2004) und die Anpassungsgeschwindigkeit von Populationen verringern (Glémin und Ronfort 2013). Bei monözischen Pflanzen kann Inzucht durch zwei verschiedene Mechanismen entstehen: (a) biparentale 
Inzucht, wenn sich eine Pflanze mit einem verwandten Individuum paart, oder (b) Selbstbefruchtung, wenn sich eine Pflanze mit sich selbst paart (Furstenau und Cartwright 2017). Biparentale Inzucht oder Paarung zwischen Verwandten kommt mit unterschiedlicher Häufigkeit in vielen natürlichen Pflanzenpopulationen vor, die oft auch beträchtliche Selbstbefruchtungsraten aufweisen (Ritland 2002, Porcher und Lande 2016). Im Gegensatz zur zufälligen Paarung führt biparentale Inzucht zu vermehrter Selbstbefruchtung oder erhöhter Homozygotie (Ritland 2002, Porcher und Lande 2016).

\section{Quellen}

Alizoti PG, Kilimis K, Gallios P (2010) Temporal and spatial variation of flowering among Pinus nigra Arn. clones under changing climatic conditions. For Ecol Manag 259:786-797. https://doi.org/10.1016/j.foreco.2009.06.029

Apsit VJ, Dyer RJ, Sork VL (2002) Patterns of mating in an insect-pollinated tree species in the Missouri Ozark Forest Ecosystem Project. In: Shifley SR; Kabrick JM (eds) Proceedings of the Second Missouri Ozark Forest Ecosystem Project Symposium: Post-treatment results of the landscape experiment. General Technical Report NC-227. US Dept of Agriculture, Forest Service, North Central Forest Experiment Station, St. Paul, MN, pp 212-226. https://doi. org/10.2737/NC-GTR-227

Aravanopoulos FA (2011) Genetic monitoring in natural perennial plant populations. Botany 89:75-81. https://doi. org/10.1139/B10-087

Aravanopoulos FA (2016) Conservation and monitoring of tree genetic resources in temperate forests. Curr For Rep 2(2):29119. https://doi.org/10.1007/s40725-016-0038-8

Aravanopoulos FA, Tollefsrud MM, Kätzel R, Soto A, Graudal L, Nagy L, Koskela J, Bozzano M, Pilipovic A, Zhelev P, Božič G (2015) Development of genetic monitoring methods for genetic conservation units of forest trees in Europe. European Forest Genetic Resources Programme (EUFORGEN), Bioversity International, Rome, Italy

Bergmann F, Gregorius HR, Larsen JB (1990) Levels of genetic variation in European Silver fir (Abies alba) - Are They Related to the Species Decline? Genetica 82(1):1-10. https://doi.org/10.1007/BF00057667

Bhumibhamon S (1978) Studies on Scots pine seed orchards in Finland with special emphasis on the genetic composition of the seed. Commun Inst For Fenn 94:1-118

Boyle TJ (2000) Criteria and indicators for the conservation of genetic diversity. In: Young A, Boshier T, Boyle T (eds) Forest conservation genetics. CSIRO Publ., Collingwood, pp 239-251

Brown AHD, Schoen DJ (1992) Plant population genetic structure and biological conservation. In: Sandlund OT, Hindar K, Brown AHD (eds) Conservation of Biodiversity for Sustainable Development Scandinavian University Press, Oslo, pp 88-104.

Burczyk J, DiFazio SP, Adams WT (2004) Gene flow in forest trees: How far do genes really travel? For Genet 11:179-192

Chuine I (2010) Why does phenology drive species distribution? Philos Trans R Soc Lond B Biol Sci 365:3149-3160. https://doi.org/10.1098/rstb.2010.0142

de Melo RB, Franco AC, Silva CO, Piedade MTF, Ferreira CS (2015) Seed germination and seedling development in response to submergence in tree species of the Central Amazonian floodplains. AoB Plants 7:plv041. https://doi. org/10.1093/aobpla/plv041

Del Castillo RF, Trujillo S (2008) Effect of inbreeding depression on outcrossing rates among populations of a tropical pine. New Phytol 177:517-524. https://doi.org/10.1111/j.1469-8137.2007.02260.x

Ducci F, De Cuyper B, Pâques LE, Proietti R, Wolf H (2012) Reference protocols for assessment of trait and reference genotypes to be used as standards in international research projects. CRA SEL, Arezzo, Italy

El-Kassaby YA, Fashler AMK, Sziklai O (1984) Reproductive phenology and its impact on genetically improved seed production in a Douglas-fir seed orchard. Silvae Genet 33:120-125.

El-Kassaby YA, Ritland L, Fashler AMK, Devitt D (1988) The role of reproductive phenology upon the mating system of a Douglas-fir seed orchard. Silvae Genet 37: 76-82

Feld CK, da Silva PM, Sousa JP, De Bello F, Bugter R, Grandin U, Hering D, Lavorel S, Mountford O, Pardo I, Pärtel M, Römbke J, Sandin L, Jones KB, Harrison P (2009) Indicators of biodiversity and ecosystem services: a synthesis across ecosystems and spatial scales. OIKOS 118:1862-1871. https://doi.org/10.1111/j.1600-0706.2009.17860.x

Furstenau TN, Cartwright RA (2017) The impact of self-incompatibility systems on the prevention of biparental inbreeding. PeerJ 5:e4085. https://doi.org/10.7717/peerj.4085/supp-1

Geburek T (2004) Die Weitergabe genetischer Information - eine wichtige Komponente bei der Waldverjüngung. BFWPraxisinformation 4:18-20. 
Glémin S, Ronfort J (2013) Adaptation and maladaptation in selfing and outcrossing species: new mutations versus standing variation. Evolution 67:225-240. https://doi.org/10.1111/j.1558-5646.2012.01778.x

Graudal L, Aravanopoulos F, Bennadji Z, Changtragoon S, Fady B, Kjær ED, Loo J, Ramamonjisoa L, Vendramin GG (2014) Global to local genetic diversity indicators of evolutionary potential in tree species within and outside forests. For Ecol Manag 333:35-51. https://doi.org/10.1016/j.foreco.2014.05.002

Gregorius HR, Krauhausen J, Müller-Starck G (1986) Spatial and temporal genetic differentiation among the seed in a stand of Fagus sylvatica L. Heredity 57:255-262. https://doi.org/10.1038/hdy.1986.116

Hartl DL, Clark AG (1989) Principles of population genetics, 2nd edn. Sinauer Associates, Sunderland, Massachusetts, USA

Konnert M, Maurer W, Degen B, Kätzel R (2011) Genetic monitoring in forests - early warning and controlling system for ecosystemic changes. Iforest 4:77-81. https://doi.org/10.3832/ifor0571-004

Leroy T, Roux C, Villate L, Bodénès C, Romiguier J, Paiva JAP, Dossat C, Aury JM, Plomion C, Kremer A, (2017) Extensive recent secondary contacts between four European white oak species. New Phytol 214:865-878. https://doi. org/10.1111/nph.14413

Mallet J (2001) Gene flow. In: Woiwod IP, Reynolds DR, Thomas CD (eds) Insect movement: Mechanisms and consequences: Proceedings of the Royal Entomological Society‘s 20th Symposium. CABI Publishing, Wallingford, UK, pp 337-360

Merriam-Webster (n.d.) "Outcrossing". Merriam-Webster.com Dictionary. https://www.merriam-webster.com/dictionary/ outcrossing. Accessed 16 December 2019

Merriam-Webster Inc. (2003) Merriam-Webster's collegiate dictionary, 11th edn. Merriam-Webster Incorporated, Springfield, Massachusetts, USA

Müller-Starck G (1995) Genetic variation in high elevated populations of Norway spruce (Picea abies (L.) Karst.) in Switzerland. Silvae Genet 44:356-361

Müller-Starck G., Ziehe M., Schubert R. (2005) Genetic diversity parameters associated with viability selection, reproductive efficiency, and growth in forest tree species. In: Scherer-Lorenzen M, Körner C, Schulze ED (eds) Forest diversity and function. Ecological studies (Analysis and synthesis), vol 176. Springer, Berlin, Heidelberg, pp 87-108. https://doi.org/10.1007/3-540-26599-6_5

Mund M, Kutsch WL, Wirth C, Kahl T, Knohl A, Skomarkova MV, Schulze ED (2010) The influence of climate and fructification on the inter-annual variability of stem growth and net primary productivity in an old-growth, mixed beech forest. Tree Physiol 30:689-704. https://doi.org/10.1093/treephys/tpq027

Namkoong G, Boyle T, Gregorious HR, Joly H, Savolainen O, Ratman W, Young A (1996) Testing criteria and indicators for assessing the sustainability of forest management: genetic criteria and indicators. Working paper No. 10. Centre for International Forestry Research, Bogor, Indonesia. https://doi.org/10.17528/cifor/000070

Neale DB, Wheeler NC (2019) Hybridization and Introgression. In: The Conifers: Genomes, Variation and Evolution. Springer, Cham, pp 387-429. https://doi.org/10.1007/978-3-319-46807-5_15

O'Connell LM, Mosseler A, Rajora OP (2006) Impacts of forest fragmentation on the mating system and genetic diversity of white spruce (Picea glauca) at the landscape level. Heredity 97 (6): 418-426. https://doi.org/10.1038/sj.hdy.6800886.

Paland S, Schmid B (2003) Population size and the nature of genetic load in Gentianella germanica. Evolution 57:22422251. https://doi.org/10.1111/j.0014-3820.2003.tb00236.x

Porcher E, Lande R (2016) Inbreeding depression under mixed outcrossing, self-fertilization and sib-mating. BMC Evol Biol 16:105. https://doi.org/10.1186/s12862-016-0668-2

Rajora OP, Mosseler A, Major JE (2000) Indicators of population viability in red spruce, Picea rubens. II. Genetic diversity, population structure, and mating behavior. Can J Bot 78:941-956. https://doi.org/10.1139/b00-066

Rajora OP, Mosseler A (2001) Challenges and opportunities for conservation of forest genetic resources. Euphytica 118:197-212. https://doi.org/10.1023/A:1004150525384

Rajora OP, Mosseler A, Major JE (2002) Mating system and reproductive fitness traits of eastern white pine (Pinus strobus) in large, central versus small, isolated, populations. Can J Bot 80(11): 1173-1184. doi:10.1139/B02-105.

Rao NK, Hanson J, Dulloo ME, Ghosh K, Nowell D, Larinde M (2006) Manual of seed handling in genebanks. Handbooks for Genebanks No. 8. Bioversity International, Rome, Italy

Ritland K (1989) Correlated matings in the partial selfer Mimulus guttatus. Evolution 43:848-859. https://doi. org/10.1111/j.1558-5646.1989.tb05182.x

Ritland K (2002) Extensions of models for the estimation of mating systems using $n$ independent loci. Heredity 88:221-228. https://doi.org/10.1038/sj.hdy.6800029

Seifert T, Müller-Starck G (2009) Impacts of fructification on biomass production and correlated genetic effects in Norway spruce (Picea abies [L.] Karst.). Eur J For Res 128:155. https://doi.org/10.1007/s10342-008-0219-5 
Selås V, Piovesan G, Adams JM, Bernabei M (2002) Climatic factors controlling reproduction and growth of Norway spruce in southern Norway. Can J For Res 32:217-225. https://doi.org/10.1139/x01-192

Smouse PE, Sork VL (2004) Measuring pollen flow in forest trees: An exposition of alternative approaches. For Ecol Manag 197:21-38. https://doi.org/10.1016/j.foreco.2004.05.049

Soltis P S, Soltis DE (2009) The role of hybridization in plant speciation. Annu Rev Plant Biol 60:561-588. https://doi. org/10.1146/annurev.arplant.043008.092039

Sork VL, Smouse PE (2006) Genetic analysis of landscape connectivity in tree populations. Landsc Ecol 21:821-836. https://doi.org/10.1007/s10980-005-5415-9

Sparks TH, Butchart SHM, Balmford A, et al. (2011) Linked indicator sets for addressing biodiversity loss. Oryx 45:411-419. https://doi.org/10.1017/S003060531100024X

Stebbins GL, Hartl DL (1988) Comparative evolution: Latent potentials for anagenetic advance. Proc Natl Acad Sci USA 85(14):5141-5145

Tallmon DA, Luikart G, Beaumont MA (2004) Comparative evaluation of a new effective population size estimator based on approximate Bayesian computation. Genetics 167:977-988. https://doi.org/10.1534/genetics.103.026146

Encyclopaedia Britannica (2019) "Gene flow«. Encyclopædia Britannica. https://www.britannica.com/science/gene-flow. Accessed 16 December 2019

The International Seed Testing Association (ISTA) (2020) International Rules for Seed Testing. Bassersdorf, Switzerland. https://doi.org/10.15258/istarules.2020.F

UNEP/WCMC (2011) National Indicators, Monitoring and Reporting for the Strategic Plan for Biodiversity 2011-2020

Vit P, Wolfova K, Urfus T, Tajek P, Suda J (2014) Interspecific hybridization between rare and common plant congeners inferred from genome size data: assessing the threat to the Czech serpentine endemic Cerastium alsinifolium. Preslia 86:95-117

Wang Z, Wang L, Liu Z, Li Y, Liu Q, Liu B (2016) Phylogeny, seed trait, and ecological correlates of seed germination at the community level in a degraded sandy grassland. Front Plant Sci 17. https://doi.org/10.3389/fpls.2016.01532

Weir BS (1979) Inferences about linkage disequilibrium. Biometric 35(1):235-254. https://doi.org/10.2307/2529947

Whitehead MR, Lanfear R, Mitchell RJ, Karron JD (2018). Plant mating systems often vary widely among populations. Front Ecol Evol 6. https://doi.org/10.3389/fevo.2018.00038 


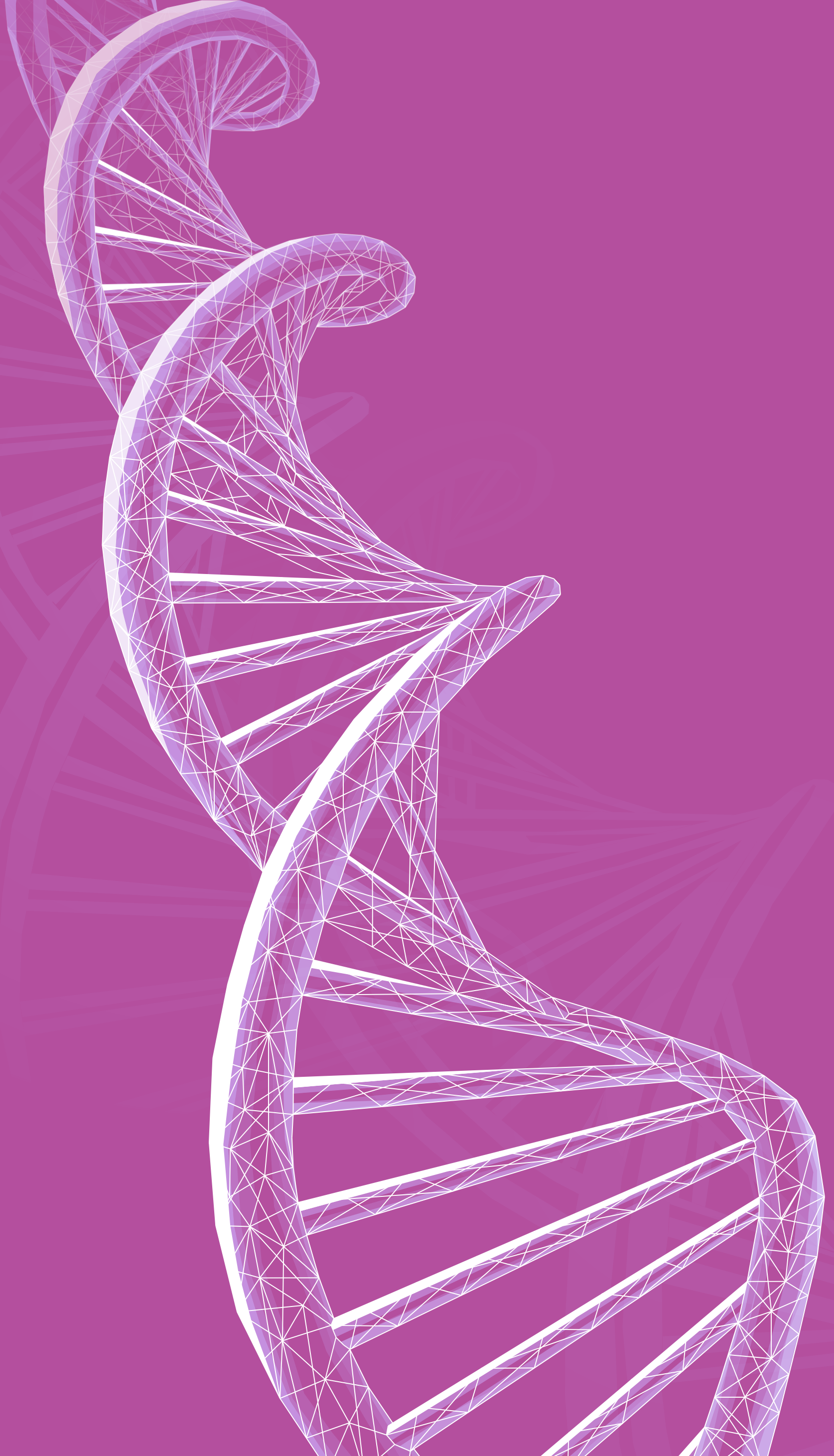




\section{势 \\ LIFE13 ENV/SI/000148}

\section{Handbuch zum Forstgenetisches Monitoring}

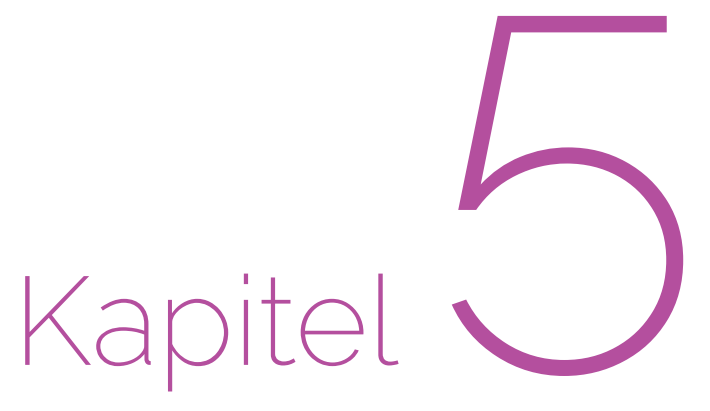

\section{GELÄNDEARBEITEN}

Darius KAVALIAUSKAS', Barbara FUSSI', Filippos A. ARAVANOPOULOS²,

Paraskevi ALIZOTI², Marjana WESTERGREN ${ }^{3}$, Marko BAJC ${ }^{3}$, Rok DAMJANIĆ3

Natalija DOVČ${ }^{3}$, Ermioni MALLIAROU ${ }^{2}$, Evangelia AVRAMIDOU 2,4 ,

Dalibor BALLIAN ${ }^{3,5}$, Pavlos BEKIAROGLOU ${ }^{6}$, Gregor BOŽIČ ${ }^{3}$, Andrej BREZNIKAR7,

Pavlos CHASILIDIS ${ }^{6}$, Anna-Maria FARSAKOGLOU ${ }^{2,8}$, Domen FINŽGAR ${ }^{3,9}$,

Ioannis GANOPOULOS ${ }^{2,10}$, Fotios KIOURTSIS ${ }^{6}$, Monika KONNERT',

Nataša ŠIBANC ${ }^{3}$, Nikolaos TOURVAS², Hojka KRAIGHER ${ }^{3}$

Zitat: Kavaliauskas et al. (2020) Geländearbeiten. In: Bajc et al. (Ed.) Handbuch zum forstgenetischen Monitoring. Slowenisches Forstinstitut: Verlag Silva Slovenica, Ljubljana, S. 49-69. http://dx.doi.org/10.20315/SFS.176

Institut:

1. Bayerisches Amt für Waldgenetik (AWG), Deutschland

2. Aristoteles-Universität Thessaloniki (AUTH), Griechenland

3. Slowenisches Forstinstitut (SFI), Slowenien

4. Institut für Mediterrane Waldökosysteme, ELGO DEMETER, Griechenland

5. Forstfakultät, Universität Sarajevo, Bosnien und Herzegowina

6. Generaldirektion für Forst und Landwirtschaft, Dezentrale Verwaltung von MazedonienThrakien, Griechenland

7. Slowenische Forstverwaltung (SFS), Slowenien

8. Europäisches Programm für forstgenetische Ressourcen (EUFORGEN), Europäische Forstinstitut (EFI) (EFI), Spanien

9. Institut für Evolutionäre Biologie, Universität von Edinburgh, Großbritannien

10. Institut für Pflanzenzüchtung und genetische Ressourcen, HAO ELGO DEMETER, Griechenland 


\subsection{EINLEITUNG}

Dieses Kapitel enthält detaillierte Empfehlungen zur Vorbereitung und Durchführung der regelmäßigen Außenaufnahmen im Rahmen des forstgenetischen Monitorings (FGM), nachdem die FGM-Fläche ausgewählt und eingerichtet wurde. Die regelmäßige Arbeit auf der FGM-Fläche hängt vom FGM-Niveau (Basis, Standard oder Intensiv) ab, das regelmäßig erfasst werden muss (z.B. phänologische Beobachtungen, Mortalität, Abundanz der Naturverjüngung, Probenahme usw.). Um vergleichbare Ergebnisse zu erhalten, müssen die Arbeit im Gelände und die Verfahren zur Datenerhebung optimiert und standardisiert werden, sodass die aus den Laboruntersuchungen gewonnenen Informationen bestätigt bzw. ergänzt werden können. Detaillierte Verfahrensanweisungen für die Arbeit im Gelände sind daher von zentraler Bedeutung für das FGM. Nach einer gewissen Vorbereitung und Schulung können die regelmäßigen Außenaufnahmen im Prinzip von technischem Personal, Försterlnnen oder Wissenschaftlerlnnen ausgeführt werden. 


\subsection{IM GELÄNDE ERFASSTE VERIFIKATOREN UND HINTERGRUNDINFORMATIONEN}

Eine Liste der Verifikatoren und Hintergrundinformationen, die im Zuge der Außenaufnahmen auf den verschiedenen FGM-Niveaus (Basis-, Standard- oder Intensiv) erfasst werden sollen, sind in der Tabelle 5.1 aufgeführt (Beispiel aus dem FGM-Leitfaden der Rotbuche).

Tabelle 5.1: Liste der Verifikatoren und Hintergrundinformationen, die während der Außenaufnahmen auf den Monitoringflächen der Rotbuche zu erfassen sind; jeweils mit Kurzbeschreibung und Beobachtungshäufigkeit.

\begin{tabular}{|c|c|c|c|c|}
\hline & Name & Basisniveau & Standardniveau & Intensivniveau \\
\hline \multirow{5}{*}{ 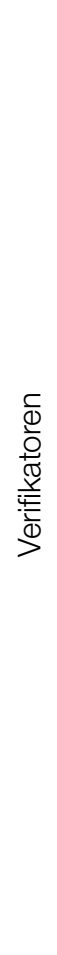 } & \multirow[t]{2}{*}{$\begin{array}{l}\text { Mortalität / } \\
\text { Überlebensrate }\end{array}$} & $\begin{array}{l}\text { Altbäume: Zählung der } \\
\text { verbleibenden markierten Bäume } \\
\text { alle } 10 \text { Jahre und nach jedem } \\
\text { extremen Witterungsereignis/ } \\
\text { jeder Störung }\end{array}$ & wie Basisniveau & wie Basisniveau \\
\hline & & Naturverjüngung: / & $\begin{array}{l}\text { Zählung der verbleibenden } \\
\text { Sämlinge auf den NV-Plots, } \\
\text { zweimal pro Jahrzehnt }\end{array}$ & wie Standardniveau \\
\hline & \multirow[b]{2}{*}{ Fruktifikation } & $\begin{array}{c}\text { bestandesweise Schätzung; } \\
\text { jährlich }\end{array}$ & $\begin{array}{l}\text { Erfassung auf Einzelbaumebene, } \\
\text { während zwei bedeutenden } \\
\text { Blühereignissen pro Jahrzehnt, } \\
\text { idealerweise in gleichen } \\
\text { Abständen * }\end{array}$ & $\begin{array}{l}\text { Erfassung auf Einzelbaumebene, } \\
\text { während zwei bedeutenden } \\
\text { Blühereignissen pro Jahrzehnt, } \\
\text { idealerweise in gleichen } \\
\text { Abständen * }\end{array}$ \\
\hline & & $\begin{array}{l}\text { bestandesweise Schätzung; } \\
\text { jährlich }\end{array}$ & $\begin{array}{l}\text { Erfassung auf Einzelbaum- } \\
\text { ebene im selben Jahr, in dem } \\
\text { die Erfassung der Blüte auf } \\
\text { Basisniveau erfolgt (unabhängig } \\
\text { von der Fruktifikationsintensität) * }\end{array}$ & $\begin{array}{l}\text { Zählung der Früchte in } \\
\text { den gleichen Jahren, in } \\
\text { denen die Bewertung der } \\
\text { Blüte auf Intensivniveau } \\
\text { erfolgt, unabhängig von der } \\
\text { Fruktifikationsintensität* } \\
\text { Bei jedem erfassten Fruktifika- } \\
\text { tionsereignis wird auch Saatgut } \\
\text { für Laboranalysen gesammelt }\end{array}$ \\
\hline & $\begin{array}{l}\text { Abundanz der } \\
\text { Naturverjüngung }\end{array}$ & $\begin{array}{c}\text { bestandesweise Schätzung; } \\
\text { jährlich }\end{array}$ & $\begin{array}{l}\text { Zählung der Sämlinge im 1. und } \\
\text { 6. Jahr nach jedem erfassten } \\
\text { Fruktifikationsereignis }\end{array}$ & $\begin{array}{l}\text { Zählung der Sämlinge im 1., 6., } \\
\text { 11. und 16. Jahr nach jedem } \\
\text { erfassten Fruktifikationsereignis }\end{array}$ \\
\hline \multirow{5}{*}{ 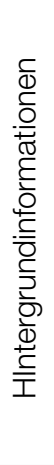 } & $\begin{array}{l}\text { Durchmesser- } \\
\text { klassenver- } \\
\text { teilung }\end{array}$ & / & Messung alle 10 Jahre & wie Standardniveau \\
\hline & $\begin{array}{l}\text { Höhenklassen- } \\
\text { verteilung }\end{array}$ & / & Messung alle 10 Jahre & Same as standard level \\
\hline & $\begin{array}{c}\text { wie } \\
\text { Standardniveau }\end{array}$ & / & $\begin{array}{c}\text { Individual tree level observation, } \\
\text { every } 5 \text { years }\end{array}$ & $\begin{array}{l}\text { Individual tree level observation, } \\
\text { every year }\end{array}$ \\
\hline & Austrieb & / & $\begin{array}{l}\text { Erfassung auf Einzelbaumebene; } \\
\text { alle } 5 \text { Jahre }\end{array}$ & $\begin{array}{c}\text { Erfassung auf Einzelbaumebene; } \\
\text { jährlich }\end{array}$ \\
\hline & Seneszenz & / & $\begin{array}{l}\text { Erfassung auf Einzelbaumebene; } \\
\text { alle } 5 \text { Jahre }\end{array}$ & $\begin{array}{l}\text { Erfassung auf Einzelbaumebene; } \\
\text { jährlich }\end{array}$ \\
\hline & $\begin{array}{l}\text { Blühsynchroni- } \\
\text { sation }\end{array}$ & / & / & $\begin{array}{l}\text { Erfassung auf Einzelbaum- } \\
\text { ebene, während jedes erfassten } \\
\text { bedeutenden Blühereignisses }\end{array}$ \\
\hline
\end{tabular}

* Idealerweise sollte mindestens ein größeres Fruktifikationsereignis pro Jahrzehnt bewertet werden. Ein bedeutendes Blühereignis führt jedoch nicht unbedingt zu einem bedeutenden Fruktifikationsereignis. Wenn auf das bewertete Blühereignis kein wesentliches Fruktifikationsereignis folgt, muss die Bewertung sowohl der Blüte als auch der Fruchtbildung beim nächsten bedeutenden Blühereignis wiederholt werden, unabhängig von der Zeit, die zwischen aufeinanderfolgenden bedeutenden Blühereignissen liegt. Erhebungen auf Basisniveau werden zur Identifizierung bedeutender Blüh- und Fruktifikationsereignisse verwendet. 


\subsubsection{Verifikator: Mortalität/ Überlebensrate}

Eine Veränderung der Mortalität oder der Überlebensrate (Mortalität = 1-Überlebensrate) deutet auf einen zugrundeliegenden Selektionsdruck hin, d.h. auf einen Rückgang der Population, wenn der Wert für Mortalität zunimmt. Die Mortalität / Überlebensrate bezieht sich auf die Anzahl der Bäume, die im Vergleich zum Ausgangswert (und der vorhergehenden Erfassung) abgestorben sind. Der Grund für den Rückgang sollte untersucht und wenn möglich aufgezeichnet werden (Extremwetterereignisse, Krankheit, Alter etc.). Um die Ursache des Rückgangs und seine räumliche Ausdehnung zu bestimmen (ist die höhere Mortalität lokal begrenzt oder weiter verbreitet), sollten die ortsansässigen Försterlnnen hinzugezogen werden.

\subsubsection{Altbäume}

Der Verifikator für die Mortalität von Altbäumen wird geschätzt, indem die verbleibenden lebenden Beobachtungsbäume alle 10 Jahre und nach jedem extremen Witterungsereignis bzw. jeder Störung gezählt werden. Die Mortalität ist die Differenz zwischen der ursprünglichen Anzahl markierter Beobachtungsbäume und den davon verbleibenden lebenden Bäumen der ursprünglichen 50 Beobachtungsbäume.

\subsubsection{Naturverjüngung}

Die Mortalität/ Überlebensrate der Naturverjüngung wird nur etwa alle 5 Jahre für das Standard- bzw. Intensivniveau erfasst, berechnet anhand der Zählung der NV-Abundanz.

Die Mortalität der Naturverjüngung wird auf Grundlage des Verifikators „Abundanz der Naturverjüngung“ von zwei aufeinanderfolgenden Erhebungen berechnet (die zweimal im Jahrzehnt durchgeführt werden, idealerweise etwa alle 5 Jahre).

\subsubsection{Verifikator: Abundanz der Naturverjüngung}

Dieser Verifikator beschreibt das Vorkommen und die Abundanz der Naturverjüngung auf der Monitoringfläche. Für das Basisniveau wird dieser Verifikator jedes Jahr im Herbst auf Bestandesebene erfasst. Zur Beurteilung der Situation auf der gesamten Monitoringfläche werden Expertenmeinungen herangezogen. Zwei Werte sollten hierzu erfasst werden, einer für die neue Naturverjüngung (Keimlinge aus dem laufenden Jahr), einer für die etablierte Naturverjüngung (kleine Bäume, die den neuen Bestand bilden).

Für das Standard- und Intensivniveau wird dieser Verifikator durch Zählung der Keimlinge in jedem der 20 NV-Plots erfasst. Die Zählung beginnt im ersten Herbst nach der Keimung im Anschluss an ein erfasstes Fruktifikationsereignis und wird für das Standardniveau im 5. Herbst, für das Intensivniveau im 5., 10. und 15. Herbst wiederholt. Die Zeit zwischen Fruktifikationsereignis und Keimung hängt von der Keimruhe und der betrachteten Baumart ab. Alle Keimlinge in den 20 Naturverjüngungsplots müssen gezählt werden. Etablierte Verjüngung in den Naturverjüngungsplots darf nicht mitgezählt werden. Bei der nächsten Zählung wird nur etablierte Verjüngung im entsprechenden Alter gezählt, d.h. im 6. Jahr 5-jährige Jungpflanzen.

Da auf jedem $1 \mathrm{~m}^{2}$-NV-Plot viele Keimlinge bzw. etablierte Naturverjüngung vorhanden sein können, wird zur Erleichterung der Zählung die Verwendung eines „Gitternetzes“ empfohlen, d.h. die Unterteilung der NV-Plots in kleinere Quadrate. Ein einfacher und effizienter Weg, dies in der Fläche umzusetzen, besteht darin, ein Netz aus Schnüren oder Seilen zu erstellen, dessen Ecken an den Metallstäben befestigt werden, die zur Markierung der NV-Plots verwendet werden (Abbildung 5.1; Unterkapitel 3.2.3.2). 


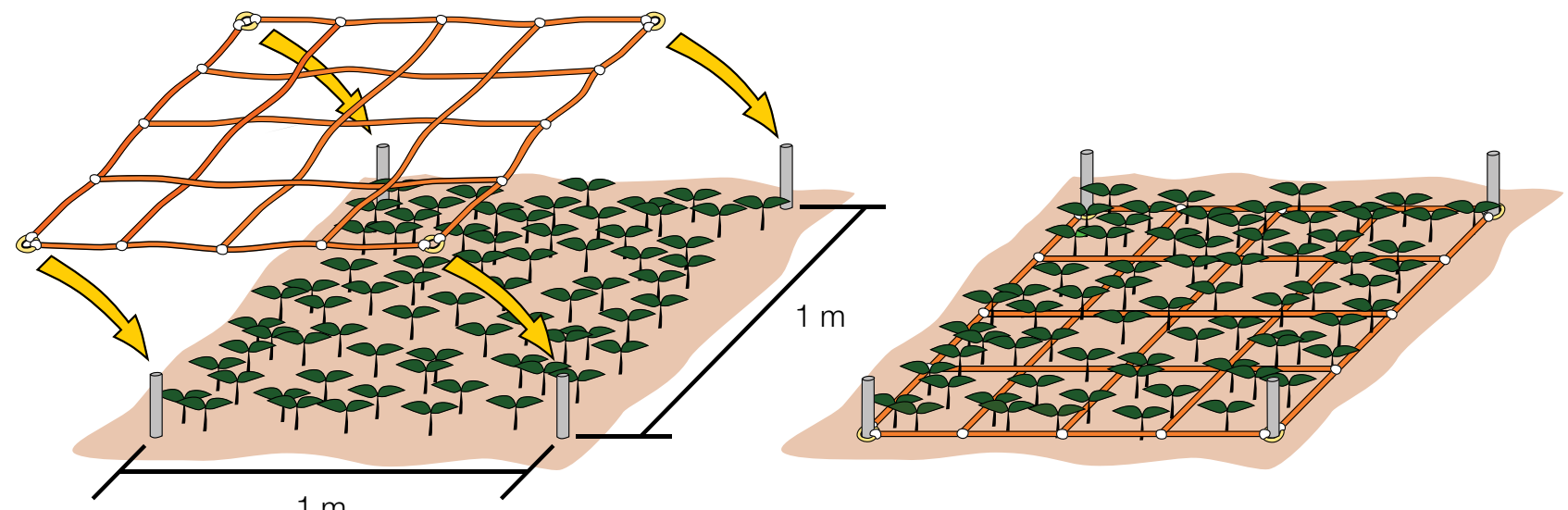

Abbildung 5.1: Die Zählung der Keimlinge bzw. der etablierten Verjüngung zur Erfassung der Abundanz der Naturverjüngung erfolgt am besten mithilfe eines Gitternetzes. Ein Netz aus Schnüren oder Seilen wird an den Metallstäben befestigt, die zur Markierung der NV-Plots verwendet werden. Die Pflanzen werden dann in jeder Zelle des Gitters separat gezählt und die Zahlen dann zusammengefasst, um die Summe für den gesamten NV-Plot zu erhalten. Ein solcher Ansatz erleichtert die Erfassung, da es im Vergleich zur Zählung über den gesamten NV-Plot viel einfacher ist, zu verfolgen, welche Pflanzen bereits gezählt wurden und welche nicht.

\subsubsection{Hintergrundinformation: Durchmesserklassenverteilung}

Der BHD [cm] wird in 1,30 m Höhe, d.h. ungefähr in Brusthöhe eines Erwachsenen im rechten Winkel zur Sprossachse mit einer Kluppe gemessen. Alternativ kann ein Maßband verwendet werden, mit dem zunächst der Baumumfang gemessen und dann der Durchmesser berechnet wird. Wird eine Kluppe verwendet, müssen zwei um $90^{\circ}$ versetzte Messungen vorgenommen werden, aus denen dann ein Mittelwert berechnet wird, um Bäume mit asymmetrischem Stammquerschnitt adäquat zu berücksichtigen. Wenn ein Baum mehrstämmig ist, werden alle Durchmesser der einzelnen Stämme gemessen und der Mittelwert berechnet und dokumentiert. Hier sollte ein Vermerk gemacht werden, dass der Baum mehrstämmig ist inklusive Angabe der Anzahl der gemessenen Stämme. Auf geneigtem Gelände muss der BHD vom Unterhang aus im rechten Winkel zur Sprossachse gemessen werden. Die Durchmesserklassenverteilung wird als Teil der deskriptiven Statistik der Bestandesdaten geschätzt.

Erforderliche Ausrüstung:

- eine Kluppe oder alternativ ein Maßband, mit dem zunächst der Baumumfang gemessen und dann der Durchmesser berechnet wird.

\subsubsection{Hintergrundinformation: Höhenklassenverteilung}

Die Baumhöhe [m mit einer Dezimalstelle] wird vom Boden bis zum höchsten Punkt der Krone gemessen, idealerweise mit einem Klinometer oder einem Teleskopmessstab (für kleine Bäume).

Erforderliche Ausrüstung:

- Hypsometer/ Maßband für Höhenmessung

- Teleskopmessstab (für kleine Bäume) 


\subsection{PHÄNOLOGISCHE BEOBACHTUNGEN}

\subsubsection{Einführung in die Phänologie}

Unter Phänologie versteht man die Beobachtung des zeitlichen Ablaufs biologischer Ereignisse wie z.B. Blüte oder Blattaustrieb bei Pflanzen. Phänologische Prozesse (z.B. Austrieb, Blüte etc.) werden durch zahlreiche umweltbedingte (z.B. Kältereiz, Temperatursumme etc.) und physiologische Faktoren ausgelöst, sind aber auch in hohem Maße genetisch bedingt (Ducci et al. 2012). Daten über den Zeitpunkt und die Dauer bestimmter phänologischer Ereignisse (Austrieb, Blüte, Blattseneszenz etc.) liefern wichtige Hinweise für das Verständnis des tatsächlichen Zustandes der Bäume und Waldbaumpopulationen in der sich verändernden Umwelt. Zeitliche Verschiebungen von phänologischen Ereignissen können durch verschiedene Faktoren verursacht werden, z.B. Klimaschwankungen und -veränderungen oder andere Umweltveränderungen, was nicht nur den Zustand der einzelnen Bäume, sondern auch ökologische Prozesse (z.B. Paarungssystem) auf Populationsebene beeinflusst (Beuker et al. 2010). Daten über die phänologischen Phasen (sog. Phänophasen) von Austrieb, Blüte, Blattseneszenz etc. werden für eine integrierte Bewertung verschiedener Aspekte innerhalb des FGM benötigt. Die Fähigkeit einer Art, sich über phänologische Verschiebungen langfristig an die abiotischen Umweltbedingungen anzupassen, kann als ein Indikator für ihre Anfälligkeit gegenüber zukünftigen klimatischen Veränderungen angesehen werden. Das Hauptziel der phänologischen Beobachtungen auf den FGM-Flächen ist es, zusätzliche und ergänzende Informationen über Zustand und Entwicklung phänologischer Charakteristika in Bezug auf das Wachstum des Waldbestandes im Laufe des Jahres zu liefern. Die im Zuge der phänologischen Beobachtungen gewonnenen Daten tragen zum FGM bei und ermöglichen es, Zustand und Tendenzen der Entwicklungsstadien der Waldbaumpopulation über das Jahr sowie ihre Abhängigkeit von verschiedenen Bedingungen zu bestimmen. Es ist wichtig, Tendenzen und mögliche Faktoren (natürliche und/ oder anthropogene) zu erkennen, die eine Veränderung des Zeitpunkts und der Dauer phänologischer Stadien verursachen (Anfangszeitpunkt, Dauer, Intensität) (Beuker et al. 2010). Verschiebungen in der Phänologie der Arten können somit zu Störungen in Ökosystemprozessen und -leistungen führen, von denen die menschlichen Lebensgrundlagen abhängen.

\subsubsection{Phänologische Verifikatoren und Hintergrundinformationen}

\subsubsection{Verifikator: Blüte}

Die Phänologie der Blüte ist die Beobachtung des zeitlichen Ablaufs der männlichen und weiblichen Blütenentwicklung über die Erfassung verschiedener Phänophasen (Ducci et al. 2012). Die Phänologie der Blüte ist ein entscheidender Faktor, der die reproduktive Fitness eines Baumes beeinflusst, und zwar über den Genaustausch zwischen Genotypen, der die genetische Variation des entstandenen Saatguts und den Überlebenserfolg der daraus hervorgegangenen Keimlinge bestimmt (Alizoti et al. 2010).

Die phänologischen Beobachtungen werden über ein Bewertungsschema erfasst, das für die Beurteilung der Entwicklungsphasen (Phänophasen) männlicher und weiblicher Blüten von ruhenden Blütenknospen bis hin zu voll entwickelten Blüten/Zapfen/Strobili herangezogen werden kann. Phänologische Beobachtungen berücksichtigen dabei das phänologische Stadium (Phänophase), den erfassten Teil der Baumkrone (oben, Mitte, unten) und die Beobachtungsrichtung (N-Norden; NO-Nord-Osten; O-Osten; SO-Süd-Osten; S-Süden; SW-Süd-Westen; W-Westen; NW-Nord-Westen; ALLE - alle Richtungen um die Krone herum). Die Daten werden für die Erstellung von Phänogrammen verwendet, die den Beginn, die Dauer und das Ende des Phänomens angeben. Dieser Verifikator beschreibt das Auftreten der Blüte (Anteil der Bäume) und die Blühintensität. 


\section{Verfahren zur Erfassung der Blüte für die einzelnen FGM-Niveaus:}

\subsection{Basisniveau}

Der Verifikator wird jährlich auf Bestandesebene erfasst. Die Erfassung erfolgt zum Zeitpunkt der Hauptblüte. Die Schätzung des durchschnittlichen Zustands erfolgt nach einer Begehung der gesamten Monitoringfläche. Es werden zwei Werte erfasst: einer für die Blühintensität, ausgedrückt als mittlerer Kronenanteil in Blüte; und einer für den Anteil der blühenden Bäume im Bestand.

\begin{tabular}{clc} 
Code Blühintensität auf Bestandesebene & Mittlerer Anteil der Kronen in Blüte [\%] \\
\hline 1 & Keine Blüte: Keine oder nur gelegentlich auftretende Blüten & $0-10$ \\
\hline 2 & Schwache Blüte: Einige Blüten erscheinen an den Bäumen & $>10-30$ \\
\hline 3 & Mäßige Blüte: Mäßig viele Blüten an den Bäumen & $>30-60$ \\
\hline 4 & Starke Blüte: Reichlich Blüten an den Bäumen & $>60-90$ \\
\hline 5 & Extreme Blüte: Enorme Anzahl von Blüten an den Bäumen & $>90$ \\
\hline
\end{tabular}

\begin{tabular}{lr} 
Code Anteil der Bäume im Bestand mit dem entsprechenden Stadium der Blühintensität (\%) \\
\hline 1 & $0-10$ \\
\hline 2 & $>10-30$ \\
\hline 3 & $>30-60$ \\
\hline 4 & $>60-90$ \\
\hline 5 & $>90$ \\
\hline
\end{tabular}

\subsection{Standardniveau}

Der Verifikator wird während zweier bedeutender Blüteereignisse pro Jahrzehnt aufgezeichnet, idealerweise mit einem ähnlichen zeitlichen Abstand. Er wird für alle 50 Beobachtungsbäume auf Einzelbaumebene erfasst. Ein bedeutendes Blühereignis liegt vor, wenn die Blühintensität auf Basisniveau als stark oder extrem eingeschätzt wird (Code 4 oder 5) und der Anteil der Bäume mit der angegebenen Blühintensität über 60\% liegt (Code 4 oder 5). Die Erfassung erfolgt zum Zeitpunkt der Hauptblüte. Für jeden Beobachtungsbaum wird ein Wert erfasst.

Vorgehen für die Außenaufnahmen:

1. Die phänologischen Beobachtungen der Blüte werden an den ausgewählten und markierten FGMBeobachtungsbäumen durchgeführt (50 Bäume pro FGM-Fläche).

2. Die Beobachtungen müssen für jeden Baum einzeln mithilfe eines Fernglases oder anhand von Digitalfotos durchgeführt werden.

3. Der erfasste Teil der Krone wird im Erfassungsformular angegeben (1. oberes Kronendrittel/ 2. mittleres Kronendrittel/ 3. oberes und mittleres Kronendrittel). Wenn möglich, sollte die ganze Krone, zumindest aber der oberste Teil (Kronenspitze) untersucht werden.

4. Die Himmelsrichtung, in die der Teil der Krone zeigt, an dem die Untersuchungen vorgenommen wurden, muss im Erfassungsformular dokumentiert werden (N-Norden; NO-Nord-Osten; O-Osten; SO-Süd-Osten; S-Süden; SW-Süd-Westen; W-Westen; NW-Nord-Westen; ALLE - alle Richtungen um die Krone herum).

5. Wenn nur ein Teil der Krone aus einer Richtung sichtbar ist, dann sollten bei nachfolgenden phänologischen Erfassungen im selben Jahr sowie in folgenden Jahren der gleiche Teil der Krone und die gleiche Untersuchungsrichtung berücksichtigt werden.

6. Die Erfassung der Blüte muss in regelmäßigen Abständen einmal pro Woche durchgeführt werden. Bei einigen Baumarten können sich Phänologie von Blüte und Austrieb zeitlich überschneiden. 
7. DieBlüte verschiedener Baumarten kannje nach Umweltbedingungen und Biologie der Art zu unterschiedlichen Zeiten stattfinden.

\begin{tabular}{clc} 
Code & Blühintensität auf Bestandesebene & Mittlerer Anteil der Krone in Blüte [\%] \\
\hline 1 & Keine Blüte: Keine oder nur gelegentlich auftretende Blüten & $0-10$ \\
\hline 2 & Schwache Blüte: Einige Blüten erscheinen an den Bäumen & $>10-30$ \\
\hline 3 & Mäßige Blüte: Mäßig viele Blüten an den Bäumen & $>30-60$ \\
\hline 4 & Starke Blüte: Reichlich Blüten an den Bäumen & $>60-90$ \\
\hline 5 & Extreme Blüte: Enorme Anzahl von Blüten an den Bäumen & $>90$ \\
\hline
\end{tabular}

\subsection{Intensivniveau}

Der Verifikator wird während zweier bedeutender Blüteereignisse pro Jahrzehnt aufgezeichnet, idealerweise mit einem ähnlichen zeitlichen Abstand. Er wird für alle 50 Beobachtungsbäume auf Einzelbaumebene erfasst. Ein bedeutendes Blühereignis liegt vor, wenn die Blühintensität auf Basisniveau als stark oder extrem eingeschätzt wird (Code 4 oder 5) und der Anteil der Bäume mit der angegebenen Blühintensität über 60\% liegt (Code 4 oder 5). Im Durchschnitt sind zwei Begehungen auf der Monitoringfläche erforderlich: die erste früh genug, um das Frühstadium der Blüte zu beobachten, die zweite zum Zeitpunkt der Hauptblüte.

Für die Entwicklung weiblicher und männlicher Blüten bei den einzelnen Baumarten werden verschiedene Blühstadien beschrieben; diese sind in den FGM-Leitfäden der Baumarten enthalten.

\begin{tabular}{lr} 
Code Anteil der Krone in Blüte [\%, männliche und weibliche Blüten] & $0-10$ \\
\hline 1 & $>10-30$ \\
\hline 2 & $>30-60$ \\
\hline 3 & $>60-90$ \\
\hline 4 & $>90$ \\
\hline 5 & \\
\hline
\end{tabular}

\subsubsection{Verifikator: Fruktifikation}

Die Intensität und Periodizität der Fruktifikation zwischen aufeinanderfolgenden Jahren mit starker Fruchtbildung ist artspezifisch und variiert je nach Wetterbedingungen, Ressourcenverfügbarkeit, Abundanz von Pollenspendern bei windbestäubten Arten und genetischer Kontrolle (Mund et al. 2010 und dort zitierte Referenzen). Der Beginn der Fruchtbildung ist für den Baum ein wichtiges Zeichen, das auf seine reproduktive Reife hinweist und darauf hindeutet, dass ein Teil der Ressourcen, die bis zu diesem Zeitpunkt vollständig für vegetatives Wachstum und Abwehr aufgewendet wurden, von diesem Zeitpunkt an für die Reproduktion verwendet wird (Seifert und MüllerStarck 2009).

In der Verfahrensanweisung für die phänologischen Erfassungen wird ein Bewertungsschema beschrieben, das für die Erfassung der Fruktifikation verwendet werden kann. Die phänologischen Beobachtungen berücksichtigen die Periodizität und die Intensität der Fruktifikation. Je nach Monitoringniveau (Basis/ Standard/ Intensiv) werden die Daten auf Bestandes- bzw. auf Einzelbaumebene erfasst. Dieser Verifikator beschreibt das Auftreten und die Häufigkeit der Fruchtbildung. 


\section{Verfahren zur Erfassung der Fruktifikation für die einzelnen FGM-Niveaus:}

\subsection{Basisniveau}

Der Verifikator wird jährlich auf Bestandesebene erfasst. Die Schätzung des durchschnittlichen Zustands erfolgt nach einer Begehung der gesamten Monitoringfläche. Es werden zwei Werte erfasst: einer für die Intensität der Fruktifikation und einer für den Anteil fruchttragender Bäume im Bestand.

\begin{tabular}{llr}
\hline \multicolumn{2}{l}{ Code Intensität der Fruktifikation auf Bestandesebene } & Mittlerer Anteil der Krone mit Fruchtbehang [\%] \\
\hline $\begin{array}{llr}\text { Keine Fruchtbildung: Keine oder nur gelegentlich auftretende Früchte } \\
\text { an den Bäumen }\end{array}$ & $0-10$ \\
\hline 2 & Schwache Fruchtbildung: Einige Früchte an den Bäumen & $>10-30$ \\
\hline 3 & Mäßige Fruchtbildung: Mäßig viele Früchte an den Bäumen & $>60-90$ \\
\hline 4 & Starke Fruchtbildung: Reichlich Früchte an den Bäumen & $>90$ \\
\hline 5 & Extreme Fruchtbildung: Enorme Anzahl von Früchten an den Bäumen & $0-10$ \\
\hline & & $>10-30$ \\
\hline Code Anteil der Bäume im Bestand mit dem entsprechenden Stadium der Fruktifikationsintensität [\%] & $>30-60$ \\
\hline 1 & & $>60-90$ \\
\hline 2 & & $>90$ \\
\hline 4 & & $>00$ \\
\hline 5 & & $>00$ \\
\hline
\end{tabular}

\subsection{Standardniveau}

Die Erfassung des Verifikators erfolgt bei den meisten Baumarten in denselben Jahren wie die Bewertung der Blüte auf Standardniveau (unabhängig von der Fruktifikationsintensität). Eine Ausnahme stellen Kiefernarten dar, bei denen die Reifung der Zapfen und die Freisetzung der Samen im zweiten Jahr nach der Blüte erfolgt. Im Idealfall sollten zwei Fruktifikationsereignisse pro Dekade erfasst werden, und zwar für alle 50 Beobachtungsbäume auf Einzelbaumebene.

Vorgehen für die Außenaufnahmen:

1. Die phänologischen Beobachtungen der Fruchtbildung werden an den ausgewählten und markierten FGMBeobachtungsbäumen durchgeführt (50 Bäume pro FGM-Fläche).

2. Die Beobachtungen müssen für jeden Baum einzeln mithilfe eines Fernglases durchgeführt werden, wobei der Kronenanteil erfasst wird, der Früchte bzw. reife Zapfen trägt (siehe untenstehende Tabelle).

3. Der erfasste Teil der Krone wird im Erfassungsformular angegeben (1. oberes Kronendrittel/ 2. mittleres Kronendrittel/ 3. oberes und mittleres Kronendrittel). Wenn möglich, sollte die ganze Krone, zumindest aber der oberste Teil (Kronenspitze) untersucht werden.

4. Die Himmelsrichtung, in die der Teil der Krone zeigt, an dem die Untersuchungen vorgenommen wurden, muss im Erfassungsformular dokumentiert werden (N-Norden; NO-Nord-Osten; O-Osten; SO-Süd-Osten; S-Süden; SW-Süd-Westen; W-Westen; NW-Nord-Westen; ALLE - alle Richtungen um die Krone herum).

5. Wenn nur ein Teil der Krone aus einer Richtung sichtbar ist, dann sollten bei nachfolgenden phänologischen Erfassungen im selben Jahr sowie in folgenden Jahren der gleiche Teil der Krone und die gleiche Untersuchungsrichtung berücksichtigt werden.

6. Die Erfassung der Fruchtbildung muss einmal während der Fruktifikation und einmal vor dem Samen- bzw. Fruchtfall oder -ausbreitung erfolgen. 


\begin{tabular}{clr}
\hline Code Intensität der Fruktifikation auf Bestandesebene & Mittlerer Anteil der Krone mit Fruchtbehang [\%] \\
\hline 1 & $\begin{array}{l}\text { Keine Fruchtbildung: Keine oder nur gelegentlich auftretende Früchte } \\
\text { an den Bäumen }\end{array}$ & $0-10$ \\
\hline 2 & Schwache Fruchtbildung: Einige Früchte an den Bäumen & $>10-30$ \\
\hline 3 & Mäßige Fruchtbildung: Mäßig viele Früchte an den Bäumen & $>30-60$ \\
\hline 4 & Starke Fruchtbildung: Reichlich Früchte an den Bäumen & $>60-90$ \\
\hline 5 & Extreme Fruchtbildung: Enorme Anzahl von Früchten an den Bäumen & $>90$ \\
\hline
\end{tabular}

\subsection{Intensivniveau}

Die Erfassung des Verifikators erfolgt für alle 50 Beobachtungsbäume auf Einzelbaumebene in denselben Jahren wie die Bewertung der Blüte auf Intensivniveau (unabhängig von der Fruktifikationsintensität). Sie wird durchgeführt, bevor die Zapfen beginnen zu zerfallen. Der Verifikator wird als Durchschnitt von drei Zählrunden durch das Zählen von Früchten unter Nutzung eines Fernglases erfasst. Jede Zählrunde besteht aus der Anzahl der Früchte, die der Beobachter in 30 Sekunden zählt. Bei allen Bäumen sollte das gleiche Kronendrittel untersucht werden. Sobald ein Kronendrittel für die Beobachtung ausgewählt wurde, sollte dieses für jede weitere Erhebung dieses Verifikators ausgewählt werden. Für die Zählung wird das obere Kronendrittel dem unteren und mittleren Drittel vorgezogen.

Es werden zwei Werte erfasst: die Anzahl der Zapfen und das untersuchte Kronendrittel.

Im Idealfall sollte pro Jahrzehnt ein auf ein bedeutendes Blühereignis folgendes größeres Fruktifikationsereignis erfasst werden. Ein bedeutendes Blühereignis führt jedoch nicht unbedingt zu einem bedeutenden Fruktifikationsereignis. Wenn auf das bewertete Blühereignis kein wesentliches Fruktifikationsereignis folgt, muss die Bewertung sowohl der Blüte als auch der Fruchtbildung beim nächsten bedeutenden Blühereignis wiederholt werden, unabhängig von der Zeit, die zwischen aufeinanderfolgenden bedeutenden Blühereignissen liegt. Erhebungen auf Basisniveau werden genutzt, um bedeutende Fruktifikationsereignisse zu identifizieren. Ein bedeutendes Fruktifikationsereignis liegt vor, wenn die Fruktifikationsintensität auf Basisniveau als stark oder extrem eingeschätzt wird (Code 4 oder 5) und der Anteil der Bäume mit der angegebenen Fruktifikationsintensität über 60\% liegt (Code 4 oder 5).

Anzahl der in 30 Sekunden gezählten Zapfen (Mittelwert aus 3 Zählrunden)

$x$

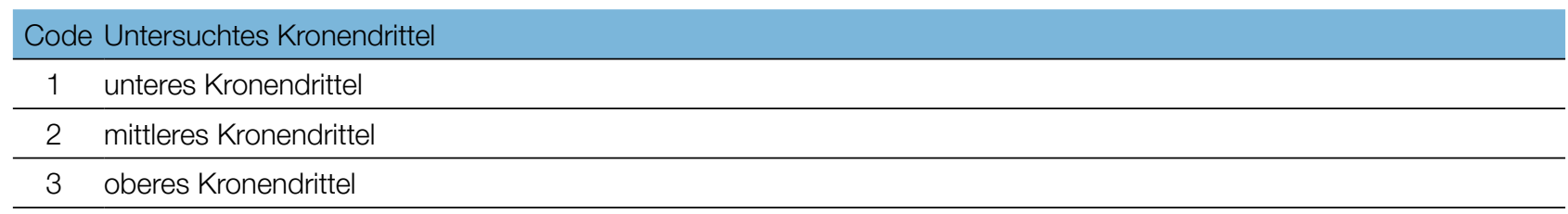

\subsubsection{Hintergrundinformation: Austrieb}

Die Hintergrundinformation Austrieb von Knospenöffnung bis Blattentfaltung beschreibt die Austriebsstadien von ruhenden Knospen bis zum Streckungswachstum des Triebes. Die Daten über Zeitpunkt und Dauer des Austriebes liefern wichtige Informationen für das Verständnis des tatsächlichen Zustands der Bäume und Bestände in der sich verändernden Umwelt.

Die phänologischen Beobachtungen der Knospe werden über ein Bewertungsschema erfasst, das für die Beurteilung der Entwicklungsphasen (Phänophasen) von ruhender Knospe bis zum Streckungswachstum des Triebes herangezogen werden kann. Die phänologischen Beobachtungen berücksichtigen hierbei das Stadium der Phänophase sowie den Anteil der Krone, der betroffen ist. Der Austrieb beschreibt den Prozess des Austreibens. Die Aufzeichnung erfolgt nur auf Standard- und Intensivniveau. 


\section{Verfahren zur Erfassung des Austriebs für die einzelnen FGM-Niveaus:}

\subsection{Standardniveau}

Auf Standardniveau wird der Austrieb alle 5 Jahre für alle 50 Beobachtungsbäume auf Einzelbaumebene beobachtet. Für jeden Baum werden zwei Werte erfasst: das Austriebsstadium und der entsprechende Kronenanteil. Die graphische Darstellung sowie das Bewertungsschema der Austriebsstadien sind in den FGMLeitfäden für die einzelnen Baumarten enthalten.

Vorgehen für die Außenaufnahmen:

1. Die phänologischen Beobachtungen des Austriebs werden an den ausgewählten und markierten FGMBeobachtungsbäumen durchgeführt (50 Bäume pro FGM-Fläche).

2. Die Beobachtungen müssen für jeden Baum einzeln mithilfe eines Fernglases oder anhand von Digitalfotos durchgeführt werden.

3. Der erfasste Teil der Krone wird im Erfassungsformular angegeben (1. oberes Kronendrittel/ 2. mittleres Kronendrittel/ 3. oberes und mittleres Kronendrittel). Wenn möglich, sollte die ganze Krone, zumindest aber der oberste Teil (Kronenspitze) untersucht werden.

4. Die Himmelsrichtung, in die der Teil der Krone zeigt, an dem die Untersuchungen vorgenommen wurden, muss im Erfassungsformular dokumentiert werden (N-Norden; NO-Nord-Osten; O-Osten; SO-Süd-Osten; S-Süden; SW-Süd-Westen; W-Westen; NW-Nord-Westen; ALLE - alle Richtungen um die Krone herum).

5. Wenn nur ein Teil der Krone aus einer Richtung sichtbar ist, dann sollten bei nachfolgenden phänologischen Erfassungen im selben Jahr sowie in folgenden Jahren der gleiche Teil der Krone und die gleiche Untersuchungsrichtung berücksichtigt werden.

6. Die Erfassung des Austriebs muss in regelmäßigen Intervallen (einmal pro Woche) während des gesamten Austriebszeitraums durchgeführt werden. Die Dauer des Austriebszeitraums hängt von der Biologie der untersuchten Baumart und den Umweltbedingungen ab.

7. Die Erfassung des Austriebs muss früh genug begonnen werden, um bereits die ganz frühen Stadien zu erfassen, wenn zwischen den einzelnen Baumindividuen signifikante Differenzierungen auftreten.

8. Die Beobachtungen werden beendet, wenn alle Beobachtungsbäume das Ende des Austriebs (Stadium 4) erreicht haben (baumartenspezifische phänologische Verfahren). Erfasst wird jeweils das am weitesten fortgeschrittene Stadium (Phänophase).

\begin{tabular}{cr} 
Code Anteil der Krone mit dem entsprechenden Austriebsstadium [\%] & \\
\hline 1 & $>0-33$ \\
\hline 2 & $>33-66$ \\
\hline 3 & $>66-99$ \\
\hline 4 & 100 \\
\hline
\end{tabular}

\subsection{Intensivniveau}

Auf Intensivniveau wird der Austrieb jährlich für alle 50 Beobachtungsbäume auf Einzelbaumebene erhoben, mit derselben Verfahrensweise wie auf Standardniveau. Details dazu sind im Kapitel 5.3.2.3.1 Standardniveau zu finden. 


\subsubsection{Hintergrundinformation: Seneszenz}

Die Seneszenz beschreibt den Prozess der Blattalterung. Sie ist ein wichtiges Merkmal, das die Länge der Wachstumsperiode von Arten, die ihre Blätter im Herbst abwerfen, beeinflussen kann und stark von Umweltund genetischen Faktoren beeinflusst wird. Die Daten über Zeitpunkt und Dauer der Seneszenz liefern wichtige Informationen für das Verständnis des tatsächlichen Zustands der Bäume und Bestände in der sich verändernden Umwelt.

Die phänologischen Beobachtungen der Seneszenz werden über ein Bewertungsschema erfasst, das für die Erfassung der Seneszenz herangezogen werden kann. Die Daten werden auf Bestandes- und auf Einzelbaumebene erfasst. Die Erfassung dieser Hintergrundinformation wird nur für das Standard- und das Intensivniveau durchgeführt. Die phänologischen Beobachtungen berücksichtigen hierbei das Stadium der Phänophase sowie den erfassten Teil der Baumkrone.

\section{Verfahren zur Erfassung der Seneszenz:}

\subsection{Standardniveau}

Auf Standardniveau wird die Seneszenz auf Einzelbaumebene bei allen 50 Beobachtungsbäumen alle 5 Jahre erfasst. Für jeden Baum werden zwei Werte erfasst: einer für das Stadium der Seneszenz und einer für den entsprechenden Kronenanteil. Die graphische Darstellung der Alterungsstadien ist in den FGM-Leitfäden für die einzelnen Baumarten enthalten.

Vorgehen für die Außenaufnahmen:

1. Die phänologischen Beobachtungen der Seneszenz werden an den ausgewählten und markierten FGMBeobachtungsbäumen durchgeführt (50 Bäume pro FGM-Fläche).

2. Die Beobachtungen müssen für jeden Baum einzeln mithilfe eines Fernglases oder, falls notwendig, anhand von Digitalfotos durchgeführt werden.

3. Der erfasste Teil der Krone wird im Erfassungsformular angegeben (1. oberes Kronendrittel/ 2. mittleres Kronendrittel/ 3. oberes und mittleres Kronendrittel). Wenn möglich, sollte die ganze Krone, zumindest aber der oberste Teil (Kronenspitze) untersucht werden.

4. Die Himmelsrichtung, in die der Teil der Krone zeigt, an dem die Untersuchungen vorgenommen wurden, muss im Erfassungsformular dokumentiert werden (N-Norden; NO-Nord-Osten; O-Osten; SO-Süd-Osten; S-Süden; SW-Süd-Westen; W-Westen; NW-Nord-Westen; ALLE - alle Richtungen um die Krone herum).

5. Wenn nur ein Teil der Krone aus einer Richtung sichtbar ist, dann sollten bei nachfolgenden phänologischen Erfassungen im selben Jahr sowie in folgenden Jahren der gleiche Teil der Krone und die gleiche Untersuchungsrichtung berücksichtigt werden.

7. Die Seneszenz sollte zwei bis drei Mal im Herbst erfasst werden (Zeit und Dauer der Beobachtungen hängen von der Biologie der Art und den Umweltbedingungen ab).

8. Das letzte Stadium (Stadium Nummer 4) gilt dann als erreicht, wenn ein oder mehrere Blätter (einschließlich derer, die kürzlich von der Pflanze abgefallen sind) ihre Herbstfärbung erreicht haben. Vollkommen trockene oder tote Blätter, die an der Pflanze verbleiben, sollten hierbei nicht berücksichtigt werden.

9. Der Anteil der Blätter im sichtbaren Teil der Krone, die sich in dem beschriebenen Stadium befinden oder dieses bereits hinter sich gelassen haben, müssen mithilfe des folgenden Schemas zur Klassifizierung der Seneszenz erfasst werden. 


\begin{tabular}{ll} 
Code & Stadium der Seneszenz \\
\hline 1 & Blätter sind grün \\
\hline 2 & Blattfarbe wechselt von grün zu gelb (grünlich-gelb) \\
\hline 3 & Blattfarbe wechselt von gelb zu braun (bräunlich) \\
\hline 4 & Blätter sind braun/ abgefallen \\
\hline
\end{tabular}

\begin{tabular}{lr}
\hline Code Anteil der Krone mit dem entsprechenden Seneszenzstadium [\%] & $>0-33$ \\
\hline 1 & $>33-66$ \\
\hline 2 & $>66-99$ \\
\hline 3 & 100 \\
\hline 4 & \\
\hline
\end{tabular}

\subsection{Intensivniveau}

Auf Intensivniveau wird die Blattseneszenz jährlich für alle 50 Beobachtungsbäume auf Einzelbaumebene erhoben, mit derselben Verfahrensweise wie auf Standardniveau. Details dazu sind im Kapitel 5.3.2.4.1 Standardniveau zu finden.

\subsubsection{Hintergrundinformation: Blühsynchronisation}

Die Blühsynchronisation ist der Teil der Blühphänologie, der sich auf den Zeitpunkt der Entwicklung der männlichen und weiblichen Blüten konzentriert, indem sie die verschiedenen Phänophasen erfasst (Ducci et al. 2012). Die Blühsynchronisation wird nur auf Intensivniveau erfasst und basiert auf den für den Verifikator „Blüte“ erhobenen Daten (siehe 5.3.2.1). Sie wird verwendet, um festzustellen, ob die männliche und weibliche Blüte innerhalb des untersuchten Bestandes gleichzeitig stattfindet.

\subsection{Intensivniveau}

Die Blühsynchronisation wird jährlich für alle 50 Beobachtungsbäume auf Einzelbaumebene erfasst; und zwar für jedes erfasste bedeutende Blühereignis und im selben Jahr, in dem auch Samen beprobt werden (wie für den Verifikator „Blüte” auf Intensivniveau).

\subsection{PROBENNAHME}

\subsubsection{Probenahmeverfahren für die DNA-Analyse}

Die Probenahme ist ein wesentlicher Bestandteil des forstgenetischen Monitorings. Daher sind standardisierte Verfahren zur Probenahme erforderlich, um aus der DNA-Analyse optimale Ergebnisse zu erhalten. Die Verfahren sowie die zur Probenahme benötigte Ausrüstung und Materialien sind in diesem Kapitel beschrieben. Weiterhin werden artspezifische Beispiele und Hinweise für die Probenahme erörtert (z.B. mögliche Optionen das zu beprobende Material betreffend, Besonderheiten bei der Sammlung von Saatgut zur Untersuchung etc.).

Erforderliche Ausrüstung:

- Plastik-/ Papiertüten für das Probenmaterial (100 Tüten für 50 Proben von Altbäumen und 50 Naturverjüngungsproben);

- Astschere/ -schneider oder Messer;

- Plastik-/Aluminiumschilder; 
- Akkubohrschrauber, zusätzliche Akkus;

- Bohrer mit 6-10 mm Durchmesser, zusätzliche Bohrer;

- 0.5-Liter-Waschflasche mit destilliertem Wasser zum Reinigen des Bohrers, zusätzlicher Wasserkanister mit 5 Liter destilliertem Wasser;

- Baumwolltaschen oder Schachteln für Samen bzw. Zapfen;

- Plastikbeutel mit Silikagel, um die Proben während der Probennahme und des Transports trocken zu halten;

- wasserfeste Stifte;

- Wärmeisolierende Kisten, z.B. aus Styropor, mit Kühlpacks zum Schutz der Proben vor übermäßigen Temperaturschwankungen

\subsubsection{Beprobung von Altbäumen}

Alle Beobachtungsbäume innerhalb der FGM-Fläche werden beprobt (50 fortpflanzungsfähige Bäume für einhäusige Arten; 25 weibliche und 25 männliche Bäume für zweihäusige und funktionell zweihäusige Arten). Für jeden Baum wird das Material in einem eigenen Plastik-, Papier- oder Baumwollbeutel aufbewahrt. Für hybridisierende Arten und Arten mit vegetativer Vermehrung (Klone), kann die anfängliche Anzahl der zu beprobenden und zu genotypisierenden adulten Bäume höher sein (z.B. 100, siehe Tabelle 5.2), da nur artenreine Individuen und nur jeweils ein einziges Individuum desselben Genotyps in das Monitoring einbezogen werden können. Wenn die anfängliche DNA-Analyse einen sehr hohen Anteil an Hybridisierung ergibt, sollte ein anderer Bestand für das FGM in Betracht gezogen werden (es sei denn, das besondere Ziel ist die Überwachung eines Hybridbestands).

\section{Ein Hinweis zur Stichprobengröße für zweihäusige Arten:}

Es ist zu beachten, dass 25 männliche und 25 weibliche Bäume bei zweihäusigen oder funktionell zweihäusigen Arten die Hälfte des möglichen Beitrags der Eltern zur nächsten Generation im Vergleich zu 50 fortpflanzungsfähigen Bäumen bei einhäusigen Arten darstellen. Die Entscheidung, mit der gleichen Gesamtzahl erwachsener Fortpflanzungsbäume für zweihäusige und einhäusige Arten zu arbeiten, beruhte in erster Linie auf praktischen Überlegungen, nämlich die Erhöhung der Arbeitsbelastung und der Kosten zu vermeiden, wenn insgesamt 100 fortpflanzungsfähige Bäume beobachtet werden (insbesondere in Bezug auf phänologische Beobachtungen und andere Geländearbeiten) und möglicherweise eine übermäßige Vergrößerung der Monitoringfläche. Die Anwender sollten sich dieses Problems der Stichprobengröße bei zweihäusigen Arten bewusst sein.

Mögliches Probenmaterial für die genetische Analyse (Abb. 5.2: a, b, c, d):

- Zweige mit Knospen (2-3 Zweige pro Baum, 5-10 cm lang mit 1 oder 2 Knospen), geschnitten mit Astschere oder Messer;

- frische Blätter/ Nadeln (5-10 frische Blätter/ 20-30 Nadeln von jedem Baum);

- Holz samt einem Teil des Kambiums, entnommen aus jedem Beobachtungsbaum mittels Bohrung (Bohrtiefe ca. 4 cm). Die Entnahme erfolgt entweder mithilfe eines Akkuschraubers (Menge ca. 2 ml, gemessen in einem Eppendorf-Röhrchen); oder mittels eines Zuwachsbohrers (Entnahme von 2 Holzkernen mit jeweils $3 \mathrm{~cm}$ Länge). 

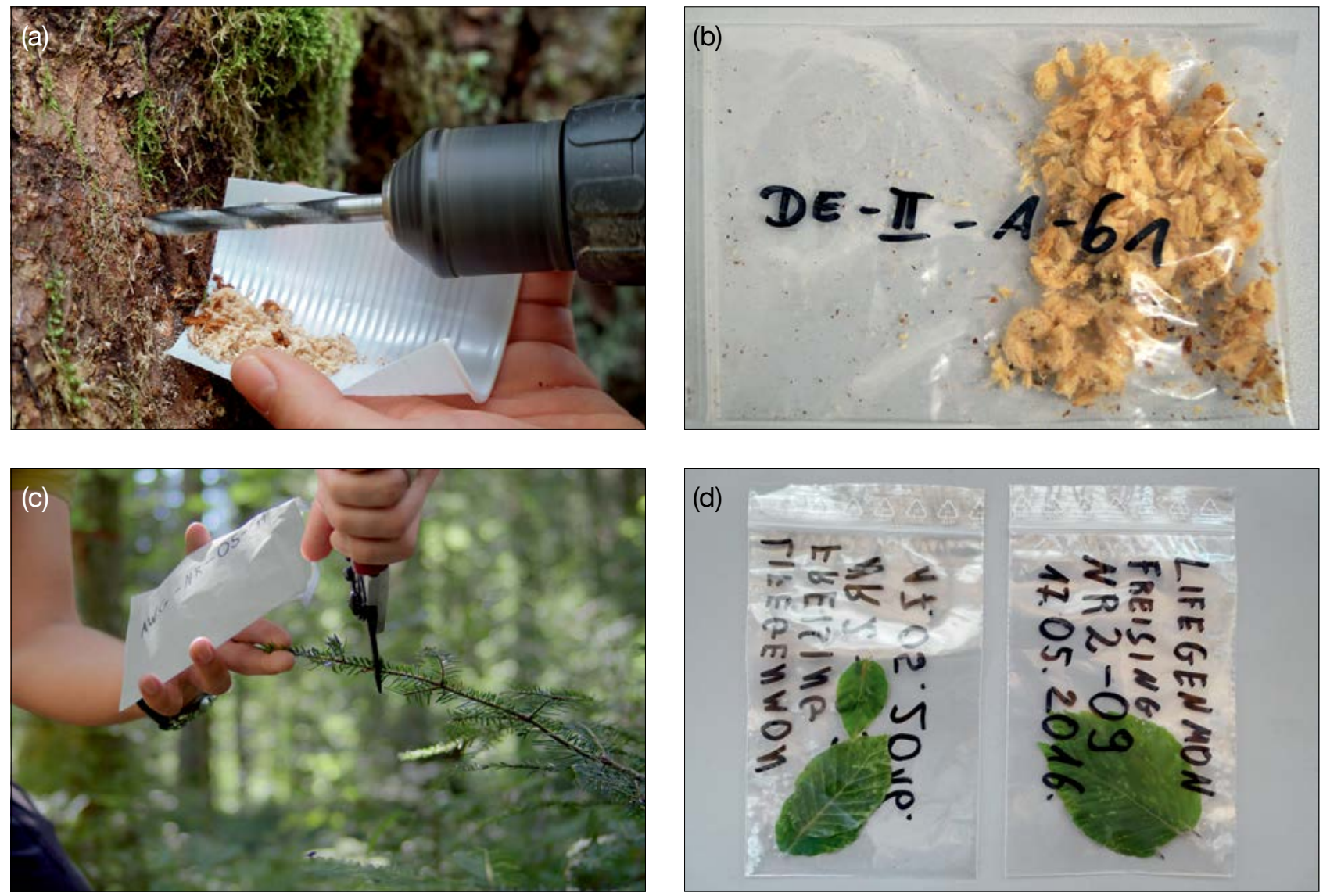

Abbildung 5.2: Probenmaterial für die genetische Analyse (a und b - Holz mit einem Teil des Kambiums; c und d frische Blätter oder Nadeln).

Von den oben genannten Optionen wird die Art von Material ausgewählt, die einfacher zu sammeln ist. Die entnommenen Proben für die genetische Analyse können eine Kombination verschiedener Materialien sein, z.B. Knospen, frische Blätter, Holz mit einem Teil des Kambiums. Bevor mit der Probennahme begonnen wird, muss die Erlaubnis der Waldbesitzerin/ des Waldbesitzers für das jeweilige Verfahren für die Entnahme von Material eingeholt werden (z.B. im Fall von Bohrungen). Laubbäume reagieren empfindlicher auf die Entnahme von Bohrproben, sodass hier weniger invasive Methoden zu bevorzugen sind (Blätter, Zweige mit Knospen). Wenn die Bohrung von Laubbäumen jedoch zwischen Januar und März (außerhalb der Vegetationsperiode) durchgeführt wird, heilen die Wunden schneller. Um negative Auswirkungen auf die Holzqualität (Stammholz) zu vermeiden, ist es besser, im Stumpf zu bohren, d.h. im untersten Teil des Stammes, in Bodennähe. Bei Nadelbäumen füllt sich die Bohrwunde in sehr kurzer Zeit mit Harz.

Die Beutel mit Material für die DNA-Analyse müssen systematisch und einheitlich beschriftet werden. Die Beschriftung der Proben im LIFEGENMON-Projekt erfolgte nach dem folgenden Schema: DE-I-FSY-A-01

DE - Ländercode (z.B. DE - Germany/Deutschland);

I - FGM-Bestandesnummer;

FSY - Lateinischer Artname Fagus sylvatica;

A - Altbaum;

01 - Baumnummer von 01 bis 50.

Es ist empfehlenswert, alle Arten von Proben in Isolierboxen (wie z.B. Styroporkisten, wie sie für den Versand von temperaturempfindlichen Materialien verwendet werden) mit einigen Kühlakkus zu verwenden, um übermäßige Temperaturschwankungen im Feld und während des Transports zu vermeiden. 


\subsubsection{Beprobung von Naturverjüngung (NV)}

Die Beprobung der Naturverjüngung sollte auf den 20 NV-Teilflächen (neben den Plots zur Erfassung der Abundanz-/Überlebensrate von $1 \mathrm{~m}^{2}$ ) im 3. Jahr nach der Keimung erfolgen (an den dann 3 Jahre alten Pflanzen). Es werden 50 NV-Proben gesammelt: 3 Pflanzen aus 10 zufällig ausgewählten NV-Plots, 2 aus den anderen 10 Plots. Bei hybridisierenden Arten und Arten mit vegetativer Vermehrung (Klone) sollten 100 etablierte Jungpflanzen beprobt und genotypisiert werden. Der Anteil der Hybridisierung [\%] wird aus den Ergebnissen für alle 100 Proben berechnet, 50 nicht-hybridisierte Individuen mit eindeutigen Genotypen werden dann zufällig für die Berechnung anderer molekulargenetischer Verifikatoren und Hintergrundinformationen ausgewählt.

Für die DNA-Extraktion geeignetes NV-Probenmaterial:

- Zweige mit Knospen (2-3 Zweige pro Baum, 5-10 cm lang mit 1 oder 2 Knospen), geschnitten mit Astschere oder Messer;

- frische Blätter/ Nadeln (5 frische Blätter/ 10-20 Nadeln von jeder Pflanze);

Empfehlung: Die Menge des Pflanzenmaterials für die DNA-Extraktion kann reduziert werden; in der Regel reicht es aus, 2-3 Knospen/ Blätter für die DNA-Extraktion zu sammeln. Es ist jedoch immer besser, ein paar Knospen mehr für Wiederholungen im Labor zu haben. Für jeden Baum wird das Material in einem eigenen Plastik-, Papier- oder Baumwollbeutel aufbewahrt.

Die Beutel mit Material für die DNA-Extraktion müssen systematisch und einheitlich beschriftet werden. Die Beschriftung der Proben im LIFEGENMON-Projekt erfolgte nach dem folgenden Schema: DE-I-FSY-NR-01

DE - Ländercode (z.B. DE - Germany/Deutschland);

I - FGM-Bestandesnummer;

FSY - Lateinischer Artname Fagus sylvatica;

NR - Naturverjüngung;

01 - Baumnummer von 01 bis 50.

\subsubsection{Saatgutbeprobung}

Saatgut wird für die DNA-Analyse und für die Saatgutprüfung im FGM auf Intensivniveau benötigt.

Der Zeitpunkt der Saatgutgewinnung ist von Land zu Land unterschiedlich und hängt von der Biologie der Zielart und den ökologischen bzw. klimatischen Bedingungen eines bestimmten Gebiets ab. Im Fall von Abies alba beginnt die Saatguternte in Mitteleuropa normalerweise Ende August, in Südeuropa jedoch im September/ Oktober; die Saatgutgewinnung von Fagus sylvatica beginnt in der Regel im September und kann bis in den November dauern.

- Die Samen müssen von den 20 ausgewählten Samenbäumen gewonnen werden, wobei mindestens 200-300 Samen pro Mutterbaum von mehreren verschiedenen Zweigen entnommen werden müssen (eine höhere Anzahl von Samen wird benötigt, um sicherzugehen, dass eine ausreichende Anzahl an lebensfähigen Samen dabei ist). Pro Baum werden 20 gefüllte Samen für die DNA-Analyse verwendet, das entspricht einer Gesamtzahl von 400 Samen für alle beprobten Samenbäume pro Erfassung. Bei hybridisierenden Arten werden 30 volle Samen pro Baum für die DNA-Analyse verwendet; der Hybridisierungsanteil [\%] wird aus den Ergebnissen für alle 600 Samen berechnet. 400 Samen der reinen Zielart (ohne Hybridanteil) werden dann zufällig für die Berechnung anderer molekularer Verifikatoren und Hintergrundinformationen ausgewählt.

- Samen von Fagus sylvatica werden gesammelt, indem man auf die Bäume klettert, mehrere Äste (falls erforderlich) abschneidet und die Früchte mit den Samen darin direkt von den Ästen pflückt.

- Samen von Abies alba werden gesammelt, indem man auf die Bäume klettert und die Zapfen vor dem Öffnen der Zapfenschuppen pflückt (wenn die Zapfenschuppen noch geschlossen sind, bleiben die Samen noch im Zapfen) (Abb. 5.3). 


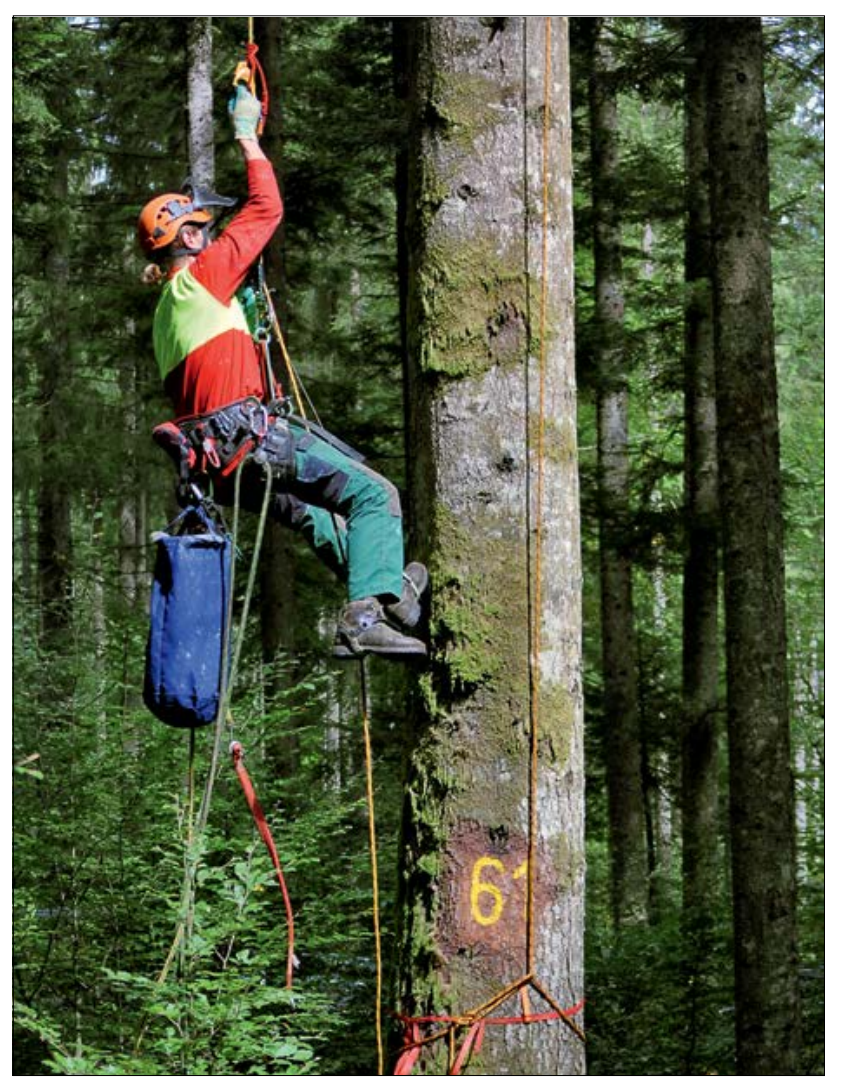

Abbildung 5.3: Zapfenpflücken bei Abies alba auf der FGM-Versuchsfläche (Deutschland)
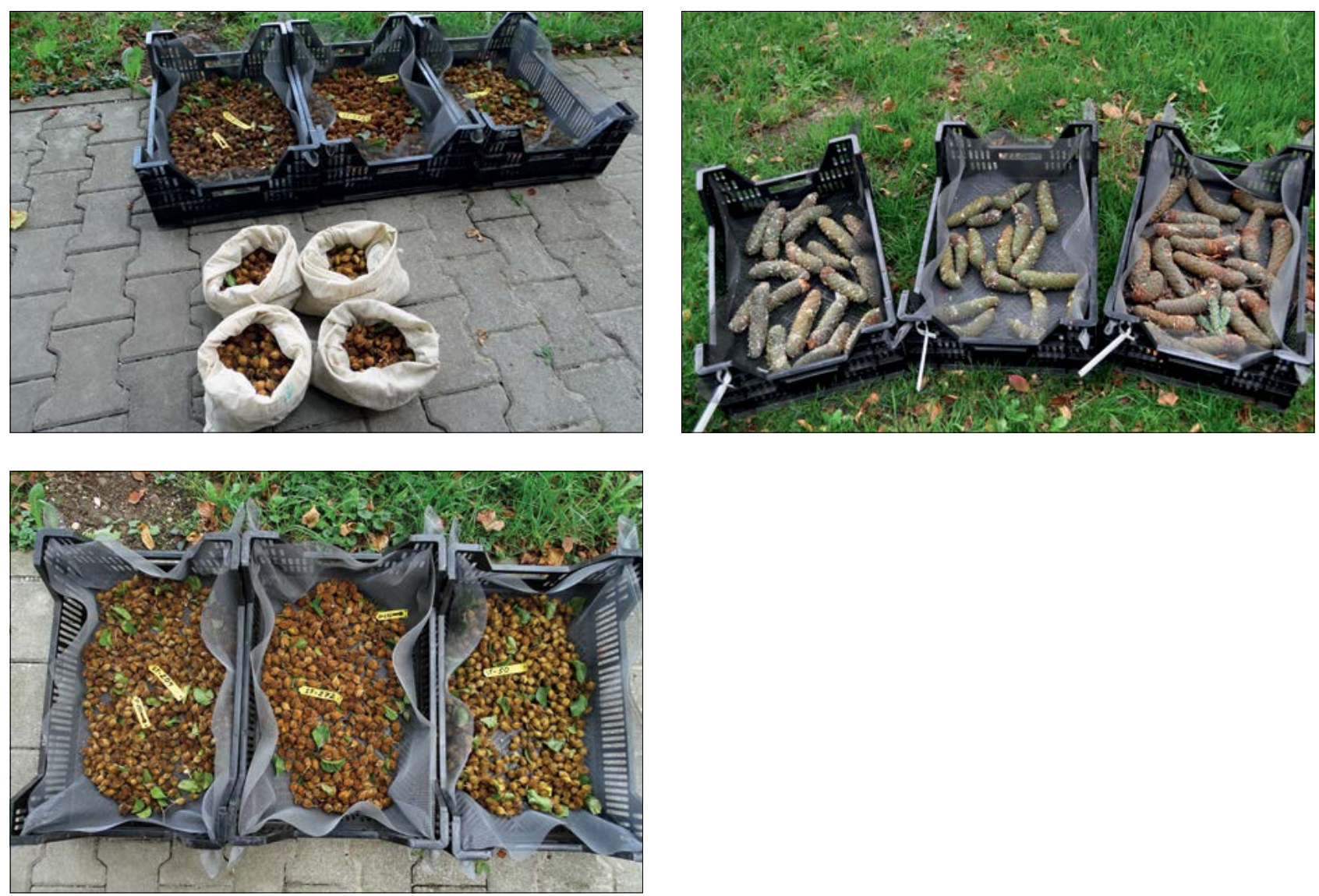

Abbildung 5.4: Gesammeltes Saatgut/ Zapfen (Fagus sylvatica und Abies alba) 
- Für jeden Baum wird das Saatgut in einem eigenen Baumwollbeutel bzw. einer Kiste aufbewahrt und gekennzeichnet (Fig. 5.4).

- Die Beutel mit Saatgut müssen systematisch und einheitlich beschriftet werden. Die Beschriftung der Proben im LIFEGENMON-Projekt erfolgte nach dem folgenden Schema: DE-I-FSY-ST-X

DE - Ländercode (z.B. DE - Germany/Deutschland);

I - FGM-Bestandesnummer;

FSY - Lateinischer Artname Fagus sylvatica;

ST - Samenbaum;

X - Baumnummer wie auf dem Samenbaum angegeben (die Nummerierung muss so bleiben, wie sie bei der Auswahl der Altbäume angegeben wurde).

Das gesamte für die DNA-Analyse gesammelte Pflanzenmaterial wird bei einer Temperatur von etwa $2-3^{\circ} \mathrm{C}$ aufbewahrt werden (nicht gefroren/ nicht unter $0^{\circ} \mathrm{C}$ ), jedoch nicht länger als 3 Tage, bis es so schnell wie möglich an das DNA-Labor geschickt wird. Für den Transport von Samen und Zapfen zum DNA-Labor steht mehr Zeit zur Verfügung, da hier keine Gefahr des Abbaus von DNA besteht.

\subsubsection{Probenahme für die Saatgutprüfung}

Nach den Regeln der ISTA (2020) besteht das Ziel der Saatgutprobenahme darin, eine für die Saatgutprüfung geeignete Probengröße zu erhalten. Im Rahmen des FGM wird eine Probe für die Saatgutprüfung aus der FGM-Fläche gewonnen, indem kleine Portionen von Saatgut nach dem Zufallsprinzip an verschiedenen Positionen entnommen und zu einer Gesamtprobe gemischt werden. Jede Stufe der Probennahme muss mit geeigneten Methoden und Geräten durchgeführt werden. In diesem Kapitel wird das Verfahren der Saatgutprobennahme für die Sammlung von leichtem (windverbreitetem) und schwerem Saatgut für die Saatgutprüfung bei Zielbaumarten im Rahmen des FGM beschrieben.

\subsection{Saatgutprobenahme für die Saatgutprüfung bei schwerfrüchtigen Baumarten (e.g. Fagus sp., Quercus sp.)}

Das schwere Saatgut bestimmter Baumarten, wie z.B. Fagus sp. und Quercus sp., muss in Mastjahren unmittelbar nach dem Samenfall vom Boden gesammelt werden, damit es getestet werden kann. Der Zeitpunkt der Samengewinnung vom Boden ist von Land zu Land unterschiedlich und hängt von der Biologie der Zielbaumart und den ökologischen/ klimatischen Bedingungen eines bestimmten Gebiets ab. In Mitteleuropa zum Beispiel muss das Saatgut von Fagus sy/vatica im Oktober-November nach dem Samenfall gesammelt werden. Saatgut von Quercus sp. muss für die Saatgutprüfung im Herbst direkt nach dem Samenfall gesammelt werden. Die Saatgutprobe muss repräsentativ sein; daher muss das Saatgut auf der gesamten FGM-Fläche gesammelt werden. Dazu wird das Sammeln von Saatgut systematisch durchgeführt, von einem Rand der FGM-Fläche zum anderen, wobei alle 10 Meter eine kleine Menge verfügbare bzw. sichtbare Samen vom Boden aufgelesen werden (siehe Abb. 5.5).

Das Saatgut von Prunus avium wird durch Baumklettererlnnen geerntet, bevor die Früchte reifen und von Vögeln gefressen werden. Der Zeitpunkt für das Sammeln der Früchte kann sich auch hier von Land zu Land unterscheiden, je nach den ökologischen/ klimatischen Bedingungen im jeweiligen Gebiet. Meistens werden in Europa die Samen der Wildkirsche vom späten Frühjahr bis Mitte des Sommers gesammelt.

Für die Saatgutprüfung werden laut ISTA (2020) für verschiedene Baumarten unterschiedliche Mengen an Saatgut benötigt (Tabelle 5.2). Saatgut von verschiedenen FGM-Flächen muss in separaten Baumwollbeuteln oder perforierten Kisten gelagert werden, die mit einem Etikett versehen sein sollten. Das gesamte Saatgut muss so schnell wie möglich nach der Saatgutentnahme an das Saatgutprüflabor geschickt werden. 
(a)
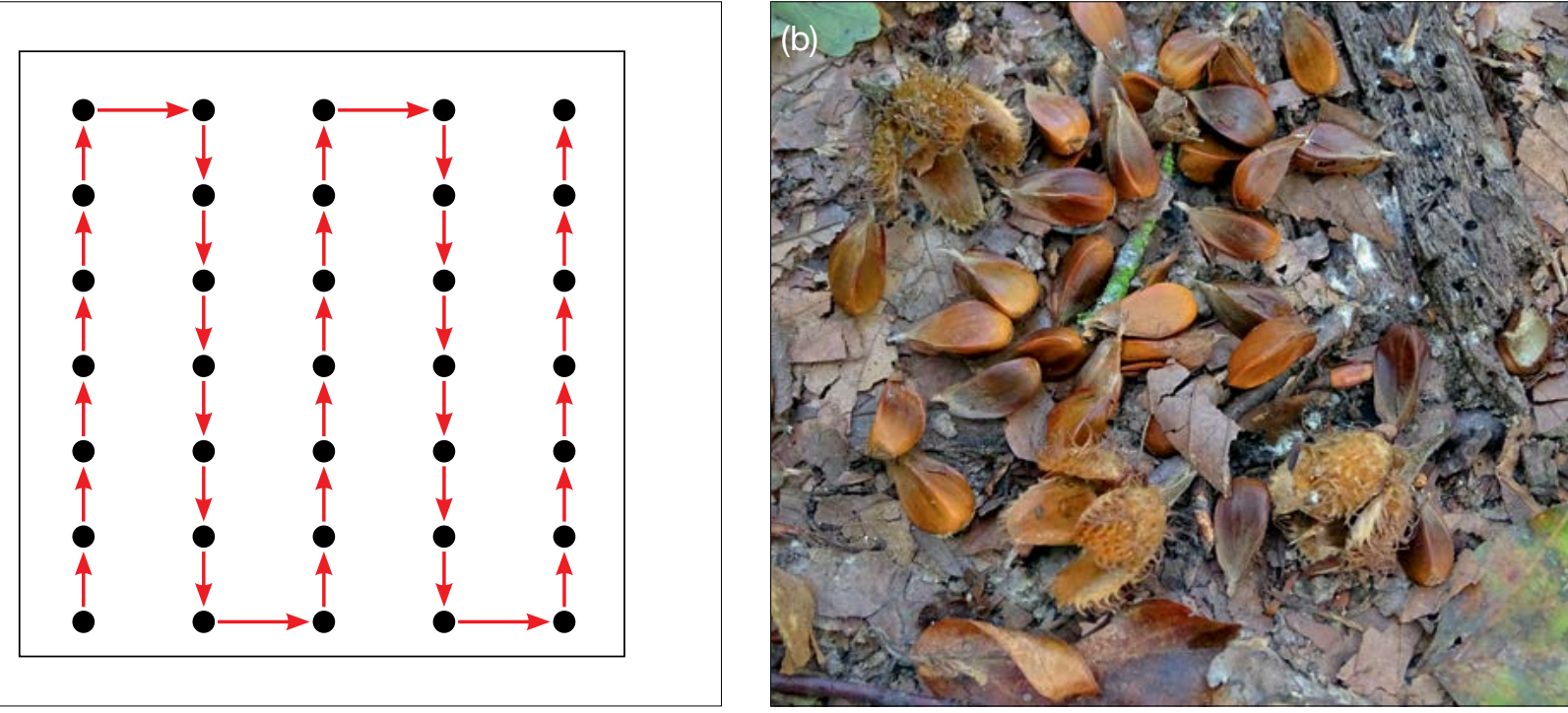

Abbildung 5.5: Systematische Saatgutprobennahme vom Boden (links); Samen von Fagus sylvatica auf dem Waldboden (rechts).

\subsection{Saatgutprobenahme für die Saatgutprüfung bei leichtfrüchtigen (windverbreiteten) Baumarten (z.B. Abies sp., Populus sp., Pinus sp., Fraxinus sp.)}

Bei Baumarten mit leichtem Samengewicht (windverbreitete Arten) wie Abies sp., Populus sp., Pinus sp., kann das Saatgut für die Saatgutprüfung nicht vom Boden gesammelt werden. Diese Option würde einen übermäßigen Aufwand an Zeit und Mühe bedeuten. Bei Nadelbäumen sollten die reifen Zapfen vor dem Öffnen der Zapfenschuppen und dem Abwurf der Samen gesammelt werden; der Zeitpunkt des Samenfalls bzw. der Saatgutgewinnung ist bei den verschiedenen Arten unterschiedlich (z.B. wird bei Abies sp. das Saatgut eines Samenjahrs nach der Blüte noch im selben Jahr verbreitet, während bei Pinus sp. der Samen erst zwei Jahre nach der Blüte freigesetzt wird). Daher muss das Saatgut bzw. die Zapfen dieser Arten von Zapfenpflückern direkt vom Baum geerntet werden. Für die Saatgutprüfung von Abies sp. kann z.B. eine Mischprobe aus den Zapfen verwendet werden, die für die DNA-Analyse gesammelt wurden:

- Von jedem der 20 ausgewählten Samenbäume müssen mindestens 10 Zapfen gesammelt werden (von allen Bäumen sollte jeweils ungefähr die gleiche Anzahl von Zapfen gesammelt werden (10 Zapfen pro Baum/ 200 Zapfen pro 20 Samenbäume) (Abb. 5.6);

- Die samengefüllten Zapfen müssen von Baumkletterern direkt vom Ast gepflückt werden;

- Zapfen von verschiedenen Mutterbäumen müssen in separaten Baumwollbeuteln oder Kisten gelagert werden, bis sich ihre Schuppen öffnen (z.B. induziert durch ein Verfahren zum Öffnen der Zapfenschuppen, hierbei werden die Zapfen zunächst eingeweicht und dann für einige Tage in Kammern mit kontrollierter Temperatur unter $50^{\circ} \mathrm{C}$ gelagert);

- Danach müssen die Zapfen 2-3 Monate an einem trockenen Ort mit guter Belüftung aufbewahrt werden, bis sich die Zapfenschuppen öffnen und die Samen herausfallen;

- das Saatgut von allen 10 Zapfen eines Einzelbaumes sollte gemischt werden;

- Ungefähr 200 Samen (ca. 20 g Samen, je nach Baumart) müssen für die genetische Analyse gewonnen werden (20 Samen pro Baum werden analysiert, jedoch werden für die DNA-Analyse mehr Samen benötigt, da einige leer sein können) und der Rest der Samen wird für die Saatgutprüfung verwendet;

- Das restliche Saatgut der 20 Samenbäume muss gemischt werden, und $120 \mathrm{~g}$ der reinen Saatgutmischung (das entspricht ca. 3000 Samen für Abies ssp.) werden für die Saatgutprüfung verwendet (Tabellen 5.2 und 5.3). 


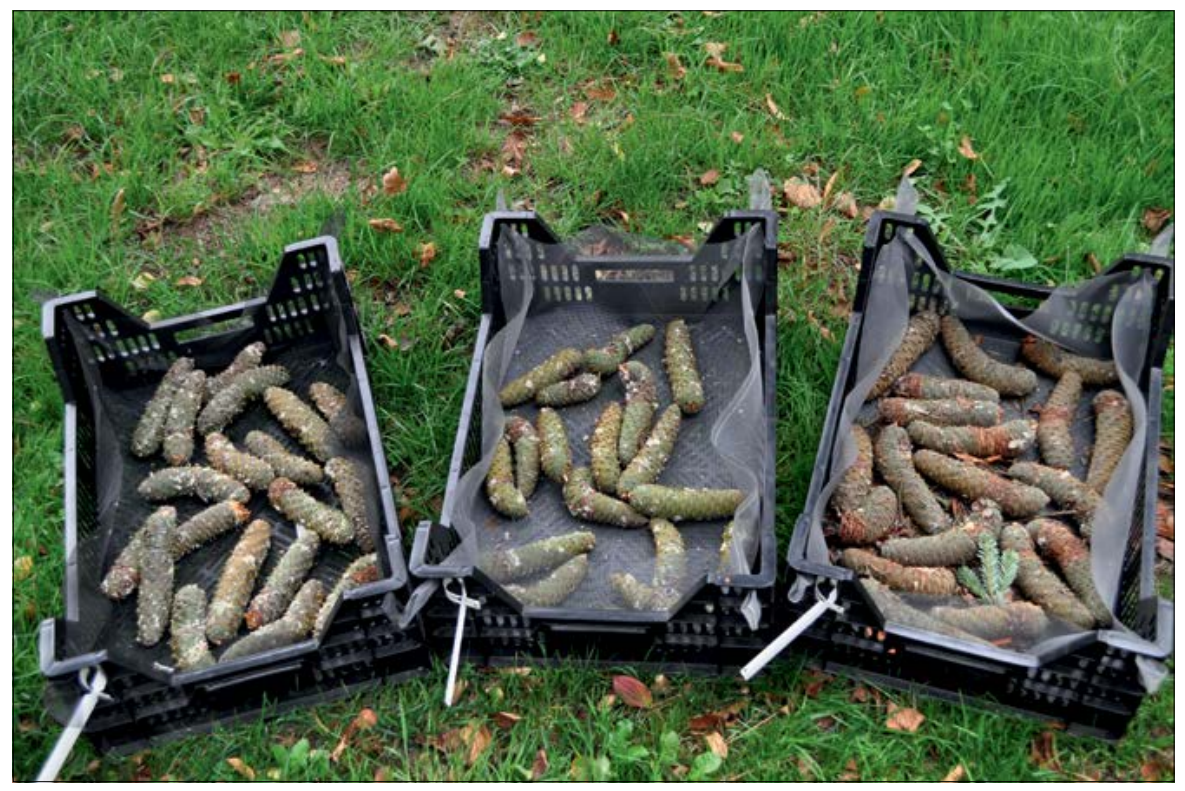

Abbildung 5.6: Zapfen von Abies alba, gepflückt von drei verschiedenen Samenbäumen

Das Saatgut von Fraxinus sp. muss gesammelt werden, bevor die Samen herunterfallen (der Zeitpunkt für die Saatgutsammlung kann von Land zu Land unterschiedlich sein und hängt von der Biologie der Art und den ökologischen/ klimatischen Bedingungen bestimmter Gebiete ab). Daher muss das Saatgut durch Baumklettererlnnen geerntet werden.

Die Lebensdauer des Saatguts von Populus sp. ist sehr begrenzt (2-4 Tage), daher muss es so bald wie möglich nach dem Erscheinen der weißen, baumwollähnlichen Fasern von Baumkletterern gesammelt werden (normalerweise im Mai, das kann aber von Land zu Land unterschiedlich sein und hängt von der Biologie der Art und den ökologischen/ klimatischen Bedingungen eines bestimmten Gebiets ab).

Tabelle 5.2: Saatgutprüfung und Stichprobengröße:DieProbengrößeleitet sichvon einemnominalen Tausendkorngewicht für jede Baumart ab, das auf Basis der vorliegenden Fakten für die Mehrheit der untersuchten Proben angemessen sein dürfte.

\begin{tabular}{lccc} 
& Maximales Gewicht der & \multicolumn{2}{c}{ Minimales Probengewicht } \\
\cline { 3 - 4 } Baumart & 1000 & Eingereichte Probe [g] & benötigte Menge [g] \\
\hline Abies alba Mill. & 5000 & 240 & 120 \\
\hline Fagus sylvatica L. & 1000 & 1000 & 600 \\
\hline Fraxinus spp. & 1000 & 400 & 200 \\
\hline Pinus nigra J. F. Arnold & 50 & 100 & 50 \\
\hline Populus spp & 1000 & 5 & 2 \\
\hline Prunus avium (L.) L. & 5000 & 500 Samen & 450 \\
\hline Quercus spp. & & 500 Samen \\
\hline
\end{tabular}


Tabelle 5.3: Übersicht über das benötigte Material für die genetische Analyse und Saatgutprüfung innerhalb des FGM.

\begin{tabular}{|c|c|c|}
\hline Genetische Analys & (DNA-Extraktion) & \\
\hline & Reine Arten & Arten mit Hybridisierung/ Klone \\
\hline \multirow{4}{*}{ Altbäume } & Einhäusige Arten: & Einhäusige Arten: \\
\hline & 50 fortpflanzungsfähige Bäume & $\begin{array}{c}50 \text { fortpflanzungsfähige Bäume (genotypisiert als } \\
\text { Teil des Auswahlverfahrens der Bäume; wenn } \\
\text { Hybride/Klone vorhanden sind, sollen weitere } 50 \\
\text { Bäume genotypisiert warden; } 50 \text { nicht-hybride } \\
\text { Bäume mit einem einzigartigen Genotyp sollen dann } \\
\text { zufällig für FGM ausgewählt werden) }\end{array}$ \\
\hline & $\begin{array}{l}\text { Zweihäusige oder funktionell zweihäusige Arten } \\
\text { (z.B. Gemeine Esche): }\end{array}$ & $\begin{array}{l}\text { Zweihäusige oder funktionell zweihäusige Arten } \\
\text { (z.B. Gemeine Esche): }\end{array}$ \\
\hline & 25 weibliche und 25 männliche Bäume & 25 weibliche und 25 männliche Bäume \\
\hline Naturverjüngung & 50 etablierte Individuen aus Naturverjüngung & $\begin{array}{c}100 \text { etablierte Individuen aus Naturverjüngung } \\
\text { (alle genotypisiert, } 50 \text { nicht-hybride Individuen mit } \\
\text { einem einzigartigen Genotyp sollen dann zufällig } \\
\text { für; falls notwendig, müssen weitere } 50 \text { Individuen } \\
\text { genotypisiert werden) }\end{array}$ \\
\hline Samen & $\begin{array}{c}\text { Getrennte Beerntung von } 20 \text { ausgewählten } \\
\text { Samenbäumen; mindestens } 200 \text { - } 300 \text { Samen } \\
\text { pro Baum sollten von verschiedenen Ästen } \\
\text { eingesammelt und gemischt werden; } 20 \\
\text { Samen pro Baum werden analysiert, insgesamt } \\
400 \text { Samen }\end{array}$ & $\begin{array}{l}\text { Getrennte Beerntung von } 20 \text { ausgewählten } \\
\text { Samenbäumen; mindestens } 200 \text { - } 300 \text { Samen } \\
\text { pro Baum sollten von verschiedenen Ästen } \\
\text { eingesammelt und gemischt werden; } 30 \text { Samen pro } \\
\text { Baum werden analysiert, insgesamt } 600 \text { Samen }\end{array}$ \\
\hline \multicolumn{3}{|l|}{ Saatgutprüfung } \\
\hline Samen & \multicolumn{2}{|c|}{$\begin{array}{c}\text { Gemischtes, vom Boden gesammeltes Saatgut oder Mischprobe aus Zapfen und Samen, gesammelt } \\
\text { von } 20 \text { Einzelbäumen (Tabelle 5.2) }\end{array}$} \\
\hline
\end{tabular}

\section{Quellen}

Alizoti PG, Kilimis K, Gallios P (2010) Temporal and spatial variation of flowering among Pinus nigra Arn. clones under changing climatic conditions. For Ecol Manag 259:786-797. https://doi.org/10.1016/j.foreco.2009.06.029

Beuker E, Raspe S, Bastrup-Birk A, Preuhsler T (2010) Phenological Observations. Manual Part VI. In: Manual on methods and criteria for harmonized sampling, assessment, monitoring and analysis of the effects of air pollution on forests. UNECE, ICP Forests, Hamburg

Ducci F, De Cuyper B, Pâques LE, Proietti R, Wolf H (2012) Reference protocols for assessment of trait and reference genotypes to be used as standards in international research projects. CRA SEL, Arezzo, Italy

Mund M, Kutsch WL, Wirth C, Kahl T, Knohl A, Skomarkova MV, Schulze ED (2010) The influence of climate and fructification on the inter-annual variability of stem growth and net primary productivity in an old-growth, mixed beech forest. Tree Physiol 30:689-704. https://doi.org/10.1093/treephys/tpq027

Seifert T, Müller-Starck G (2009) Impacts of fructification on biomass production and correlated genetic effects in Norway spruce (Picea abies [L.] Karst.). Eur J For Res 128:155. https://doi.org/10.1007/s10342-008-0219-5

The International Seed Testing Association (ISTA) (2020) International Rules for Seed Testing. Bassersdorf, Switzerland. https://doi.org/10.15258/istarules.2020.F 


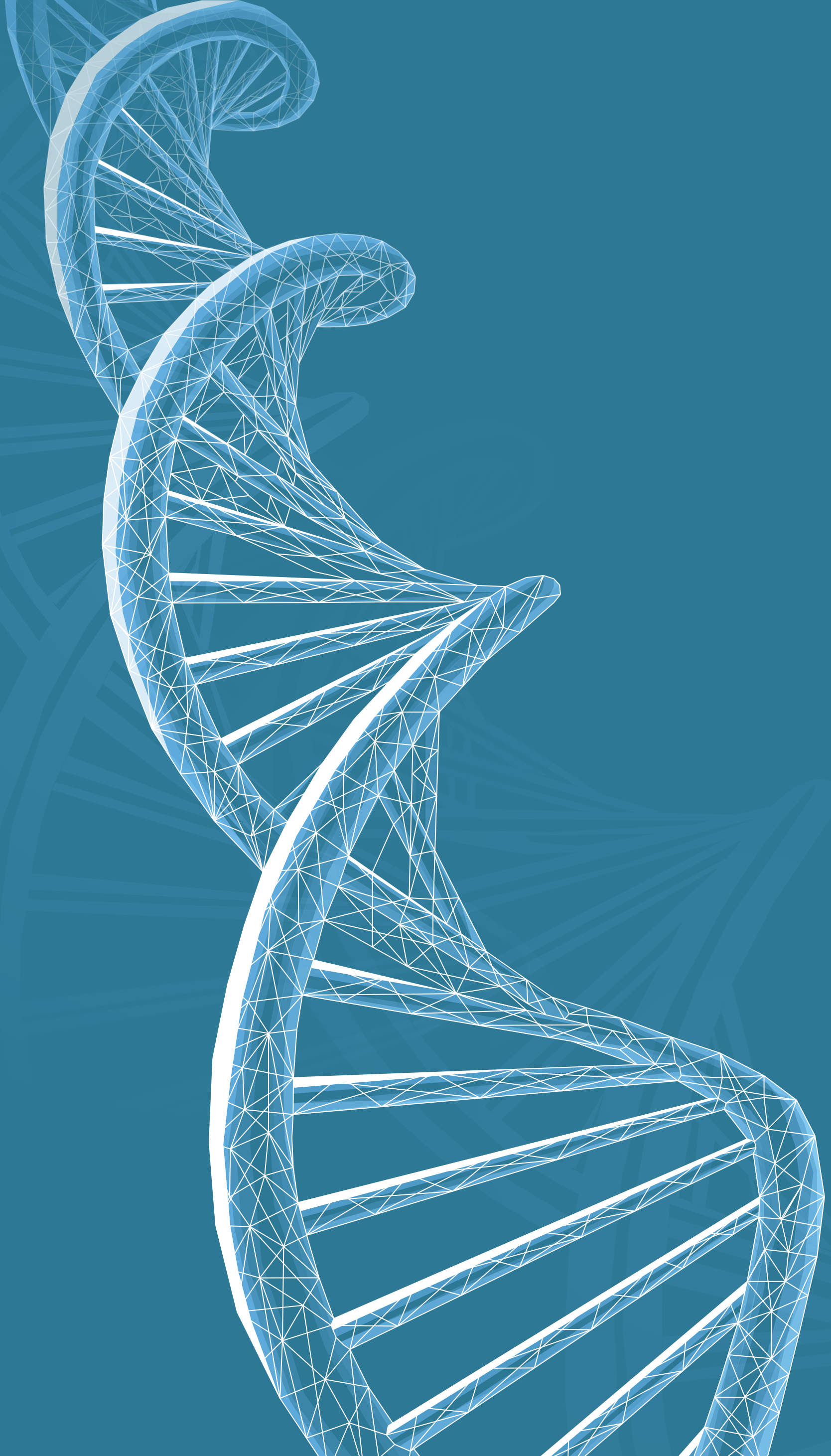




\section{WHDH}

\section{Handbuch zum Forstgenetisches Monitoring}

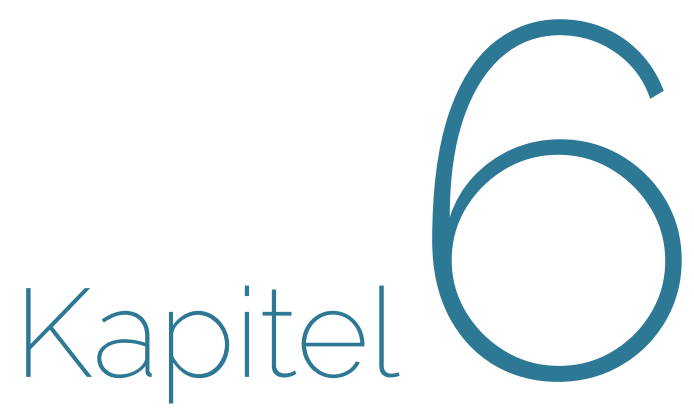

\section{LABOR- UND DATENANALYSEN}

Filippos A. ARAVANOPOULOS ${ }^{1}$, Barbara FUSSI², Marjana WESTERGREN ${ }^{3}$, Marko BAJC ${ }^{3}$, Darius KAVALIAUSKAS², Nikolaos TOURVAS ${ }^{1}$, Rok DAMJANIĆ3, Natalija DOVČํ, Nataša ŠIBANC ${ }^{3}$, Paraskevi ALIZOTI', Ermioni MALLIAROU', Evangelia AVRAMIDOU11,4 Evangelos BARBAS', Gregor BOŽIČㄴ Philip BRAILEY-JONES ${ }^{3}$, Anna-Maria FARSAKOGLOU ${ }^{1,5}$, Domen FINŽGAR ${ }^{3,6}$, Ioannis GANOPOULOS ${ }^{1,7}$, Monika KONNERT ${ }^{2}$, Hojka KRAIGHER1 ${ }^{3}$

Zitat: Aravanopoulos et al. (2020) Labor- und Datenanalysen. In: Bajc et al. (Ed.) Handbuch zum forstgenetischen Monitoring. Slowenisches Forstinstitut: Verlag Silva Slovenica, Ljubljana, S. 71-140. http://dx.doi.org/10.20315/SFS.176

Institut:

1. Aristoteles Universität von Thessaloniki (AUTh), Griechenland

2. Bayerisches Amt für Waldgenetik (AWG), Deutschland

3. Slowenisches Forstinstitut (SFI), Slowenien

4. Institut für Mediterrane Waldökosysteme, DEMETER, Griechenland

5. Europäisches Programm für forstgenetische Ressourcen (EUFORGEN), Europäische Forstinstitut (EFI) (EFI), Spanien

6. Institut für Evolutionäre Biologie, Universität von Edinburgh, Großbritannien

7. Institut für Pflanzenzüchtung und genetische Ressourcen, HAO ELGO DEMETER, Griechenland 


\subsection{EINLEITUNG}

Laboranalysen machen einen großen Teil des forstgenetischen Monitorings (FGM) aus. Alle drei Indikatoren ((1) Selektion, (2) genetische Variation und (3) Genfluss/Paarungssystem), die in diesem Projekt untersucht wurden, basieren auf Daten und Ergebnissen von Laboruntersuchungen. Die FGM-Laboranalysen umfassen drei wesentliche Schwerpunkte: (1) Probenaufbereitung und -lagerung, (2) Saatgutprüfung und (3) DNA-Analyse. Der erste Teil ist von besonderer Bedeutung, da die Lagerung von Pflanzengewebe und DNA essentiell für die Möglichkeit einer erneuten Untersuchung älterer Proben ist, z.B. zur Anwendung eines verbesserten Verfahrens oder einer neuen analytischen Methode. In einem Monitoring-Verfahren wie dem FGM, das auf der Überwachung von Entwicklungen im Verlauf der Zeit beruht, ist diese Möglichkeit extrem wichtig für einen korrekten Probenvergleich. Im Zusammenhang mit der Fitness ist auch die Saatgutprüfung ein sehr wichtiger Parameter, der für die Ausführung des FGM-Intensivniveaus erforderlich ist. Die DNA-Analyse bildet die einzige Grundlage zur Bewertung der Indikatoren "genetische Variation“ und "Genfluss-/Paarungssystem" und trägt außerdem durch $\mathrm{F}_{\mathrm{st}}$-Ausreißertests zum Indikator „Selektion“ bei. Darüber hinaus beinhaltet dieses Kapitel Informationen über Datenbanken, Plausibilitätsprüfung und Datenfilterung. Es schließt mit einem wichtigen Einblick in die Interpretation der Daten des forstgenetischen Monitorings, verbunden mit notwendigen Maßnahmen auf der Monitoringfläche und vielem mehr.

\subsection{PROBENAUFBEREITUNG UND -LAGERUNG}

\subsubsection{Probenaufbereitung}

Für die Handhabung und Vorbereitung aller Probentypen gelten die gleichen grundlegenden Regeln. Die Befolgung der Labornorm ISO/IEC 17025:2017 wird empfohlen.

a. Gewährleisten Sie die Nachverfolgbarkeit aller Proben und Analysen. Stellen Sie sicher, dass alle Proben in allen Analysephasen korrekt und konsistent gekennzeichnet werden, beginnend mit der Kennzeichnung vor Ort im Bestand. Es ist äußerst wichtig, zuverlässige Aufzeichnungen über alle Proben und Analysen zu führen

b. Verhindern Sie eine Kreuzkontaminierung von Proben. Alle Oberflächen und Werkzeuge, die bei der Probenaufbereitung verwendet werden, müssen dekontaminiert werden, um den Transfer von DNA zwischen verschiedenen Proben zu verhindern. Es gibt eine Reihe kommerzieller Produkte (in Flüssig- oder Schaumform), um DNA auf Oberflächen zu zerstören. Mit 5\%-Natriumhypochlorit ( $\mathrm{NaClO}$ ) kann jedoch das gleiche Ergebnis erreicht werden. Werkzeuge, die zur Probenaufbereitung verwendet werden (Pinzetten, Scheren, Messer, Lochstanzen usw.), müssen zwischen den einzelnen Proben dekontaminiert werden. Eine einfache und schnelle Lösung dafür ist Verbrennen. Der kontaminierte Teil von Werkzeugen kann direkt in der Flamme eines Bunsenbrenners ausgebrannt oder in Ethanol getaucht und angezündet werden. Lassen Sie die Werkzeuge 15-20 Sekunden abkühlen, bevor Sie sie für die nächste Probe verwenden.

c. Probengefäße zur Aufbewahrung von pflanzlichen Gewebeproben und DNA müssen steril sowie frei von DNA/ RNA, Nuklease und Pyrophosphat sein. Für die Lagerung von Proben bei extrem niedrigen Temperaturen (unter $-70^{\circ} \mathrm{C}$ ) müssen geeignete Kryo-Röhrchen, Behälter und Etiketten/Markierstifte verwendet werden, die ihre Beschaffenheit und Funktion bei derart niedrigen Temperaturen beibehalten. Zahlreiche geeignete Produkte sind kommerziell erhältlich.

d. Alle Verbrauchsmaterialien (wie z.B. Pipettenspitzen zur Aliquotierung extrahierter DNA) und Medien (wie z.B. Puffer zur DNA-Lagerung) müssen steril sowie frei von DNA/RNA, Nuklease und Pyrophosphat sein.

\subsubsection{Probenlagerung}

Das Verfahren zur Lagerung von frischem Pflanzengewebe für DNA-Analysen hängt von der Art des Gewebes und der Zeit ab, in der die Proben im Labor verarbeitet werden können. Im Allgemeinen sollten die Proben so 
schnell wie möglich verarbeitet und so gelagert werden, dass der DNA-Abbau minimiert wird. Zur Lagerung von Saatgut für die Prüfung der Keimfähigkeit siehe Unterkapitel 6.2.2.4.

\subsubsection{Lagerung von Pflanzengewebeproben für die DNA-Extraktion bei der Probenahme vor Ort}

\subsubsection{1 "Nass"-Verfahren}

Viele Arten von Pflanzengewebe können bei der Probenahme vor Ort stabil gelagert werden, indem man sie in einen fest verschließbaren Plastikbeutel (ZIP-Lock) legt und vor direkter Sonneneinstrahlung und schwankenden Temperaturen schützt. Styroporkisten, wie sie z.B. für den Versand temperaturempfindlicher Materialien verwendet werden, sind eine bequeme Lösung, um Temperaturschwankungen zu puffern und Schutz vor direkter Sonneneinstrahlung sicherzustellen. In die Kiste sollte auch ein Kühlakku gelegt werden, wobei darauf zu achten ist, dass die Proben nicht in direkten Kontakt damit kommen. Auf diese Weise gesammelte und gelagerte Proben sollten innerhalb desselben Tages in eine kontinuierliche Kühlvorrichtung überführt werden (Prendini et al. 2002).

\subsubsection{2 "Trocken”-Verfahren}

Die schnelle Trocknung von pflanzlichen Gewebeproben mittels Silikagel ist eine weitere gängige Möglichkeit, um einen übermäßigen Abbau der DNA zu verhindern, bis die Proben im Labor eintreffen. Die Proben sollten in beschriftete Papierbeutel gegeben und dann zusammen mit Silikagel in fest verschließbaren Plastikbeuteln (ZIP-Lock) gesichert werden. Verwenden Sie relativ zur Menge des Pflanzengewebes mindestens die 10-fache Menge an Silikagel mit Feuchtigkeitsindikator (Gewichtsverhältnis Silikagel:Probe von 10:1). Die Beutel mit den Proben und dem Silikagel sollten in fest verschlossenen Plastikkisten geschützt vor direkter Sonneneinstrahlung aufbewahrt werden. Die Trocknung der Proben bei der Probenahme vor Ort ist nur bei Proben ratsam, die ein großes Oberfläche-zu-Volumen-Verhältnis aufweisen, wie z.B. Blätter oder Nadeln. Größere Zweige, Früchte oder ähnlich dicke Gewebetypen brauchen zu lange zum Trocknen, was möglicherweise zum DNA-Abbau führt. Daher wird empfohlen, solche Proben bei niedrigeren Temperaturen aufzubewahren (siehe 6.2.2.1.1) und innerhalb desselben Tages in eine kontinuierliche Kühlvorrichtung zu überführen (Prendini et al. 2002, Chase und Hills 1991).

\subsubsection{Lagerung von Pflanzengewebeproben für die DNA-Extraktion im Labor}

\subsection{Kurzfristige Lagerung}

Proben der meisten frischen Pflanzengewebe (Zweige mit Blättern/Nadeln/Knospen, Rinde mit Kambium) können bei $+2^{\circ} \mathrm{C}$ bis $+4^{\circ} \mathrm{C}$ für 2-3 Tage ohne signifikante Auswirkungen auf die Quantität oder Qualität der DNA stabil gelagert werden (Sytsma und Schaal 1985; Prendini et al. 2002). Bei Saatgut ist die Gefahr des DNA-Abbaus im Allgemeinen deutlich geringer, so dass dieses je nach Baumart bei $+2^{\circ} \mathrm{C}$ bis $+4^{\circ} \mathrm{C}$ für Wochen oder sogar Monate stabil gelagert werden kann. Um Pilzwachstum zu verhindern, wird jedoch empfohlen, den Feuchtegehalt regelmäßig zu kontrollieren.

\subsection{Mittelfristige Lagerung}

Frische Pflanzengewebeproben können für mehrere Jahre in einem Gefrierschrank (-20/-80 $\mathrm{C})$ gelagert werden. Obwohl der biologische (enzymatische) Abbau der DNA im gefrorenen Zustand weitgehend gehemmt ist, kann es dennoch zu einem chemischen DNA-Abbau kommen. Es wird daher empfohlen, nach Möglichkeit eher langfristige Lagerungsstrategien anzuwenden (Prendini et al. 2002, Campbell et al. 2018). 


\subsection{Langzeitlagerung}

Für die langfristige Lagerung wird vorzugsweise die Aufbewahrung der Proben im Glaszustand empfohlen (unterhalb der Glasübergangstemperatur für wasserbasierte Materialien). In diesem Zustand werden sowohl der biologische als auch der chemische Abbau der DNA bis zum maximal möglichen Grad gehemmt (Campbell et al. 2018, Center for Plant Conservation 2020). Für die Langzeit-Kryokonservierung werden Proben normalerweise in FlüssigstickstoffDampfphasen-Kryokonservierungssystemen oder speziellen Ultratiefkühlschränken mit extrem niedriger Temperatur gelagert, die beide in der Lage sind, die Temperatur für biologische Proben unter dem Glasübergangspunkt zu halten (zwischen -132 und $-136^{\circ} \mathrm{C}$, Prendini et al. 2002). Da Kryokonservierungssysteme eine spezielle Infrastruktur erfordern und mit erheblichen Anfangsinvestitionen und Betriebskosten verbunden sind, sind sie für viele Forschungseinrichtungen häufig nicht realisierbar (Campbell et al. 2018, Center for Plant Conservation 2020).

Viele pflanzliche Gewebe können bei $-70^{\circ} \mathrm{C}$ bis $-80^{\circ} \mathrm{C}$ für die Extraktion von DNA langfristig stabil gelagert werden. Neubig et al. (2014) zeigten jedoch, dass eingefrorenes Pflanzenmaterial unabhängig davon, ob es bei $-20^{\circ} \mathrm{C}$ oder $-80^{\circ} \mathrm{C}$ gelagert wurde, seine hohe Qualität über 24 Jahre beibehielt. Insbesondere Samen behalten auch ohne Kryokonservierung qualitativ hochwertige DNA bei, und DNA von hoher Qualität kann auch aus alten nicht lebensfähigen Samen extrahiert werden, wenn sie unter stabilen Bedingungen bei oder unter $-20^{\circ} \mathrm{C}$ gehalten werden (Walters et al. 2006). Obwohl die Kryokonservierung zweifellos der zuverlässigste und sicherste Ansatz für die Langzeitlagerung von Pflanzengewebe mit geringem Risiko des DNA-Abbaus ist, kann eine gute Konservierung von DNA in Pflanzengeweben auch bei höheren Temperaturen unter Null erreicht werden (Walters et al. 2006, Neubig et al. 2014). Um das Risiko eines DNA-Abbaus zu minimieren, sollten die folgenden Empfehlungen für die Langzeitlagerung von Pflanzengewebeproben befolgt werden:

a. Stabile Lagerbedingungen müssen gewährleistet und Temperaturschwankungen vermieden werden. Im Allgemeinen ist es umso besser, je niedriger die Lagertemperatur ist. Eine Langzeitlagerung unterhalb des Glasübergangspunkts, d.h. eine Kryokonservierung ist empfehlenswert, gefolgt von einer Lagerung bei $-80^{\circ}$ $\mathrm{C}$ und schließlich bei $-20^{\circ} \mathrm{C}$. Lagerung bei Temperaturen über $-20^{\circ} \mathrm{C}$ ist zu vermeiden.

b. Einfrier- und Auftauzyklen verursachen eine Schädigung des Gewebes und der DNA (siehe Kasten 6.1 und 6.2). Daher ist es ratsam, Pflanzengewebeproben in mehreren Replikaten zu lagern, damit nur ein Replikat aus der Lagerung genommen und zur DNA-Extraktion aufgetaut wird, anstatt die gesamte Menge aufzutauen. Die Replikate sollten nach Möglichkeit auf mindestens zwei Speichersysteme aufgeteilt werden, um das Risiko zu minimieren, dass bei einem plötzlichen Geräteausfall alle Replikate verloren gehen.

c. Da die meisten Prozesse des DNA-Abbaus von der Anwesenheit von Wasser abhängen, kann das Austrocknen der Proben (durch Gefriertrocknung oder durch Silikagel) vor dem Einfrieren einen zusätzlichen Schutz gegen den Abbau der DNA bieten, insbesondere im Falle des Auftauens durch Gerätestörungen. Insbesondere hartnäckig auszutrocknendes Saatgut sollte vor dem Einfrieren bis zu einer Woche an der Luft getrocknet werden (Walters et al. 2006).

d. Wenn ausreichende Ressourcen zur Verfügung stehen, ist es ratsam, DNA-Extrakte zusätzlich zu Pflanzengewebeproben zu lagern, da extrahierte DNA-Proben stabiler als Gewebe sind (Prendini et al. 2002). Weitere Informationen zur Lagerung von DNA-Proben finden Sie in Kapitel 6.2.2.3.

\section{Box 6.1: EINFRIER-AUFTAU-ZYKLEN, Teil I}

Bei allen Lagerungsverfahren, bei denen pflanzliche Gewebeproben eingefroren werden, sollte ein wiederholtes Einfrieren und Auftauen unbedingt vermieden werden! Neben einem möglichen direkten Beitrag zum DNA-Abbau (siehe Infokasten „Einfrier-Auftau-Zyklen, Teil II“ in Box 6.2) führen Einfrier-AuftauZyklen zum Aufbrechen von Zell- und Organell-Membranen, wodurch die DNA DNA-abbauenden Enzymen ausgesetzt wird und das Risiko einer enzymatischen DNA-Degradation beim Auftauen der Proben erhöht wird (Campbell et al. 2018). 


\subsubsection{Lagerung der extrahierten DNA}

Sachgemäße Lagerungsbedingungen stellen sicher, dass die Quantität und Qualität der extrahierten DNA auf dem für nachfolgende Analysen erforderlichen Niveau erhalten bleiben. Obwohl die DNA als ein ziemlich stabiles biologisches Makromolekül gilt, ist sie dennoch anfällig für den Abbau durch verschiedene Mechanismen. Unter der Annahme, dass die Nukleaseaktivität im Pflanzengewebe während der DNA-Extraktion vollständig eliminiert wird, stellt der chemische Abbau die größte Bedrohung für die Erhaltung der DNA dar (Adams et al. 1999, Briggs 1999, Bada et al. 1999, Soltis und Soltis 1993, Thomas und Paabo 1994, Yagi et al. 1996). Darüber hinaus ist DNA empfindlich gegenüber hohen Temperaturen und ionisierender Strahlung (einschließlich Teilen des ultravioletten Spektrums), so dass alle Vorsichtsmaßnahmen getroffen werden sollten, um zu vermeiden, dass die DNA solchen Bedingungen ausgesetzt wird. (Prendini et al. 2002, Campbell et al. 2018)

In wässrigen Lösungen - dem bevorzugten Medium für die Lagerung von DNA - sind hydrolytische Spaltung, Desaminierung, Depurinierung, Depyrimidinierung und oxidative Schädigung die wesentlichen Ursachen des DNA-Abbaus (Briggs 1999, Bada et al. 1999, Thomas und Paabo 1994). Hydrolyse, Desaminierung, Depurinierung und Depyrimidierung können durch eine Lagerung der DNA in gepufferten alkalischen Lösungen (pH 8,0 9,0) gehemmt werden, da diese Abbauprozesse unter sauren Bedingungen katalysiert werden. Die oxidative Schädigung wird in Gegenwart von Metallkationen (Fe3+, Cu2+ usw.) durch eine Fenton-Reaktion verstärkt, wobei bereits bei Konzentrationen über $5 \times 10^{-9}$ (ppb; Teile pro Milliarde) eine schädigende Wirkung eintritt. Daher wird einer Zugabe von Chelatbildnern wie EDTA zur DNA-Lagerlösung empfohlen (Prendini et al. 2002).

\subsection{Strategien zur Lagerung von DNA}

Unabhängig von der gewählten Lagerungsstrategie ist es immer empfehlenswert, aus einer DNA-Probe mehrere Aliquots herzustellen, so dass ein Aliquot sofort für weitergehende Analysen verwendet werden kann, während die restlichen langfristig gelagert werden. Der Zeitraum, über den DNA konserviert werden kann, hängt sowohl von den Lagerungsbedingungen als auch von der Quantität, Beschaffenheit und Reinheit der extrahierten DNA DNA (Tabelle 6.1).

Für die Lagerung extrahierter DNA-Proben gelten ähnliche Regeln wie für die Lagerung frischer Gewebeproben. Die sicherste Strategie ist die Lagerung von DNA im Glaszustand, d.h. unterhalb der Glasübergangstemperatur für wasserbasierte Polymerlösungen; insbesondere wenn eine sehr langfristige Lagerung angestrebt wird (Campbell et al. 2018).

Obwohl bei der Lagerung getrockneter DNA-Proben bei Raumtemperatur gewisse Fortschritte erzielt wurden sowohl in Form kommerzieller Systeme als auch „laborintern“ entwickelter Verfahren - ist es verfrüht, den Übergang zur trockenen DNA-Lagerung bei Raumtemperatur zu empfehlen; insbesondere für Proben mit einer höheren Inhibitorenkonzentration (wie z.B. bei Pflanzengewebe) und bei längeren Lagerungszeiträumen (Ivanova und Kuzmina 2013).

Die Firma Qiagen GmbH, ein etablierter Hersteller von DNA/RNA-Extraktionskits, führt aktuell interne Tests durch die darauf hindeuten, dass hochmolekulare DNA in Tris-EDTA-basierter Lösung mit einem pH von 8,5 bei $-20^{\circ} \mathrm{C}$ für mindestens 16 Jahre und bei $+2^{\circ} \mathrm{C}$ bis $+8^{\circ} \mathrm{C}$ für mindestens 8 Jahre sicher gelagert werden kann, wenn die DNA eine hohe Reinheit aufweist (Abwesenheit von Nukleaseaktivität) (Hartmann et al. 2016). Es wird darauf hingewiesen, dass die in den Qiagen-Versuchen verwendete DNA aus Blutproben isoliert wurde, und dass Pflanzenmaterial im Hinblick auf die Entfernung von Verunreinigungen während des DNA-Extraktionsprozesses meist deutlich problematischer ist, weshalb bei der Entscheidung über die am besten geeignete Lagerungsstrategie für pflanzliche DNA-Proben Vorsicht geboten ist. 
Tabelle 6.1: Gängige Strategien zur Lagerung von DNA-Proben. RT - Raumtemperatur.

\begin{tabular}{llll} 
Lagerungsstrategie & Bedingungen & Medium & Zeitraum $^{1}$ \\
\hline Kurzfristig & $+2^{\circ} \mathrm{C}$ bis $+8^{\circ} \mathrm{C}$ & $10 \mathrm{mM}$ Tris-HCl, 0.5mM EDTA, pH $8.5-9.0$ & Wochen bis Monate \\
\hline Mittelfristig & $-20 /-80^{\circ} \mathrm{C}$ & $10 \mathrm{mM}$ Tris-HCl, 0.5mM EDTA, pH $8.5-9.0$ & mehrere Jahre \\
\hline Langfristig & $-80^{\circ} \mathrm{C}$, ausgefällt & Ethanol & Jahre bis Jahrzehnte \\
\hline Sehr langfristig & $-196^{\circ} \mathrm{C}$ (Flüssigstickstoff) & $10 \mathrm{mM}$ Tris-HCl, 0.5mM EDTA, pH $8.5-9.0$ & Jahrzehnte \\
\hline Sehr langfristig & $\begin{array}{l}-136 \text { bis }-150^{\circ} \mathrm{C} \\
(\text { Ultratiefkühlschrank) }\end{array}$ & $10 \mathrm{mM}$ Tris-HCl, 0.5mM EDTA, pH $8.5-9.0$ & Jahrzehnte \\
\hline Sehr langfristig & $\begin{array}{l}\text { RT, getrocknet (frei von } \\
\text { Wasser) }\end{array}$ & divers $^{2}$ & Jahrzehnte $^{3}$ \\
\hline
\end{tabular}

${ }^{1}$ Die angegebenen Zeiträume sollten als Anhaltspunkte betrachtet werden, die auf den in der Literatur angegebenen Werten und Erfahrungen der am LIFEGENMON-Projekt beteiligten Laboratorien basieren.

${ }^{2}$ Die meisten Ansätze zur Lagerung von DNA-Proben in getrockneter Form basieren auf der Verwendung einer Schutzmatrix, wie z.B. Trehalose oder Polyvinylalkohol (PVA). Um einen Abbau der DNA zu verhindern, müssen die getrockneten DNA-Proben vor Rehydrierung und Temperaturschwankungen geschützt werden.

${ }^{3}$ Die Entfernung von Wasser gewährleistet theoretisch einen ähnlichen Schutz gegen den Abbau von DNA wie die Kryokonservierung, hängt jedoch stark von der vollständigen Verhinderung der Rehydratisierung von ausgetrockneten DNA-Proben ab, was auf lange Sicht oft schwierig zu erreichen ist.

\section{Box 6.2: EINFRIER-AUFTAU-ZYKLEN, Teil II}

Obwohl in molekulargenetischen Laboren allgemeinhin bekannt, sind die tatsächlichen Auswirkungen wiederholter Einfrier-Auftau-Zyklen auf die DNA-Qualität nach wie vor durchaus umstritten. Eine Studie von Schuster und Appleby (1983) enthielt keine Hinweise auf eine DNA-schädigende Wirkung wiederholter Einfrier-Auftau-Zyklen, und stellte die Verwendung radioaktiv markierter DNA in früheren Studien in Frage, da statt der Anzahl der Einfrier-Auftau-Zyklen möglicherweise die radioaktive Markierung die Ursache für den DNA-Abbau sein könnte. Gemäß dem Sprichwort „better safe than sorry“ (Vorsicht ist besser als Nachsicht) wird daher weiterhin empfohlen, DNA-Proben in Aliquots zu lagern, um nicht nur den Abbau durch wiederholte Einfrier-Auftau-Zyklen sondern auch durch chemische Degradation zu minimieren und gleichzeitig die Gefahr der Kontamination der gesamten DNA-Probe zu verringern (Prendini et al. 2002, Campbell et al. 2018).

\subsubsection{Lagerung von Saatgut für die Saatgutprüfung}

Saatgut für die im Rahmen des FGM durchgeführten Saatguttests sollte im reifen Zustand kurz vor oder während der natürlichen Samenausbreitung gesammelt werden (Hay und Smith 2003). Wird Saatgut zu früh gesammelt (unreifes Saatgut), kann es seine Lebensfähigkeit verlieren und keimt ggf. während der Saatguttests nicht (Pedrini et al. 2020, De Vitis et al. 2020). Eine Ausnahme ist die Sammlung der sogenannten „grünen Samen“ von Fraxinus spp. falls diese Samen für die sofortige Keimfähigkeitsprüfung verwendet werden sollen. Die Gewinnung einer für eine Monitoringfläche repräsentativen Probe für die FGM-Saatgutprüfung erfolgt, indem nach dem Zufallsprinzip an verschiedenen Stellen der Monitoringfläche oder in verschiedenen Teilen der Krone (wenn Samen/Zapfen durch Klettern direkt vom Baum geerntet werden) kleine Saatgutmengen gesammelt und zu einer Mischprobe kombiniert werden. Alternativ können Teile des von 20 Bäumen für DNA-Analysen gesammelten Saatguts gemischt und für Saatguttests verwendet werden. Jede Phase der Saatgutprüfung muss mit geeigneten Methoden und Geräten gemäß den ISTA-Vorschriften durchgeführt werden (2020, verfügbar unter https://www.seedtest.org/en/ ista-rules-2019-_content---1--3410.html). Da die Ergebnisse der Saatgutprüfung von entscheidender Bedeutung für das FGM sind (z.B. für die Schätzung der tatsächlichen Inzuchtrate), müssen die Saatguttests im selben Jahr bzw. in derselben Saison durchgeführt werden, in dem bzw. der das Saatgut gesammelt wird. Eine längere Lagerung des Saatguts kann die Keimfähigkeit drastisch verringern und die Ergebnisse des Keimfähigkeitstests (KT) und des topografischen Tetrazoliumtests (TT; biochemischer Test auf Lebensfähigkeit) beeinflussen, 
insbesondere bei Arten, deren Samen nicht lange lagerfähig sind. Daher muss die Saatgutprüfung unmittelbar nach Eintreffen des Saatguts im Prüflabor erfolgen.

\subsection{SAATGUTPRÜFUNG}

Die Saatguttests (Prüfung des Gewichts, der Keimfähigkeit und der Lebensfähigkeit des Saatguts) sind gemäß den Methodenvorschriften für Saatgutprüfung der International Seed Testing Association (ISTA, 2020, verfügbar unter https://www.seedtest.org/en/ista-rules-2019-_content---1--3410.html) durchzuführen. Der Probenumfang wird aufgrund der nominalen Tausendkornmasse der jeweiligen Art bestimmt, die nach den vorliegenden Erkenntnissen für die Mehrheit der getesteten Proben angemessen sein dürfte; mit Ausnahme von Quercus und Prunus spec., bei denen die Probengröße 500 Samen betragen sollte.

Die Methoden zur Saatgutprüfung für die sieben Zielbaumarten des LIFEGENMON-Projekts sind in Tabelle 6.2. dargestellt. Beispielsweise wurde im Rahmen des LIFEGENMON-Projekts für Abies alba nur ein KT-Test und für Fagus sylvatica nur ein TT-Test durchgeführt. Es ist zwar grundsätzlich möglich, für beide Arten beide Tests (TT und KT) durchzuführen, aber der wesentlich schneller durchführbare TT-Test wird bevorzugt.

Tabelle 6.2: Von der ISTA (2020) empfohlene Saatguttests für die Zielbaumarten des LIFEGENMON-Projekts

\begin{tabular}{|c|c|c|}
\hline Baumart & $\begin{array}{c}\text { Empfohlene Saatguttests gemäß ISTA } \\
\text { (2020): } \\
\text { KT - Keimfähigkeitstest } \\
T \text { - topografischer Tetrazoliumtest }\end{array}$ & Anmerkungen \\
\hline Abies alba Mill. & $\mathrm{KT}$ & 21 Tage Vorkühlung und Keimdauer von bis zu 28 Tagen \\
\hline Fagus sylvatica L. & TT & $\begin{array}{c}\text { Bei Anwendung des KT: Keimdauer von bis zu } 24 \text { Wochen } \\
\text { (Aufhebung der Keimruhe) }\end{array}$ \\
\hline Fraxinus spp. & TT & $\begin{array}{l}\text { Bei Anwendung des KT: } 9 \text { Monate Stratifizierung und } \\
\text { Keimdauer von bis zu } 56 \text { Tagen* }\end{array}$ \\
\hline Pinus nigra J. F. Arnold & KT & Keimdauer von bis zu 21 Tagen \\
\hline Populus spp. & $\mathrm{KT}$ & Keimdauer von bis zu 10 Tagen \\
\hline Prunus avium (L.) L. & $\mathrm{TT}$ & $\begin{array}{c}\text { Bei Anwendung des KT: 3-4 Monate Vorkühlung und } \\
\text { Keimdauer von bis zu } 28 \text { Tagen }\end{array}$ \\
\hline Quercus spp. & KT & $\begin{array}{c}\text { Keimdauer von bis zu } 28 \text { Tagen (Vorbehandlung wird } \\
\text { empfohlen; siehe spezifische Hinweise) }\end{array}$ \\
\hline
\end{tabular}

* Wenn Samen von Fraxinus excelsior und F. angustifolia grün gesammelt werden, bevor sich die Keimhemmung entwickelt, keimen sie schnell. 


\subsubsection{Gewinnung von Abies alba-Saatgut für die Saatgutprüfung}

Nach Ernte der Zapfen:

- Die Zapfen der einzelnen Bäume müssen separat in gekennzeichneten Plastikkisten aufbewahrt werden.

- Der Boden der Kisten muss mit einem Netz abgedeckt werden, damit die Samen nicht durch die Löcher im Kistenboden herausfallen können (siehe Abb. 6.1a).
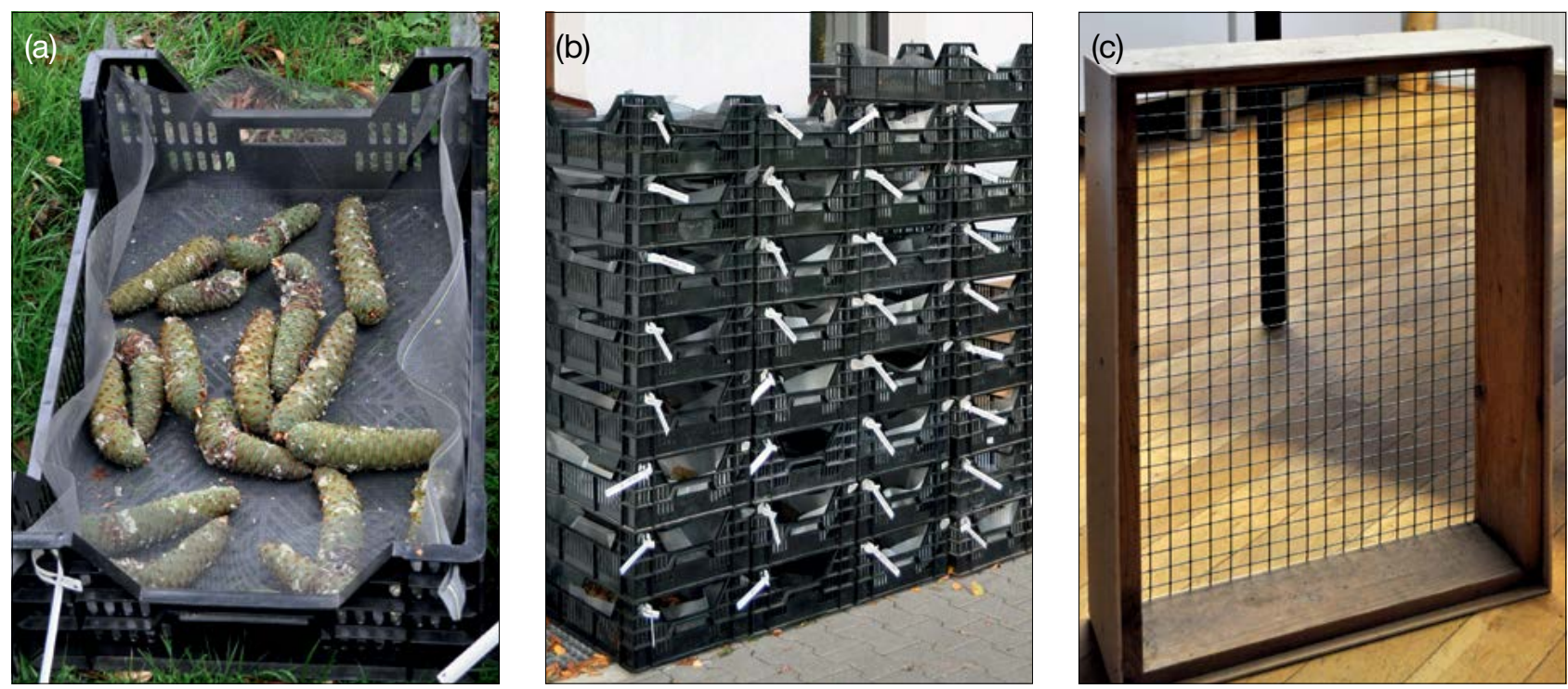

Abbildung 6.1: Kisten zur Aufbewahrung von Abies alba-Zapfen, bis die Zapfenschuppen abgefallen und die Samen freigesetzt sind (a und b); Sieb zur Trennung der Samen von anderen Zapfenbestandteilen nach dem Zerfall der Abies alba-Zapfen (c) (Fotos: Darius Kavaliauskas)

- Die Kisten mit den Zapfen müssen einige Monate lang an einem gut belüfteten Ort aufbewahrt werden, bis die Zapfenschuppen abfallen (Abb. 6.1b).

- Nachdem die die Zapfenschuppen von Abies alba vollständig abgefallen sind, müssen die Samen der einzelnen Bäume separat gereinigt werden (siehe Abb. 6.1c) Sieb zur Trennung der Samen von Abies spec. von Zapfenteilen, Flügeln, usw.).

\subsubsection{Vorbereitung von Fagus sylvatica- und Abies alba/A. borisii-regis-Saatgut für die Saatgutprüfung}

- Nach der Reinigung der Samen von Verunreinigungen, wird für Abies sp. $120 \mathrm{~g}$ und für Fagus sylvatica $600 \mathrm{~g}$ Saatgut für weitere Untersuchungen verwendet. Das Saatgut ist eine Mischprobe, bestehend aus gleichen Teilen aller beprobten Bäume. Leere Samen sollten während der Reinigung nicht entfernt werden.

- Alle Analysen sind nach den ISTA-Vorschriften (2020) durchzuführen. Der Probenumfang wird aufgrund der nominalen Tausendkornmasse der jeweiligen Art bestimmt, die nach den vorliegenden Erkenntnissen für die Mehrheit der getesteten Proben angemessen sein dürfte.

Anmerkung: Für das FGM wird nur reines Saatgut verwendet, Es ist daher keine Reinheitsbestimmung erforderlich, da die gesamte Saatgutsammlung mit dem Ziel erfolgt, das Gewicht von 1000 Samen zu analysieren und nur die Keimfähigkeits- bzw. Lebensfähigkeitsprüfung durchzuführen; es sei denn, es sollen zusätzlich auch Schädlinge oder Krankheiten identifiziert werden. 
Tabelle 6.3: Umfang der Gesamtprobe und der für die Analyse benötigten Menge für die Samen ausgewählter Baumarten, modifiziert nach ISTA (2020).

\begin{tabular}{lcc} 
Baumart & Eingereichte Probe & benötigte Menge \\
\hline Abies alba & $240 \mathrm{~g}$ & $120 \mathrm{~g}$ \\
\hline Fagus sylvatica & $1000 \mathrm{~g}$ & $600 \mathrm{~g}$ \\
\hline Fraxinus spp. & $400 \mathrm{~g}$ & $200 \mathrm{~g}$ \\
\hline Pinus nigra & $100 \mathrm{~g}$ & $50 \mathrm{~g}$ \\
\hline Populus spp. & $5 \mathrm{~g}$ & $2 \mathrm{~g}$ \\
\hline Prunus avium & 500 Samen & 500 Samen \\
\hline Quercus spp. & 500 Samen & 500 Samen \\
\hline
\end{tabular}

\section{Gewichtsbestimmung}

Die Gewichtsbestimmung muss nach den ISTA-Vorschriften (2020) erfolgen.

Die zu analysierende Probe/Partie besteht aus reinem Saatgut. Eine Veränderung des Feuchtigkeitsgehalts der Samen ist möglichst zu vermeiden, indem diese vor der Prüfung nur für kurze Zeit und in feuchtigkeitsundurchlässigen Behältern gelagert werden.

Zählung von Replikaten: Aus der Probe/Partie werden nach dem Zufallsprinzip, von Hand oder mit einem Keimzählgerät, acht Replikate von je 100 Samen ausgezählt. Jedes Replikat wird in Gramm auf die gleiche Anzahl von Dezimalstellen genau gewogen.

\section{Berechnung und Darstellung der Ergebnisse}

- Wenn die Zählung maschinell erfolgt, berechnen Sie das Gewicht von 1000 Samen aus dem Gewicht der gesamten Probe/Partie.

- Erfolgt die Zählung mittels Replikaten, berechnen Sie das Durchschnittsgewicht von 1000 Samen aus dem Gewicht von acht oder mehr 100-Korn-Replikaten.

- Das Ergebnis wird mittels folgender Formel bestimmt (unter Verwendung der genauen Dezimalstellen):

$$
\text { Gewicht von } 1000 \text { Samen }(g)=\frac{(\text { Summe von 8 Replikaten }(g) \times 10)}{8}
$$

\section{Keimfähigkeitstest}

Die Keimfähigkeitstests müssen nach den ISTA-Vorschriften (2020) erfolgen und die unten erläuterte vereinfachte Darstellung berücksichtigen.

\section{Keimprozent}

Das Keimprozent gibt den Anteil der Samen an, der unter den in Tabelle 6.4 angegebenen Bedingungen und innerhalb des angegebenen Zeitraums als normal eingestufte Sämlinge hervorgebracht hat.

\section{Wesentliche Keimlingsstrukturen}

Die folgenden Strukturen sind für die weitere Entwicklung eines Keimlings zu einer als „tauglich“ angesehenen Pflanze essentiell: Wurzel - Keimwurzel (Radicula); Sprossachse; Keimblätter; Terminalknospen.

\section{Normale Keimlinge}

Normale Keimlinge zeigen das Potential für eine kontinuierliche Entwicklung zu tauglichen Pflanzen, wenn sie in qualitativ hochwertigem Substrat und unter günstigen Feuchtigkeits-, Temperatur- und Strahlungsbedingungen 
herangezogen werden. Um als normal eingestuft zu werden, muss ein Keimling einer der folgenden Kategorien entsprechen:

1. Intakte Keimlinge: Keimlinge mit vollständigen und gut entwickelten wesentlichen Strukturen, die in ihren Proportionen ausgewogen und gesund sind.

2. Keimlinge mit leichten Mängeln: Keimlinge, die vereinzelt leichte Mängel in ihren wesentlichen Strukturen aufweisen, sofern sie eine ansonsten zufriedenstellende und ausgewogene Entwicklung aufweisen, die mit der von intakten Keimlingen derselben Prüfpartie vergleichbar ist.

3. Keimlinge mit Sekundärinfektion: Keimlinge, die der obigen Kategorie 1 oder 2 entsprochen hätten, die jedoch von Pilzen oder Bakterien aus anderen Quellen als dem elterlichen Samen befallen sind.

\section{Anormale Keimlinge}

Anormale Keimlinge zeigen nicht das Potential, sich zu normalen Pflanzen zu entwickeln, wenn sie in qualitativ hochwertigem Substrat und unter günstigen Feuchtigkeits-, Temperatur- und Strahlungsbedingungen herangezogen werden.

Folgende Keimlinge werden als anormal eingestuft:

- 1. Beschädigte Keimlinge: Keimlinge, bei denen eine der wesentlichen Strukturen fehlt oder die so stark und irreparabel geschädigt sind, dass eine ausgewogene Entwicklung nicht zu erwarten ist.

- 2. Deformierte und unproportional ausgereifte Keimlinge: Keimlinge mit schwacher Entwicklung oder physiologischen Störungen oder bei denen wesentliche Strukturen deformiert oder überproportional stark geschädigt sind.

- 3. Verdorbene Keimlinge: Keimlinge, bei denen eine der wesentlichen Strukturen infolge einer Primärinfektion so krank oder zerfallen ist, dass eine normale Entwicklung verhindert wird.

\section{Mehrkeimiges Saatgut}

Samen, die mehr als einen Keimling erzeugen können.

\section{Ungekeimtes Saatgut}

Saatgut, das bei der Prüfung unter den in Tabelle 6.4 angegebenen Bedingungen bis zum Ende der Prüfdauer nicht gekeimt hat, wird wie folgt klassifiziert:

- 1. Harte Samen: Saatgut, das am Ende der Prüfdauer noch hart ist, weil es kein Wasser aufgenommen hat.

- 2. Frische Samen: anderes Saatgut (außer harte Samen), das unter den Bedingungen der Keimfähigkeitsprüfung nicht gekeimt ist, das jedoch sauber und fest ist und das Potential hat, sich zu einem normalen Keimling zu entwickeln.

- 3. Tote Samen: Saatgut, das am Ende der Prüfdauer weder hart noch frisch ist, noch irgendeinen Teil eines Keimlings hervorgebracht hat.

- 4. Andere Kategorien: Unter bestimmten Umständen können hohle und ungekeimte Samen weiter nach den in den ISTA-Vorschriften 5.2.7.A beschriebenen Klassen kategorisiert werden.

Nicht gekeimte Samen müssen untersucht und der Prozentsatz der leeren Samen bestimmt werden. Dieser Wert wird zur Berechnung des Prozentsatzes der gefüllten Samen verwendet, welcher ein Verifikator des Intensivniveaus für den Indikator "Selektion" ist. Folglich darf die Entfernung leerer Samen vor dem Keimungstest (oder dem biochemischen Lebensfähigkeitstest) nicht durchgeführt werden, es sei denn, es wird eine separate Bestimmung des Prozentsatzes leerer Samen vorgenommen, dies erhöht jedoch die Arbeitsbelastung und die Anzahl von Samen, die für die Tests notwendig sind. Der Prozentsatz der leeren Samen wird auf die gleiche Weise berechnet wie der Prozentsatz der Keimung (siehe „Berechnung und Angabe der Ergebnisse“ unten und Abschnitt 6.5.5.1.2). 


\section{Materialien}

Papier und Sand sind häufig verwendete Substrate gemäß Tabelle 6.4. Boden und künstlicher Kompost sind keine empfohlenen primären Testsubstrate. Sie sind jedoch in besonderen Fällen zulässig.

\section{Zu analysierende Probe}

Nach dem Zufallsprinzip werden aus dem reinen Saatgut 400 Samen in Replikaten von je 100 entnommen und in gleichmäßigem und der Samengröße entsprechendem Abstand auf dem feuchten Substrat verteilt. Die Replikate können in Untergruppen von 50 oder 25 Samen aufgeteilt werden, abhängig von der Größe der Samen und dem zwischen diesen erforderlichen Abstand.

Mehrkeimiges Saatgut wird für den Keimtest nicht zerlegt, sondern wie Einzelkorn-Saatgut geprüft.

\section{Prüfdauer}

Die artspezifische Dauer der Keimfähigkeitsprüfung ist in Tabelle 6.3.2 angegeben. Der für die Aufhebung der Keimruhe erforderliche Behandlungszeitraum vor oder während der ISTA-Prüfung, ist nicht Teil der Prüfdauer.

\section{Auswertung}

Für die Auswertung des Tests müssen die wesentlichen Strukturen der Keimlinge ausreichend entwickelt sein, um die Erkennung von Anomalien zu ermöglichen.

Wenn auf Papier getestetes Saatgut Keimlinge erzeugt, die nicht ohne weiteres ausgewertet werden können, sollte der Test in Sand oder qualitativ hochwertigem Boden bei den in Tabelle 6.3. angegebenen Temperaturen und unter günstigen Feuchtigkeits- und Strahlungsbedingungen wiederholt werden.

Die Einstufung von ungekeimten Samen als „frische Samen“ kann erst am Ende des Keimfähigkeitstests erfolgen. Die Klassifikation von hohlem und insektengeschädigtem Saatgut kann vor der Keimprüfung erfolgen.

Mehrkeimiges Saatgut wird als einzelne Einheit gezählt, und das Testergebnis gibt den Anteil der Einheiten an, die mindestens einen normalen Keimling hervorgebracht haben. Darüber hinaus kann zusätzlich die Anzahl normaler Keimlinge, die von 100 Saatguteinheiten erzeugt wurden, oder die Anzahl der Saatguteinheiten, die einen, zwei oder mehr normale Keimlinge erzeugt haben, bestimmt werden.

\section{Berechnung und Darstellung der Ergebnisse}

Die Ergebnisse werden als prozentualer Anteil angegeben. Wenn vier 100-Samen-Replikate eines Tests innerhalb des maximal tolerierten Bereichs liegen, stellt deren Durchschnitt das Keimprozent dar, welches auf dem modifizierten Zertifikat (Grundlage ist das Internationale Saatgutanalysezertifikat der ISTA) anzugeben ist. Der durchschnittliche Prozentsatz wird auf die nächste ganze Zahl gerundet.

Die Tabelle 6.4. „Keimungsverfahren“ enthält die zulässigen Substrate, die Prüfdauer sowie empfohlene zusätzliche Behandlungen für Samen mit Keimruhe:

- Substrate - Die Reihenfolge der alternativen Substrate ist gleich und gibt keine Präferenz an: TP - oberes Papier; BP - Zwischenpapier; S - Sand.

- Temperatur - Die Reihenfolge der anwendbaren Temperaturen ist durchgehend gleich und gibt keine Präferenz an: wechselnde Temperaturen, höchste zuerst; konstante Temperaturen, höchste zuerst.

- Erste Zählung - Der Zeitpunkt der ersten Zählung ist eine ungefähre Angabe und bezieht sich auf die höchstmöglich anwendbare Temperatur bei Papiersubstraten. Wird eine Variante mit niedrigerer Temperatur gewählt oder der Test auf Sand durchgeführt, muss die erste Zählung möglicherweise verschoben werden. Bei einer Prüfung auf Sand mit einer endgültigen Zählung nach 7-10 (14) Tagen kann die erste Zählung vollständig weggelassen werden. 
- Licht - Generell wird im Hinblick auf eine bessere Keimlingsentwicklung eine Beleuchtung während des Tests empfohlen. Ist in bestimmten Fällen Licht erforderlich, um die Keimruhe von Samen aufzuheben oder falls Licht die Keimung hemmen kann und die Substrate im Dunkeln gehalten werden sollten, ist dies in der letzten Spalte angegeben.
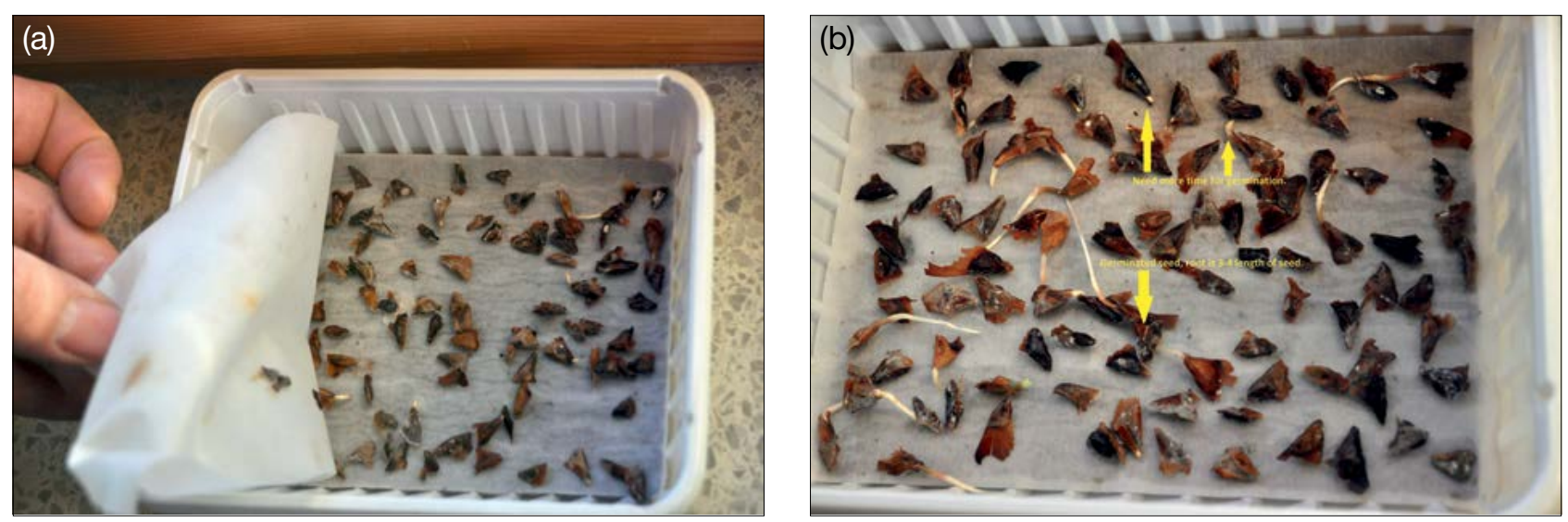

Abbildung. 6.2: (a) Schalen mit Samen (BP - Samen zwischen Papieren); (b) Beispiel: keimende Abies alba Samen (Fotos: Darius Kavaliauskas).

Tabelle 6.4. Keimungsverfahren (Wie in Spalte 6 angegeben, sind für einige der Arten Paralleltests (mit und ohne Vorkühlung) erforderlich. Die weniger empfehlenswerten Methoden sind in Klammern gesetzt.

\begin{tabular}{|c|c|c|c|c|c|}
\hline \multirow[b]{2}{*}{ Baumart } & \multicolumn{4}{|c|}{ Vorschriften für: } & \multirow{2}{*}{$\begin{array}{l}\text { Zusätzliche Anweisungen einschließlich } \\
\text { Empfehlungen zum Aufheben der } \\
\text { Keimruhe }\end{array}$} \\
\hline & Substrat & Temperatur ${ }^{\circ} \mathrm{C}$ & $\begin{array}{c}\text { Erste Zählung } \\
\text { [Tage] }\end{array}$ & $\begin{array}{c}\text { Letzte Zählung } \\
\text { [Tage] }\end{array}$ & \\
\hline Abies alba & TP / BP & $\begin{array}{c}20^{\circ} \mathrm{C} \text { für } 16 \mathrm{~h} / \\
30^{\circ} \mathrm{C} \text { für } 8 \mathrm{~h}\end{array}$ & 7 & 28 & 21 Tage bei $3-5^{\circ} \mathrm{C}$ vorkühlen \\
\hline Fagus sylvatica & TP & $\begin{array}{c}3^{\circ} \mathrm{C} \text { für } 16 \mathrm{~h} / \\
5^{\circ} \mathrm{C} \text { für } 8 \mathrm{~h}\end{array}$ & - & - & $\begin{array}{l}\text { 1. Die Prüfdauer hängt von der } \\
\text { Keimruhe ab und kann im Extremfall } \\
\text { etwa } 24 \text { Wochen betragen. } \\
\text { 2. Verwenden Sie den TT } \\
\text { (Tetrazolium-Test). }\end{array}$ \\
\hline Pinus nigra & TP & $\begin{array}{c}20^{\circ} \mathrm{C} \text { für } 16 \mathrm{~h} / \\
30^{\circ} \mathrm{C} \text { für } 8 \mathrm{~h}\end{array}$ & 7 & $21 ;(14)$ & \\
\hline Fraxinus spp. & TP & $\begin{array}{c}20^{\circ} \mathrm{C} \text { für } 16 \mathrm{~h} / \\
30^{\circ} \mathrm{C} \text { für } 8 \mathrm{~h}\end{array}$ & 14 & 56 & $\begin{array}{l}\text { 1. Saatgut für } 2 \text { Monate bei } 20 \mathrm{C} \\
\text { vorbehandeln, gefolgt von } 7 \\
\text { Monaten bei } 3-5^{\circ} \mathrm{C} \text {. } \\
\text { 2. Verwenden Sie den TT } \\
\text { (Tetrazolium-Test). }\end{array}$ \\
\hline Prunus avium & $S$ & $\begin{array}{l}20^{\circ} \mathrm{C} \text { für } 16 \mathrm{~h} / \\
30^{\circ} \mathrm{C} \text { für } 8 \mathrm{~h}\end{array}$ & 7 & 28 & $\begin{array}{l}\text { 1. 3-4 Monate bei } 3-5^{\circ} \mathrm{C} \text { vorkühlen. } \\
\text { 2. Verwenden Sie den TT } \\
\text { (Tetrazolium-Test). }\end{array}$ \\
\hline Populus spp. & TP & $\begin{array}{c}20^{\circ} \mathrm{C} \text { für } 16 \mathrm{~h} / \\
30^{\circ} \mathrm{C} \text { für } 8 \mathrm{~h}\end{array}$ & 3 & 10 & \\
\hline Quercus spp. & TS; (S) & $20^{\circ} \mathrm{C}(24 \mathrm{~h})$ & 7 & 28 & $\begin{array}{l}\text { Saatgut für bis zu } 48 \text { h einweichen; am } \\
\text { Narbenende des Samens abschneiden } \\
\text { und Perikarp entfernen. }\end{array}$ \\
\hline
\end{tabular}

Die Abkürzungen haben die folgenden Bedeutungen:
TP - auf der Papieroberseite;
$S$ - Sand;
$\mathrm{BP}$ - zwischen Papierlagen;
TS - auf Sand liegend;

TT - topografischer Tetrazolium-Test; 
Besonderheiten von Abies spp.: Für den Keimtest von Abies alba werden vier Replikate von je 100 Samen verwendet (insgesamt 400 Samen). Die Samen von Abies alba werden im Kühlschrank bei 3-5 ${ }^{\circ} \mathrm{C}$ für 21 Tage vorgekühlt. Gemäß ISTA (2020) ist das Substrat TP - auf der Papieroberseite; das Testsubstrat für Abies alba kann jedoch (optional) auch BP sein - zwischen Papierlagen (Abb. 6.2a). Darunterliegend kann etwas zusätzliches Zellulosepapier verwendet werden, um die notwendige Feuchtigkeit besser zu speichern. Alle Replikate müssen 28 Tage lang in Keimkammern aufbewahrt werden (die Dauer kann um zwei Wochen verlängert werden). Es werden zwei Temperaturbereiche für die Keimung verwendet, die während der gesamten Testdauer täglich wiederholt werden: 16 Stunden bei $20^{\circ} \mathrm{C}$ und 8 Stunden bei $30^{\circ} \mathrm{C}$. Die erste Zählung der gekeimten Samen erfolgt am 7. Tag (Zählung der Samen pro Replikat, die eine Wurzel mit einer Länge der 3-4fachen Samenlänge gebildet haben). Bis zum Ende des Keimtests werden die gekeimten Samen alle 7 Tage gezählt (Abb. 6.2b).

Die Ergebnisse werden jeweils in Prozent als Durchschnitt der vier Replikate angegeben: Anteil normaler sowie anormaler Keimlinge, sowie die Anteile harter, frischer und toter Samen. Die restlichen ungekeimten Samen müssen mit dem Skalpell geöffnet werden, um zu beurteilen, warum diese nicht gekeimt sind (mögliche Gründe: hohle Samen; frische Samen; harte Samen; tote Samen).

\subsubsection{Biochemischer Test auf Lebensfähigkeit - Der topografische Tetrazolium-Test (TT)}

Vorbereitung und Behandlung des Saatguts

Das Saatgut ist so vorzubereiten, dass das Eindringen der Tetrazoliumlösung erleichtert wird. Die vorbereiteten Samen oder Embryonen werden dann bei der in den ISTA-Vorschriften beschriebenen Temperatur und für die dort angegebene Dauer in die Tetrazoliumlösung eingelegt. Am Ende dieses Zeitraums wird die Lösung abgegossen, das Saatgut mit Wasser abgespült und untersucht.

Bei der Untersuchung wird jeder Samen anhand der beobachteten Anfärbungsmuster und der Gewebefestigkeit als lebensfähig oder nicht lebensfähig klassifiziert.

Spezifische Anweisungen für die Vorbereitung, Behandlung und Bewertung für jede der zugelassenen Arten sind in den ISTA-Vorschriften (2020) und in Tabelle 6.3.3 enthalten.

Besonderheiten für Fagus sylvatica: Für den Tetrazoliumtest von Fagus sylvatica werden vier Replikate von je 100 Samen verwendet (insgesamt 400 Samen). Das Perikarp muss bei allen Samen entfernt werden, bevor diese dann 18 Stunden lang bei $20^{\circ} \mathrm{C}$ in Wasser eingeweicht werden. Danach wird die Samenschale entfernt und die Samen werden für $\sim 10-18$ Stunden bei $30^{\circ} \mathrm{C}$ in $1 \%$ iger Tetrazolium-Lösung eingeweicht. Nach dem Anfärben werden die Keimblätter geöffnet und die Samen begutachtet. Die maximal zulässige Fläche von ungefärbtem, weichem oder nekrotischem Gewebe ist: Keimwurzelspitze, 1/3 des distalen Bereichs der Keimblätter, falls die Schädigung nur oberflächlich ist.

Die Ergebnisse werden als Prozent der lebensfähigen Samen, nicht lebensfähigen Samen (z.B. Insektenschäden oder während des TT nicht gefärbt) und hohlen Samen angegeben.

Die Tabelle 6.5. beschreibt die Verfahren für die Befeuchtung (Art und Dauer), die Vorbereitung des befeuchteten Saatguts vor der Färbung, die Anfärbung selbst (Konzentration der Lösung und Dauer), und wie der Samen freigelegt wird, um das Ausmaß der Färbung zu beurteilen. Die in Spalte 4 angegebene Färbedauer basiert auf einer Temperatur von $30^{\circ} \mathrm{C}$. Normalerweise sind alle Samen mit einem vollständig gefärbten Embryo und solche mit partiell ungefärbten oder nekrotischen Teilen, wie in Spalte 6 vermerkt, lebensfähig. Bei einigen Arten muss auch das Endosperm (echtes Endosperm, Perisperm, Gametophytengewebe) vollständig gefärbt sein. Bei der Beurteilung ist zu beachten, dass der Same in seiner Gesamtheit berücksichtigt werden muss; wird also ein Bestandteil während der Vorbereitung vor der Färbung entfernt, gilt dieser als vollständig gefärbt oder als Teil der maximalen Fläche, die nicht gefärbt werden kann. 
Tabelle 6.5. Verfahren für Tetrazoliumtests

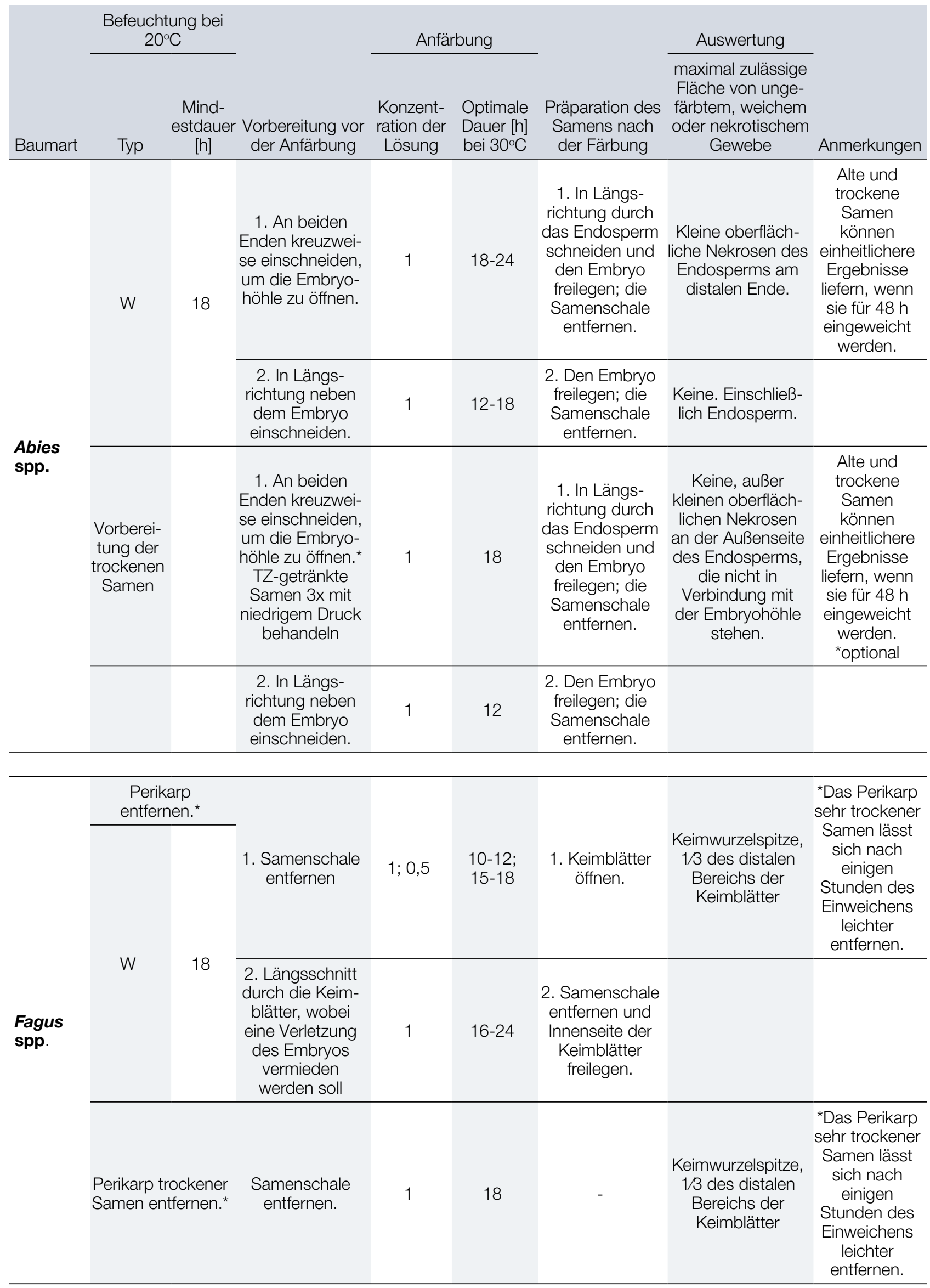




\begin{tabular}{|c|c|c|c|c|c|c|c|c|}
\hline \multirow[b]{2}{*}{ Baumart } & \multicolumn{2}{|c|}{$\begin{array}{l}\text { Befeuchtung bei } \\
20^{\circ} \mathrm{C}\end{array}$} & \multirow[b]{2}{*}{$\begin{array}{l}\text { Vorbereitung vor } \\
\text { der Anfärbung }\end{array}$} & \multicolumn{2}{|c|}{ Anfärbung } & \multirow[b]{2}{*}{$\begin{array}{l}\text { Präparation des } \\
\text { Samens nach } \\
\text { der Färbung }\end{array}$} & \multirow{2}{*}{$\begin{array}{c}\text { Auswertung } \\
\text { maximal zulässige } \\
\text { Fläche von unge- } \\
\text { färbtem, weichem } \\
\text { oder nekrotischem } \\
\text { Gewebe }\end{array}$} & \multirow{2}{*}{ Anmerkungen } \\
\hline & Typ & $\begin{array}{c}\text { Mind- } \\
\text { estdauer } \\
\text { [h] }\end{array}$ & & $\begin{array}{l}\text { Konzent- } \\
\text { ration der } \\
\text { Lösung }\end{array}$ & $\begin{array}{l}\text { Optimale } \\
\text { Dauer [h] } \\
\text { bei } 30^{\circ} \mathrm{C}\end{array}$ & & & \\
\hline \multirow{4}{*}{$\begin{array}{l}\text { Fraxinus } \\
\text { spp. }\end{array}$} & \multicolumn{2}{|c|}{$\begin{array}{l}\text { Perikarp } \\
\text { entfernen.* }\end{array}$} & \multirow{2}{*}{$\begin{array}{l}\text { Die Samenschale } \\
\text { von beiden } \\
\text { Rändern her } \\
\text { einschneiden, } \\
\text { so dass die } \\
\text { zwei Hälften des } \\
\text { Endosperms } \\
\text { sichtbar sind. }\end{array}$} & \multirow[b]{2}{*}{1} & \multirow[b]{2}{*}{$18-24^{*}$} & \multirow{2}{*}{$\begin{array}{l}\text { Den Embryo ex- } \\
\text { ponieren, indem } \\
\text { das Endosperm } \\
\text { in zwei Hälften } \\
\text { geteilt wird. }\end{array}$} & \multirow{2}{*}{$\begin{array}{l}\text { Keine, außer } \\
\text { kleinen Nekrosen } \\
\text { auf dem } \\
\text { Endosperm (die } \\
\text { sich nicht in der } \\
\text { Nähe des Embryos } \\
\text { befinden). }\end{array}$} & \multirow{2}{*}{$\begin{array}{l}{ }^{\star} \text { Frisch geern- } \\
\text { tetes Saatgut } \\
\text { benötigt nur } \\
\text { 8-10 h. }\end{array}$} \\
\hline & W & 18 & & & & & & \\
\hline & \multicolumn{2}{|c|}{$\begin{array}{l}\text { Perikarp trockener } \\
\text { Samen entfernen.* }\end{array}$} & \multirow{2}{*}{$\begin{array}{l}\text { In Längsrichtung } \\
\text { auf beiden } \\
\text { Seiten ein } \\
\text { kleines Stück } \\
\text { abschneiden, } \\
\text { um die Embryo- } \\
\text { höhle zu öffnen. }\end{array}$} & \multirow[b]{2}{*}{1} & \multirow[b]{2}{*}{$18^{*}$} & \multirow{2}{*}{$\begin{array}{l}\text { Den Embryo ex- } \\
\text { ponieren, indem } \\
\text { das Endosperm } \\
\text { in zwei Hälften } \\
\text { geteilt wird. }\end{array}$} & \multirow{2}{*}{$\begin{array}{c}\text { Keine, außer } \\
\text { kleinen Nekrosen } \\
\text { auf dem } \\
\text { Endosperm (die } \\
\text { sich nicht in der } \\
\text { Nähe des Embryos } \\
\text { befinden). }\end{array}$} & \multirow{2}{*}{$\begin{array}{c}{ }^{*} \text { Frisch geern- } \\
\text { tetes Saatgut } \\
\text { benötigt nur } \\
8 \mathrm{~h}\end{array}$} \\
\hline & W & 18 & & & & & & \\
\hline
\end{tabular}

\begin{tabular}{|c|c|c|c|c|c|c|c|}
\hline $\begin{array}{l}\text { Pinus } \\
\text { nigra }\end{array}$ & $\begin{array}{l}\text { Vorbereitung der } \\
\text { trockenen Samen }\end{array}$ & $\begin{array}{l}\text { Kreuzweise 1/3 } \\
\text { vom distalen } \\
\text { Ende des } \\
\text { Endosperms } \\
\text { einschneiden, um } \\
\text { die Embryohöhle } \\
\text { zu öffnen. }\end{array}$ & 1 & 18 & $\begin{array}{l}\text { Embryo und } \\
\text { Endosperm aus } \\
\text { der Samenscha- } \\
\text { le extrahieren. }\end{array}$ & $\begin{array}{l}\text { Keine, einschließ- } \\
\text { lich Endosperm, } \\
\text { mit Ausnahme } \\
\text { kleiner oberfläch- } \\
\text { licher Nekrosen an } \\
\text { der Außenseite des } \\
\text { Endosperms, die } \\
\text { nicht in Verbindung } \\
\text { mit der Embryo- } \\
\text { höhle stehen. }\end{array}$ & $\begin{array}{l}\text { Embryonen, } \\
\text { die kürzer } \\
\text { als } 1 / 3 \text { der } \\
\text { Embryohöhle } \\
\text { sind, sind } \\
\text { nicht lebens- } \\
\text { fähig. }\end{array}$ \\
\hline
\end{tabular}

\begin{tabular}{|c|c|c|c|c|c|c|c|c|}
\hline & $\begin{array}{r}\text { Die } \\
\text { brech } \\
\text { dist } \\
\text { ein kl } \\
\text { Keir } \\
\text { schnei } \\
\text { Same }\end{array}$ & $\begin{array}{l}\text { auf- } \\
\text { nd am } \\
\text { Ende } \\
\text { Stück } \\
\text { ab- } \\
\text { der die } \\
\text { itzen. }\end{array}$ & $\begin{array}{l}\text { Die Samenschale } \\
\text { entfernen, die } \\
\text { Samen ein- } \\
\text { weichen und } \\
\text { das Wasser } \\
\text { für mindestens } \\
5 \text { h stündlich }\end{array}$ & $1 ; 0,5$ & $\begin{array}{l}8-12 \\
12-18\end{array}$ & $\begin{array}{l}\text { Keimblätter } \\
\text { spreizen. }\end{array}$ & $\begin{array}{l}\text { Keimwurzelspitze, } \\
\text { 1/3 des distalen } \\
\text { Bereichs der } \\
\text { Keimblätter }\end{array}$ & $\begin{array}{c}{ }^{*} \text { Großsa- } \\
\text { mige Arten } \\
\text { benötigen } \\
\text { eine längere } \\
\text { Färbezeit (24 } \\
\text { h). }\end{array}$ \\
\hline & W & 18 & wechseln. & & & & & \\
\hline Prunus & Kerne & echen. & & & & & & *Großsa- \\
\hline spp. & W & 18 & & & & & & $\begin{array}{l}\text { mige Arten } \\
\text { benötiaen }\end{array}$ \\
\hline & $\begin{array}{c}\text { Wasse } \\
\text { falls } \\
\text { (Ge } \\
\text { Bitt }\end{array}$ & $\begin{array}{l}\text { chseln, } \\
\text { endig } \\
\text { nach } \\
\text { idel) }\end{array}$ & $\begin{array}{l}\text { Samenschale } \\
\text { entfernen. }\end{array}$ & 1 & 18 & $\begin{array}{l}\text { Keimblätter } \\
\text { spreizen. }\end{array}$ & $\begin{array}{l}\text { Keimwurzelspitze, } \\
\text { 1/3 des distalen } \\
\text { Bereichs der } \\
\text { Keimblätter }\end{array}$ & $\begin{array}{l}\text { eine längere } \\
\text { Färbezeit } \\
\text { (24 h). } \\
\text { ** Keimblätter } \\
\text { von Prunus } \\
\text { persica } \\
\text { und Prunus } \\
\text { domestica vor- } \\
\text { sichtig öffnen. }\end{array}$ \\
\hline
\end{tabular}

Die Abkürzungen haben die folgenden Bedeutungen:

W - in Wasser;

$\mathrm{BP}+\mathrm{W}$ - langsames Befeuchten, gefolgt von mindestens 2-3 h in Wasser, um alle Samen vollständig mit Wasser zu sättigen. 


\subsection{DNA-ANALYSEN}

\subsubsection{DNA-Extraktion}

Der Erfolg aller molekulargenetischen Analysen hängt direkt von der Qualität und Quantität ihres Produkts ab: der DNA. Daher sollte dem Prozess der DNA-Extraktion große Aufmerksamkeit geschenkt werden, damit die Qualität und Quantität der isolierten DNA ausreichend für die erfolgreiche Durchführung der nachfolgenden Analysen ist.

Der Schwerpunkt dieses Kapitels liegt nicht auf der umfassenden Erörterung aller bestehenden Vorschriften für die Extraktion von DNA aus Pflanzengewebe - dafür sind diese zu zahlreich - sondern auf der Darstellung der Ansätze, die von den am LIFEGENMON-Projekt beteiligten Laboren verwendet oder erfolgreich getestet wurden.

In ausreichender Qualität und Quantität kann DNA sowohl mit kommerziellen, säulenbasierten DNAExtraktionskits erfolgreich isoliert werden als auch mit herkömmlichen Labormethoden, die auf selbst hergestellten Reagenzlösungen basieren.

\subsubsection{Quantität des für die DNA-Extraktion zu verwendenden Pflanzengewebes}

DieoptimaleMengeanPflanzengewebefürdieDNA-ExtraktionhängtvomverwendetenExtraktionsverfahrenab. Esist ratsam, dievon HerstellernkommerziellerDNA-Extraktionskits oder Autoren klassischerDNA-Extraktionsvorschriften

Box 6.3: Tipps \& Tricks: Alternativen zur Bestimmung des Gewichts von Pflanzengewebe für die DNA-Extraktion

1. Zählen Sie an einer zufälligen Teilmenge von Proben (10-15) die Anzahl der „Einheiten ab, die der empfohlenen Menge (Masse) an Pflanzengewebe entsprechen, die für die Probe verwendet werden sollen; Beispiele für solche „Einheiten sind: a) Koniferen: eine bestimmte Anzahl von Nadeln; b) Laubblätter: Kreise gleichen Durchmessers, die mit einem Locher aus den Blättern gestanzt werden (siehe Abbildung 6.3); c) Knospen: eine bestimmte Anzahl von Knospen.

(a)
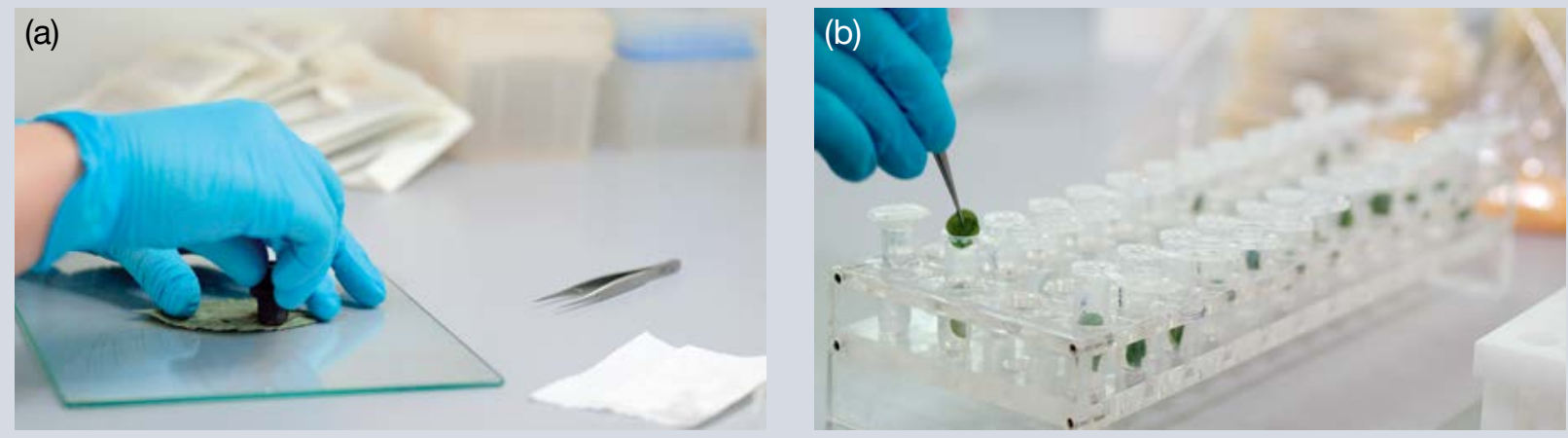

Abbildung 6.3: (a) Scheiben werden mit einem Stanzwerkzeug aus getrockneten Buchenblättern geschnitten;

(b) Eine bestimmte Anzahl von Scheiben, die der erforderlichen Masse an Pflanzenmaterial entsprechen, wird in

Röhrchen zur DNA-Extraktion gegeben. (Fotos: Mark Walter)

2. Berechnen Sie die durchschnittliche Anzahl dieser „Einheiten, die der empfohlenen Menge (Masse) an Pflanzengewebe entspricht.

3. Verwenden Sie anstelle des Abwiegens die durchschnittliche Anzahl der „Einheiten für alle zu analysierenden Proben. Stellen Sie sicher, dass eine Vergleichbarkeit bestehen bleibt $-z$.B. Nadeln und Blätter von ungefähr gleicher Größe. Berücksichtigen Sie das Alter der analysierten Pflanzen und den Reifegrad des verwendeten Gewebes - Blätter von jungen Pflanzen oder nicht voll ausgebildete Blättern sind dünner als ältere Blätter, so dass ggf. mehr Material erforderlich ist, um die erforderliche Masse zu erreichen. Bestimmen Sie diesen Wert für jede Art, Altersgruppe und jeden Gewebetyp einzeln. 
empfohlenen Mengen zu verwenden. Obwohl es auf den ersten Blick unverhältnismäßig erscheinen mag, kann die Verwendung größerer Mengen als empfohlen, negative Auswirkungen auf die Quantität und insbesondere die Qualität (Reinheit) der isolierten DNA haben. In manchen Fällen kann die Verwendung von mehr Pflanzenmaterial zu besseren Ergebnissen führen; dies sollte jedoch zunächst an einer geringen Probenanzahl überprüft werden, da die Ergebnisse anhängig von der Pflanzenart und dem Gewebetyp sind.

Das Einwiegen der einzelnen Gewebeproben kann sehr zeitaufwendig sein, insbesondere wenn mit vielen Proben gleichzeitig gearbeitet wird. Um den Arbeitsaufwand und die für die Erledigung dieses Arbeitsschritts erforderliche Zeit zu reduzieren, können vereinfachte Ansätze verwendet werden (siehe Box 6.3 Tipps \& Tricks: Alternativen zur Bestimmung des Gewichts von Pflanzengewebe für die DNA-Extraktion).

Die Verwendung einer standardisierten Gewebemenge minimiert die Variabilität der DNA-Quantität und -Reinheit zwischen den Proben.

\subsubsection{Aufschluss des Pflanzengewebes}

Ein guter Aufschluss des Gewebes ist entscheidend für die erfolgreiche Extraktion der DNA aus pflanzlichen Geweben. Je feiner die Gewebepartikel sind, desto besser ist die Diffusion der Reagenzien in das Gewebe. Die verschiedenen Verfahrensweisen zum Aufschluss von pflanzlichem Gewebe sind in Tabelle 6.6 zusammengefasst.

Tabelle 6.6: Verfahren zum Aufschluss von Pflanzengewebe. Manuell - Aufschluss unter Verwendung von Mörser und Stößel oder 1,5/2,0-ml-Röhrchen und Mikrostößel; Kugeln / Mühle - Aufschluss mit einer Kugelmühle und Mahlkugeln; Puffer - bezieht sich auf den ersten im DNA-Extraktionsverfahren verwendeten Puffer, der die DNA stabilisiert und die enzymatische (nukleolytische) Aktivität hemmt.

\begin{tabular}{lcccc}
\hline Zustand des Gewebes & Puffer & Manuell & Kugeln / Mühle & Anmerkungen \\
\hline Frisch & + & + & - & - \\
\hline Frisch & - & + & + & 2 \\
\hline Frisch & + & - & - & + \\
\hline Gefroren (Flüssig- $\left.\mathrm{N}_{2}\right)$ & - & + & + & + \\
\hline Gefroren (Flüssig- $\left.\mathrm{N}_{2}\right)$ & - & - & - & 3 \\
\hline Getrocknet & - & - & + & + \\
\hline Getrocknet & - & + & & \\
\hline
\end{tabular}

${ }_{1}^{1}$ Nicht empfehlenswert, da während des Aufschlusses Zell- und Organellenmembranen zerrissen und die Nukleinsäuren Nukleasen ausgesetzt werden.

${ }^{2}$ Die Bewegung der Mahlkügelchen durch den Puffer verursacht aufgrund von Reibung und starken Scherkräften einen Temperaturanstieg, der zur Fragmentierung der DNA führen kann.

${ }^{3}$ Beim manuellen Aufschluss von getrocknetem Pflanzengewebe sollte besonders darauf geachtet werden, Kreuzkontaminationen zwischen den Proben zu vermeiden, da die Verbreitung von pulverförmigen, getrockneten Gewebepartikeln in offenen Systemen schwer kontrollierbar ist.

Im Vergleich zum manuellen Aufschluss wird üblicherweise aus den folgenden Gründen die Verwendung von Kugelmühlen oder ähnlichen elektrischen Aufschlussgeräten empfohlen: a) Zeitersparnis, da die gleichzeitige Bearbeitung vieler Proben ermöglicht wird - bis zu 192 Proben bei Verwendung von 96-Well-Microplatten; b) einheitlichere Aufschlussbedingungen, geringere Variabilität zwischen den einzelnen Proben sowie zwischen verschiedenen Extraktionen.

Der Aufschluss von getrocknetem oder in Flüssigstickstoff gefrorenem Gewebe ist dem von frischem Gewebe vorzuziehen. Bei der Verwendung von in Flüssigstickstoff gefrorenem Gewebe ist darauf zu achten, dass während des Aufschlusses ein übermäßiger Temperaturanstieg vermieden wird, und dass nur Geräte/ Verbrauchsmaterialien verwendet werden, die für derartig niedrige Temperaturen ausgelegt sind. 


\subsubsection{DNA-Extraktionsverfahren}

Die im LIFEGENMON-Projekt verwendeten oder von den beteiligten Laboren erfolgreich getesteten DNAExtraktionsverfahren sind in Tabelle 6.7 aufgelistet. Es ist erwähnenswert, dass es viele verschiedene Protokolle für die DNA-Extraktion aus pflanzlichen Geweben gibt, mit der in Quantität und Qualität gute DNA erzielt werden kann, sowohl in Form kommerziell erhältlicher Kits als auch klassischer Laborverfahren.

Die meisten klassischen Verfahren zur DNA-Extraktion aus Pflanzengewebe basieren entweder auf dem CTAB-basierten Verfahren, das zuerst von Doyle und Doyle (1987) beschrieben wurde, oder auf dem SDSbasierten Verfahren von Dellaporta et al. (1983). Verschiedene Modifikationen und Anwendungen der genannten Verfahren wurden von Demeke und Jenkins (2010) sowie Nishiguchi et al. (2002) zusammenfassend diskutiert. Ein modifiziertes CTAB-DNA-Extraktionsverfahren, das vom bereits für zahlreiche Pflanzengewebeproben erfolgreich angewendet wurde (angepasst an 96-Well-Mikroplatten).

Derzeit sind viele für Pflanzengewebe geeignete, säulenbasierte DNA-Extraktionskits kommerziell erhältlich. Sowohl die forstgenetischen Labore der AUTh als auch des SFI erzielen mit solchen Kits gute Ergebnisse.

Sowohl die klassischen Laborverfahren als auch die kommerziellen Kits haben Vor- und Nachteile. Die Wahl des DNA-Extraktionsverfahrens hängt letztlich von den Präferenzen des jeweiligen Labors ab. Molekulargenetische Labore, die sich am forstgenetischen Monitoring beteiligen möchten, sollten die innen bereits vertrauten DNAExtraktionsverfahren verwenden, mit denen sie kontinuierlich gute Ergebnisse erzielen.

Tabelle 6.7: DNA-Extraktionsverfahren, die von den am LIFEGENMON-Projekt beteiligten Laboren zur DNA-Extraktion aus Pflanzengeweben verwendet werden. AWG - Bayerisches Amt für Waldgenetik, Deutschland; AUTh - AristotelesUniversität Thessaloniki, Griechenland; SFI - Slowenisches Forstinstitut, Slowenien. $\mathrm{LN}_{2}$ - Flüssigstickstoff.

\begin{tabular}{lccc} 
Labor & Probenaufbereitung & Gewebeaufschluss & DNA-Extraktion \\
\hline AWG & $\begin{array}{c}\text { Trocknung, Silikagel, } \\
\text { Gefriertrocknung }\end{array}$ & Kugelmühle, getrocknet & Modifiziertes CTAB-Protokoll \\
\hline AUTh & Gefrieren & Manuell, gefroren in LN2 & $\begin{array}{c}\text { Macherey-Nagel, NucleoSpin } \\
\text { Plant II Kit }\end{array}$ \\
\hline SFI & Trocknung, Gefriertrocknung & Kugelmühle, getrocknet & Qiagen, DNeasy Plant 96 Kit \\
\hline
\end{tabular}

\subsubsection{DNA-Quantität, -Reinheit und -Unversehrtheit}

Unabhängig vom verwendeten DNA-Extraktionsverfahren ist es wichtig, die Quantität und Qualität der extrahierten DNA zu beurteilen. Dies ist vor allem beim Testen eines neuen Verfahrens relevant, sollte aber standardmäßig bei jeder durchgeführten DNA-Extraktion zumindest an einer Teilmenge der Proben durchgeführt werden, vorzugsweise sogar an allen Proben. Auf diese Weise können die DNA-Konzentrationen standardisiert werden, was nachfolgende Analysen wesentlich erleichtert (Guichoux at al. 2011). Ein gängiger Ansatz zur Beantwortung der Frage nach der Quantität und Reinheit der DNA ist die spektrophotometrische Analyse von DNA-Proben. Dabei wird die Absorption bei $230 \mathrm{~nm}, 260 \mathrm{~nm}$ und $280 \mathrm{~nm}$ gemessen. Das Absorptionsmaximum von DNA liegt bei $260 \mathrm{~nm}$, während Wellenlängen von $230 \mathrm{~nm}$ und $280 \mathrm{~nm}$ verwendet werden, um das Vorhandensein von Restverunreinigungen mithilfe der Absorptionsverhältnisse von 260 nm/230 nm und 260 nm/280 nm zu beurteilen (für Details siehe Tabelle 6.8). Als Faustregel wird abhängig von der Art des verwendeten Gewebes eine DNA-Konzentration von etwa $100 \mathrm{ng} / \mathrm{\mu l}$ angestrebt. Die Messgenauigkeit der DNA-Reinheitsprüfung mittels Absorption hängt von der DNA-Konzentration selbst ab. Daher weisen sowohl die A260/280- als auch die A260/230-Verhältnisse bei DNA-Konzentrationen unter $50 \mathrm{ng} / \mathrm{\mu l}$ eine beträchtliche Variabilität auf, weshalb mindestens 3 Wiederholungsmessungen empfohlen werden (Koetsier und Cantor 2019). Ebenso sind die Absorptionsmessungen sensitiv gegenüber dem pH-Wert der Lösung, wobei saure DNA-Lösungen im Allgemeinen niedrigere Werte des A260/280-Verhältnisses ergeben, während basische DNA-Lösungen dazu neigen, das A260/280-Verhältnis höher anzugeben als es tatsächlich ist(Wilfinger et al. 1997). 
Zusätzlich zur Prüfung der DNA-Quantität und -Reinheit wird empfohlen, die Integrität der extrahierten DNA zu beurteilen. Diese kann durch eine 1\%ige Agarose-Gelelektrophorese beurteilt werden. Eine qualitativ hochwertige DNA-Extraktion wird durch eine deutliche DNA-Bande von über $10 \mathrm{kbp}$ Größe durch eine scharfe Linie mit wenig nachfolgendem Schmieren angezeigt.

Tabelle: 6.8: Erläuterung der Absorptionsverhältnisse bei 260/280 nm und 260/230 nm von extrahierten DNA-Proben.

\begin{tabular}{|c|c|c|c|}
\hline $\begin{array}{c}\text { Absorptions-ver- } \\
\text { hältnis }\end{array}$ & $\begin{array}{l}\text { Absorptions-ver- } \\
\text { hältnis reiner DNA }\end{array}$ & Niedriges Absorptionsverhältnis & Hohes Absorptionsverhältnis \\
\hline \multirow{3}{*}{$260 / 280 \mathrm{~nm}$} & \multirow{3}{*}{$\sim 1,8$} & Eiweiß-Verunreinigungen & \multirow{3}{*}{$\begin{array}{l}\text { Hohe RNA-Konzentration (>15\% } \\
\text { der gesamten Nukleinsäuren) }\end{array}$} \\
\hline & & $\begin{array}{c}\text { Phenol (Verschleppung aus der } \\
\text { DNA-Extraktion oder Restverunreinigung } \\
\text { aus Pflanzengewebe - Polyphenole) }\end{array}$ & \\
\hline & & Sehr geringe DNA-Konzentration & \\
\hline \multirow{3}{*}{$260 / 230 \mathrm{~nm}$} & \multirow{3}{*}{$2,0-2,2$} & $\begin{array}{l}\text { Polysaccharide (häufiges Problem bei } \\
\text { pflanzlichen Geweben) }\end{array}$ & \multirow{3}{*}{$\begin{array}{l}\text { Unterschiedliche Konzentrationen } \\
\text { von freiem EDTA in der Eichprobe } \\
\text { und den extrahierten DNA-Proben } \\
\text { können zu A260/230-Verhältnissen } \\
>3,0 \text { führen. }\end{array}$} \\
\hline & & $\begin{array}{c}\text { Phenol (Verschleppung aus der } \\
\text { DNA-Extraktion oder Restverunreinigung } \\
\text { aus Pflanzengewebe - Polyphenole) }\end{array}$ & \\
\hline & & $\begin{array}{l}\text { Restliche chaotrope Salze (wie z.B. } \\
\text { Guanidin, das häufig in säulenbasierten } \\
\text { DNA-Extraktionskits verwendet wird) }\end{array}$ & \\
\hline
\end{tabular}

\subsubsection{Genetische Marker}

\subsubsection{Auswahl genetischer Marker}

Obwohl neue Technologien entstanden sind, sind Mikrosatelliten immer noch die am häufigsten verwendete Marker in der Populationsgenetik natürlicher Populationen. Aufgrund ihrer hohen Mutationsraten (Whittaker et al. 2003) sind Mikrosatelliten ausgezeichnete Marker für die Untersuchung genetischer Monitoringindikatoren: (i) genetische Drift und (ii) Genfluss (Selkoe und Toonen 2006). Nichtsdestotrotz sind Mikrosatelliten dafür bekannt, dass sie mit systematischen Fehlern wie Allelausfällen und Nullallelen behaftet sind (Flores-Rentería und Krohn 2013, Oddou-Muratorio et al. 2009). Trotz der Tatsache, dass es für das Abschätzen von etwaigen systematischen Fehlern spezielle Softwareprogramme gibt, stimmen deren Schlussfolgerungen selten vollständig überein. Daher stellen derartige Fehler einen Genauigkeitsverlust dar. Eine Möglichkeit zur Minderung der nachteiligen Auswirkungen solcher systematischen Fehler bereits vor Beginn eines genetischen Monitoringprojekts, besteht darin, die vorgeschlagenen Marker in kleinen Versuchen vorab zu überprüfen. Obwohl dadurch die Kosten für die initiale Abschätzung des genetischen Zustands deutlich erhöht werden, könnte dies angesichts der Vorteile einer erhöhten Zuverlässigkeit der Ergebnisse lohnenswert sein.

Eine anderes mögliches genetisches Markersystem für das genetische Monitoring sind EinzelnukleotidPolymorphismen (SNP). Vermeintlich neutrale SNPs bieten im Vergleich zu Mikrosatelliten robustere Schätzungen der demografischen Statistiken, da SNPs auf mehrere Chromosomen und Contigs verstreut sind, wodurch WissenschaftlerInnen eine repräsentativere Stichprobe des Genoms erhalten können. Abgesehen von demografischen Bewertungen ermöglichen in Genregionen liegende SNPs die Prüfung der Indikatorauswahl mittels molekularen Daten (Brousseau et al. 2016, Csilléry et al. 2014, Roschanski et al. 2016). Während bei einigen Arten SSR-Marker existieren, die mit kodierenden DNA-Regionen (EST-SSRs) verbunden sind, erlaubt die in den meisten populationsgenetischen Studien verwendete geringe Anzahl von Loci (normalerweise 10-20 Loci) nicht genug Aussagekraft für die Erkennung von Ausreißern. Große SNP-Datensets, die mit zeitgenössischen Techniken wie der RAD-Sequenzierung, der Genotypisierung durch Sequenzierung und sogar der Exom-Sequenzierung gewonnen werden, sind in den letzten Jahren für Populationsstudien zunehmend üblich geworden (Benestan et al. 2015, Tyrmi et al. 2020). Wahrscheinlich werden auf absehbare Zeit jedoch kleine SNP-Datensets, wie sie durch KASP-Assays gewonnen werden (Csilléry et al. 2014; Roschanski et al. 2016), für das genetische Monitoring 
von Waldbaumpopulationen ökonomisch sinnvoller sein. Der Nachteil solch kleinskaliger Untersuchungen ist ihre notorische Anfälligkeit für systematische Fehler aufgrund des hohen genetischen Abstands (Nei 1973) zwischen den für die Locus-Identifikation verwendeten Individuen und den genotypisierten Proben (Albrechtsen et al.2010). Für die Zwecke des forstgenetischen Monitorings auf Bestandsebene ist dies nicht notwendigerweise schädlich; vorausgesetzt, der Anteil der in einem Datensatz vorhandenen SNPs ohne systematische Fehler (d.h. an polymorphen Standorten) ist ausreichend groß für eine genaue Berechnung demografischer Parameter. Dennoch ist bei Vergleichen zwischen Populationen aus verschiedenen Regionen und/oder Evolutionslinien im Rahmen eines umfassenden forstgenetischen Monitorings insbesondere dann Vorsicht geboten, wenn es um eine Entscheidung über ihren Erhaltungszustand geht. In diesem Fall können die Diversitätsstatistiken mit systematischen Fehlern behaftet sein und zu falschen Entscheidungen der Forstfachleute führen.

Letztlich werden diese Fragen an Bedeutung verlieren, da das forstgenetische Monitoring zunehmend die oben genannten robusteren Methoden der Genomanalyse einsetzen wird, auch wenn diese ebenfalls nicht frei von systematischen Fehlern sind (Lowry et al. 2017). Die langfristige Lagerung von DNA früherer Beprobungszeitpunkte könnte die beste Voraussetzung für sachkundige Vergleiche mit zukünftigen Proben sein.

\subsubsection{Mikrosatelliten-Marker (SSRs)}

\subsection{Auswahl geeigneter Mikrosatelliten-Marker (SSRs)}

Suchen Sie in der verfügbaren wissenschaftlichen Literatur nach den vorhandenen SSRs und konsultieren Sie KollegInnen aus anderen Laboren, die Erfahrung in der Arbeit mit SSRs für die betreffende Art haben. Bei der Auswahl geeigneter SSR-Marker aus der Literatur oder bei der Entwicklung neuer Marker wird empfohlen, die folgenden Kriterien zu berücksichtigen:

- SSRs mit vollkommenen Repeats (= sich wiederholende Sequenzmotive) werden gegenüber solchen mit unvollkommenen Repeats bevorzugt, da bei letzteren keine Äquivalenz zwischen der detektierten Allellänge und der Sequenz besteht - mehrere Allele gleicher Größe können unterschiedliche Nukleotidsequenzen aufweisen (Estoup et al. 1995). Derartige Unterschiede bleiben bei der Fragmentanalyse unentdeckt und führen zu einem reduzierten beobachteten SSR-Polymorphismus mit unvollkommenen Repeats (Urquhart et al. 1994, Estoup et al. 2001, Gusmão et al. 2006, Guichoux et al. 2011).

- SSR-Wiederholungseinheiten umfassen typischerweise 1-6 Nukleotide (sog. Short Tandem Repeats; STR). SSRs mit Dinukleotidwiederholungen werden am häufigsten verwendet. Da sie meist schmalere Allelbereiche haben, können in einer einzigen Multiplex-PCR mehr davon kombiniert werden. Diese neigen jedoch häufig dazu, PCR-Artefakte wie z.B. Stotterbanden zu produzieren (Chambers und MacAvoy 2000), was die Auswertung der Allele erschwert (Levinson und Gutman 1987, Meldgaard und Morling 1997). SSRs mit längeren Wiederholungseinheiten sind Berichten zufolge deutlich weniger anfällig für Stotterbanden (Edwards et al. 1991. Flores-Rentería und Krohn 2013) und werden manchmal für Anwendungen in der Forensik und Abstammungsforschung bevorzugt (Kirov et al. 2000, Cipriani et al. 2008).

- Um Polymorphismus zu gewährleisten, ist die Auswahl von SSR-Loci mit einer ausreichenden Anzahl von Wiederholungen notwendig. SSRs mit zahlreichen Wiederholungen können jedoch auch unerwünschte Merkmale aufweisen, wie z.B. einen erhöhten Allelausfall (Kirov at al. 2000, Buchan et al. 2005) und Stotterbanden (Hoffman und Amos 2005). Eine mittlere Anzahl von Wiederholungen ist ideal, da dies einen guten Kompromiss zwischen einem ausreichenden Level an Polymorphismus und der Vermeidung einiger Nachteile darstellt, die mit sehr hohen Mutationsraten verbunden sind. Van Asch et al. (2010) empfehlen für beste Ergebnisse die Verwendung von SSR-Loci mit 12-16 Wiederholungen.

- Wählen Sie bei der Auswahl von SSR-Markern aus veröffentlichten Studien diejenigen aus, bei denen die Häufigkeit von Nullallelen nicht mehr als 10\% beträgt, vorzugsweise auch weniger (Oddou-Muratorio et al. 2009). 
- Wenn Verknüpfungskarten verfügbar sind, wählen Sie SSRs von möglichst vielen verschiedenen Chromosomen aus.

- Konzentrieren Sie sich auf die SSRs, die bei einer möglichst großen Anzahl von Proben sowie bei Proben aus verschiedenen Teilen des Verbreitungsgebietes der betreffenden Art erfolgreich eingesetzt wurden, da dies die Wahrscheinlichkeit des Auftretens systematischer Fehler minimiert.

- Wird das Monitoring in einer Region durchgeführt, in der für die betreffende Art eine Hybridisierung erwartet wird, wählen Sie Marker aus, die bereits erfolgreich auf Übertragbarkeit zwischen den hybridisierenden Arten getestet wurden. Es wird empfohlen, Tests an Proben beider Arten durchzuführen, um die Aussagekraft der verwendeten SSRs zu überprüfen. Ein Fehlen nachweisbarer Allele sowie hohe Nullallelhäufigkeiten deuten auf Probleme beim Primer-Annealing hin (Mutationen in der an die SSR angrenzenden Annealing-Region in einer der Spezies); diese SSRs sollten vermieden oder die Primer angepasst werden.

- Da es wünschenswert ist, so viele SSRs-Marker wie möglich in einer einzigen Multiplex-PCR-Reaktion zu kombinieren, müssen die Annealing-Temperaturen der Primer und die Allelbereiche der Marker berücksichtigt werden. Marker mit überlappenden Allelbereichen müssen mit verschiedenen Fluorophoren markiert oder separat amplifiziert und analysiert werden. Die Annealing-Temperaturen $\left(T_{m}\right)$ der Primer in einer MultiplexPCR sollten sich idealerweise um nicht mehr als $2-3^{\circ} \mathrm{C}$, keinesfalls jedoch um mehr als $5^{\circ} \mathrm{C}$ unterscheiden (Butler et al. 2005a, Guichoux et al. 2011, Hill et al. 2009).

- Die Gesamtzahl der verwendeten SSRs hängt von der zu beantwortenden Frage, den verfügbaren Ressourcen und den Merkmalen der einzelnen SSRs (Polymorphismus) ab. In der Regel werden in populationsgenetischen Studien 10-25 SSRs verwendet.

- Beginnen Sie immer mit einer größeren Anzahl potenzieller SSRs, für den Fall dass einige der SSRs nicht die gewünschte Aussagekraft entfalten.

\subsection{PCR}

Die Amplifikation von SSR-Markern wird bevorzugt mittels Multiplex-PCR (Polymerase-Kettenreaktion) durchgeführt (Chamberlain et al. 1988, Edwards und Gibbs 1994), da dieser Ansatz den Probendurchsatz stark erhöht und gleichzeitig die Kosten und den Arbeitsaufwand pro Probe reduziert (Elnifro et al. 2000, Lederer et al. 2000, Galan et al. 2003, Renshaw et al. 2006).

Es ist das Ziel des Multiplexing, die gewünschte Anzahl von SSR-Markern (in der Regel 10-25) in möglichst wenigen PCR-Reaktionen zu kombinieren, wobei jedem Marker ein bestimmter Fluorophor-Farbstoff zugeordnet wird. Die Multiplex-PCR ist eine empfindliche Technologie, und es müssen viele Variablen berücksichtigt werden, um effiziente und robuste Multiplex-Reaktionen zu entwickeln (Guichoux et al. 2011), beginnend mit der Auswahl oder Entwicklung von Primern. Spezialisierte, kommerziell erhältliche PCR-Multiplex-Kits (wie z.B. Qiagen Multiplex PCR Kit, KAPA Biosystems KAPA2G Fast Multiplex mix, etc.) erleichtern die Optimierung von MultiplexPCR erheblich.

Die Allelbereiche von Markern, die mit dem gleichen Fluorophor markiert sind, dürfen sich nicht überlappen. Marker mit überlappenden Allelbereichen können nur dann in derselben Multiplex-Reaktion kombiniert werden, wenn sie mit verschiedenen Fluorophoren markiert sind. Die Anzahl und Art der unterschiedlichen Fluorophore (verschiedenfarbige emittierte Fluoreszenz), die eingesetzt werden können, hängen von der verwendeten Kapillarelektrophorese-Detektionsplattform ab. In der Regel liegen sie im Bereich von 4 bis 6, von denen ein Farbkanal immer dem internen Größenstandard zugeordnet ist.

Die Annealing-Temperaturen der verwendeten Primer sollten hoch sein - idealerweise $58^{\circ} \mathrm{C}$ oder höher - und sich zwischen den Primerpaaren nicht übermäßig unterscheiden (Butler et al. 2005a, Hill et al. 2009, Qiagen 2010). 
Um eine erfolgreiche Co-Amplifikation verschiedener SSR-Marker zu erreichen, müssen die Primer auf mögliche Sekundärstrukturbildung, Primer-Dimerisierung und Wechselwirkungen mit anderen verwendeten Primern geprüft werden (Vallone und Butler 2004, van Asch et al. 2010). Frei verfügbare Softwareprogramme wie z.B. Multiplex Manager v1.2 (Holleley und Geerts 2009) wurden entwickelt, um die Entwicklung einer optimalen Multiplexing-Lösung unter Berücksichtigung bereits vorliegender Markerinformationen zu unterstützen.

Die Menge an Template-DNA, die jeder PCR-Reaktion zugesetzt wird, ist von entscheidender Bedeutung und sollte standardisiert werden. Obwohl zu wenig Template-DNA zu einer niedrigen Signalintensität, MarkerUngleichgewichten und Allelausfall führen kann, ist eine zu große DNA-Menge meist problematischer (Livingstone et al. 2009, Guichoux et al. 2011). Exzessive Mengen an Template-DNA können zu einem Fluoreszenzsignal außerhalb der Skalenbereiche führen, was zu sogenannten Pull-up-Effekten, Marker-Ungleichgewichten, Doppelpeaks und verstärkten Stotterbanden führen kann (Kline et al. 2005). Die empfohlene Konzentration der Template-DNA in der Multiplex-PCR liegt zwischen 0,5 und $4 \mathrm{ng} / \mathrm{\mu l}$.

Die optimale Annealing-Temperatur für die Multiplex-PCR sollte empirisch ermittelt werden. Verwenden Sie die $T_{m}$ des Primerpaares mit der niedrigsten $T_{m}$ als Ausgangspunkt. PCR-Cycler mit Gradienten-Funktion beschleunigen die Temperaturoptimierungsphase erheblich, da bis zu 6 verschiedene Temperaturen gleichzeitig getestet werden können.

Es ist ratsam, die Primer für jeden SSR-Marker zunächst einzeln in Einzel-PCR-Ansätzen an einem Satz repräsentativer Proben zu testen (validieren), insbesondere wenn die Primer neu entwickelt wurden. Die verwendeten Proben sollten im Idealfall repräsentativ für die genetische Vielfalt (unter Berücksichtigung verschiedener Populationen) der untersuchten Art (oder Populationen) sein, um spätere Probleme aufgrund systematischer Fehler zu vermeiden und möglichst viele verschiedene Allele abzudecken. SSR-Marker, die einen hohen Anteil an Nullallelen, exzessives Stottern, Doppelpeaks und/oder andere Artefakte aufweisen, sollten verworfen oder die Primer für deren Amplifikation bereits während der Einzel-PCR modifiziert werden (Guichoux et al. 2011). Marker, die einzeln erfolgreich funktionieren, werden dann für denselben Probensatz im MultiplexPCR getestet. Die als Ergebnis erhaltenen Genotypdaten aus der Einzel- und Multiplex-Amplifikation müssen dann verglichen und die Multiplex-Reaktionen weiter optimiert werden (problematische Marker ggf. verwerfen), bis diese effizient laufen.

Selbst wenn Marker in der Einzel-PCR gut funktionieren, ist die Amplifikation in der Multiplex-PCR oft nicht optimal. Nachfolgend sind die häufigsten Probleme und Empfehlungen zu deren Behebung aufgeführt.

a. Marker-Ungleichgewichte sind das Ergebnis einer heterogenen Amplifikation verschiedener Marker in derselben Multiplex-PCR, was zu unterschiedlichen Signalintensitäten der einzelnen Marker führt. Moderne Detektoren verfügen über breite dynamische Messbereiche, die eine zuverlässige Detektion von Signalen mit sehr unterschiedlichen Intensitäten ermöglichen. Je gleichmäßiger das Signal jedoch ist, desto zuverlässiger und einfacher ist die automatische Auswertung von Elektropherogrammen. Eine häufige Ursache für das Ungleichgewicht zwischen Markern sind Unterschiede der $\mathrm{T}_{m}$ der eingesetzten Primer. Um dieses Problem zu beheben, kann eine Touchdown-PCR verwendet werden (Rithidech und Dunn 2003, Renshaw et al. 2006). Ist die $T_{m}$ nicht der Grund für das beobachtete Amplifikations-Ungleichgewicht, kann das Problem durch eine Anpassung der Primerkonzentrationen - eine Erhöhung der schwächsten Marker und/oder Verringerung der stärksten - gelöst werden.

b. Stottern ist ein häufiges Phänomen, das auf die Amplifikation von PCR-Produkten zurückzuführen ist, die sich vom ursprünglichen Allel durch eine oder wenige Wiederholungen unterscheiden. Verursacht wird dies durch ein Verrutschen der DNA-Polymerase (sog. Slippage) (Levinson und Gutman 1987, Meldgaard und Morling 1997). Stotter-Peaks sind in der Regel kürzer als das ursprüngliche Allel. Es werden mehrere Ansätze zur Reduzierung des Stotterns vorgeschlagen: i) Senkung der Denaturierungstemperatur auf $83^{\circ} \mathrm{C}$ (Olejniczak und Krzyzosiak 2006); ii) Zugabe von PCR-Zusätzen wie Rinderserumalbumin (BSA), Formamid oder Dimethylsulfoxid; iii) Verwendung spezialisierter Multiplex-PCR-Kits und/oder neuer modifizierter Polymerasen, wie z.B. Fusions-Polymerasen (Fazekas et al. 2010); iv) Modifikation von Primern unter 
Einbeziehung eines Teils der Mikrosatellitenregion (Flores-Rentería und Whipple 2011); v) Verwendung von SSRs mit einer längeren Wiederholungseinheit (mehr als 2 Nukleotide). Im Allgemeinen ist geringes oder mäßiges Stottern im Hinblick auf die genaue Bestimmung der Allele und deren Größe kein besonderes Problem, erhöht jedoch möglicherweise den Aufwand durch eine manuelle Überprüfung der Ergebnisse der automatisierten Größenbestimmung.

C. Doppelpeaks (A+ -Effekt) werden durch eine unvollständige Anlagerung von Adenin an PCR-Fragmente durch Taq-Polymerase verursacht, was zu doppelten Peaks führt: dem „echten Template-DNA-Fragment“ sowie einem zusätzlichen Peak, der 1 bp länger ist und dem adenylierten Fragment entspricht. Doppelpeaks können die automatische Peak-Identifikation beeinträchtigen, insbesondere bei Heterozygoten mit benachbarten Allelen. Eine vollständige Adenylierung und damit eine Verringerung der Intensität von Doppelpeaks kann erreicht werden, indem i) die Menge der Template-DNA auf 10 ng reduziert wird (Lederer et al. 2000, Butler 2005b); ii) die Primer-Konzentration verringert wird; iii) die Anzahl der PCR-Zyklen reduziert wird, oder iv) andere Arten von DNA-Polymerasen verwendet werden (Hu 1993, Vallone et al. 2008).

d. Primer-Dimere und andere Artefakt-Banden. Bei der Multiplex-PCR können verschiedene Artefakte erzeugt werden, darunter auch solche, die aus der Komplementarität von Teilsequenzen zwischen Primern desselben Primerpaares sowie zwischen Primern verschiedener Marker resultieren (Brownie et al. 1997, Hill et al. 2009). Artefakte in Form zusätzlicher Banden können durch unspezifisches Primer-Annealing oder pseudogene Amplifikation entstehen. Eine erhöhte Stringenz der PCR-Bedingungen (höhere AnnealingTemperatur, kürzere Annealing-Zeiten) kann manchmal die Artefaktbildung reduzieren, aber die beste Garantie gegen die Bildung solcher Artefakte ist in erster Linie ein sorgfältiges Primer- und Multiplex-PCR-Design. Wenn Artefakte das Erkennen von Allelen (Allel-Calling) nicht stören, können sie bei der manuellen Auswertung einfach weggelassen werden. Manchmal ist es jedoch am besten, solche Marker aus der Multiplex-PCR auszuschließen oder die Primer für deren Amplifikation zu modifizieren (Guichoux et al. 2011).

Obwohl die in der Literatur beschriebenen SSR-Multiplex-PCR Methoden einen guten Ausgangspunkt darstellen, liefern die aufgeführten PCR-Bedingungen und -Protokolle selten sofort optimale Ergebnisse. Es ist davon auszugehen, dass vor einer routinemäßigen Anwendung der Multiplex-SSR-Analyse mit hohem Durchsatz zuerst zumindest ein gewisses Maß an Optimierung durchgeführt werden muss.

\subsection{Fragmentanalyse}

DieFragmentanalysevonSSR-Markernumfasst dieVorbereitungvonPCR-amplifiziertenProben, dieanschließende Trennung und Detektion der PCR-Amplikons mit einer automatisierten hochauflösenden KapillarelektrophoreseDetektionsplattform (sog. Sequenzierern oder Sequenziergeräten) und die Rohdatenanalyse (AllelgrößenBestimmung und Binning). Soweit nicht anders angegeben, basieren die unten aufgeführten Informationen auf Benutzerhandbüchern und Analysevorschriften, die von den Herstellern (Applied biosystems/Thermo Fisher Scientific 2010, 2014) der Kapillarelektrophorese-Systeme entwickelt wurden, sowie auf eigenen Verfahren und Erfahrungen der am LIFEGENMON-Projekt beteiligten Laboren.

\section{a. Verdünnung der PCR-Proben}

Moderne genetische Analysegeräte verfügen über hochempfindliche Fluoreszenz-Detektoren. Dies erfordert häufig eine reduzierte Konzentration von Fluorophor-markierten PCR-Amplikons, damit die emittierte Fluoreszenz in den empfohlenen Detektionsbereich fällt. Ein „Überladen“ der Probe sollte vermieden werden, da diese nicht nur die Signalintensität und -auflösung beeinträchtigen, sondern auch zu einer Verstopfung der Kapillaren führen kann. Der Grad der Verdünnung hängt von der Empfindlichkeit und dem Detektionsbereich des genetischen Analysegeräts, der Effizienz sowie der Anzahl der PCR-Amplifikationszyklen für die verwendeten SSR-Marker und Fluorophore ab und muss für jede Multiplex-PCR empirisch bestimmt werden. Im Allgemeinen sind bis zu 100-fache Verdünnungen erforderlich. Die Verdünnungen sollten so optimiert werden, dass das durchschnittliche Verhältnis der Peakintensität von Probe zu Standardgröße zwischen 3:1 und 1:1 liegt. PCR-Proben können mit Formamid oder molekularbiologisch einwandfreiem Wasser (frei von Nukleinsäuren und DNasen/RNasen) 
verdünnt werden. Verdünnte Proben sollten so schnell wie möglich verarbeitet und so wenig wie möglich dem Umgebungslicht ausgesetzt werden, um ein „Ausbleichen“ der Fluorophore zu verhindern.

\section{b. Denaturierung verdünnter PCR-Proben}

Die Denaturierung von PCR-Amplikons ist notwendig, da während der Elektrophorese nur einzelsträngige DNA (ssDNA) in Korrelation zur jeweiligen Fragmentgröße wandert. Verdünnte PCR-Proben werden mit einem internen Größenstandard, der in einer formamidhaltigen Pufferlösung verdünnt ist, zusammengeführt und bei $95^{\circ} \mathrm{C}$ für $3-5$ Minuten inkubiert, um eine vollständige Denaturierung der dsDNA-Fragmente zu erreichen. Es sind verschiedene Größenstandards erhältlich, die unterschiedliche DNA-Fragmentgrößenbereiche abdecken. Es sollte darauf geachtet werden, einen Größenstandard zu wählen, der sich über den gesamten Allelbereich der analysierten SSR-Marker erstreckt. Befolgen Sie die Herstelleranweisungen bezüglich der empfohlenen Verhältnisse für die einzelnen Komponenten der Denaturierungsmischung, z.B. Formamid, Probe und Größenstandard. In Kontakt mit Wasser hydrolysiert Formamid zu Ameisensäure und Formiat, wodurch sich die Denaturierungseffizienz verringert. Darüber hinaus wandern die Formiat-Ionen während der elektro-kinetischen Injektion bevorzugt in die Kapillaren und verursachen einen Abfall der Signalintensität. Formamid sollte bei $-20^{\circ} \mathrm{C}$ gelagert und mehr als zweimaliges Einfrieren/Auftauen vermieden werden. Es wird daher empfohlen, Aliquots von Formamid vorzubereiten, um dessen Abbau zu vermeiden. Denaturierte PCR-Produkte werden am besten sofort analysiert, da die Signalintensität mit der Lagerungsdauer abnimmt. Denaturierte Proben sollten bei Raumtemperatur nicht länger als 24 Stunden, bei $2-8^{\circ} \mathrm{C}$ nicht länger als 5 Tage, und bei $-20^{\circ} \mathrm{C}$ maximal für 1 Woche gelagert werden.

\section{c. Kapillarelektrophorese}

Bei den meisten modernen Detektionsplattformen erfolgt die elektrophoretische Trennung von DNA-Fragmenten hoch automatisiert, und es sind nur sehr wenige Eingriffe des Personals erforderlich; abgesehen vom Befüllen der Platten mit denaturierten Proben, dem Hochladen oder Erstellen der Probenliste und der Auswahl des geeigneten Laufprotokolls. Auch die mit den genetischen Analysegeräten gelieferte Betriebssoftware enthält Laufprotokolle, die für verschiedene Arten von Analysen optimiert sind. Je nach verwendetem Analysegerät ist in der Regel eine gewisse Optimierung der Probeninjektion und der Testbedingungen (Injektions- und Laufzeit, Injektions- und Laufspannung) möglich, wodurch die Datenqualität, die Präzision zwischen den verschiedenen Läufen und/oder der Durchsatz verbessert werden können. Labore sollten derartige Anpassungen mit Vorsicht angehen und die entsprechenden technischen Dokumente und/oder autorisierte technische BeraterInnen konsultieren, bevor sie die Bedingungen der Elektrophorese verändern, und die modifizierten Laufprotokolle gründlich validieren, um optimale Ergebnisse zu gewährleisten.

Die Injektionszeit beeinflusst sowohl die Signalintensität als auch dessen zeitliche Auflösung. Eine längere Injektionszeit kann bei Proben mit niedriger PCR-Produktkonzentration die Signalintensität verbessern, aber gleichzeitig verringern längere Injektionszeiten die Auflösung und das Verhältnis von Peakhöhe zu -breite. Eine Erhöhung der Injektionsspannung wirkt sich auf die Signalintensität aus, hat jedoch keinen signifikanten Einfluss auf die Auflösung. Dennoch werden niedrigere Spannungen bevorzugt, um eine bessere Genauigkeit des Injektionszeitpunkts und damit eine bessere Reproduzierbarkeit bei der Probenzuführung über Proben und Probenläufe hinweg zu gewährleisten.

Jede Änderung der Elektrophoresebedingungen muss den Bereich der DNA-Fragmentlängen (allelische Bereiche der analysierten SSR-Marker und interner Größenstandard) und die notwendige Auflösung berücksichtigen. Meistens wird eine Optimierung der Laufzeiten durchgeführt, um den Durchsatz zu erhöhen. Die optimale Laufzeit für eine gegebene Laufspannung sollte durch Probeläufe ermittelt werden. Die Elektrophoreselaufzeit sollte etwa 10\% länger sein als die Migrationszeit des größten zu analysierenden DNA-Fragments. Im Allgemeinen sollten zwei Standardfragmente, die geringfügig kürzer als das kleinste analysierte Fragment sind, und zwei Standardfragmente, die geringfügig länger als das längste analysierte Fragment sind, einbezogen werden, um eine akkurate Erstellung von Größenstandards zu gewährleisten. Eine Erhöhung der ElektrophoreseLaufspannung verkürzt die Laufzeiten, wird jedoch nicht empfohlen, da höhere Migrationsgeschwindigkeiten zu einer suboptimalen Trennung der Fragmente und einer Verringerung der Auflösung führen können. 


\section{d. Bestimmung der Allelgrößen: „Allel-Calling“ und „Binning“}

Nach der Generierung der Rohdaten mithilfe genetischer Analysegeräte müssen die entsprechenden Genotypen ausgelesen werden. Das Auslesen der Genotypen besteht aus zwei aufeinanderfolgenden Schritten: dem sog. Allel-Calling, der Bestimmung der tatsächlichen Allelgröße (Allelgröße ausgedrückt als die tatsächlich detektierte Fragmentgröße in Dezimalzahlen) und dem Binning (Zuweisung der tatsächlichen Allelgrößen zu diskreten ganzzahligen Einheiten, die sich voneinander durch die Größe der Wiederholungseinheit unterscheiden) (Idury und Cardon 1997).

Das Allel-Calling umfasst die Identifizierung der den Allelen entsprechenden Peaks im Elektropherogramm und die Bestimmung ihrer tatsächlichen Größe (Länge). Softwareprogramme, die mit den KapillarelektrophoreseSystemen geliefert werden, z.B. Peak Scanner, MSA und GeneMapper von Applied biosystems/Thermo Fisher Scientific, GenomeLab (Beckman Coulter/Sciex) sowie Software von Drittanbietern wie z.B. Geneious (Biomatters Ltd.), ermöglichen ein hohes Maß an Automatisierung des Allel-Callings und können in der Regel viele gängige Probleme bei der Genotypisierung lösen, darunter Stotter-Peaks, übermäßiges Grundrauschen, durch Fremdkörper oder Mikroblasen verursachte „Signalspitzen“, sowie Peaks außerhalb des Skalenbereichs (Guichoux et al. 2011). Abhängig von der Qualität der Marker erfordert das Allel-Calling jedoch ein gewisses $\mathrm{Maß}$ an manueller Nachbearbeitung, was arbeitsintensiv sein kann und per definitionem ein gewisses Maß an Subjektivität und Fehlern mit sich bringt. Daher ist es wichtig, gut funktionierende Marker auszuwählen, die Multiplex-PCR so weit wie möglich zu optimieren (Scandura et al. 2006, Guichoux et al. 2011) und konsistente Regeln für die manuelle Bearbeitung über alle Marker, Proben und Projekte hinweg anzuwenden.

Das Binning - der nächste Schritt der Genotypisierung - ist von entscheidender Bedeutung, da Inkonsistenzen und willkürliche Entscheidungen beim Binning als eine wesentliche Ursache SSR-basierter Genotypisierungsfehler angesehen werden (Ewen et al. 2000, Weeks at al. 2002, Morin et al. 2010). Viele Softwarepakete, die von den Herstellern von Kapillarelektrophorese-Systemen oder von Drittanbietern entwickelt wurden, ermöglichen ein automatisches Binning. Es wird jedoch empfohlen, die Bins während der ersten Phase der Bin-Erstellung und der anschließenden Analyse manuell zu überprüfen - zu verifizieren - und gegebenenfalls anzupassen. Es ist ratsam, die Rohdaten mit den tatsächlich detektierten Allelgrößen zu speichern, um diese später zu Referenzzwecken sowie für Vergleiche verwenden zu können. Eine einfache, schnelle und effiziente Methode zur Bestimmung von Bin-Schwellenwerten ist die Erstellung von Verteilungsplots der tatsächlichen Allelgrößen (Abbildung 6.4). Dies kann durch den Export der Rohdaten der DNA-Fragmentgrößen in eine Tabellenkalkulation, die Sortierung der Werte nach ihrer Größe und die Erstellung von Streudiagrammen der kumulativen Allelgrößen für jeden Marker erfolgen (Jayashree et al. 2006, Guichoux et al. 2011). Basierend auf diesen Verteilungen können dann an Stellen, an denen Abstufungen in regelmäßigen Größenklassen beobachtet werden, Bins definiert werden. Die Verteilungsplots von Allelgrößen können darüber hinaus weiteren Zwecken dienen:

a. Sie stellen eine nützliche visuelle Hilfe zur schnellen Identifizierung von Allelen dar, die von der erwarteten Periodizität der Repeats abweichen, d.h. von „mutierten Allelen“ oder sogenannten "Off-ladder-Varianten“ oder „Phantombins“. Wenn solche Off-ladder-Allele erkannt werden, sollte eine manuelle Überprüfung erfolgen, um festzustellen, ob deren Größe echt ist oder möglicherweise das Ergebnis eines inkonsistenten Allel-Callings aufgrund von Stottern, Doppelpeaks oder anderen Artefakt-Peaks. In solchen Fällen wird empfohlen, zusätzlich unter optimalen Bedingungen eine Einzel-PCR durchzuführen, um zu prüfen, ob auch unter diesen Off-ladder-Fragmente produziert werden. Ist dies der Fall, und wird eine derartige Allelvariante bei mehreren verschiedenen Individuen bestätigt, ist es wahrscheinlich, dass ein solches Allel tatsächlich echt ist und als ein einzigartiges, mutiertes Allel mit einem eigenen Bin berücksichtigt werden sollte.

b. Sie ermöglichen die Identifizierung der „Alleldrift“, d.h. eines Phänomens, bei dem die detektierten Abstände zwischen benachbarten Allelen geringfügig von der erwarteten Wiederholungslänge abweichen - bei Dinukleotid-SSRs kann dieser Abstand zwischen 1,8 bis 2,2 bp variieren (Amos et al. 2007); zusätzlich kann sich der Abstand zwischen benachbarten Allelen über den gesamten Allelbereich hinweg verändern. 


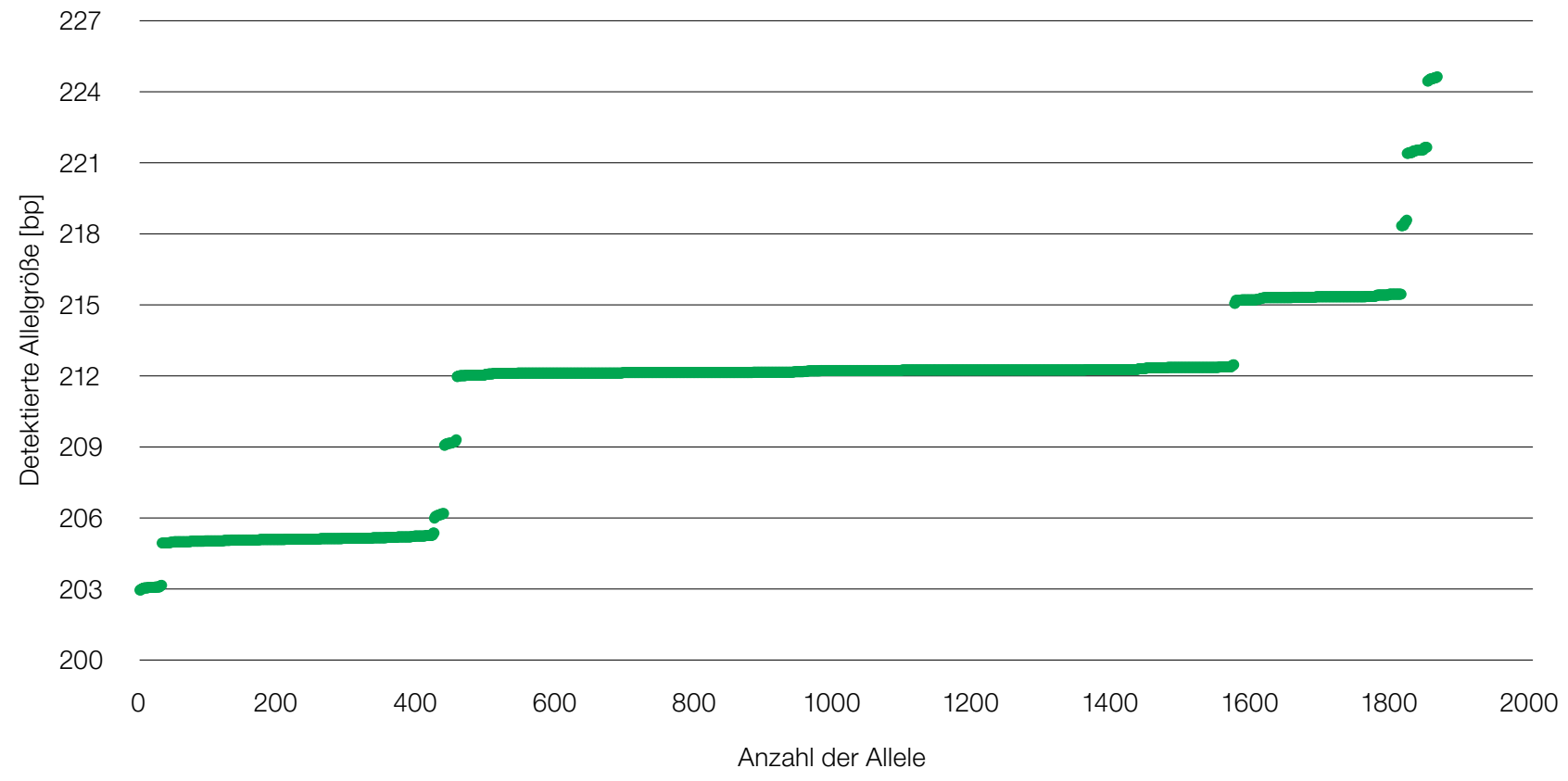

Abbildung 6.4.: Größenverteilung von 1864 detektierten Allelen für den Trinukleotid-Repeatmarker Aag01 für Abies alba Mill. Die meisten Allele folgen der erwarteten Periodizität von 3 bp, mit Ausnahme eines Allels mit der erwarteten Größe von 206 bp, bei dem zwei Varianten nachgewiesen wurden - die erwartete 206-bp-Variante und eine Off-ladderVariante mit 205 bp, die in dieser speziellen Population eines der häufigeren Allele darstellt. Die manuelle Überprüfung ergab, dass das Vorhandensein sowohl der erwarteten als auch der Off-ladder-Variante nicht das Ergebnis einer inkonsistenten Allelbestimmung war, da Aag01 grundsätzlich ein Marker mit regelmäßigen Mustern ohne Doppelpeaks mit geringfügigem Stottern ist. Zusätzlich wurden mehrere Individuen identifiziert, die sowohl die 205- als auch die 206-bp-Variante trugen, und das Vorhandensein beider Varianten wurde auch bei sich reproduzierenden Altbäumen, Samen und natürlicher Verjüngung unterschiedlichen Alters festgestellt. In diesem Fall wurde die 205-bp-Variante als ein einzigartiges „mutiertes“ Allel betrachtet, das sich von dem erwarteten 206-bp-Allel unterscheidet.

c. Sie können verwendet werden, um Verschiebungen der detektierten Allelgrößen aufgrund von HardwareFehlfunktionen, Verschleiß oder degradierten Verbrauchsmaterialien zu erkennen. In dieser Funktion sollten die Verteilungsplots der Allelgrößen-Rohdaten zusammen mit der Analyse von Standardproben immer dann in Betracht gezogen werden, wenn Änderungen am Analyseverfahren vorgenommen werden; z.B. ein Wechsel des Fluorophors oder der Polymerase, Änderungen der PCR-Zyklusprotokolle, der PCR-MixZusammensetzung, der Elektrophorese-Reagenzien (Polymer- und Kapillartyp) oder der ElektrophoreseBedingungen, da all diese Faktoren die detektierte Größe der DNA-Fragmente beeinflussen können (Hartzell et al. 2003, Sgueglia et al. 2003, Hahn et al. 2001, Ghosh et al. 1997). Werden aufgrund von Veränderungen Verschiebungen in den detektierten Allelgrößen festgestellt, sollten die Bins entsprechend angepasst werden.

d. Sie können als Teil der Datenintegritätsprüfung verwendet werden, um Allelgrößen außerhalb der erwarteten Schwellenwerte zu identifizieren (siehe Unterkapitel 6.5.4.1).

\subsubsection{Einzelnukleotid-Polymorphismus-Marker (SNPs)}

\subsection{Auswahl geeigneter SNP-Marker}

Suchen Sie in der verfügbaren wissenschaftlichen Literatur nach den vorhandenen SSRs und konsultieren Sie KollegInnenaus anderen Laboren, dieErfahrung in derArbeitmit denentsprechenden Genotypisierungsplattformen und der betreffenden Art haben. Bei der Auswahl geeigneter SNP-Marker aus der Literatur oder bei der Entwicklung neuer Marker sollten die folgenden Kriterien berücksichtigt werden:

- Wenn Genkarten verfügbar sind, wählen Sie SNPs von möglichst vielen verschiedenen Chromosomen aus. 
- Konzentrieren Sie sich auf die SNPs, die bereits bei einer möglichst großen Anzahl von Proben sowie bei Proben aus verschiedenen Teilen des Verbreitungsgebietes der betreffenden Art erfolgreich eingesetzt wurden, da dies die Wahrscheinlichkeit des Auftretens systematischer Fehler minimiert. Der gleiche Rat gilt für Referenzproben, die für die Entwicklung eines neuen SNP-Panels verwendet werden.

- Wird das Monitoring in einer Region durchgeführt, in der für die betreffende Art eine Hybridisierung erwartet wird, wählen Sie Marker aus, die bereits erfolgreich auf Übertragbarkeit zwischen den hybridisierenden Arten getestet wurden. Es wird empfohlen, Tests an Proben beider Arten durchzuführen, um die Aussagekraft der verwendeten SNPs zu überprüfen.

- Je nach Forschungsfrage könnten gengebundene oder neutrale SNPs am besten geeignet sein.

- Beginnen Sie immer mit einer größeren Anzahl potenzieller SNP-Loci, da viele von diesen ggf. aufgrund fehlender Werte, fehlender Variation (geringe Häufigkeit des selteneren Allels) oder systematischer Fehler ausfallen könnten.

- Die Gesamtzahl der verwendeten SSRs hängt von der zu beantwortenden Frage und den verfügbaren Ressourcen ab. So reichen schätzungsweise ca. 180 nicht verknüpfte SNPs für eine genaue Schätzung der effektiven Populationsgröße aus (Waples und Do 2010).

- Wenn die Anzahl der verfügbaren SNPs für Ihre Forschungsfrage nicht ausreicht und keine Ressourcen für die Entwicklung eines größeren Panels zur Verfügung stehen, ziehen Sie die Verwendung von SNPs in Betracht, die bei phylogenetisch verwandten Arten nachgewiesen wurden. Erwarten Sie jedoch hohe Ausfallraten.

- Während die Übertragbarkeit von SNPs zwischen Genotypisierungsplattformen im Allgemeinen hoch ist, ist mit einem gewissen Verlust an Varianten zu rechnen (Semagn et al. 2014).

- Wenn Sie eine Multiplex-Genotypisierungsplattform mit einem hohem Durchsatz verwenden (z.B. Genotypisierung durch Sequenzierung, RAD-seq), stellen Sie sicher, dass Sie über die nötigen Rechenressourcen für die Analyse des Datensatzes verfügen.

\subsection{Anforderungen an DNA für die Analyse von SNP-Markern}

Die DNA-Anforderungen für die Analyse von SNP-Markern hängen vom verwendeten Genotypisierungsverfahren und/oder dem Dienstleister ab. Was die Qualität betrifft, so sind genomische DNA-Extrakte von hoher Reinheit und Integrität erforderlich. Um beste Ergebnisse zu gewährleisten, sollten die DNA-Extrakte UVAbsorptionsverhältnisse von A260/A280 > 1,8 und A260/A230 = 1,8-2,0 aufweisen. Ausführlichere Erläuterungen zur Bewertung der DNA-Qualität finden Sie in Unterkapitel 6.4.1.4.

Die am LIFEGENMON-Projekt beteiligten Labore waren bei der Analyse von SNP-Markern auf Outsourcing angewiesen. Die unten dargestellten DNA-Mengenangaben sollen als allgemeine Richtlinien dienen, da die erforderlichen Mengen je nach Analyse und Dienstleister variieren.

Für SNP-Analysen mittels Hochdurchsatz-Sequenzierung (high throughput sequencing; HTS), wie z.B. RADSequenzierung, wird eine Gesamtmenge von ca. 3 mg DNA in Konzentrationen von 50 - 100 ng/ $\mu$ l benötigt.

Für SNP-Analysen mittels KASP (Kompetitive Allel-spezifische PCR) hängt die benötigte DNA-Menge sowohl von der Größe des Genoms des betreffenden Organismus als auch von der Anzahl der analysierten SNP-Marker ab. Für Genome im Bereich von 2-3,5 Gbp werden ca. 10 ng DNA pro SNP-Marker benötigt. Für die Analyse von

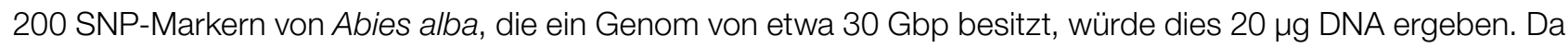
solche DNA-Mengen manchmal schwer zu beschaffen sind, kann vor der eigentlichen KASP eine Amplifikation des ganzen Genoms (Whole Genome Amplification; WGA) durchgeführt werden, um eine ausreichende Menge an Template-DNA zu produzieren. Allerdings kann dieser vorbereitende Schritt die Fehlerrate beim Benennen der Basen (Base-Call) erhöhen. Bei Genomen von 2-3,5 Gbp reichen etwa 50 ng genomische DNA für die KASPAnalyse von 500-1000 SNPs mit vorbereitender WGA mittels Primer Extension Preamplification (PEP) aus. 


\subsection{DATENANALYSEN}

\subsubsection{Einleitung}

Das forstgenetische Monitoring (FGM) zielt darauf ab, für eine Waldpopulation die langfristige Überlebensfähigkeit, Fortpflanzungsfähigkeit sowie Anpassungsfähigkeit in Bezug auf rasche Umweltveränderungen zu beurteilen (Fussi et al. 2016). Die drei Indikatoren (1) Selektion, (2) genetische Variation und (3) Genfluss/Paarungssystem werden mit einer Reihe von Verifikatoren überwacht. Dazu müssen sowohl Mess- und Bewertungsdaten vor Ort im Bestand als auch Labor- und molekulare Markerdaten gesammelt/produziert und analysiert werden, um die Verifikatoren für die oben genannten drei Indikatoren regelmäßig zu bewerten. Die Erhebung/Produktion und Analyse der Daten müssen standardisiert und die Daten für langfristige Vergleiche verfügbar sein.

Um die Ergebnisse im Zeitvergleich betrachten zu können, sollte für die Bewertung der Verifikatoren derselbe Satz genetischer Marker (z.B. Mikrosatelliten - nSSRs, Einzelnukleotid-Polymorphismen - SNPs) verwendet und analysiert werden. Angesichts der raschen technologischen Fortschritte und der Zunahme verfügbarer Marker ist es ratsam, Gewebeproben für spätere genetische Analysen aufzubewahren, um Vergleichbarkeit sicherzustellen. Ein zusätzlicher Nutzen besteht darin, dass standardisierte Daten von mehreren FGM-Flächen einer Baumart verglichen werden können, um zu prüfen, ob eine bestimmte Population besser oder schlechter abschneidet als die anderen.

Dieses Kapitel beschreibt die Erfassung und Bewertung von Daten, einschließlich (a) Datentypen (Daten aus Außenaufnahmen, molekulare Daten), (b) Datenfilterung, (c) Datenanalyse (R-Skript-Tool, genetische Software, usw.) und -Interpretation, sowie (d) Datenspeicherung. Um langfristig vergleichbare Ergebnisse des forstgenetischen Monitorings zu gewährleisten, sollten die beschriebenen, im Rahmen des LIFEGENMONProjekts standardisierten Verfahren befolgt werden.

\subsubsection{Datenbank}

Datenbanken sind in Spalten und Zeilen angeordnete Datensätze (analog zu Microsoft Excel oder ähnlichen Programmen), die jedoch in Beziehungen miteinander verbunden sind. Tabellen haben ihre eigene vordefinierte Struktur, die sicherstellt, dass die Daten im richtigen Format und am richtigen Ort vorliegen. Mithilfe von Formularen geben Benutzerlnnen die Daten in systematischer und geordneter Weise in die Datenbank ein. Die Datenbank ermöglicht es dann den BenutzerInnen, die richtigen Daten schnell und einfach abzurufen. Im Vergleich zu Microsoft Excel haben Datenbanktabellen normalerweise sehr strenge Regeln, welche Daten in welcher Form eingegeben werden können. Dies ist für die Vermeidung von Eingabefehlern durch Benutzerlnnen sehr wichtig. Dies sind jedoch nicht die einzigen Fehler, die bei der Verwendung einer Datenbank vermieden werden können. So zeigten beispielsweise Ziemann et al. (2016) bei einer systematischen Auswertung führender Genomik-Journale, dass etwa ein Fünftel der Arbeiten im Anhang Excel-Genlisten mit fehlerhaft konvertierten Gennamen enthielten.

\subsubsection{LIFEGENMON-Datenbank}

Im FGM liegen viele verschiedene Datentypen vor, z.B. genetische, phänologische, und meteorologische Daten sowie andere vor Ort im Bestand erhobene Daten. Eine Datenbank, die all diese Datentypen enthält, erleichtert und beschleunigt die Identifikation zeitlicher Veränderungen und die Interpretation von Ergebnissen. Hinsichtlich der Datenbankauswahl gibt es viele Optionen. Im LIFEGENMON-Projekt wurden zwei Datenbankmanagementsysteme getestet: Open Foris und eine unabhängige (standalone) PostgreSQL-Datenbank. Das zugrundeliegende Datenbankschema ist für beide Datenbanken identisch (Abb. 6.5) und basiert auf Richtlinien, die Teil dieses Handbuchs sind und als Vorlage für die Anlage einer derartigen Datenbank dienen können.

\section{Open Foris}

Open Foris ist eine Sammlung freier und quelloffener (open source) Software-Tools, die eine flexible und effiziente Datenerfassung, Analyse und Berichterstattung ermöglichen. Open Foris Collect ist der beste Einstieg in die Arbeit mit Inventurdaten, die u.a. auf vor Ort im Bestand erhobenen Daten beruhen. Es bietet eine schnelle, 
einfache und flexible benutzerfreundliche Schnittstelle für die Einrichtung eines Datenerfassungsformulars. Collect arbeitet mit zahlreichen Datentypen und komplexen Validierungsregeln sowie einer mehrsprachigen Umgebung. Dank seiner benutzerfreundlichen Oberfläche bietet es eine effektive Open-Source-Lösung für Forschungsprojekte, die hinsichtlich eines professionellen Datenbankmanagements finanziell limitiert sind. Open Foris verfügt auch über ein Tool namens Calc, mit dem R-Skripte erstellt und automatisierte Berechnungen durchgeführt werden können. Open Foris basiert standardmäßig auf einer SQLite-Datenbank oder PostgreSQL. Die Daten werden jedoch in binärer Form gespeichert und sind mit SQL-Abfragen nicht direkt zugänglich (d.h. sie müssen erst in andere Formate konvertiert werden). In einigen Fällen ist Open Foris langsam, insbesondere bei dem für genetische Daten häufigen Einfügen größerer Datenmengen in Tabellen.

\section{PostgreSQL}

PostgreSQL ist ein freies und quelloffenes relationales Datenbankverwaltungssystem. Es blickt auf eine lange Entwicklungsgeschichte zurück und hat sich aufgrund von Zuverlässigkeit, Funktionsrobustheit und

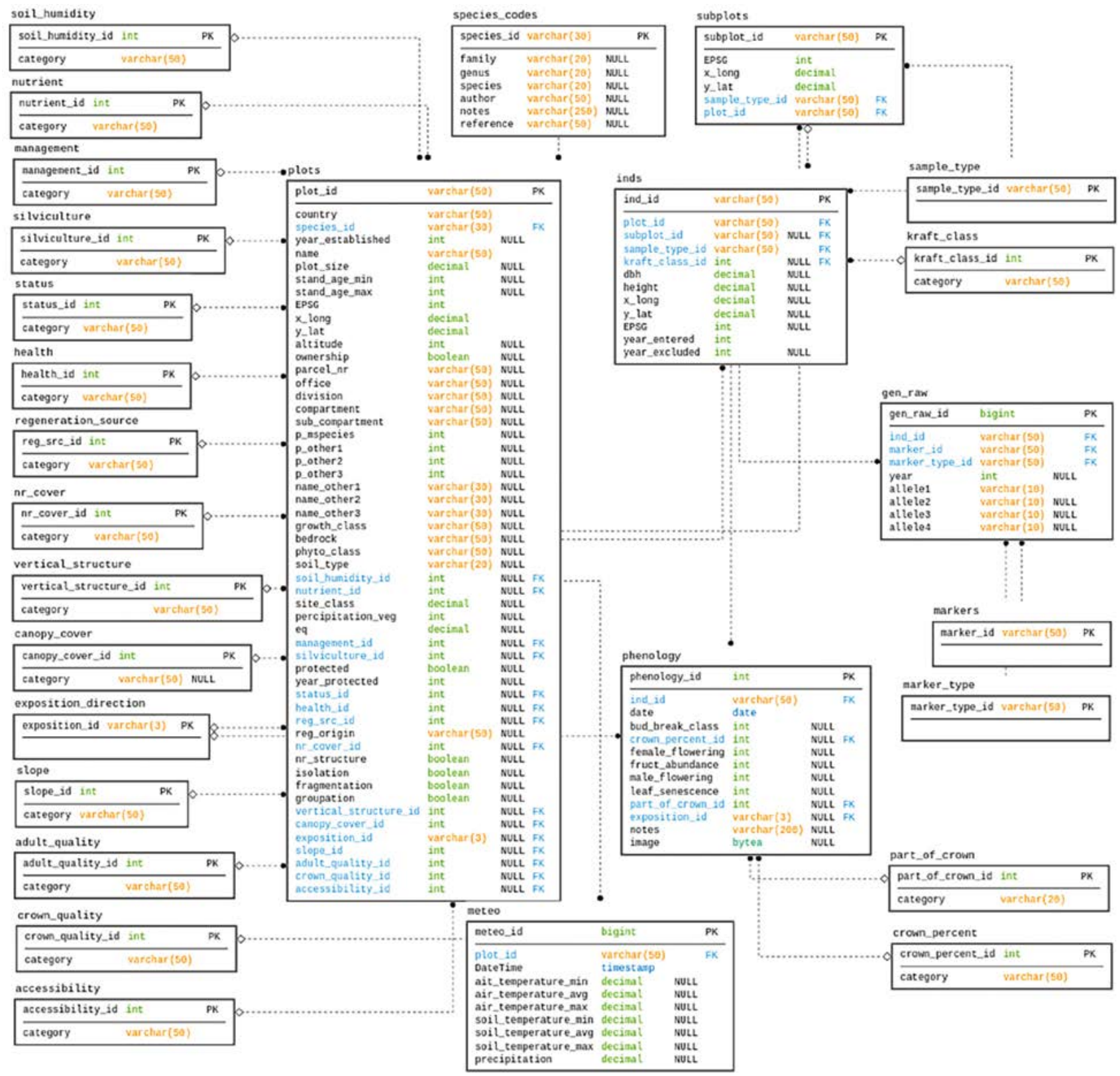

Abbildung 6.5: Schematische Darstellung des Datenbankdesigns. In Tabellen stellt die erste Spalte die Spaltennamen dar, die zweite Spalte ist der zulässige Datentyp, z.B. int, NULL - dieses Feld kann bei der Dateneingabe übersprungen werden, PK - Primärschlüssel, FK - Fremdschlüssel. 
Leistungsfähigkeit einen guten Ruf erworben. Im Vergleich zu Open Foris liegen die Hauptvorteile in der besseren Leistung, Stabilität, den unbegrenzten Möglichkeiten der Nutzerkontrolle, Modifikationen und Interaktionen mit verschiedenen Programmiersprachen, z.B. den für Datenanalysen gängigen Sprachen R und Python. Im LIFEGENMON-Projekt wurde eine R-Anwendung (easyRpopgen) zur Visualisierung und Analyse der FGMErgebnisse erstellt (siehe Kapitel 6.5.4.4.) Der derzeit einzige kleinere Vorteil von Open Foris im Vergleich zum standalone PostgreSQL ist die integrierte Benutzeroberfläche.

In Zukunft könnte Open Foris die Art und Weise der Datenspeicherung verändern. Eine mit der Open ForisBenutzeroberfläche verbundene PostgreSQL-Datenbank könnte eine sehr attraktive Möglichkeit sein, da wir aktuell empfehlen, ausschließlich PostgreSQL zu verwenden und nur bei Bedarf eine den Anforderungen des FGM entsprechende Benutzeroberfläche zu entwickeln.

\subsubsection{Auswertung der im Bestand erhobenen Daten}

Potentielle Verifikatoren der Selektion in einer Population lassen sich anhand von Veränderungen in der Populationsdemografie beurteilen, wie z.B. Sterblichkeitsraten, der Häufigkeit von aus Naturverjüngung entstandenen Bäumen, Geschlechterverhältnissen und Altersklassenverteilungen. Diese demografischen Faktoren werden durch den Reproduktionserfolg und die Fähigkeit einer Kohorte beeinflusst, sich an Stressoren wie Umweltbelastungen, Krankheiten und Verbiss anzupassen - und spiegeln somit den natürlichen, auf die Population wirkenden Selektionsdruck wider. Die Selektion kann auch anhand der Blühphänologie beurteilt werden, die eine wichtige Komponente der reproduktiven Fitness von Individuen (Munguía-Rosas et al. 2011) und Ausdruck evolutionär getriebener Anpassungsstrategien ist (Kudo 2006).

\subsubsection{Plausibilitätsprüfung der im Bestand erhobenen Daten}

Im Bestand werden für die Monitoringbäume Verifikatoren und Hintergrundinformationen erfasst, darunter Mortalität, Abundanz der Naturverjüngung, Brusthöhendurchmesser (BHD), Höhenklassenverteilung und phänologische Verläufe (inklusive Austrieb, Blüte und Seneszenz) beurteilt. Vom Standpunkt der Datenerhebung aus stellt die in situ-Bewertung dieser Eigenschaften eine Herausforderung dar. Beobachtungs- und Protokollierungsfehler können die durch innerartliche Variation und mikroklimatische Effekte bedingte natürliche Variabilität phänotypischer Daten um 1-2 Wochen erhöhen (Schaber und Badeck 2002, und darin enthaltene Quellen). Sie können auch zu fälschlichen Beobachtungen führen, die für eine bestimmte Methode unerwartet sind, wie z.B. ungewöhnlich hohe Werte für Baumdurchmesser oder -höhe. Daher ist es notwendig, dass die Wissenschaftlerlnnen bei der Durchführung der Analysen und der Zusammenstellung der Daten zunächst mit Vorsicht und Aufmerksamkeit vorgehen. Außerdem sollten die Daten nach der Erfassung streng auf mögliche Fehler überprüft werden, welche die Integrität der Daten beeinträchtigen könnten. Eine Möglichkeit, um bei den für FGM typischerweise sehr unterschiedlichen Datentypen und Verfahren die Datenplausibilität zu gewährleisten, ist die Verwendung eines Datenbanksystems (siehe Unterkapitel 6.5.2.1 LIFEGENMON-Datenbank).

Ausreißer sind Datenpunkte, die weit außerhalb des erwarteten Bereichs oder der erwarteten Verteilung der erhobenen Daten liegen. Sie können mögliche Indikatoren für falsch gemessene oder beschriftete Daten sein und müssen daher vor der Analyse der Daten identifiziert werden. Die vorsichtige Eliminierung von Ausreißern ist eine wirksame Methode zur Verbesserung der Zuverlässigkeit phänologischer Zeitreihen (Linkosalo et al. 1996). Die grafische Diagnose mittels Boxplots ist eine einfache Methode zur Eliminierung von Ausreißern aus Datensätzen. In einem klassischen Boxplot werden diejenigen Werte als Ausreißer bezeichnet, die kleiner oder größer als das 1,5-fache des Interquartilsabstands aller Messwerte sind, und die durch einen außerhalb der Antennen (whisker) des Boxplots liegende Datenpunkte visualisiert sind. Bei normalverteilten Daten kann für die Ausreißererkennung auch ein Z-Score-Ansatz verfolgt werden, bei dem Rohdaten in z-Scores transformiert werden:

$$
z_{i}=\frac{x_{i}-\bar{x}}{s}
$$


wobei $z_{i}=$ normalisierter $z$-Score,$x_{i}=$ nicht transformierter Originalwert, $\bar{x}=$ Mittelwert der Stichprobe, und $s=$ Standardabweichung der Stichprobe. Datenpunkte werden als Ausreißer betrachtet, wenn der z-Score größer als ein gegebener Schwellenwert ist, beispielsweise größer als 3 Standardabweichungen des Mittelwerts (z.B. implementiert von Gerard et al. (2020)). Ein Diskordanztest mit einem ähnlichen Ansatz wird von King (1953) vorgestellt, der auch auf normalverteilte Daten angewendet werden kann. Dabei wird eine Teststatistik $T_{i}$ berechnet, indem der Abstand eines Extremwerts vom nächstliegenden Wert im Gesamtdatensatz mit dem Wert selbst verglichen wird, wenn $T_{i}$ einen kritischen Wert überschreitet (ausführlich erläutert in Barnett und Lewis 1978). Dieser Test wurde in Linkosalo et al. (1996) implementiert. Auch „Monats“-Fehler (Protokollierungsfehler, bei dem der Beobachtungsmonat falsch zugeordnet wurde) können aufgrund der großen Abweichung solcher Werte zuverlässig durch die verteilungsfreie 30-Tage-Residuenregel erkannt werden (Schaber und Badeck 2002). Die Verwendung eines oder einer Kombination dieser Ansätze sollte die Erkennung und Korrektur bzw. Eliminierung von Ausreißern ermöglichen.

Schließlich ist auch die Expertise des WissenschaftlerInnen ein wichtiger Faktor bei der Identifikation von unrealistischen Werten, die aber möglicherweise immer noch innerhalb eines gegebenen Verteilungsmodells liegen und daher durch die statistische Ausreißererkennung nicht entfernt werden können, wie z.B. ungewöhnlich große Baumdurchmesser für die entsprechende Art. Da die Phänologie Phänomene mit natürlichen, aufeinander folgenden Abläufen beschreibt (z.B. erfolgt der Austrieb vor der Blüte, und diese vor der Blattseneszenz), müssen die Daten außerdem auf Sinnhaftigkeit überprüft werden, um sicherzustellen, dass die Erfassung dieser Variablen tatsächlich in einer logischen Reihenfolge erfolgte.

\subsubsection{Analyse der im Bestand erhobenen Daten}

\subsection{VERIFIKATOREN}

Beim forstgenetischen Monitoring werden die Verifikatoren für den Indikator „Selektion“ über einen Zeitraum von vielen Jahren zu verschiedenen Zeitpunkten im Jahresverlauf gemessen. Für die meisten Verifikatoren können für verschiedene Zeiträume Mittelwerte auf Populationsebene berechnet werden. Im Allgemeinen können die Verifikatoren über Jahre und Populationen hinweg durch verschiedene parametrische und nichtparametrische statistische Verfahren verglichen werden, je nach Art der abhängigen Variablen. Bei Verifikatoren, bei denen es sich um numerische Variablen handelt, erfolgt der Vergleich des Populations-Mittelwerts in verschiedenen Jahren mit Hilfe von linearen Regressionsmodellen oder gemischten linearen Modellen. In Letzteren kann ein Zufallseffekt definiert werden, was vor allem wichtig ist, wenn die Beobachtungen/Messungen an denselben Objekten durchgeführt werden. Für Verifikatoren, die unter Verwendung einer Codierung eingeschätzt werden, kann eine ordinale Regression (z.B. clmm-Modell in R, bei dem ein Zufallseffekt definiert werden kann) oder ein Kruskal-Wallis-Test durchgeführt werden. Zähldaten folgen normalerweise der Poisson-Verteilung, so dass für entsprechende Verifikatoren die Poisson-Regression (verallgemeinerte lineare Modelle oder verallgemeinerte gemischte Modelle der Poisson-Familie) für die Analyse genutzt werden kann.

\subsection{Mortalität / Überlebensrate}

\section{Hintergrund}

Der Verifikator "Mortalität / Überlebensrate“ bezieht sich auf die Anzahl der Bäume die seit der Erstaufnahme (bzw. der letzten Datenerhebung) abgestorben sind. Eine Veränderung der Mortalität oder Überlebensrate (1 Mortalität) deutet auf einen zugrundeliegenden Selektionsdruck hin, d.h. bei einer Erhöhung der Mortalitätsrate auf ein Absterben. Der Verifikator ist daher ein wichtiger Indikator für einen möglichen, auf eine Population wirkenden Selektionsdruck, da die überlebenden Bäume wahrscheinlich eine gewisse Anpassungsreaktion auf einen solchen Druck zeigen. 


\section{Berechnung}

Die Mortalität wird als Mortalitätsrate ausgedrückt und nach folgender Gleichung berechnet:

$$
m=1-\left(\frac{N_{1}}{N_{0}}\right)^{1 / t}
$$

wobei $\mathrm{N}_{0}$ und $\mathrm{N}_{1}$ die Baumzählungen zu Beginn und Ende des Monitoringintervalls sind und t die Länge des Monitoringintervalls in Jahren angibt. Die nach dieser Gleichung berechnete Mortalitätsrate ist die jährliche Mortalitätsrate. Sie ist konstant, was bedeutet, dass sie als durchschnittliche jährliche Mortalitätsrate für das entsprechende Jahrzehnt interpretiert wird. Wird der Exponent weggelassen, ist das Ergebnis eine 10-Jahres-Mortalitätsrate.

Wenn ursprüngliche Beobachtungsbäume aufgrund von Bewirtschaftungsmaßnahmen ersetzt werden mussten, kann die Mortalität auch als die absolute Anzahl toter Bäume pro 50 Bäume über einen Zeitraum von 10 Jahren ausgedrückt werden, berechnet durch Subtraktion der verbleibenden lebenden Bäume von den ursprünglich markierten Bäumen:

$$
\text { Mortalität }=N_{\mathrm{o}}-N_{1}
$$

Wobei $N_{0}$ die ursprüngliche Anzahl der Bäume und $N_{1}$ die Anzahl der verbliebenen lebenden Bäume ist. Wenn einer der ursprünglichen 50 Beobachtungsbäume im Zuge von Bewirtschaftungsmaßnahmen gefällt wird, sollte der Ersatzbaum sowohl in die Anzahl der ursprünglichen als auch der verbleibenden Bäume einbezogen werden. Gefällte Bäume werden nicht als tote Bäume betrachtet. Die anfängliche Anzahl der Bäume in jedem Zehnjahresintervall beträgt stets 50 (siehe Abschnitt 3.4.2 Ersatz von Bäumen).

Der Unterschied in der Mortalität zwischen zwei Datenerhebungen wird durch einen Kettenindex und die Wachstumsrate beschrieben, wobei der Wert der Mortalität in der Datenerhebung c immer mit der Mortalität in der Datenerhebung c - 1 verglichen wird.

\subsection{Abundanz der Naturverjüngung (NV) \\ Hintergrund}

Bei der Erhaltung von Waldbeständen tragen viele natürliche Faktoren zur Mortalität bei, darunter Alterung, Herbivorie und Krankheiten sowie mögliche Durchforstungs- oder Holzerntemaßnahmen. Um Nachhaltigkeit zu gewährleisten, muss ein Waldbestand daher durch die Etablierung junger Bäume kontinuierlich erneuert werden. Dies kann durch künstliche oder natürliche Verjüngung sowie einer Kombination dieser erreicht werden. Bei der künstlichen Verjüngung werden Bäume außerhalb des Waldes, d.h. in Baumschulen, aufgezogen und in einem angemessenen Alter in den Wald verpflanzt. Bei Naturverjüngung erneuern sich Waldbestände hingegen durch Bäume, die sich an Ort und Stelle aus den vom Altbestand produzierten Samen entwickeln. Der durch die Naturverjüngung geschaffene Baumbestand ist daher ein Indikator für zugrunde liegende Selektionsprozesse, die auf den Fortpflanzungserfolg, die Überlebensrate von Keimlingen und Jungpflanzen und die Mortalitätsrate von Altbäumen (welche den Genpool beeinträchtigt, aus dem heraus sich ein Walbestand regenerieren kann) auswirken. Die Abundanz der Naturverjüngung ist definiert als die Anzahl der Sämlinge pro Flächeneinheit.

\section{Berechnung}

Auf Basisniveau wird die NV-Abundanz anhand von Experteneinschätzungen bezüglich des Vorhandenseins einer ausreichenden Menge an NV auf der FGM-Fläche erfasst. Auf Standard- und Intensivniveau wird sie durch Zählung aller Pflanzen auf zwanzig $1 \mathrm{~m}^{2}$-Plots nach verschiedenen Fruktifikationsereignissen gemäß artspezifischer Leitfäden bestimmt. Wie bei der Mortalität erfolgt diese Beurteilung auf der Populationsebene und kann qualitativ zwischen Zeiträumen/Altersklassenkohorten verglichen werden. 
Auf Basisniveau wird die Veränderung der NV-Abundanz über die Jahre auf der Grundlage von Experteneinschätzungen beschrieben. Auf Standardniveau wird die NV-Abundanz im Jahr $t$ auf der ersten Gruppe von NV-Plots mit der NV-Abundanz im Jahr $t+6$ auf der zweiten Gruppe von NV-Plots verglichen, wenn das nächste Fruktifikationsereignis nach 6 Jahren bewertet wird. Auf beiden Gruppen von NV-Plots werden die Sämlinge nach 5 Jahren erneut gezählt (im Jahr $t+5$ für den ersten Satz von NV-Plots und im Jahr $t+11$ für den zweiten Satz von NV-Plots). Auf die gleiche Weise wird die Häufigkeit der 5-jährigen Sämlinge auf beiden Sätzen von NV-Plots verglichen. Für die Analyse eignet sich ein Modell, das die diskrete Natur der Zählvariablen berücksichtigt, wie z.B. das Poisson-Regressionsmodell. Auf Intensivniveau werden die Sämlinge auf jedem Satz von NV-Plots zusätzlich auch nach 10 und 15 Jahren gezählt. Die Analyse wird analog zum Standardniveau durchgeführt, indem die NV-Abundanz derselben Alterskohorte verglichen wird.

\subsection{Blüte}

\section{Hintergrund}

Die Blühphänologie umfasst die Untersuchung der Entwicklungszeitpunkte der männlichen und weiblichen Blüten durch Erfassung der verschiedenen Phänophasen (Ducci et al. 2012). Die Blühphänologie ist ein entscheidender Faktor für die reproduktive Fitness der Bäume, da sie über den Genaustausch zwischen Genotypen die genetische Diversität der produzierten Samen und somit den Überlebenserfolg der daraus entstehenden Sämlinge bestimmt (Alizoti et al. 2010).

\section{Berechnung}

Die phänologischen Beobachtungen umfassen die Beurteilung der Blühhäufigkeit und des Anteils blühender Bäume auf Bestandesebene (FGM-Basisniveau) und auf Einzelbaumebene (FGM-Standardniveau) sowie die Entwicklungsphasen (Phänophasen) der männlichen und weiblichen Blüten von den ruhenden Blütenknospen hin zu voll entwickelten Blüten/Zapfen/Strobili (FGM-Intensivniveau). Die Daten werden für die Beurteilung der Blühfrequenz und des Anteils blühender Bäume (Basis- und Standardniveau) verwendet. Zusätzliche Daten (Intensivniveau) werden für die Erstellung von Phänogrammen verwendet, die den Beginn, die Dauer, das Ende und die Synchronisation der Blüte und der verschiedenen Phänophasen angeben. Diese Daten werden mit Hilfe parametrischer und nichtparametrischer statistischer Methoden analysiert, um die Signifikanz phänologischer Unterschiede zwischen einzelnen Bäumen innerhalb einer Population oder zwischen Populationen zu beurteilen. Zur Beurteilung der Daten zur Blütephänologie kann jede Software eingesetzt werden, die parametrische und nichtparametrische statistische Analysen durchführt (d.h. SPSS, R).

\subsection{Fruktifikation}

\section{Hintergrund}

Die Intensität und Periodizität einzelner Fruktifikationsjahre ist artspezifisch und variiert je nach Witterung, Ressourcenverfügbarkeit und genetischer Kontrolle (Mund et al. 2010 und darin enthaltene Referenzen). Der Beginn der Fruktifikation ist ein wichtiges Zeichen für die Reifephase der Bäume, das anzeigt, dass die zuvor für vegetatives Wachstum und Schutz aufgewendeten Ressourcen nun auch für die Reproduktion bereitgestellt werden (Seifert und Müller-Starck 2009).

\section{Berechnung}

Die phänologischen Beobachtungen berücksichtigen die Periodizität und Intensität der Fruchtbildung. Die Daten werden auf Bestandes- (Basisniveau) und Einzelbaumebene (Intensivniveau) erhoben und mit Hilfe parametrischer und nichtparametrischer statistischer Methoden analysiert, um die Signifikanz phänologischer Unterschiede zwischen einzelnen Bäumen innerhalb einer Population oder eines Bestandes zu beurteilen. Zur Beurteilung der Fruktifikationsdaten kann jede Software eingesetzt werden, die parametrische und nichtparametrische statistische Analysen durchführt (d.h. SPSS, R). 


\subsection{Hintergrundformationen}

\subsection{Eschentriebsterben (nur Fraxinus excelsior)}

Hintergrund

Dies ist eine Hintergrundinformation, die nur beim FGM der Gemeinen Esche (Fraxinus excelsior) verwendet wird. Der Erreger des Eschentriebsterbens bei F. excelsior ist der Pilz Hymenoscyphus fraxineus. Die Krankheitssymptome traten erstmals Anfang der 1990er Jahre in europäischen $F$. excelsior-Populationen auf und führten zu einer weit verbreiteten Epidemie, die noch immer andauert. Die Krankheit ist durch nekrotische Veränderungen an den Blättern, Zweigen und Stämmen infizierter Wirtspflanzen gekennzeichnet, die zum Welken der Blätter und Absterben der Krone führen (neuere Untersuchungen wurden von Gross et al. 2013 zusammengefasst). Der Schweregrad der Schädigung steht in engem Zusammenhang mit dem genetischen Potenzial eines Individuums oder einer Population, Resistenzen gegen den verursachenden pilzlichen Erreger zu entwickeln. Es wurden bereits genetische Marker identifiziert, die darauf hindeuten, dass die Resistenz gegen das Eschentriebsterben ein polygenes Merkmal ist, das möglicherweise sowohl auf natürliche Selektions- als auch auf Zuchtprogramme gut reagiert (Harper et al. 2016, Stocks et al. 2019). Das Eschentriebsterben übt daher wahrscheinlich einen sehr starken Selektionsdruck auf Populationen von F. excelsior aus. Es kann sowohl durch die visuelle in situ-Inspektion kranker und gesunder Bäume als auch mithilfe von molekulargenetischen Markern, die eine erhöhte Resistenz verleihen können, wirksam überwacht werden (Menkis et al. 2019).

\section{Berechnung}

Anzeichen für eine Selektion im Hinblick auf die Resistenz gegenüber dem Eschentriebsterben können für Kohorten gleichen Alters zwischen verschiedenen Monitoringzeitpunkten und zwischen Populationen verglichen werden, indem bei erkrankten Bäumen jeder Kohorte und Population fortlaufend die Mortalitätsraten und die Kronenschädigung aufgrund des Eschentriebsterbens sowie die Ausbreitung der Krankheit überwacht werden.

Für die Analyse können die Anteile der Eschen mit verschiedenen Schädigungsgraden (\% Blattverlust) berechnet werden. Mittels einer Varianzanalyse (ANOVA) mit dem LSD-Post-Hoc-Test (least significant difference) können signifikante Unterschiede im Blattverlust zwischen verschiedenen Zeiträumen für die Mittelwerte der einzelnen Blattverlustklassen analysiert werden.

Für die Analyse können Softwareprogramme wie SPSS oder Programmiersprachen wie R oder Python verwendet werden.

\subsection{Geschlechterverhältnis (nur zweihäusige Arten)}

\section{Hintergrund}

Das Geschlechterverhältnis bezieht sich auf die Erfassung des individuellen Geschlechts bei zweihäusigen Baumarten. Es ist üblicherweise ausgewogen, wie es das Fisher'sche Gesetz erwartet (Fisher 1930), oder tendenziell leicht männlich verzerrt (Lloyd 1974, Barrett et al. 2010). In Bezug auf die ökologische Genetik der Geschlechterverhältnisse stellten Barret et al. (2010) fest, dass die Geschlechterverhältnisse vor allem aufgrund des zwischen den Geschlechtern ungleichen Ressourceneinsatzes für die Fortpflanzung, wie z.B. ein früherer Beginn der männlichen Blüte, eine häufigere Blüte bei männlichen Individuen und einer höheren Mortalität weiblicher Individuen, männlich verzerrt sind. Dieser Effekt kann sich jedoch mit zunehmendem Alter einer Kohorte und mit zunehmender Fortpflanzungsaktivität der weiblichen Bäume abschwächen. Die Überwachung der Geschlechterverhältnisse in Populationen zweihäusiger Baumarten ist aufgrund der Auswirkungen auf die effektive Populationsgröße wichtig. Populationen mit unausgewogenen Geschlechterverhältnissen haben tendenziell niedrigere effektive Populationsgrößen (Wright 1938). Eine verringerte effektive Populationsgröße kann wiederum zu einer verringerten Wirksamkeit der natürlichen Selektion in einer Population führen, da die effektive Größe des verfügbaren genetischen Potentials abnimmt. Letzteres führt zu einer Erhöhung von genetischer Drift und Inzuchtraten und infolgedessen zum Verlust von genetischer Variabilität (Charlesworth 2009). Veränderungen 
des Geschlechterverhältnisses zwischen Kohorten wie z.B. Altbäumen und Naturverjüngung können daher ein Hinweis auf die genetische Fähigkeit einer Kohorte sein, auf natürliche Selektion zu reagieren, sowie auf deren langfristige Überlebensfähigkeit und Beständigkeit.

\section{Berechnung}

Da die beobachteten Häufigkeiten der Geschlechter mit erwarteten Häufigkeiten verglichen werden - sozusagen mit dem theoretisch erwarteten Geschlechterverhältnis oder den Verhältnissen zu verschiedenen Zeitpunkten kann der Chi-Quadrat-(x2)- oder der G-Test verwendet werden.

Für detailliertere Auswertungen unter Einbeziehung von mehr Daten kann eine loglineare Analyse durchgeführt werden, um mögliche Korrelationen zwischen dem Geschlechterverhältnis einer Population und anderen Merkmalen mit Zeitbezug zu finden.

Liegen auch Daten anderer räumlicher Orte (Plots) vor, kann ein Gauß'sches verallgemeinertes lineares gemischtes Modell (GLMM) verwendet werden, um die zeitliche und räumliche Variation der Geschlechterverhältnisse zu quantifizieren. Dabei wird das Geschlechterverhältnis als eine Funktion des Jahres, der geografischen x- und y-Koordinaten und deren Interaktion modelliert. Ort und Jahr sollten als Zufallseffekte einbezogen werden, um die Unabhängigkeit der Zählungen am gleichen Ort und im gleichen Jahr zu berücksichtigen.

Für die Analyse können Softwareprogramme wie SPSS oder Programmiersprachen wie R oder Python verwendet werden.

\subsection{Durchmesser- und Höhenklassenverteilung}

\section{Hintergrund}

Die Höhe und der Brusthöhendurchmesser (BHD) von Bäumen sind Größenmaße, die repräsentativ für das Baumalter sein können. Darüber hinaus hat die Baumgröße Auswirkungen auf die Blühphänologie, wobei dieser Effekt bei jährlich blühenden Bäumen am stärksten ausgeprägt ist (Otárola et al. 2013). Die Baumgröße kann die Blühphänologie beeinflussen, indem sie die Lichtverfügbarkeit und den Ressourcenzugang modifiziert (Muller-Landau et al. 2006) - und damit zur Fähigkeit von Bäumen beiträgt, zu reproduzieren und ihre Gene an die nächste Generation weiterzugeben. Die Verteilungskurven von Baumdurchmesser und -höhe in einem Monitoringbestand sind Ausdruck des aktuellen und historischen Selektionsdrucks, und deren Auswirkungen auf die Sukzession in der Kronenschicht (Buchholz und Pickering 1978).

\section{Berechnung}

Um einen Einblick in die Variabilität der BHD- und Höhenklassenverteilungen verschiedener Zeiträume zu erhalten, sollten die Daten zunächst graphisch dargestellt werden. Zur Visualisierung kann mit der Methode der kleinsten Quadrat eine nichtlineare Exponentialfunktion an die Verteilungen angepasst werden (n/s-Funktion in R-PaketStatistiken (R Core Team 2020)). Für den quantitativen Vergleich von Verteilungen kann der Anderson-DarlingAnpassungs-Test verwendet werden (alternativ zum Kolmogorov-Smirnov-Test). Hierfür können die Funktionen adKSampleTest oder - für den Vergleich aller Datenpaare -adAllPairsTest im R-Paket PMCMRplus (Pohlert 2020) genutzt werden.

Da die Baumgröße mit verschiedenen Verifikatoren und Umweltparametern korreliert ist, können unter Berücksichtigung dieser Korrelationen weitere Analysen durchgeführt werden. Beispielsweise kann mit einer linearen Regression geprüft werden, ob die Residuen von BHD und Baumhöhe z.B. mit der Temperatur oder dem Niederschlag korreliert sind. Eine solche Analyse kann Aufschluss darüber geben, ob eine Temperaturerhöhung einen negativen Einfluss auf BHD und Baumhöhen hat. 


\subsection{Austrieb}

Hintergrund

Der Blattaustrieb umfasst den Zeitraum vom Ende der Knospenruhe bis zum Abschluss des Längenwachstums der Jungtriebe (Ende der Blattentfaltung). Informationen über den Zeitpunkt und die Dauer des Austriebs liefern wichtige Informationen über den aktuellen Zustand von Bäumen und Waldbaumpopulationen unter sich ändernden Umweltbedingungen. Es ist wichtig, Trends und mögliche Faktoren (natürliche und/oder anthropogene) zu erkennen, die Änderungen der phänologischen Stadien (Beginn, Dauer und Intensität) verursachen (Beuker et al. 2010).

\section{Berechnung}

Die phänologischen Beobachtungen umfassen das Austriebsstadium und den entsprechenden Kronenanteil. Die Beobachtungen werden während der Austriebsperiodewöchentlich an 50 Bäumen durchgeführt. Die Daten werden für die Erstellung von Phänogrammen verwendet, die den Beginn, die Dauer und das Ende der Austriebsstadien auf Einzelbaumebene darstellen. Die Daten werden außerdem mit parametrischen und nichtparametrischen statistischen Methoden analysiert, um die Signifikanz phänologischer Unterschiede zwischen Einzelbäumen innerhalb einer Population oder zwischen Populationen zu beurteilen. Zur Beurteilung der phänologischen Austriebsdaten kann jede Software eingesetzt werden, die parametrische und nichtparametrische statistische Analysen ermöglicht (d.h. SPSS, R).

\subsection{Blühsynchronisation}

\section{Hintergrund}

Die Blühsynchronisation ist ein Teil der Blühphänologie, die sich auf die Entwicklung der männlichen und weiblichen Blüten konzentriert, und diesbezüglich die verschiedenen Phänophasen beschreibt (Ducci et al. 2012). Die Hintergrundinformation „Blühsynchronisation“ wird nur auf Intensivniveau erfasst und basiert auf den für den Verifikator „Blüte“ erhobenen Daten. Diese werden verwendet, um festzustellen, ob die männliche und weibliche Blüte innerhalb eines Monitoringbestands gleichzeitig stattfindet.

\section{Berechnung}

Die phänologischen Beobachtungen umfassen die Entwicklungsphasen (Phänophasen) der männlichen und weiblichen Blüten von den schlafenden Blütenknospen bis hin zu voll entwickelten Blüten/Zapfen/Strobili. Die Daten werden für die Erstellung von Phänogrammen verwendet, die den Beginn, die Dauer, das Ende und die Synchronisation der Blüte und der verschiedenen Phänophasen auf Einzelbaumebene darstellen. Die Daten werden außerdem mit Hilfe parametrischer und nichtparametrischer statistischer Methoden analysiert, um die Signifikanz der phänologischen Unterschiede zwischen Einzelbäumen innerhalb einer Population oder zwischen Populationen zu beurteilen. Dafür kann jede Software eingesetzt werden, die parametrische und nichtparametrische statistische Analysen ermöglicht (d.h. SPSS, R).

Die Blühsynchronisation wird unter Verwendung des phänologischen Überlappungsindex $\left(P O_{i j}\right)$ nach Askew und Blush (1990) bewertet:

$$
\begin{gathered}
P O_{o}=\sum_{j=1}^{t} \sum_{k=1}^{t} \frac{P O_{j k}}{(t(t-1))} \\
P O_{j k}=\frac{\sum_{i=1}^{n}\left(s_{i j k}-\Delta_{i j k}\right)}{\sum_{i=1}^{n} s_{i j k}}
\end{gathered}
$$

Gesamtindex der phänologischen Überlappung für alle auskreuzenden Paarungskombinationen zwischen allen

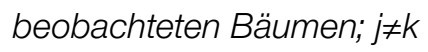

Index der phänologischen Überlappung des Baumes $j$ und des Baumes $k$ über $n$ Beobachtungen $i ; j \neq k$ 


$$
\Delta_{i j k}=\left|m_{i k}-p_{i j}\right|
$$

Der absolute Wert der Differenz zwischen $m_{i k}$ und $p_{i j} ; j \neq k$

$p_{i j}=$ Anteil der beobachteten männlichen Blüten des Individuums $j$, die am Tag $i$ Pollen abgeben; $m_{i k}=$ Anteil der beobachteten weiblichen Blüten des Individuums $k$, die am Tag $i$ empfänglich sind;

$s_{i j k}=$ der größere Wert von $p_{i j}$ und $m_{j k}$;

\subsection{Seneszenz}

\section{Hintergrund}

Die Blattseneszenz ist die Gesamtheit degenerativer Ereignisse, welche die Stoffwechselaktivitäten verringern und den Tod von Zellen, Geweben und Blattorganen verursachen (Lim et al. 2007). Daten zum Zeitpunkt und der Dauer der Blattseneszenz liefern wichtige Informationen zum Verständnis des tatsächlichen Zustands der Bäume und Waldbaumpopulationen in einer sich verändernden Umwelt.

\section{Berechnung}

Die phänologischen Beobachtungen umfassen eine Code zur Beurteilung der Blattseneszenz, das Seneszenzstadium und den entsprechenden Kronenanteil. Die Daten werden für dieErstellung von Phänogrammen verwendet, die den Beginn, die Dauer und das Ende der Seneszenz auf Einzelbaumebene darstellen. Die Daten werden außerdem mit Hilfe von parametrischen und nichtparametrischen statistischen Methoden analysiert, um die Signifikanz der phänologischen Unterschiede zwischen Einzelbäumen innerhalb einer Population oder zwischen Populationen zu beurteilen. Zur Auswertung von Seneszenzdaten kann jede Software eingesetzt werden, die parametrische und nichtparametrische statistische Analysen ermöglicht (d.h. SPSS, R).

\subsubsection{Auswertung molekularer Daten}

\subsubsection{Plausibilitätsprüfung molekularer Daten}

Um ausreichende statistische Aussagekraft für nachfolgende Analysen zu erhalten, genotypisieren Wissenschaftlerlnnen Proben üblicherweise anhand einer Auswahl hypervariabler Mikrosatelliten-Loci. Es wird jedoch angenommen, dass diese Loci höhere Fehlerraten aufweisen (Flores-Rentería und Krohn 2013), was wiederum zu einer geringeren Aussagekraft und systematisch verfälschten Schlussfolgerungen führen kann (Dąbrowski et al. 2015).

Eines der häufigsten Probleme bei der Mikrosatelliten-Genotypisierung ist das Vorhandensein von Stotterbanden. Diese entstehen beim Verrutschen der DNA-Polymerase (sog. slippage) und können hohe Fehlerraten verursachen, insbesondere im Fall von Heterozygoten mit benachbarten Allelen (Clarke et al. 2001). In der Planungsphase eines Projekts sollten Trinucleotid-Wiederholungsmarker gegenüber DinucleotidMikrosatelliten bevorzugt werden, da sie im Allgemeinen eine geringere Häufigkeit dieses Phänomens aufweisen (Flores-Rentería und Krohn 2013). Darüber hinaus wurden Primer vorgeschlagen, die einen Teil der Mikrosatellitenregion einschließen, um einem Verrutschen vorzubeugen (Flores-Rentería und Whipple 2011). Eine Reduzierung des Stotterns kann auch durch die Optimierung der PCR-Reaktionsbedingungen und -programme erreicht werden (Einzelheiten siehe 6.4.2.2.2 d). Letztlich können auch nach der Optimierung im Labor noch Stotterbanden vorhanden sein, die ein erneutes Screening problematischer Proben erfordern (Dewoody et al. 2006). Die Software Micro-Checker (Van Oosterhout et al. 2004) kann eingesetzt werden, um Loci aufzuspüren, die möglicherweise aufgrund von Stottern falsch bewertet wurden, indem Defizite von Heterozygoten mit benachbarten Allelen identifiziert werden.

Allelausfälle oder die Dominanz kurzer Allele beschreiben das stochastische Versagen des größten Allels in einer heterozygoten Probe bei der PCR-Amplifikation. Dies wird verursacht durch: (i) eine geringe Qualität und Quantität der Template-DNA (Taberlet et al. 1996) und (ii) die kompetitive Wesensart der PCR (d.h. kürzere Allele werden effektiver amplifiziert als längere Allele) (Gagneux et al. 1997). Da dieses Problem nicht systematisch 
auftritt, erhöhen ein DNA-Reinigungsschritt und/oder eine zweite PCR-Amplifikation die Chancen, ausgefallene Allele nachzuweisen (Flores-Rentería und Krohn 2013). Ein Zeichen für einen Allelausfall an einem Locus ist das Vorhandensein einer großen Menge von Homozygoten an den Extremen des Allelbereichs, die mit der Software Micro-Checker identifiziert werden können (Van Oosterhout et al. 2004).

Werden Allele aufgrund von Mutationen in den Primerbindungsregionen systematisch nicht amplifiziert, werden sie als Nullallele bezeichnet (Oddou-Muratorio et al. 2009). Abgesehen von den üblichen mit Genotypisierungsfehlern verbundenen Problemen, wie z.B. systematische Fehler in Statistiken zur genetischen Diversität/Differenzierung, ist eine wichtige Konsequenz von Nullallelen der Ausschluss korrekter Eltern in Abstammungsanalysen (Dakin und Avise 2004). Es stehen mehrere Softwareprogramme zur Verfügung, so dass Wissenschaftlerlnnen das Auftreten und die Häufigkeit von Nullallelen berechnen können, z.B. genepop (Rousset 2008), ML-NullFreq (Kalinowski und Taper 2006), Micro-Checker (Van Oosterhout et al. 2004) und Cervus (Summers und Amos 1997). Existierende Diskrepanzen zwischen den Softwarepaketen im Hinblick auf die geschätzte Anzahl und/oder Häufigkeit von Nullallelen erschweren jedoch eindeutige Schlussfolgerungen. Aus diesem Grund wird vorgeschlagen, mehrere Methoden anzuwenden und deren Medianwerte zu verwenden (Dąbrowski et al. 2015). Nunziata et al. (2015) schlossen Loci mit Nullallelen aus, wenn die $F_{\text {st }}$-Werte zwischen verschiedenen Stichprobenpunkten niedriger waren als bei Einbeziehung von Loci mit Nullallelen.

Stochastische Genotypisierungsfehler können auch durch menschliche Fehleinschätzungen während des Scoring-Prozesses entstehen. Eine Liste privater Allele, wie sie von GenAlEx (Peakall und Smouse 2006) oder poppr (Kamvar et al. 2014) bereitgestellt wird, liefert Anhaltspunkte für Allele, die genauer untersucht werden sollten. Besondere Aufmerksamkeit sollte Allelen gewidmet werden, die das Marker-Repeat-Motiv nicht einhalten. Dies allein ist jedoch nicht notwendigerweise ein Grund für die Entfernung dieser Allele, da eine Markierung außerhalb des Repeat-Motivs eine bewusste Wahl zur genaueren Erfassung der Diversität sein kann, insbesondere im Fall zusammengesetzter Mikrosatelliten (z.B. (GT)6(ACA)9) (Flores-Rentería und Krohn 2013). Vorsicht ist auch beim Nachweis von Allelen geboten, die bislang noch nicht in der Literatur beschrieben wurden und/oder außerhalb des angegebenen Bereichs liegen. Wenn ein solches Allel mehrfach im Datensatz vorkommt, gibt es keinen Grund, seine Existenz anzuzweifeln. Wird dieses Allel dagegen nur in einer einzigen Probe gefunden, ist eine Wiederholung der PCR-Reaktion empfehlenswert (Flores-Rentería und Krohn 2013).

Eine Hauptkomponentenanalyse (Principal Components Analysis; PCA) kann sich ebenfalls als nützlich erweisen, um Scoring-Fehler aufzudecken. Proben, die scheinbar weit von ihrer jeweiligen Grundgesamtheit entfernt liegen, sollten manuell überprüft werden. Darüber hinaus ist es mit einer Hauptkomponentenanalyse möglich, etwaige Artefakt-Allele zu identifizieren, die sich bei der Probendifferenzierung als sehr einflussreich erweisen. Dies kann leicht überprüft werden, indem man die Ladungen der Allele, die eine Hauptkomponente im R-Paket adegenet (Jombart 2008) bilden, mit der Funktion loadingplot grafisch darstellt.

Liegt in einem Multiplex-PCR-Szenario die Konzentration der PCR-Produkte um ein Vielfaches über dem empfohlenen Bereich, so kann es zu einer spektralen Überlappung der Farbstoffe kommen (Flores-Rentería und Krohn 2013). In diesem Fall würde das Elektropherogramm Artefakt-Peaks enthalten, die von echten Allelen eines anderen Kanals stammen; ein Phänomen, das in der Literatur als „Bleedthrough“ oder „Pull-up“ bekannt ist. Eine Bewertung dieser Artefakt-Peaks als reale Allele würde zu einer Doppelerfassung desselben Allels sowie einer scheinbaren Verbindung zwischen zwei Allelen verschiedener Loci führen. Dies wiederum erzeugt möglicherweise ein Signal, das als falsches Kopplungsungleichgewicht (LD) zwischen den Loci erkennbar ist. Daher sollte ein signifikantes Kopplungsungleichgewicht zwischen Markern mit überlappenden PCR-Produkten genauer untersucht werden.

Grundsätzlich sollten Wissenschaftlerlnnen versuchen, in der Planungsphase eines Projekts so viele Informationen wie möglich über die Reproduzierbarkeit von Markern zwischen Laboren und dem Auftreten unerwünschter Wechselwirkungen zwischen Loci (d.h. echte Kopplungsungleichgewichte) aus der veröffentlichten Literatur zu entnehmen. Darüber hinaus wird empfohlen, eine repräsentative Stichprobe des Datensatzes (z.B. 10\%) zum 
Zweck der Qualitätskontrolle erneut zu analysieren (Dewoody et al. 2006). Nach dem Datenvergleich muss die Fehlerquote für jeden Locus sowie über alle Loci hinweg wie folgt ausgewiesen werden:

- Fehlerrate pro Reaktion: Anteil der PCR-Reaktionen, die mindestens ein falsches Allel liefern, an der Gesamtzahl der Reaktionen, sowie

- Fehlerquote pro Allel: Anteil der fehlerhaften Allele an der Gesamtzahl der Allele (Hoffman und Amos 2005).

\subsubsection{Filterung molekularer Daten}

Die Datenfilterung ist ein wichtiger Schritt zur Ableitung robuster Ergebnisse aus den Rohdaten. Filter sind insbesondere essentiell um die Auswirkungen fehlender Werte abzumildern und die Effekte verschiedener evolutionärer Prozesse zu entflechten.

Bei der Datenfilterung besteht der erste Schritt in der Eliminierung von Loci mit großen Mengen fehlender Werte (der Grenzwert ist vor Beginn der Analyse zu definieren). Im zweiten Schritt werden einzelne Proben, die einen vorab definierten Anteil fehlender Werte überschreiten, ebenfalls aus allen weiteren Analysen entfernt.

Die Festlegung eines globalen Grenzwertes für fehlende Werte für Loci (z.B. 10\%) basiert auf der Erwartung, dass die fehlenden Werte relativ gleichmäßig über alle Kohorten und Stichproben verteilt sind. Diese Annahme ist jedoch v.a. dann nicht gesichert, wenn geografisch isolierte Proben oder Proben aus verschiedenen phylogenetischen Linien gemeinsam analysiert werden (z.B. Abies alba und A. borisii-regis). In diesen Fällen besteht eine hohe Wahrscheinlichkeit, dass es aufgrund des hohen genetischen Abstands zwischen den zur Identifikation des Locus verwendeten Individuen einerseits und den genotypisierten Proben andererseits zu systematischen Fehlern kommt. Es ist bekannt, dass SNP-Arrays besonders anfällig für diese Art von systematischen Fehlern sind (Albrechtsen et al. 2010). Beispielsweise hatten die griechischen Populationen von A. borisii-regis und Fagus sylvatica im LIFEGENMON-Datensatz laut den SNP-Daten eine niedrigere genetische Diversität als ihre mitteleuropäischen Pendants, wiesen jedoch im SSR-Datensatz ähnliche Werte auf. Diese Diskrepanzen könnten das Ergebnis systematischer Fehler sein, so dass bei derartigen Versuchsdesigns die Durchführung der Filterung auf Ebene der Kohorten vorteilhaft sein kann.

Als dritter Schritt kann zusätzlich ein Filter auf Basis der Frequenz des selteneren Allels (Minor Allele Frequency, MAF) eingesetzt werden. Das Grundprinzip dieses Filters ist die Eliminierung nicht-informativer Marker und potenzieller Genotypisierungsfehler, welche Schlussfolgerungen erschweren (Roesti et al. 2012). Für SSRs wird üblicherweise ein MAF-Filter von $5 \%$ oder $1 \%$ verwendet, da diese Marker relativ wenige Informationen liefern. Es kann jedoch nützlich sein, die Allelhäufigkeit dieser Loci im zeitlichen Verlauf zu überwachen. Dies gilt insbesondere, wenn diese mit exprimierten Sequenzen (EST-SSRs) verknüpft sind, da solche Loci potenziell einen Einblick in die adaptive genetische Vielfalt geben können. Die im Vergleich zur Genotypisierung mit neuen (next generation) Sequenziertechnologien geringe technische Fehlerquote der SNP-Genotypisierung mittels KASP (Semagn et al. 2014) bedeutet, dass es bei diesem Verfahren wahrscheinlich zu offensiv ist, Loci mit niederfrequenten Polymorphismen aus allen nachfolgenden Analysen auszuschließen. Dies gilt insbesondere für kleinere Datensätze, wo es zum Verlust privater Allele kommen und das Signal des Genflusses geschwächt werden kann. Daher wird vorgeschlagen, nur Marker zu entfernen, bei denen niederfrequente Allele bis zu zweimal im Datensatz vorkommt (Pluess et al. 2016) oder einen MAF-Filter zu verwenden, der gemäß dem Handbuch der jeweiligen Software speziell auf Analysen angewendet wird, die diesen Schritt explizit erfordern (z.B. Schätzung der effektiven Populationsgröße, $F_{\text {ST }}$-Ausreißertests, usw.).

Das Kopplungsungleichgewicht (LD) stellt eine zusätzliche Überlegung bei der Analyse von molekularen MarkerDatensätzen dar. Das Vorhandensein von LD zwischen Loci-Paaren könnte auf die physische Nähe dieser Loci im Genom hindeuten; es könnte aber die Folge einer Drift zwischen ungebundenen Loci sein. Werden verknüpfte Marker nicht verworfen, führt dies zu fehlerhaften Schätzungen von Variablen, die von diesem Signal abhängen, wie z.B. bei der Schätzung der effektiven Populationsgröße $\left(N_{e}\right)$ mittels der LD-Methode (Hill 1981). Für die LDBerechnung stehen mehrere Softwarepakete zur Verfügung, wie z.B. Arlequin (Excoffier und Lischer 2010) und 
das R-Paket poppr (Kamvar et al. 2014). Da es sich um ein Verfahren handelt, bei dem mehrere Hypothesen getestet werden, ist die Wahrscheinlichkeit für die fälschliche Identifikation von LD zwischen einem Loci-Paar recht hoch. Daher sollten unbedingt mehrere Testkorrekturen durchgeführt werden. Bei SSR-Daten wird dies in der Regel durch die Anwendung der sequentiellen Bonferroni-Korrektur erreicht (Rice 1989). Bei SNPDatensätzen ist diese Korrektur möglicherweise zu konservativ, so dass stattdessen die Falscherkennungsrate (false discovery rate; FDR) (Benjamini und Hochberg 1995) angewendet wird. Für diese Berechnungen steht das R-Paket multcomp (Hothorn et al. 2008) zur Verfügung.

Die Berechnung zusammenfassender Statistiken für einen Datensatz, der potenziell einer Selektion ausgesetzte Loci enthält, könnte das Signal demografischer Prozesse verschleiern. Aus diesem Grund ist es ratsam, bei demografischen Analysen alle Loci zu entfernen, bei denen es deutliche Hinweise auf adaptive Polymorphismen gibt. Diese Loci weisen $F_{S T}$-Ausreißerwerte auf und werden meist durch eine oder vorzugsweise mehrere Methoden zur Ermittlung von $F_{S T}$-Ausreißern erkannt (für Details siehe Kap. 6.5.4.3.2.3 „F-basierter Ausreißertest").

Auch das Vorhandensein eines höheren Anteils von Nullallelen in einem Datensatz kann sich auf die Berechnung zusammenfassender Statistiken auswirken. Das Vorliegen von Nullallelen kann mit verschiedenen Softwareprogrammen überprüft werden (z.B. Micro-Checker (Van Oosterhout et al. 2004), CERVUS (Kalinowski et al. 2007), R-Paket PopGeneReport (Adamack und Gruber 2014)). Sind sehr viele Nullallele vorhanden, ist die Eliminierung der entsprechenden Loci aus der weiteren Analyse empfehlenswert (Chapuis et al. 2008, Belletti et al. 2012).

\subsection{Filterung von SNP-Daten}

Für die LIFEGENMON-Datensätze folgte die Behandlung fehlender Daten ähnlichen in der Literatur beschriebenen Arbeiten (Csilléry et al. 2020; Heer et al. 2018).

\subsubsection{Datenauswertung}

\subsection{Verifikatoren}

\subsection{Allelhäufigkeiten}

\section{Hintergrund}

Loci und Allele sind die grundlegenden, in der Populationsgenetik gemessenen Einheiten. Ein Locus ist eine spezifische genetische Einheit, die untersucht wird, wie z.B. ein gesamtes Gen, ein einzelnes Nukleotid-Basenpaar (A-T und C-G) oder eine Kette von Nukleotiden. Von jedem genetischen Locus kann es mehrere Varianten geben, die als Allele bezeichnet werden. Einzelnukleotid-Polymorphismen (SNPs) sind Substitutionen eines einzelnen Nukleotids an einer bestimmten Position im Genom. In einem diploiden Organismus kann ein SNP-Locus daher entweder zwei Kopien desselben Allels enthalten (d.h. ein monomorpher Locus) oder zwei verschiedene Allele (d.h. ein polymorpher Locus). Einfache Sequenzwiederholungen (SSRs, auch Mikrosatelliten genannt) sind Sätze von sich wiederholenden DNA-Sequenzen an einem Locus auf einem Chromosom. Sie können daher mehrere Substitutionen und mehr als zwei Allele enthalten.

Die Variabilität von Allelen über Loci hinweg grenzt Individuen und Populationen genetisch voneinander ab und ist die Grundlage aller nachfolgenden Methoden der Populationsgenetik. Die Allelhäufigkeit entspricht der relativen Häufigkeit der Chromosomen, die ein bestimmtes Allel tragen, bei allen Individuen innerhalb einer Population. Sie wird aus der Häufigkeit der beobachteten Genotypen innerhalb einer Population berechnet.

\section{Berechnung}

Betrachtet man einen SNP innerhalb einer diploiden Population mit den Allelen B und b, so werden die Genotyphäufigkeiten als BB (homozygot B), bb (homozygot b) und Bb (heterozygot) dargestellt. Die Allelhäufigkeit wird wie folgt berechnet: 


$$
\begin{gathered}
p=f(B B)+\frac{1}{2} f(B b) \\
q=f(b b)+\frac{1}{2} f(B b) \\
p+q=1
\end{gathered}
$$

wobei:

$f(B B) / f(B b) / f(b b)=$ Genotyphäufigkeiten; $p=$ Häufigkeit des Allels B; $q$ = Häufigkeit des Allels b

\subsection{Allelische Vielfalt}

\section{Hintergrund}

Die Anzahl der Allele $(A)$ und der Allelreichtum $\left(A_{r}\right)$ sind repräsentativ für das Ausmaß der Variabilität innerhalb einer Population. Dies ist v.a. im Zusammenhang mit der langfristigen Erhaltung wichtig, da davon ausgegangen wird, dass Populationen mit einer höheren genetischen Diversität besser in der Lage sind, auf Selektionsdruck zu reagieren und die Gesundheit ihrer Individuen zu erhalten (Petit et al. 2008). $A_{r}$ kann auch ein nützlicher Indikator für zurückliegende Populationsflaschenhälse oder -rückgänge sein (Nei et al. 1975).

Das in einer untersuchten Population identifizierte $A$ ist abhängig von der Stichprobengröße, da mit zunehmender Stichprobengröße die Chance für die Identifikation neuer Allele zunimmt. $A_{r}$ wird daher als Spezialfall von $A$ verwendet, korrigiert um Stichprobengrößenunterschiede zwischen den Populationen unter Anwendung von Verdünnung (rarefaction) (Kalinowski 2004).

Die effektive Anzahl von Allelen ( $A e$ ) repräsentiert die tatsächliche genetische Vielfalt, die bei zahlreichen Individuen innerhalb einer Population vorhanden ist. Ae ist die Anzahl der Allele, die an jedem Locus in einer Population gemäß dem Hardy-Weinberg (H-W)-Gleichgewicht zu erwarten wäre. Sie steht daher in engem Zusammenhang mit der erwarteten Heterozygotie einer Population (He). Dies wird auch als "Nei's Genetische Diversität, D“ / ,Genvielfalt, v' bezeichnet; wiederum ein Spezialfall von $A_{r}$, wie von Kalinowski (2004) definiert. Wie $\mathrm{Ae}$ ist $\mathrm{He}$ der gemäß $H$-W-Gleichgewicht erwartete Anteil der Heterozygoten, und kann somit auf der Grundlage dieser Prinzipien berechnet werden. Sind die Allelhäufigkeiten ungleich, ist $A e$ oft weit niedriger als $A$. Allele mit geringen Häufigkeiten tragen wenig zu Ae bei. Dies ist oft auf mehrere Merkmale der Population zurückzuführen, wie z.B. schwankende Populationsgrößen über die Generationen hinweg, überlappende Generationen, nicht-zufällige Paarungen (sexuelle Selektion, usw.), die Anzahl der Nachkommen, die von Individuen produziert werden, die mehr Variabilität aufweisen als gemäß Zufall erwartet, sowie unausgewogene Geschlechterverhältnisse.

\section{Berechnung}

\section{Anzahl von Allelen $(A)$}

$$
\begin{array}{cc}
A=\left(\frac{1}{I}\right) A_{i}=\frac{\sum_{i=1}^{I} A_{i}}{I} & \text { Anzahl von Allelen }(\mathrm{A}) \\
A p=\sum_{i=1}^{I} A p_{i} & \text { Anzahl privater Allele }\left(A_{p}\right)
\end{array}
$$

wobei

$A=$ mittlere Anzahl der Allele pro Locus; $A_{i}=$ Anzahl der Allele an einem bestimmten Locus; $A_{p}=$ Anzahl privater Allele in einer Population; $A_{p i}=$ Anzahl privater Allele, die an einem bestimmten Locus innerhalb einer Population identifiziert wurden; I = Gesamtzahl der betrachteten Loci; $i$ = spezifischer Locus. 


\section{Allelreichtum $\left(A_{r}\right.$ und $\left.p A_{r}\right)$}

$$
\begin{gathered}
N_{j}=\sum N_{g j} \\
Q_{g j G}=\frac{\left(\begin{array}{c}
\left.N_{j}-N_{g j}\right) \\
G
\end{array}\right)}{\left(\begin{array}{c}
N_{j} \\
G
\end{array}\right)} \\
P_{g j G}=1-Q_{g j G} \\
A_{r i}=\sum_{g=1}^{G} P_{g j G} \\
A_{r}=\frac{\sum_{i=1}^{I} A_{r i}}{I} \\
p A_{r i}=\sum_{g=1}^{G}\left[P_{g j G\left(\prod_{j^{\prime}=1, j^{\prime} \neq j}^{J} Q_{g j^{\prime} G}\right)}\right] \\
p A_{r}=\frac{\sum_{i=1}^{I} p A_{r i}}{I}
\end{gathered}
$$

Stichprobengröße der Population j am Locus i

Wahrscheinlichkeit, in der Stichprobe G der Population $j$ keine Allele vom Typ g zu finden

Wahrscheinlichkeit, in der Stichprobe G der Population j mindestens ein Allel vom Typ $g$ zu finden

Geschätzter Allelreichtum des Locus i in der Stichprobe G der Population $j$

Mittlerer Allelreichtum über alle Loci

Geschätzte Vielfalt privater Allele am Locus i in der Stichprobe G der Population j

Mittlere Vielfalt privater Allele über alle Loci

wobei

$N_{j}=$ Stichprobengröße der Population j an einem gegebenen Locus i; $N_{g j}=$ Anzahl der Kopien eines Allels $g$ am Locus i in einem einzelnen Individuum (Stichprobe) aus der Population j; $g=$ spezifisches Allel innerhalb des Locus i; $G$ = Unterstichprobe der betrachteten Allele am Locus i in der Population j; I = Gesamtzahl der betrachteten Loci; $i=$ spezifischer Locus; $Q_{g j G}=$ Wahrscheinlichkeit, keine Allele vom Typ $g$ in der Stichprobe $G$ der Population j zu finden; $P_{g j G}=$ Wahrscheinlichkeit, mindestens ein Allel vom Typ $g$ in der Stichproben $\mathrm{G}$ der Population j zu finden; $A_{r i}=$ geschätzte Allelhäufigkeit am Locus i in der Stichprobe G der Population j; $A_{r}=$ mittlere Allelhäufigkeit über alle Loci der Population j; $p A_{r i}=$ geschätzte Vielfalt privater Allele am Locus i in der Stichprobe $G$ der Population j; $p A_{r}=$ mittlere Vielfalt privater Allele über alle Loci der Population j.

\section{Effektive Anzahl von Allelen (Ae)}

Die effektive Anzahl von Allelen Ae über alle Loci in einer Population wird als arithmetisches Mittel berechnet, da dieses besonders empfindlich auf die kleinsten Werte eines Datensatzes reagiert und daher kleinere Vorgängerpopulationen stärker widerspiegelt als das arithmetische Mittel. Damit ist der harmonische Mittelwert besser geeignet, um die langfristigen Auswirkungen von Flaschenhälsen (wenn eine Population für einen bestimmten Zeitraum erheblich reduziert wird) und Gründungseffekten (ein kleiner Teil einer größeren Population wird geografisch isoliert) auf die genetische Variation durch Drift zu beurteilen.

$$
H o=\frac{\sum f(B b)}{I}
$$

Beobachtete Heterozygosität (Ho)

Für Loci mit 2 Allelen

$$
H e_{i}=1-p^{2}-q^{2}=2 p q
$$

Erwartete Heterozygosität pro Locus (Hej)

Für Loci mit 2 oder mehr Allelen

$$
H e_{i}=1-\sum p_{i}^{2}
$$




$$
\begin{array}{cc}
H e=\frac{\sum_{i}^{I} H e_{i}}{I} & \text { Erwartete Heterozygosität }(H e) \\
A e_{i}=\frac{1}{\left(1 / H e_{i}\right)}=\frac{1}{\sum p_{i}^{2}} & \text { Effektive Anzahl von Allelen pro Locus (Ae) }
\end{array}
$$

Wobei

$H o=$ Mittlere beobachtete Heterozygotie; $\mathrm{He}_{i}=$ Erwartete Heterozygotie für einen spezifischen Locus; $\mathrm{He}=$ Mittlere erwartete Heterozygotie; $A e_{i}=$ effektive Anzahl von Allelen an einem spezifischen Locus; $A e=$ harmonischer Mittelwert der effektiven Anzahl von Allelen über alle Loci in einer Population; I = Die Gesamtzahl der betrachteten Loci; $i$ = spezifischer Locus.

\subsection{Effektive Populationsgröße (Ne)}

\section{Hintergrund}

Die effektive Populationsgröße (Ne) ist ein Ansatz zur Quantifizierung des Ausmaßes der genetischen Drift, die in einer Population zu einem bestimmten Zeitpunkt auftritt. Es handelt sich dabei um die Größe einer idealisierten Population (unter H-W-Gleichgewicht), die von einer Generation zur nächsten die Heterozygotie mit der gleichen Geschwindigkeit verlieren würde wie die beobachtete Population. Populationen erleben oft dramatische Größenschwankungen von einer Generation zur nächsten (z.B. Flaschenhalseffekt). Dies führt zu Raten der genetischen Drift, die höher sind, als man aufgrund der gemessenen Populationsgröße erwarten kann. Darüber hinaus wird Ne beeinflusst durch sich überlappende Generationen, die räumliche Verteilung der Individuen sowie durch eine sehr variable Anzahl von Nachkommen pro „Familie“ (was zu einer Nicht-Poisson-Verteilung führt) und durch variable Anteile von männlichen und weiblichen Individuen.

\section{Berechnung}

Eine relativ einfache Möglichkeit zur Ermittlung von Ne besteht in der Berechnung des harmonischen Mittels der gemessenen Populationsgröße über die Anzahl der betrachteten Generationen. Dieser Ansatz wird verwendet, da er besonders empfindlich auf die kleinsten Werte eines Datensatzes reagiert und daher kleinere Vorgängerpopulationen stärker widerspiegelt als das arithmetische Mittel. Diese Berechnung berücksichtigt nur schwankende Populationsgrößen, gibt einen jedoch leicht aus demografischen Daten zu berechnenden Hinweis auf Ne zur Verwendung im langfristigen genetischen Monitoring.

$$
N e=\frac{1}{\frac{1}{T} \sum_{t=1}^{T} \frac{1}{N_{t}}}
$$

Effektive Populationsgröße (Ne)

ODER

$$
N e=\frac{1}{\left(\sum_{t=1}^{T} \frac{1}{N_{t}}\right) / T}
$$

Effektive Populationsgröße (Ne)

wobei

$\mathrm{Ne}=$ Effektive Populationsgröße; $T$ = Gesamtanzahl der betrachteten Generationen; $t$ = spezifische Generation; $N_{t}=$ gemessene Populationsgröße in der Generation $t$. 


\subsection{Latentes genetisches Potential (LGP)}

\section{Hintergrund}

Das latente genetische Potential (LGP) wurde erstmals von Bergmann et al. (1990) definiert, um zwischen dem physiologischen und dem evolutionären Anpassungspotential einer Population zu unterscheiden. Sie beschreiben das „wirksame genetische Potential“ als den Teil der genetischen Zusammensetzung, der das Überleben der Population unter den gegenwärtig realisierten Bedingungen garantiert und der effektiven Anzahl von Allelen (Ae / v) entspricht. Der restliche Teil der genetischen Information ist in diesem Zusammenhang gegenwärtig „latent“ und hängt mit seltenen Allelen in der Population zusammen, die eine bedeutende Rolle für die zukünftige Anpassung unter drastisch veränderten Umweltbedingungen spielen können, was insbesondere für Erhaltungsmaßnahmen von großer Bedeutung sein kann (Aravanopoulos 2016). Das LGP beschreibt daher die Anpassungsfähigkeit einer Population, da es die Differenz zwischen der beobachteten und der erwarteten Anzahl von Allelen in einer Population über alle (beobachteten) Loci hinweg widerspiegelt.

Das LGP wurde verwendet, um sowohl auf die Anpassungsfähigkeit von Populationen an veränderte Bedingungen als auch auf die negativen Auswirkungen von Stressoren zu schließen. So beispielsweise verringern die Reduktion von Populationen durch Durchforstungsmaßnahmen und Habitatfragmentierung sowohl das LGP als auch die hypothetische gametische Multilocus-Diversität $\left(v_{\text {gam }}\right)$ der Population (Rajora et al. 2000, O‘Connell et al. 2006). Es wurde jedoch auch gezeigt, dass das LGP gegenüber anderen Stressoren wie z.B. Waldbränden resistent ist (Rajora und Pluhar 2003).

\section{Berechnung}

$$
\begin{gathered}
H e_{i}=1-\sum p_{i}^{2} \\
A e_{i}=\frac{1}{\left(1 / H e_{i}\right)}=\frac{1}{\sum p_{i}^{2}} \\
L G P=\sum_{i}^{I} A_{i}-A e_{i}
\end{gathered}
$$

Erwartete Heterozygosität (He)

Effektive Anzahl von Allelen (Ae)

Latentes genetisches Potential (LGP)

wobei

$H e_{i}=$ Erwartete Heterozygosität an einem spezifischen Locus; $A e_{i}=$ Effektive Anzahl von Allelen an einem spezifischen Locus; $A_{i}=$ Beobachtete Anzahl von Allelen an einem spezifischen Locus; $L P G$ = Latentes genetisches Potential einer Population; $p_{i}=$ Häufigkeit eines Allels an einem spezifischen Locus; I = Gesamtanzahl der Loci in einer Population; $i$ = spezifisches Allel.

\subsection{Inzuchtkoeffizient (FIS)}

\section{Hintergrund}

Der Inzuchtkoeffizient ist eine vom lokalen F abgeleitete F-Statistik. Sie ist ein Maß für den Mangel an Heterozygotie in einer Population, d.h. das Ausmaß der in der Population beobachteten Heterozygotie im Vergleich zu dem nach den Hardy-Weinberg-Prinzipien erwarteten Ausmaß. $F$ kann berechnet und zerlegt werden, um die durch unterschiedliche Antriebskräfte auf verschiedenen Ebenen der Populationsstruktur entstandene Heterozygotie zu berücksichtigen. Die beiden am häufigsten verwendeten Statistiken sind der Inzuchtkoeffizient $\left(F_{I S}\right)$ und der Fixierungsindex $\left(F_{S T}\right)$. Ersterer stellt den bei einer Teilpopulation beobachteten Heterozygotiemangel dar, der auf Inzucht hinweist; letzterer den Heterozygotiemangel eines Individuums innerhalb der Gesamtpopulation, der analog auf den Wahlund-Effekt hinweist. Insbesondere $F_{\text {IS }}$ kann als Korrelation von sich vereinigenden Gameten relativ zu einer zufällig aus einer Teilpopulation gezogenen Stichprobe von Gameten betrachtet werden. 


\section{Berechnung}

Um F-Statistiken zu berechnen, müssen zunächst die beobachtete und erwartete Heterozygotie einer Population bestimmt werden. Sie wird als Mittelwert über alle Loci innerhalb einer Population dargestellt.

$$
\begin{array}{cc}
H o_{i}=f(B b) & \text { Beobachtete Heterozygosität (Ho) } \\
H e_{i}=1-\sum p_{i}^{2} & \text { Erwartete Heterozygosität (He) } \\
F=\sum_{i=1}^{I} \frac{H o_{i}}{H e_{i}} / I & \text { Lokales } F \\
F_{I S}=\sum_{i=1}^{I} \frac{H e_{i}-H o_{i}}{H e_{i}} / I & \text { Inzuchtkoeffizient }\left(F_{/ S}\right)
\end{array}
$$

wobei

$\mathrm{Ho}_{i}=$ Beobachtete Heterozygosität an einem spezifischen Locus; $\mathrm{He}_{i}=$ Erwartete Heterozygosität an einem spezifischen Locus; $F=$ Lokales $F$ einer Population; $F_{I S}=$ Inzuchtkoeffizient einer Population; I = Gesamtanzahl der betrachteten Loci; $i=$ spezifischer Locus; $p_{i}=$ Häufigkeit eines Allels an einem spezifischen Locus.

\subsection{Kopplungsungleichgewicht (LD)}

\section{Hintergrund}

Das Kopplungsungleichgewicht (LD) ist die nicht-zufällige Assoziation von Allelen an verschiedenen Loci in jeder Population (Weir 1979). Bei einem Kopplungsgleichgewicht (LE) würden Allele zufällig assoziiert werden. Das LD kann sowohl global und für alle Loci innerhalb einer Population als auch paarweise für jeden Locus berechnet werden. Das LD zwischen Loci kann durch mehrere populationsgenetische Prozesse beeinflusst werden, darunter Selektion, Genfluss, genetische Drift und Mutation, sowie durch demografische Eigenschaften wie Populationsstruktur, asexuelle Reproduktion, Flaschenhalseffekte und Inzucht. Während sich unter völlig neutralen Bedingungen Loci nach LE entwickeln würden, ermöglichen diese Prozesse das Fortbestehen von LD in einer Population (ausführlich in einem Bericht von Slatkin (2008)). Das globale paarweise LD zwischen Loci kann vor der Erstellung anderer genetischer Statistiken zur Filterung von Markern verwendet werden.

\section{Berechnung}

Werden mehrere Loci betrachtet, kann diese Kenngröße in einem einzigen Wert, dem Assoziationsindex $\left(I_{A}\right)$, zusammengefasst werden. Aufgrund der Art und Weise der Bestimmung von $V_{o}$ und $V_{e}$ reagiert der $I_{A}$ sensitiv bezüglich der betrachteten Anzahl von Loci und nimmt mit zunehmender Anzahl von Loci ebenfalls zu. Angesichts dessen haben Agapow und Burt (2001) die Methode verbessert, um eine nicht-verzerrte Assoziationsstatistik (d.h. ohne systematische Fehler) zu erhalten $(d)$.

$$
\begin{gathered}
V_{o}=\sum \operatorname{var}_{i^{1}}+2 \sum \sum \operatorname{cov}_{i^{1}, i^{2}} \\
V_{e}=\sum \operatorname{var}_{i} \\
I_{A}=\frac{V_{o}}{V_{e}}-1
\end{gathered}
$$

Beobachtete Varianz der paarweisen Abstände zwischen Loci $\left(V_{0}\right)$

Erwartete Varianz der paarweisen Abstände zwischen Loci $\left(V_{e}\right)$

Assoziationsindex $\left(I_{A}\right)$ 


$$
\bar{r}_{d}=\frac{\sum \sum \operatorname{cov}_{i^{1}, i^{2}}}{\sum \sum \sqrt{\operatorname{var}_{i^{1}} \cdot \operatorname{var}_{i^{2}}}} \quad \text { Verzerrungsfreier Assoziationsindex }\left(r_{d}\right)
$$

wobei

$I_{A}=$ Assoziationsindex zwischen mehreren Loci in einer Population; $V_{e}=$ Erwartete Varianz der paarweisen Abstände zwischen Loci bei Kopplungsgleichgewicht; $V_{0}=$ Beobachtete Varianz der paarweisen Abstände zwischen Loci; $i=$ spezifischer Locus; 11 / i2= zwei gegensätzliche Loci; var $_{i}=$ Varianz der paarweisen Abstände zwischen einem spezifischen Locus und anderen Loci; $\operatorname{Cov}_{i 1, i 2}=$ Covarianz der Abstände, summiert über alle Locuspaare in einem Datensatz; $r_{d}=$ Verzerrungsfreier Assoziationsindex.

\subsection{Genfluss (Nm)}

\section{Hintergrund}

Der Genfluss (die Genmigration) ist die Bewegung oder Einbringung von genetischem Material (DNA) (durch Kreuzung) von einer Population einer Art in eine andere (Ein- und Auswanderung). Dadurch verändert sich die Zusammensetzung des Genpools (Allelhäufigkeiten) der aufnehmenden Population. Die Messung des Genflusses liefert indirekte Informationen über den Grad der Migration zwischen Teilpopulationen (Burczyk et al. 2004). Der Genfluss (Nm) kann als die effektive Anzahl der zwischen den Teilpopulationen pro Generation ausgetauschten Migranten interpretiert werden (Wright 1969). Beide Nm-Schätzmethoden (basierend auf $F_{S T}$ und privaten Allelen) gehen von Neutralität aus, so dass jede Art von Selektion zu einer Verzerrung führt (Yamamichi und Innan 2012). Die auf $F_{S T}$ und der Häufigkeit privater Allele basierenden Nm-Schätzungen ermöglichen jedoch ein gewisses Verständnis der auftretenden Migration und sind für das FGM nützlich. So z.B. deutet ein hoher Nm auf einen starken Genfluss sowie stabilere und intaktere genetische Prozesse hin.

\section{Berechnung}

Nach dem Inselmodell von Wright (1931) wird aus dem geschätzten Grad der genetischen Differenzierung $\left(F_{S T}\right)$ zwischen Populationen einer Art auf Nm geschlossen - der Anzahl der zugewanderten Individuen, die pro Generation in eine Population einwandern (Wright 1969).

$$
N m=\left(\frac{1-F_{S T}}{4 F_{S T}}\right)
$$

Eine weitere Methode zur Abschätzung des Genflusses ist die Methode der privaten Allele (Slatkin 1985). Diese Methode erfordert einen größeren Stichprobenumfang, um eine ausreichende Anzahl privater Allele (Allele, die nur in einer Population vorkommen) zu erhalten. Die Idee hinter dieser Methode ist, dass bei einem starken Genfluss die nur in einer Population vorkommenden privaten Allele sehr selten sind, weil sie möglicherweise durch neue Mutationen verursacht wurden, die noch keine Zeit hatten, sich auszubreiten (Slatkin 1985, 1987). Slatkin (1985) zeigte, dass der Logarithmus von Nm linear mit dem Algorithmus der durchschnittlichen Häufigkeit privater Allele korreliert ist. Im Rahmen des LIFEGENMON-Projekts wurde die Methode der privaten Allele von Slatkin (1985) verwendet, die in der Software GenePop (siehe unten) implementiert ist. Diese Software berechnet basierend auf der Methode der privaten Allele eine Multilocus-Schätzung der effektiven Anzahl von Migranten (Nm) nach Slatkin (1985) sowie Slatkin und Barton (1989). Es werden vier Schätzwerte für Nm geliefert, drei unter Verwendung der in Barton und Slatkin (1986) veröffentlichten Regressionsgeraden, und ein unter Verwendung der Werte der nächstliegenden Regressionsgerade korrigierter Schätzwert, wie von Barton und Slatkin (1986) beschrieben.

Genepop-Referenz-Webseite: https://kimura.univ-montp2.fr/ rousset/Genepop.htm

Genepop ist auch als R-Paket bei CRAN und als eigenständige ausführbare Datei verfügbar. Beide basieren auf der neuesten Version des Genepop-Quellcodes (C++), Version 4.7.3 (06. Dezember 2019; Rousset 2008, Rousset 2017). 


\subsection{Multilocus-Auskreuzungsrate der Population}

\section{Hintergrund}

Auskreuzung fördert den Genfluss, homogenisiert Populationen, erhöht die Heterozygotie und begünstigt das gametische Kopplungsgleichgewicht (Del Castillo und Trujillo 2008). Die globalen Auskreuzungsraten von Multilocus- ( $t m$ ) und Einzellocus-Populationen ( $t s$ ) können als ein und derselbe Parameter betrachtet werden. Genauere Schätzungen der natürlichen Auskreuzungsraten sollten jedoch unter Verwendung von MultilocusModellen beurteilt werden, z.B. dem gemischten Paarungsmodell (Ritland und Jain 1981, Ritland 2002). Die Multilocus-Auskreuzungsrate einer Population (tm) ist der geschätzte Anteil der ausgekreuzten Nachkommen, die von einem einzelnen mütterlichen Elternteil oder von der Gesamtpopulation produziert werden, wobei Auskreuzungsereignisse die Paarung zwischen verwandten und nicht verwandten Individuen einschließen (Ritland 2002).

\section{Berechnung}

Basierend auf dem gemischten Paarungsmodell wurde auf der Basis von Einzel- und Multilocus-Genotypen das Schätzverfahren für Auskreuzungsraten nach Ritland (2002) angewendet $\left(t_{s}\right.$ - Einzellocus- und $t_{m}$ - MultilocusAuskreuzungsraten). Es wird angenommen, dass die geschätzten Multilocus-Auskreuzungsraten (tm) genauere Ergebnisseim VergleichzuEinzellocus-Schätzwerten liefern (Ritland und Jain 1981, Ritland2002). Multilocus- $\left(t_{m}\right.$ ) und Einzellocus-Auskreuzungsraten (ts) können mittels MLTRgeschätzt werden (Ritland 2002). DieVarianzschätzungen im Rahmen des LIFEGENMON-Projekts wurden auf der Grundlage von 10.000 Wiederholungen (Bootstraps) berechnet. Bootstrapping ist eine nicht-parametrische Methode zur Ermittlung des Standardfehlers (oder der Varianz) von Schätzungen. Beim Bootstrapping wird davon ausgegangen, dass die Beobachtungen unabhängig sind, und es wird eine angemessene Anzahl von Beobachtungen benötigt. Der Standardfehler wird während der Berechnung mit MLTR (Ritland 2002) basierend auf einer ausgewählten Anzahl von Bootstraps geschätzt. Die für das Bootstrapping erforderliche erneute Stichprobenziehung (Resampling) kann innerhalb von Familien oder Individuen in Familien durchgeführt werden (Ritland 2002). Für die Daten des LIFEGENMON-Projektes wurde das Resampling auf Ebene der Familie durchgeführt, da die tatsächlichen Parameter des Paarungssystems zwischen Familien variierten.

$$
\begin{array}{rlrl}
\hat{t}_{m} & =1-\hat{s}_{m} & & \text { Individuelle Multilocus-Auskreuzungsrate } \\
\hat{s}_{m} & =\frac{I_{m}-P_{m}^{s}}{P_{m}^{s}-P_{m}^{t}} & & \text { Individuelle Multilocus-Selbstungsrate } \\
\operatorname{Var}\left(\hat{s}_{m}\right) & =\frac{P_{m}^{t}\left(1-P_{m}^{t}\right)}{\left(P_{m}^{S}-P_{m}^{t}\right)^{2}} & & \text { Varianz der individuellen } \\
& \text { Multilocus-Selbstungsrate }
\end{array}
$$

wobei

die Wahrscheinlichkeit ist, einen möglichen Multilocus-Genotyp $m$ des Nachkommens für den gegebenen Elterngenotyp zu beobachten; $s$ in den oben genannten Formeln steht für Selbstung, $t$ steht für Auskreuzung. wenn der Genotyp $m$ der beobachtete Genotyp des Nachkommens ist und 0, wenn er es nicht ist;

$$
P_{m}^{S}=\prod_{l o c i} P_{k l(m)}^{i j, s} \quad P_{m}^{t}=\prod_{l o c i} P_{k l(m)}^{i j, t}
$$

wobei

$P_{k l}^{i j}$ die Wahrscheinlichkeit ist, den Genotyp des Nachkommens $A_{k} A_{l} z u$ beobachten, bei einem gegebenen Elterngenotyp $A_{i} A_{j}$; $s$ in in den oben genannten Formeln steht für Selbstung, $t$ steht für Auskreuzung. 


$$
P_{k l}^{i j, s}=\left(2-\delta_{k l}\right) D_{k}^{i j} D_{l}^{i j} \quad P_{k l}^{i j, t}=\frac{1}{2}\left(2-\delta_{k l}\right)\left(D_{k}^{i j} p_{l}+D_{l}^{i j} p_{k}\right)
$$

wobei

$D_{k}^{i j}$ und $D_{l}^{i j}$ die Wahrscheinlichkeiten sind, dass das Allel $k$ oder das Allel / an den Nachkommen weitergegeben wird, bei einem gegebenen Elterngenotyp $A_{i} A_{j}$; und sind die Allelfrequenzen der Allele / und $k$ in der Population; ist ein Kronecker Operator der gleich 1 gesetzt wird, wenn die Allele / und $k$ gleich sind oder gleich 0, wenn sie verschieden sind.

$$
D_{k}^{i j}=\left(\frac{\delta_{i k}+\delta_{j k}}{2}\right) \quad D_{l}^{i j}=\left(\frac{\delta_{i l}+\delta_{j l}}{2}\right)
$$

Die Multilocus- (tm) und die Einzellocus-Auskreuzungsrate (ts) der Population variieren von 0 bis 1; in einigen Fällen auch $\mathrm{tm}=1,2$ (unveröffentlichte LIFEGENMON-Ergebnisse). Wenn die Multilocus-Auskreuzungsrate (tm) der Population nahe oder gleich 1 ist (tm $\geq 1$ ), bedeutet dies, dass die Nachkommen ausgekreuzt werden (keine Selbstbefruchtung). Ist die Multilocus-Auskreuzungsrate (tm) der Population niedriger als 1 ist (tm $<1$ ), dann bedeutet dies, dass ein Teil der Nachkommenschaft aus Selbstbefruchtung stammen.

MLTR-Referenz-Webseite: http://kermitzii.com/softwares/

\subsection{Tatsächliche Inzuchtrate}

Hintergrund

Unter Inzucht versteht man die Paarung von Individuen, die durch ihre Abstammung miteinander verwandt sind. Inzucht (Paarung zwischen nahen Verwandten) erhöht die Homozygotie der Nachkommen und führt in der Regel zu einer verringerten Fitness. Bei homozygoten Genotypen werden schädliche rezessive Allele freigelegt, und die Vorteile von Heterozygotie in überdominanten Loci gehen verloren (Aravanopoulos und Zsuffa 1998). Die Inzuchtrate gibt die Zunahme des durchschnittlichen Inzuchtniveaus in einer Population von einer Generation zur nächsten an.

\section{Berechnung}

Die Berechnung der tatsächlichen Inzuchtrate (Einzellocus und Multilocus) basiert auf Saatgutdaten und genetischen Daten. Die Berechnung der Inzuchtraten kann markerbasiert erfolgen. Da jedoch eine potenzielle Inzuchtdepression die Samenentwicklung und Keimung negativ beeinflussen kann, sind tatsächliche Inzuchtraten zuverlässiger. Die tatsächliche Inzuchtrate wird durch die Kombination von Inzuchtschätzungen aufgrund der Analyse des Paarungssystems und Inzuchtschätzungen auf der Basis von Samenmerkmalen berechnet (Rajora et al. 2000a).

$$
\text { Tatsächliche Inzuchtrate }=\frac{B+C \cdot \hat{s}_{m}}{B+C}
$$

wobei

$B$ der geschätzte Anteil an Inzuchtsamen ist und berechnet wird als $(1-C) \cdot F$, wobei $F$ der geschätzte Anteil an leeren Samen ist, der der Selbstung zugeschrieben wird und auf Vorwissen basiert (z. B. aus veröffentlichter Literatur über die jeweilige Art). In Ermangelung vorheriger Informationen ist die Zuordnung von 80 \% (d.h. $F$ $=0,8)$ der leeren Samen als Ergebnis von Selbstung eine vernünftige Wahl (Rajora et al. 2000a, basierend auf Picea glauca (Moench) Voss - Daten); $C$ ist der Anteil der vollen Samen (siehe Abschnitte 6.3 und 6.5.5.1.1 zur Bestimmung des Anteils der vollen Samen); s_m ist der Multilocus-Wert der Selbstungsrate (Ritland 2002), für die entsprechende Gleichung siehe 6.5.4.3.1.8. 


\subsection{HINTERGRUNDINFORMATIONEN}

\subsection{Interspezifische Hybridisierung}

Hintergrund

Der Begriff der interspezifischen Hybridisierung bezeichnet die Hybridisierung zwischen Organismen, die als unterschiedliche Arten angesehen werden. Um zwischen artreinen Individuen und interspezifischen Hybriden unterscheiden zu können, wird ein Satz verifizierter Referenzproben beider (oder weiterer) hybridisierender Arten benötigt. Artreine Genotypdaten können dann zur Simulation von Hybridgenotypen mittels Softwareprogrammen wie HybridLab (Nielsen et al. 2006) oder dem R-Paket adegenet (Jombart 2008, Jombart und Ahmed 2011) verwendet werden. „Artreine“ und „hybride" Referenzgruppen können dann in die STRUCTURE-Analyse (Pritchard et al. 2000) oder in ein anderes Clustering-Programm einbezogen werden, um den Grad der Hybridisierung zwischen einzelnen Arten in natürlichen Gemeinschaften zu bestimmen.

STRUCTURE ist ein eigenständiges Programm, das nicht leicht in $\mathrm{R}$ zu implementieren ist und dessen Analysen relativ langsam laufen. R-basierte Alternativen sind snapclust und eine Diskriminanzanalyse der Hauptkomponenten (Discriminate Analysis of Principal Components; DAPC), bei denen es sich um komplementäre Methoden zur Clusterung von Arten/Populationen und nachfolgende Visualisierung der Cluster mit Hilfe des R-Pakets adegenet handelt. Die drei beschriebenen Implementierungen versuchen jeweils, Individuen aufgrund ihrer genetischen Ähnlichkeit in Gruppen zusammenzufassen. Sie können dabei sowohl zur Beurteilung der Hybridisierung zwischen Arten und der zugrunde liegenden Populationsstruktur als auch zur Beurteilung der Divergenz zwischen hypothetischen Populationen innerhalb der Arten (oder deren Abwesenheit, bezeichnet als Beimischung) verwendet werden.

\section{Überblick über den STRUCTURE-Algorithmus}

Für die Zuordnung von Individuen zu einer Art oder Gruppe nutzt STRUCTURE eine modellbasierte ClusteringMethode zur Ableitung der Populationsstruktur unter Verwendung von Genotypdaten, die aus nicht verknüpften Markern bestehen. STRUCTURE geht von einem Modell aus, in dem es $K$ Populationen oder Arten gibt, von denen jede durch einen Satz von Allelhäufigkeiten je Locus charakterisiert ist. Die Individuen werden auf der Grundlage ihrer Genotypen wahrscheinlichkeitsbasiert einer Population/Art oder gleichzeitig zwei oder mehr Populationen/Arten zugeordnet. STRUCTURE schätzt dabei die Allelhäufigkeiten in jedem Cluster und die Populations-/Artzugehörigkeit jeder einzelnen Probe. Markov-Ketten-Monte-Carlo-Permutationen werden verwendet, um über den Parameterraum zu integrieren und Cluster-Zuordnungen vorzunehmen. Der optimale Wert von $K$ für einen bestimmten Satz von Individuen wird post-hoc mit der Evanno-Methode bestimmt (Evanno et al. 2005). Die STRUCTURE-Analyse muss daher für viele Werte von $K$ durchgeführt werden, wodurch sich die Laufzeit der Analyse erhöht. STRUCTURE geht sowohl von einem $H$-W-als auch einem Kopplungsgleichgewicht aus. Deshalb ist es wichtig, von diesen Annahmen abweichende Individuen und Loci vor der Analyse zu filtern.

\section{Überblick über den Snapclust-Algorithmus}

Snapclust (implementiert im R-Paket adegenet, Jombart 2008; Jombart und Ahmed 2011) ist ein genetischer Clustering-Ansatz, der „modellbasierte“ und "geometriebasierte“ Methoden kombiniert, um schneller als vollständig „,modellbasierte“ Ansätze (wie z.B. STRUCTURE) Individuen effektiv zu Clustern zuzuordnen. Snapclust stützt sich dabei auf das H-W-Gleichgewicht, um die Wahrscheinlichkeit einer gegebenen Clustering-Lösung zu berechnen.

Snapc/ust weist den Individuen Gruppen zu (basierend auf der vom Benutzer vorgegebenen Gruppenanzahl K) und durchläuft dann so lange Iterationen des Snapclust-Modells, bei denen die Individuen jedes Mal neu zugewiesen werden, bis zwei aufeinander folgende Modelle konvergieren (d.h. die logarithmischen Wahrscheinlichkeiten in zwei aufeinander folgenden Iterationen vernachlässigbar werden $\left.\left(10^{-10}\right)\right)$.

Snapclust erfordert auch, dass die Gesamtzahl der vorhandenen Cluster a priori festgelegt wird; im Gegensatz zur STRUCTURE-Analyse, wo dies post-hoc erfolgt. Zur Beurteilung der optimalen Anzahl von Clustern können 
mehrere Informationskriterien verwendet werden. Zwei beliebte Statistiken sind AIC (Akaike Information Criterion; Akaike et al. 1998) und BIC (the Bayesian Information Criterion; Schwarz 1978). Alle drei Statistiken messen die Abweichung des Modells (mangelnde Anpassungsgüte), sanktionieren jedoch die Komplexität des Datensatzes in unterschiedlichem Maße. Werden diese Statistiken verwendet, um die optimale Anzahl von Clustern für einen Datensatz zu identifizieren, wird das Snapclust-Modell über mehrere potenzielle Werte von K (z.B. 1-20) iteriert, und die gewählte(n) Statistik(en) wird/werden für jedes resultierende Modell berechnet. Das Ergebnis kann grafisch dargestellt werden, um die Modelle statistisch zu vergleichen. Im Allgemeinen weisen niedrigere Werte der o.g. Statistiken auf eine bessere Anpassungsgüte des Modells hin. In der Praxis weist jedoch die drastische Abnahme einer Statistik mit zunehmendem $K$ höchstwahrscheinlich auf die optimale Anzahl von Clustern hin (Jombart et al. 2010).

\section{Diskriminanzanalyse der Hauptkomponenten (DAPC)}

Die DAPC verwendet die Hauptkomponenten (PCA) zusammen mit einer Diskriminanzanalyse (DA) zur Identifikation genetischer Strukturen. Sie unterscheidet sich von anderen Ansätzen wie Snapclust und STRUCTURE dadurch, dass es sich um einen ausschließlich "geometrischen“ Ansatz handelt, bei dem die Individuen basierend auf ihren Abständen im genetischen Raum geclustert werden, ohne spezifische populationsgenetische Modelle anzunehmen (Jombart et al. 2010).

Wie in der veröffentlichten Methodeneinführung von Jombart et al. (2010) erläutert, versucht die DAPC, die Limitierungen der beiden konstituierenden Verfahren zu reduzieren. Die PCA kann zwar die Gesamtvariabilität zwischen Individuen erfassen, aber die Unterschiede zwischen Gruppen nicht von den Unterschieden innerhalb von Gruppen differenzieren. Die DA wiederum zerlegt die genetische Variation in eine „Zwischen-den-Gruppen“sowie eine „Innerhalb-von-Gruppen“-Komponente und versucht gleichzeitig erstere zu maximieren und Letztere zu minimieren, was die Einteilung von Individuen in vordefinierte Gruppen ermöglicht. Die DA wird durch die Notwendigkeit limitiert, dass die Anzahl der Variablen (Allele) geringer als die Anzahl der Beobachtungen (Individuen) sein muss, was zumindest in SNP-Datensätzen oft nicht der Fall ist. Sie wird weiterhin durch die in zusammengesetzten Datensätzen üblichen Korrelationen zwischen Variablen erschwert. Bei der DAPC werden die Daten zunächst mit Hilfe einer PCA transformiert, deren Variablenwerte danach (unter Verwendung der PCA-Achsen) einer DA unterzogen werden. Dadurch wird sichergestellt, dass die an die DA übermittelten Variablen nicht korreliert sind und dass ihre Anzahl geringer ist als die der analysierten Individuen. Als Methode zur Visualisierung der a priori (von Snapclust-abgeleiteten) Cluster-Diversität im reduzierten Datenraum kann die DAPC kann zur Ergänzung der Snapclust-Analyse verwendet werden.

\subsection{Gametische Diversität ( $\left.\mathrm{v}_{\mathrm{gam}}\right)$}

\section{Hintergrund}

Die gametische Diversität (hypothetische gametische Multilocus-Diversität; $v_{\text {gam }}$ ) ist ein Spezialfall der genetischen Diversität, der die potentielle Vielfalt des gametischen Outputs einer Population charakterisiert. Sie bezeichnet das adaptive/evolutionäre Potential einer sich sexuell fortpflanzenden Population, d.h. die effektive Anzahl von Multilocus-Gameten, die produziert werden können (Gregorius 1978). Bei der $v_{g a m}$-Berechnung wird angenommen, dass sich die untersuchten Loci im Kopplungsgleichgewicht befinden und dass keine Selektion (Fertilitätsselektion) in der Population erfolgt (d.h. dass die Individuen keinen Fitnessvorteil durch Merkmale haben, welche die Anzahl der Nachkommen erhöhen) (Hattemer 1991). Es handelt sich daher nur um eine hypothetische Abschätzung dieser Fähigkeit.

Die genetische Diversität innerhalb einer Population ist notwendig für deren Anpassung und Überleben in heterogenen Umgebungen (Müller-Starck 1995). Als Maß für die Fähigkeit einer Population, genetische Variation zu erzeugen und damit die Anpassung an veränderte Umweltbedingungen zu erleichtern (Gregorius et al. 1986), kann $v_{\text {gam }}$ ein Indikator für die Reaktionsfähigkeit und Resistenz einer Population im Hinblick auf langfristige Umweltbelastungen sein. Dies wurde z.B. bei der Rotbuche (Fagus sylvatica) nachgewiesen, wo $v_{\text {gam }}$ bei „luftverschmutzungstoleranteren“ Teilpopulationen um 90 \% höher war als bei „empfindlicheren“ Teilpopulationen 
(Müller-Starck 1989). $v_{\text {gam }}$ wurde auch verwendet, um die potentiell reduzierte Fähigkeit eines Genpools zur Anpassung an sich verändernde Bedingungen nach anthropogenen Störungen wie z.B. Holzeinschlag nachzuweisen (Wickneswari et al. 2004).

\section{Berechnung}

$v_{\text {gam }}$ wird als Produkt der Einzellocus-Diversität $(A e)$ über alle Loci berechnet. Es erfordert daher zunächst eine Berechnung von $\mathrm{He}$ und $\mathrm{Ae}$ für jeden Locus.

$$
\begin{gathered}
H e_{i}=1-\sum p_{i}^{2} \\
A e_{i}=\frac{1}{\left(1 / H e_{i}\right)}=\frac{1}{\sum p_{i}^{2}} \\
v_{\text {gam }}=\prod_{i}^{I} A_{e i}
\end{gathered}
$$

Erwartete Heterozygosität pro Locus (He)

Erwartete Anzahl von Allelen pro Locus (Ae)

Hypothetische gametische Multilocus-

Diversität $\left(v_{\text {gam }}\right)$

wobei:

$p_{i}=$ Allelhäufigkeit des Hauptallels an einem bestimmten Locus; $H e_{i}=$ Erwartete Heterozygosität an einem bestimmten Locus; $A e_{i}=$ Erwartete Anzahl von Allelen an einem bestimmten Locus; $v_{\text {gam }}=$ Hypothetische gametische Multilocus-Diversität, I = Gesamtanzahl ungekoppelter Loci; $i$ = spezifischer Locus.

\subsection{F-basierter Ausreißertest}

\section{Hintergrund}

Genetische Marker lassen sich in zwei Kategorien einteilen; je nachdem, ob sie mutmaßlich von Selektionsdruck betroffen sind oder nicht. Neutrale Marker haben keine (oder nur sehr geringe) Auswirkungen auf die Fitness und werden daher durch neutrale stochastische Prozesse statt durch natürlichen (oder künstlichen) Selektionsdruck getrieben (Kimura 1983). Im Gegensatz dazu werden Marker, die unter Selektionsdruck stehen, als nichtneutrale, adaptive oder Ausreißer-Loci bezeichnet. Es besteht ein wachsendes Interesse daran, nicht-neutrale Marker zusammen mit neutralen Markern zu verwenden, um das Anpassungspotenzial einer Population an sich ändernde Umweltbedingungen zu bewerten (Eizaguirre und Baltazar-Soares 2014) und im genetischen Monitoring einzusetzen (Funk et al. 2012). Traditionelle populationsgenetische Analysen neigen jedoch dazu, ausschließlich neutrale Marker zu verwenden, welche die geografische Struktur von Teilpopulationen und die genetische Vernetzung widerspiegeln, die durch genetische Drift, Mutationen und Ausbreitungslimitierung bestimmt wird. Dies macht neutrale Marker v.a. nützlich, um zurückliegende demografische Prozesse zu bewerten.

Der wichtigste Ansatz zur Erkennung von Signalen natürlicher Selektion in einer Population besteht in der Suche nach Loci mit unerwartet großen Unterschieden in den Allelhäufigkeiten zwischen den Populationen (Lewontin und Krakauer 1973). Ausreißertests werden in der Regel mit dem Fixationsindex $F_{S T}$ in eigenständigen Anwendungen wie Lositan (Antao et al. 2011) und Bayescan (Fischer et al. 2011) durchgeführt. In R kann die $F_{S^{-}}$ Ausreißererkennung mit der OutFLANK-Methode (Whitlock und Lotterhos 2015) einfach und schnell implementiert werden.

\section{Übersicht über den Algorithmus}

Nachfolgend wird eine vereinfachte Beschreibung des OutFLANK-Algorithmus vorgestellt. Eine detailliertere Beschreibung ist in der originalen Publikation von Whitlock und Lotterhos (2015) zu finden. Beim OutFLANKAlgorithmus werden zunächst Loci mit geringer Heterozygotie entfernt (d.h. He $<0,1$ in der Gesamtpopulation und SNPs mit einem Anteil des selteneren Allels < 0,05). Als gewähltes Maß der genetischen Differenzierung wird $F_{S T}^{\prime}$ separat für jeden Locus berechnet und über alle betrachteten Loci gemittelt. Dabei handelt es sich 
um eine Variation des Fixationsindex $\left(F_{S T}\right)$ gemäß der Definition von Weir und Cockerham (1984), welche bei der Berechnung der Varianzkomponente nicht mit der Stichprobengröße korrigiert wird.

$$
F_{s t}=\frac{\operatorname{var}_{a}}{\operatorname{var}_{a}+\operatorname{var}_{b}+\operatorname{var}_{c}} \quad F_{S T}(\text { Weir und Cockerham 1984) }
$$

wobei:

${ } r_{a}=$ 'Zwischen-Populationen-'Varianzkomponenteeines Allels; var $_{b}=$ 'Zwischen Individuen in einer Teilpopulation'Varianzkomponente; var $_{c}=$ 'Zwischen-Gameten innerhalb von Individuen'-Varianzkomponente.

Loci innerhalb der oberen und unteren 5\%-Perzentile der $F_{S T}^{\prime}$-Werte werden vorübergehend ausgeschlossen. Aus den reduzierten $F^{\prime}{ }_{S T}$-Werten wird ein $\mathrm{X}^{2}$-Verteilungsmodell erstellt. Anschließend wird ein auf der Verteilung der $F_{S T}^{\prime}$-Werte basierendes Wahrscheinlichkeitsmodell verwendet, um die Freiheitsgrade (df) des Modells zu ermitteln. Sobald sowohl die Null- $\chi 2$-Verteilung der $F_{S T}^{\prime}$-Werte als auch die $d f$ bekannt sind, kann diese Verteilung verwendet werden, um auf eine diversifizierende Selektion zu testen, bei der die $F_{S T}^{\prime}$-Werte auf das rechte Ende der Verteilung fallen. Dies wird zahlreiche Male wiederholt, wobei alle Ausreißerloci iterativ entfernt werden, bis keine neuen Ausreißerloci mehr erkannt werden.

\subsection{Effektive Anzahl von Pollenspendern (Nep)}

\section{Hintergrund}

Die effektive Anzahl von Pollenspendern ist die Anzahl der Pollenspender, die zu jeder Samenfamilie beitragen. Da die Pollenspender unter den Nachkommen nicht gleichmäßig vertreten sind, ist diese Zahl oft viel kleiner als die absolute Zahl der beitragenden Pollenspender (Sork et al. 1999, Smouse and Sork 2004, Sork and Smouse 2006). Die effektive Anzahl der Pollenspender ist ein ausgezeichneter Indikator für die genetische Vielfalt einer Samenpartie. Ist die Zahl der effektiven Pollenspender klein, ist die Nachkommenschaft möglicherweise genetisch weniger divers (Apsit et al. 2002).

\section{Berechnung}

Die Anzahl der effektiven Pollenspender $N_{e p}$ (Ritland 1989), die zu jeder Samenfamilie beitragen, kann basierend auf der mittels MLTR (Ritland 2002) bestimmten Multilocus-Korrelation der Vaterschaft (rp) geschätzt werden, gemäß der Formel:

$$
N e p=\frac{1}{r p}
$$

wobei rp der Korrelation der Vaterschaft im MLTR entspricht (Ritland 2002).

MLTR-Referenz-Webseite: http://kermitzii.com/softwares/

\subsection{Biparentale Inzucht}

\section{Hintergrund}

Biparentale Inzucht oder Paarung zwischen Verwandten kommt mit unterschiedlicher Häufigkeit in vielen natürlichen Pflanzenpopulationen vor, die oft auch beträchtliche Selbstbefruchtungsraten aufweisen (Ritland 2002, Porcher und Lande 2016). Im Gegensatz zur zufälligen Paarung führt biparentale Inzucht zu scheinbarer Selbstbefruchtung oder erhöhter Homozygotie (Ritland 2002). Daher ist das Ausmaß der biparentalen Inzucht ein wichtiger Parameter für die genetischen Erhaltungsmaßnahmen und genetisches Monitoring. 


\section{Berechnung}

Einzellocus- (ts) und Multilocus-Auskreuzungsraten ( $t m)$ werden verwendet, um die biparentale Inzucht $(B /)$ (Paarung unter Verwandten) zu berechnen (Biparentale Inzucht $=t m-t s$ ).

$$
B I=(t m-t s)
$$

wobei tm die Multilocus-Auskreuzungsrate und ts die Einzellocus -Auskreuzungsrate im MLTR ist (Ritland 2002).

Bei Vorliegen echter Selbstbefruchtung kann nach Ritland (2002) die Differenz zwischen den geschätzten Multilocus- ( $t m$ ) und Einzellocus-Auskreuzungsraten ( $t s)$ zur Abschätzung des Ausmaßes biparentaler Inzucht verwendet werden. Ritland (2002) stellt jedoch fest, dass diese Differenz immer eine Unterschätzung darstellt, da sie von der Anzahl der betrachteten Loci abhängt. Eine höhere Anzahl von Loci liefert Schätzwerte der biparentalen Inzucht, die näher am wahren Wert liegen (Ritland, 2002).

Die biparentale Inzucht kann mittels MLTR auf Basis von Bootstraps geschätzt werden (Ritland, 2002). Bootstrapping ist eine nicht-parametrische Methode zur Ermittlung des Standardfehlers (oder der Varianz) von Schätzungen. Beim Bootstrapping wird davon ausgegangen, dass die Beobachtungen unabhängig sind, und es wird eine angemessene Anzahl von Beobachtungen benötigt. Der Standardfehler wird während der Berechnung mit MLTR (Ritland 2002) basierend auf einer ausgewählten Anzahl von Bootstraps geschätzt. Die für das Bootstrapping erforderliche erneute Stichprobenziehung (Resampling) kann innerhalb von Familien oder Individuen in Familien durchgeführt werden (Ritland 2002). Das Resampling wurde auf Ebene der Familie durchgeführt, da die tatsächlichen Parameter des Paarungssystems zwischen Familien variierten. Die Differenz zwischen den beiden Schätzwerten ( $t m-t s$ ) liefert somit ein Maß für die Häufigkeit von Paarungsereignissen zwischen nahen Verwandten (Ritland, 2002).

MLTR-Referenz-Webseite: http://kermitzii.com/softwares/

Wenn es zur Paarung zwischen Verwandten kommt, sollte die Einzellocus-Selbstbefruchtungsrate höher sein als die Multilocus-Selbstbefruchtungsrate. Die Differenz ist eine Mindestschätzung der scheinbaren Selbstbefruchtungsrate durch biparentale Inzucht (Ritland 2002). Liegt die biparentale Inzucht nahe Null, deutet dies auf keine Paarung unter Verwandten hin. Ist die Einzellocus-Auskreuzungsrate (ts) geringfügig kleiner als die Multilocus-Auskreuzungsrate ( $t s<t m$ ), deutet dies auf eine geringe Wahrscheinlichkeit für biparentale Inzucht hin. 


\subsection{Verwendete Softwareprogramme und -pakete}

Tabelle 6.9: Zur Berechnung von Verifikatoren erforderliche Softwareprogramme und -pakete. Sind R-Pakete von anderen Paketen abhängig, wurden diese Pakete ebenfalls berücksichtigt. Wenn R-Pakete Funktionen aus anderen Paketen importieren, wurden sie nicht berücksichtigt, da diese innerhalb des importierenden Pakets nutzbar sind. Um Platz zu sparen und die Lesbarkeit zu erhalten, wird für R-Pakete die Quellenangabe jeweils nur bei ihrer ersten Erwähnung in der Tabelle aufgeführt.

\section{Verifikator}

1. Allelhäufigkeit

2. Allelische Vielfalt

3. Effektive Populationsgröße

4. Latentes genetisches Potentia

5. Inzuchtkoeffizient

6. Kopplungsungleichgewicht

7. Multilocus-Auskreuzungsrate der Population

8. Genfluss (Nm)

\section{Erforderliche Softwareprogramme und -pakete}

R-Software: adegenet (Jombart 2008; Jombart und Ahmed 2011), ade4 (Dray und Dufour 2007)

R-Software: custom function (Dupuis et al. 2018); matrixStats (Bengtsson 2014), dplyr (Wickham et al. 2020), pegas (Paradis 2010), adegenet, ape, ggplot2 (Wickham 2016), DescTools (Signorell 2020), PopGenReport (Adamack und Gruber 2014), knitr (Xie 2020), poppr (Kamvar et al. 2014), mmod (Winter 2012)

R-Software: custom function, adegenet, ade4

R-Software: poppr, adegenet, ade4, custom function

R-Software: hierfstat (Goudet 2005), matrixStats

R-Software: poppr, adegenet, ade4

MLTR-Software (Ritland, 2002)

Die GenePop-Software ist sowohl als eigenständiges Programm (Rousset, 2008, Rousset 2017) als auch als R-Paket auf CRAN verfügbar.

Beide basieren auf der neuesten Version des Genepop-Quellcodes $(\mathrm{C}++)$, Version 4.7.3 (6. Dezember 2019; Rousset, 2008, Rousset 2017)

\begin{tabular}{|c|c|}
\hline \multicolumn{2}{|l|}{ Hintergrundinformation } \\
\hline 9. Interspezifische Hybridisierung & $\begin{array}{l}\text { STRUCTURE-Software (Pritchard et al. 2000; Hubisz et al. 2009). } \\
\text { R-Software: pophelper (Francis 2017), dplyr, tidyr Wickham und Henry 2020), } \\
\text { gridExtra (Baptiste 2020), plyr, adegenet, ade4, ggplot2, cairo (Urbanek und } \\
\text { Horner 2020) }\end{array}$ \\
\hline $\begin{array}{l}\text { 10. Hypothetische gametische } \\
\text { Multilocus-Diversität }\end{array}$ & R-Software: poppr, adegenet, ade4, custom function \\
\hline 11. F-basierter Ausreißertest & R-Software: dartR (Gruber et al. 2018), adegenet, ade4 \\
\hline 12. Biparentale Inzucht & MLTR-Software (Ritland 2002) \\
\hline 13. Effektive Anzahl von Pollenspendern & MLTR-Software (Ritland 2002) sowie Formel von Ritland (1989) \\
\hline
\end{tabular}

Anmerkung: poppr, dartR und pegas sind von adegenet abhängig. adegenet ist abhängig von ade4. Pophelper ist abhängig von cairo und ggplot2. PopGenReport ist abhängig von adegenet und knitr.

\subsubsection{4 easyRpopgen: Ein R-Skript zur Berechnung genetischer Parameter aus SSR- und SNP-Daten}

\subsection{Zweck}

easyRpogen ist eine quelloffene, webbasierte Shiny-Anwendung, die entwickelt wurde, um die Analyse und Interpretation von Ergebnissen aus populationsgenetischen Studien v.a. in der R-Programmierumgebung zu erleichtern. Sie ist in der Lage, gängige genetische Marker wie Einzelnukleotid-Polymorphismen (SNPs) und einfache Sequenzwiederholungen (SSRs, üblicherweise bezeichnet als Mikrosatelliten) effizient zu verarbeiten. Es gibt zwar viele eigenständige Programme (z.B. GenAIEx) und R-Pakete in CRAN und anderen Repositorien, die für diesen Zweck eingesetzt werden können, aber eine umfassende Analyse erfordert oft den Wechsel zwischen Programmen oder die Suche nach dem richtigen R-Paket für eine gewünschte Funktion. Dies wird durch die Anzahl der verfügbaren R-Pakete erschwert, welche eine Reihe von sich überlappenden und unterschiedlichen Funktionen enthalten. Die Zusammenführung dieser Pakete und Funktionen kann für Wissenschaftlerlnnen zeit- und arbeitsintensiv und schwer verständlich sein; insbesondere für diejenigen, die nicht bereits mit der R-Programmierumgebung vertraut sind. 
easyRpopgen vereinfacht und rationalisiert diesen Prozess, indem es die Funktionen mehrerer dieser Pakete mit anderen Funktionen in einer neuartigen Plattform kombiniert, die stabil läuft und allgemein zugänglich ist. easyRpopgen basiert im Kern auf dem Grundgerüst der R-Pakete zur genetischen Analyse (darunter poppr, ade4, adegenet, pegas, hierfstat und PopGenReport) und führt deren einzelne Funktionen in einer umfänglich nutzbaren Analyseplattform zusammen.

Die Anwendung wurde von Anfang an so konzipiert, dass sie sowohl als integraler Bestandteil der Datenanalyse und Ergebniskommunikation innerhalb des LIFEGENMON-Projekts als auch als eigenständige Anwendung verwendet werden kann, und von allen interessierten und in diesem Forschungsbereich arbeitenden Wissenschaftlerlnnen genutzt werden kann. Sie ist daher auf die in diesem Projekt verwendeten Forschungsfragen und -methoden zugeschnitten, aber allgemein genug gehalten, damit möglichst viele andere Wissenschaftlerlnnen von den im Rahmen des Pakets durchführbaren Analysen profitieren können.

\subsubsection{2 Überblick über die Anwendung}

\section{Datenimport und filterung}

Genetische Markerdaten können aus csv-Dateien im Stil von GenAlEx-, Genemapper- oder STRUCTUREformatierten Daten importiert werden. Die importierten Datendateien werden in ein Genind-Objekt konvertiert, welches der primäre Dateityp für die Datenspeicherung in vielen der aggregierten Pakete ist. Dieser Dateityp kann sowohl SNP- als auch SSR-Daten verarbeiten und enthält alle zugehörigen Metadaten, die somit in allen Analysen zusammen mit den Daten verfügbar sind. Neben dem Import von Daten aus diesen gängigen Dateiformaten können für die Zwecke des LIFEGENMON-Projekts Daten auch direkt vom LIFEGENMON-Server in die Anwendung importiert werden. Auch Phänologiedaten können direkt vom LIFEGENMON-Server in die Anwendung importiert werden.

Beim Importieren von Daten definieren die NutzerInnen eine Projekt-ID (z.B. LGM_Abies), welche mit allen Dateien und Berichten verknüpft wird, die später aus der Anwendung exportiert werden. Auf diese Weise lässt sich leicht nachvollziehen, welche Analysephasen für das jeweilige Projekt durchgeführt wurden.

Für die importierten Daten können auch Populationsstraten definiert werden. Dies ist sowohl für das LIFEGENMONProjekt als auch für den allgemeinen Gebrauch nützlich. Die im Rahmen des Projekts definierten Populationen wurden sowohl nach Standort (Slowenien, Deutschland und Griechenland) als auch nach Altersklasse (Altbäume, Naturverjüngung und Samen) unterteilt. Die unabhängige Definition der Straten bedeutet, dass die Analysen unter Berücksichtigung interaktiver und verschachtelter Effekte durchgeführt werden können.

Die Daten können vor Beginn der Analysen gefiltert werden. Zu den Filterparametern gehören fehlende Daten (fehlende Loci und fehlende Individuen), geringe Frequenz des selteneren Allels (MAF), globales Kopplungsungleichgewicht und Hardy-Weinberg-Gleichgewicht $(H-W)$. Der Zweck dieser Schritte der Datenfilterung besteht sowohl darin, lückenhafte Daten zu entfernen, die sich unverhältnismäßig stark auf die Analyseergebnisse auswirken können, als auch potenziell falsch sequenzierte Daten zu entfernen, indem Datensätze mit einer über die Mehrzahl der Proben auffällig hohen Abweichung vom H-W entfernt werden. Auch die Eliminierung von Loci mit Kopplungsungleichgewicht beseitigt etwaige negative Auswirkungen auf die Ergebnisse, da viele Analysen ein Gleichgeweicht der Loci erfordern und Loci im Ungleichgewicht effektiv als Doppelzählungen wirken. Die Nutzerlnnen können wählen, ob sie nur einige oder alle dieser Schritte der Datenfilterung durchführen wollen, und mit welcher Stringenz fehlende Werte und geringe Allelhäufigkeiten gefiltert werden sollen. Dies trägt sowohl etwaigen Präferenzen der Nutzerlnnen in Bezug auf Datenfilterung Rechnung als auch der Tatsache, dass einige Daten bereits vorgefiltert in die Anwendung importiert werden.

Während der Datenfilterung kann mit dem R-Paket pcadapt auch die Ausreißererkennung durchgeführt werden. Dieses erzeugt zwei Datensätze für den Export - einen „neutralen“ Datensatz, der sich aus nicht als aktiv von Selektionsprozessen betroffenen Markern zusammensetzt, und einen „Ausreißer“-Datensatz aus solchen, die unter Selektionsdruck stehen. Dies ermöglicht die Abgrenzung zwischen den Effekten von Demografie- und 


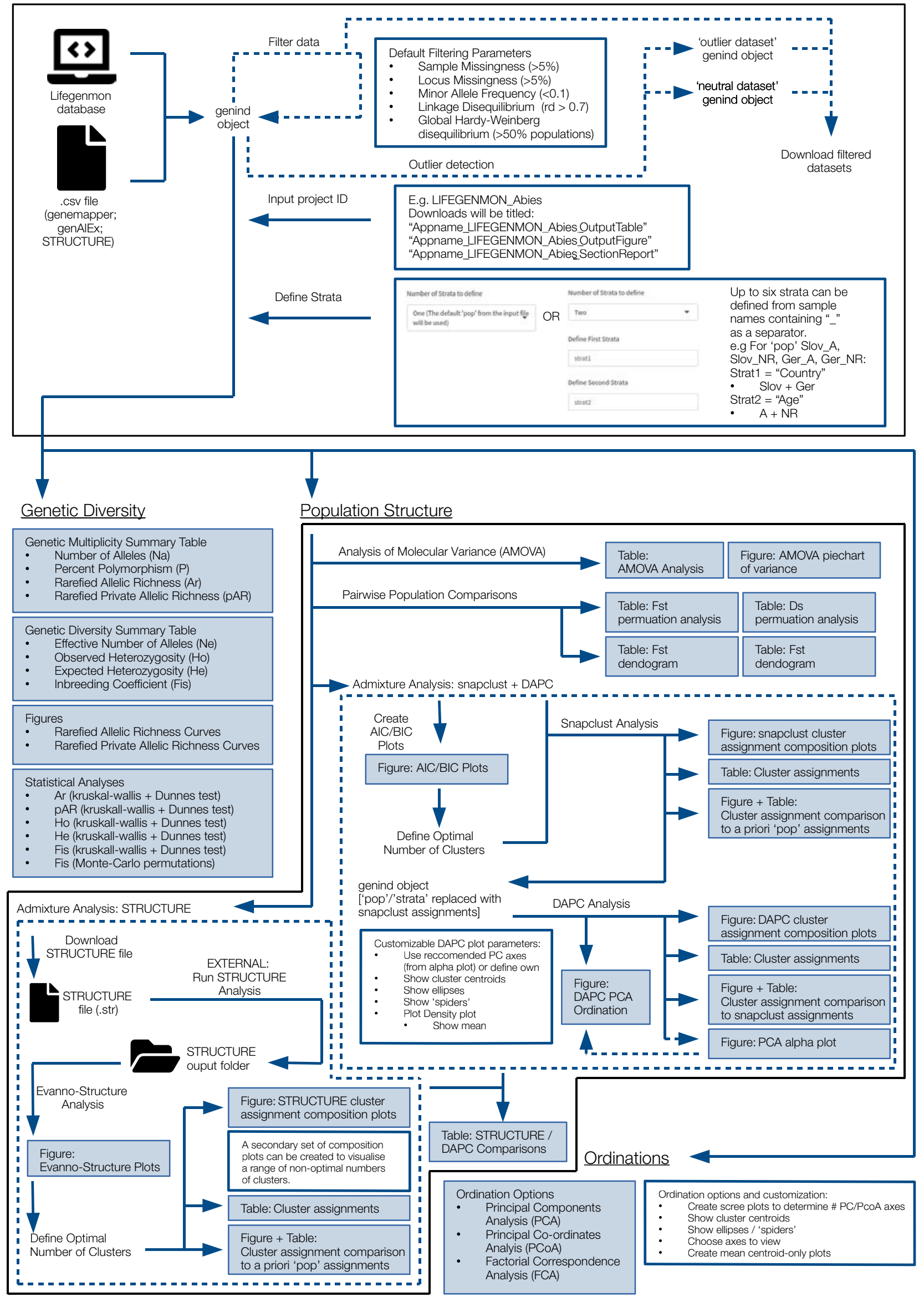

Abbildung 6.6: Schematische Darstellung der mit der easyRpopgen-Anwendung ausführbaren genetischen Analysen 
Selektionsprozessen auf die Populationsentwicklung. Wird die Ausreißererkennung nicht durchgeführt oder die Datenfilterung insgesamt übersprungen, so wird für alle weiteren Schritte der gesamte ungefilterte importierte Datensatz verwendet.

\section{Datenanalyse und Berichterstellung}

Die genetischen Analysen sind innerhalb der Anwendung in drei diskrete Bereiche unterteilt:

- Genetische Vielfalt

- Populationsstruktur

- Ordinationen

Die in diesen Bereichen generierten Metriken sind in den vorhergehenden Abschnitten des Handbuchs (Verifikatoren) beschrieben, so dass an dieser Stelle darauf nicht detailliert eingegangen wird. Die von der Anwendung berechneten Metriken und durchgeführten statistischen Analysen sind zusammenfassend im nachfolgenden „Schema der genetischen Analysen“ dargestellt (Abb. 6.6). Die drei Bereiche der genetischen Analysen - und viele der darin enthaltenen Berechnungen - können je nach den Bedürfnissen der Nutzerlnnen getrennt voneinander durchgeführt werden. Jede erzeugte Abbildung und Tabelle kann entweder separat heruntergeladen werden, oder es kann ein Bericht erstellt werden, der für den jeweiligen Bereich alle erzeugten Ergebnisse enthält.

Die Analyse phänologischer Daten erfolgt in einem separaten Teil der Anwendung, der den Aktivitäten im Zusammenhang mit dem LIFEGENMON-Projekt gewidmet ist und für den eine Anmeldung erforderlich ist. In diesem Bereich können phänologische Daten aus der LIFEGENMON-Datenbank heruntergeladen und zwischen Standorten und Jahren verglichen werden. Ähnlich wie bei der Analyse der genetischen Daten kann auch ein Bericht über diese Auswertungen erstellt werden.

Alle Analysen innerhalb der Anwendung werden auf Knopfdruck durchgeführt, so dass keine R-Programmierkenntnisse erforderlich sind. Die Ausführung des R-Codes erfolgt im Hintergrund, wobei im Front-End der Anwendung nur die generierten Grafiken und Tabellen angezeigt werden. Aus Gründen der Transparenz und Reproduzierbarkeit können Nutzerlnnen jedoch auch auf die zugrunde liegenden R-Skripte zugreifen.

\subsubsection{Auswertung der Daten von Saatguttests}

\subsubsection{Verifikatoren}

\subsection{Anteil lebensfähiger Samen}

Hintergrund

Die Schätzung des Anteils lebensfähiger Samen erfolgt auf Ebene der beprobten Einzelbäume, an denen Früchte/ Samen beprobt wurden. Eine Veränderung des Anteils voller Samen deutet auf einen Selektionsdruck (im Falle einer Reduktion) oder eine Erholung (im Falle einer Erhöhung) hin. Der Anteil voller Samen ist auch ein wichtiger Parameter für die Interpretation von Werten der effektiven Populationsgröße der nachfolgenden Kohorte.

\section{Berechnung}

Die Berechnung basiert auf der in Prozent umgerechneten Anzahl voller Samen in einer Zufallsstichprobe (normalerweise 400 Samen), die für den Keimtest (GT) oder den biochemischen Test auf Lebensfähigkeit (TT) verwendet wird.

Der Anteil an vollen Samen kann auch als 1 - Prozentsatz an leeren Samen berechnet werden, der ebenfalls am Ende des GT oder TT bestimmt wird. 


\subsection{Keimprozent}

\section{Hintergrund}

Das Keimprozent gibt den Anteil der Samen an, die unter den artspezifischen Bedingungen und innerhalb des festgelegten Zeitraums als normal beurteilte Sämlinge hervorgebracht haben (ISTA 2020). Mit einem Keimtest wird in der Regel beurteilt, welcher Anteil der Samen unter günstigen Bedingungen keimen und normale Keimlinge hervorbringen wird, die über die lebenswichtigen Strukturen (Wurzeln, Triebe und ausreichende Nährstoffreserven) verfügen und in der Lage sind, sich zu fortpflanzungsfähigen Pflanzen zu entwickeln. Gemäß ISTA (2020) werden nach dem Zufallsprinzip insgesamt 400 Samen in Replikaten von je 100 aus dem reinen Saatgut entnommen. Die artspezifische Dauer der Keimfähigkeitsprüfung ist unterschiedlich und kann bei Bedarf gemäß den ISTA-Vorschriften verlängert werden. Jeder Keimling muss nach den allgemeinen Grundsätzen (ISTA 2020) bewertet werden. Wenn vier 100-Samen-Replikate eines Tests innerhalb des maximal tolerierten Bereichs liegen, stellt deren Durchschnitt das Keimprozent dar, welches zu berichten ist. Saatgut, das unter den spezifischen Bedingungen am Ende der Prüfdauer nicht gekeimt hat, wird wie folgt klassifiziert: hartes Saatgut; frisches Saatgut; totes Saatgut; andere Kategorien (unter bestimmten Umständen können hohles und ungekeimtes Saatgut weiter nach den in den ISTA-Vorschriften (2020) beschriebenen Klassen kategorisiert werden).

\section{Berechnung}

Das Ergebnis der Keimfähigkeitsprüfung wird als Durchschnitt von vier 100-Samen-Replikaten berechnet. Es wird als prozentualer Anteil normal entwickelter Keimlinge angegeben. Der Prozentsatz wird auf die nächste ganze Zahl berechnet (0,5 wird aufgerundet). Der Anteil anormaler Keimlinge sowie die Anteile harter, frischer, toter und leere Samen werden analog berechnet. Die Summe der Prozentsätze normaler Keimlinge, anomaler Keimlinge und ungekeimter Samen muss 100 betragen (ISTA 2020).

Alternativ zur Keimfähigkeitsprüfung kann für Arten mit lang anhaltender Samenruhe ein biochemischer Test auf Lebensfähigkeit (Tetrazolium-Test) durchgeführt werden. Auch hier werden vier Replikate von je 100 Samen verwendet und wie in den ISTA-Vorschriften (2020) ausführlich beschrieben behandelt. Die Anzahl der als lebensfähig bewerteten Samen wird je Replikat bestimmt und der prozentuale Anteil lebensfähiger Samen wie o.a. berechnet. Der Anteil von nicht lebensfähigem Saatgut und hohlen Samen wird analog berechnet.

\subsubsection{Schlüsselverifikatoren}

Für die Durchführung des forstgenetischen Monitorings (FGM) anhand der drei Indikatoren wird eine Auswahl von Verifikatoren oder Hintergrundinformationen auf das Basis-, Standard- oder Intensivniveau vorgestellt (siehe Kapitel 4). Davon werden drei Verifikatoren als „Schlüsselverifikatoren“ vorgeschlagen, die gegenüber den anderen eine besonders herausragende Bedeutung haben. Die Ausweisung als „Schlüsselverifikatoren“ verleiht innen eine besondere Bedeutung im Rahmen der Interpretation der Daten des forstgenetischen Monitorings (siehe Kapitel 6.5.6. unten).

Die wichtigsten Verifikatoren für die Bewertung des Indikators „Selektion“ sind die Verifikatoren auf Basisniveau. Insbesondere die Abundanz der Naturverjüngung hat dabei eine hohe Priorität, da sie die realisierte Fitness auf der Bestandsebene widerspiegelt. Naturverjüngung ist das realisierte Ergebnis von Blüte, Fruktifikation, Saatgutentwicklung und Keimung, und eine Kompensation der Sterblichkeit der Altbäume. Daher wird dieser Parameter als wichtigster Verifikator für den Indikator „Selektion“ betrachtet.

Für den Indikator "genetische Variation" sind die Standardniveau-Verifikatoren am wichtigsten, unter ihnen insbesondere die effektive Populationsgröße. Ein Absinken der effektiven Populationsgröße unter einen akzeptablen Schwellenwert deutet sowohl auf den Beginn zufälliger und stochastischer Prozesse in der Population als auch auf den Beginn von Inzucht hin, was dazu führt, dass genetische Drift eine größere Rolle als Selektionsprozesse spielt. Daher ist die effektive Populationsgröße essentiell für das forstgenetische Monitoring und somit der wichtigste Verifikator für den Indikator "genetische Variation“. 
Für den Indikator "Genfluss/Paarungssystem“ existieren ausschließlich Verifikatoren auf Intensivniveau. Unter innen ist die tatsächliche Inzuchtrate von besonderer Bedeutung. Dieser Verifikator berücksichtigt sowohl die markerbasierte Inzuchtrate als auch den Anteil voller Samen, einem Anzeichen für eine mögliche Inzuchtdepression. Die tatsächliche Inzuchtrate wird daher als der wichtigste Verifikator für den Indikator "Genfluss/Paarungssystem“ einstuft.

\subsubsection{Interpretation von Werten: schrittweise Reaktion auf Veränderungen innerhalb von 10 Jahren}

Das forstgenetische Monitoring steht heute vor drei großen Hindernissen und Herausforderungen: (a) dem Mangel an historischen Daten bzw. oder Ausgangsdaten, (b) der Verwendung von Proxies für die genetische Vielfalt und (c) dem Fehlen etablierter Verfahren für den Vergleich von FGM-Indikatoren im zeitlichen Verlauf. Hier konzentrieren wir uns auf die dritte Herausforderung, da die ersten beiden quasi per definitionem adressiert werden: Das forstgenetische Monitoring erhebt per se historische Daten und verwendet darüber hinaus echte genetische Diversitäts- und Differenzierungswerte statt Proxies. In dieser Hinsicht arbeitet das FGM nicht mit Schwellenwerten, sondern mit Referenzpunkten und deren Vergleich. Referenzpunkte sind spezifische Werte für messbare Eigenschaften biologischer Systeme, die als Richtwerte für das Management von forstgenetischen Ressourcen und wissenschaftliche Beratung dienen. Absolute Schwellenwerte (sog. trigger points) sind exakt definierte Referenzpunkte, bei denen angesichts inakzeptabler Risiken oder irreversibler Schäden Erhaltungsmaßnahmen ausgelöst werden (Grant 2007). Die Festlegung von Schwellenwerten kann schwierig sein, da diese fallabhängig sind und sich wahrscheinlich von Art zu Art unterscheiden (Flanagan et al. 2018, Atkinson et al. 2004). Daher sind statistisch signifikante und/oder kritische Unterschiede zwischen zeitlichen Referenzpunkten zu bevorzugen, wobei zu berücksichtigen ist, dass auch kritische Unterschiede im Prinzip Schwellenwerte darstellen.

Mehrere Autoren haben die Bedeutung der Festlegung von Schwellenwerten oder kritischen Unterschieden für genetisches Monitoring betont (Aravanopoulos 2011, Bruford et al. 2017, Namkoong et al. 2002, Leroy et al. 2018, Hoban et al. 2014). Grundsätzlich ist es nicht ungewöhnlich, statistisch signifikante Unterschiede zwischen verschiedenen Populationen oder in denselben Populationen im Lauf der Zeit festzustellen. Wird genetisches Monitoring als Frühwarnsystem für genetische Veränderungen genutzt, besteht erst dann ein Anlass zur Sorge, wenn zusätzlich zur Feststellung statistisch signifikanter Unterschiede im zeitlichen Vergleich auch deren Ausmaß beträchtlich ist. Dieses Ausmaß, d.h. der kritische Unterschied oder Schwellenwert zwischen verschiedenen zeitlichen Bewertungen, wird für jeden Verifikator auf der Grundlage früherer Empfehlungen festgelegt, die meist auf der vorhandenen, begrenzten Literatur, Expertenmeinungen und Ad-hoc-Einschätzungen basieren. Das Bootstrapping über Marker zur Generierung von 1000 Replikaten, für die nachfolgend ein Konfidenzintervall berechnet wird, ist derzeit für die meisten Verifikatoren auf Grundlage molekularer Daten die am besten geeignete Methode zur Prüfung der statistischen Signifikanz zeitlicher Vergleiche (implementiert in GenAlEx (Peakall und Smouse 2006)).

In der Literatur werden für vergleichende Zwecke generell drei Grade kritischer Unterschiede identifiziert: (a) statistisch signifikante Unterschiede (ssd), (b) statistisch signifikante Unterschiede, die den Ausgangswert um $\geq$ 25\% überschreiten, und (c) statistisch signifikante Unterschiede, die den Ausgangswert um $\geq 50 \%$ überschreiten (Aravanopoulos 2011, 2016, Boyle 2000, Namkoong et al. 1996, Namkoong et al. 2002).

Für die meisten Verifikatoren kann ein ANOVA-Verfahren (wie z.B. ein t-Test) verwendet werden, um auf statistisch signifikante Unterschiede zwischen den Werten verschiedener zeitlicher Erhebungen zu testen. Die Behandlung einiger spezifischer Verifikatoren, die vom obigen Ansatz abweichen, wird im Folgenden erörtert.

Potentiell signifikante Unterschiede des Verifikators „Allelhäufigkeiten“ können identifiziert werden, indem Kontingenztabellen erstellt werden und eine entsprechende Analyse mit dem exakten Test nach Fisher oder alternativ mit dem x2-Unabhängigkeitstest (oder G-Test) durchgeführt wird. Der Test nach Fisher ist als exakte, direktional durchzuführende Statistik zu bevorzugen, während der $x$ 2-Unabhängigkeitstest eine geschätzte 
Statistik ist, die außerdem dadurch limitiert ist, dass die erwartete Häufigkeit in jeder Zelle der Kontingenztabelle $\geq 5.0$ betragen muss.

DerVerifikator „effektive Populationsgröße (Ne)"stellt eine Ausnahmevon der Regel der Verwendung vergleichender Referenzpunkte dar. Für diesen Verifikator wird ein minimaler Schwellenwert (trigger) von $\mathrm{Ne} \geq 500$ vorgeschlagen. Dieser Wert basiert auf einer Neubewertung von Fallstudien und Simulationen, die darauf hindeuten, dass bei einem $\mathrm{Ne} \geq 100$ der Verlust der Gesamtfitness nach fünf Generationen auf $<10 \%$ begrenzt werden kann, und oder dass bei einem $\mathrm{Ne} \geq 500$ genetische Erosion verhindert und die adaptive genetische Diversität erhalten wird (Frankham et al. 2014, Hoban et al. 2014, Willoughby et al. 2017, Leroy et al. 2018, Hoban et al. 2020).

Der Verifikator „Kopplungsungleichgewicht (LD)“ ist potenziell am schwierigsten korrekt einzuschätzen. Das LD variiert zwischen Populationen, Individuen sowie Chromosomen innerhalb eines Individuums, und sogar in verschiedenen Regionen innerhalb eines Chromosoms (Aravanopoulos 2014, Evans und Cardon 2005, Weiss und Clark 2002). Daher ist es wichtig, dass stets die gleichen Gene in den zeitlichen Vergleich einbezogen werden. Es werden zwei Maße des LD verwendet: der Korrelationskoeffizient $r 2$ nach Pearson (Hill und Robertson 1968) und der standardisierte Kopplungsungleichgewicht-Koeffizient $D^{\prime}$ (Lewontin 1964). Ihre Signifikanz wird mit dem Spearman-Rangkorrelationstest geprüft (Evans und Cardon 2005).

Die Ergebnisse des forstgenetischen Monitorings sollten anhand vorab definierter Kriterien für signifikante Veränderungen bewertetwerden(Aravanopoulos2011, Flanagan etal. 2018). Insgesamt sind für die Parameterwerte (Verifikatoren) eher kleine Unterschiede zu erwarten. Angesichts der empfohlenen Stichprobengrößen ist es sehr wahrscheinlich, zumindest für die demografischen Parameter deutliche und möglicherweise statistisch signifikante Unterschiede zu finden. Die biologische Interpretation und Bedeutung solcher Unterschiede muss auf nicht-statistischen Grundlagen ermittelt werden. Dabei ist zu berücksichtigen, dass deren biologische Bedeutung eine Einschätzung der zugrunde liegenden biologischen (genökologischen) Prozesse erfordert, die mit dem forstgenetischen Monitoring beobachtet werden. Im Folgenden wird ein Schema für die Beurteilung verschiedener Veränderungsgrade im zeitlichen Vergleich gegeben.

Tabelle 1. Grad der kritischen Veränderung zwischen zeitlichen Bewertungen sowie Reaktions- und Handlungsempfehlungen (ssd: statistisch signifikante Unterschiede).

\begin{tabular}{cccc} 
Nr. & Grad der Veränderung & Reaktions-grad & Maßnahme \\
\hline 1 & ssd; außerhalb des 95\% Konfidenzintervalls & 1. Grad & Försterln zur Situation vor Ort konsultieren \\
\hline 2 & $\begin{array}{c}\text { ssd; sowie 25\% Unterschied zum } \\
\text { Ausgangswert (Basislinie) }\end{array}$ & 2. Grad & $\begin{array}{c}\text { Revision der Waldbau-/ Bewirtschaftungsplä- } \\
\text { ne, Förderung von NV }\end{array}$ \\
\hline 3 & $\begin{array}{c}\text { ssd; sowie 50\% Unterschied zum } \\
\text { Ausgangswert (Basislinie) }\end{array}$ & 3. Grad & $\begin{array}{c}\text { Intensive Überwachung des Bestands, ex situ- } \\
\text { Erhaltungsmaßnahmen in Betracht ziehen }\end{array}$ \\
\hline
\end{tabular}

Die vollständige Unabhängigkeit zwischen Parametern kann nicht erreicht werden, und auch Interdependenzen zwischen Indikatoren und Parametern lassen sich nicht vollständig vermeiden. Dadurch könnte es Situationen geben, in denen in Bezug auf kritische Veränderungen „widersprüchliche“ Ergebnisse beobachtet werden (Namkoong et al. 2002, Aravanopoulos 2011). In diesem Zusammenhang wird im Folgenden für jedes Niveau die Mindestanzahl der Verifikatoren aufgeführt, die einen negativen Trend (2. oder 3. Reaktionsgrad) aufweisen müssen, um eine Maßnahme auszulösen:

Basisniveau: Mortalität, NV-Abundanz, Fruktifikation, Blüte; 3 dieser 4 Verifikatoren müssen einen negativen Trend aufweisen (darunter zwingend die NV-Abundanz).

Standardniveau: die 4 Verifikatoren des Basisniveaus, plus Allelhäufigkeiten, Allelische Vielfalt (SSR), Kopplungsungleichgewicht (SNP), latentes genetisches Potential, $F_{\text {is }}$-Inzuchtkoeffizient, effektive Populationsgröße (Ne); 6 dieser 10 Verifikatoren müssen einen negativen Trend aufweisen (darunter zwingend die NV-Abundanz und die effektive Populationsgröße Ne). 
Intensivniveau: die 10 Verifikatoren des Standardniveaus, plus Genfluss, Multilocus-Auskreuzungsrate der Population, tatsächliche Inzuchtrate; 8 dieser 13 Verifikatoren müssen einen negativen Trend aufweisen (darunter zwingend die NV-Abundanz, die effektive Populationsgröße Ne und die tatsächliche Inzuchtrate).

\section{Quellen}

Adamack AT, Gruber B (2014) PopGenReport: simplifying basic population genetic analyses in R. Methods Ecol Evol 5(4):384-387. https://doi.org/10.1111/2041-210X.12158

Adams RP, Zhong M, Fei Y (1999) Preservation of DNA in plant specimens-inactivation and reactivation of DNAses in field specimens. Mol Ecol 8:681-683. https://doi.org/10.1046/j.1365-294X.1999.84600.x

Agapow PM, Burt A (2001) Indices of multilocus linkage disequilibrium. Mol Ecol Notes 1:101-102. https://doi. org/10.1046/j.1471-8278.2000.00014.x

Akaike H, Pazen E, K Tanabe, Kitagawa G (1998) Selected papers of Hirotugo Akaike. Springer Science \& Business Media. https://doi.org/10.1007/978-1-4612-1694-0

Albrechtsen A, Nielsen FC, Nielsen R (2010) Ascertainment biases in SNP chips affect measures of population divergence. Mol Biol Evol 27(11):2534-2547. https://doi.org/10.1093/molbev/msq148

Alizoti PG, Kilimis K, Gallios P (2010) Temporal and spatial variation of flowering among Pinus nigra Arn. clones under changing climatic conditions. For Ecol Manag 259:786-797. https://doi.org/10.1016/j.foreco.2009.06.029

Amos W, Hoffman Jl, Frodsham A et al (2007) Automated binning of microsatellite alleles: problems and solutions. Mol Ecol Notes 7:10-14. https://doi.org/10.1111/j.1471-8286.2006.01560.x

Antao T, Pérez-Figueroa A, Luikart, G (2011) Early detection of population declines: high power of genetic monitoring using effective population size estimators. Evol Appl 4(1):144-154. https://doi.org/10.1111/j.1752-4571.2010.00150.x

Applied biosystems/Thermo Fisher Scientific (2014) User guide: DNA fragment analysis by capillary electrophoresis, Revision B. Thermo Fisher Scientific Inc., Carlsbad

Applied biosystems/Thermo Fisher Scientific/Hitachi (2010) Applied Biosystems 3500/3500xL Genetic Analyzer User Guide. Thermo Fisher Scientific Inc., Carlsbad

Apsit VJ, Dyer RJ, Sork VL (2002) Patterns of mating in an insect-pollinated tree species in the Missouri Ozark Forest Ecosystem Project. In: Shifley SR Kabrick, JM, (eds) Proceedings of the Second Missouri Ozark Forest Ecosystem Project Symposium: Post-treatment Results of the Landscape Experiment. Gen. Tech. Rep. NC-227. St. Paul, MN: U.S. Dept. of Agriculture, Forest Service, North Central Forest Experiment Station, pp 212-226

Aravanopoulos FA (2011) Genetic monitoring in natural perennial plant populations. Botany 89(2):75-81. https://doi. org/10.1139/b10-087

Aravanopoulos FA (2014) Genomics of Trees. In: Ramawat KG, Merillon JM, Ahuja MR (eds) Tree Biotechnology. CRC Press, Boca Raton, pp 514-557

Aravanopoulos FA (2016) Conservation and monitoring of tree genetic resources in temperate forests. Curr For Rep 2(2):29119. https://doi.org/10.1007/s40725-016-0038-8

Aravanopoulos FA, Zsuffa L (1998) Heterozygosity and biomass production in Salix eriocephala. Heredity 81:396-403. https://doi.org/10.1046/j.1365-2540.1998.00409.x

Askew GR, Blush ThD (1990) Short note: An index of phenological overlap in flowering for clonal conifer seed orchards. Silvae Genet 39(3-4): 168-171.

Atkinson AJ, Trenham PC, Fisher RN, Hathaway SA, Johnson BS, Torres SG, Moore YC (2004) Designing monitoring programs in an adaptive management context for regional multiple species conservation plans. U.S. Geological Survey Technical Report, USGS Western Ecological Research Center, Sacramento

Bada JL, Wang XYS, Hamilton H (1999) Preservation of key biomolecules in the fossil record - current knowledge and future challenges. Philos Trans R Soc Lond, B, Biol Sci 354(1379):77-86. https://doi.org/10.1098/rstb.1999.0361

Baptiste A (2020) GridExtra: Miscellaneous functions for 'grid' graphics. R Package Version 2.3. http://cran.r-project.org/ package $=$ gridExtra. Accessed 28 October 2020

Barnett B, Lewis T (1978) Outliers in statistical data. Wiley, New York

Barrett SCH, Yakimowski SB, Field DL, Pickup M (2010) Ecological genetics of sex ratios in plant populations. Philos Trans R Soc Lond, B, Biol Sci 365(1552):2549-2557. https://doi.org/10.1098/rstb.2010.0002

Barton NH, Slatkin M (1986) A quasi-equilibrium theory of the distribution of rare alleles in a subdivided population. Heredity, 56(3):409. https://doi.org/10.1038/hdy.1986.63 
Belletti P, Ferrazzini D, Piotti A, Monteleone I, Ducci F (2012) Genetic variation and divergence in Scots pine (Pinus sylvestris L.) within its natural range in Italy. Eur J Forest Res 131:1127-1138. https://doi.org/10.1007/s10342-011-0584-3

Benestan L, Gosselin T, Perrier C, Sainte-Marie B, Rochette R, Bernatchez L (2015) RAD genotyping reveals fine-scale genetic structuring and provides powerful population assignment in a widely distributed marine species, the American lobster (Homarus americanus). Mol Ecol 24 (13):3299-3315. https://doi.org/10.1111/mec.13245

Bengtsson H (2014) MatrixStats: Methods That Apply to Rows and Columns of a Matrix. R Package Version 0.10.1. rdrr.io. https://rdrr.io/rforge/matrixStats/man/matrixStats-package.html. Accessed 17 November 2020

Benjamini Y, Hochberg Y (1995) Controlling the false discovery rate: a practical and powerful approach to multiple testing. J R Stat Soc Series B Stat Methodol 57(1):289-300

Bergmann F, Gregorius HR, Larsen JB (1990) Levels of genetic variation in European Silver fir (Abies alba) - Are They Related to the Species Decline? Genetica 82(1):1-10. https://doi.org/10.1007/BF00057667.

Beuker E, Raspe S, Bastrup-Birk A, Preuhsler T (2010) Phenological Observations. Manual Part VI. In: Manual on methods and criteria for harmonized sampling, assessment, monitoring and analysis of the effects of air pollution on forests. UNECE, ICP Forests, Hamburg

Boyle TJ (2000) Criteria and indicators for the conservation of genetic diversity. In: Young A, Boshier T, Boyle T (eds) Forest conservation genetics. CSIRO Publ., Collingwood, pp 239-251

Briggs DEG (1999) Molecular taxonomy of animal and plant cuticles - selective preservation and diagenesis. Philos Trans $R$ Soc Lond, B, Biol Sci 354:7-16. https://doi.org/10.1098/rstb.1999.0356

Brousseau L, Postolache D, Lascoux M, Drouzas A D, Källman T, Leonarduzzi C, Liepelt S, et al (2016) Local adaptation in European Firs assessed through extensive sampling across altitudinal gradients in Southern Europe. PLoS ONE 11(7):1-16. https://doi.org/10.1371/journal.pone.0158216

Brownie J, Shawcross S, Theaker J, Whitcombe D, Ferrie R, Newton C, Little S (1997) The elimination of primer-dimer accumulation in PCR. Nucleic Acids Res 25:3235-3241.https://dx.doi.org/10.1093/nar/25.16.3235

Bruford MW, Davies N, Dulloo ME, Faith DP and M Walters (2017) Monitoring changes in genetic diversity. In: Walters M, Scholes RJ (eds) The GEO handbook on biodiversity observation networks, Springer Nature, Switzerland, pp 107-128

Buchan JC, Archie EA, Van Horn RC, Moss CJ, Alberts SC (2005) Locus effects and sources of error in noninvasive genotyping. Mol Ecol Notes 5:680-683.https://doi.org/10.1111/j.1471-8286.2005.01002.x

Buchholz K, Pickering, JL (1978) DBH-distribution analysis: an alternative to stand-age analysis. Bull Torrey Bot Club 105(4):1-282.https://doi.org/10.2307/2484921

Burczyk J, DiFazio, SP, Adams WT (2004). Gene flow in forest trees: how far do genes really travel? Forest Genetics 11(3-4):179.

Butler JM (2005a) Constructing STR multiplex assays. In: Carracedo A (ed) Forensic DNA typing protocols. Methods in Molecular Biology, Humana Press, pp 53-65.

Butler JM (2005b) Forensic DNA typing: biology, technology, and genetics of STR Markers. Elsevier Academic Press, London

Campbell LD, Astrin JJ, DeSouza Y, Giri J, Patel AA, Rawley-Payne M, Rush A and Sieffert N (2018) The 2018 Revision of the ISBER Best Practices: Summary of Changes and the Editorial Team's Development Process. Biopreservation and Biobanking 16(1): 3-6. https://doi.org/10.1089/bio.2018.0001

Center for Plant Conservation (2020) Guidelines for Tissue Collection and Storage Related to Genetic Studies of Rare Plants. CPC Best Plant Conservation Practices to Support Species Survival in the Wild. https://plantnucleus.com/ best-practices/guidelines-tissue-collection-and-storage-related-genetic-studies-rare-plants. Accessed 25 November 2020

Chamberlain JS, Gibbs RA, Rainer JE, Nguyen PN, Thomas C (1988) Deletion screening of the Duchenne muscular dystrophy locus via multiplex DNA amplification. Nucleic Acids Res 16:11141-11156. https://dx.doi.org/10.1093/ nar/16.23.11141

Chambers GK, MacAvoy ES (2000) Microsatellites: consensus and controversy. Comp Biochem Physiol B Biochem Mol Biol 126:455-476. https://doi.org/10.1016/s0305-0491(00)00233-9

Chapuis M, Lecoq M, Michalakis Y, Loiseau A, Sword GA, Piry S, Estoup A (2008) Do outbreaks affect genetic population structure? A worldwide survey in Locusta migratoria a pest plagued by microsatellite null alleles. Mol Ecol 17:6403653. https://doi.org/10.1111/j.1365-294X.2008.03869.x

Charlesworth B (2009) Effective population size and patterns of molecular evolution and variation. Nat Rev Genet 10(3):195205. https://doi.org/10.1038/nrg2526

Chase M, Hills J (1991) Silica gel: an ideal material for field preservation of leaf samples for DNA studies. Taxon 40:215-220. https://doi.org/10.2307/1222975 
Cipriani G, Marrazzo MT, Di Gaspero G et al (2008) A set of microsatellite markers with long core repeat optimized for grape (Vitis spp.) genotyping. BMC Plant Biol 8:1-127. https://doi.org/10.1186/1471-2229-8-127

Clarke LA, Rebelo CS, Gonçalves J, Boavida MG, Jordan P (2001) PCR amplification introduces errors into mononucleotide and dinucleotide repeat sequences. Mol Pathol 54 (5):351-353. https://doi.org/10.1136/mp.54.5.351

Csilléry K, Lalagüe H, Vendramin GG, González-Martínez SC, Fady B, Oddou-Muratorio S (2014) Detecting short spatial scale local adaptation and epistatic selection in climate-related candidate genes in European beech (Fagus sylvatica) populations. Mol Ecol 23(19):4696-4708. https://doi.org/10.1111/mec.12902

Csilléry K, Ovaskainen O, Sperisen C, Buchmann N, Widmer A, Gugerli F (2020) Adaptation to local climate in multi-trait space: evidence from Silver fir (Abies alba Mill.) populations across heterogeneous environment. Heredity 124(1):77.92. https://doi.org/10.1038/s41437-019-0240-0

Dąbrowski MJ, Bornelöv S, Kruczyk M, Baltzer N, Komorowski J (2015) True null allele detection in microsatellite loci: a comparison of methods, assessment of difficulties and survey of possible improvements. Mol Ecol Res 15(3):477-488. https://doi.org/10.1111/1755-0998.12326

Dakin EE, Avise JJ (2004) Microsatellite null alleles in parentage analysis. Heredity 93(5):504-509. https://doi.org/10.1038/ sj.hdy.6800545

De Vitis M, Hay FR, Dickie, JB, Trivedi C, Choi J, Fiegener R. (2020). Seed storage: maintaining seed viability and vigor for restoration use. Restor Ecol 28(S3):S249-S255 https://doi.org/10.1111/rec.13174

Del Castillo RF, Trujillo S (2008) Effect of inbreeding depression on outcrossing rates among populations of a tropical pine. New Phytol 177(2):517-524. https://doi.org/10.1111/j.1469-8137.2007.02260.x

Dellaporta SL, Wood J, Hicks JB (1983) A plant DNA minipreparation: version II. Plant Mol Biol Rep 1:19-21. https://doi. org/10.1007/BF02712670

Demeke T, Jenkins GR (2010) Influence of DNA extraction methods, PCR inhibitors and quantification methods on real-time PCR assay of biotechnology-derived traits. Anal Bioanal Chem Res 396(6):1977-1990. https://doi.org/10.1007/ s00216-009-3150-9

Dewoody J, Nason JD, Hipkins VD (2006) Mitigating scoring errors in microsatellite data from wild populations: Review. Mol Ecol Notes 6(4):951-957.https://doi.org/10.1111/j.1471-8286.2006.01449.x

Doyle JJ, Doyle JL (1987) A rapid DNA isolation procedure from small quantities of fresh leaf tissue. Phyto Bull 19:11-15.

Dray S, Dufour AB (2007) The Ade4 package: implementing the duality diagram for ecologists. J Stat Soft 22(4):1-20. https://doi.org/10.18637/jss.v022.i04

Ducci F, De Cuyper B, Pâques LE, Proietti R, Wolf H (2012) Reference protocols for assessment of trait and reference genotypes to be used as standards in international research projects. CRA SEL-Arezzo, Italy

Dupuis JR, Jeffrey CO, Brunet BMT, Longcore T, Johnson JJ, Sperling FAH (2018) Genomic data indicate ubiquitous evolutionary distinctiveness among populations of California metalmark butterflies. Conserv Genet 19 (5):1097-1108. https://doi.org/10.1007/s10592-018-1081-8

Edwards A, Civitello A, Hammond HA, Caskey CT (1991) DNA typing and genetic mapping with trimeric and tetrameric tandem repeats. Am J Hum Genet 49:746-756.

Edwards MC, Gibbs RA. 1994. Multiplex PCR: advantages, development, and applications. PCR Meth Appl 3:65-75. https://doi.org/10.1101/gr.3.4.s65

Eizaguirre C, Baltazar-Soares M (2014) Evolutionary conservation-evaluating the adaptive potential of species. Evol Appl 7(9):963-967. https://doi.org/10.1111/eva.12227

Elnifro EM, Ashshi AM, Cooper RJ, Klapper PE (2000) Multiplex PCR: optimization and application in diagnostic virology. Clin Microbiol Rev 13:559-570. https://doi.org/10.1128/cmr.13.4.559-570.2000

Estoup A, Garnery L, Solignac M, Cornuet JM (1995) Microsatellite variation in honeybee (Apis mellifera L.) populations: hierarchical genetic structure and test of the infinite allele and stepwise mutation models. Genetics, 140:679-695.

Estoup A, Wilson IJ, Sullivan C, Cornuet JM, Moritz C (2001) Inferring population history from microsatellite and enzyme data in serially introduced cane toads, Bufo marinus. Genetics 159(4):1671-1687.

Evanno G, Regnaut S, Goudet J (2005) Detecting the number of clusters of individuals using the software STRUCTURE: a simulation study. Mol Ecol 14: 2611-2620. doi: 10.1111/j.1365-294X.2005.02553.x

Evans DM, LR Cardon (2005) A comparison of linkage disequilibrium patterns and estimated population recombination rates across multiple populations. Am J Hum Genet 76:681-687. https://doi.org/10.1086/429274

Ewen KR, Bahlo M, Treloar SA et al (2000) Identification and analysis of error types in high-throughput genotyping. Am J Hum Genet 67:727-736. https://doi.org/10.1086/303048

Excoffier L, Lischer HEL (2010) Arlequin suite ver. 3.5: A new series of programs to perform population genetics analyses under Linux and Windows. Mol Ecol Res 10 (3):564-567. https://doi.org/10.1111/j.1755-0998.2010.02847.x 
Fazekas AJ, Steeves R, Newmaster SG (2010) Improving sequencing quality from PCR products containing long mononucleotide repeats. BioTechniques 48:277-281. https://doi.org/10.2144/000113369

Fischer MC, Foll M, Excoffier L, Heckel G (2011) Enhanced AFLP genome scans detect local adaptation in high-altitude populations of a Small rodent (Microtus arvalis). Mol Ecol 20(7):1450-1462. https://doi. org/10.1111/j.1365-294X.2011.05015.x

Fisher RA (1930) The genetical theory of natural selection, Oxford University Press, London

Flanagan SP, Forester BR, Latch EK, Aitken SN, Hoban S (2018) Guidelines for planning genomic assessment and monitoring of locally adaptive variation to inform species conservation. Evol Appl 11:1035-1052. https://doi.org/10.1111/ eva.12569

Flores-Rentería L, Krohn A (2013) Scoring microsatellite loci. Microsatellites. In: Kantartzi SK (ed) Methods in Molecular Biology. Humana Press, Totowa, pp 319-336

Flores-Rentería L, Whipple AV (2011) A new approach to improve the scoring of mononucleotide microsatellite loci. Am J Bot 98 (3):e51-e53. https://doi.org/10.3732/ajb.1000428

Francis RM (2017) Pophelper: An R package and web app to analyse and visualize population structure. Mol Ecol Res 17(1):27-32. https://doi.org/10.1111/1755-0998.12509

Frankham R, Bradshaw CJ, Brook BW (2014) Genetics in conservation management: Revised recommendations for the 50/500 rules, Red List criteria and population viability analyses. Biol Conserv 170:56-63. https://doi.org/10.1016/j. biocon.2013.12.036

Funk WC, McKay JK, Hohenlohe PA, Allendorf FW (2012) Harnessing genomics for delineating conservation units. Trends Ecol Evol 27(9):489-496. https://doi.org/10.1016/j.tree.2012.05.012

Fussi B, Westergren M, Aravanopoulos F, Baier R, Kavaliauskas D, Finžgar D, Alizoti P, Božič G, Avramidou E, Konnert M, Kraigher H (2016) Forest genetic monitoring: an overview of concepts and definitions. Environ Monit Assess 188(8):112. https://doi.org/10.1007/s10661-016-5489-7

Gagneux, P, Boesch C, Woodruff DC (1997) Microsatellite scoring errors associated with non-invasive genotyping based on nuclear DNA amplified from shed hair. Mol Ecol 6(9):861-68. https://doi.org/10.1111/j.1365-294X.1997.tb00140.x

Galan M, Cosson JF, Aulagnier S, Maillard JC, Thévenon S, Hewison AJM (2003) Cross-amplification tests of ungulate primers in roe deer (Capreolus capreolus) to develop a multiplex panel of 12 microsatellite loci. Mol Ecol Notes 3:142-146. https://doi.org/10.1046/j.1471-8286.2003.00384.x

Gerard FF, George CT, Hayman G, Chavana-Bryant C, Weedon GP (2020) Leaf phenology amplitude derived from MODIS NDVI and EVI: maps of leaf phenology synchrony for Meso- and South America. Geosci Data J 7(1):13-26. https://doi. org/10.1002/gdj3.87

Ghosh S, Karanjawala ZE, Hauser ER et al (1997) Methods for precise sizing, automated binning of alleles, and reduction of error rates in largescale genotyping using fluorescently labelled dinucleotide markers.

Goudet J (2005) Hierfstat, a package or R to compute and test hierarchical F-statistics. Mol Ecol Notes 2:184-186. https:// doi.org/10.1111/j.1471-8286.2004.00828.x

Grant WS (2007) Status and trends in genetic resources of captured fisheries. In: Bartley DM, Harvey BJ, Pullin RSV (eds) Workshop on status and trends in aquatic genetic resources. FAO Publ., Rome, pp 29-81

Gregorius H (1978) The concept of genetic diversity and its formal relationship to heterozygosity and genetic distance. Math Biosci 41(3-4):253-71. https://doi.org/10.1016/0025-5564(78)90040-8

Gregorius HR, Krauhausen J, Müller-Starck G (1986) Spatial and temporal genetic differentiation among the seed in a stand of Fagus sylvatica I. Heredity 57:255-262. https://doi.org/10.1038/hdy.1986.116

Gross A, Holdenrieder O, Pautasso M, Queloz V, Sieber TN (2013) Hymenoscyphus pseudoalbidus, the causal agent of European ash dieback. Mol Plant Pathol 15(1):5-21. https://doi.org/10.1111/mpp.12073

Gruber B, Unmack PJ, Berry OF, Georges A (2018) Dartr: An R package to facilitate analysis of SNP data generated from reduced representation genome sequencing. Mol Ecol Res 18(3):691-699. https://doi.org/10.1111/1755-0998.12745

Guichoux E, Lagache L, Wagner S, Chaumeil P, LéGer P, Lepais O, Lepoittevin C, Malausa T, Revardel E, Salin F et al (2011) Current trends in microsatellite genotyping. Mol Ecol Res 11:591-611. https://doi. org/10.1111/j.1755-0998.2011.03014.x

Gusmão L, Butler JM, Carracedo A et al (2006) DNA commission of the international society of forensic genetics (ISFG):an update of the recommendations on the use of Y-STRs in forensic analysis. Int J Legal Med 20:191-200. https://doi. org/10.1007/s00414-005-0026-1

Hahn M, Wilhelm J, Pingoud A (2001) Influence of fluorophore dye labels on the migration behaviour of polymerase chain reaction-amplified short tandem repeats during denaturing capillary electrophoresis. Electrophoresis 22:2691-2700. https://doi.org/10.1002/1522-2683(200108)22:13 
Harper AL, Mckinney LV, Nielsen LR, Havlickova L, Li Y, Trick M, Bancroft I (2016) Molecular markers for tolerance of European ash (Fraxinus excelsior) to dieback disease identified using Associative Transcriptomics. Sci Rep 6(1):1-7. https://doi.org/10.1038/srep19335

Hartmann C, Lennartz K, Ibrahim H, Coz A, Kasper Y, Lenz C, Mathur D, Polidori M (2016) Application note: stable 16-year storage of DNA purified with the QIAamp® DNA Blood Mini Kit. Qiagen GmbH. https://www.qiagen.com/us/ resources/download.aspx?id=705c6944-4633-4101-8500-a6642d253a0e\&lang=en Accessed 1 October 2020

Hartzell B, Graham K, McCord B (2003) Response of short tandem repeat systems to temperature and sizing methods. Forensic Sci Int 133:228-234. https://doi.org/10.1016/s0379-0738(03)00074-4

Hattemer HH (1991) Genetic variation in European populations of forest trees. In: Müller-Starck G, Ziehe M (eds) J.D. Sauerlander's Verlag, Frankfurt am Main, pp 271

Hay FR, Smith RD (2003) Seed maturity: when to collect seeds from wild plants. In: Smith RD, Dickie JB, Linington SH, Pritchard HW, Pro-bert RJ (eds) Seed conservation: turning science into practice. The Royal Botanic Gardens Kew, Richmond, pp 97-133

Heer K, Behringer D, Piermattei A, Bässler C, Brandl R, Fady B, Jehl H, et al (2018) Linking dendroecology and association genetics in natural populations: stress responses archived in tree rings associate with SNP genotypes in Silver fir (Abies alba Mill.). Mol Ecol 27(6):1428-1438. https://doi.org/10.1111/mec.14538

Hill CR, Butler JM, Vallone PM (2009) A 26plex autosomal STR assay to aid human identity testing. J Forensic Sci 54:10081015. https://doi.org/10.1111/j.1556-4029.2009.01110.x

Hill WG (1981) Estimation of effective population size from data on linkage disequilibrium. Genet Res 38(3):209-216. https:// doi.org/10.1017/S0016672300020553

Hill WG, Robertson A (1968) Linkage disequilibrium in finite populations. Theor Appl Genet 38:226-231. https://doi. org/10.1007/BF01245622

Hoban S, Arntzen J A, Bruford MW, Godoy JA, Rus Hoelzel A, Segelbacher G, Bertorelle G et al (2014) Comparative evaluation of potential indicators and temporal sampling protocols for monitoring genetic erosion. Evol Appl 7:984-998. https://doi.org/10.1111/eva.12197

Hoban S, Bruford M, D'Urban JJ et al (2020): Genetic diversity targets and indicators in the CBD post-2020 Global Biodiversity Framework must be improved. Biol Conserv 248:108654. https://doi.org/10.1016/j.biocon.2020.108654

Hoffman Jl, Amos W (2005) Microsatellite genotyping errors: detection approaches, common sources and consequences for paternal exclusion. Mol Ecol 14(2):599-612. https://doi.org/10.1111/j.1365-294X.2004.02419.x

Holleley CE, Geerts PG (2009) Multiplex manager 1.0: a cross-platform computer program that plans and optimizes multiplex PCR. BioTechniques 46:511-517. https://doi.org/10.2144/000113156

Hothorn T, Frank Bretz, Westfall P (2008) Simultaneous inference in general parametric models. Biom J 50(3):346-363. https://doi.org/10.1002/bimj.200810425

Hu G (1993) DNA Polymerase-catalyzed addition of nontemplated extra nucleotides to the 3' of a DNA fragment. DNA Cell Biol 12:763-770. https://doi.org/10.1089/dna.1993.12.763

Hubisz MJ, Falush D, Stephens M, Pritchard JK (2009) Inferring weak population structure with the assistance of sample group information. Mol Ecol Res 9(5):1322-1332. https://doi.org/10.1111/j.1755-0998.2009.02591.x

Idury RM, Cardon LR (1997) A simple method for automated allele binning in microsatellite markers. Genome Res 7:11041109. https://doi.org/10.1101/gr.7.11.1104

ISTA (2020) International Rules for Seed Testing. International Seed Testing Assoc., Zurich

Ivanova N, Kuzmina K (2013) Protocols for dry DNA storage and shipment at room temperature. Mol Ecol Resour 13(5):890-898. https://doi.org/10.1111/1755-0998.12134

Jayashree B, Reddy PT, Leeladevi Y, Crouch JH, Mahalakshmi V et al (2006) Laboratory information management software for genotyping workflows: applications in high throughput crop genotyping. BMC Bioinform 7:383. https://doi. org/10.1186/1471-2105-7-383

Jombart T (2008) Adegenet: an R package for the multivariate analysis of genetic markers. Bioinformatics 24(11):14031405. https://doi.org/10.1093/bioinformatics/btn129

Jombart T, Ahmed I (2011) Adegenet 1.3-1: new tools for the analysis of genome-wide SNP Data. Bioinformatics 27(21):3070-3071. https://doi.org/10.1093/bioinformatics/btr521

Jombart T, Devillard S, Balloux F (2010) Discriminant analysis of principal components: a new method for the analysis of genetically structured populations. BMC Genet 11(94):1-15. https://doi.org/10.1371/journal.pcbi.1000455

Kalinowski ST (2004) Counting alleles with rarefaction: private alleles and hierarchical sampling designs. Conserv Genet 5(4):539-43. https://doi.org/10.1023/B:COGE.0000041021.91777.1a 
Kalinowski ST, Taper ML (2006) Maximum likelihood estimation of the frequency of null alleles at microsatellite loci. Conserv Genet 7(6):991-995. https://doi.org/10.1007/s10592-006-9134-9

Kalinowski ST, Taper ML, Marshall TC (2007) Revising how the computer program CERVUS accommodates genotyping error increases success in paternity assignment. Mol Ecol 16: 1099-1106. http://dx.doi. org/10.1111/j.1365-294X.2007.03089.x

Kamvar ZN, Tabima JF, Grünwald NJ (2014) Poppr: an R package for genetic analysis of populations with clonal, partially clonal, and/or sexual reproduction. PeerJ 2:e281. https://doi.org/10.7717/peerj.281

Kimura M (1983) The neutral theory of molecular evolution. Cambridge University Press, Cambridge. https://doi. org/10.1017/CBO9780511623486

King EP (1953) On some procedures for the rejection of suspected data. J Am Stat Assoc 48(263):531-533. https://doi.org/ 10.1080/01621459.1953.10483490

Kirov G, Williams N, Sham P, Craddock N, Owen MJ (2000) Pooled genotyping of microsatellite markers in parent-offspring trios. Genome Res 10:105-115. https://doi.org/10.1101/gr.10.1.105

Kline MC, Duewer DL, Redman JW, Butler JM (2005) Results from the NIST 2004 DNA quantitation study. J Forensic Sci 50:571-578

Koetsier G, Cantor E (2019) Technical note: A practical guide to analysing nucleic acid concentration and purity with microvolume spectrophotometers. New England Biolabs Inc. https://www.neb.com/-/media/catalog/application-notes/ mvs_analysis_of_na_concentration_and_purity.pdf?rev=be7c8e19f4d34e558527496ea51623dc. Accessed 19th October 2020

Kudo G (2006) Flowering phenologies of animal-pollinated plants: reproductive strategies and agents of selection. In: Harder LD, Barrett SCH (eds) Ecology and evolution of flowers. Oxford Univ. Press, New York, pp 139-158

Lederer T, Seidl S, Graham B, Betz P (2000) A new pentaplex PCR system for forensic casework analysis. Int J Legal Med 114:87-92. https://doi.org/10.1007/s004140000161

Leroy G, Carroll EL, Bruford MW, DeWoody A, Strand A, Waits L, Wang J (2018) Next-generation metrics for monitoring genetic erosion within populations of conservation concern. Evol Appl 11:1066-1083. https://doi.org/10.1111/eva.12564

Levinson G, Gutman GA (1987) Slipped-strand mispairing: a major mechanism for DNA sequence evolution. Mol Biol Evol 4:203-221. https://doi.org/10.1093/oxfordjournals.molbev.a040442

Lewontin RC (1964) The interaction of selection and linkage. I. General considerations; heterotic models. Genetics 49:49-67.

Lewontin RC, Krakauer J (1973) Distribution of gene frequency as a test of the theory of the selective neutrality of polymorphisms. Genetics 74(1):175-195.

Lim PO, Kim HJ, Nam HG (2007) Leaf senescence. Annu Rev Plant Biol 58(1):115-136. https://doi.org/10.1146/annurev. arplant.57.032905.105316

Linkosalo T, Hakkinen R, Hari P (1996) Improving the reliability of a combined phenological time series by analyzing observation quality. Tree Physiol 16(7):661-664. https://doi.org/10.1093/treephys/16.7.661

Livingstone D, Freeman B, Tondo CL, Cariaga KA, Oleas NH, Meerow AW, Schnell RJ, Kuhn DN (2009) Improvement of high-throughput genotype analysis after implementation of a dual-curve Sybr Green I-based quantification and normalization procedure. HortScience 44:1228-1232. https://doi.org/10.21273/HORTSCI.44.5.1228

Lloyd DG (1974) Theoretical sex ratios of dioecious and gynodioecious angiosperms. Heredity 32(1):11-34. https://doi. org/10.1038/hdy.1974.2.

Lowry DB, Hoban S, Kelley JL, Lotterhos KE, Reed LK, Antolin MF, Storfer A (2017) Breaking RAD: An evaluation of the utility of restriction site-associated DNA sequencing for genome scans of adaptation. Mol Ecol Res 17(2):142-52. https://doi.org/10.1111/1755-0998.12635

Meldgaard M, Morling N (1997) Detection and quantitative characterization of artificial extra peaks following polymerase chain reaction amplification of 14 short tandem repeat systems used in forensic investigations. Electrophoresis 18:1928-1935. https://doi.org/10.1002/elps.1150181107

Menkis A, Bakys R, Åslund MS, Davydenko K, Elfstrand M, Stenlid J, Vasaitis R (2019) Identifying Fraxinus excelsior tolerant to ash dieback: Visual field monitoring versus a molecular marker. For Pathol 50(1), e12572. https://doi. org/10.1111/efp.12572

Morin PA, Martien KK, Archer FI et al (2010) Applied conservation genetics and the need for quality control and reporting of genetic data used in fisheries and wildlife management. Heredity 101:1-10. https://doi.org/10.1093/jhered/esp107

Muller-Landau HC, Condit RS, Chave J, Thomas SC, Bohlman SA, Bunyavejchewin S, Ashton, P et al (2006) Testing metabolic ecology theory for allometric scaling of tree size, growth, and mortality in tropical forests. Ecol Lett 9(5):575588. https://doi.org/10.1111/j.1461-0248.2006.00904.x 
Müller-Starck G (1989). Genetic Implications of Environmental Stress in Adult Forest Stands of Fagus Sylvatica L. In Genetic Effects of Air Pollutants. In: Scholz G, Gregorius HR, Rudin D (eds) Forest Tree Populations. Springer, Berlin, pp 128-142

Mund M, Kutsch WL, Wirth C, Kahl T, Knohl A, Skomarkova MV, Schulze ED (2010) The influence of climate and fructification on the inter-annual variability of stem growth and net primary productivity in an old-growth, mixed beech forest. Tree Physiol 30:689-704. https://doi.org/10.1093/treephys/tpq027

Müller-Starck G (1995) Genetic variation in high elevated populations of Norway spruce (Picea abies L. Karst.) in Switzerland. Silvae Genet 44:5-6.

Munguía-Rosas MA, Ollerton J, Parra-Tabla V, De-Nova JA (2011) Meta-analysis of phenotypic selection on flowering phenology suggests that early flowering plants are favoured. Ecol Lett 14(5):511-521. https://doi. org/10.1111/j.1461-0248.2011.01601.x

Namkoong G, Boyle T, El-Kassaby YA, Palmberg-Lerche C, Eriksson G, Gregorius HR, Joly H, Kremer A, Savolainen O, Wickneswari R, Young A, Zeh-Nlo M, Prabhu R (2002) Criteria and indicators for sustainable forest management: assessment and monitoring of genetic variation. Forest Resources Div. FAO, Rome

Namkoong G, Boyle T, Gregorious HR, Joly H, Savolainen O, Ratman W, Young A (1996) Testing criteria and indicators for assessing the sustainability of forest management: genetic criteria and indicators. Centre for International Forestry Research (CIFOR), Bogor

Nei M (1973) Analysis of gene diversity in subdivided populations. Proc Natl Acad Sci USA 70:3321-3323. https://doi. org/10.1073/pnas.70.12.3321

Nei M, Maruyama T, Chakraborty R (1975) The bottleneck effect and genetic variability in populations. Evolution 29(1): 1-10. https://doi.org/10.2307/2407137

Neubig KM, Whitten WM, Abbott JR, Elliott S, Soltis DE, Soltis PS (2014) Variables affecting DNA preservation in archival plant specimens. In: Applequist WL, Campbell LM (eds) DNA banking for the 21st century: proceedings of the US workshop on DNA banking. William L. Brown Center at the Missouri Botanical garden, St. Louis, Missouri, pp 81-112

Nielsen EE, Bach LA, Kotlicki P (2006) Hybridlab (Version 1.0): A program for generating simulated hybrids from population samples. Mol Ecol Notes 6(4):971-973. https://doi.org/10.1111/j.1471-8286.2006.01433.x

Nishiguchi MK, Doukakis P, Egan M, Kizirian D, Phillips A, Prendini L, Rosenbaum HC, Torrres E, Wyner Y, DeSalle R, Giribet G (2002) DNA isolation procedures. In: DeSalle R, Giribet G, Wheeler W (eds) Methods and tools in biosciences and medicine - Techniques in molecular systematics and evolution. Birkhäuser Verlag / Springer Basel AG, Basel, pp 249-287

Nunziata SO, Scott DE, Lance SL (2015) Temporal genetic and demographic monitoring of pond-breeding amphibians in three contrasting population systems. Conserv Genet 16:1335-1344. https://doi.org/10.1007/s10592-015-0743-z

O'Connell LM, Mosseler A, Rajora OP (2006) Impacts of forest fragmentation on the mating system and genetic diversity of white spruce (Picea glauca) at the landscape level. Heredity 97 (6): 418-426. https://doi.org/10.1038/sj.hdy.6800886.

Oddou-Muratorio S, Vendramin GG, Buiteveld J, Fady B (2009) Population estimators or progeny Tests: what Is the best method to assess null allele frequencies at SSR loci? Conserv Genet 10(5):1343-1347. https://doi.org/10.1007/ s10592-008-9648-4

Olejniczak M, Krzyzosiak WJ (2006) Genotyping of simple sequence repeats factors implicated in shadow band generation revisited. Electrophoresis 27:3724-3734. https://doi.org/10.1002/elps.200600136

Otárola MF, Sazima M, Solferini VN (2013) Tree size and its relationship with flowering phenology and reproductive output in Wild Nutmeg trees. Ecol Evol 3(10):3536-3550 https://doi.org/10.1002/ece3.742

Paradis E (2010) Pegas: an R package for population genetics with an integrated-modular approach. Bioinformatics 26(3):419-420. https://doi.org/10.1093/bioinformatics/btp696.

Peakall R, Smouse PE (2006) Genalex 6: Genetic analysis in Excel. Population genetic software for teaching and research. Mol Ecol Notes 6(1):288-295 https://doi.org/10.1111/j.1471-8286.2005.01155.x

Pedrini S, Gibson-Roy P, Trivedi C, Gálvez-Ramírez C, Hardwick K, Shaw N, Frischie S, Laverack G, Dixon K (2020) Collection and production of native seeds for ecological restoration. Restor Ecol 28:S227-S237. https://doi.org/10.1111/ rec.13190

Petit RJ, El Mousadik A, Pons O (2008) Identifying populations for conservation on the basis of genetic markers. Conserv Biol 12(4):844-855. https://doi.org/10.1111/j.1523-1739.1998.96489.x

Pluess AR, Frank A, Heiri C, Lalagüe H, Vendramin GG, Oddou-Muratorio S (2016) Genome-environment association study suggests local adaptation to climate at the regional scale in Fagus sylvatica. New Phytol 210 (2):589-601. https:// doi.org/10.1111/nph.13809

Pohlert T (2020) Calculate pairwise multiple comparisons of mean rank sums extended. R package version 1.7.0. PMCMRplus. https://CRAN.R-project.org/package=PMCMRplus. Accessed 30 October 2020 
Porcher E, Lande R (2016) Inbreeding depression under mixed outcrossing, self-fertilization and sib-mating. BMC Evol Biol 16(1):105. https://doi.org/10.1186/s12862-016-0668-2

Prendini L, Hanner R, DeSalle R (2002) Obtaining, storing, and archiving specimens and tissue samples for use in molecular studies. In: DeSalle R, Giribet G, Wheeler W (eds) Methods and tools in biosciences and medicine Techniques in molecular systematics and evolution. Birkhäuser Verlag / Springer Basel AG, Basel, pp 176-248.

Pritchard, JK, Stephens M, Donnelly P (2000) Inference of population structure using multilocus genotype data. Genetics 155: 945-959. https://doi.org/10.1007/s10681-008-9788-0

Qiagen (2010) Multiplex PCR Kit Handbook. https://www.qiagen.com/si/resources/download.aspx?id=a541a49c-cd0640ca-b1d2-563d0324ad6c\&lang=en. Accessed 10 October 2020

R Core Team (2020) R: A language and environment for statistical computing. R Foundation for Statistical Computing. https://www.R-project.org/. Accessed 28 October 2020

Rajora OP, Mosseler A, Major JE (2000a) Indicators of population viability in red spruce, Picea rubens. II. Genetic diversity, population structure, and mating behavior. Can J Bot 78:941-956. https://doi.org/10.1139/b00-066

Rajora OP, Rahman MH, Buchert GP, Dancik BP (2000b) Microsatellite DNA analysis of genetic effects of harvesting in old-growth eastern white pine (Pinus strobus) in Ontario, Canada. Mol Ecol 9(3):339-348. https://doi. org/10.1046/j.1365-294X.2000.00886.x

Rajora OP, Pluhar SA (2003) Genetic diversity impacts of forest fires, forest harvesting, and alternative reforestation practices in black spruce (Picea mariana). Theor Appl Genet 106(7):1203-1212. https://doi.org/10.1007/ s00122-002-1169-9

Renshaw MA, Saillant E, Bradfield SC, Gold JR (2006) Microsatellite multiplex panels for genetic studies of three species of marine fishes: red drum (Sciaenops ocellatus), red snapper (Lutjanus campechanus), and cobia (Rachycentron canadum). Aquaculture 253:731-735. https://doi.org/10.1016/j.aquaculture.2005.09.012

Rice WR (1989) Analyzing table of statistical tests. Evolution 43(1):223-225. https://doi.org/10.1111/j.1558-5646.1989. tb04220.x

Rithidech K, Dunn JJ (2003) Combining multiplex and touchdown PCR for microsatellite analysis. Methods Mol Biol 226:295-300. https://doi.org/10.1385/1-59259-384-4:295

Ritland K (1989) Correlated matings in the partial selfer Mimulus guttatus. Evolution 43(4):848-859. https://doi. org/10.1111/j.1558-5646.1989.tb05182.x

Ritland K (2002) Extensions of models for the estimation of mating systems using an independent loci. Heredity 88:221-228. https://doi.org/10.1038/sj.hdy.6800029

Ritland K, Jain S (1981) A model for the estimation of outcrossing rate and gene frequencies using an independent loci. Heredity 47(1):35-52. https://doi.org/10.1038/hdy.1981.57

Roesti M, Salzburger W, and Berner D (2012) Uninformative polymorphisms bias genome scans for signatures of selection. BMC Evol Biol 12(1):94. https://doi.org/10.1186/1471-2148-12-94

Roschanski AM, Csilléry K, Liepelt S, Oddou-Muratorio S, Ziegenhagen B, Huard F, Ullrich KK, Postolache D, Vendramin GG, Fady B (2016) Evidence of divergent selection for drought and cold tolerance at landscape and local scales in Abies alba Mill. In the French Mediterranean Alps. Mol Ecol 25(3):776-794. https://doi.org/10.1111/mec.13516

Rousset F (2008) Genepop'007: A complete re-implementation of the Genepop Software for Windows and Linux. Mol Ecol Res 8(1):103-106.https://doi.org/10.1111/j.1471-8286.2007.01931.x

Rousset F (2017) Genepop version 4.6. 9. Semantic Scholar. https://www.semanticscholar.org/paper/Genepop-version4.6.9-Rousset/88ae28e934a876a0fd981468cfe8d0517b40714b. Accessed 30 October 2020

Scandura M, Capitani C, lacolina L, Marco A (2006) An empirical approach for reliable microsatellite genotyping of wolf DNA from multiple non-invasive sources. Conserv Genet 7:813-823. https://doi.org/10.1007/s10592-005-9106-5

Schaber J, Badeck, FW (2002) Evaluation of methods for the combination of phenological time series and outlier detection. Tree Physiol 22(14):973-982. https://doi.org/10.1093/treephys/22.14.973

Schuster D, Appleby D (1983) Does freezing and thawing of DNA solutions insert nicks in the double helix. Focus 5(2):1. https://doi.org/10.1.1.713.3395

Schwarz G (1978) Estimating the dimension of a model. Ann Stat 6(2):462-464.

Seifert T, Müller-Starck G (2009) Impacts of fructification on biomass production and correlated genetic effects in Norway spruce (Picea abies [L.] Karst.). Eur J For Res 128:155. https://doi.org/10.1007/s10342-008-0219-5

Selkoe KA, Toonen RJ (2006) Microsatellites for ecologists: a practical guide to using and evaluating microsatellite markers. Ecol Lett 9(5):615.629. https://doi.org/10.1111/j.1461-0248.2006.00889.x 
Semagn K, Babu R, Hearne S, Olsen M (2014) Single nucleotide polymorphism genotyping using kompetitive allele specific PCR (KASP): overview of the technology and its application in crop improvement. Mol Breed 33(1):1-14. https://doi. org/10.1007/s11032-013-9917-x

Sgueglia J, Geiger S, Davis J (2003) Precision studies using the ABI Prism 3100 Genetic Analyzer for forensic DNA analysis. Anal Bioanal Chem 376:1247-1254. https://doi.org/10.1007/s00216-003-1998-7

Signorell A (2020) Tools for Descriptive Statistics. DescTools. https://cran.r-project.org/package=DescTools. Accessed 30 October 2020

Slatkin M (1985) Rare alleles as indicators of gene flow. Evolution 39(1):53-65. https://doi.org/10.1111/j.1558-5646.1985. tb04079.x

Slatkin M (1987) Gene flow and the geographic structure of natural populations. Science 236(4803):787-792. https://doi. org/10.1126/science.3576198

Slatkin M, Barton NH (1989) A comparison of three indirect methods for estimating average levels of gene flow. Evolution 43(7):1349-1368. https://doi.org/10.1111/j.1558-5646.1989.tb02587.x

Slatkin, M (2008) Linkage disequilibrium: understanding the genetic past and mapping the medical future. Nat Rev Genet 9(6):477-485. https://doi.org/10.1038/nrg2361.Linkage

Smouse PE, Sork VL (2004) Measuring pollen flow in forest trees: a comparison of alternative approaches. Forest Ecol Manage 197:21-38. https://doi.org/10.1016/j.foreco.2004.05.049

Soltis PS, Soltis DE (1993) Ancient DNA. Prospects and limitations. N Z J Bot 31:203-209. https://doi.org/10.1080/002882 5X.1993.10419497

Sork VL, Nason J,Campbell DR, Fernández, J F (1999) Landscape approaches to the study of gene flow in plants. Trends in Ecol Evol 14(6):219-224. https://doi.org/10.1016/s0169-5347(98)01585-7

Sork VL, Smouse PE (2006) Genetic analysis of landscape connectivity in tree populations. Landscape Ecol 21(6):821-836. https://doi.org/10.1007/s10980-005-5415-9

Stocks JJ, Metheringham CL, Plumb WJ, Lee SJ, Kelly LJ, Nichols RA, Buggs, RJA (2019) Genomic basis of European ash tree resistance to ash dieback fungus. Nat Ecol Evol 3(12):1686-1696. https://doi.org/10.1038/s41559-019-1036-6

Summers K, Amos W (1997) Behavioral, ecological, and molecular genetic analyses of reproductive strategies in the Amazonian Dart-Poison Frog, Dendrobates ventrimaculatus. Behav Ecol 8(3):260-267. https://doi.org/10.1093/ beheco/8.3.260

Sytsma KJ, Schaal BA (1985) Genetic variation, differentiation, and evolution in a species complex of tropical shrubs based on isozymic data. Evolution 39:582-593. https://doi.org/10.1111/j.1558-5646.1985.tb00396.x

Taberlet P, Griffin S, Goossens B, Questiau S, Manceau V, Escaravage N, Waits LP, Bouvet J (1996) Reliable genotyping of samples with very low DNA quantities using PCR. Nucleic Acids Res 24(16):3189-3194. https://doi.org/10.1093/ nar/24.16.3189

Thomas WK, Paabo S (1994) DNA sequences from old tissue remains. In: Zimmer EA, White TJ, Cann RL, Wilson AC (eds) Methods in Enzymology. Molecular Evolution: Producing the Biochemical Data. Academic Press, San Diego, pp 406-419.

Tyrmi JS, Vuosku J, Acosta JJ, Li Z, Sterck L, Cervera MT, Savolainen O, Pyhäjärvi T (2020) Genomics of clinal local adaptation in Pinus sylvestris under continuous environmental and spatial genetic setting. G3: Genes, Genomes, Genetics 10(8):2683-2696. https://doi.org/10.1534/g3.120.401285

Urbanek S, Horner J (2020) Cairo: R graphics device using cairo graphics library for creating high-quality bitmap (PNG, JPEG, TIFF), vector (PDF, SVG, PostScript) and display (X11 and Win32) output. R Package Version 1.5-12.2. Https:// CRAN.R-Project.Org/Package=Cairo. Accessed 28 October 2020

Urquhart A, Kimpton CP, Downes TJ, Gill P (1994) Variation in Short Tandem Repeat sequences-a survey of twelve microsatellite loci for use as forensic identification markers. International Journal of Legal Medicine 107:13-20. https:// doi.org/10.1007/BF01247268

Vallone PM, Butler JM (2004) AutoDimer: a screening tool for primer dimer and hairpin structures. BioTechniques 37:226-231. https://doi.org/10.2144/04372ST03

Vallone PM, Hill CR, Butler JM (2008) Demonstration of rapid multiplex PCR amplification involving 16 genetic loci. Forensic Sci Int Genet 3:42-45. http://dx.doi.org/10.1016/j.fsigen.2008.09.005

van Asch B, Pinheiro R, Pereira R et al (2010) A framework for the development of STR genotyping in domestic animal species: characterization and population study of 12 canine X-chromosome loci. Electrophoresis 31:303-308. https:// doi.org/10.1002/elps.200900389

Van Oosterhout C, Hutchinson WF, Wills DP, Shipley P (2004) MICRO-CHECKER: software for identifying and correcting genotyping errors in microsatellite data. Mol Ecol Notes 4(3):535-538. https://doi.org/10.1111/j.1471-8286.2004.00684.x 
Walters C, Reilley AA, Reeves PA, Baszczak J, Richards CM (2006) The utility of aged seeds in DNA banks. Seed Sci Res 16(3):169. https://doi.org/10.1079/SSR2006246

Waples RS, Do C (2010) Linkage disequilibrium estimates of contemporary Ne using highly variable genetic markers: a largely untapped resource for applied conservation and evolution. Evol Appl 3(3):244-262.

Weeks DE, Conley YP, Ferrell RE, Mah TS, Gorin MB (2002) A tale of two genotypes: consistency between two highthroughput genotyping centers. Genome Res 12:430-435. https://dx.doi.org/10.1101/gr.211502

Weir BS (1979) Inferences about linkage disequilibrium. Biometric 35(1):235-254. https://doi.org/10.2307/2529947

Weir BS, Cockerham CC (1984) Estimating F-statistics for the analysis of population structure. Evolution 38(6):1358-1370. https://doi.org/10.2307/2408641

Weiss KM, Clark AG (2002) Linkage disequilibrium and the mapping of complex human traits. Trends Genet 18:19-24. https://doi.org/10.1016/s0168-9525(01)02550-1

Whitlock MC, Lotterhos KE (2015) Reliable detection of loci responsible for local adaptation: Inference of a null model through trimming the distribution of FST. Am Nat 186:S24-S36. https://doi.org/10.1086/682949

Whittaker, JC, Harbord RM, Boxall N, Mackay I, Dawson G, Sibly RM (2003) Likelihood-based estimation of microsatellite mutation rates. Genetics 164(2):781-787.

Wickham H (2016) Ggplot2: Elegant graphics for data analysis. Springer-Verlag, New York

Wickham H, François R, Henry L, Müller K (2020) Dplyr: A grammar of data manipulation. Cran. https://CRAN.R-project. org/package=dplyr. Accessed 29 October 2020

Wickham H, Henry L (2020) Tidyr: Easily tidy data with 'spread' and 'gather' functions. Cran. https://cran.r-project.org/web/ packages/tidyr/index.html. Accessed 28 October 2020

Wickneswari R, Ho WS, Lee KS, Lee CT (2004) Impact of disturbance on population and genetic structure of tropical forest trees. For Genet 11(3-4):193-201.

Wilfinger WW, Mackey K, Chomczynski P (1997) Effect of pH and ionic strength on the spectrophotometric assessment of nucleic acid purity. BioTechniques 22:474-481. https://doi.org/10.2144/97223st01

Willoughby JR, Ivy, JA, Lacy RC, Doyle JM, DeWoody JA (2017) Inbreeding and selection shape genomic diversity in captive populations: Implications for the conservation of endangered species. PLoS ONE 12(4):e0175996. https://doi. org/10.1371/journal.pone.0175996

Winter DJ (2012) MMOD: an R library for the calculation of population differentiation statistics. Molecular Ecology Resources 12(6):1158-1160. https://doi.org/10.1111/j.1755-0998.2012.03174.x

Wright S (1931) Evolution in Mendelian populations. University of Chicago Press, Chicago

Wright S (1938) Size of population and breeding structure in relation to evolution. Science 87:430-431. https://www.jstor. org/stable/2457575

Wright S (1969) Evolution and the genetics of populations: The theory of gene frequencies. The University of Chicago Press, Chicago

Xie, Y (2020) Knitr: A General-Purpose Package for Dynamic Report Generation in R. R Package Version 1.28. Cran. https://cran.r-project.org/web/packages/knitr/index.html. Accessed 28 October 2020

Yagi N, Satonaka K, Horio M, Shimogaki H et al (1996) The role of DNAse and EDTA on DNA degradation in formaldehyde fixed tissues. Biotech Histochem 71:123-129. https://doi.org/10.3109/10520299609117148

Yamamichi M, Innan H (2012) Estimating the migration rate from genetic variation data. Heredity 108(4):362-363. https://doi. org/10.1038/hdy.2011.83

Ziemann M, Eren Y, El-Osta A (2016) Gene name errors are widespread in the scientific literature. Genome Biol 17:177. https://doi.org/10.1186/s13059-016-1044-7 



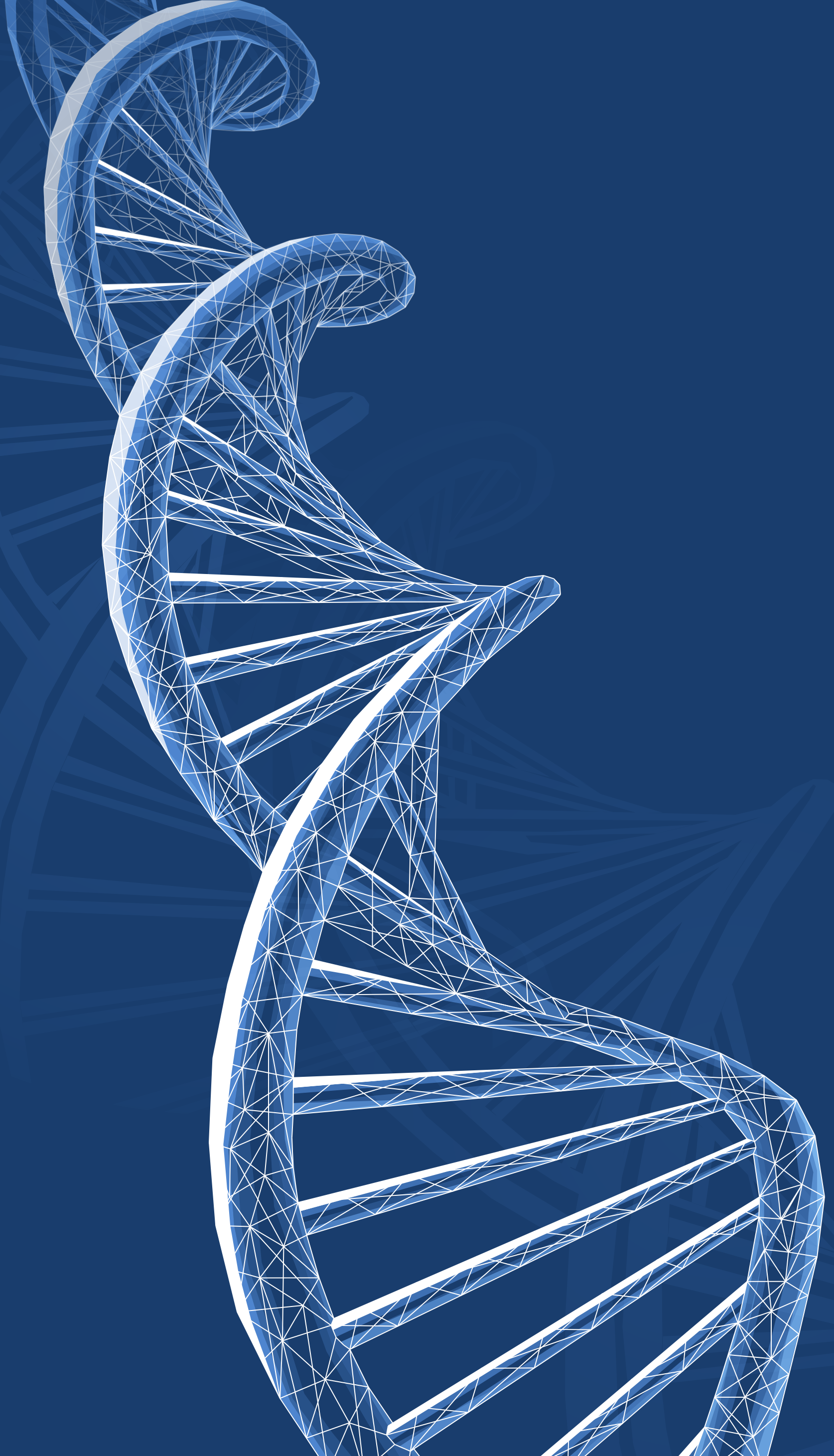




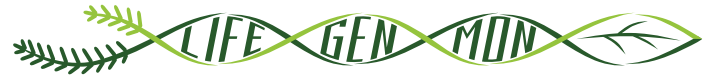 \\ LIFE13 ENV/S/ $/ 000148$}

\section{Handbuch zum Forstgenetisches Monitoring}

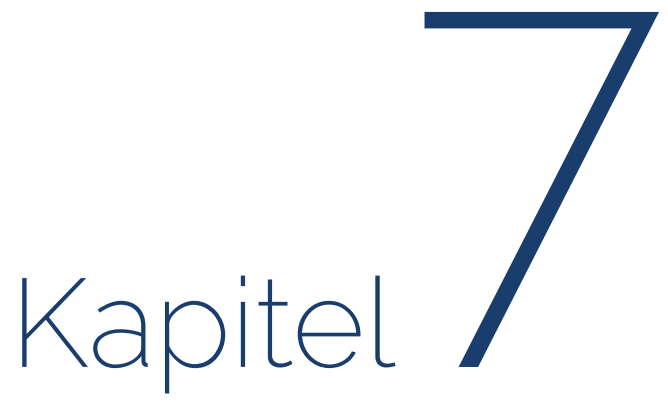

\section{KOSTEN DES FGM}

Marko BAJC ${ }^{1}$, Filippos A. ARAVANOPOULOS ${ }^{3}$, Darius KAVALIAUSKAS ${ }^{2}$, Marjana WESTERGREN' ${ }^{1}$, Fotios KIOURTSIS ${ }^{4}$, Evangelia AVRAMIDOU ${ }^{3,6}$, Pavlos BEKIAROGLOU ${ }^{4}$, Pavlos CHASILIDIS ${ }^{4}$, Rok DAMJANIĆ ${ }^{1}$, Natalija DOVIČ ${ }^{1}$, Domen FINŽGAR ${ }^{1,5}$, Barbara FUSSI' ${ }^{2}$ Ermioni MALLIAROU ${ }^{3}$, Georgios ROUSAKIS ${ }^{4}$, Chryse SARVANI ${ }^{4}$, Hojka KRAIGHER ${ }^{1}$

Zitat: Bajc et al. (2020) Kosten des FGM. In: Bajc et al. (Ed.) Handbuch zum forstgenetischen Monitoring. Slowenisches Forstinstitut: Verlag Silva Slovenica, Ljubljana, S. 143-158. http://dx.doi. org/10.20315/SFS.176

Institut:

1. Slowenisches Forstinstitut (SFI), Slowenien

2. Bayerisches Amt für Waldgenetik (AWG), Deutschland

3. Aristoteles-Universität Thessaloniki (AUTh), Griechenland

4. Generaldirektion für Forst und Landwirtschaft, Dezentrale Verwaltung von MazedonienThrakien, Griechenland

5. Institut für Evolutionsbiologie, Universität Edinburgh, UK

6. Institut für Mediterrane Waldökosysteme, DEMETER, Griechenland 


\subsection{EINLEITUNG}

Ziel dieses Kapitels ist es, die mit der Durchführung des forstgenetischen Monitorings verbundenen Kosten darzustellen. Die in diesem Dokument vorgestellte Kostenschätzung basiert auf der Analyse der tatsächlichen Kosten der im Rahmen des LIFEGENMON-Projekts durchgeführten Aktivitäten. Jede teilnehmende Partnerinstitution erfasste ihre Kosten einschließlich Materialkosten, ausgelagerten Kosten, Reisekosten und Arbeitskosten während der gesamten Projektdauer. Die Kosten wurden in drei grundlegende Kostenarten unterteilt: 1) Materialkosten, 2) Personalkosten (effektive Arbeit) und 3) Reisekosten. Da die Kosten der Personenarbeitsstunden für die einzelnen Tarifgruppen von Land zu Land sehr unterschiedlich sein können, werden die Personalkosten sowohl als Personenstunden (Zeitaufwand) als auch als tatsächliche Lohnkosten dargestellt. Die Kosten wurden pro Baumart/Land/Monitoringniveau/Indikator/Verifikator untersucht.

\subsection{KOSTENSCHÄTZUNG}

\subsubsection{Annahmen zur Kostenschätzung}

Da die für die Durchführung des forstgenetischen Monitorings anfallenden Kosten von vielen verschiedenen Faktoren abhängen, einschließlich der Biologie der überwachten Baumarten und der Entfernung zu den Monitoringflächen, wurden bei den vorgestellten Berechnungen zur Kostenabschätzung bestimmte Annahmen berücksichtigt, um die Ergebnisse zwischen den Ländern so vergleichbar wie möglich zu machen:

1. Die Kosten wurden für ein 10-Jahres Monitoringintervall berechnet.

2. Beide untersuchten Arten, sowohl die Rotbuche (Fagus sylvatica L.) als auch die Weißtanne/König-BorisTanne (Abies alba Mill./Abies borisii-regis Mattf.) sind bestandsbildende Arten. Es ist davon auszugehen, dass für verstreut vorkommende Arten alle Außenaufnahmen unvermeidbar mehr Personenstunden erfordern würden.

3. Die Kosten werden inklusive Mehrwertsteuer ausgewiesen (Deutschland 19\%, Griechenland 24\%, Slowenien $22 \%)$.

4. Die hier veranschlagten Kosten gelten für optimierte Arbeitsabläufe, wie sie routinemäßig von gründlich eingearbeitetem und erfahrenem Personal durchgeführt werden. Hierbei ist zu berücksichtigen, dass bei der Einführung neuer Methoden oder Untersuchungsverfahren während der Einarbeitungs- und Optimierungsphase zusätzliche Kosten entstehen können.

5. Auswahl der Monitoringflächen: Im Zuge der Auswahl der Monitoringflächen wurden fünf (5) Besuche der in Frage kommenden Flächen mit einer durchschnittlichen Entfernung von 100 km zwischen betreuender Institution und Monitoringfläche berechnet.

6. Materialkosten: Hier wurden die von den LIFEGENMON-Projektpartnern gemeldeten tatsächlichen Kosten für Material und ausgelagerte Tätigkeiten einbezogen.

7. Arbeitskosten: Berücksichtigt wurden die durchschnittlichen Gesamtkosten pro Personenarbeitsstunde je Tarifgruppe und Land.

8. Die Reisekosten wurden für alle Länder und Baumarten kalkulatorisch veranschlagt ausgehend von einer Entfernung von $100 \mathrm{~km}$ zwischen der Versuchsfläche und der betreuenden Institution. Die Reisezeiten wurden anhand der durchschnittlichen Reisegeschwindigkeit zu den LIFEGENMON FGM-Flächen für jedes Land separat berechnet.

9. Einrichtung der Monitoringfläche: Während des LIFEGENMON-Projekts wurden mehrere Änderungen am ursprünglichen FGM-Verfahren vorgenommen: 1) Das Design der FGM-Flächen wurde dahingehend geändert, dass - wo immer möglich - sowohl die Auswahl des Standorts innerhalb des untersuchten Bestandes als 
auch die der Einzelbäume innerhalb der Monitoringfläche randomisiert wurde; 2) der Stichprobenumfang wurde für Altbäume von 250 auf 50 und für Naturverjüngung (NV) von 200 auf 50 reduziert. Grundlage hierfür war eine Untersuchung zur Bestimmung der minimal erforderlichen Anzahl von Proben für die Bewertung molekulargenetischer Verifikatoren auf Basis der im Rahmen der ersten FGM-Untersuchung gewonnenen Daten. Weiterhin wurde die Anzahl der Naturverjüngungs- (NV)-Plots innerhalb der FGM-Fläche von 4 NR-Flächen auf 20 NR-Flächen erhöht (für Einzelheiten siehe Kapitel 3 „Einrichtung und Instandhaltung der Monitoringflächen“). Das neue Flächendesign wurde nur in Slowenien getestet. Alle mit dem veränderten Design sowie dem reduzierten Stichprobenumfang zusammenhängenden Kosten wurden durch die Anpassung der Kosten aller Partner um denselben Umrechnungsfaktor, ermittelt durch den Vergleich der Kosten des verbesserten Designs der Monitoringflächen in Slowenien mit den dort ermittelten Kosten des ursprünglichen Flächendesigns berechnet.

\section{Außenaufnahmen und Messungen:}

Die berücksichtigte Anzahl der Begehungen, die für die Außenaufnahmen erforderlich waren, basiert auf den erfassten Durchschnittswerten aller drei am LIFEGENMON-Projekt beteiligten Länder. Die tatsächliche Anzahl der Flächenbesuche hängt von der untersuchten Baumart sowie den lokalen Umweltbedingungen ab.

a. Mortalität / Überlebensrate: Für alle Monitoringniveaus: Erfassung aller 50 untersuchten Bäume je Monitoringniveau.

\section{b. Austrieb:}

Basisniveau: nicht untersucht;

Standardniveau: zwei Erfassungen je Monitoringintervall, sechs Werte pro Erfassung;

Intensivniveau: zehn Erfassungen je Monitoringintervall, sechs Werte pro Erfassung.

\section{c. Blüte:}

Basisniveau: zehn Erfassungen je Monitoringintervall auf Bestandesebene, ein Wert pro Erfassung;

Standard- und Intensivniveau: zwei Erfassungen je Monitoringintervall auf Einzelbaumebene, zwei Werte pro Erfassung.

\section{d. Fruktifikation:}

Basisniveau: zehn Erfassungen je Monitoringintervall auf Bestandesebene, ein Wert pro Erfassung;

Standard- und Intensivniveau: zwei Erfassungen je Monitoringintervall auf Einzelbaumebene, zwei Werte pro Erfassung.

\section{e. Abundanz der Naturverjüngung (NV):}

Basisniveau: zehn Erfassungen je Monitoringintervall auf Bestandesebene, ein Wert pro Erfassung; Standardniveau: drei Erfassungen von NV-Plots je Monitoringintervall, ein Wert pro Erfassung; Intensivniveau: drei Erfassungen von NV-Plots während des ersten Monitoringintervalls, sechs Erfassungen von NV-Plots während der folgenden Monitoringintervalle, ein Wert pro Erfassung.

\section{f. Seneszenz:}

Basisniveau: nicht untersucht;

Standardniveau: zwei Erfassungen je Monitoringintervall, zwei Werte pro Erfassung;

Intensivniveau: zehn Erfassungen je Monitoringintervall, zwei Werte pro Erfassung. 


\section{g. Durchmesserklassenverteilung:}

Basisniveau: nicht untersucht;

Standard- und Intensivniveau: eine Erfassung aller 50 untersuchten Altbäume je Monitoringintervall, ein Wert pro Erfassung.

\section{h. Höhenklassenverteilung:}

Basisniveau: nicht untersucht;

Standard- und Intensivniveau: eine Erfassung aller 50 untersuchten Altbäume je Monitoringintervall, ein Wert pro Erfassung.

i. In Griechenland wurde die phänologische Beurteilung mittels hochauflösender Fotodokumentation und Drohnenbildern durchgeführt, gefolgt von einer digitalen Bildanalyse. Obwohl dieser Ansatz eine vollständige Dokumentation und Verifizierung der Beobachtungen ermöglicht, erwies er sich im Vergleich zur visuellen Erfassung vor Ort als wesentlich zeit- und arbeitsintensiver. Es wird daher nicht empfohlen, inn als FGM-Standardverfahren im FGM zu vorzusehen.

\section{Probennahme für die Laboranalyse:}

\section{a. Altbäume:}

Basisniveau: nicht untersucht;

Standard- und Intensivniveau: eine Erfassung aller 50 untersuchten Altbäume im ersten Monitoringintervall.

\section{b. Naturverjüngung:}

Basisniveau: nicht untersucht;

Standard- und Intensivniveau: eine Erfassung von 50 NV-Keimlingen für jedes untersuchte Fruktifikationsereignis je Monitoringintervall; das entspricht zwei Begehungen und 100 NV-Befunden je Monitoringintervall.

\section{Saatgut:}

Basis- und Standardniveau: nicht untersucht;

Intensivniveau: Beprobung von Samen von 20 der 50 Altbäume, zufällig ausgewählt für jedes untersuchte Fruktifikationsereignis je Monitoringintervall; das entspricht zwei Flächenbesuchen je Monitoringintervall.

12. Laboranalysen: Für die Genotypisierung wurde nur die Analyse der SSR-Marker bei der Gesamtberechnung berücksichtigt. SNP-Marker wurden im LIFEGENMON-Projekt zwar auch analysiert, allerdings nur für eine Teilmenge von Proben aus dem ersten Monitoringintervall, weshalb mit dem SNP-Datensatz nicht alle Vergleichsanalysen durchgeführt werden konnten. Zusätzlich wurde für jede der untersuchten Arten eine unterschiedliche Anzahl von SNPs und Proben analysiert, wodurch der Kostenvergleich weniger aussagekräftig ist.

13. In den dargestellten Tabellen wurden alle Werte auf den nächstliegenden ganzzahligen Wert gerundet.

14. Alle Kosten wurden berechnet für die Untersuchung einer einzelnen Monitoringfläche für eine Baumart.

15. Die Kosten eines durchschnittlichen 10-Jahres-Monitoringintervalls wurden aus dem Durchschnitt der ersten 50 Monitoringjahre berechnet, d.h. der ersten fünf Monitoringintervalle. 


\subsubsection{Kostenschätzung}

\subsubsection{Kosten für ein durchschnittliches 10-Jahres FGM-Intervall je Baumart, Land und Monitoringniveau}

Ausführlichere Informationen zur Kostenabschätzung, einschließlich Informationen über die für die Durchführung der verschiedenen Monitoringaktivitäten erforderlichen Personenstunden je Tarifgruppe sind im Anhang im Unterkapitel 10.3 „Supplementary tables for Chapter 7: Cost assessment“ aufgeführt.

Tabelle 7.1: Kosten eines durchschnittlichen 10-Jahres Monitoringintervalls pro Fläche, Baumart, Land und Monitoringniveau. Alle angegebenen Werte in Euro $(€)$. DE - Deutschland; GR p - Griechenland, photographische Analyse; GR v - Griechenland, visuelle Aufnahme vor Ort; SI - Slowenien.

\begin{tabular}{|c|c|c|c|c|c|c|c|}
\hline Niveau & Land & $\begin{array}{l}\text { Flächenaus- } \\
\text { wahl }\end{array}$ & $\begin{array}{l}\text { Flächenein- } \\
\text { richtung }\end{array}$ & $\begin{array}{l}\text { Außenaufnah- } \\
\text { men }\end{array}$ & Messungen & Laboranalyse & Summe \\
\hline \multirow{3}{*}{ Basis } & $\mathrm{DE}$ & 832 & 426 & 9,472 & 0 & 0 & 10,730 \\
\hline & $\mathrm{GR}$ & 388 & 307 & 4,422 & 0 & 0 & 5,117 \\
\hline & $\mathrm{SI}$ & 415 & 186 & 4,883 & 0 & 0 & 5,484 \\
\hline \multirow{4}{*}{ Standard } & $\mathrm{DE}$ & 832 & 2,184 & 25,530 & 460 & 5,198 & 34,203 \\
\hline & GR $p$ * & 388 & 1,455 & 25,328 & 377 & 3,182 & 30,729 \\
\hline & $\mathrm{GR} v$ * & 388 & 1,455 & 12,329 & 377 & 3,182 & 17,730 \\
\hline & $\mathrm{SI}$ & 415 & 1,235 & 14,286 & 346 & 3,522 & 19,805 \\
\hline \multirow{4}{*}{ Intensiv } & $\mathrm{DE}$ & 832 & 2,184 & 53,872 & 6,434 & 21,088 & 84,409 \\
\hline & GR $p^{*}$ & 388 & 1,455 & 79,735 & 12,036 & 18,605 & 112,219 \\
\hline & $\mathrm{GR} v$ * & 388 & 1,455 & 26,697 & 12,036 & 18,605 & 59,181 \\
\hline & SI & 415 & 1,235 & 31,880 & 5,748 & 18,394 & 57,674 \\
\hline \multicolumn{8}{|c|}{ Abies alba Mill./ Abies borisii-regis Mafft. } \\
\hline Niveau & Land & $\begin{array}{l}\text { Flächenaus- } \\
\text { wahl }\end{array}$ & $\begin{array}{l}\text { Flächenein- } \\
\text { richtung }\end{array}$ & $\begin{array}{l}\text { Außenaufnah- } \\
\text { men }\end{array}$ & Messungen & Laboranalyse & Summe \\
\hline \multirow{3}{*}{ Basis } & $\mathrm{DE}$ & 832 & 426 & 9,472 & 0 & 0 & 10,730 \\
\hline & GR & 388 & 307 & 4,422 & 0 & 0 & 5,117 \\
\hline & $\mathrm{SI}$ & 415 & 186 & 4,883 & 0 & 0 & 5,484 \\
\hline \multirow{4}{*}{ Standard } & $\mathrm{DE}$ & 832 & 2,184 & 23,272 & 415 & 5,198 & 31,900 \\
\hline & GR $p^{*}$ & 388 & 1,455 & 22,156 & 377 & 2,856 & 27,232 \\
\hline & $\mathrm{GR} v$ * & 388 & 1,455 & 11,642 & 377 & 2,856 & 16,718 \\
\hline & $\mathrm{SI}$ & 415 & 1,235 & 13,420 & 346 & 3,309 & 18,726 \\
\hline \multirow{4}{*}{ Intensiv } & $\mathrm{DE}$ & 832 & 2,184 & 47,367 & 5,670 & 20,892 & 76,945 \\
\hline & GR $p$ * & 388 & 1,455 & 63,843 & 7,044 & 16,007 & 88,737 \\
\hline & $\mathrm{GR} v$ * & 388 & 1,455 & 23,330 & 7,044 & 16,007 & 48,224 \\
\hline & $\mathrm{SI}$ & 415 & 1,235 & 28,147 & 4,184 & 16,577 & 50,559 \\
\hline
\end{tabular}

* In Griechenland wurde die phänologische Beurteilung mithilfe hochauflösender Digitalphotographie und Bildanalyse durchgeführt, was die Gesamtkosten des FGM im Vergleich zu dem in Deutschland und Slowenien angewandten Ansatz, der sich auf visuelle Erfassung vor Ort stützte, deutlich erhöhte. Um besser vergleichbare Ergebnisse zu erhalten, wurden die erwartbaren Kosten für die visuelle Erfassung der Phänologie in Griechenland auf Grundlage von Daten aus Deutschland und Slowenien ebenfalls erhoben. 


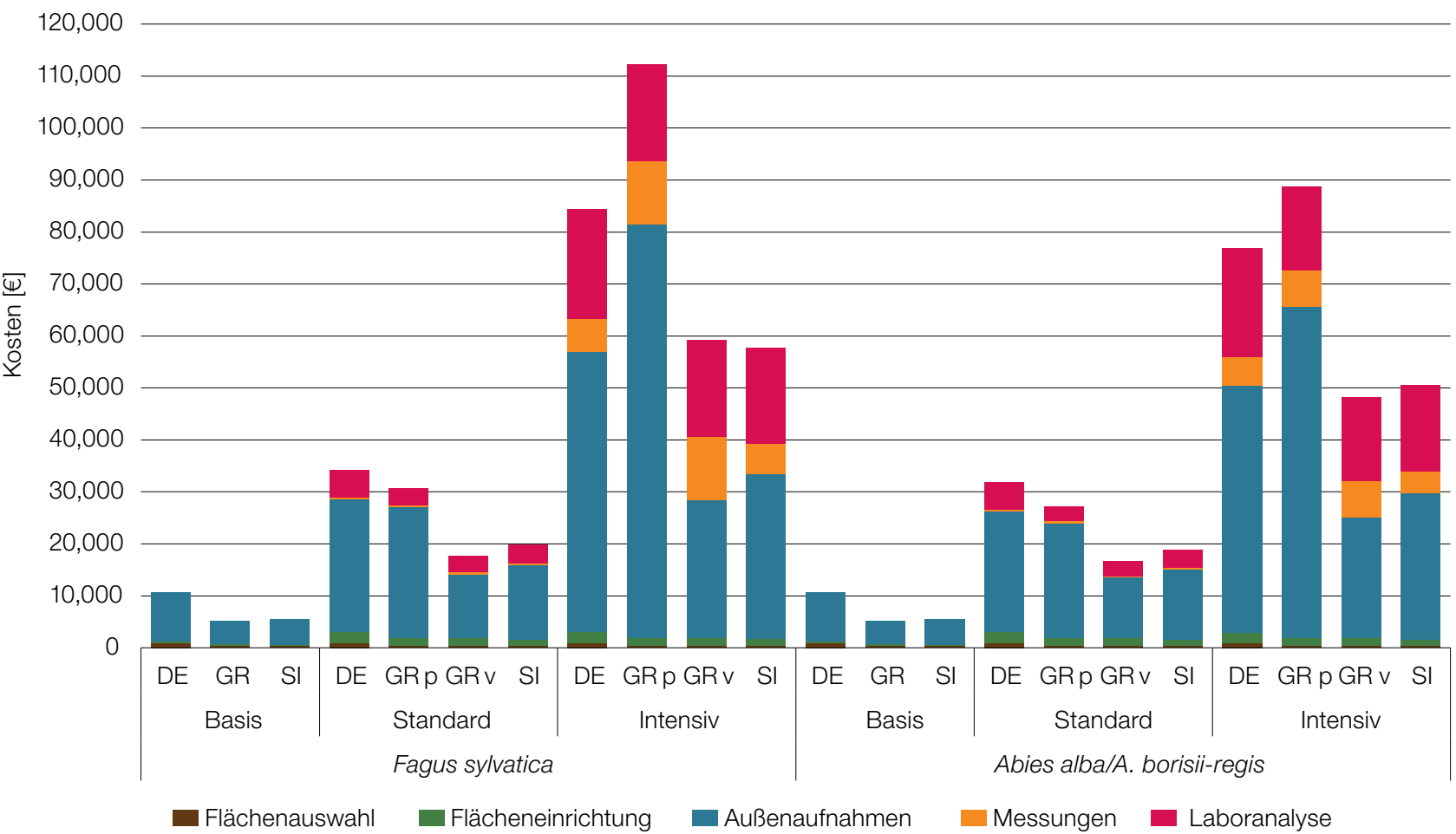

Abbildung 7.1: Kostenabschätzung für das forstgenetische Monitoring der Rotbuche (Fagus sy/vatica) und Weißtanne/ König-Boris-Tanne (Abies alba/Abies borisii-regis) für ein durchschnittliches 10-Jahres Monitoringintervall. DE Deutschland; GR p - Griechenland, photographische Analyse; GR v - Griechenland, visuelle Aufnahme vor Ort; SI - Slowenien.

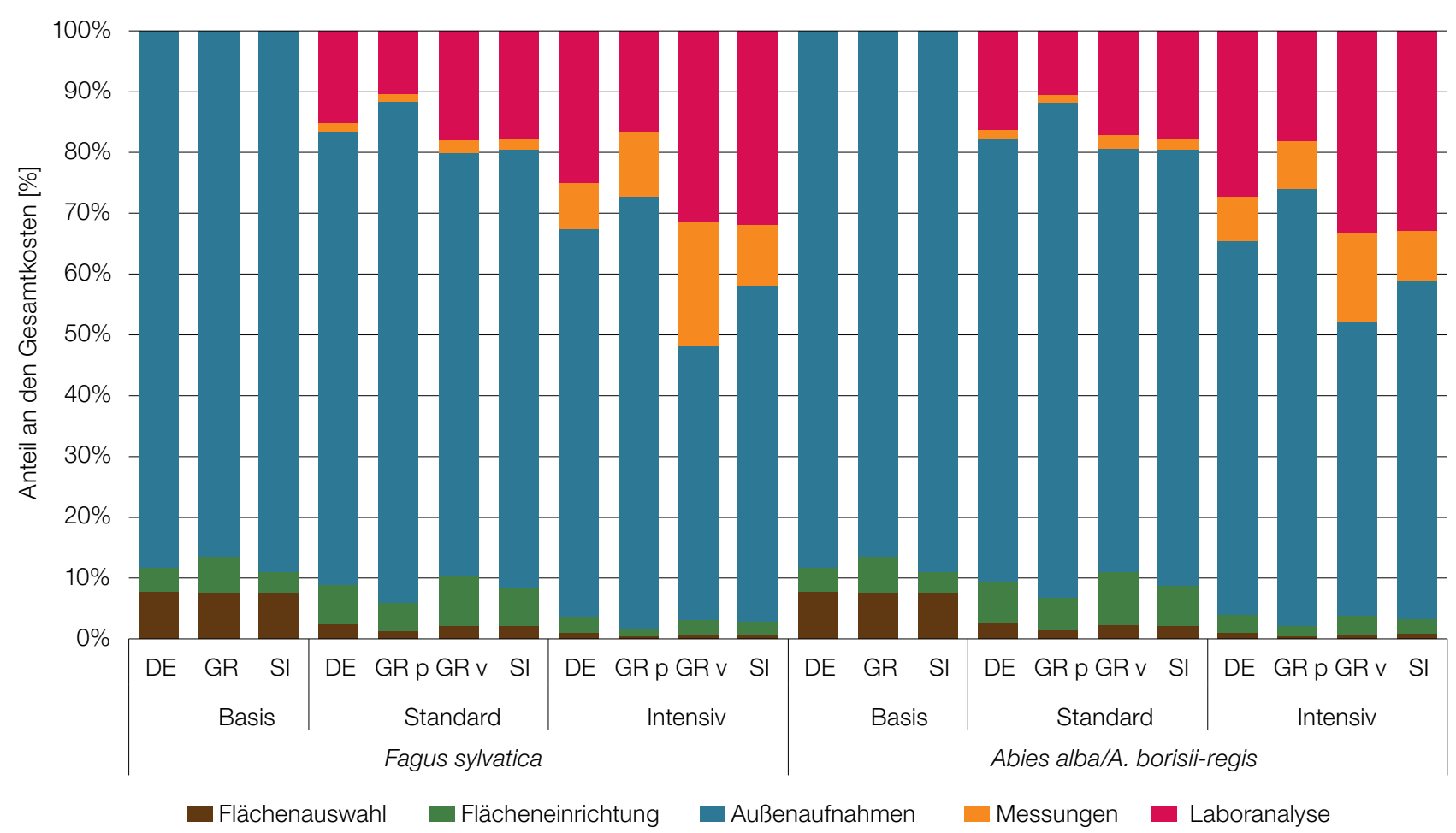

Abbildung 7.2: Relativer Anteil der verschiedenen forstgenetischen Monitoringaktivitäten der Rotbuche (Fagus sylvatica) und Weißtanne/König-Boris-Tanne (Abies alba/Abies borisii-regis) an den Gesamtkosten für ein durchschnittliches 10Jahres Monitoringintervall. DE - Deutschland; GR p - Griechenland, photographische Analyse; GR v - Griechenland, visuelle Aufnahme vor Ort; $\mathrm{SI}$ - Slowenien. 
Tabelle 7.2: Beitrag der verschiedenen Kostenarten zu den Gesamtkosten eines durchschnittlichen 10-jährigen forstgenetischen Monitoringintervalls pro Versuchsfläche, Baumart, Land und Monitoringniveau. Zu den Reisekosten zählen die Kosten für gefahrene Kilometer, Tagegeld und die Arbeitsstunden am Steuer. DE - Deutschland; GR p Griechenland, photographische Analyse; GR v - Griechenland, visuelle Aufnahme vor Ort; SI - Slowenien.

\begin{tabular}{|c|c|c|c|c|c|}
\hline Niveau & Land & $\begin{array}{c}\text { Material } \\
{[€]}\end{array}$ & $\begin{array}{c}\text { Effektive Arbeitszeit } \\
{[€]}\end{array}$ & $\begin{array}{c}\text { Reisekosten } \\
{[€]}\end{array}$ & $\begin{array}{c}\text { Summe } \\
{[€]}\end{array}$ \\
\hline \multirow{3}{*}{ Basis } & $\mathrm{DE}$ & 105 & 5,565 & 5,060 & 10,730 \\
\hline & GR & 87 & 2,188 & 2,842 & 5,117 \\
\hline & SI & 13 & 2,596 & 2,875 & 5,484 \\
\hline \multirow{4}{*}{ Standard } & $\mathrm{DE}$ & 1,972 & 21,744 & 10,487 & 34,203 \\
\hline & $G R p^{*}$ & 1,957 & 22,240 & 6,532 & 30,729 \\
\hline & $G R v^{*}$ & 1,957 & 9,241 & 6,532 & 17,730 \\
\hline & SI & 1,978 & 10,693 & 7,134 & 19,805 \\
\hline \multirow{4}{*}{ Intensiv } & $\mathrm{DE}$ & 16,828 & 44,459 & 23,122 & 84,409 \\
\hline & $G R p^{*}$ & 24,601 & 72,227 & 15,391 & 112,219 \\
\hline & $G R v^{*}$ & 24,601 & 19,188 & 15,391 & 59,181 \\
\hline & SI & 17,735 & 22,434 & 17,505 & 57,674 \\
\hline
\end{tabular}

\begin{tabular}{|c|c|c|c|c|c|}
\hline Niveau & Land & $\begin{array}{c}\text { Material } \\
{[€]}\end{array}$ & $\begin{array}{c}\text { Effektive Arbeitszeit } \\
{[€]}\end{array}$ & $\begin{array}{c}\text { Reisekosten } \\
{[€]}\end{array}$ & $\begin{array}{c}\text { Summe } \\
{[€]}\end{array}$ \\
\hline \multirow{3}{*}{ Basis } & DE & 105 & 5,565 & 5,060 & 10,730 \\
\hline & GR & 87 & 2,188 & 2,842 & 5,117 \\
\hline & SI & 13 & 2,596 & 2,875 & 5,484 \\
\hline \multirow{4}{*}{ Standard } & DE & 1,972 & 20,164 & 9,764 & 31,900 \\
\hline & GR $p^{*}$ & 1,659 & 19,536 & 6,037 & 27,232 \\
\hline & $G R v^{*}$ & 1,659 & 9,022 & 6,037 & 16,718 \\
\hline & SI & 1,737 & 10,474 & 6,515 & 18,726 \\
\hline \multirow{4}{*}{ Intensiv } & DE & 16,852 & 40,640 & 19,453 & 76,945 \\
\hline & GR $p^{*}$ & 17,147 & 58,707 & 12,883 & 88,737 \\
\hline & $G R v^{*}$ & 17,147 & 18,194 & 12,883 & 48,224 \\
\hline & $\mathrm{SI}$ & 14,078 & 21,805 & 14,676 & 50,559 \\
\hline
\end{tabular}

* In Griechenland wurde die phänologische Beurteilung mithilfe hochauflösender Digitalphotographie und Bildanalyse durchgeführt, was die Gesamtkosten des FGM im Vergleich zu dem in Deutschland und Slowenien angewandten Ansatz, der sich auf visuelle Erfassung vor Ort stützte, deutlich erhöhte. Um besser vergleichbare Ergebnisse zu erhalten, wurden die erwartbaren Kosten für die visuelle Erfassung der Phänologie in Griechenland auf Grundlage von Daten aus Deutschland und Slowenien ebenfalls erhoben. 


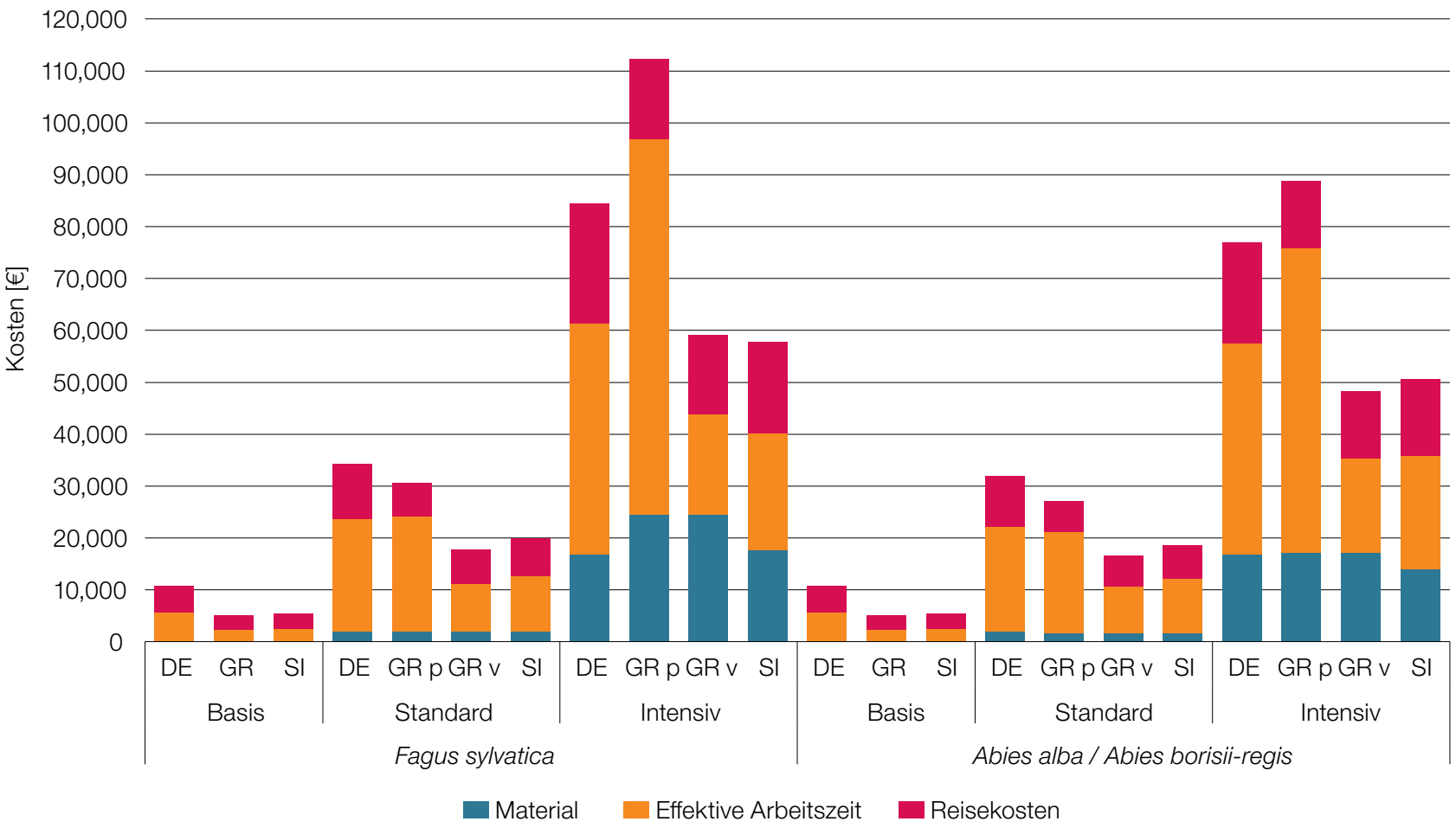

Abbildung 7.3: Beitrag der verschiedenen Kostenarten zu den Gesamtkosten pro Versuchsfläche für Rotbuche (Fagus sy/vatica) und Weißtanne/König-Boris-Tanne (Abies alba/Abies borisii-regis) für ein durchschnittliches 10-Jahres forstgenetisches Monitoringintervall. Zu den Reisekosten zählen die Kosten für gefahrene Kilometer, Tagegeld und die Arbeitsstunden am Steuer. DE - Deutschland; GR p - Griechenland, photographische Analyse; GR v - Griechenland, visuelle Aufnahme vor Ort; SI - Slowenien.

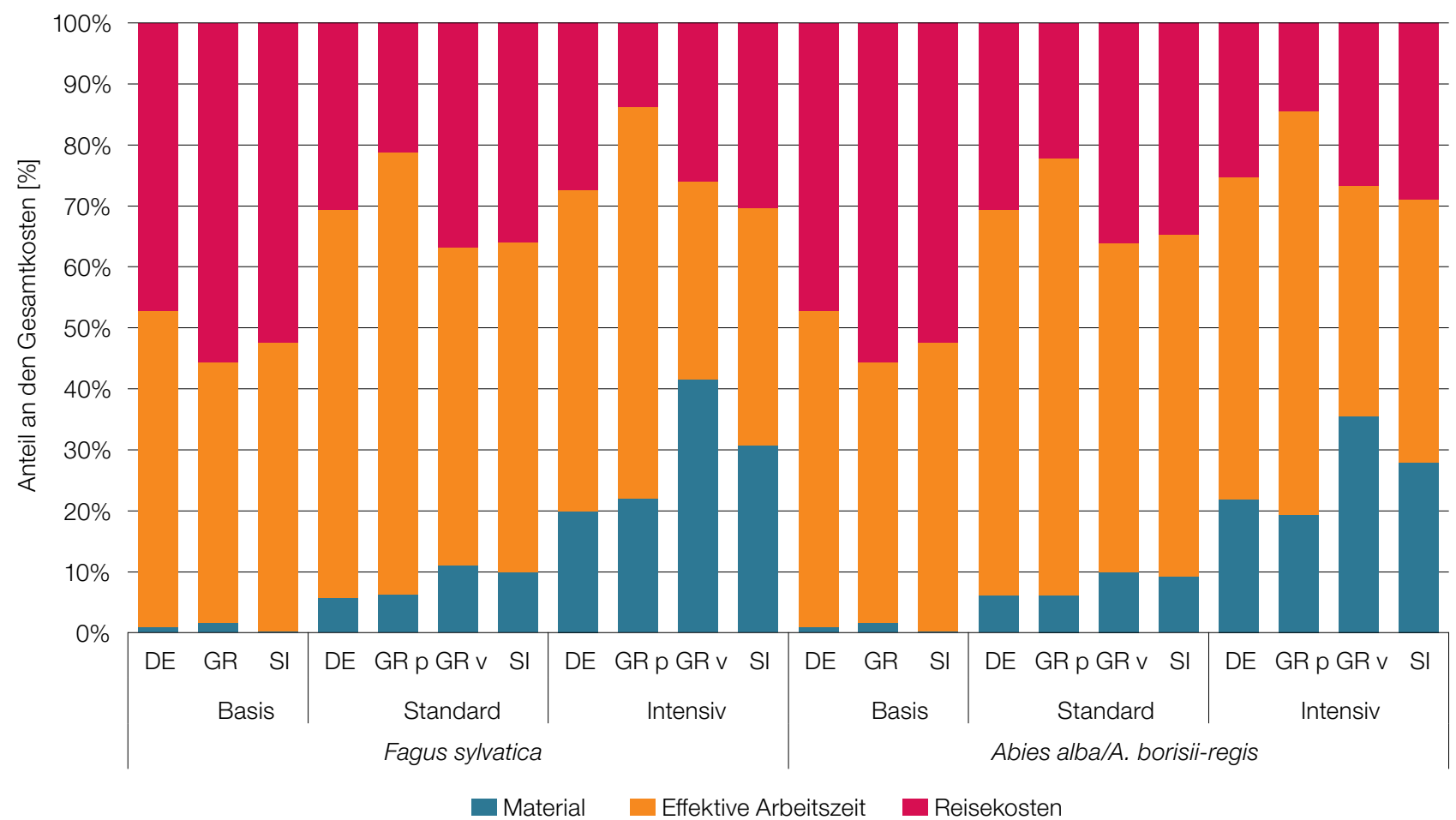

Abbildung 7.4: Relativer Anteil der verschiedenen Kostenarten an den Gesamtkosten pro Versuchsfläche für Rotbuche (Fagus sy/vatica) und Weißtanne/König-Boris-Tanne (Abies alba/Abies borisii-regis) für ein durchschnittliches 10-Jahres Monitoringintervall. Zu den Reisekosten zählen die Kosten für gefahrene Kilometer, Tagegeld und die Arbeitsstunden am Steuer. DE - Deutschland; GR p - Griechenland, photographische Analyse; GR v - Griechenland, visuelle Aufnahme vor Ort; SI - Slowenien. 


\subsubsection{Kosten je Indikator}

Tabelle 7.3: Beitrag der genetischen Indikatoren Selektion, Genetische Variation und Genfluss/ Paarungssystem zu den Gesamtkosten für ein durchschnittliches 10-Jahres Monitoringintervall pro Versuchsfläche, Baumart, Land und Monitoringniveau. DE - Deutschland; GR p - Griechenland, photographische Analyse; GR v - Griechenland, visuelle Aufnahme vor Ort; SI - Slowenien.

\begin{tabular}{|c|c|c|c|c|c|}
\hline Niveau & Land & $\begin{array}{l}\text { Selektion } \\
{[€]}\end{array}$ & $\begin{array}{l}\text { Genetische } \\
\text { Variation } \\
{[€]}\end{array}$ & $\begin{array}{c}\text { Genfluss / } \\
\text { Paarungssystem } \\
{[€]}\end{array}$ & $\begin{array}{c}\text { Summe } \\
{[€]}\end{array}$ \\
\hline \multirow{3}{*}{ Basis } & DE & 10,730 & 0 & 0 & 10,730 \\
\hline & GR & 5,117 & 0 & 0 & 5,117 \\
\hline & SI & 5,484 & 0 & 0 & 5,484 \\
\hline \multirow{4}{*}{ Standard } & DE & 27,038 & 7,166 & 0 & 34,203 \\
\hline & GR p* & 26,249 & 4,480 & 0 & 30,729 \\
\hline & $G R v^{\star}$ & 13,251 & 4,480 & 0 & 17,730 \\
\hline & SI & 15,111 & 4,693 & 0 & 19,805 \\
\hline \multirow{4}{*}{ Intensiv } & DE & 54,877 & 13,766 & 15,766 & 84,409 \\
\hline & GR $p^{*}$ & 80,350 & 11,844 & 20,025 & 112,219 \\
\hline & $\mathrm{GR} v^{*}$ & 27,311 & 11,844 & 20,025 & 59,181 \\
\hline & $\mathrm{SI}$ & 32,430 & 11,626 & 13,617 & 57,674 \\
\hline \multicolumn{6}{|c|}{ Abies alba Mill./ Abies borisii-regis Mafft. } \\
\hline Niveau & Land & $\begin{array}{c}\text { Selektion } \\
{[€]}\end{array}$ & $\begin{array}{c}\text { Genetische } \\
\text { Variation } \\
{[€]} \\
\end{array}$ & $\begin{array}{c}\text { Genfluss / } \\
\text { Paarungssystem } \\
{[€]}\end{array}$ & $\begin{array}{c}\text { Summe } \\
{[€]}\end{array}$ \\
\hline \multirow{3}{*}{ Basis } & DE & 10,730 & 0 & 0 & 10,730 \\
\hline & GR & 5,117 & 0 & 0 & 5,117 \\
\hline & SI & 5,484 & 0 & 0 & 5,484 \\
\hline \multirow{4}{*}{ Standard } & $\mathrm{DE}$ & 24,780 & 7,121 & 0 & 31,900 \\
\hline & GR $p^{*}$ & 23,078 & 4,154 & 0 & 27,232 \\
\hline & $G R v^{*}$ & 12,564 & 4,154 & 0 & 16,718 \\
\hline & $\mathrm{SI}$ & 14,246 & 4,480 & 0 & 18,726 \\
\hline \multirow{4}{*}{ Intensiv } & DE & 48,372 & 13,607 & 14,966 & 76,945 \\
\hline & GR $p^{*}$ & 64,457 & 10,328 & 13,951 & 88,737 \\
\hline & $G R v^{*}$ & 23,945 & 10,328 & 13,951 & 48,224 \\
\hline & SI & 28,697 & 10,566 & 11,296 & 50,559 \\
\hline
\end{tabular}

* In Griechenland wurde die phänologische Beurteilung mithilfe hochauflösender Digitalphotographie und Bildanalyse durchgeführt, was die Gesamtkosten des FGM im Vergleich zu dem in Deutschland und Slowenien angewandten Ansatz, der sich auf visuelle Erfassung vor Ort stützte, deutlich erhöhte. Um besser vergleichbare Ergebnisse zu erhalten, wurden die erwartbaren Kosten für die visuelle Erfassung der Phänologie in Griechenland auf Grundlage von Daten aus Deutschland und Slowenien ebenfalls erhoben. 


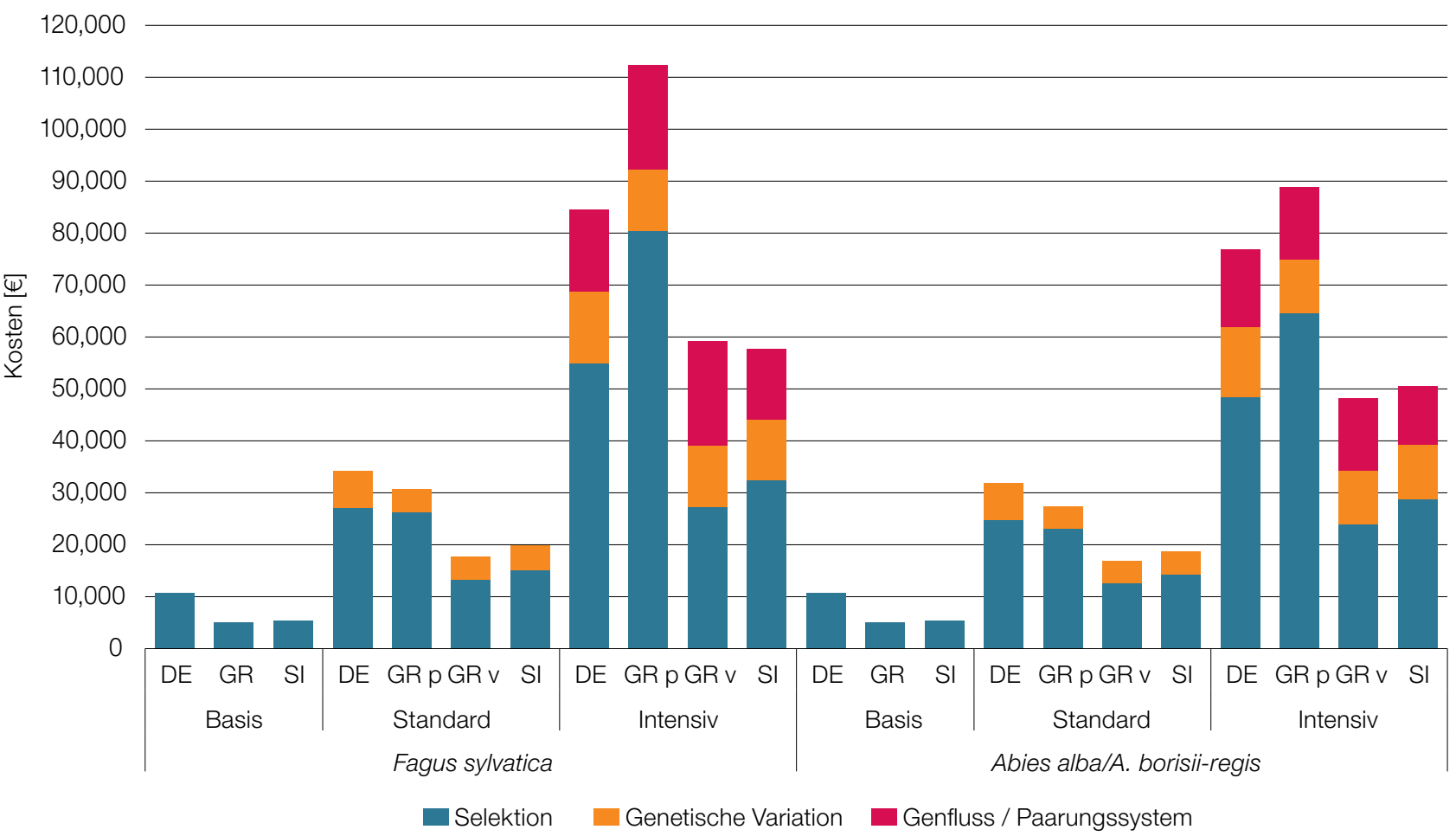

Abbildung 7.5: Beitrag der verschiedenen Indikatoren - Selektion, Genetische Variation, Genfluss/Paarungssystem - zu den Gesamtkosten pro Versuchsfläche für das forstgenetische Monitoring der Rotbuche (Fagus sylvatica L.) und Weißtanne/ König-Boris-Tanne (Abies alba Mill./Abies borisii-regis Mafft.) für ein durchschnittliches 10-Jahres Monitoringintervall. DE - Deutschland; GR p - Griechenland, photographische Analyse; GR v - Griechenland, visuelle Aufnahme vor Ort; SI - Slowenien.

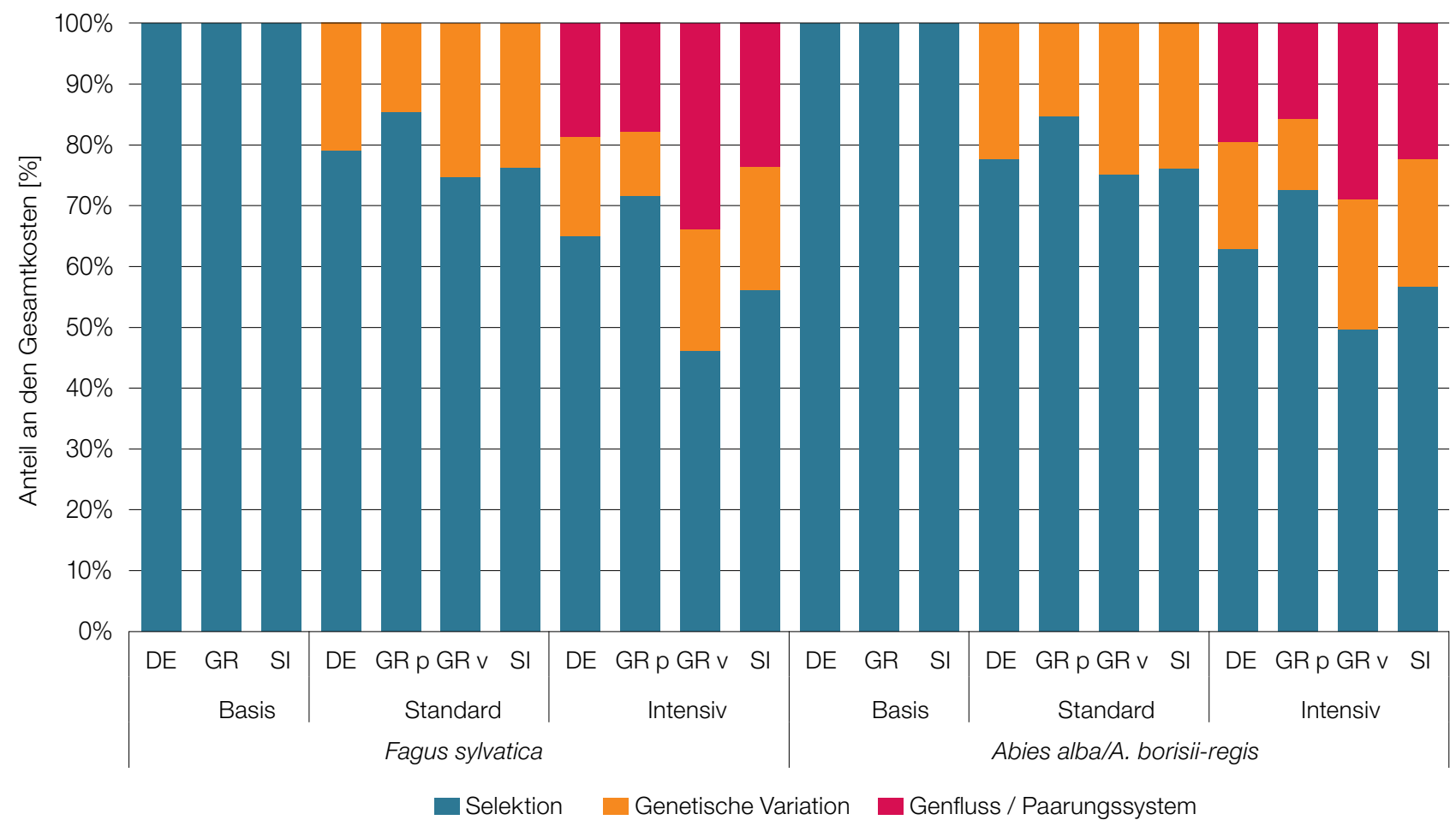

Abbildung 7.6: Relativer Anteil der verschiedenen Indikatoren - Selektion, Genetische Variation, Genfluss/ Paarungssystem - zu den Gesamtkosten pro Monitoringfläche für das forstgenetische Monitoring der Rotbuche (Fagus sylvatica L.) und Weißtanne/ König-Boris-Tanne (Abies alba Mill./Abies borisii-regis Mafft.) für ein durchschnittliches 10Jahres Monitoringintervall. DE - Deutschland; GR p - Griechenland, photographische Analyse; GR v - Griechenland, visuelle Aufnahme vor Ort; SI - Slowenien. 


\subsubsection{Kosten je Verifikator}

Tabelle 7.4: Kosten der einzelnen Verifikatoren/ Hintergrundinformationen eines durchschnittlichen 10-JahresMonitoringintervalls pro Versuchsfläche, Baumart, Land und Monitoringniveau; basierend auf Durchschnittswerten für Rotbuche und Weißtanne/ König-Boris-Tanne. Für Griechenland wurden die erwartbaren Kosten für die visuelle Erfassung vor Ort berücksichtigt. Für alle Länder wurde eine Entfernung von 100 km zu den FGM-Versuchsflächen angenommen. DE - Deutschland; GR - Griechenland; SI - Slowenien. NV-Abundanz - Abundanz der Naturverjüngung; AF - Allelhäufigkeiten; LGP - Latentes genetisches Potential; $F_{I S}$ - Inzuchtkoeffizient; $N_{e}$ - Effektive Populationsgröße; AR - Allelische Vielfalt; LD - Kopplungsungleichgewicht; Intersp. Hybr. - Interspezifische Hybridisierung; $t_{m}$ - Multilocus- Auskreuzungsrate der Population; $N_{m}$ - geschätzter Genfluss; $V_{G A M}$ - Hypothetische gametische Multilocus-Diversität; $N_{e p}$ - Effektive Anzahl von Pollenspendern; Typ: V - Verifikator; BI - Hintergrundinformation. Indikator: I - Selektion; II - Genetische Variation; III Genfluss / Paarungssystem; Total 1 - Gesamtkosten für eine durchschnittliche einhäusige, nicht-hybridisierende Baumart; Total 2 - Gesamtkosten für eine zweihäusige Baumart mit allen verfügbaren Verifikatoren / Hintergrundinformationen.

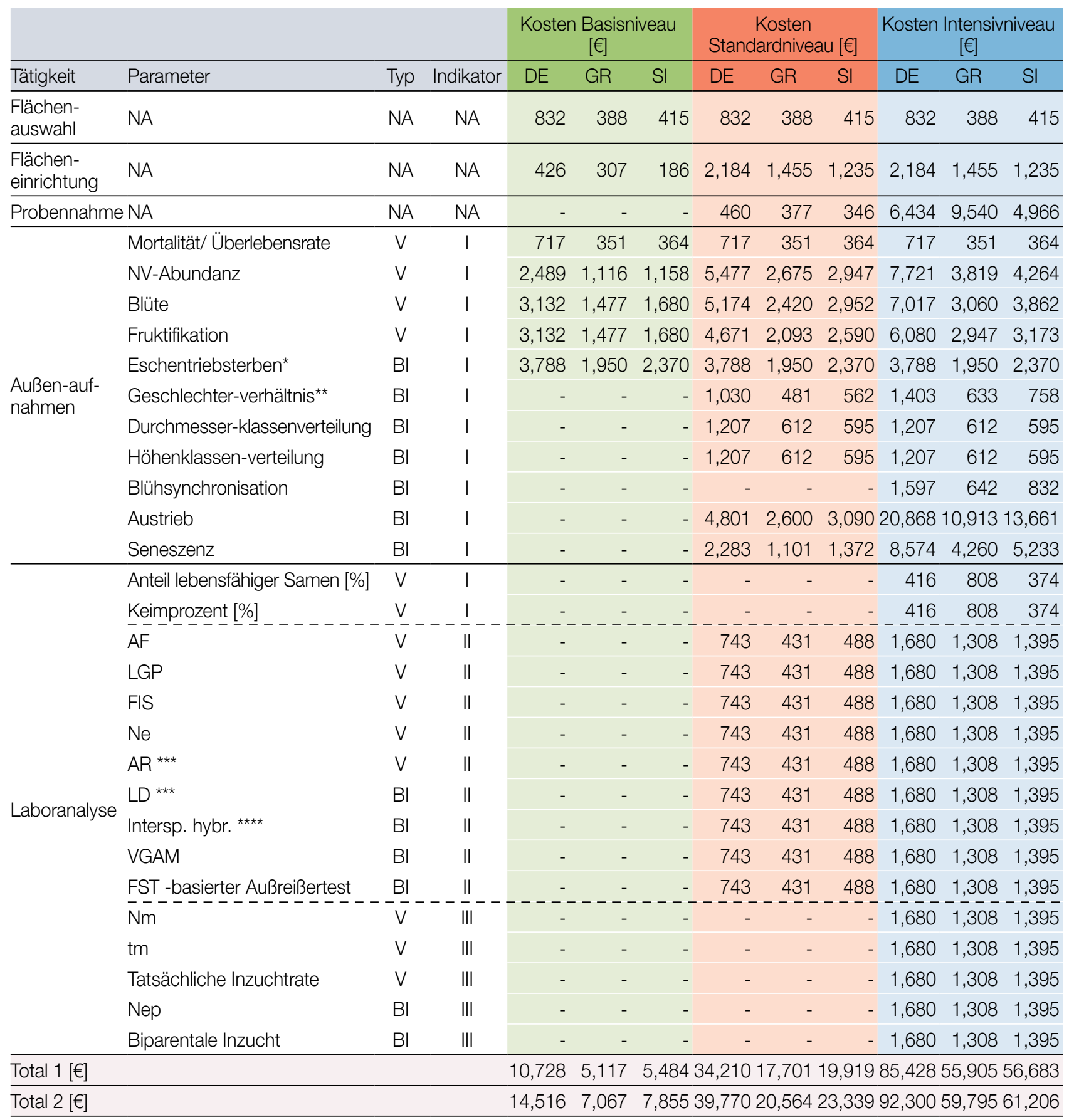

* nur Fraxinus excelsior; ${ }^{* *}$ zweihäusige Arten; ${ }^{* \star *}$ AR - nur SSR-Marker, LD - nur SNP-Marker; ${ }^{\star * \star \star}$ nur für Arten, bei denen interspezifische Hybridisierung natürlich vorkommt 


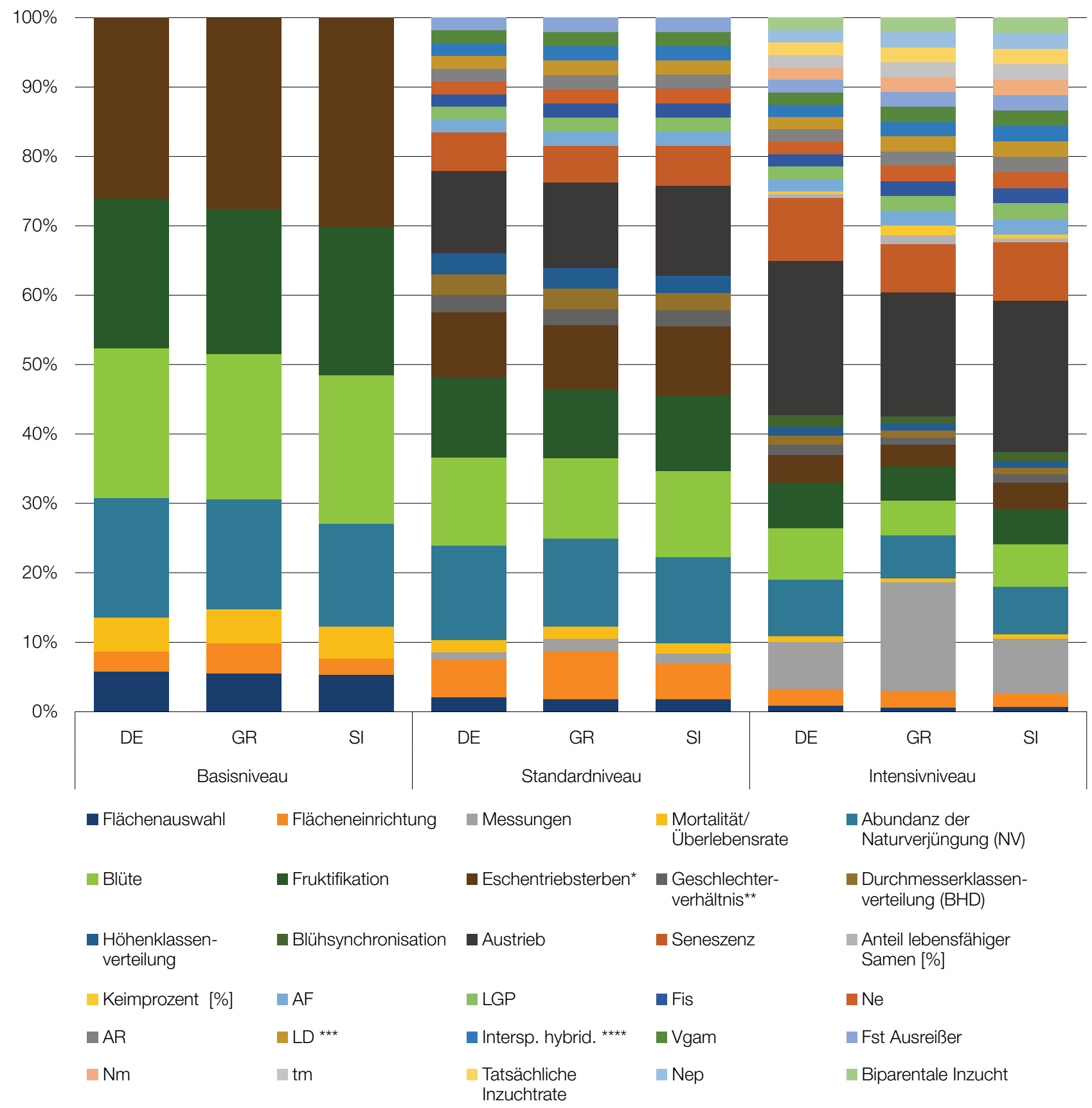

Abbildung 7.7: Relativer Anteil der verschiedenen Verifikatoren und Hintergrundinformationen zu den Gesamtkosten eines durchschnittlichen 10-Jahres-Monitoringintervalls pro Versuchsfläche, Baumart, Land und Monitoringniveau; basierend auf Durchschnittswerten für Rotbuche und Weißtanne/ König-Boris-Tanne. Für Griechenland wurden die erwartbaren Kosten für die visuelle Erfassung vor Ort berücksichtigt. Für alle Länder wurde eine Entfernung von $100 \mathrm{~km} z u$ den FGM-Versuchsflächen angenommen. DE - Deutschland; GR - Griechenland; SI - Slowenien. Plot select. - Auswahl der Monitoringflächen; Plot establ. - Einrichtung der Monitoringflächen; NV-Abundanz - Abundanz der Naturverjüngung; DBH class distr. - Durchmesserklassenverteilung (BHD); Height class distr. - Höhenklassenverteilung; Flowering synch. - Blühsynchronisation; AF - Allelhäufigkeiten; LGP - Latentes genetisches Potential; $\mathrm{F}_{\text {IS }}$ - Inzuchtkoeffizient; $\mathrm{N}_{\mathrm{e}}-$ Effektive Populationsgröße; AR - Allelische Vielfalt; LD - Kopplungsungleichgewicht; Intersp. Hybr. - Interspezifische Hybridisierung; $\mathrm{t}_{\mathrm{m}}$ - Multilocus-Auskreuzungsrate der Population; $\mathrm{N}_{\mathrm{m}}$ - geschätzter Genfluss; $\mathrm{V}_{\mathrm{GAM}}$ - Hypothetische gametische Multilocus-Diversität; $\mathrm{N}_{\mathrm{ep}}$ - Effektive Anzahl von Pollenspendern; Biparent. inbr. - Biparentale Inzucht.

* nur Fraxinus excelsior; ${ }^{* *}$ zweihäusige Arten; ${ }^{* \star *}$ AR - nur SSR-Marker, LD - nur SNP-Marker; ${ }^{* \star * \star}$ nur für Arten, bei denen interspezifische Hybridisierung natürlich vorkommt 


\subsubsection{Kosten für ein durchschnittliches 10-Jahres Monitoringintervall gemittelt über die} teilnehmenden Länder und betrachteten Baumarten

Tabelle 7.5: Kosten eines durchschnittlichen 10-Jahres-Monitoringintervalls pro forstgenetischer Monitoringfläche und -niveau. Berücksichtigt wurden Durchschnittswerte, gemittelt aus den Daten für alle drei teilnehmenden Länder und beide Baumarten. Für Griechenland wurden die erwartbaren Kosten für die visuelle Erfassung vor Ort berücksichtigt. Für alle Länder wurde eine Entfernung von 100 km zu den FGM-Versuchsflächen angenommen. SD - Standardabweichung.

\begin{tabular}{lrrrrrrrrrrrrr} 
Niveau & \multicolumn{1}{c}{ Flächenauswahl Flächeneinrichtung Außenaufnahmen } & \multicolumn{1}{c}{ Messungen } & \multicolumn{4}{c}{ Laboranalysen } & Summe \\
\hline & {$[€]$} & SD & {$[€]$} & SD & {$[€]$} & SD & {$[€]$} & SD & {$[€]$} & SD & {$[€]$} & SD \\
\hline Basis & 545 & 203 & 307 & 98 & 6,259 & 2,280 & 0 & 0 & 0 & 0 & 7,110 & 2,564 \\
Standard & 545 & 203 & 1,625 & 406 & 16,747 & 5,514 & 387 & 40 & 3,878 & 954 & 23,180 & 7,074 \\
Intensiv & 545 & 203 & 1,625 & 406 & 35,215 & 11,333 & 6,853 & 2,477 & 18,594 & 1,928 & 62,832 & 13,346 \\
\hline
\end{tabular}

Tabelle 7.6: Anteil der verschiedenen Kostenarten zu den Gesamtkosten eines durchschnittlichen 10-JahresMonitoringintervalls pro forstgenetischer Monitoringfläche und -niveau. Berücksichtigt wurden Durchschnittswerte, gemittelt aus den Daten für alle drei teilnehmenden Länder und beide Baumarten. Für Griechenland wurden die erwartbaren Kosten für die visuelle Erfassung vor Ort berücksichtigt. Für alle Länder wurde eine Entfernung von 100 km zu den FGM-Flächen angenommen. SD - Standardabweichung.

\begin{tabular}{|c|c|c|c|c|c|c|c|c|c|c|c|c|}
\hline \multirow[t]{2}{*}{ Niveau } & \multicolumn{2}{|c|}{ Material } & \multicolumn{2}{|c|}{$\begin{array}{c}\text { Effektive } \\
\text { Arbeitszeit }\end{array}$} & \multicolumn{2}{|c|}{$\begin{array}{c}\text { Effektive } \\
\text { Arbeitszeit }\end{array}$} & \multicolumn{2}{|c|}{ Reisekosten } & \multicolumn{2}{|c|}{ Reisekosten } & \multicolumn{2}{|c|}{ Summe } \\
\hline & {$[€]$} & SD & [man h] & SD & {$[€]$} & $\mathrm{SD}$ & [man h] & SD & {$[€]$} & SD & {$[€]$} & SD \\
\hline Basis & 68 & 40 & 152 & 3 & 3,450 & 1,505 & 93 & 7 & 3,593 & 1,038 & 7,110 & 2,564 \\
\hline Standard & 1,879 & 130 & 614 & 28 & 13,556 & 5,285 & 233 & 42 & 7,745 & 1,726 & 23,180 & 7,074 \\
\hline Intensiv & 17,873 & 3,224 & 1,314 & 68 & 27,786 & 10,595 & 551 & 152 & 17,172 & 3,379 & 62,832 & 13,346 \\
\hline
\end{tabular}

\subsubsection{Auswirkungen der Fahrentfernung auf die Kosten eines durchschnittlichen 10-Jahres-Monitoringintervalls}

Die Reisekosten können einen wesentlichen Anteil der Gesamtkosten für das forstgenetische Monitoring ausmachen; im Durchschnitt 52\%, 34\% und 27\% der Gesamtkosten für die Monitoringniveaus Basis-, Standardund Intensiv, ausgehend von einer Entfernung von 100 km zur FGM-Fläche. Die Fahrstrecke zur FGM-Fläche variiert in der Praxis zwangsläufig. Beim LIFEGENMON-Projekt zum Beispiel betrug die Fahrstrecke zu den Monitoringflächen zwischen $15 \mathrm{~km}$ und $175 \mathrm{~km}$. Daher wurden die Auswirkungen der Fahrentfernung auf die Kosten für ein durchschnittliches 10-Jahres Monitoringintervall am Beispiel einer Rotbuchen-Monitoringfläche in Slowenien folgendermaßen untersucht:

- Die Kosten wurden für ein 10-Jahres FGM-Intervall berechnet, basierend auf den Durchschnittswerten der ersten 50 Jahre des Monitorings.

- Die Reisekosten wurden für drei verschiedene Entfernungen zwischen Partnerinstitution und Monitoringfläche berechnet: $25 \mathrm{~km}, 100 \mathrm{~km}$ und $175 \mathrm{~km}$. Andere Kostenarten, z.B. Materialkosten und effektive Arbeitskosten blieben dagegen unverändert. 
80,000

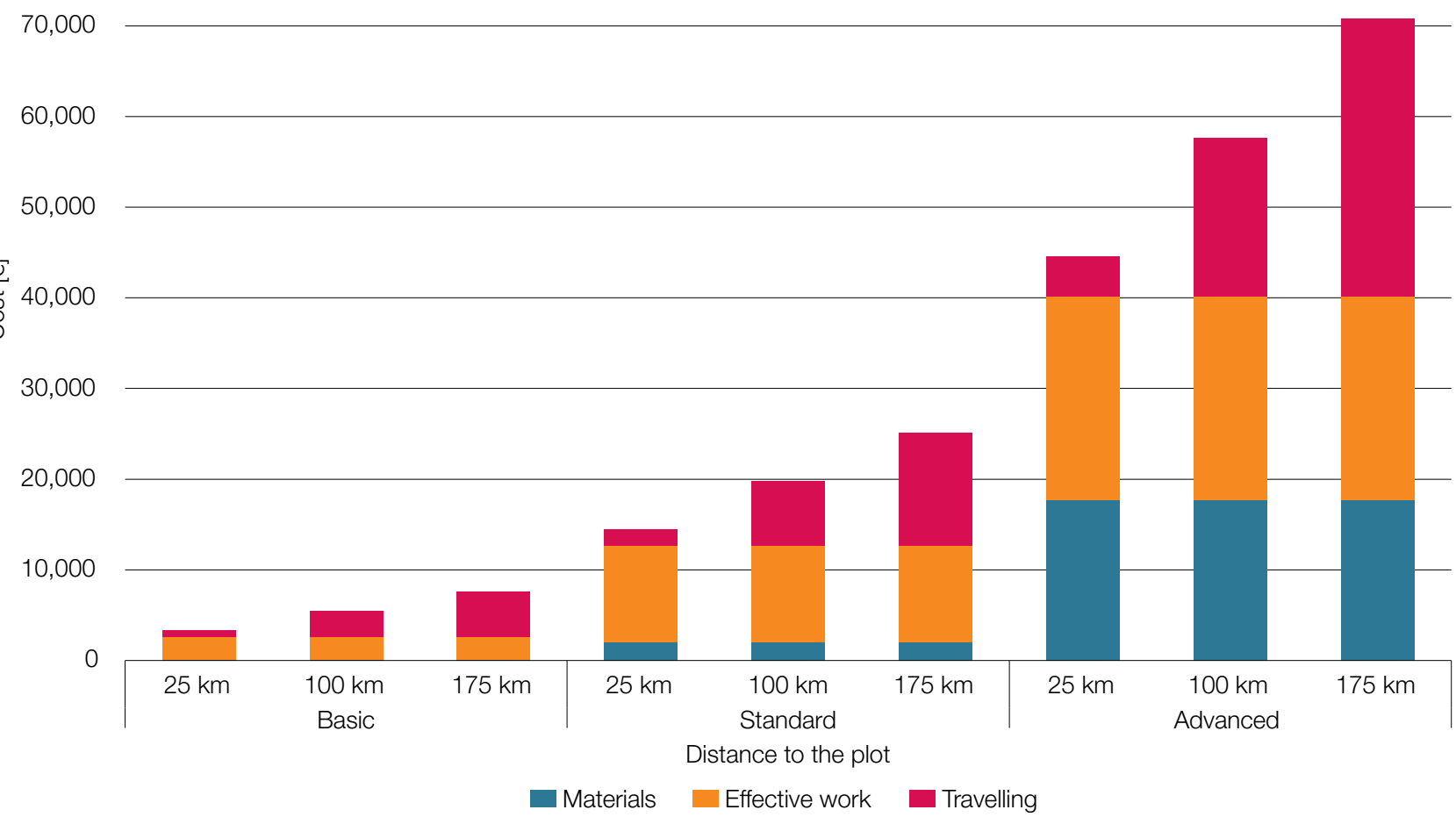

Abbildung 7.8: Beitrag der verschiedenen Kostenarten zu den Gesamtkosten eines durchschnittlichen 10-JahresMonitoringintervalls einer Rotbuchen-Monitoringfläche (Fagus sylvatica L.) in Slowenien in Bezug zur Fahrentfernung. Es werden drei unterschiedliche Werte (jeweils $25 \mathrm{~km}, 100 \mathrm{~km}$ und $175 \mathrm{~km}$ ) für die Fahrentfernung für alle drei Monitoringniveaus, d.h. Basis (1-3), Standard (4-6) und Intensiv (7-9) dargestellt.

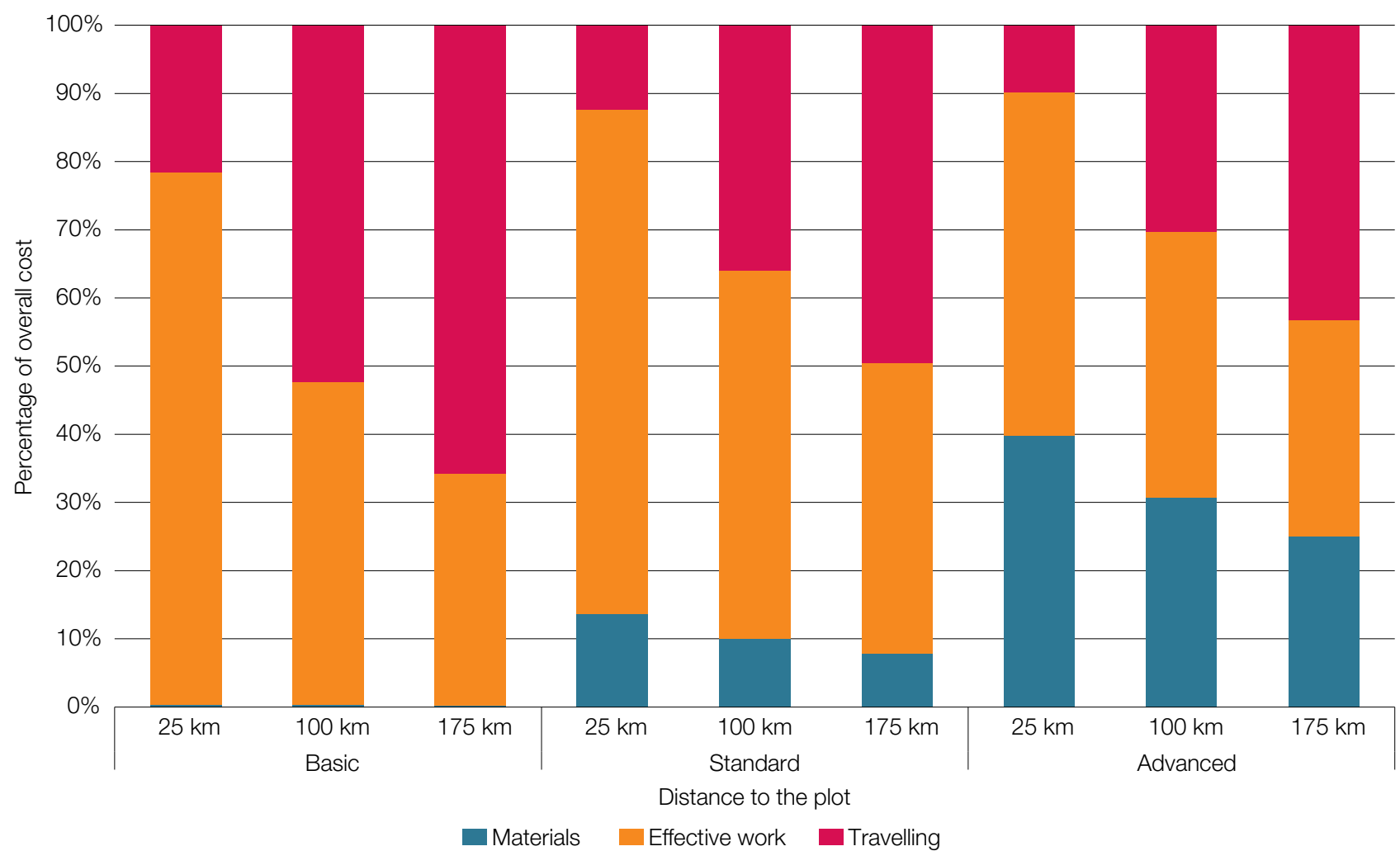

Abbildung 7.9: Relativer Anteil der verschiedenen Kostenarten an den Gesamtkosten für das forstgenetische Monitoring einer Rotbuchen-Monitoringfläche (Fagus sylvatica L.) in Slowenien eines durchschnittlichen 10-Jahres-Monitoringintervalls unter Berücksichtigung der Fahrentfernung. Es werden drei unterschiedliche Werte (jeweils $25 \mathrm{~km}, 100 \mathrm{~km}$ und $175 \mathrm{~km}$ ) für die Fahrentfernung für alle drei Monitoringniveaus, d.h. Basis (1-3), Standard (4-6) und Intensiv (7-9) dargestellt. 
Tabelle 7.7: Anteil der verschiedenen Kostenarten an den Gesamtkosten eines durchschnittlichen 10-JahresMonitoringintervalls für eine Rotbuchen (Fagus sylvatica L.) - Monitoringfläche in Slowenien in Abhängigkeit von der Fahrentfernung.

\begin{tabular}{lccccc} 
Niveau & $\begin{array}{c}\text { Entfernung zur } \\
\text { Monitoringfläche } \\
{[\mathrm{km}]}\end{array}$ & $\begin{array}{c}\text { Material } \\
{[€]}\end{array}$ & $\begin{array}{c}\text { Effektive Arbeitszeit } \\
{[€]}\end{array}$ & $\begin{array}{c}\text { Reisekosten } \\
{[€]}\end{array}$ & $\begin{array}{c}\text { Summe } \\
{[€]}\end{array}$ \\
\hline \multirow{3}{*}{ Basis } & 25 & 13 & 2,596 & 719 & 3,328 \\
& 100 & 13 & 2,596 & 2,875 & 5,484 \\
\hline \multirow{3}{*}{ Standard } & 175 & 13 & 2,596 & 5,031 & 7,641 \\
\hline \multirow{3}{*}{ Intensiv } & 25 & 1,978 & 10,693 & 1,784 & 14,454 \\
& 100 & 1,978 & 10,693 & 7,134 & 19,805 \\
\hline & 175 & 1,978 & 10,693 & 12,485 & 25,156 \\
\hline
\end{tabular}

\subsection{SCHLUSSFOLGERUNGEN UND EMPFEHLUNGEN}

In Hinblick auf die für die Durchführung von FGM notwendigen Aktivitäten tragen die Außenaufnahmen und Messungen am meisten zu den Gesamtkosten des FGM bei (Tabelle 7.1, Abbildungen 7.1 und 7.2). Bei einer Fahrstrecke von 100 km zur Monitoringfläche machen Außenaufnahmen und Messungen im Durchschnitt 88\%, 72\% und 55\% der Gesamtkosten für das Basis-, Standard- und Intensivniveau aus.

Von den drei Kostenarten trägt die effektive Arbeitszeit den größten Anteil zu den Gesamtkosten des FGM bei. Bei einer Fahrstrecke von 100 km zur Monitoringfläche macht die effektive Arbeitszeit durchschnittlich 47\%, 57\% und $43 \%$ der Gesamtkosten für das Basis-, Standard- und Intensivniveau aus.

Die Reisekosten (Kosten für gefahrene Kilometer, Tagegeld und die Arbeitsstunden am Steuer) können einen erheblichen Einfluss auf die Gesamtkosten des forstgenetischen Monitorings haben. Bei einer Entfernung von 100 km zur Monitoringfläche machen die Reisekosten durchschnittlich 52\%, 34\% and 27\% der Gesamtkosten für das Basis-, Standard- und Intensivniveau aus. Der Anteil der Reisekosten an den Gesamtkosten für FGM hängt direkt von der Fahrentfernung ab und kann bei größeren Entfernungen für alle Monitoringniveaus über $40 \%$ der Gesamtkosten betragen (siehe Tabelle 7.7, Abbildungen 7.8 und 7.9).

Der Beitrag der Materialkosten (Verbrauchsgüter/ Betriebsstoffe, Material und ausgelagerte Arbeiten, die für die Durchführung von FGM-Aktivitäten nötig sind) zu den Gesamtkosten des FGM variiert für die einzelnen Monitoringniveaus erheblich und beträgt durchschnittlich 1\%, 9\% und 30\% der Gesamtkosten für das Basis-, Standard- und Intensivniveau. Neben mehr Verbrauchsgütern, die für die Laboranalyse erforderlich sind, tragen die Beprobungen beim Intensivniveau mit einem Anteil von durchschnittlich 25\% entscheidend zu den Materialkosten bei.

Zwischen den beiden untersuchten Baumarten wurden für das Basisniveau keine signifikanten Unterschiede bei den Gesamtkosten für FGM festgestellt, aber für das Standard- bzw. Intensivniveau waren die FGM-Gesamtkosten für Weißtanne/ König-Boris-Tanne durchschnittlich 6\% bzw. 13\% niedriger als für Rotbuche. Der Grund hierfür ist, dass der Parameter Seneszenz für Abies nicht untersucht wurde. Ähnliches ist für andere Vergleiche von bestandsbildenden Laub- und Nadelbaumarten zu erwarten.

Beide im Rahmen des LIFEGENMON-Projekts untersuchten Baumarten sind bestandsbildend und einhäusig. Die Kosten für FGM an einzelbaumweise eingemischten Arten, zweihäusigen Arten und hybridisierenden bzw. klonbildenden Arten sind voraussichtlich wesentlich höher, da mehr Außenaufnahmen, Untersuchungen (Geschlechterverhältnis, Eschentriebsterben (Fraxinus excelsior)) und/oder zusätzliche Laboranalysen (Bestimmung der Klone bzw. Hybriden) durchgeführt werden müssen. Ausgehend von den geschätzten 
Kosten für Verifikatoren und Hintergrundinformationen (Tabelle 7.4) wären die Gesamtkosten für das FGM einzelbaumweise eingemischter zweihäusiger Arten, die die Auswertung aller vorgeschlagenen Verifikatoren und Hintergrundinformationen erfordern, für das Basisniveau mindestens 39\% höher, 17\% für das Standardniveau und $8 \%$ für das Intensivniveau.

Die erhobenen (oder geschätzten) Kosten für FGM sind in Deutschland am höchsten - im Durchschnitt 84\% höher als in Griechenland und 72\% höher als in Slowenien; die Kosten für FGM in Slowenien waren 7\% höher als in Griechenland. Der bei weitem wichtigste Grund für die beobachteten Unterschiede bei den Kosten für das FGM sind die Personalkosten für die einzelnen Tarifgruppen.

\subsubsection{Empfehlungen für Maßnahmen zur Kosteneinsparung}

1. Gut ausgebildetes und erfahrenes Personal sollte für die Durchführung aller FGM-Aktivitäten eingesetzt werden. Erfahrenes Personal kann seine Aufgaben schneller und mit weniger Fehlern, die eine Wiederholung der Aufgabe erfordern würden, ausführen und so Zeit und Geld sparen.

2. Einige Erhebungen oder Messungen können im Rahmen derselben Begehung der Monitoringfläche durchgeführt werden. So können zum Beispiel sowohl die Erfassung der GPS-Koordinaten als auch die Messung von BHD und Höhe der ausgewählten Bäume von zwei Technikern alle am selben Tag durchgeführt werden. Auf diese Weise reduzieren sich die Anzahl der Besuche auf der Beobachtungsfläche sowie die Reisekosten.

3. Es ist empfehlenswert, die photographische Dokumentation nicht als Routineverfahren für die phänologische Beurteilung zu verwenden, da dies die Gesamtkosten für das FGM auf dem Standard- und Intensivniveau um durchschnittlich $77 \%$ erhöht!

4. Die variabelste Kostenart sind die Reisekosten. Da es sich beim FGM um einen langwierigen Prozess handelt, können die Reisekosten erheblich zu den Gesamtkosten für das FGM beitragen. Um den Anteil der Reisekosten an den Gesamtkosten für FGM zu reduzieren, können folgende Maßnahmen in Betracht gezogen werden:

- Im Zuge des FGM-Flächenauswahlverfahrens werden in der Regel mehrere verschiedene Flächen inspiziert und auf ihre Eignung hin beurteilt. Wenn mehrere Monitoringflächen alle Kriterien für eine FGM-Fläche erfüllen (Kapitel 2), wählen Sie diejenige aus, die der mit der Durchführung des FGM betrauten Partnerinstitution am nächsten liegt.

- Beziehen Sie die zuständige Forstverwaltung oder einen gleichwertigen Ansprechpartner in die Durchführung der Außenaufnahmen und Messungen für das FGM mit ein. Die Forstverwaltung ist in der Regel als Netzwerk organisiert mit lokalen Forstämtern, die über das ganze Land verteilt sind. Ortsansässige oder in der Nähe wohnende Förster sind mit den Wäldern in ihrem Zuständigkeitsbereich sehr vertraut und müssen daher viel kürzere Wege zu den in ihrem Revier befindlichen FGM-Flächen zurücklegen. Ein entsprechendes Training von Förstern (und anderem Personal) ist auch hier von höchster Bedeutung, um die Konsistenz und Vergleichbarkeit der Außenaufnahmen und Messungen zu gewährleisten - dafür sollten Workshops und Schulungen organisiert werden.

- Bei der Durchführung arbeitsintensiver Außenaufnahmen, die nicht innerhalb eines Tages erledigt werden können, wie z.B. die Einrichtung der Monitoringflächen oder die Probennahme von Saatgut, ist es ratsam, für FGM-Flächen, die längere Anfahrtszeiten erfordern, sollte das Personal vor Ort übernachten und nicht jeden Tag zur Fläche und zurückfahren. Auf diese Weise fallen weniger Fahrten an und pro Tag kann effektiv mehr Arbeit erledigt werden, was letztlich die Gesamtkosten trotz der zusätzlichen Unterbringungskosten reduziert.

- Für arbeitsintensive Außenaufnahmen sollte nach Möglichkeit mehr Personal für eine Aufgabe zur Verfügung stehen. Mehr Leute können in derselben Zeit mehr Arbeit erledigen, während gleichzeitig die Reisekosten pro Kopf und die Anzahl der zur Erledigung der Aufgabe erforderlichen Reisen reduziert werden.

5. Möglichkeiten zur internationalen Zusammenarbeit sollten in Betracht gezogen werden - Länder mit demselben Artenspektrum und denselben Vegetationszonen müssen nicht zwangsläufig ein separates FGM durchführen. 



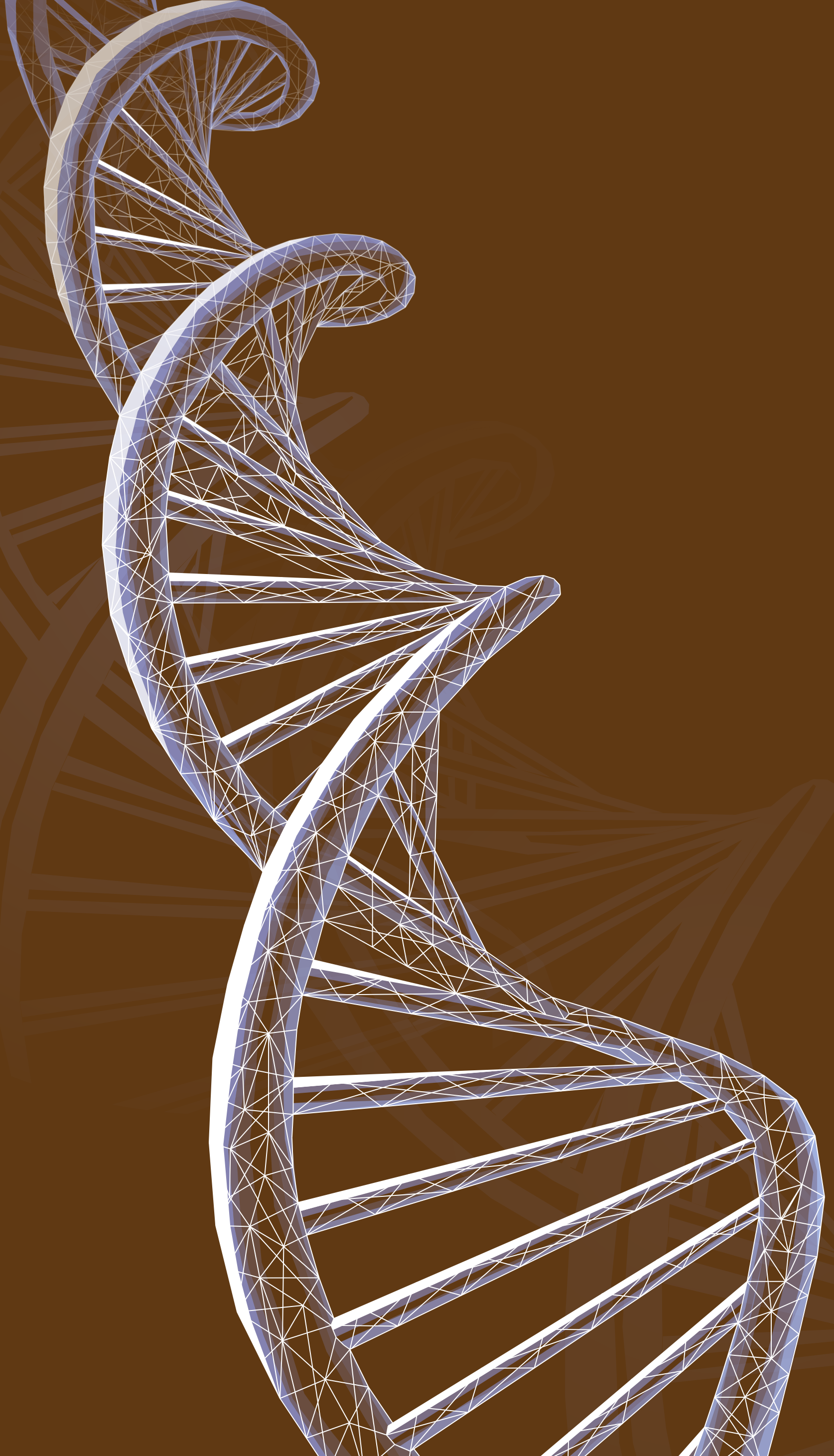




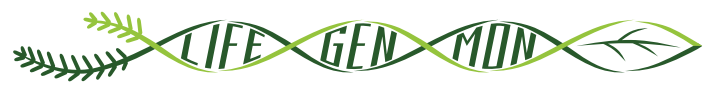 \\ LIFE13 ENV/S/ $/ 000148$}

\section{Handbuch zum Forstgenetisches Monitoring}

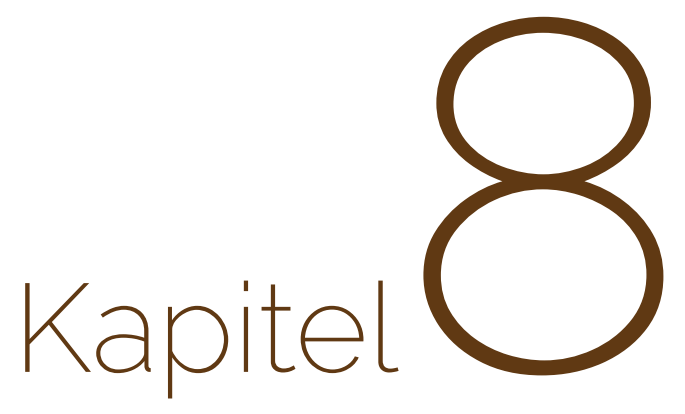

\section{ENTSCHEIDUNGSHILFE FÜR DIE AUSWAHL DES FGM-NIVEAUS}

Marjana WESTERGREN'1, Marko BAJC', Filippos A. ARAVANOPOULOS², Rok DAMJANIĆ 1 , Barbara FUSSI ${ }^{3}$, Darius KAVALIAUSKAS ${ }^{3}$, Fotios KIOURTSIS ${ }^{4}$,

Paraskevi ALIZOTI², Andrej BREZNIKAR ${ }^{5}$, Hojka KRAIGHER ${ }^{1}$

Zitat: Westergren et al. (2020) Entscheidungshilfe für die Auswahl des FGM-Niveaus. In: Bajc et al. (Ed.) Handbuch zum forstgenetischen Monitoring. Slowenisches Forstinstitut: Verlag Silva Slovenica, Ljubljana, S. 161-167. http://dx.doi.org/10.20315/SFS.176

Institut:

1. Slowenisches Forstinstitut (SFI), Slowenien

2. Aristoteles Universität von Thessaloniki (AUTh), Griechenland

3. Bayrisches Amt für Waldgenetik (AWG), Deutschland

4. Dezentrale Verwaltung Mazedonien-Thrakien, Generaldirektion für Forst und Landwirtschaft, Griechenland

5. Slowenische Staatsforsten, Slowenien 


\subsection{EINFÜHRUNG UND ZIELSTELLUNG}

Dieses Kapitel richtet sich an die politischen Entscheidungsträgerlnnen auf lokaler, nationaler, regionaler und europäischer Ebene, um unter Berücksichtigung der zu beantwortenden Fragen, der vorhandenen personellen und finanziellen Ressourcen sowie des verfügbaren Fachwissens das am besten geeignete forstgenetische Monitoringniveau auszuwählen. Um die auf nationaler Ebene relevantesten Fragen zu bestimmen, wird den politischen Entscheidungsträgern empfohlen, WissenschaftlerInnen mit Expertise in Bezug auf Waldökosysteme und Genetik zu konsultieren.

Die Kombination der Informationen in den folgenden Tabellen kann bei der Entscheidung für ein bestimmtes forstgenetisches Monitoringniveau hilfreich sein. In Tabelle 8.1 ist eine Auswahl von Fragen aufgelistet, die im Rahmen des vorgeschlagenen FGM-Verfahrens anhand der mittels Verifikatoren und Hintergrundinformationen gewonnenen Daten beantwortet werden können. Die Kosten für die Erfassung der einzelnen Verifikatoren über einen Zeitraum von 10 Jahren sind in Tabelle 8.2 aufgeführt.

\subsection{FRAGEN, DIE MITTELS FGM BEANTWORTET WERDEN KÖNNEN}

Eine nicht abschließende Liste von Fragen, die mittels FGM beantwortet werden können, ist in Tabelle 8.1 aufgeführt.

Tabelle 8.1: Eine Auswahl von Fragen, die mithilfe des jeweiligen forstgenetischen Monitoringniveaus beantwortet werden können.

\begin{tabular}{|c|c|c|c|}
\hline \multirow[b]{2}{*}{ Frage } & \multicolumn{3}{|c|}{ forstgenetisches Monitoringniveau } \\
\hline & Basis & Standard & Intensiv \\
\hline $\begin{array}{l}\text { Findet die Fruktifikation ausreichend häufig statt (wie für eine bestimmte Baumart } \\
\text { erwartet)? }\end{array}$ & $x$ & $x$ & $x$ \\
\hline Ist die Fruktifikation ausreichend stark (wie für eine bestimmte Baumart erwartet)? & $x$ & $x$ & $x$ \\
\hline $\begin{array}{l}\text { Gibt es eine unerwartete Mortalität, die einen Populationsrückgang verursachen } \\
\text { kann? }\end{array}$ & $x$ & $\mathrm{x}$ & $x$ \\
\hline $\begin{array}{l}\text { Gibt es genug Naturverjüngung, um das evolutionäre Potenzial der Baumart zu } \\
\text { erhalten? }\end{array}$ & $x$ & $x$ & $x$ \\
\hline $\begin{array}{l}\text { Ist die effektive Populationsgröße ausreichend, um das Evolutionspotential } \\
\text { aufrechtzuerhalten? }\end{array}$ & & $x$ & $x$ \\
\hline $\begin{array}{l}\text { Erfährt die Population einen langfristigen Abwärtstrend, wie von demographischen } \\
\text { Modellen prognostiziert? }\end{array}$ & & $x$ & $x$ \\
\hline $\begin{array}{l}\text { Ist die Variabilität in der Population (genetische V. - molekulare Marker, } \\
\text { phänotypische V. - Merkmalsvariation) groß genug, um das evolutionäre Potenzial } \\
\text { aufrechtzuerhalten? }\end{array}$ & & $\mathrm{x}$ & $\mathrm{x}$ \\
\hline $\begin{array}{l}\text { Was ist der Grund für eine geringe Verjüngungsdichte (unzureichende Blüte, } \\
\text { mangelnde Synchronisation zwischen männlicher und weiblicher Blüte, Absterben } \\
\text { von Samen oder geringe Keimprozente)? }\end{array}$ & & & $\mathrm{x}$ \\
\hline Liegt in einer Population eine hohe Inzuchtrate vor? Nimmt diese zu? & & & $x$ \\
\hline $\begin{array}{l}\text { Kann der Genfluss aus anderen Populationen dem Rückgang der beobachteten } \\
\text { Population entgegenwirken? }\end{array}$ & & & $x$ \\
\hline $\begin{array}{l}\text { Hat die Population das Potenzial, die umweltbedingten Herausforderungen zu } \\
\text { bewältigen? }\end{array}$ & & & $x$ \\
\hline
\end{tabular}

Auf dem Basisniveau liefert der Indikator "Selektion“ mit seinen Verifikatoren ein ausreichendes Mindestmaß an Informationen um einzuschätzen, ob ein Waldbestand vom Rückgang bedroht ist. Die Überwachung dieses Indikators auf Basisniveau kann jedoch nicht die zugrunde liegenden Ursachen für Veränderungen aufzeigen. 
Innerhalb der Indikatoren sollten stets alle Verifikatoren auf dem gewählten Niveau erfasst werden, um für das jeweilige Monitoringniveau einen vollständigen Einblick in den betreffenden Indikator zu erhalten. Die vier Basisniveau-Verifikatoren des Indikators „Selektion“ (d.h. die mindestens zu erfassenden Verifikatoren) können aufzeigen, wann eine beobachtete Population schrumpft, geben jedoch keinen Einblick in die möglichen Ursachen des Rückgangs. Dazu müssen die beiden anderen Indikatoren sowie Verifikatoren auf einem höheren Niveau erfasst und analysiert werden.

\subsection{KOSTEN DES FORSTGENETISCHEN MONITORINGS}

Die pro Verifikator während eines zehnjährigen Zeitraums anfallenden Kosten für das Monitoring einer einzigen forstgenetischen Monitoringfläche - bestehend aus 50 Altbäumen (alle Monitoringniveaus) und zusätzlich 40 Naturverjüngungsplots (je $1 \mathrm{~m}^{2}$; für Standard- und Intensivniveau) - wurden als Durchschnittskosten von sechs
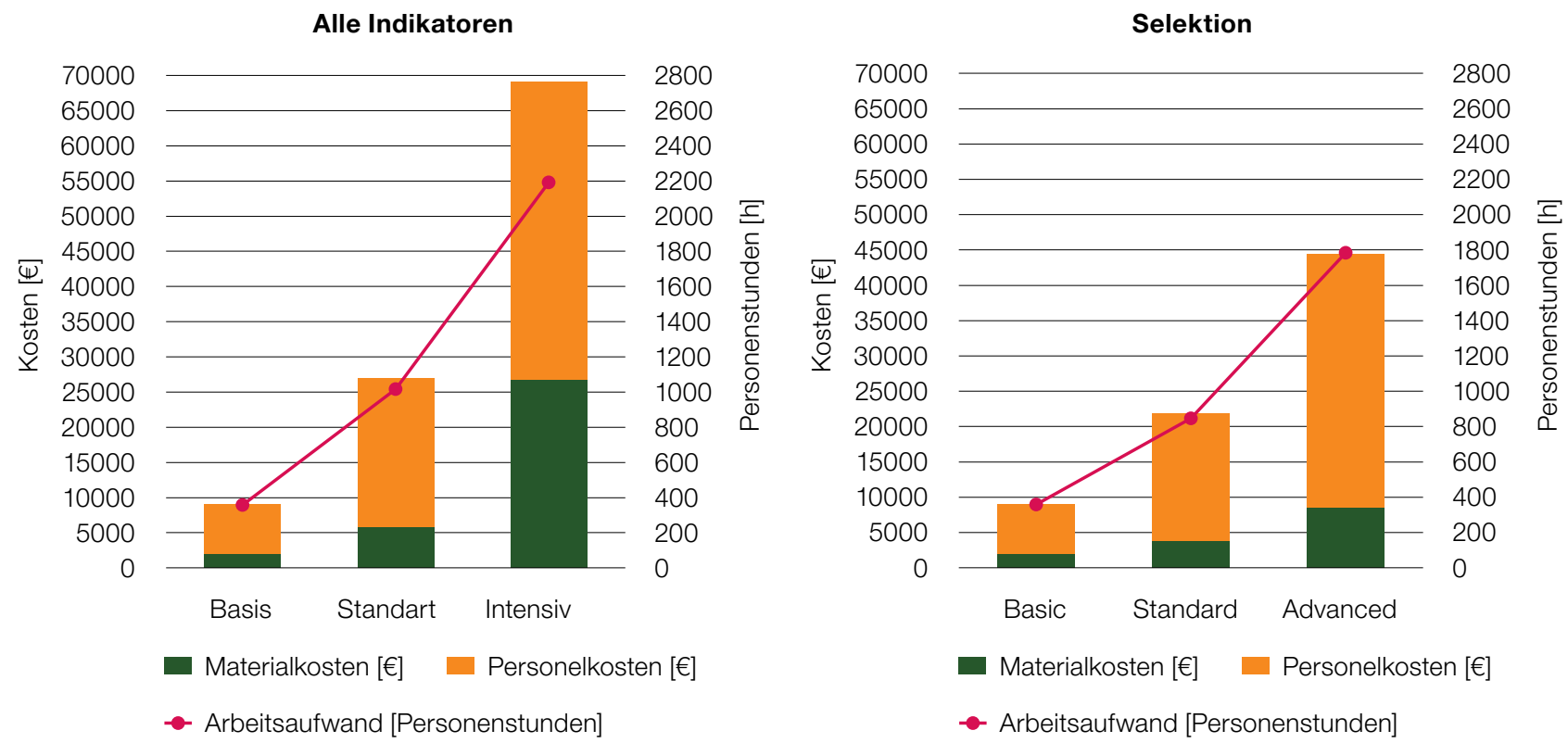

Genetische Variation

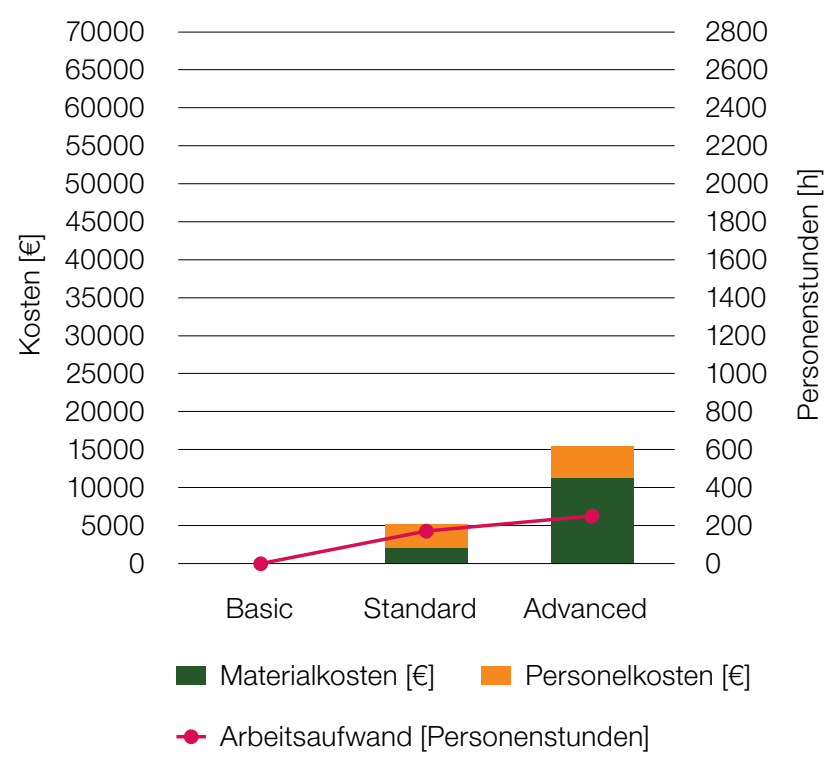

Genfluss/Paarungssystem

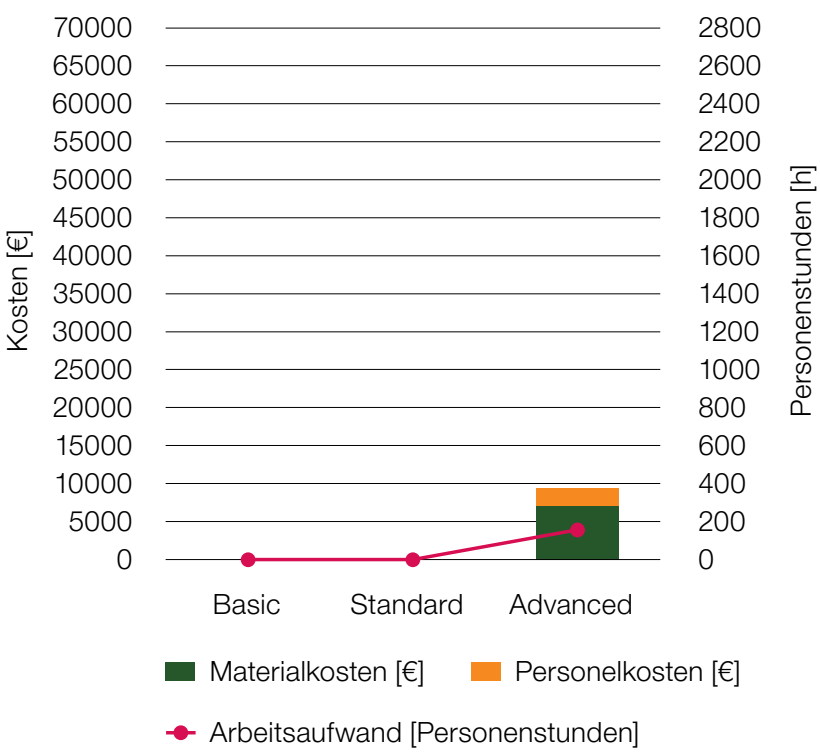

Abbildung 8.1: Gesamtkosten des forstgenetischen Monitorings pro Jahrzehnt, Materialkosten und Zeitbedarf je Monitoringniveau. Linke Y-Achse $=$ Kosten in Euro, rechte Y-Achse $=$ Personenstunden 
Monitoringflächen in drei Ländern (Deutschland, Slowenien, Griechenland) für zwei bestandesbildende Baumarten berechnet: die Rotbuche (Fagus sylvatica L.) und die Weißtanne / König-Boris-Tanne (Abies alba Mill./A. borisii regis Mafft.). Die Kosten pro Verifikator basieren auf den in Kapitel 7 (Kostenbewertung) beschriebenen Annahmen und Erfassungshäufigkeiten der jeweiligen Verifikatoren. Die Kosten werden unterteilt in:

- Materialkosten: Verbrauchsmaterial, Entfernung der An- und Abreise, Verpflegung sowie extern beauftragte Probenahme und genetische Analysen

- Personenstunden: Arbeitsstunden, die für die Durchführung der Außenaufnahmen, Probenahmen, Laborarbeiten und Genotypisierung benötigt werden

Die durchschnittlichen Kosten pro Verifikator und Hintergrundinformation sowie für die Auswahl und Einrichtung der Monitoringflächen und die Probenahme sind in Tabelle 8.2 dargestellt. Auf dem Basisniveau liegen die durchschnittlichen Gesamtkosten des forstgenetischen Monitorings pro Jahrzehnt bei ca. 2.000 EUR und 360 Personenstunden. Auf dem Standard- und Intensivniveau betragen die Gesamtkosten des forstgenetischen Monitorings pro Jahrzehnt in etwa 5.900 EUR und 1.020 Personenstunden bzw. 26.800 EUR und 2.190 Personenstunden.

Die Gesamtkosten für die Erfassung des Indikators „Selektion“ pro Jahrzehnt belaufen sich auf dem Basisniveau auf etwa 2.000 EUR und 360 Personenstunden, auf dem Standardniveau auf 3.800 EUR und 850 Personenstunden und auf dem Intensivniveau auf 8.500 EUR und 1.790 Personenstunden. Die Kosten für die Erfassung des Indikators „Genetische Variation“ belaufen sich auf dem Standardniveau auf ca. 2.100 EUR und 170 Personenstunden und auf dem Intensivniveau auf ca. 11.250 EUR und 250 Personenstunden. Die Kosten für die Erfassung des Indikators „Genfluss/Paarungssystem“, die nur auf dem Intensivniveau durchgeführt wird, betragen pro Jahrzehnt ca. 7.000 EUR und 160 Personenstunden. 
Tabelle 8.2: Kosten und Informationswert von Verifikatoren und Hintergrundinformationen, Flächenauswahl, Flächeneinrichtung und Probenahme für die Überwachung von 50 Altbäumen und 40 Naturverjüngungsplots über einen Zeitraum von 10 Jahren. Die Kosten sind unterteilt in Materialkosten, einschließlich Verbrauchsmaterial, Fahrentfernung zur Monitoringfläche (Hin- und Rückfahrt), Verpflegung und Auftragsvergabe für die Probenahmen/ genetischen Analysen, sowie Personenstunden, einschließlich der für Außenaufnahmen, Probenahmen, Reisen, Laborarbeiten, Genotypisierung und Datenanalyse benötigten Arbeitsstunden. Typ des Verifikators: V = Verifikator, BI = Hintergrundinformation. Informationswert: $\mathrm{H}=$ hoch, $M=$ mittel, $L=$ niedrig. Art der Arbeit: $F=$ Außenaufnahmen, $L=$ Laborarbeit. Graue Schattierung: der Verifikator wird auf einem bestimmten Niveau nicht erfasst. Die Werte sind gerundet auf die nächsten 10 EUR bzw. 5 Personenstunden.

\begin{tabular}{|c|c|c|c|c|c|c|c|c|c|c|}
\hline \multirow[b]{2}{*}{ Indikator } & \multirow[b]{2}{*}{ Verifikator } & \multirow[b]{2}{*}{ Typ } & \multirow[b]{2}{*}{$\begin{array}{c}\text { Infor- } \\
\text { mati- } \\
\text { onswert }\end{array}$} & \multirow[b]{2}{*}{$\begin{array}{l}\text { Art der } \\
\text { Arbeit }\end{array}$} & \multicolumn{2}{|c|}{ Basisniveau } & \multicolumn{2}{|c|}{ Standardniveau } & \multicolumn{2}{|c|}{ Intensivniveau } \\
\hline & & & & & $\begin{array}{l}\text { Material } \\
{[€]}\end{array}$ & $\begin{array}{c}\text { Arbeit } \\
\text { [Perso- } \\
\text { nen-h] }\end{array}$ & $\begin{array}{l}\text { Material } \\
{[€]}\end{array}$ & $\begin{array}{l}\text { Arbeit } \\
\text { [Perso- } \\
\text { nen-h] }\end{array}$ & $\begin{array}{l}\text { Material } \\
{[€]}\end{array}$ & $\begin{array}{c}\text { Arbeit } \\
\text { [Perso- } \\
\text { nen-h] }\end{array}$ \\
\hline \multirow{13}{*}{ Selektion } & Mortalität/ Überlebensrate & V & M & $\mathrm{F}$ & 20 & 20 & 20 & 20 & 20 & 20 \\
\hline & NV-Abundanz & V & $\mathrm{H}$ & $\mathrm{F}$ & 240 & 60 & 450 & 155 & 620 & 230 \\
\hline & Blüte & V & M & $\mathrm{F}$ & 580 & 65 & 750 & 125 & 860 & 175 \\
\hline & Fruktifikation & V & M & $\mathrm{F}$ & 580 & 65 & 690 & 110 & 690 & 160 \\
\hline & $\begin{array}{l}\text { Anteil lebensfähiger Samen } \\
{[\%]}\end{array}$ & V & $L$ & L & & & & & 160 & 20 \\
\hline & Keimprozent [\%] & V & $L$ & $L$ & & & & & 160 & 20 \\
\hline & Eschentriebsterben & $\mathrm{Bl}$ & $L$ & $\mathrm{~F}$ & 430 & 110 & 430 & 110 & 430 & 110 \\
\hline & Geschlechterverhältnis & $\mathrm{Bl}$ & $L$ & $\mathrm{~F}$ & & & 150 & 25 & 170 & 35 \\
\hline & $\begin{array}{l}\text { Durchmesser-klassenver- } \\
\text { teilung }\end{array}$ & $\mathrm{BI}$ & $L$ & $\mathrm{~F}$ & & & 40 & 35 & 40 & 35 \\
\hline & Höhenklassenverteilung & $\mathrm{Bl}$ & $L$ & $\mathrm{~F}$ & & & 40 & 35 & 40 & 35 \\
\hline & Blühsynchronisation & $\mathrm{Bl}$ & $\mathrm{L}$ & $\mathrm{F}$ & & & & & 0 & 45 \\
\hline & Austrieb & $\mathrm{Bl}$ & $\mathrm{L}$ & $\mathrm{F}$ & & & 630 & 130 & 3,160 & 605 \\
\hline & Seneszenz & $\mathrm{Bl}$ & $\mathrm{L}$ & $\mathrm{F}$ & & & 230 & 60 & 1,150 & 240 \\
\hline \multirow{9}{*}{$\begin{array}{l}\text { Genetische } \\
\text { Variation }\end{array}$} & Allelhäufigkeiten & V & M & L & & & 210 & 15 & 1,040 & 20 \\
\hline & $\begin{array}{l}\text { Latentes genetisches } \\
\text { Potential }\end{array}$ & V & M & $\mathrm{L}$ & & & 210 & 15 & 1,040 & 20 \\
\hline & Inzuchtkoeffizient & V & M & $L$ & & & 210 & 15 & 1,040 & 20 \\
\hline & Effektive Populationsgröße & V & $\mathrm{H}$ & L & & & 210 & 15 & 1,040 & 20 \\
\hline & Allelische Vielfalt & V & M & $L$ & & & 210 & 15 & 1,040 & 20 \\
\hline & Kopplungsungleichgewicht & V & M & $L$ & & & 210 & 15 & 1,040 & 20 \\
\hline & $\begin{array}{l}\text { Interspezifische } \\
\text { Hybridisierung }\end{array}$ & $\mathrm{Bl}$ & $L$ & $L$ & & & 210 & 15 & 1,040 & 20 \\
\hline & gametische Diversität & $\mathrm{BI}$ & $L$ & $L$ & & & 210 & 15 & 1,040 & 20 \\
\hline & F-basierter Ausreißertest & $\mathrm{Bl}$ & $L$ & L & & & 210 & 15 & 1,040 & 20 \\
\hline \multirow{5}{*}{$\begin{array}{l}\text { Genfluss / } \\
\text { Paarungs- } \\
\text { system }\end{array}$} & Genfluss & V & M & $\mathrm{L}$ & & & & & 1,040 & 20 \\
\hline & $\begin{array}{l}\text { Multilocus-Auskreuzungs- } \\
\text { rate der Population }\end{array}$ & V & M & $\mathrm{L}$ & & & & & 1,040 & 20 \\
\hline & Tatsächliche Inzuchtrate & V & $\mathrm{H}$ & $L$ & & & & & 1,040 & 20 \\
\hline & $\begin{array}{l}\text { Effektive Anzahl von } \\
\text { Pollenspendern }\end{array}$ & $\mathrm{BI}$ & $L$ & $L$ & & & & & 1,040 & 20 \\
\hline & Biparentale Inzucht & $\mathrm{BI}$ & $L$ & $L$ & & & & & 1,040 & 20 \\
\hline \multirow{3}{*}{$\begin{array}{l}\text { Allgemeine } \\
\text { Aktivitäten }\end{array}$} & Flächenauswahl & NA & NA & NA & 70 & 20 & 70 & 20 & 70 & 20 \\
\hline & Flächeneinrichtung & NA & NA & NA & 120 & 10 & 600 & 50 & 600 & 50 \\
\hline & Probenahme & NA & NA & NA & 0 & 0 & 92 & 20 & 5,130 & 100 \\
\hline
\end{tabular}




\subsection{INFORMATIONSWERT DER FGM-VERIFIKATOREN}

Drei Verifikatoren wurde ein hoher Informationswert zugewiesen: der Abundanz der Naturverjüngung (Basis-, Standard- und Intensivniveau; Indikator „Selektion“), der effektiven Populationsgröße (Standard- und Intensivniveau; Indikator "genetische Variation") und der tatsächlichen Inzuchtrate (Intensivniveau; Indikator "Genfluss /Paarungssystem"). Diese drei Verifikatoren liefern direkt Auskunft darüber, ob die beobachtete Population von einem Rückgang bedroht und eine sofortige Änderung der forstlichen Bewirtschaftung erforderlich ist. Ist keine Naturverjüngung vorhanden, kann sich der Bestand nicht erneuern. Bei einer zu geringen effektiven Populationsgröße ist die Anzahl der Eltern, die zur nächsten Generation beitragen, möglicherweise zu gering, um die genetische Variation in der beobachteten Population zu erhalten. Wird die tatsächliche Inzuchtrate (eine Kombination von Markern und Saatgutmerkmalen) sehr hoch, kann dies zur Allelfixierung und einer Verringerung der genetischen Diversität der Population führen.

Bei allen anderen Verifikatoren wird davon ausgegangen, dass sie einen mittleren Informationswert haben. Diese sind einzeln betrachtet schwer zu interpretieren, ergeben aber in der Gesamtschau einen vollständigeren Einblick in den Zustand der beobachteten Population. Sie liefern außerdem Informationen, die bei der Interpretation der drei Verifikatoren mit hohem Informationswert hilfreich sein können.

Den Hintergrundinformationen wurde grundsätzlich ein geringer Informationswert beigemessen. Diese sind jedoch entscheidend für die Interpretation der Verifikatoren mit mittlerem und hohem Informationswert.

\subsection{FGM-INDIZIERTE BEWIRTSCHAFTUNGSMASSNAHMEN}

Je nach Entwicklung der Werte eines Verifikators kann das Monitoringniveau vom Basisniveau auf Standardoder Intensivniveau erhöht werden, um nach Gründen für beobachtete Trends zu suchen. Alternativ können unterschiedliche forstliche Bewirtschaftungsmaßnahmen zur Anwendung kommen. Um Anpassung zu fördern und genetische Vielfalt zu erhalten, sollten diese vor allem waldbauliche Maßnahmen einschließen, die dynamische genetische Prozesse fördern (Koskela et al. 2013); d.h. insbesondere Maßnahmen, mit denen die Anzahl der sich fortpflanzenden Bäume stabilisiert bzw. erhöht und das Überleben der Verjüngung verbessert werden, wie z.B. durch Schaffung adäquater Lichtverhältnisse, Einzelpflanzenschutz, Beseitigung/Bekämpfung von Unterwuchs und Unkraut, Bodenvorbereitung, Waldbrandverhütung und Regulierung des verbeißenden Schalenwilds (einschließlich Zaunbau).

Die aktive Verjüngung eines Bestandes kann auch für einige Jahre aufgeschoben werden, um die Etablierung von Naturverjüngung abzuwarten. Durchforstungen sind förderlich, sollten aber die Anzahl der sich fortpflanzenden Bäume (d.h. die effektive Populationsgröße) nicht zu stark reduzieren. Bei Durchforstungen sollte eine große Variabilität der Bäume in Bezug auf das Blüh- und Austriebsverhalten (d.h. Früh- und Spätblüher, früh- und spättreibende Individuen) erhalten bleiben. Im Gegensatz zu der weithin akzeptierten Annahme, dass eine effektive Populationsgröße von 50 oder mehr Altbäumen ausreicht, um dem Rückgang der Fitness einer Population entgegenzuwirken, wurde dieser Grenzwert in der neueren Fachliteratur auf 100 erhöht (Frankham et al. 2014). Bei einer effektiven Populationsgröße von 100 oder mehr beträgt der Verlust der Gesamtfitness über fünf Generationen hinweg unter natürlichen Bedingungen weniger als 10\%, während für die Erhaltung des evolutionären Potenzials zur langfristigen Sicherung der reproduktiven Fitness eine effektive Populationsgröße von 1000 oder mehr erforderlich ist (Frankham et al. 2014). Hoban et al. (2020) verorteten die effektive Größe einer Population, bei der ihre Fähigkeit, sich an Umweltveränderungen anzupassen, reduziert ist, bei 500 Individuen.

\subsection{BOTSCHAFTEN FÜR POLITISCHE ENTSCHEIDUNGSTRÄGER}

Forstgenetische Ressourcen kennen keine Grenzen. Um forstliche Genressourcen zu fördern, zu erhalten, zu managen und zu nutzen, ist eine regionale Zusammenarbeit anzustreben. 
Umweltveränderungen und forstliche Bewirtschaftungsmaßnahmen können die genetische Vielfalt beeinflussen. Die gegenwärtige Geschwindigkeit des Klimawandels und die Waldbewirtschaftung haben aktuell die stärksten direkten Auswirkungen auf zukünftige Generationen von Waldbäumen.

Genetisches Monitoring ist notwendig, um Informationen in eine nachhaltige Waldbewirtschaftung einfließen zu lassen. Das forstgenetische Monitoring ist das einzige Instrument, um die Anpassung von Bäumen an sich verändernde Bedingungen in verschiedenen Teilen ihres Verbreitungsgebietes (Kerngebiet, Ränder) zu beobachten; und zwar unabhängig davon, ob sie durch Naturverjüngung, durch unterstützten Genfluss oder Migration, oder durch Pflanzung entstanden sind. Das FGM liefert unschätzbare Informationen für eine nachhaltige Waldbewirtschaftung.

Forstgenetisches Monitoring kann an die relevanten Fragen und die verfügbaren Ressourcen angepasst werden. Das forstgenetische Monitoring kann in der Praxis auf Basis-, Standard- und Intensivniveau angewandt werden. Das gewählte Niveau hängt von der beobachteten Population, den vordringlichen Fragen und dem gewünschten Detaillierungsgrad sowie von den verfügbaren finanziellen Mitteln, Personalressourcen und Expertisen ab.

Gute Zusammenarbeit ist für die Umsetzung des forstgenetischen Monitorings unabdingbar. Die Durchführung des forstgenetischen Monitorings erfordert eine Kooperation zwischen Försterlnnen und Wissenschaftlerlnnen mit dem erforderlichen Fachwissen.

Die langfristige Aufbewahrung der zu Beginn des Monitorings erfassten Gewebeproben und Daten ist essentiell. Langfristige Möglichkeiten zur Lagerung von Gewebeproben oder DNA sowie zur Datenspeicherung sind notwendig, damit das forstgenetische Monitoring sein volles Potenzial entfalten kann. Die Verfügbarkeit von Proben oder DNA für alle Monitoringjahre ermöglicht es den Laboren, alle Proben - vom "Zeitpunkt Null“ an - erneut zu analysieren, sobald fortgeschrittenere und aussagekräftigere DNA-Analyseansätze zur Verfügung stehen. Diese Lagerungsmöglichkeiten können zentralisiert oder auf nationaler Ebene organisiert werden.

Der Transfer von forstlichem Vermehrungsgut innerhalb einer Region kann die Anpassung von Wäldern an das künftige Klima und an sich verändernde Umweltbedingungen unterstützen. Forstgenetische Ressourcen aus Nachbarländern und Ländern innerhalb des Spektrums der erwarteten zukünftigen Klimabedingungen könnten die Widerstandsfähigkeit der Wälder erhöhen, wenn Anreicherungspflanzungen mit forstlichem Vermehrungsgut aus diesen Regionen durchgeführt werden.

Der Transfer von forstlichem Vermehrungsgut über Ländergrenzen hinweg muss den gesetzlichen Bestimmungen entsprechen. Rechtliche Anforderungen für die Verwendung von forstlichem Vermehrungsgut aus anderen Ländern innerhalb des nationalen Territoriums und für den grenzüberschreitenden Transfer von forstlichem Vermehrungsgut aus Nicht-EU- und Nicht-OECD-Ländern sind einzuhalten. Innerhalb des nationalen Territoriums ist eine professionelle Beratungsstelle/Institution einzurichten, welche Entscheidungen über die Verwendung von forstlichem Vermehrungsgut aus nicht-nationalen forstlichen Genressourcen unterstützt.

\section{Quellen}

Frankham R, Bradshaw CJA, Brook BW (2014) Genetics in conservation management: Revised recommendations for the 50/500 rules, Red List criteria and population viability analyses. Biol Conserv 170:56-63. https://doi.org/10.1016/j. biocon.2013.12.036

Hoban S, Bruford M, Jackson DJ et al (2020) Genetic diversity targets and indicators in the CBD post-2020 Global Biodiversity Framework must be improved. Biol Conserv 248:108654. https://doi.org/10.1016/j.biocon.2020.108654

Koskela J, Lefèvre F, Schueler S, Kraigher H, Olrik DC, Hubert J, et al (2013) Translating conservation genetics into management: pan-European minimum requirements for dynamic conservation units of forest tree genetic diversity. Biol Conserv 157:39-49. https://doi.org/10.1016/j.biocon.2012.07.023 


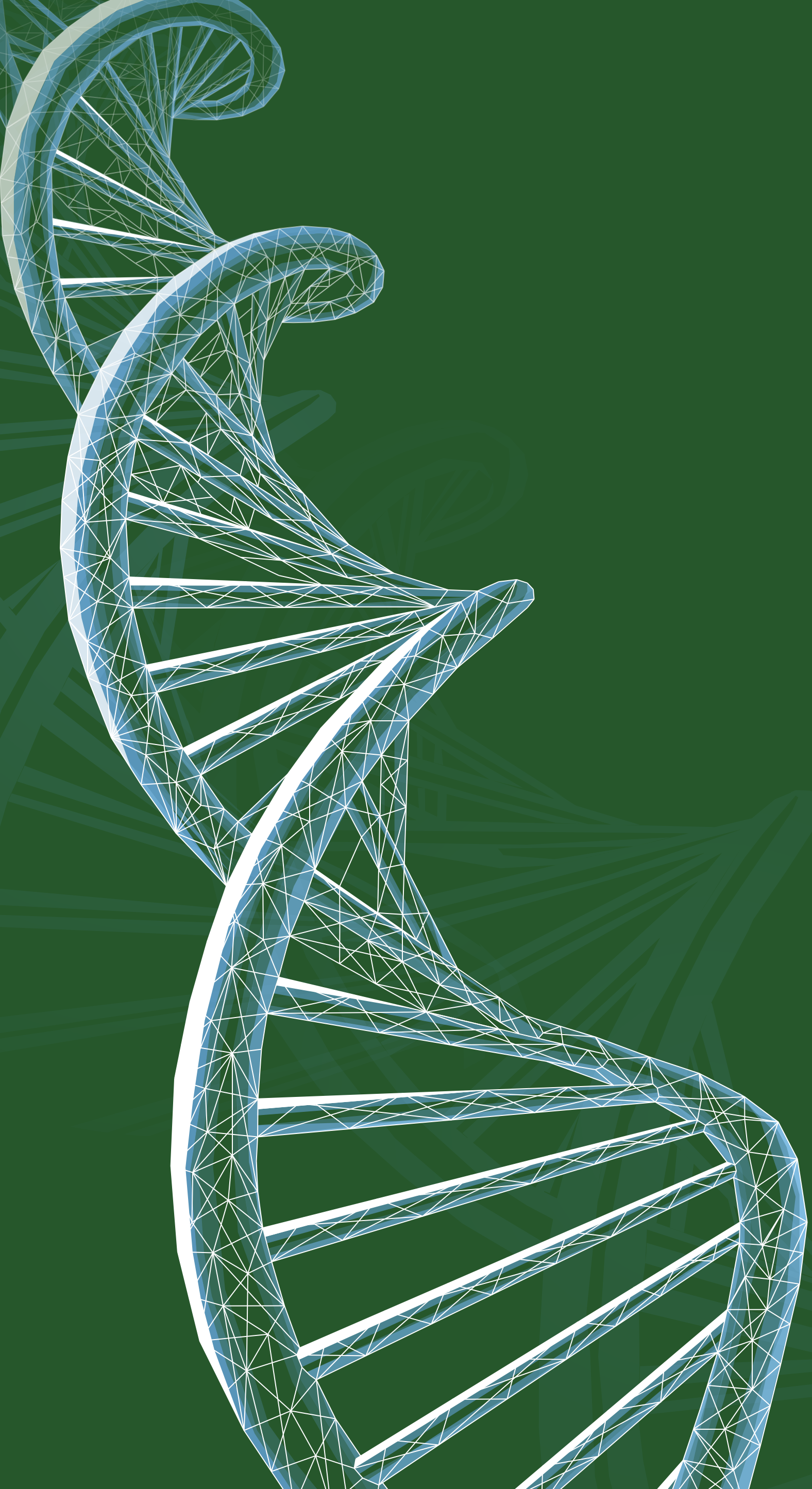




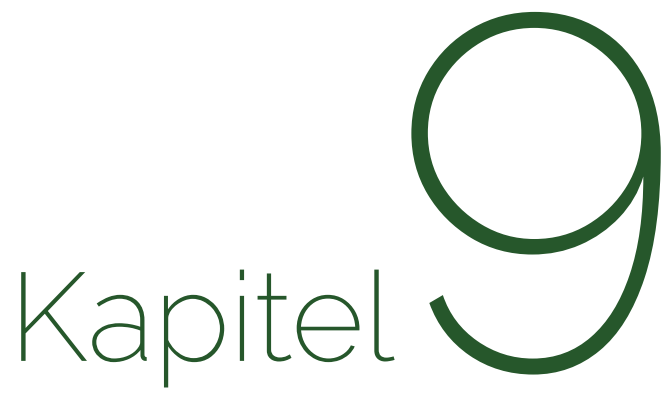

\section{BAUMARTEN-LEITFÄDEN FÜR FORSTGENETISCHES MONITORING}

Darius KAVALIAUSKAS', Marjana WESTERGREN², Paraskevi ALIZOTI', Gregor BOŽIČ², Barbara FUSSI ${ }^{1}$, Kristina SEVER ${ }^{4}$, Andrej BREZNIKAR ${ }^{4}$, Marko BAJC2 ${ }^{2}$, Filippos A. ARAVANOPOULOS ${ }^{3}$, Dalibor BALLIAN 2,5 , Evangelos BARBAS ${ }^{3}$, Sandor BORDACS ${ }^{6}$, Rok DAMJANIĆ2 ${ }^{2}$ Natalija DOVČ2, Domen FINŽGAR ${ }^{2,7}$, Berthold HEINZE' ${ }^{8}$, Fotios KIOURTSIS ${ }^{9}$, Monika KONNERT'1, Nikolaos TOURVAS ${ }^{3}$, Zvonimir VUJNOVIĆ ${ }^{10}$, Peter ŽELEZNIK², Hojka KRAIGHER ${ }^{2}$

Zitat: Kavaliauskas et al. (2020) Baumarten-Leitfäden für forstgenetisches Monitoring. In: Bajc et al. (Ed.) Handbuch zum forstgenetischen Monitoring. Slowenisches Forstinstitut: Verlag Silva Slovenica, Ljubljana, S. 169-171. http://dx.doi.org/10.20315/SFS.176

Institut:

1. Bayerisches Amt für Waldgenetik (AWG), Deutschland

2. Slowenisches Forstinstitut (SFI), Slowenien

3. Aristoteles Universität von Thessaloniki (AUTh), Griechenland

4. Slowenische Staatsforsten (ZGS), Slowenien

5. Forstfakultät, Universität von Sarajevo, Bosnien und Herzegowina

6. Szent-István-Universität, Budapest, Ungarn

7. Institut für Evolutionäre Biologie, Universität von Edinburgh, Großbritannien

8. Österreichisches Bundesforschungszentrum für Wald (BFW), Österreich

9. Dezentrale Verwaltung Mazedonien-Thrakien, Generaldirektion für Forst und Landwirtschaft, Griechenland

10. Kroatisches Forstliches Forschungsinstitut, Jastrebarsko, Kroatien 


\subsection{EINLEITUNG}

Im Rahmen des LIFEGENMON-Projekts wurden für sieben ausgewählte Baumarten und -artengruppen (Abies alba Mill./Abies borisii-regis Mattf. -Gruppe, Fagus sylvatica L., Fraxinus excelsior L., Pinus nigra J. F. Arnold, Populus nigra L., Prunus avium (L.) L., Quercus petraea (Matt.) Liebl./Quercus robur L.-Gruppe) Leitfäden für das forstgenetische Monitoring (FGM) entwickelt, um die Durchführung des genetischen Monitorings dieser Baumarten auf europäischer Ebene zu erleichtern. Die Leitfäden bieten eine präzise Anleitung zur Auswahl, Einrichtung und Instandhaltung forstgenetischer Monitoringflächen sowie zur Erfassung aller Verifikatoren (z. B. Mortalität/Überlebensrate, Blüte, Fruktifikation, Abundanz der Naturverjüngung) sowie Hintergrundinformationen (z. B. Durchmesser- und Höhenklassenverteilung, Austrieb, Blattseneszenz, usw.) für die ausgewählten Baumarten auf unterschiedlichen Monitoringniveaus (Basis-, Standard- und Intensivniveau). Der Schwerpunkt liegt auf der Spezifität des forstgenetischen Monitorings für die jeweilige Baumart oder Artengruppe (Tabelle 9.1) unter Berücksichtigung ihrer Biologie (Paarungs-/Reproduktionssystem, Ökologie, usw.), ihrer Verbreitung (fragmentiert oder kontinuierlich) und ihres spezifischen ökonomischen und ökologischen Wertes. Daher repräsentieren die ausgewählten Baumarten ein breites Spektrum biologischer, ökologischer und naturschutzfachlicher Aspekte, so dass die resultierenden artspezifischen Leitfäden nicht nur für die sieben Arten sondern auch für eine breitere Anwendung innerhalb der europäischen Forstwirtschaft geeignet sind. Die Leitfäden für das forstgenetische Monitoring von Fagus sy/vatica und Abies alba/Abies borisii-regis wurden auf Grundlage der Ergebnisse und Erfahrungen aus laufenden FGM-Aktivitäten im LIFEGENMON-Projekt in Bezug auf diese Arten in Deutschland, Slowenien und Griechenland erstellt. Insgesamt wurden sechs FGM-Flächen eingerichtet: drei für Fagus sylvatica und drei für Abies alba/Abies borisii-regis. Diese Monitoringflächen werden auch zukünftig für forstgenetische Monitoring- und Forschungsaktivitäten zur Verfügung stehen.

Die FGM-Leitfäden der sieben ausgewählten Baumarten(-gruppen) sollen zum Aufbau eines europaweiten Netzwerks forstgenetischer Monitoringflächen für die frühzeitige Beurteilung der Auswirkungen des Klimawandels auf die genetische Diversität von Waldbaumpopulationen beitragen, damit ein entsprechendes adaptives Management rechtzeitig, effizient und effektiv umgesetzt werden kann.

Die Leitfäden richten sich in erster Linie an das Personal, welches die für das FGM erforderlichen Außenaufnahmen durchführt, und enthält detaillierte Anweisungen zur Durchführung regelmäßiger Beobachtungen und Messungen für ein derartiges Monitoring, wie z. B. phänologische Beobachtungen, Bewertung der Mortalität/Überlebensrate sowie der Abundanz von Naturverjüngung, usw. Um im Zeitverlauf vergleichbare Ergebnisse (verschiedene Jahre, ggf. wechselndes Personal) zu gewährleisten, müssen Außenaufnahmen und Datenerfassungsverfahren methodisch standardisiert werden. Nach entsprechenderVorbereitung und Schulung können dieAußenaufnahmen von wissenschaftlich-technischem Personal, Försterlnnen oder Wissenschaftlerlnnen durchgeführt werden. Da viele der Beobachtungen im Bestand von einer visuellen Beurteilung abhängen und zumindest bis zu einem gewissen Grad der individuellen Interpretation unterliegen, wird die Organisation entsprechender Schulungen zur Durchführung der Außenaufnahmen empfohlen, um ein höchstmögliches Maß an Vergleichbarkeit und Belastbarkeit der erfassten Daten zu gewährleisten. 
Tabelle 9.1. Liste der Baumarten, für die im Rahmen des LIFEGENMON-Projekts FGM-Leitfäden erstellt wurden. Alle sieben ausgewählten Arten(-gruppen) werden als ökologisch und wirtschaftlich wichtig angesehen. Erhaltungszustand - IUCN (in Europa, gemäß der Roten Liste der IUCN): LC - nicht gefährdet (least concern), NT - potenziell gefährdet (near threatened), DD - unzureichende Datengrundlage (data deficient), NE - nicht ausgewertet (not evaluated); Populationsentwicklung (in Europa, gemäß Roter Liste der IUCN): — - stabil, $\downarrow$ - abnehmend, ? - unbekannt, NE - (not evaluated); Verteilung: B - bestandsbildend, NB - nicht-bestandesbildend/verstreut; Klassifizierung: L - Laubbaum, N - Nadelbaum; Bestäubung: W - windbestäubt, I - insektenbestäubt; Monözie/Diözie: M - monözisch (einhäusig), D - diözisch (zweihäusig).

\begin{tabular}{|c|c|c|c|c|c|c|}
\hline Baumart & $\begin{array}{l}\text { IUCN-Erhal- } \\
\text { tungs-zustand- }\end{array}$ & $\begin{array}{l}\text { Populations- } \\
\text { entwicklung }\end{array}$ & Verteilung & Klassifikation & Bestäubung & $\begin{array}{c}\text { Monözie/ } \\
\text { Diözie }\end{array}$ \\
\hline Fagus sylvatica & LC $^{1}$ & -1 & B & $L$ & W & $M$ \\
\hline $\begin{array}{l}\text { Abies albal } \\
\text { Abies borisii-regis }\end{array}$ & $\begin{array}{l}\mathrm{LC}^{1} \\
\mathrm{NE}\end{array}$ & $\overline{\mathrm{NE}}^{1}$ & B & $\mathrm{N}$ & W & M \\
\hline Populus nigra & $\mathrm{DD}^{3}$ & $\downarrow^{3}$ & NB & L & W & $\mathrm{D}$ \\
\hline Fraxinus excelsior & $N T^{4}$ & $\downarrow 4$ & $\mathrm{~B} / \mathrm{NB}$ * & $L$ & W & $M$ \\
\hline Pinus nigra & LC $^{5}$ & -5 & $\mathrm{~B}$ & $\mathrm{~N}$ & W & M \\
\hline Prunus avium & $\operatorname{LC}^{6}$ & -6 & NB & $L$ & I & M \\
\hline $\begin{array}{l}\text { Quercus roburl } \\
\text { Quercus petraea }\end{array}$ & $\begin{array}{l}\text { LC }^{7} \\
\text { LC }^{8}\end{array}$ & $\begin{array}{l}\downarrow^{7} \\
?^{8}\end{array}$ & $\mathrm{~B}$ & $\mathrm{~L}$ & W & $M$ \\
\hline
\end{tabular}

* Die Gemeine Esche kann Reinbestände bilden, ist aber meist in kleineren Gruppen in Mischbeständen anzutreffen, ähnlich wie bei nicht-bestandesbildenden Arten mit verstreuter Verbreitung.

\section{Quellenangaben zur Tabelle}

1. Barstow M, Beech E. 2018. Fagus sylvatica. The IUCN Red List of Threatened Species 2018: e.T62004722A62004725. Accessed 04 December 2020: https://dx.doi.org/10.2305/IUCN.UK.2018-1.RLTS.T62004722A62004725.en.

2. Farjon, A. 2017. Abies alba. The IUCN Red List of Threatened Species 2017: e.T42270A83978869. Accessed 04 December 2020: https://dx.doi.org/10.2305/IUCN.UK.2017-2.RLTS.T42270A83978869.en.

3. Harvey-Brown, Y., Barstow, M., Mark, J. \& Rivers, M.C. 2017. Populus nigra. The IUCN Red List of Threatened Species 2017: e.T63530A68106816. Accessed 04 December 2020: https://dx.doi.org/10.2305/IUCN.UK.2017-3.RLTS. T63530A68106816.en.

4. Khela, S. \& Oldfield, S. 2018. Fraxinus excelsior. The IUCN Red List of Threatened Species 2018: e.T203367A67807718. Accessed 04 December 2020: https://dx.doi.org/10.2305/IUCN.UK.2018-1.RLTS. T203367A67807718.en.

5. Farjon, A. 2013. Pinus nigra. The IUCN Red List of Threatened Species 2013: e.T42386A2976817. Accessed 04 December 2020: https://dx.doi.org/10.2305/IUCN.UK.2013-1.RLTS.T42386A2976817.en.

6. Rivers, M.C. 2017. Prunus avium. The IUCN Red List of Threatened Species 2017: e.T172064A50673544. Accessed 04 December 2020: https://dx.doi.org/10.2305/IUCN.UK.2017-3.RLTS.T172064A50673544.en.

7. Gorener, V., Khela, S. \& Barstow, M. 2017. Quercus petraea. The IUCN Red List of Threatened Species 2017: e.T62539A3116237. Accessed 04 December 2020: https://dx.doi.org/10.2305/IUCN.UK.2017-3.RLTS. T62539A3116237.en.

8. Barstow, M. \& Khela, S. 2017. Quercus robur. The IUCN Red List of Threatened Species 2017: e.T63532A3126467. Accessed 04 December 2020: https://dx.doi.org/10.2305/IUCN.UK.2017-3.RLTS.T63532A3126467.en. 
9.2 LEITFÄDEN FÜR DAS GENETISCHE MONITORING DER AUSGEWÄLTEN SIEBEN ARTEN 


\section{Leitfaden für das genetische Monitoring der}

\subsubsection{Weißtanne \\ (Abies alba Mill.) \\ und}

\section{König-Boris-Tanne (Abies borisii-regis Mattf.)}

Darius KAVALIAUSKAS', Barbara FUSSI', Dalibor BALLIAN²,3,

Paraskevi ALIZOTI'4, Nikolaos TOURVAS ${ }^{4}$, Gregor BOŽIČ², Evangelos BARBAS ${ }^{4}$, Marjana WESTERGREN², Marko BAJC², Rok DAMJANIĆ2, Natalija DOVČ²,

Filippos A. ARAVANOPOULOS ${ }^{4}$, Hojka KRAIGHER ${ }^{2}$

Botanische lllustrationen von Anja RUPAR

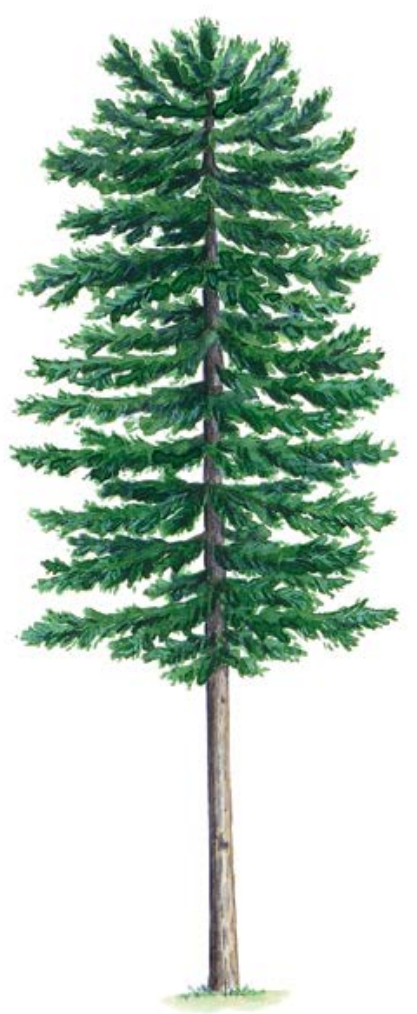

Zitat: Kavaliauskas et al. (2020) Leitfaden für das genetische Monitoring der Weißtanne (Abies alba Mill.) und König-Boris-Tanne (Abies borisii-regis Mattf.). In: Bajc et al. (Ed.) Handbuch zum Forstgenetischen Monitoring. Slowenisches Forstinstitut: Verlag Silva Slovenica, Ljubljana, S. 173-190. http://dx.doi.org/10.20315/SFS.176

4. Aristoteles Universität von Thessaloniki (AUTH), Griechenland 


\section{ZUSAMMENFASSUNG}

Die Weißtanne (Abies alba Mill.) und die König-Boris-Tanne (Abies borisii-regis Mattf.) sind windbestäubte, einhäusige, meist auskreuzende Nadelbaumarten der Gattung Abies. Die Weißtanne ist in mehreren europäischen Ländern aus ökonomischer und ökologischer Sicht eine der bedeutendsten Waldbaumarten. Die König-BorisTanne ist ein wichtiger natürlicher Hybrid von Abies alba und Abies cephalonica Loudon, der hauptsächlich in Griechenland vorkommt. Aufgrund der klimatischen Veränderungen sind beide Arten zahlreichen Gefährdungen und Herausforderungen ausgesetzt, weshalb sie für das forstgenetische Monitoring in Betracht kommen.

Dieser Leitfaden beschreibt die Weißtanne und die König-Boris-Tanne sowie ihre Reproduktion, Umwelt und Gefährdung. Er enthält außerdem eine Anleitung zur Einrichtung genetischer Monitoringflächen und zur Erfassung aller vor Ort im Bestand zu erhebenden Verifikatoren und phänologischen Daten auf Basis-, Standard- und Intensivniveau.

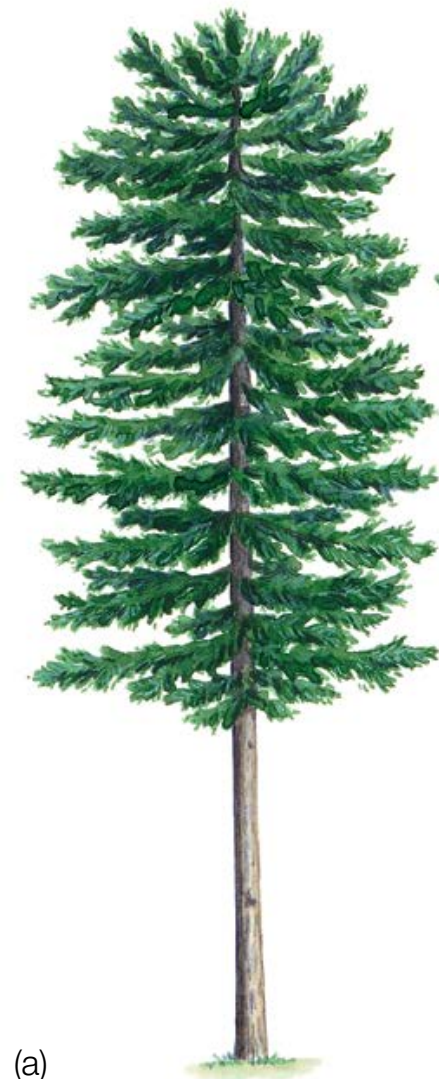

(a)

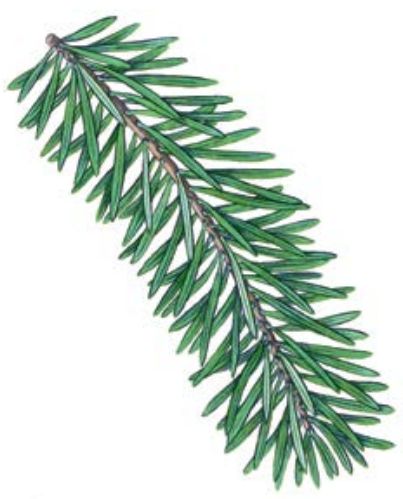

(c)

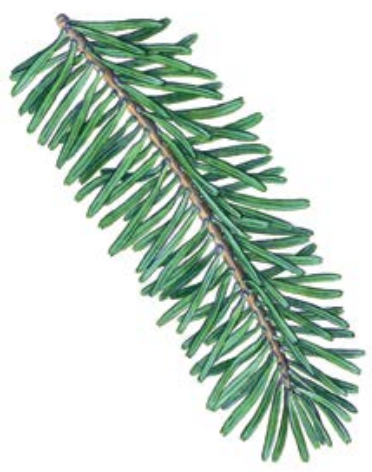

(d)

Abbildung 1: Habitus der Weißtanne (Abies alba) (a); ein Keimling der Weißtanne/König-Boris-Tanne (b); ein Zweig mit Nadeln der König-Boris-Tanne (c) und der Weißtanne (d).

\section{BESCHREIBUNG DER BAUMART}

Die Weißtanne und die König-Boris-Tanne (Abbildung 1) sind einhäusige Nadelbaumarten, die unter optimalen Bedingungen mehr als 50 m (60 m) Höhe und mehr als 1,5 m (2,0 m) Durchmesser (BHD) erreichen können $[1,4,16,28]$. Durch das im Alter geringe Wachstum des Haupttriebs verlieren ältere Bäume ihr kegelförmiges Aussehen und werden an der Spitze oval (Abbildung 1 (a)). Das Holz harzt nicht und hat keinen farbigen Kern. Die Äste stehen meist waagerecht und mehr oder weniger eben (nicht hängend) in deutlichen Quirlen. Die Rinde ist rau, aber bis zum Alter von 50 Jahren relativ glatt. Mit zunehmendem Alter nimmt die Rinde die Form quadratischer Korkplatten an, welche fest am Stamm haften und schwer abzutrennen sind [1, 4, 7, 26, 27, 28 usw.]. Die Nadeln der Weißtanne sind auf der Oberseite dunkelgrün und glänzend, während die Unterseite zwei silbergrüne wachsartige Streifen mit 6-8 Reihen von Spaltöffnungen (Stomata) aufweist [16, 28]. 


\section{REPRODUKTION}

Abies alba und Abies borisii-regis sind windbestäubte, einhäusige, meist auskreuzende Arten mit einer Chromosomenzahl von 2n=24. Bei beiden Arten werden die Samen vom Wind verbreitet. Die weiblichen Blüten haben die Form kleiner Zapfen und befinden sich auf den oberen Zweigen. Die männlichen Blüten (Kätzchen) befinden sich in der Regel etwas tiefer in der Krone, am Ansatz der Nadeln. Sie sind etwa $2 \mathrm{~cm}$ lang und weisen zwei Pollensäcke auf. Die Weißtanne blüht im Frühling, je nach Höhenlage und Breitengrad von April bis Juni [1, 4, 7, 26, 27, 28].

Tannen sind langlebige Baumarten, die ihre Fortpflanzungsfähigkeit frühestens im Alter von 20 Jahren, im Mittel jedoch erst im Alter von 60 Jahren erreichen [14]. Die weiblichen Blüten sind zapfenförmig, im jungen Alter dunkelgrün, eiförmig, etwa $2 \mathrm{~cm}$ lang und aufrecht stehend. Der reife Zapfen ist (dunkel) gelblich, zylindrisch, bis zu $16 \mathrm{~cm}$ lang und bis zu $5 \mathrm{~cm}$ breit. Die Zapfen stehen immer aufrecht auf den Zweigen und zerfallen noch im selben Jahr. Im Oktober fallen die Zapfenschuppen mit den Samen ab und die nackte Zapfenspindel verbleibt auf dem Zweig. Die geflügelten Samen werden durch den Wind verbreitet. Junge Bäume fruktifizieren alle zwei Jahre; alte Bäume und solche in höheren Lagen seltener, d.h. alle drei Jahre oder in noch größeren Abständen [1, 4, 7, 26, 27, 28]. Einige Bäume können jedoch jedes Jahr fruktifizieren (LIFEGENMON-Beobachtungen auf der FGM-Fläche von Abies alba in Süddeutschland).

Trotz ihrer starken Pollenproduktion gilt die Weißtanne als schwacher Samenproduzent, da sich nur wenige Knospen zu weiblichen Blüten entwickeln. Auch Insektenbefall, Spätfröste Ende Mai und Anfang Juni (je nach Höhenlage $[8,10])$ sowie unzureichende Bestäubung verringern die Samenproduktion drastisch $[6,15,17,18$, 19, 20, 23, 24, 25]. Der gesamte Zyklus von der Blüte bis zur Samenreifung und -verbreitung findet in einem Jahr statt. Der Zeitraum von der Blüte über die Bestäubung bis zur Reifung des Samens dauert 90 bis 120 Tage [3, 9, 12, 13, 29]. Die Reifung und Verbreitung der Samen der Weißtanne erfolgt zwischen September und November.

\section{UMWELT}

Die Weißtanne ist in Mitteleuropa und in Teilen Ost- und Südeuropas verbreitet [4, 26, 27, 28]. Das Verbreitungsgebiet der König-Boris-Tanne ist auf den südlichen Teil der Balkanhalbinsel beschränkt. Die Weißtanne ist eine Art des gemäßigten, durch den Ozean abgemilderten Kontinentalklimas, und sie bevorzugt im Gegensatz zu anderen mediterranen Abies-Arten kühlere und feuchtere Bedingungen. Die Weißtanne toleriert ein breites Spektrum von Böden mit unterschiedlichen Nährstoffgehalten und Alkalinitätsniveaus, mit Ausnahme verdichteter und hydromorpher Böden [16]. Sie bevorzugt tiefgründige und feuchte, jedoch nicht zu nasse Böden mit einem pH-Wert von sauer bis neutral. Die Weißtanne ist eine sehr schattentolerante Baumart, die lange im dichten Unterstand von Plenterwäldern überdauern kann [16, 28]. Sie kann Reinbestände bilden, ist jedoch meist in Mischbeständen zu finden; nahe der oberen Baumgrenze in Mischung mit Fichte (Picea abies (L.) H. Karst.) oder Kiefer (Pinus sylvestris L.) sowie in tieferen Lagen mit Rotbuche (Fagus sylvatica L.) [1, 16, 28, 4 und darin enthaltene Quellen].

\section{GEFÄHRDUNG}

Weißtannen sind sehr temperaturempfindlich, da insbesondere Weißtannenverjüngung oft durch Spätfröste im Frühjahr geschädigt wird [21]. Junge Weißtannen sind bis zum Alter von 3 Jahren sehr empfindlich gegen Trockenheit; wenn diese länger andauert, können die jungen Pflanzen nicht überleben [1, 4, 22]. Darüber hinaus sind Weißtannenjungpflanzen sehr verbissanfällig. Die Weißtanne ist auch empfindlich gegenüber Waldbränden und Luftverschmutzung, insbesondere in Bezug auf winterliche $\mathrm{SO}_{2}$-Belastung [16 und darin enthaltene Quellen]. Durch den Klimawandel sind Weißtannen anfälliger für Krankheiten und Schädlinge. So z.B. haben Misteln und Borkenkäfer die Weißtanne im Mittelmeerraum bereits geschädigt, insbesondere in Gebieten, in denen häufiger Dürreperioden auftreten [16 und darin enthaltene Quellen]. Insekten wie Ips typographus (L.), Cinaria pectinatae (Nördlinger) und Epinotia nigricana (Herrich-Schäffer) befallen die Rinde und Knospen der Weißtanne. Die Pilze Armillaria mellea (Vahl) P.Kumm agg. und Heterobasidion annosum (Fr.) Bref. verursachen Stockfäule und Windwurf [16 und darin enthaltene Quellen]. 


\section{EINRICHTUNG UND INSTANDHALTUNG VON MONITORINGFLÄCHEN}

Die Weißtanne ist eine bestandesbildende Baumart, die Rein- oder Mischbestände mit Fichte, Kiefer, Rotbuche und anderen Baumarten bilden kann [1, 28, 4 und darin enthaltene Quellen]. Daher kann - wie bei anderen bestandesbildenden Baumarten wie z.B. Fagus sylvatica - für das forstgenetische Monitoring von Abies alba und Abies borisii-regis das reguläre FGM-Verfahren angewendet werden. Die wichtigsten Schritte für eine erfolgreiche Einrichtung von FGM-Flächen für Abies alba und Abies borisii-regis ist die Auswahl der FGM-Flächen nach festgelegten Kriterien (z.B. sollte Waldbeständen eine hohe Priorität eingeräumt werden, für die bereits eine hohe Datendichte und präzise Flächendokumentation existieren) [2].

Das forstgenetische Monitoring von Abies borisii-regis kann jedoch aufgrund der geografisch unzusammenhängenden Verteilung, der Biologie (z.B. Hybridisierung) und der Gefährdung (z.B. Klimawandel, Schädlinge und Krankheiten) dieser Art eine größere Herausforderung darstellen, so dass ggf. größere Monitoringflächen erforderlich sind. Die Größe und Form der FGM-Flächen sollten daher angepasst an die lokalen Gegebenheiten flexibel sein, aus praktischen Gründen jedoch nicht größer als 10 ha.

EineforstgenetischeMonitoringflächeumfasst50fortpflanzungsfähigeAltbäumemiteinemBrusthöhendurchmesser $(B H D)$ von mehr als $15 \mathrm{~cm}$ und einem Mindestabstand von $30 \mathrm{~m}$ zwischen je zwei beliebigen Bäumen. Ein Baum gilt als fortpflanzungsfähig, wenn er blüht. Der BHD und die soziale Stellung eines Baumes können als Anhaltspunkte für die Identifizierung fortpflanzungsfähiger Bäume verwendet werden, wenn die Monitoringfläche außerhalb der Blütezeit angelegt wird. Dabei sollte auf das Fachwissen des zuständigen Försters zurückgegriffen werden. Bei der Neueinrichtung einer Monitoringfläche sollten alle Bäume beschriftet und ihre Koordinaten erfasst werden. Gleichzeitig können die jeweiligen BHD gemessen und Proben für die DNA-Extraktion gesammelt werden.

Darüber hinaus muss in der Monitoringfläche auch ausreichend Naturverjüngung vorhanden sein.

Erforderliche Ausrüstung:

- ein Gerät zur Entfernungsmessung (empfehlenswert ist ein Fernglas mit Entfernungsmesser)

- ein Kompass

- Farbe und Pinsel oder Farbspray zum Kennzeichnen der Bäume

- eine Kluppe für BHD-Messungen und

- ein ausreichend präzises GPS-Gerät, welches das Speichern von Baumkoordinaten ermöglicht

\subsection{Einrichtung der Monitoringfläche}

\subsubsection{Auswahl des Mittelpunkts}

Das allgemeine Verfahren für eine Zufallsauswahl der Monitoringfläche besteht aus den folgenden Schritten (Abbildung 2 links):

- zufällige Auswahl eines Punktes (grüner Punkt) entlang einer an der Bestandesgrenze verlaufenden Forststraße oder eines Waldweges auf einer Karte;

- Einzeichnen einer annähernd senkrecht zur Straße verlaufenden Linie an diesem zufällig entlang der Straße ausgewählten Punkt;

- zufällige Auswahl eines Punktes auf der Linie (roter Punkt) - dieser Punkt stellt den Mittelpunkt der forstgenetischen Monitoringfläche dar.

Der Mindestabstand zwischen dem ausgewählten Mittelpunkt und der Bestandesgrenze beträgt ca. $150 \mathrm{~m}$. Wenn der ausgewählte Mittelpunkt diese Anforderung nicht erfüllt, muss nach dem oben beschriebenen Verfahren ein neuer Punkt ausgewählt werden. 
(a)

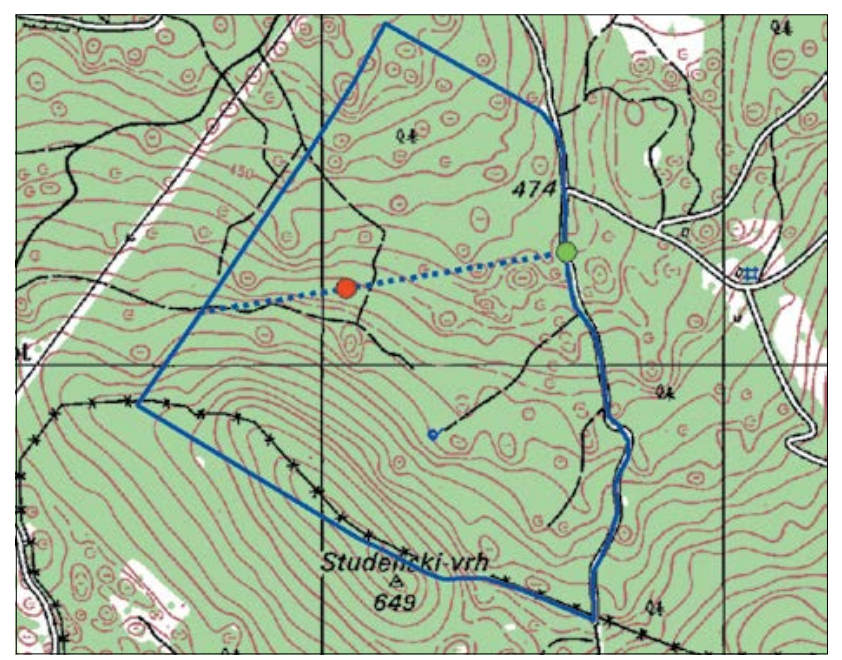

(b)

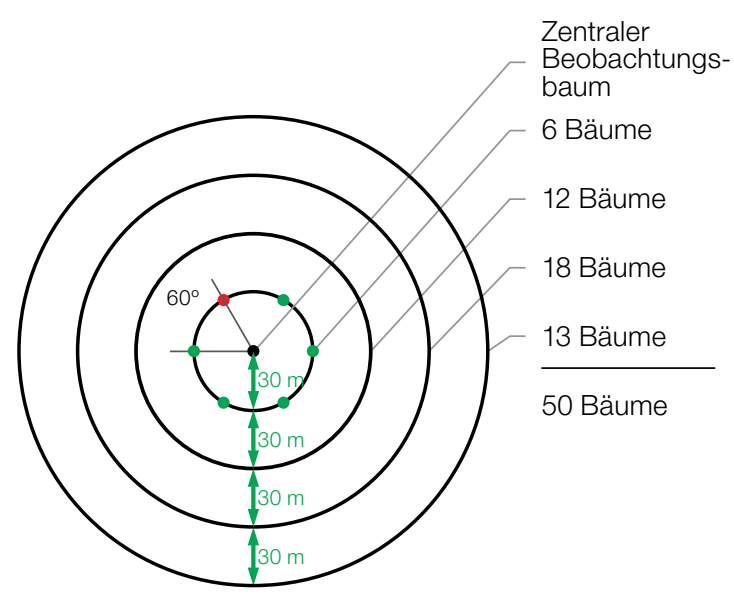

Abbildung 2: Zufällige Auswahl des Mittelpunkts der forstgenetischen Monitoringfläche (a); Auswahl von Bäumen in konzentrischen Kreisen mit einem zunehmenden Radius von 30 m um den zuvor ausgewählten zentralen Beobachtungsbaum (b).

Anstelle des oben beschriebenen Verfahrens können auch entsprechende Werkzeuge zur Erstellung von Zufallspunkten in GIS-Software verwendet werden.

Für die Nutzung im Gelände sollten die Koordinaten des ausgewählten Punktes in einem GPS-Gerät gespeichert werden.

\subsubsection{Einrichtung der Monitoringfläche}

Vor Ort im Bestand wird ein zentraler Beobachtungsbaum der Monitoringfläche bestimmt und mit der Nummer 1 gekennzeichnet. Dieser Baum entspricht dem der gespeicherten GPS-Koordinate am nächsten stehende, fortpflanzungsfähige Baum.

In konzentrischen Kreisen mit einem zunehmenden Radius von $30 \mathrm{~m}$ um den zentralen Beobachtungsbaum werden weitere Altbäume ausgewählt (Abbildung 2 rechts). Der erste Baum in jedem Kreis sollte nach dem Zufallsprinzip ausgewählt werden, was auf verschiedene Weise geschehen kann: durch Verwendung eines zufälligen Azimuts, der vom zentralen Beobachtungsbaum aus eingemessen wird (Tabelle 1), durch Folgen der Richtung des Sekundenzeigers auf einer analogen Uhr oder durch eine andere Vorgehensweise, die eine objektive Auswahl ermöglicht. Die verbleibenden Bäume in jedem Kreis werden mit einem entsprechend größeren Azimut ausgewählt, um einen Mindestabstand von 30 m zwischen je zwei beliebigen Bäumen zu gewährleisten:

- $+60^{\circ}$ im ersten Kreis

- $+30^{\circ} \mathrm{im}$ zweiten Kreis

$\cdot+20^{\circ}$ im dritten Kreis

$\cdot+15^{\circ}$ im vierten Kreis

Sollte es nicht möglich sein, 6, 12 bzw. 18 Bäume in den inneren 3 Kreisen zu finden (Abbildung 2b), werden im äußersten Kreis zusätzliche Bäume ausgewählt. 
Tabelle 1: Zufällig generierte Azimute, die für die Auswahl des ersten Baumes in jedem Kreis verwendet werden können.

\begin{tabular}{rrrrrrrrrr}
\hline 108 & 15 & 186 & 35 & 178 & 29 & 305 & 351 & 44 & 150 \\
\hline 232 & 23 & 160 & 141 & 112 & 292 & 216 & 83 & 245 & 214 \\
\hline 63 & 65 & 345 & 234 & 95 & 78 & 279 & 323 & 40 & 236 \\
\hline 201 & 313 & 275 & 144 & 182 & 68 & 268 & 289 & 185 & 92 \\
\hline 356 & 177 & 93 & 1 & 145 & 198 & 287 & 251 & 224 & 142 \\
\hline
\end{tabular}

\subsubsection{Kennzeichnung der Bäume}

Alle 50 ausgewählten Beobachtungsbäume müssen mit einer entsprechenden Nummer und idealerweise mit einem um den Stamm herum laufenden Streifen gekennzeichnet werden, um die Sichtbarkeit der Bäume aus allen Richtungen zu erhöhen. Die Koordinaten jedes Baumes (X/Y) müssen erfasst werden (GPS erforderlich). Die bei der Auswahl der Altbäume vergebenen Baumnummern müssen über den gesamten Monitoringzeitraum beibehalten werden. (GPS erforderlich). Die bei der Auswahl der Altbäume vergebenen Baumnummern müssen über den gesamten Monitoringzeitraum beibehalten werden.

Markieren Sie den zentralen Beobachtungsbaum (Nummer 1) mit zwei oder mehr Streifen, um inn von anderen Bäumen zu unterscheiden (Abbildung 3a). Es wird empfohlen, die Baumnummer stets auf der vom zentralen Beobachtungsbaum abgewandten Seite der Bäume anzubringen, da dies die Lokalisierung des zentralen Beobachtungsbaum v.a. von den äußeren Kreisen der Monitoringfläche aus erleichtert (Abbildung 3b). In einigen Fällen kann es hilfreich sei, die Bäume auf der von Straßen/Wegen abgewandten Seite zu kennzeichnen, um Missverständnisse mit Erholungssuchenden zu vermeiden.

\subsection{Einrichtung von Naturverjüngungs-Plots}

Die Einrichtung von Plots für das Monitoring der Naturverjüngung (NV) sollte während der Keimungsperiode nach einem starken oder extremen Fruktifikationsereignis erfolgen.

Bereiche mit aufgelaufener Naturverjüngung aus dem letzten Mastjahr (sogenannte Verjüngungscluster) sollten vor Ort vermessen und ihre Position erfasst werden (GPS-Koordinaten, Nummer des Beobachtungsbaumes
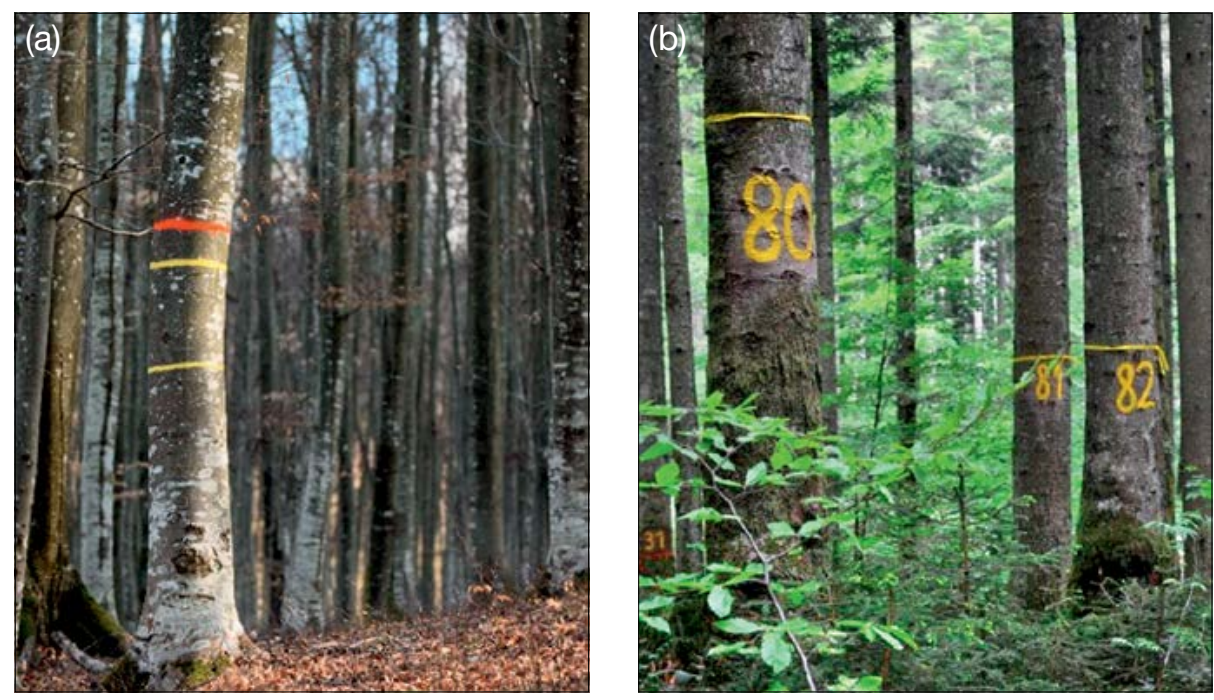

Abbildung 3: a) Der zentrale Beobachtungsbaum der forstgenetischen Monitoringfläche ist mit mehreren Streifen markiert, um inn von anderen Bäumen zu unterscheiden (das Foto links zeigt beispielhaft die Kennzeichnung einer Buchen-FGM-Fläche); b) die Nummerierung der ausgewählten Bäume erfolgt auf der vom zentralen Beobachtungsbaum abgewandten Seite (das Foto rechts zeigt beispielhaft die Markierungen auf einer Weißtannen-FGM-Fläche). 
neben dem Verjüngungscluster). Von allen erfassten Verjüngungsclustern sollten nach dem Zufallsprinzip 20 für die Einrichtung von NV-Plots ausgewählt werden. Wenn 20 oder weniger natürliche Verjüngungscluster vorhanden sind, sollten alle verwendet werden.

Innerhalb jedes ausgewählten Verjüngungsclusters ist ein $1 \mathrm{~m}^{2}$ großer Plot einzurichten und mit Metallstäben zu markieren. Die Metallstäbe sollten an jeder Ecke der Teilfläche so tief wie möglich in den Boden getrieben werden, damit sie nicht von Tieren entfernt werden können. Die oberen Spitzen der Metallstäbe sollten farbig markiert werden, um ihre Sichtbarkeit zu verbessern.

\subsection{Instandhaltung der Monitoringfläche}

\subsubsection{Allgemeine Instandhaltung}

Die Kennzeichnung der Bäume und NV-Plots muss periodisch (alle 2 Jahre) überprüft und bei Bedarf erneuert werden.

\subsubsection{Ersatz von Bäumen}

Wenn ein ausgewählter Beobachtungsbaum stirbt oder im Zuge der forstlichen Bewirtschaftung gefällt wird, muss er ersetzt werden. Dabei sollte der dem abgestorbenen/gefällten Baum nächstgelegene geeignete Baum ausgewählt werden, wobei der Mindestabstand von 30 m zum nächsten Beobachtungsbaum erfüllt sein muss. Andernfalls ist ein Baum aus der Peripherie (vorzugsweise im äußeren Kreis) der Monitoringfläche zu wählen. Der Ersatzbaum wird mit der nächsten verfügbaren Zahl über 50 gekennzeichnet, d.h. 51, 52, 53, usw., um ihn eindeutig von den ursprünglich 50 ausgewählten Beobachtungsbäumen zu unterscheiden.

Wenn die Baumkrone z.B. durch Wind-, Eis- oder Schneebruch geschädigt ist, der Baum aber weiterhin fruktifiziert, wird der Baum im Monitoringprogramm belassen. Ist der Schaden zu schwerwiegend und eine Fruktifikation nicht mehr zu erwarten, muss der Baum ersetzt werden. 


\section{ERFASSUNG VON VERIFIKATOREN UND HINTERGRUNDINFORMATIONEN}

Auf der Monitoringfläche werden periodisch Verifikatoren und Hintergrundinformationen erfasst. Verifikatoren werden genutzt, um die genetischen Eigenschaften der Population und ihre Anpassung an Umweltveränderungen und/oder Bewirtschaftung zu verfolgen, während Hintergrundinformationen aufgezeichnet werden, um die Interpretation der Verifikatoren zu unterstützen. Verifikatoren können auf drei verschiedenen Intensitätsniveaus erfasst werden: Basis, Standard und Intensiv.

Höherrangigere Niveaus (Standard, Intensiv) müssen stets auch die Erfassung der Verifikatoren auf allen niedrigeren Niveaus (Basis, Standard) einschließen. Dies ist für die Aufzeichnung von Hintergrundinformationen nicht erforderlich.

Tabelle 2: Liste der Verifikatoren und Hintergrundinformationen, die während der Außenaufnahmen auf den AbiesMonitoringflächen zu erfassen sind; jeweils mit Kurzbeschreibung und Beobachtungshäufigkeit.

\begin{tabular}{|c|c|c|c|c|}
\hline & Bezeichnung & Basisniveau & Standardniveau & Intensivniveau \\
\hline \multirow{5}{*}{ 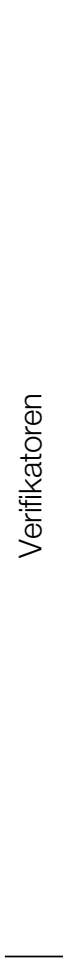 } & \multirow[t]{2}{*}{$\begin{array}{l}\text { Mortalität / } \\
\text { Überlebensrate }\end{array}$} & $\begin{array}{l}\text { Altbäume: Zählung der } \\
\text { verbleibenden markierten Bäume } \\
\text { alle } 10 \text { Jahre und nach jedem } \\
\text { extremen Witterungsereignis/ } \\
\text { jeder Störung }\end{array}$ & wie Basisniveau & wie Basisniveau \\
\hline & & Naturverjüngung: / & $\begin{array}{l}\text { Zählung der verbleibenden } \\
\text { Sämlinge auf den NV-Plots, } \\
\text { zweimal pro Jahrzehnt }\end{array}$ & wie Standardniveau \\
\hline & \multirow[b]{2}{*}{ Fruktifikation } & $\begin{array}{l}\text { bestandesweise Schätzung; } \\
\text { jährlich }\end{array}$ & $\begin{array}{l}\text { Erfassung auf Einzelbaumebene, } \\
\text { während zwei bedeutenden } \\
\text { Blühereignissen pro Jahrzehnt, } \\
\text { idealerweise in gleichen } \\
\text { Abständen * }\end{array}$ & $\begin{array}{l}\text { Erfassung auf Einzelbaumebene, } \\
\text { während zwei bedeutenden } \\
\text { Blühereignissen pro Jahrzehnt, } \\
\text { idealerweise in gleichen } \\
\text { Abständen * }\end{array}$ \\
\hline & & $\begin{array}{c}\text { bestandesweise Schätzung; } \\
\text { jährlich }\end{array}$ & $\begin{array}{l}\text { Erfassung auf Einzelbaum- } \\
\text { ebene im selben Jahr, in dem } \\
\text { die Erfassung der Blüte auf } \\
\text { Basisniveau erfolgt (unabhängig } \\
\text { von der Fruktifikationsintensität) * }\end{array}$ & $\begin{array}{l}\text { Zählung der Früchte in den } \\
\text { gleichen Jahren, in denen } \\
\text { die Bewertung der Blüte } \\
\text { auf Intensivniveau erfolgt, } \\
\text { unabhängig von der Frukti- } \\
\text { fikationsintensität* Bei jedem } \\
\text { erfassten Fruktifikations- } \\
\text { ereignis wird auch Saatgut für } \\
\text { Laboranalysen gesammelt }\end{array}$ \\
\hline & $\begin{array}{l}\text { Abundanz der } \\
\text { Naturverjüngung }\end{array}$ & $\begin{array}{l}\text { bestandesweise Schätzung; } \\
\text { jährlich }\end{array}$ & $\begin{array}{l}\text { Zählung der Sämlinge im 1. und } \\
\text { 6. Jahr nach jedem erfassten } \\
\text { Fruktifikationsereignis }\end{array}$ & $\begin{array}{l}\text { Zählung der Sämlinge im 1., } 6 . \text {, } \\
\text { 11. und 16. Jahr nach jedem } \\
\text { erfassten Fruktifikationsereignis }\end{array}$ \\
\hline \multirow{4}{*}{ 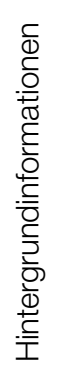 } & $\begin{array}{l}\text { Durchmesser- } \\
\text { klassen-vertei- } \\
\text { lung }\end{array}$ & / & Messung alle 10 Jahre & wie Standardniveau \\
\hline & $\begin{array}{l}\text { Höhenklassen- } \\
\text { verteilung }\end{array}$ & / & Messung alle 10 Jahre & wie Standardniveau \\
\hline & Austrieb & / & $\begin{array}{l}\text { Erfassung auf Einzelbaumebene; } \\
\text { alle } 5 \text { Jahre }\end{array}$ & $\begin{array}{l}\text { Erfassung auf Einzelbaumebene; } \\
\text { jährlich }\end{array}$ \\
\hline & Seneszenz & / & $\begin{array}{l}\text { Erfassung auf Einzelbaumebene; } \\
\text { alle } 5 \text { Jahre }\end{array}$ & $\begin{array}{l}\text { Erfassung auf Einzelbaumebene; } \\
\text { jährlich }\end{array}$ \\
\hline
\end{tabular}

* Idealerweise sollte mindestens ein größeres Fruktifikationsereignis pro Jahrzehnt bewertet werden. Ein bedeutendes Blühereignis führt jedoch nicht unbedingt zu einem bedeutenden Fruktifikationsereignis. Wenn auf das bewertete Blühereignis kein wesentliches Fruktifikationsereignis folgt, muss die Bewertung sowohl der Blüte als auch der Fruchtbildung beim nächsten bedeutenden Blühereignis wiederholt werden, unabhängig von der Zeit, die zwischen aufeinanderfolgenden bedeutenden Blühereignissen liegt. Erhebungen auf Basisniveau werden zur Identifizierung bedeutender Blüh- und Fruktifikationsereignisse verwendet. 


\subsection{Verfahren zur Erfassung der Verifikatoren}

\subsubsection{Mortalität / Überlebensrate}

Die Mortalität beschreibt die Sterblichkeit von Altbäumen und Naturverjüngung. Ihr Pendant - die Überlebensratesteht für Bäume, die seit der letzten Datenerhebung noch am Leben sind. Die Überlebensrate wird berechnet als 1 - Mortalität.

\subsubsection{Altbäume: Basis-, Standard- und Intensivniveau}

Der Verifikator für die Mortalität von Abies-Altbäumen wird geschätzt, indem die verbleibenden lebenden Beobachtungsbäume alle 10 Jahre sowie nach jedem extremen Witterungsereignis bzw. jeder Störung gezählt werden. Die Mortalität ist die Differenz zwischen der ursprünglichen Anzahl markierter Beobachtungsbäume und den davon verbleibenden lebenden Bäumen der ursprünglichen 50 Beobachtungsbäume.

\subsubsection{Naturverjüngung: Standard- und Intensivniveau}

Die Mortalität der Naturverjüngung wird auf Grundlage des Verifikators „Abundanz der Naturverjüngung“ berechnet. Die Mortalität ist der Unterschied zwischen der anfänglichen Anzahl der Jungpflanzen und den Pflanzen, die zum Zeitpunkt der nächsten Zählung noch am Leben sind. Für jede Bewertungsrunde werden die Jungpflanzen zuerst im Jahr der Keimung und dann wieder nach 5 Jahren auf Standardniveau gezählt, während auf dem Intensivniveau die Zählung zusätzlich nach 10 und 15 Jahren durchgeführt wird. Die Bewertung der „Abundanz der Naturverjüngung“ erfolgt zweimal pro Jahrzehnt, idealerweise etwa alle fünf Jahre.

\subsubsection{Blüte}

Dieser Verifikator beschreibt das Auftreten der Blüte (Anteil der Bäume) und die Blühintensität (Anteil der blühenden Krone) für Abies spp. Er kann in Mitteleuropa üblicherweise von April bis Mai erfasst werden.

\subsubsection{Basisniveau}

Der Verifikator wird jährlich auf Bestandesebene erfasst. Die Erfassung erfolgt zum Zeitpunkt der Hauptblüte. Die Schätzung des durchschnittlichen Zustands erfolgt nach einer Begehung der gesamten Monitoringfläche. Es werden zwei Werte erfasst: einer für die Blühintensität, ausgedrückt als mittlerer Kronenanteil in Blüte; und einer für den Anteil der blühenden Bäume im Bestand.

\begin{tabular}{llr}
\multicolumn{2}{l}{ Code Blühintensität auf Bestandesebene } & Mittlerer Anteil der Kronen in Blüte (\%) \\
\hline \begin{tabular}{llr}
1 & Keine Blüte: Keine oder nur gelegentlich auftretende Blüten & $0-10$ \\
\hline 2 & Schwache Blüte: Einige Blüten erscheinen an den Bäumen & $>10-30$ \\
\hline 3 & Mäßige Blüte: Mäßig viele Blüten an den Bäumen & $>30-60$ \\
\hline 4 & Starke Blüte: Reichlich Blüten an den Bäumen & $>60-90$ \\
\hline 5 & Extreme Blüte: Enorme Anzahl von Blüten an den Bäumen & $>90$ \\
\hline & Anteil der Bäume im Bestand mit dem entsprechenden Stadium der Blühintensität (\%) \\
\hline Code & $0-10$ \\
\hline 1 & & $>10-30$ \\
\hline 2 & & $>30-60$ \\
\hline 3 & & $>60-90$ \\
\hline 4 & & $>90$ \\
\hline 5 & & 0
\end{tabular} \\
\hline
\end{tabular}




\subsubsection{Standardniveau}

Der Verifikator wird während zweier bedeutender Blühereignisse pro Jahrzehnt aufgezeichnet, idealerweise mit einem ähnlichen zeitlichen Abstand. Er wird für alle 50 Beobachtungsbäume auf Einzelbaumebene erfasst. Ein bedeutendes Blühereignis liegt vor, wenn die Blühintensität auf Basisniveau als stark oder extrem eingeschätzt wird (Code 4 oder 5) und der Anteil der Bäume mit der angegebenen Blühintensität über 60\% liegt (Code 4 oder 5). Die Erfassung erfolgt zum Zeitpunkt der Hauptblüte. Für jeden Beobachtungsbaum wird ein Wert erfasst.

\begin{tabular}{llr}
\multicolumn{2}{l}{ Code Blühintensität auf Bestandesebene } & Proportion of the crown flowering (\%) \\
\hline 1 & Keine Blüte: Keine oder nur gelegentlich auftretende Blüten & $0-10$ \\
\hline 2 & Schwache Blüte: Einige Blüten erscheinen an den Bäumen & $>10-30$ \\
\hline 3 & Mäßige Blüte: Mäßig viele Blüten an den Bäumen & $>30-60$ \\
\hline 4 & Starke Blüte: Reichlich Blüten an den Bäumen & $>60-90$ \\
\hline 5 & Extreme Blüte: Enorme Anzahl von Blüten an den Bäumen & $>90$ \\
\hline
\end{tabular}

\subsubsection{Intensivniveau}

Der Verifikator wird während zweier bedeutender Blühereignisse pro Jahrzehnt aufgezeichnet, idealerweise mit einem ähnlichen zeitlichen Abstand. Er wird für alle 50 Beobachtungsbäume von Abies sp. auf Einzelbaumebene erfasst. Ein bedeutendes Blühereignis liegt vor, wenn die Blühintensität auf Basisniveau als stark oder extrem eingeschätzt wird (Code 4 oder 5) und der Anteil der Bäume mit der angegebenen Blühintensität über 60\% liegt (Code 4 oder 5). Im Durchschnitt sind zwei Begehungen auf der Monitoringfläche erforderlich: der erste früh genug, um das Frühstadium der Blüte zu beobachten, der zweite zum Zeitpunkt der Hauptblüte.

Für jeden Baum werden drei Werte angegeben: weibliches Blühstadium, männliches Blühstadium $[5\}$ und der blühende Kronenanteil. Letzterer bezieht sich auf die Gesamtmenge der Blüten (männlich + weiblich) am Baum. Die Blühstadien sind in Abbildung 4 dargestellt.

Ein bedeutendes Blühereignis führt nicht unbedingt zu einem bedeutenden Fruktifikationsereignis. Wenn auf das bewertete Blühereignis kein wesentliches Fruktifikationsereignis folgt, muss die Bewertung sowohl der Blüte als auch der Fruchtbildung beim nächsten bedeutenden Blühereignis wiederholt werden. Erhebungen auf Basisniveau werden genutzt, um bedeutende Fruktifikationsereignisse zu identifizieren.

\begin{tabular}{ll}
\multicolumn{2}{l}{ Code } \\
\hline 1 & Keibliches Blühstadium Zapfen sichtbar $(1-2 \mathrm{~cm})$ \\
\hline 2 & Begonnenes Längenwachstum der Zapfen \\
\hline 3 & Zapfenfarbe hat von grün zu bräunlich gewechselt (Einschätzung der Farbe) \\
\hline
\end{tabular}

\begin{tabular}{ll}
\multicolumn{2}{l}{ Code Männliches Blühstadium } \\
\hline 1 & $\begin{array}{l}\text { Die Mikrosporophyllen beginnen sich auszudehnen, sind aber immer noch geschlossen und liegen sehr eng am } \\
\text { Zweig an (Farbe: grün / braun / dunkelrot / rotbraun) }\end{array}$ \\
\hline 2 & Die Pollensäcke sind gestreckt, geschwollen und gereift, Pollen wird freigesetzt (Farbe: gelb / dunkelrot / braun / rotbraun) \\
\hline 3 & Die Pollenfreisetzung ist abgeschlossen, die leeren Pollensäcke hängen noch am Zweig (Farbe: braun / dunkelrot / rotbraun) \\
\hline
\end{tabular}

\begin{tabular}{lr} 
Code & Anteil der Krone in Blüte (\%; männliche und weibliche Blüten) \\
\hline 1 & $0-10$ \\
\hline 2 & $>10-30$ \\
\hline 3 & $>30-60$ \\
\hline 4 & $>60-90$ \\
\hline 5 & $>90$ \\
\hline
\end{tabular}



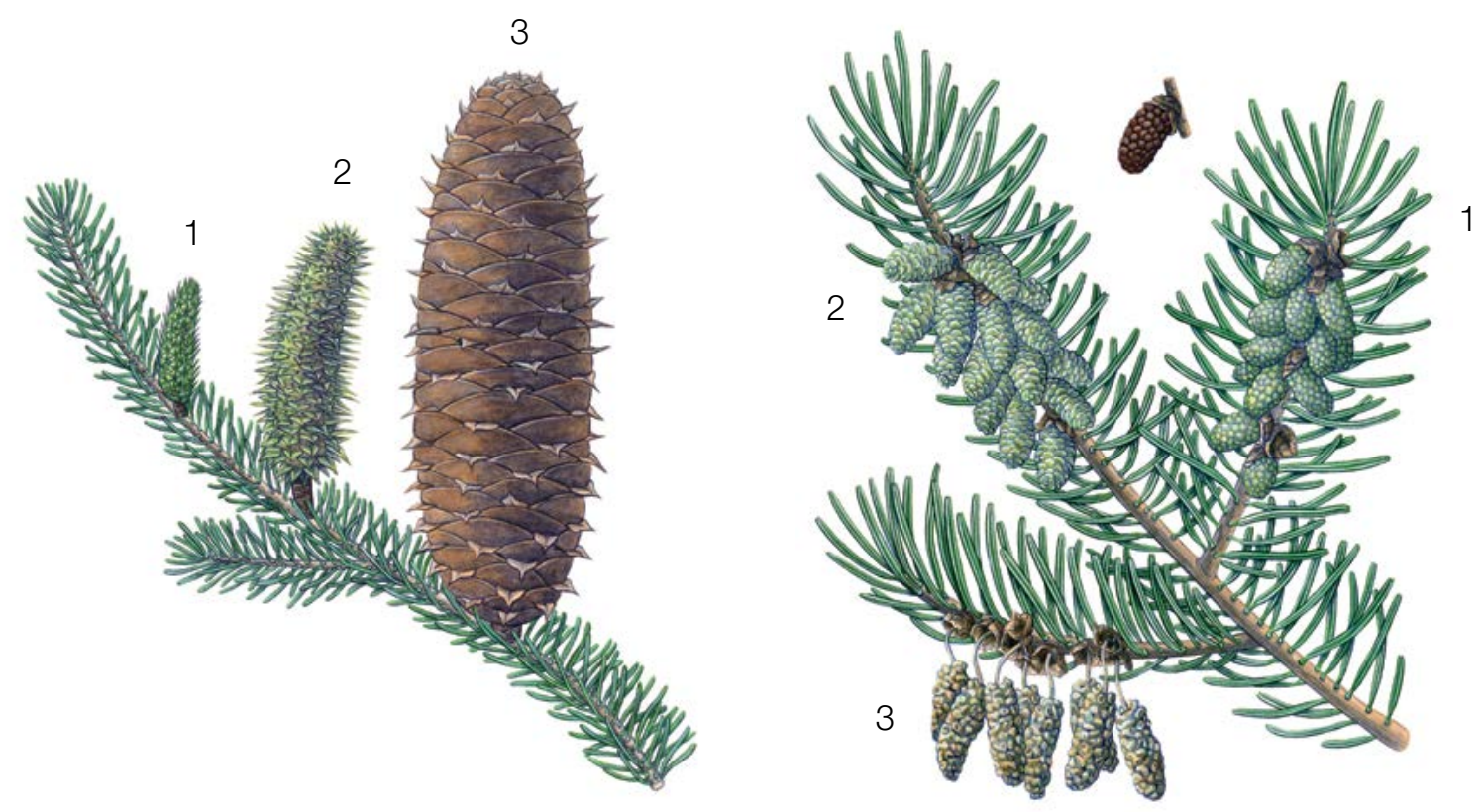

Abbildung 4: Illustrationen zur Beschreibung der weiblichen (links: 1, 2, 3) und männlichen (rechts 1, 2, 3) Blühstadien für den Verifikator „Blüte“ auf Intensivniveau.

Hintergrundinformationen zur Blühsynchronisation können anhand der für diesen Verifikator erfassten Werte für die weibliche und männliche Blüte abgeleitet werden.

\subsubsection{Fruktifikation}

Dieser Verifikator beschreibt das Auftreten und die Häufigkeit der Fruchtbildung. Die Daten für diesen Verifikator sollten während der Fruktifikationszeit von Abies sp. erhoben werden, d.h. in Mitteleuropa im August/September.

\subsubsection{Basisniveau}

Der Verifikator wird jährlich auf Bestandesebene erfasst. Die Schätzung des durchschnittlichen Zustands erfolgt nach einer Begehung der gesamten Monitoringfläche. Es werden zwei Werte erfasst: einer für die Intensität der Fruktifikation und einer für den Anteil fruchttragender Bäume im Bestand.

\begin{tabular}{llr}
\hline \multicolumn{2}{l}{ Code Intensität der Fruktifikation auf Bestandesebene } & Mittlerer Anteil der Krone mit Fruchtbehang (\%) \\
\hline 1 & $\begin{array}{l}\text { Keine Fruchtbildung: Keine oder nur gelegentlich auftretende Früchte } \\
\text { an den Bäumen }\end{array}$ & $0-10$ \\
\hline 2 & Schwache Fruchtbildung: Einige Früchte an den Bäumen & $>10-30$ \\
\hline 3 & Mäßige Fruchtbildung: Mäßig viele Früchte an den Bäumen & $>30-60$ \\
\hline 4 & Starke Fruchtbildung: Reichlich Früchte an den Bäumen & $>60-90$ \\
\hline 5 & Extreme Fruchtbildung: Enorme Anzahl von Früchten an den Bäumen & $>90$ \\
\hline
\end{tabular}

\begin{tabular}{lr} 
Code & Anteil der Bäume im Bestand mit dem entsprechenden Stadium der Fruktifikationsintensität (\%) \\
\hline 1 & $0-10$ \\
\hline 2 & $>10-30$ \\
\hline 3 & $>30-60$ \\
\hline 4 & $>60-90$ \\
\hline 5 & $>90$ \\
\hline
\end{tabular}




\subsubsection{Standardniveau}

Die Erfassung des Verifikators erfolgt in denselben Jahren wie die Bewertung der Blüte auf Standardniveau (unabhängig von der Fruktifikationsintensität). Sie wird für alle 50 Beobachtungsbäume auf Einzelbaumebene durchgeführt - und zwar bevor Zapfen beginnen zu zerfallen. Für jeden Beobachtungsbaum wird ein Wert erfasst.

Im Idealfall sollte pro Jahrzehnt ein auf ein bedeutendes Blühereignis folgendes größeres Fruktifikationsereignis erfasst werden. Ein bedeutendes Blühereignis führt jedoch nicht unbedingt $z u$ einem bedeutenden Fruktifikationsereignis. Wenn auf das bewertete Blühereignis kein wesentliches Fruktifikationsereignis folgt, muss die Bewertung sowohl der Blüte als auch der Fruchtbildung beim nächsten bedeutenden Blühereignis wiederholt werden, unabhängig von der Zeit, die zwischen aufeinanderfolgenden bedeutenden Blühereignissen liegt. Erhebungen auf Basisniveau werden genutzt, um bedeutende Fruktifikationsereignisse zu identifizieren. Ein bedeutendes Fruktifikationsereignis liegt vor, wenn die Fruktifikationsintensität auf Basisniveau als stark oder extrem eingeschätzt wird (Code 4 oder 5) und der Anteil der Bäume mit der angegebenen Fruktifikationsintensität über 60\% liegt (Code 4 oder 5).

\begin{tabular}{llr}
\multicolumn{2}{l}{ Code Intensität der Fruktifikation auf Bestandesebene } & Mittlerer Anteil der Krone mit Fruchtbehang (\%) \\
\hline 1 & $\begin{array}{l}\text { Keine Fruchtbildung: Keine oder nur gelegentlich auftretende Früchte } \\
\text { an den Bäumen }\end{array}$ & $0-10$ \\
\hline 2 & Schwache Fruchtbildung: Einige Früchte an den Bäumen & $>10-30$ \\
\hline 3 & Mäßige Fruchtbildung: Mäßig viele Früchte an den Bäumen & $>30-60$ \\
\hline 4 & Starke Fruchtbildung: Reichlich Früchte an den Bäumen & $>60-90$ \\
\hline 5 & Extreme Fruchtbildung: Enorme Anzahl von Früchten an den Bäumen & $>90$ \\
\hline
\end{tabular}

\subsubsection{Intensivniveau}

Die Erfassung des Verifikators erfolgt für alle 50 Beobachtungsbäume auf Einzelbaumebene in denselben Jahren wie die Bewertung der Blüte auf Intensivniveau (unabhängig von der Fruktifikationsintensität). Sie wird durchgeführt, bevor die Zapfen beginnen zu zerfallen. Für jeden Beobachtungsbaum wird ein Wert erfasst. Zeitgleich wird Saatgut für die Saatgut- und Genanalysen gesammelt (für die Verifikatoren und Hintergrundinformationen auf Intensivniveau).

Im Idealfall sollte pro Jahrzehnt ein auf ein bedeutendes Blühereignis folgendes größeres Fruktifikationsereignis erfasst werden. Ein bedeutendes Blühereignis führt jedoch nicht unbedingt zu einem bedeutenden Fruktifikationsereignis. Wenn auf das bewertete Blühereignis kein wesentliches Fruktifikationsereignis folgt, muss die Bewertung sowohl der Blüte als auch der Fruchtbildung beim nächsten bedeutenden Blühereignis wiederholt werden, unabhängig von der Zeit, die zwischen aufeinanderfolgenden bedeutenden Blühereignissen liegt. Erhebungen auf Basisniveau werden genutzt, um bedeutende Fruktifikationsereignisse zu identifizieren. Ein bedeutendes Fruktifikationsereignis liegt vor, wenn die Fruktifikationsintensität auf Basisniveau als stark oder extrem eingeschätzt wird (Code 4 oder 5) und der Anteil der Bäume mit der angegebenen Fruktifikationsintensität über 60\% liegt (Code 4 oder 5).

Der Verifikator wird durch das Zählen von Zapfen unter Nutzung eines Fernglases erfasst (als Durchschnitt von drei Zählrunden). Jede Zählrunde besteht aus der Anzahl der Zapfen, die der Beobachter in 30 Sekunden zählt. Bei allen Bäumen sollte das gleiche Kronendrittel untersucht werden. Sobald ein Kronendrittel für die Beobachtung ausgewählt wurde, sollte dieses für jede weitere Erhebung dieses Verifikators ausgewählt werden. Für die Zählung wird das obere Kronendrittel dem unteren und mittleren Drittel vorgezogen.

Es werden zwei Werte erfasst: die Anzahl der Zapfen und das untersuchte Kronendrittel. 


\begin{tabular}{lc}
\hline Anzahl der in 30 Sekunden gezählten Zapfen (Mittelwert aus 3 Zählrunden) & \\
\hline$X$ & Untersuchtes Kronendrittel \\
\hline Code & unteres Kronendrittel \\
\hline 1 & mittleres Kronendrittel \\
\hline 2 & oberes Kronendrittel \\
\hline 3 &
\end{tabular}

\subsubsection{Abundanz der Naturverjüngung}

Dieser Verifikator beschreibt das Vorhandensein und die Häufigkeit von Naturverjüngung auf der Monitoringfläche.

\subsubsection{Basisniveau}

Der Verifikator wird jährlich im Herbst auf Bestandesebene erfasst. Für die Schätzung der Situation auf der gesamten Monitoringfläche werden Expertenmeinungen herangezogen. Es sollten zwei Werte erfasst werden: einer für neue aufgelaufene Naturverjüngung (diesjährige Keimlinge) und einer für etablierte Naturverjüngung (ein- und mehrjährige Jungpflanzen). Da Abies sp. alle 3-5 Jahre fruktifiziert, sollte die Etablierung neuer NV im dem auf ein Mastjahr folgenden Sommer/Herbst erfasst werden.

\begin{tabular}{|c|c|}
\hline \multicolumn{2}{|r|}{ Code Beschreibung: neue aufgelaufene Naturverjüngung (diesjährige Keimlinge) } \\
\hline $1 a$ & Auf der Monitoringfläche gibt es keine oder nur sehr wenig neue Naturverjüngung \\
\hline $2 a$ & Auf der Monitoringfläche ist in ausreichender Anzahl neue Naturverjüngung vorhanden \\
\hline \multicolumn{2}{|r|}{ Code Beschreibung: etablierte Naturverjüngung (Sämlinge) } \\
\hline $1 b$ & Auf der Monitoringfläche gibt es keine oder nur sehr wenig etablierte Naturverjüngung \\
\hline $2 b$ & Auf der Monitoringfläche ist in ausreichender Anzahl etablierte Naturverjüngung vorhanden \\
\hline
\end{tabular}

\subsubsection{Standardniveau}

Die Samenruhe von Abies sp. dauert einen Winter, daher wird der Verifikator durch Zählung der Sämlinge im 1. und 6. Herbst nach jedem bewerteten Fruktifikationsereignis erfasst (das Jahr des Fruktifikationsereignisses wird als Jahr 0 betrachtet).

Zählung der Naturverjüngung:

Nach der Einrichtung der NV-Plots werden alle Abies-Sämlinge in den NV-Plots gezählt. Ältere Tannenjungpflanzen, die in den NV-Plots vorhanden sind, dürfen nicht mitgezählt werden. Bei der nächsten Zählung sind nur die Tannenjungpflanzen im entsprechenden Alter zu zählen; d.h. im 6. Jahr alle 5 Jahre alten Tannen.

\section{Anzahl der Jungpflanzen auf einem NV-Plot}

$\mathrm{X}$

Die Mortalität/Überlebensrate der Naturverjüngung wird anhand der für diesen Verifikator erfassten Werte berechnet.

Zur Einrichtung von NV-Plots siehe Kapitel 6.2 Einrichtung von Naturverjüngungs-Plots. 


\subsubsection{Intensivniveau}

Die Samenruhe von Abies sp. dauert einen Winter, daher wird der Verifikator durch Zählung der Sämlinge im 1., 6., 11. und 16. Herbst nach jedem bewerteten Fruktifikationsereignis erfasst (das Jahr des Fruktifikationsereignisses wird als Jahr 0 betrachtet).

Die nächste Runde des NV-Monitorings (Einrichtung neuer 20 NV-Plots und Schätzung der NV-Abundanz) wird mindestens 5 Jahre nach dem ersten Fruktifikationsereignis nach einem weiteren bedeutenden Fruktifikationsereignis durchgeführt (siehe Tabelle 3 für eine Darstellung der Zeitachse zur Erfassung der NVAbundanz). Es wird erwartet, dass die NV-Abundanz für ein oder zwei bedeutende Fruktifikationsereignisse pro Monitoringintervall beurteilt wird.

Tabelle 3: Zeitstrahl zur Erfassung der Abundanz der Naturverjüngung (NV). In diesem Beispiel findet das erste Fruktifikationsereignis im 2. Jahr des Beobachtungsjahrzehnts statt; das zweite erfasste Fruktifikationsereignis fünf Jahre später, d.h. im 7. Jahr des Monitorings. Da bei Abies sp. größere Fruktifikationsereignisse alle 3 - 5 Jahre auftreten, kann das Intervall zwischen zwei aufeinander folgenden größeren Fruktifikationsereignissen entsprechend variieren. Nach jedem bewerteten Fruktifikationsereignis werden 20 neue NV-Plots angelegt. Die Erfassung der NV-Abundanz auf jedem Set von 20 NV-Plots erfolgt alle fünf Jahre. Die zur jeweils erfassten NV gehörigen Fruktifikationsereignisse und der Verlauf der Monitoringaktivitäten sind in derselben Farbe schattiert. Nach der letzten Runde der NV-Zählung wird das Monitoring der NV-Abundanz auf dem entsprechenden Set von NV-Plots eingestellt und die jeweiligen NV-Plots werden aufgelöst. S - Standardniveau; I - Intensivniveau.

\begin{tabular}{|c|c|c|c|c|c|c|c|c|c|c|c|c|c|c|c|c|}
\hline Monitoringjahr & 1 & 2 & 3 & 4 & 5 & 6 & 7 & 8 & 9 & 10 & 1112 & 213 & 1415 & 1617 & 1819 & 1920212223 \\
\hline Fruktifikationsereignis & & - & & & & & - & & & & & & $\bullet$ & & & - \\
\hline $\begin{array}{l}\text { Erfassung von NV aus dem } \\
\text { ersten bewerteten Fruktifika- } \\
\text { tionsereignis [Jahre] }\end{array}$ & & 0 & 1 & 2 & 3 & 4 & 5 & 6 & 7 & 8 & 10 & 011 & 1213 & 1415 & 1617 & $\begin{array}{lllll}17 & 18 & 19 & 20 & 21\end{array}$ \\
\hline Einrichtung von NV-Plots & & & SI & & & & & & & & & & & & & \\
\hline Zählung der NV & & & SI & & & & & $\mathrm{SI}$ & & & & A & & & A & \\
\hline $\begin{array}{l}\text { Erfassung von NV aus dem } \\
\text { zweiten bewerteten Fruktifika- } \\
\text { tionsereignis [Jahre] }\end{array}$ & & & & & & & 0 & 1 & 2 & 3 & 4 & 6 & 78 & 910 & 1112 & $1213 \quad 14 \quad 15 \quad 16$ \\
\hline Einrichtung von NV-Plots & & & & & & & & SI & & & & & & & & \\
\hline Zählung der NV & & & & & & & & $\mathrm{SI}$ & & & & $\mathrm{SI}$ & & & 1 & \\
\hline
\end{tabular}

Die Mortalität/Überlebensrate der Naturverjüngung wird anhand der für diesen Verifikator erfassten Werte berechnet.

Zur Einrichtung von NV-Plots siehe Kapitel 6.2 Einrichtung von Naturverjüngungs-Plots; zur Zählung der NV siehe Kapitel 7.1.4.2 Standardniveau.

\subsection{Verfahren zur Erfassung von Hintergrundinformationen}

\subsubsection{Durchmesserklassenverteilung}

\subsubsection{Standard- und Intensivniveau}

Der BHD wird alle 10 Jahre für alle 50 Beobachtungsbäume auf Einzelbaumebene erfasst. Der BHD ist der Stammdurchmesser in 1,30 m Höhe, d.h. ungefähr auf Brusthöhe eines Erwachsenen. Hat der Baum mehr als einen Stamm, messen Sie bitte alle Stämme und erfassen Sie den Durchschnitt (versuchen Sie jedoch, Bäume mit vielen kleinen Stämmen zu vermeiden). Notieren Sie in den Anmerkungen, dass der Baum mehrstämmig ist, und geben Sie die Anzahl der gemessenen Stämme an. Ist der Baum geneigt, messen Sie den BHD senkrecht zum Baumstamm. Der BHD kann auf zwei Arten gemessen werden: 
1) mit einer Kluppe; in diesem Fall messen Sie senkrecht zueinander zwei Durchmesser und berechnen den Mittelwert

2) Messen Sie den Umfang des Baumes und berechnen Sie daraus den Durchmesser (d.h. dividieren Sie durch $\pi ; \sim 3,14)$

Der BHD wird in cm angegeben. Für nachfolgende Messungen ist stets dieselbe Methode anzuwenden.

\subsubsection{Höhenklassenverteilung}

\subsubsection{Standard- und Intensivniveau}

Die Baumhöhe wird alle 10 Jahre für alle 50 Beobachtungsbäume auf Einzelbaumebene erfasst. Die Höhe wird vom Boden bis zum höchsten Punkt der Krone gemessen, idealerweise mit einem Klinometer oder Hypsometer (z.B. Vertex). Die Höhe wird in Metern auf eine Dezimalstelle angegeben. Ist die Krone beschädigt, muss dies in den Anmerkungen zusammen mit dem mutmaßlichen Grund für den Schaden notiert werden.

\subsubsection{Austrieb}

Diese Hintergrundinformation beschreibt die Austriebsstadien. Bei der Weißtanne beginnt der Austrieb etwas später als die Blüte. Die Aufzeichnung erfolgt nur auf Standard- und Intensivniveau. Die Daten für diese Hintergrundinformation sollten in Mitteleuropa von April bis Mai erhoben werden, bis alle Beobachtungsbäume voll entwickelte Nadeln haben.

\subsubsection{Standardniveau}

Auf Standardniveau wird der Austrieb alle 5 Jahre für alle 50 Beobachtungsbäume auf Einzelbaumebene beobachtet. Gesucht werden der Beginn der Knospenöffnung (Stadium 2) und das Ende des Austriebs (Stadium 4). Die Beobachtungen werden beendet, wenn alle Bäume das Stadium 4 erreicht haben. In der Regel sind dafür 6 Begehungen erforderlich. Für jeden Baum werden zwei Werte erfasst: das Austriebsstadium und der entsprechende Kronenanteil. Die Austriebsstadien sind in Abbildung 5 dargestellt.

\begin{tabular}{|c|c|}
\hline \multicolumn{2}{|c|}{ Code Austriebsstadium (vereinfachte Stadien [5]) } \\
\hline 1 & Knospen noch von Nadeln umschlossen und nur sichtbar, wenn diese gescheitelt werden \\
\hline 2 & Knospen verlängert, Knospenschuppen und Membran sind deutlich abgelöst \\
\hline 3 & Länglicher, pinselartiger Trieb mit weichen Nadeln erscheint \\
\hline 4 & Weiche Triebe mit voll entwickelten Nadeln \\
\hline
\end{tabular}

\begin{tabular}{cc} 
Code & Anteil der Krone mit dem entsprechenden Austriebsstadium (\%) \\
\hline 1 & $>0-33$ \\
\hline 2 & $>33-66$ \\
\hline 3 & $>66-99$ \\
\hline 4 & 100 \\
\hline
\end{tabular}

\subsubsection{Intensivniveau}

Auf Intensivniveau wird der Austrieb jährlich für alle 50 Beobachtungsbäume auf Einzelbaumebene erhoben, mit derselben Verfahrensweise wie auf Standardniveau. Details dazu sind im Kapitel 7.2.3.1 Standardniveau zu finden. 


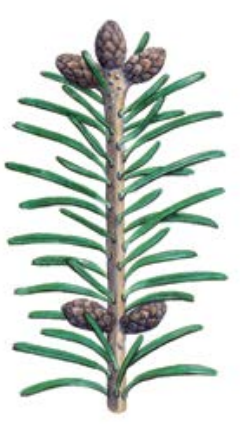

1

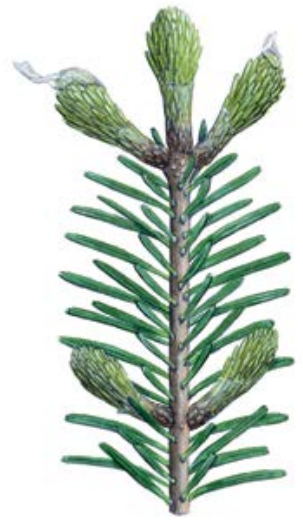

2

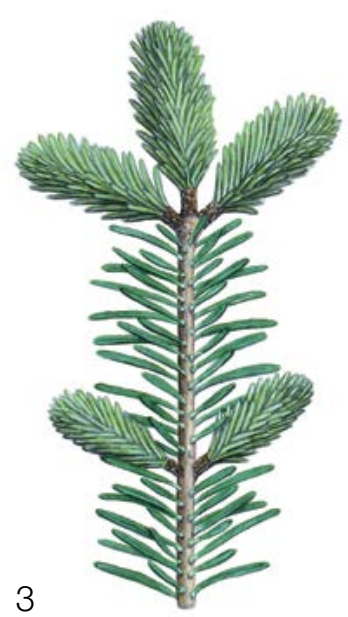

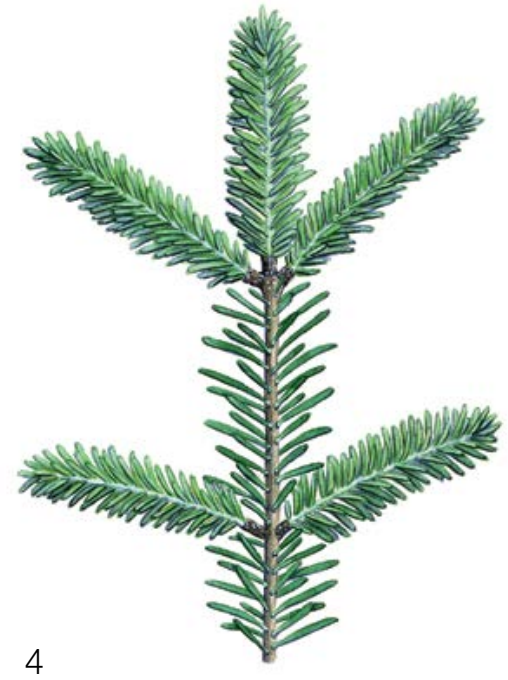

Abbildung 5: Illustration zur Beschreibung der Hintergrundinformation „Austrieb“ auf Standard- und Intensivniveau.

\subsubsection{Blühsynchronisation}

Die Hintergrundinformation „Blühsynchronisation“ wird nur auf Intensivniveau erfasst und basiert auf den für den Verifikator „Blüte“ erhobenen Daten. Sie wird verwendet, um festzustellen, ob die männliche und weibliche Blüte innerhalb des untersuchten Bestandes gleichzeitig stattfindet.

\subsubsection{Intensivniveau}

Die Blühsynchronisation wird jährlich für alle 50 Beobachtungsbäume auf Einzelbaumebene erfasst; und zwar für jedes erfasste bedeutende Blühereignis und im selben Jahr, in dem auch Samen beprobt werden (wie für den Verifikator „Blüte“ auf Intensivniveau).

\section{Formular für die Beschreibung der Monitoringfläche: 'FGM Plot description'}

Formular für die Erfassung der Verifikatoren: 'Form for recording field level verifiers within FGM'

Formular für die Aufzeichnung von Hintergrundinformationen: 'Form for recording field level background information within FGM' 


\section{Quellen}

1. Alizoti PG, Fady B, Prada MA, Vendramin GG (2011) EUFORGEN Technical guidelines for genetic conservation and use of Mediterranean firs (Abies spp). Bioversity International, Rome

2. Aravanopoulos FA, Tollefsrud MM, Graudal L, Koskela J, Kätzel R, Soto A, Nagy L, Pilipovic A, Zhelev P, Božic G and Bozzano M (2015) Development of genetic monitoring methods for genetic conservation units of forest trees in Europe. European Forest Genetic Resources Programme (EUFORGEN), Bioversity International, Rome

3. Carkin RE, Franklin JF, Booth J, Smith CE (1978) Seeding habits of upper-slope tree species: 4. Seed flight of noble fir and Pacific silver fir. Res. Note PNW-312. Corvallis, OR: USDA Forest Service, Pacific Northwest Forest and Range Experiment Station, pp 1-10

4. Caudullo G, Tinner W (2016) Abies - Circum-Mediterranean firs in Europe: distribution, habitat, usage and threats. In: San-Miguel-Ayan J, de Rigo D, Caudullo G, Houston Durran T, Mauri A (ed) European Atlas of Forest Tree Species. Publ. Off. EU, Luxembourg, pp e015be7+

5. Ducci F, De Cuyper B, Paques LE, Proietti R, Wolf H (2012) Reference protocols for assessment of trait and reference genotypes to be used as standards in international research projects. CRA SEL - Arezzo, Italy

6. Eis S (1970) Reproduction and reproductive irregularities of Abies lasiocarpa and A. grandis. Can J Botany 48:141-143. https://doi.org/10.1139/b70-018

7. Farjon A (2010) A Handbook of the World's Conifers. Brill Academic Publishers, Leiden, pp 1-1111. https://doi. org/10.1163/9789047430629

8. Fowells HA, Schubert GH (1956) Seed crops of forest trees in the pine region of California. Tech. Bull. 1150. USDA Forest Service, Washington, DC, pp 1-48

9. Franklin JF (1982) Ecology of noble fir. In: Oliver CD, Kenady RM, eds. Proceedings, Symposium on Biology and Management of True Fir in the Pacific Northwest; 1981; Seattle/Tacoma, WA. Contrib. 45. University of Washington Institute of Natural Resources, Seattle, pp 59-69

10. Franklin JF, Ritchie GA (1970) Phenology of cone and shoot development of noble fir and some associated true firs. Forest Sci 16:356-364

11. FUTMON project (2009 FUT-MON FIELD PROTOCOL PHENOLOGY (D1). http://www.futmon.org/futmon-fieldprotocols.html. Accessed 12 September 2016

12. Houle G (1992) The reproductive ecology of Abies balsamea, Acer saccharum and Betula alleghaniensis in the Tantare Ecological Reserve, Quebec. J Ecol 80:611-623

13. Houle G (1995) Seed dispersal and seedling recruitment: the missing link(s). Ecoscience 2:238-244. https://doi.org/10. 1080/11956860.1995.11682289

14. Jacobs BF, Werth CR, Guttman, SI (1984) Genetic relationships in Abies (fir) of eastern United States: an electrophoretic study. Can J Bot 62(4):609-616

15. Löffler J (1988) Do air pollutants threaten the regeneration potential of West German forests? Allg Forstzts 33:916-918

16. Mauri A, de Rigo D, Caudullo G (2016) Abies alba in Europe: distribution, habitat, usage and threats. In: San-MiguelAyan J, de Rigo D, Caudullo G, Houston Durrant T, Mauri A (ed), European Atlas of Forest Tree Species. Publ. Off. EU, Luxembourg, pp e01493b+. https://doi.org/10.2788/4251

17. Nekrasova P (1974) Losses of cone and seed crops in coniferous species. Lesovedenie 4:3-8

18. Owens JN, Molder M (1974) Bud development in western hemlock: 2. Initiation and early development of pollen cones and seed cones. Can J Bot 52:283-294. https://doi.org/10.1139/b74-037

19. Owens JN, Molder M (1977) Vegetative bud development and cone differentiation in Abies amabilis. Can J Bot 55:992-1008. https://doi.org/10.1139/b77-117

20. Owens JN, Morris SJ (1998) Factors affecting seed production in amabilis fir (Abies amabilis (L.) Mill.). Can J For Res 28:1146-1163. https://doi.org/10.1139/x98-089

21. Pintarić K (1991) Uzgajanje šuma II dio, Tehnika obnove i njege sastojina. Šumarski fakultet u Sarajevu, Sarajevo, pp $1-246$

22. Prpić B, Seletković Z (2001) Ekološka konstitucija obične jele. In: Obična jela u Hrvatskoj, Zagreb, pp 255-269

23. Shea PJ (1989a) Interactions among phytophagous insect species colonizing cones of white fir (Abies concolor). Oecologia 81:104-110. https://doi.org/10.1007/BF00377018

24. Shea PJ (1989b) Phytophagous insect complex associated with cones of white fir, Abies concolor (Gord. and Glend.) Lindl., and its impact on seed production. Can Entomol 121:699-708. doi:10.4039/Ent121699-8

25. Sidhu SS, Staniforth RJ (1986) Effects of atmospheric fluorides on foliage, and cone and seed production in balsam fir, black spruce, and larch. Can J Bot 64:923-931. https://doi.org/10.1139/b86-124 
26. Vidaković M (1982) Četinjače - morfologija i varijabilnost, JAZU i Sveuč. nakl. Liber, Zagreb, pp 1-710

27. Vidaković M (1993) Četinjače - morfologija i varijabilnost. Grafički zavod Hrvatska i Hrvatske šume, p.o. Zagreb, Zagreb, pp 1-741

28. Wolf H (2003) EUFORGEN Technical Guidelines for genetic conservation and use for silver fir (Abies alba Mill.). International Plant Genetic Resources Institute, Rome

29. Wolfenbarger DO (1946) Dispersion of small organisms: Distance dispersion rates of bacteria, spores, seeds, pollen and insects: incidence rates of diseases and injuries. Am Midl Nat 35:1-152

Die folgenden Ressourcen wurden für die derzeit akzeptierten (Dezember 2020) wissenschaftlichen Namen der in diesem Dokument erfassten oder erwähnten Arten konsultiert:

a. CABI (2020) Invasive Species Compendium. CAB International, Wallingford, UK. www.cabi.org/isc. Accessed 15 December 2020

b. EPPO (2020) EPPO Global Database (available online). https://gd.eppo.int. Accessed 15 December 2020

c. GBIF (2020) Global Biodiversity Information Facility. https://www.gbif.org Accessed 15 December 2020

d. IPNI (2020) International Plant Names Index. The Royal Botanic Gardens, Kew, Harvard University Herbaria \& Libraries \& Australian National Botanic Gardens. http://www.ipni.org, Accessed 10 December 2020

e. National Center for Biotechnology Information (NCBI) (1998) National Library of Medicine (US), National Center for Biotechnology Information, Bethesda (MD). https://www.ncbi.nlm.nih.gov/. Accessed 15 December 2020

f. The Plant List (2013) Version 1.1. http://www.theplantlist.org/. Accessed 12 December 2020

g. Tropicos.org (2020) Missouri Botanical Garden. http://www.tropicos.org. Accessed 15 December 2020

h. WFO (2020) World Flora Online. http://www.worldfloraonline.org. Accessed 15 December 2020 


\section{Leitfaden für das genetische Monitoring der}

\subsubsection{Rotbuche \\ (Fagus sylvatica L.)}

Marjana WESTERGREN ${ }^{1}$, Darius KAVALIAUSKAS², Paraskevi ALIZOTI',

Marko BAJC 1 , Filippos A. ARAVANOPOULOS ${ }^{3}$, Gregor BOŽIČ ${ }^{1}$, Rok DAMJANIĆ ${ }^{1}$, Natalija DOVČ́1, Domen FINŽGAR ${ }^{1,4}$, Barbara FUSSI², Fotios KIOURTSIS ${ }^{5}$,

Hojka KRAIGHER ${ }^{1}$

Botanische lllustrationen von Marija PRELOG

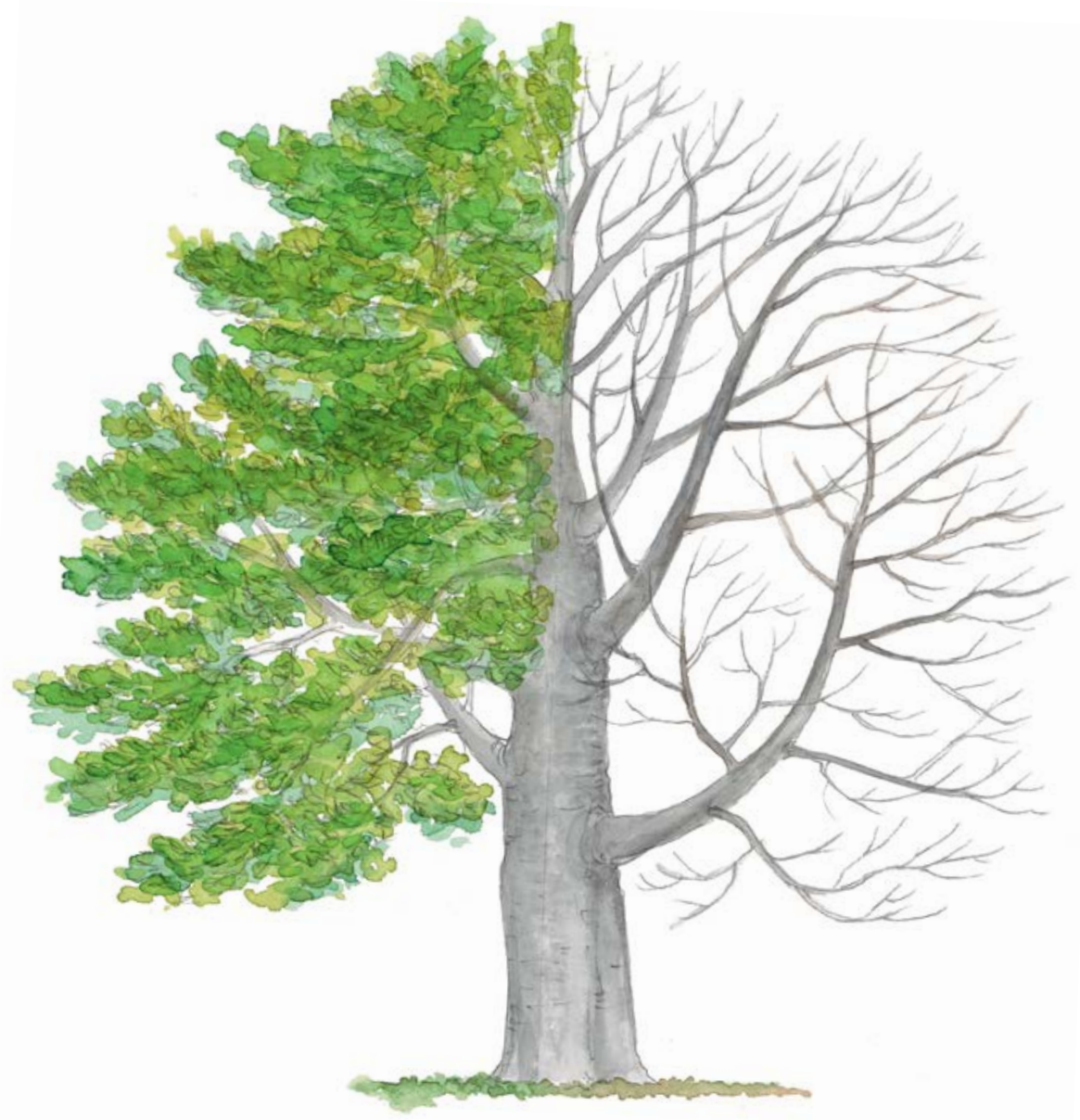

Zitat: Westergren et al. (2020) Leitfaden für das genetische Monitoring der Rotbuche (Fagus sylvatica L.). In: Bajc et al. (Ed.) Handbuch zum Forstgenetischen Monitoring. Slowenisches Forstinstitut: Verlag Silva Slovenica, Ljubljana, S. 191-207. http://dx.doi.org/10.20315/SFS.176

Institut:

1. Slowenisches Forstinstitut (SFI), Slowenien

2. Bayerisches Amt für Waldgenetik (AWG), Deutschland

3. Aristoteles Universität von Thessaloniki (AUTH), Griechenland

4. Institut für Evolutionäre Biologie, Universität von Edinburgh, Großbritannien

5. Dezentrale Verwaltung Mazedonien-Thrakien, Generaldirektion für Forst und Landwirtschaft, Griechenland 


\section{ZUSAMMENFASSUNG}

Die Rotbuche (Fagus sylvatica L.) ist eine einhäusige, bestandesbildende Laubbaumart, die in fast ganz Europa vorkommt. Diese sehr konkurrenzfähige und schattentolerante Art kann sich in Dauerwaldsystemen auf natürliche Weise regenerieren und ist besser als viele andere Arten in der Lage, die Ertragsfähigkeit der Waldböden zu erhalten. Aufgrund ihrer großen ökologischen Bedeutung und ihrem robusten Holz ist diese Baumart für das forstgenetische Monitoring prädestiniert.

Dieser Leitfaden beschreibt die Rotbuche sowie ihre Reproduktion, Umwelt und Gefährdung. Er enthält außerdem eine Anleitung zur Einrichtung genetischer Monitoringflächen und zur Erfassung aller vor Ort im Bestand zu erhebenden Verifikatoren.
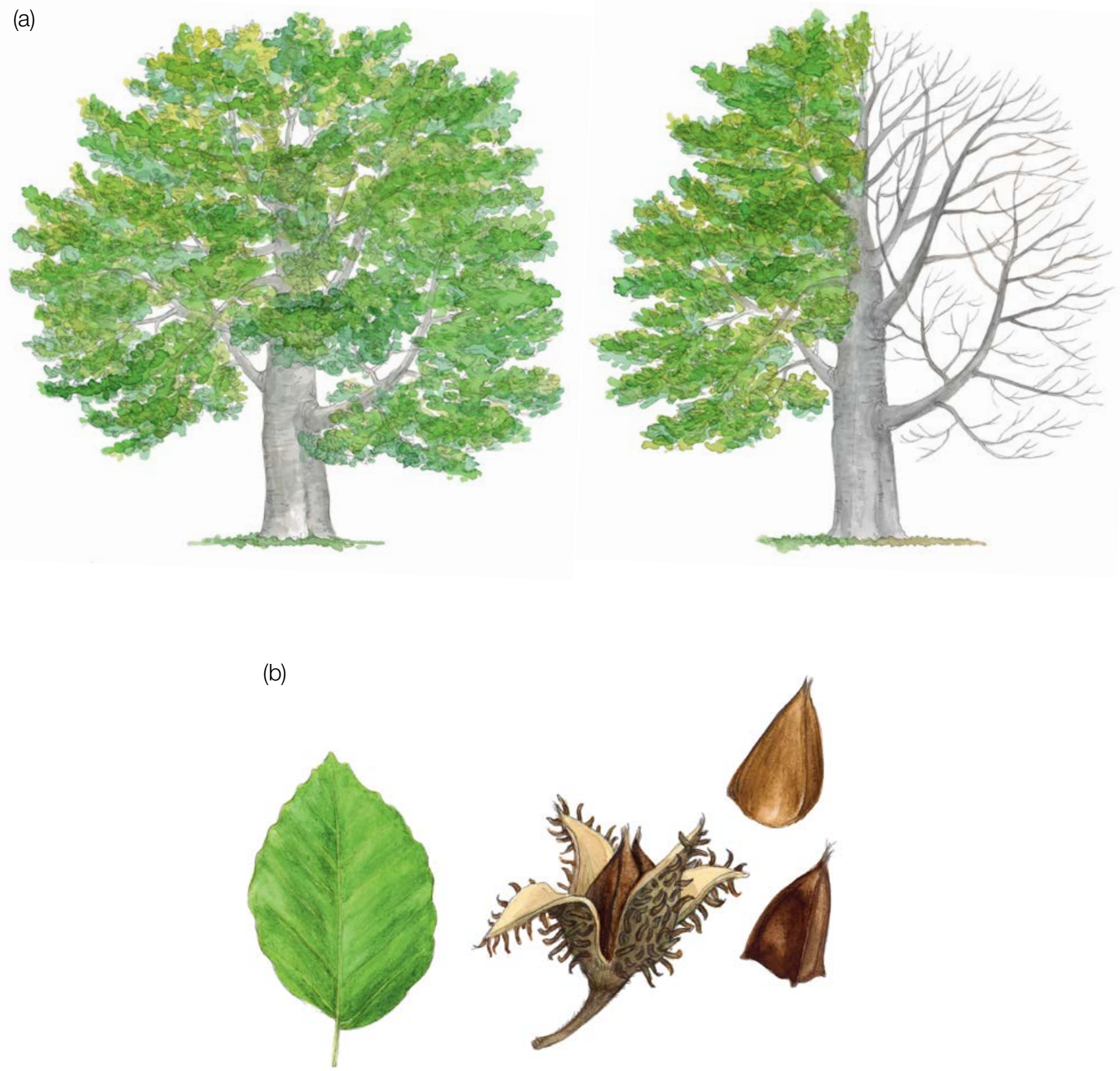

Abbildung 1: (a) Habitus der Rotbuche (Fagus sylvatica); (b) Blatt und Frucht mit Samen der Rotbuche 


\section{BESCHREIBUNG DER BAUMART}

Die Rotbuche (Abbildung 1a) ist ein großer, schattentoleranter Laubbaum, der 30-40 m - an manchen Standorten sogar bis zu $50 \mathrm{~m}$ - hoch wird [1]. Sie kann mit bis zu 250-300 Jahren ein hohes Lebensalter erreichen, obwohl sie typischerweise mit 80 bis 120 Jahren geerntet wird [1, 2]. Im Gegensatz zu vielen anderen Baumarten behält sie bis ins Alter eine hohe Wachstumsrate bei [2]. Die Rinde ist dünn, glatt, silbergrau und sehr charakteristisch [1, 2]. Die hellgrünen, eiförmigen Blätter (Abbildung 1b) mit seidigen Haaren färben sich im späten Frühjahr glänzend dunkelgrün [2]. Sie weisen beidseitig des Hauptnervs 6-7 parallele Seitennerven auf. Die Blätter sind weder gelappt noch gekerbt und haben einen kurzen Stiel. Im Winter ist die Buche leicht an den scharf zugespitzten, langen und schlanken Knospen zu erkennen, die schräg von den Zweigen abstehen [4].

Bei Sympatrie mit Fagus orientalis (Lipsky) kann es zu einer Hybridisierung zwischen den beiden Arten kommen [1].

\section{REPRODUKTION}

Die windbestäubte Buche ist eine einhäusige Art [1, 2]; die getrennten männlichen und weiblichen Blüten gehen aus derselben Knospe hervor und stehen auf einem Zweig. Die männlichen Blüten hängen in Büscheln. Die Rotbuche wird erst sehr spät mannbar; in Waldbeständen meist im Alter von 40-50 Jahren. Vollmasten treten normalerweise alle 5 bis 8 Jahre auf, manchmal in größeren Abständen, meist im Folgejahr nach heißen Sommern [1, 3].

Der Beginn des Blattaustriebs variiert von Population zu Population und von Jahr zu Jahr. Dem Austrieb, der in Mitteleuropa von Ende März bis Mai erfolgt, folgt unmittelbar die Blüte (von April bis Mai). Nachdem die weiblichen Blüten durch den Wind bestäubt wurden, entwickeln sie sich zu gut sichtbaren Früchten. Die Nüsse sind scharf dreikantig (Abbildung 1b) und stehen einzeln oder paarweise in weichdornigen Bechern [1, 2, 3]. Sie reifen und fallen zwischen September und November [3]. Buchensamen haben eine ausgeprägte Keimruhe [3].

Die Rotbuche weist Eigenschaften einer Klimaxbaumart auf. Ihre Ausbreitung und natürliche Verjüngung sind effizient, und sie ist vor allem unter schattigen Bedingungen sehr konkurrenzstark [1].

\section{UMWELT}

Die Rotbuche ist in ganz Mittel- und Westeuropa verbreitet, und reicht im Norden bis in den südlichen Teil Skandinaviens und im Süden bis nach Sizilien [1, 2]. Da sie eine feuchte Witterung mit gleichmäßig über das Jahr verteilten Niederschlägen benötigt, ist inr Verbreitungsgebiet durch hohe Sommertemperaturen, Trockenheit und geringe Feuchtigkeitsverfügbarkeit sowie in Nordwesteuropa durch Kontinentalität begrenzt [1]. Sie verträgt Winterkälte, ist aber im Frühjahr empfindlich gegenüber Spätfrösten, was ihre Verbreitung in den nördlichen borealen Regionen limitiert [1]. Sie gedeiht besonders auf mäßig nährstoffreichen, kalkhaltigen oder leicht sauren Böden; nicht jedoch auf staunassen oder verdichteten Böden [1]. Die Rotbuche ist eine bestandesbildende Baumart [2].

\section{GEFÄHRDUNG}

Die Rotbuche ist eine widerstandsfähige Baumart. Dennoch werden junge Bäume und die gleichzeitig mit den Blättern erscheinenden Blüten oft durch Spätfröste geschädigt. Bei alten Buchen kann sich ein „Rotkern“ bilden, der ihre Stabilität und den Verkaufswert des Holzes mindert. Die Buchengallmücke Mikiola fagi Hartig kann junge Buchen zum Absterben bringen und bei stark befallenen Bäumen den Zuwachs reduzieren. Die Rotbuche gehört auch zu den möglichen Wirten des Pilzes Phytophthora ramorum Werres, De Cock \& Man, einem Quarantäneschaderreger. Der Chinesische Laubholzbockkäfer Anoplophora chinensis Forster und der Asiatische Laubholzbockkäfer Anoplophora glabripennis Motschulsky, die beide aus Asien stammen, stellen für die Buche eine zunehmende Bedrohung dar [5]. 


\section{EINRICHTUNG UND INSTANDHALTUNG VON MONITORINGFLÄCHEN}

Die Rotbuche ist eine bestandesbildende Baumart, die mit Weißtanne, Rotfichte und anderen Baumarten Reinoder Mischbestände bilden kann [1].

EineforstgenetischeMonitoringflächeumfasst50fortpflanzungsfähigeAltbäumemiteinemBrusthöhendurchmesser (BHD) von mehr als $15 \mathrm{~cm}$ und einem Mindestabstand von $30 \mathrm{~m}$ zwischen je zwei beliebigen Bäumen. Ein Baum gilt als fortpflanzungsfähig, wenn er blüht. Der BHD und die KRAFT'sche Klasse eines Baumes können als Anhaltspunkte für die Identifizierung fortpflanzungsfähiger Bäume verwendet werden, wenn die Monitoringfläche außerhalb der Blütezeit angelegt wird. Dabei sollte auf das Fachwissen des zuständigen Försters zurückgegriffen werden. Bei der Neueinrichtung einer Monitoringfläche sollten alle Bäume beschriftet und ihre Koordinaten erfasst werden. Gleichzeitig können die jeweiligen BHD gemessen und Proben für die DNA-Extraktion gesammelt werden.

Erforderliche Ausrüstung:

- ein Gerät zur Entfernungsmessung (empfehlenswert ist ein Fernglas mit Entfernungsmesser)

- ein Kompass

- Farbe und Pinsel oder Farbspray zum dauerhaften Kennzeichnen der Bäume

- eine Kluppe für BHD-Messungen und

- ein ausreichend präzises GPS-Gerät, welches das Speichern von Baumkoordinaten ermöglicht

\subsection{Einrichtung der Monitoringfläche}

\subsubsection{Auswahl des Mittelpunkts}

Das allgemeine Verfahren für eine Zufallsauswahl der Monitoringfläche besteht aus den folgenden Schritten (Abbildung 2a):

- zufällige Auswahl eines Punktes (grüner Punkt) entlang einer an der Bestandesgrenze verlaufenden Forststraße oder eines Waldweges auf einer Karte;

- Einzeichnen einer annähernd senkrecht zur Straße verlaufenden Linie an diesem zufällig entlang der Straße ausgewählten Punkt;

- zufällige Auswahl eines Punktes auf der Linie (roter Punkt) - dieser Punkt stellt den Mittelpunkt der forstgenetischen Monitoringfläche dar.

Der Mindestabstand zwischen dem ausgewählten Mittelpunkt und der Bestandesgrenze beträgt ca. $150 \mathrm{~m}$. Wenn der ausgewählte Mittelpunkt diese Anforderung nicht erfüllt, muss nach dem oben beschriebenen Verfahren ein neuer Punkt ausgewählt werden.

Anstelle des oben beschriebenen Verfahrens können auch entsprechende Werkzeuge zur Erstellung von Zufallspunkten in GIS-Software verwendet werden.

Für die Nutzung im Gelände sollten die Koordinaten des ausgewählten Punktes in einem GPS-Gerät gespeichert werden.

\subsubsection{Einrichtung der Monitoringfläche}

Vor Ort im Bestand wird ein zentraler Beobachtungsbaum der Monitoringfläche bestimmt und mit der Nummer 1 gekennzeichnet. Dieser Baum entspricht dem der gespeicherten GPS-Koordinate am nächsten stehende, fortpflanzungsfähige Baum. 
(a)

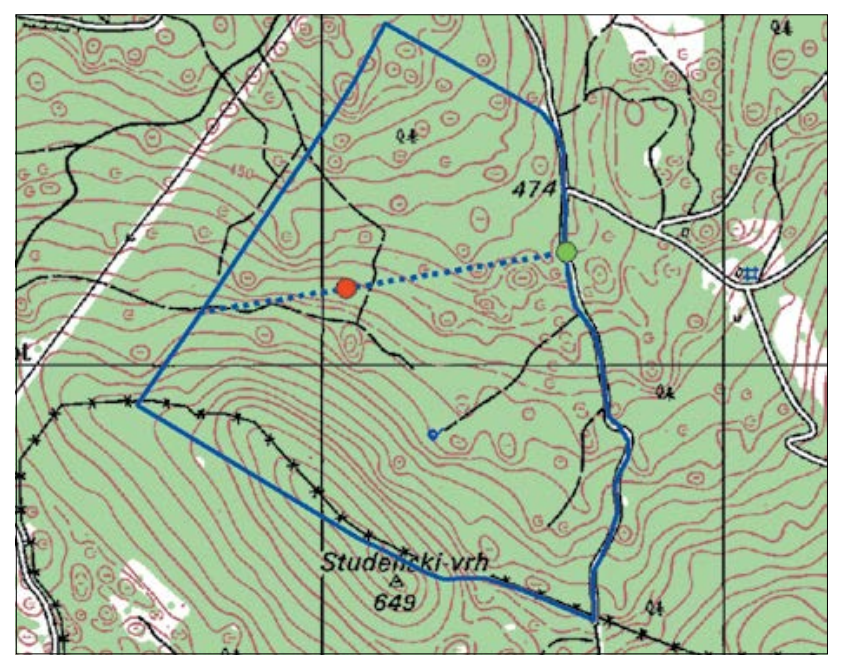

(b)

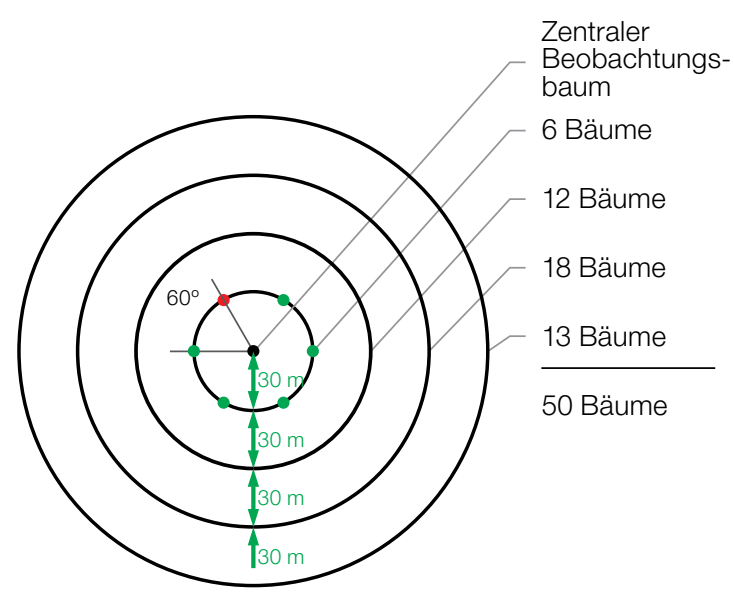

Abbildung 2: Zufällige Auswahl des Mittelpunkts der forstgenetischen Monitoringfläche (a); Auswahl von Bäumen in konzentrischen Kreisen mit einem zunehmenden Radius von $30 \mathrm{~m}$ um den zuvor ausgewählten zentralen Beobachtungsbaum (b).

In konzentrischen Kreisen mit einem zunehmenden Radius von 30 m um den zentralen Beobachtungsbaum werden weitere Altbäume ausgewählt (Abbildung 2b). Der erste Baum in jedem Kreis sollte nach dem Zufallsprinzip ausgewählt werden, was auf verschiedene Weise geschehen kann: durch Verwendung eines zufälligen Azimuts, der vom zentralen Beobachtungsbaum aus eingemessen wird (Tabelle 1), durch Folgen der Richtung des Sekundenzeigers auf einer analogen Uhr oder durch eine andere Vorgehensweise, die eine objektive Auswahl ermöglicht. Die verbleibenden Bäume in jedem Kreis werden mit einem entsprechend größeren Azimut ausgewählt, um einen Mindestabstand von 30 m zwischen je zwei beliebigen Bäumen zu gewährleisten:

$\cdot+60^{\circ}$ im ersten Kreis

- $+30^{\circ}$ im zweiten Kreis

$\cdot+20^{\circ}$ im dritten Kreis

$\cdot+15^{\circ}$ im vierten Kreis

Sollte es nicht möglich sein, 6, 12 bzw. 18 Bäume in den inneren 3 Kreisen zu finden (Abbildung 2b), werden im äußersten Kreis zusätzliche Bäume ausgewählt.

Tabelle 1: Zufällig generierte Azimute, die für die Auswahl des ersten Baumes in jedem Kreis verwendet werden können.

\begin{tabular}{rrrrrrrrrr}
108 & 15 & 186 & 35 & 178 & 29 & 305 & 351 & 44 & 150 \\
\hline 232 & 23 & 160 & 141 & 112 & 292 & 216 & 83 & 245 & 214 \\
\hline 63 & 65 & 345 & 234 & 95 & 78 & 279 & 323 & 40 & 236 \\
\hline 201 & 313 & 275 & 144 & 182 & 68 & 268 & 289 & 185 & 92 \\
\hline 356 & 177 & 93 & 1 & 145 & 198 & 287 & 251 & 224 & 142 \\
\hline
\end{tabular}

\subsubsection{Kennzeichnung der Bäume}

Jeder ausgewählte Beobachtungsbaum muss mit einer entsprechenden Nummer und idealerweise mit einem um den Stamm herum laufenden Streifen gekennzeichnet werden, um die Sichtbarkeit der Bäume aus allen Richtungen zu erhöhen. Markieren Sie den zentralen Beobachtungsbaum (Nummer 1) mit zwei oder mehr Streifen, um inn von anderen Bäumen zu unterscheiden (Abbildung 3a). Es wird empfohlen, die Baumnummer stets auf der vom zentralen Beobachtungsbaum abgewandten Seite der Bäume anzubringen, da dies die Lokalisierung des zentralen Beobachtungsbaums v.a. von den äußeren Kreisen der Monitoringfläche aus erleichtert (Abbildung 3b). 

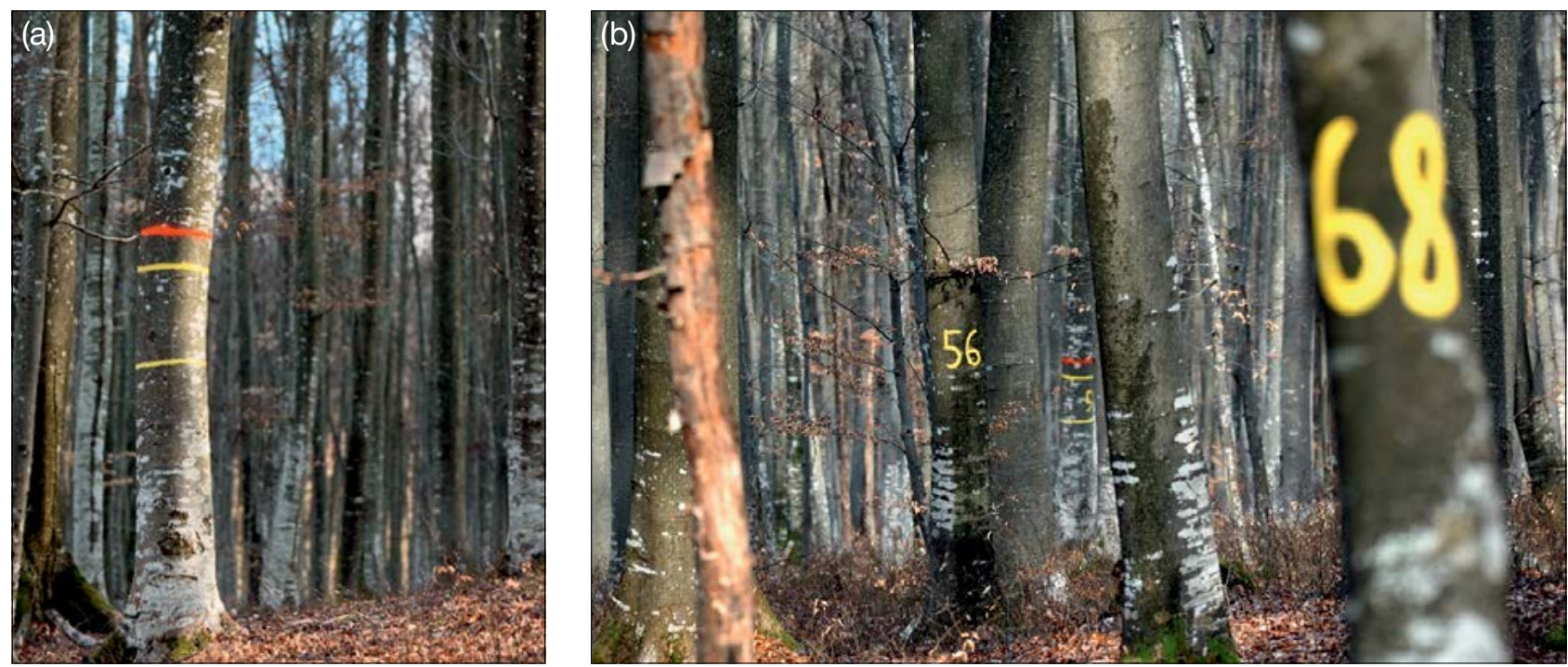

Abbildung 3: (a) Der zentrale Beobachtungsbaum auf der forstgenetischen Monitoringfläche ist mit mehreren Streifen markiert, um ihn von anderen Bäumen zu unterscheiden; (b) die Nummerierung der ausgewählten Bäume erfolgt auf der vom zentralen Beobachtungsbaum abgewandten Seite.

\subsection{Einrichtung von Naturverjüngungs-Plots}

Die Einrichtung von Plots für das Monitoring der Naturverjüngung (NV) sollte während der Keimungsperiode nach einem Halb- oder Vollmastjahr erfolgen.

Bereiche mit aufgelaufener Naturverjüngung aus dem letzten Mastjahr (sogenannte Verjüngungscluster) sollten vor Ort vermessen und ihre Position erfasst werden (GPS-Koordinaten, Nummer des Beobachtungsbaumes neben dem Verjüngungscluster). Von allen erfassten Verjüngungsclustern sollten nach dem Zufallsprinzip 20 für die Einrichtung von NV-Plots ausgewählt werden. Wenn 20 oder weniger natürliche Verjüngungscluster vorhanden sind, sollten alle verwendet werden.

Innerhalb jedes ausgewählten Verjüngungsclusters ist ein $1 \mathrm{~m}^{2}$ großer Plot einzurichten und mit Metallstäben zu markieren. Die Metallstäbe sollten an jeder Ecke der Teilfläche so tief wie möglich in den Boden getrieben werden, damit sie nicht von Tieren entfernt werden können. Die oberen Spitzen der Metallstäbe sollten farbig markiert werden, um ihre Sichtbarkeit zu verbessern.

\subsection{Instandhaltung der Monitoringfläche}

\subsubsection{Allgemeine Instandhaltung}

Die Kennzeichnung der Bäume und NV-Plots muss periodisch (alle 2 Jahre) überprüft und bei Bedarf erneuert werden.

\subsubsection{Ersatz von Bäumen}

Wenn ein ausgewählter Beobachtungsbaum stirbt oder im Zuge der forstlichen Bewirtschaftung gefällt wird, muss er ersetzt werden. Dabei sollte der dem abgestorbenen/gefällten Baum nächstgelegene geeignete Baum ausgewählt werden, wobei der Mindestabstand von 30 m zum nächsten Beobachtungsbaum erfüllt sein muss. Andernfalls ist ein Baum aus der Peripherie (vorzugsweise im äußeren Kreis) der Monitoringfläche zu wählen. Der Ersatzbaum wird mit der nächsten verfügbaren Zahl über 50 gekennzeichnet, d.h. 51, 52, 53, usw., um ihn eindeutig von den ursprünglich 50 ausgewählten Beobachtungsbäumen zu unterscheiden.

Wenn die Baumkrone z.B. durch Wind-, Eis- oder Schneebruch geschädigt ist, der Baum aber weiterhin fruktifiziert, wird der Baum im Monitoringprogramm belassen. Ist der Schaden zu schwerwiegend und eine Fruktifikation nicht mehr zu erwarten, muss der Baum ersetzt werden. 


\section{ERFASSUNG VON VERIFIKATOREN UND HINTERGRUNDINFORMATIONEN}

Auf der Monitoringfläche werden periodisch Verifikatoren und Hintergrundinformationen erfasst. Verifikatoren werden genutzt, um die genetischen Eigenschaften der Population und ihre Anpassung an Umweltveränderungen und/oder Bewirtschaftung zu verfolgen, während Hintergrundinformationen aufgezeichnet werden, um die Interpretation der Verifikatoren zu unterstützen. Verifikatoren können auf drei verschiedenen Intensitätsniveaus erfasst werden: Basis, Standard und Intensiv.

Höherrangigere Niveaus (Standard, Intensiv) müssen stets auch die Erfassung der Verifikatoren auf allen niedrigeren Niveaus (Basis, Standard) einschließen. Dies ist für die Aufzeichnung von Hintergrundinformationen nicht erforderlich.

Tabelle 2: Liste der Verifikatoren und Hintergrundinformationen, die während der Außenaufnahmen auf den BuchenMonitoringflächen zu erfassen sind; jeweils mit Kurzbeschreibung und Beobachtungshäufigkeit.

\begin{tabular}{|c|c|c|c|c|}
\hline & Bezeichnung & Basisniveau & Standardniveau & Intensivniveau \\
\hline \multirow{5}{*}{ 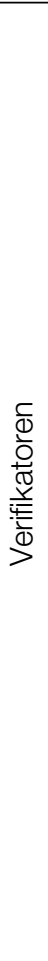 } & \multirow[t]{2}{*}{$\begin{array}{l}\text { Mortalität / } \\
\text { Überlebensrate }\end{array}$} & $\begin{array}{l}\text { Altbäume: Zählung der } \\
\text { verbleibenden markierten Bäume } \\
\text { alle } 10 \text { Jahre und nach jedem } \\
\text { extremen Witterungsereignis/ } \\
\text { jeder Störung }\end{array}$ & wie Basisniveau & wie Basisniveau \\
\hline & & Naturverjüngung: / & $\begin{array}{l}\text { Zählung der verbleibenden } \\
\text { Sämlinge auf den NV-Plots, } \\
\text { zweimal pro Jahrzehnt }\end{array}$ & wie Standardniveau \\
\hline & \multirow[b]{2}{*}{ Fruktifikation } & $\begin{array}{l}\text { bestandesweise Schätzung; } \\
\text { jährlich }\end{array}$ & $\begin{array}{l}\text { Erfassung auf Einzelbaumebene, } \\
\text { während zwei bedeutenden } \\
\text { Blühereignissen pro Jahrzehnt, } \\
\text { idealerweise in gleichen } \\
\text { Abständen * }\end{array}$ & $\begin{array}{l}\text { Erfassung auf Einzelbaumebene, } \\
\text { während zwei bedeutenden } \\
\text { Blühereignissen pro Jahrzehnt, } \\
\text { idealerweise in gleichen } \\
\text { Abständen * }\end{array}$ \\
\hline & & $\begin{array}{l}\text { bestandesweise Schätzung; } \\
\text { jährlich }\end{array}$ & $\begin{array}{l}\text { Erfassung auf Einzelbaum- } \\
\text { ebene im selben Jahr, in dem } \\
\text { die Erfassung der Blüte auf } \\
\text { Basisniveau erfolgt (unabhängig } \\
\text { von der Fruktifikationsintensität) * }\end{array}$ & $\begin{array}{l}\text { Zählung der Früchte in } \\
\text { den gleichen Jahren, in } \\
\text { denen die Bewertung der } \\
\text { Blüte auf Intensivniveau } \\
\text { erfolgt, unabhängig von der } \\
\text { Fruktifikationsintensität* } \\
\text { Bei jedem erfassten Fruktifika- } \\
\text { tionsereignis wird auch Saatgut } \\
\text { für Laboranalysen gesammelt }\end{array}$ \\
\hline & $\begin{array}{l}\text { Abundanz der } \\
\text { Naturverjüngung }\end{array}$ & $\begin{array}{l}\text { bestandesweise Schätzung; } \\
\text { jährlich }\end{array}$ & $\begin{array}{l}\text { Zählung der Sämlinge im 1. und } \\
\text { 6. Jahr nach jedem erfassten } \\
\text { Fruktifikationsereignis }\end{array}$ & $\begin{array}{l}\text { Zählung der Sämlinge im 1., } 6 . \text {, } \\
\text { 11. und 16. Jahr nach jedem } \\
\text { erfassten Fruktifikationsereignis }\end{array}$ \\
\hline \multirow{5}{*}{ 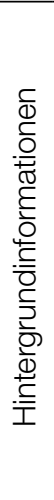 } & $\begin{array}{l}\text { Durchmesser- } \\
\text { klassen-vertei- } \\
\text { lung }\end{array}$ & l & Messung alle 10 Jahre & wie Standardniveau \\
\hline & $\begin{array}{l}\text { Höhenklassen- } \\
\text { verteilung }\end{array}$ & / & Messung alle 10 Jahre & wie Standardniveau \\
\hline & Austrieb & / & $\begin{array}{l}\text { Erfassung auf Einzelbaumebene; } \\
\text { alle } 5 \text { Jahre }\end{array}$ & $\begin{array}{l}\text { Erfassung auf Einzelbaumebene; } \\
\text { jährlich }\end{array}$ \\
\hline & Seneszenz & / & $\begin{array}{l}\text { Erfassung auf Einzelbaumebene; } \\
\text { alle } 5 \text { Jahre }\end{array}$ & $\begin{array}{l}\text { Erfassung auf Einzelbaumebene; } \\
\text { jährlich }\end{array}$ \\
\hline & $\begin{array}{l}\text { Blühsynchroni- } \\
\text { sation }\end{array}$ & / & / & $\begin{array}{l}\text { Erfassung auf Einzelbaum- } \\
\text { ebene, während jedes erfassten } \\
\text { bedeutenden Blühereignisses }\end{array}$ \\
\hline
\end{tabular}

* Idealerweise sollte mindestens ein größeres Fruktifikationsereignis pro Jahrzehnt bewertet werden. Ein bedeutendes Blühereignis führt jedoch nicht unbedingt zu einem bedeutenden Fruktifikationsereignis. Wenn auf das bewertete Blühereignis kein wesentliches Fruktifikationsereignis folgt, muss die Bewertung sowohl der Blüte als auch der Fruchtbildung beim nächsten bedeutenden Blühereignis wiederholt werden, unabhängig von der Zeit, die zwischen aufeinanderfolgenden bedeutenden Blühereignissen liegt. Erhebungen auf Basisniveau werden zur Identifizierung bedeutender Blüh- und Fruktifikationsereignisse verwendet. 


\subsection{Verfahren zur Erfassung der Verifikatoren}

\subsubsection{Mortalität / Überlebensrate}

Die Mortalität beschreibt die Sterblichkeit von Altbäumen und Naturverjüngung. Ihr Pendant - die Überlebensratesteht für Bäume, die seit der letzten Datenerhebung noch am Leben sind. Die Überlebensrate wird berechnet als 1 - Mortalität.

\subsubsection{Altbäume: Basis-, Standard- und Intensivniveau}

Verifikator für die Mortalität von Altbäumen. Die Mortalität wird geschätzt, indem die verbleibenden lebenden Beobachtungsbäume alle 10 Jahre sowie nach jedem extremen Witterungsereignis bzw. jeder Störung gezählt werden. Die Mortalität ist die Differenz zwischen der ursprünglichen Anzahl markierter Beobachtungsbäume und den davon verbleibenden lebenden Bäumen der ursprünglichen 50 Beobachtungsbäume.

\subsubsection{Naturverjüngung: Standard- und Intensivniveau}

Die Mortalität der Naturverjüngung wird auf Grundlage des Verifikators „Abundanz der Naturverjüngung“ berechnet. Die Mortalität ist der Unterschied zwischen der anfänglichen Anzahl der Jungpflanzen und den Pflanzen, die zum Zeitpunkt der nächsten Zählung noch am Leben sind. Für jede Bewertungsrunde werden die Jungpflanzen zuerst im Jahr der Keimung und dann wieder nach 5 Jahren auf Standardniveau gezählt, während auf dem Intensivniveau die Zählung zusätzlich nach 10 und 15 Jahren durchgeführt wird. Die Bewertung der „Abundanz der Naturverjüngung“ erfolgt zweimal pro Jahrzehnt, idealerweise etwa alle fünf Jahre.

\subsubsection{Blüte}

Dieser Verifikator beschreibt das Auftreten der Blüte (Anteil der Bäume) und die Blühintensität. Er kann in Mitteleuropa von April bis Mai erfasst werden.

\subsubsection{Basisniveau}

Der Verifikator wird jährlich auf Bestandesebene erfasst. Die Erfassung erfolgt zum Zeitpunkt der Hauptblüte. Die Schätzung des durchschnittlichen Zustands erfolgt nach einer Begehung der gesamten Monitoringfläche. Es werden zwei Werte erfasst: einer für die Blühintensität, ausgedrückt als mittlerer Kronenanteil in Blüte; und einer für den Anteil der blühenden Bäume im Bestand.

\begin{tabular}{clc}
\multicolumn{2}{c}{ Code Blühintensität auf Bestandesebene } & Mittlerer Anteil der Kronen in Blüte (\%) \\
\hline 1 & Keine Blüte: Keine oder nur gelegentlich auftretende Blüten & $0-10$ \\
\hline 2 & Schwache Blüte: Einige Blüten erscheinen an den Bäumen & $>10-30$ \\
\hline 3 & Mäßige Blüte: Mäßig viele Blüten an den Bäumen & $>30-60$ \\
\hline 4 & Starke Blüte: Reichlich Blüten an den Bäumen & $>60-90$ \\
\hline 5 & Extreme Blüte: Enorme Anzahl von Blüten an den Bäumen & $>90$ \\
\hline
\end{tabular}

\begin{tabular}{lr} 
Code & Anteil der Bäume im Bestand mit dem entsprechenden Stadium der Blühintensität (\%) \\
\hline 1 & $0-10$ \\
\hline 2 & $>10-30$ \\
\hline 3 & $>30-60$ \\
\hline 4 & $>60-90$ \\
\hline 5 & $>90$ \\
\hline
\end{tabular}




\subsubsection{Standardniveau}

Der Verifikator wird während zweier bedeutender Blühereignisse pro Jahrzehnt aufgezeichnet, idealerweise mit einem ähnlichen zeitlichen Abstand. Er wird für alle 50 Beobachtungsbäume auf Einzelbaumebene erfasst. Ein bedeutendes Blühereignis liegt vor, wenn die Blühintensität auf Basisniveau als stark oder extrem eingeschätzt wird (Code 4 oder 5) und der Anteil der Bäume mit der angegebenen Blühintensität über 60\% liegt (Code 4 oder 5). Die Erfassung erfolgt zum Zeitpunkt der Hauptblüte. Für jeden Beobachtungsbaum wird ein Wert erfasst.

\begin{tabular}{clr}
\multicolumn{2}{l}{ Code Blühintensität auf Bestandesebene } & Mittlerer Anteil der Kronen in Blüte (\%) \\
\hline 1 & Keine Blüte: Keine oder nur gelegentlich auftretende Blüten & $0-10$ \\
\hline 2 & Schwache Blüte: Einige Blüten erscheinen an den Bäumen & $>10-30$ \\
\hline 3 & Mäßige Blüte: Mäßig viele Blüten an den Bäumen & $>30-60$ \\
\hline 4 & Starke Blüte: Reichlich Blüten an den Bäumen & $>60-90$ \\
\hline 5 & Extreme Blüte: Enorme Anzahl von Blüten an den Bäumen & $>90$ \\
\hline
\end{tabular}

\subsubsection{Intensivniveau}

Der Verifikator wird während zweier bedeutender Blühereignisse pro Jahrzehnt aufgezeichnet, idealerweise mit einem ähnlichen zeitlichen Abstand. Er wird für alle 50 Beobachtungsbäume auf Einzelbaumebene erfasst. Ein bedeutendes Blühereignis liegt vor, wenn die Blühintensität auf Basisniveau als stark oder extrem eingeschätzt wird (Code 4 oder 5) und der Anteil der Bäume mit der angegebenen Blühintensität über 60\% liegt (Code 4 oder 5). Im Durchschnitt sind zwei Begehungen auf der Monitoringfläche erforderlich: der erste früh genug, um das Frühstadium der Blüte zu beobachten, der zweite zum Zeitpunkt der Hauptblüte.

Für jeden Baum werden drei Werte angegeben: weibliches Blühstadium, männliches Blühstadium und der blühende Kronenanteil. Letzterer bezieht sich auf die Gesamtmenge der Blüten (männlich + weiblich) am Baum. Die Blühstadien sind in Abbildung 4 dargestellt.

(a)

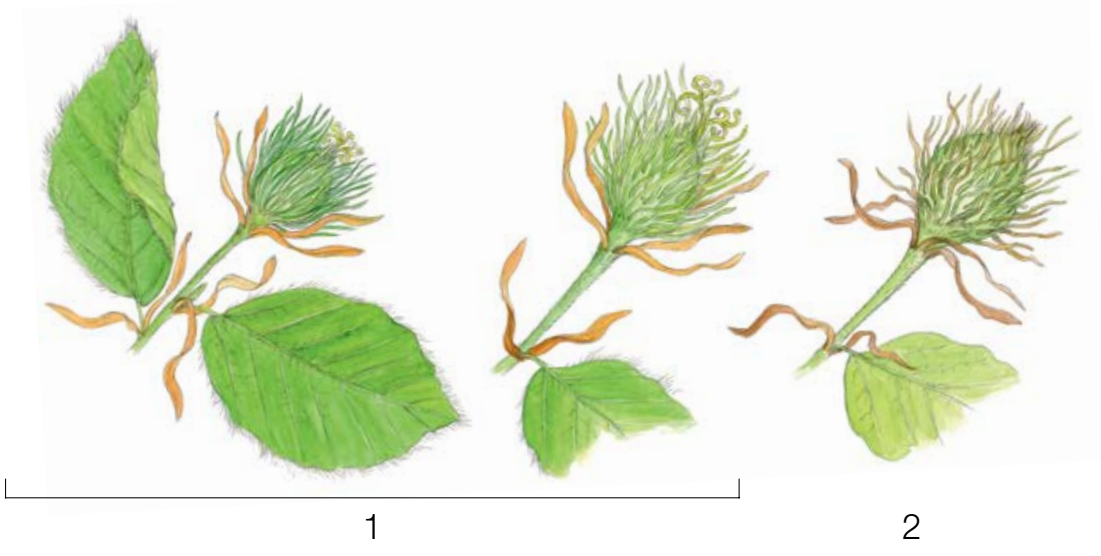

(b)
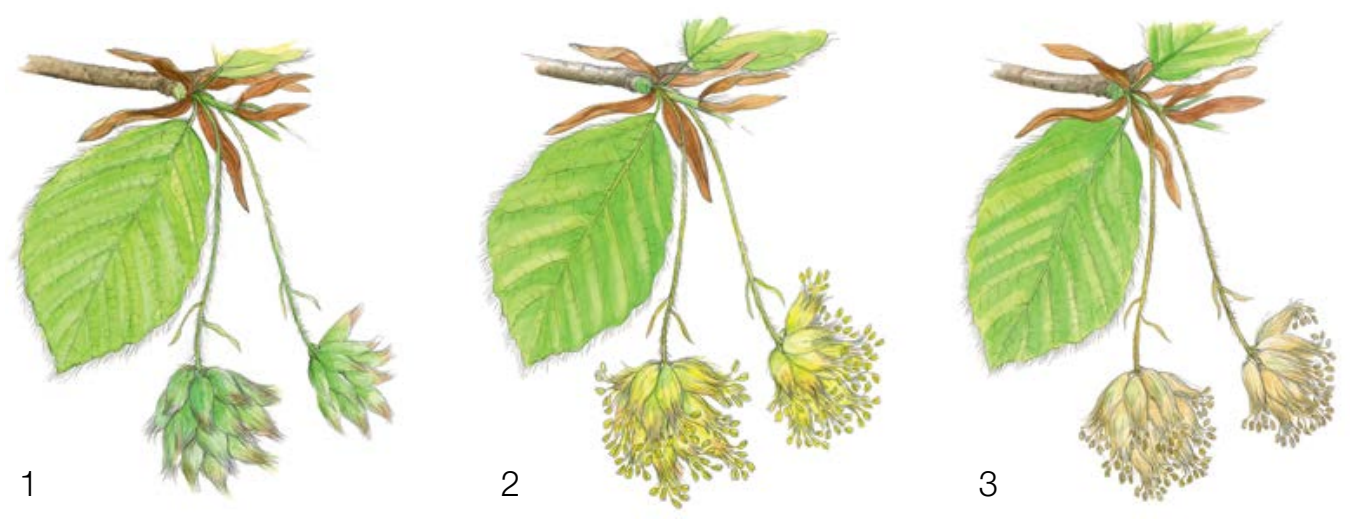

Abbildung 4: Illustrationen zur Beschreibung der weiblichen (a) und männlichen (b) Blühstadien für den Verifikator „Blüte" auf Intensivniveau. 


\begin{tabular}{|c|c|c|}
\hline \multicolumn{3}{|c|}{ Code Weibliches Blühstadium } \\
\hline 1 & voll entwickelte weibliche Blüte & \\
\hline 2 & vollständig gebildete und geformte Früchte oder Nüss & , aber noch ungeöffnete Nussschalen \\
\hline \multicolumn{3}{|c|}{ Code Männliches Blühstadium } \\
\hline 1 & verlängerter Blütenstiel - geschlossene Blüte (grün) & \\
\hline 2 & Pollen abgebende Staubgefäße (gelb) & \\
\hline 3 & leere Staubgefäße (Pollen freigesetzt) (braun) & \\
\hline Code & & Anteil der Krone in Blüte (\%; männliche und weibliche Blüten) \\
\hline 1 & & $0-10$ \\
\hline 2 & & $>10-30$ \\
\hline 3 & & $>30-60$ \\
\hline 4 & & $>60-90$ \\
\hline 5 & & $>90$ \\
\hline
\end{tabular}

Hintergrundinformationen zur Blühsynchronisation können anhand der für diesen Verifikator erfassten Werte für die weibliche und männliche Blüte abgeleitet werden.

\subsubsection{Fruktifikation}

Dieser Verifikator beschreibt das Auftreten und die Häufigkeit der Fruchtbildung. Die Daten für diesen Verifikator sollten während der Fruktifikationszeit erhoben werden, d.h. in Mitteleuropa von August bis Oktober.

\subsubsection{Basisniveau}

Der Verifikator wird jährlich auf Bestandesebene erfasst. Die Schätzung des durchschnittlichen Zustands erfolgt nach einer Begehung der gesamten Monitoringfläche. Es werden zwei Werte erfasst: einer für die Intensität der Fruktifikation und einer für den Anteil fruchttragender Bäume im Bestand.

\begin{tabular}{clr} 
Code Intensität der Fruktifikation auf Bestandesebene & Mittlerer Anteil der Krone mit Fruchtbehang (\%) \\
\hline 1 & $\begin{array}{l}\text { Keine Fruchtbildung: Keine oder nur gelegentlich auftretende Früchte } \\
\text { an den Bäumen }\end{array}$ & $0-10$ \\
\hline 2 & Schwache Fruchtbildung: Einige Früchte an den Bäumen & $>10-30$ \\
\hline 3 & Mäßige Fruchtbildung: Mäßig viele Früchte an den Bäumen & $>30-60$ \\
\hline 4 & Starke Fruchtbildung: Reichlich Früchte an den Bäumen & $>60-90$ \\
\hline 5 & Extreme Fruchtbildung: Enorme Anzahl von Früchten an den Bäumen & $>90$ \\
\hline
\end{tabular}

\begin{tabular}{lr} 
Code & Anteil der Bäume im Bestand mit dem entsprechenden Stadium der Fruktifikationsintensität (\%) \\
\hline 1 & $0-10$ \\
\hline 2 & $>10-30$ \\
\hline 3 & $>30-60$ \\
\hline 4 & $>60-90$ \\
\hline 5 & $>90$ \\
\hline
\end{tabular}




\subsubsection{Standardniveau}

Die Erfassung des Verifikators erfolgt in denselben Jahren wie die Bewertung der Blüte auf Standardniveau (unabhängig von der Fruktifikationsintensität). Sie wird für alle 50 Beobachtungsbäume auf Einzelbaumebene durchgeführt - und zwar bevor die Früchte beginnen zu fallen. Für jeden Beobachtungsbaum wird ein Wert erfasst.

Im Idealfall sollte pro Jahrzehnt ein auf ein bedeutendes Blühereignis folgendes größeres Fruktifikationsereignis erfasst werden. Ein bedeutendes Blühereignis führt jedoch nicht unbedingt zu einem bedeutenden Fruktifikationsereignis. Wenn auf das bewertete Blühereignis kein wesentliches Fruktifikationsereignis folgt, muss die Bewertung sowohl der Blüte als auch der Fruchtbildung beim nächsten bedeutenden Blühereignis wiederholt werden, unabhängig von der Zeit, die zwischen aufeinanderfolgenden bedeutenden Blühereignissen liegt. Erhebungen auf Basisniveau werden genutzt, um bedeutende Fruktifikationsereignisse zu identifizieren. Ein bedeutendes Fruktifikationsereignis liegt vor, wenn die Fruktifikationsintensität auf Basisniveau als stark oder extrem eingeschätzt wird (Code 4 oder 5) und der Anteil der Bäume mit der angegebenen Fruktifikationsintensität über 60\% liegt (Code 4 oder 5).

\begin{tabular}{clr}
\multicolumn{2}{l}{ Code Intensität der Fruktifikation auf Bestandesebene } & Mittlerer Anteil der Krone mit Fruchtbehang (\%) \\
\hline 1 & $\begin{array}{l}\text { Keine Fruchtbildung: Keine oder nur gelegentlich auftretende Früchte } \\
\text { an den Bäumen }\end{array}$ & $0-10$ \\
\hline 2 & Schwache Fruchtbildung: Einige Früchte an den Bäumen & $>10-30$ \\
\hline 3 & Mäßige Fruchtbildung: Mäßig viele Früchte an den Bäumen & $>30-60$ \\
\hline 4 & Starke Fruchtbildung: Reichlich Früchte an den Bäumen & $>60-90$ \\
\hline 5 & Extreme Fruchtbildung: Enorme Anzahl von Früchten an den Bäumen & $>90$ \\
\hline
\end{tabular}

\subsubsection{Intensivniveau}

Die Erfassung des Verifikators erfolgt für alle 50 Beobachtungsbäume auf Einzelbaumebene in denselben Jahren wie die Bewertung der Blüte auf Intensivniveau (unabhängig von der Fruktifikationsintensität). Sie wird durchgeführt, bevor die Früchte beginnen zu fallen. Für jeden Beobachtungsbaum wird ein Wert erfasst. Zeitgleich wird Saatgut für die Saatgut- und Genanalysen gesammelt (für die Verifikatoren und Hintergrundinformationen auf Intensivniveau).

Im Idealfall sollte pro Jahrzehnt ein auf ein bedeutendes Blühereignis folgendes größeres Fruktifikationsereignis erfasst werden. Ein bedeutendes Blühereignis führt jedoch nicht unbedingt $z u$ einem bedeutenden Fruktifikationsereignis. Wenn auf das bewertete Blühereignis kein wesentliches Fruktifikationsereignis folgt, muss die Bewertung sowohl der Blüte als auch der Fruchtbildung beim nächsten bedeutenden Blühereignis wiederholt werden, unabhängig von der Zeit, die zwischen aufeinanderfolgenden bedeutenden Blühereignissen liegt. Erhebungen auf Basisniveau werden genutzt, um bedeutende Fruktifikationsereignisse zu identifizieren. Ein bedeutendes Fruktifikationsereignis liegt vor, wenn die Fruktifikationsintensität auf Basisniveau als stark oder extrem eingeschätzt wird (Code 4 oder 5) und der Anteil der Bäume mit der angegebenen Fruktifikationsintensität über 60\% liegt (Code 4 oder 5).

Der Verifikator wird durch das Zählen von Früchten unter Nutzung eines Fernglases erfasst (als Durchschnitt von drei Zählrunden). Jede Zählrunde besteht aus der Anzahl der Früchte, die der Beobachter in 30 Sekunden zählt. Bei allen Bäumen sollte das gleiche Kronendrittel untersucht werden. Sobald ein Kronendrittel für die Beobachtung ausgewählt wurde, sollte dieses für jede weitere Erhebung dieses Verifikators ausgewählt werden. Für die Zählung wird das obere Kronendrittel dem unteren und mittleren Drittel vorgezogen.

Es werden zwei Werte erfasst: die Anzahl der Früchte und das untersuchte Kronendrittel. 


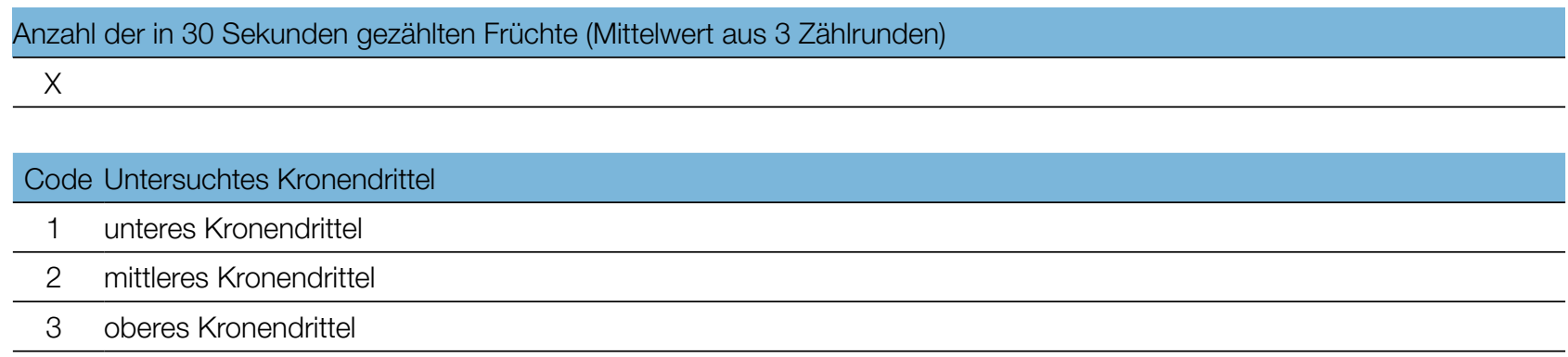

\subsubsection{Abundanz der Naturverjüngung}

Dieser Verifikator beschreibt das Vorhandensein und die Häufigkeit von Naturverjüngung auf der Monitoringfläche.

\subsubsection{Basisniveau}

Der Verifikator wird jährlich im Herbst auf Bestandesebene erfasst. Für die Schätzung der Situation auf der gesamten Monitoringfläche werden Expertenmeinungen herangezogen. Es sollten zwei Werte erfasst werden: einer für neue aufgelaufene Naturverjüngung (diesjährige Keimlinge) und einer für etablierte Naturverjüngung (Sämlinge und junge Bäume, die den neuen Bestand bilden werden).

\section{Code Beschreibung: neue aufgelaufene Naturverjüngung (diesjährige Keimlinge)}

1a Auf der Monitoringfläche gibt es keine oder nur sehr wenig neue Naturverjüngung

2a Auf der Monitoringfläche ist in ausreichender Anzahl neue Naturverjüngung vorhanden

Code Beschreibung: etablierte Naturverjüngung (Sämlinge)

1b Auf der Monitoringfläche gibt es keine oder nur sehr wenig etablierte Naturverjüngung

2b Auf der Monitoringfläche ist in ausreichender Anzahl etablierte Naturverjüngung vorhanden

\subsubsection{Standardniveau}

Der Verifikator wird durch Zählung der Sämlinge im 1. und 6. Herbst nach jedem bewerteten Fruktifikationsereignis erfasst (das Jahr des Fruktifikationsereignisses wird als Jahr 0 betrachtet).

Zählung der Naturverjüngung:

Nach derEinrichtung derNV-Plots werdenalle Buchensämlinge in den NV-Plots gezählt. Ältere Buchenjungpflanzen, die in den NV-Plots vorhanden sind, dürfen nicht mitgezählt werden. Bei der nächsten Zählung sind nur die Buchenjungpflanzen im entsprechenden Alter zu zählen; d.h. im 6. Jahr alle 5 Jahre alten Buchen.

\section{Anzahl der Jungpflanzen auf einem NV-Plot}

$$
\mathrm{X}
$$

Die Mortalität/Überlebensrate der Naturverjüngung wird anhand der für diesen Verifikator erfassten Werte berechnet.

Zur Einrichtung von NV-Plots siehe Kapitel 6.2 Einrichtung von Naturverjüngungs-Plots. 


\subsubsection{Intensivniveau}

Der Verifikator wird durch das Zählen der Sämlinge im 1., 6., 11. und 16. Herbst nach jedem bewerteten Fruktifikationsereignis erfasst (das Jahr des Fruktifikationsereignisses wird als Jahr 0 betrachtet).

Tabelle 3: Zeitstrahl zur Erfassung der Abundanz der Naturverjüngung (NV). In diesem Beispiel findet das erste Fruktifikationsereignis im 2. Jahr des Beobachtungsjahrzehnts statt; das zweite erfasste Fruktifikationsereignis fünf Jahre später, d.h. im 7. Jahr des Monitorings. Nach jedem bewerteten Fruktifikationsereignis werden 20 neue NV-Plots angelegt. Die Erfassung der NV-Abundanz auf jedem Set von 20 NV-Plots erfolgt alle fünf Jahre. Die zur jeweils erfassten NV gehörigen Fruktifikationsereignisse und der Verlauf der Monitoringaktivitäten sind in derselben Farbe schattiert. Nach der letzten Runde der NV-Zählung wird das Monitoring der NV-Abundanz auf dem entsprechenden Set von NV-Plots eingestellt und die jeweiligen NV-Plots werden aufgelöst. S - Standardniveau; I - Intensivniveau.

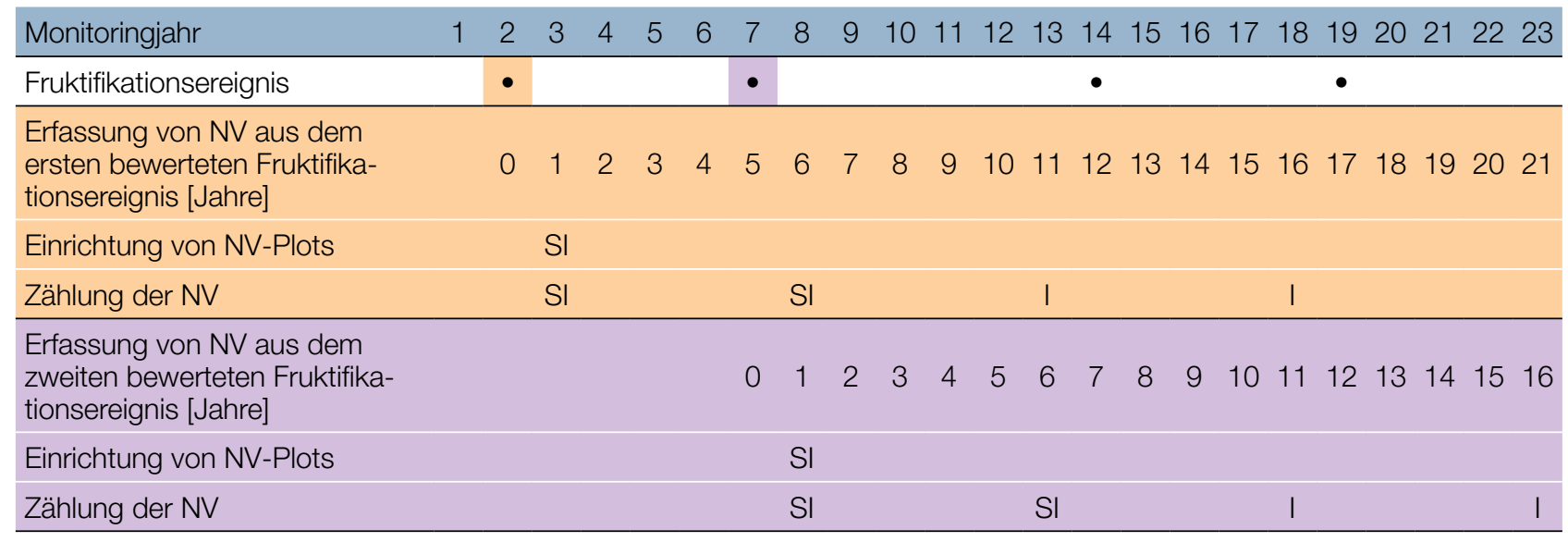

Die Mortalität/Überlebensrate der Naturverjüngung wird anhand der für diesen Verifikator erfassten Werte berechnet.

Zur Einrichtung von NV-Plots siehe Kapitel 6.2 Einrichtung von Naturverjüngungs-Plots; zur Zählung der NV siehe Kapitel 7.1.4.2 Standardniveau.

\subsection{Verfahren zur Erfassung von Hintergrundinformationen}

\subsubsection{Durchmesserklassenverteilung}

\subsubsection{Standard- und Intensivniveau}

Der BHD wird alle 10 Jahre für alle 50 Beobachtungsbäume auf Einzelbaumebene erfasst. Der BHD ist der Stammdurchmesser in 1,30 m Höhe, d.h. ungefähr auf Brusthöhe eines Erwachsenen. Hat der Baum mehr als einen Stamm, messen Sie bitte alle Stämme und erfassen Sie den Durchschnitt (versuchen Sie jedoch, Bäume mit vielen kleinen Stämmen zu vermeiden). Notieren Sie in den Anmerkungen, dass der Baum mehrstämmig ist, und geben Sie die Anzahl der gemessenen Stämme an. Ist der Baum geneigt, messen Sie den BHD senkrecht zum Baumstamm. Der BHD kann auf zwei Arten gemessen werden:

1) mit einer Kluppe; in diesem Fall messen Sie senkrecht zueinander zwei Durchmesser und berechnen den Mittelwert

2) Messen Sie den Umfang des Baumes und berechnen Sie daraus den Durchmesser (d.h. dividieren Sie durch $\pi ; \sim 3,14)$

Der BHD wird in cm angegeben. Für nachfolgende Messungen ist stets dieselbe Methode anzuwenden. 


\subsubsection{Höhenklassenverteilung}

\subsubsection{Standard- und Intensivniveau}

Die Baumhöhe wird alle 10 Jahre für alle 50 Beobachtungsbäume auf Einzelbaumebene erfasst. Die Höhe wird vom Boden bis zum höchsten Punkt der Krone gemessen, idealerweise mit einem Klinometer oder Hypsometer (z.B. Vertex). Die Höhe wird in Metern auf eine Dezimalstelle angegeben. Ist die Krone beschädigt, muss dies in den Anmerkungen zusammen mit dem mutmaßlichen Grund für den Schaden notiert werden.

\subsubsection{Austrieb}

Diese Hintergrundinformation beschreibt die Austriebsstadien. Die Aufzeichnung erfolgt nur auf Standard- und Intensivniveau. Die Daten für diese Hintergrundinformation sollten in Mitteleuropa ab Ende März erhoben werden, bis alle Beobachtungsbäume voll entwickelte Blätter haben.

\subsubsection{Standardniveau}

Auf Standardniveau wird der Austrieb alle 5 Jahre für alle 50 Beobachtungsbäume auf Einzelbaumebene beobachtet. Gesucht werden der Beginn der Knospenöffnung (Stadium 3) und das Ende der Blattentfaltung (Stadium 5). Die Beobachtungen werden beendet, wenn alle Bäume das Stadium 5 erreicht haben. In der Regel sind dafür 6 Begehungen erforderlich. Für jeden Baum werden zwei Werte erfasst: das Austriebsstadium und der entsprechende Kronenanteil. Die Austriebsstadien sind in Abbildung 5 dargestellt.

\begin{tabular}{|c|c|}
\hline \multicolumn{2}{|c|}{ Code Austriebsstadium } \\
\hline 1 & schlafende Winterknospe \\
\hline 2 & geschwollene und verlängerte Knospen \\
\hline 3 & beginnende Knospenöffnung (erstes Grün ist sichtbar) \\
\hline 4 & gefaltete und behaarte Blätter erscheinen; einzeln sichtbare gefaltete und behaarte Blätter \\
\hline 5 & Blätter vollständig entfaltet, glatt und hellgrün \\
\hline
\end{tabular}

\begin{tabular}{lr} 
Code & Anteil der Krone mit dem entsprechenden Austriebsstadium (\%) \\
\hline 1 & $>0-33$ \\
\hline 2 & $>33-66$ \\
\hline 3 & $>66-99$ \\
\hline 4 & 100 \\
\hline
\end{tabular}

\subsubsection{Intensivniveau}

Auf Intensivniveau wird der Austrieb jährlich für alle 50 Beobachtungsbäume auf Einzelbaumebene erhoben, mit derselben Verfahrensweise wie auf Standardniveau. Details dazu sind im Kapitel 7.2.3.1 Standardniveau zu finden. 
1

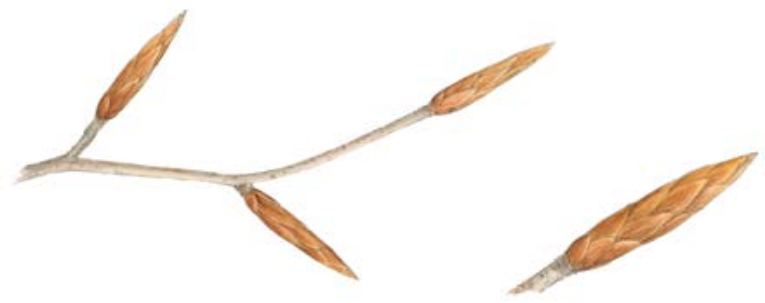

3

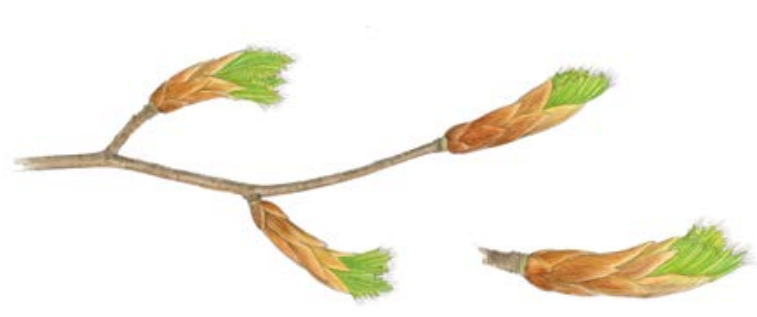

2

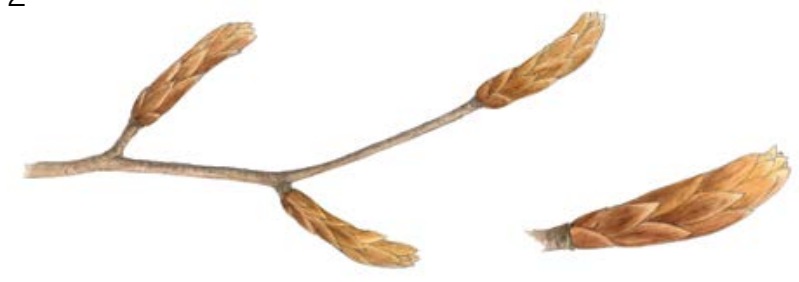

4

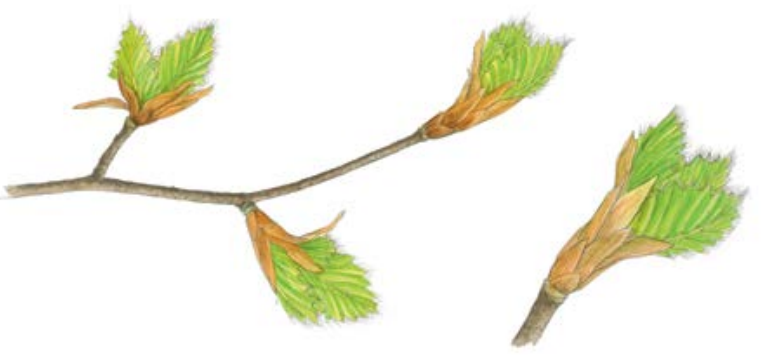

5

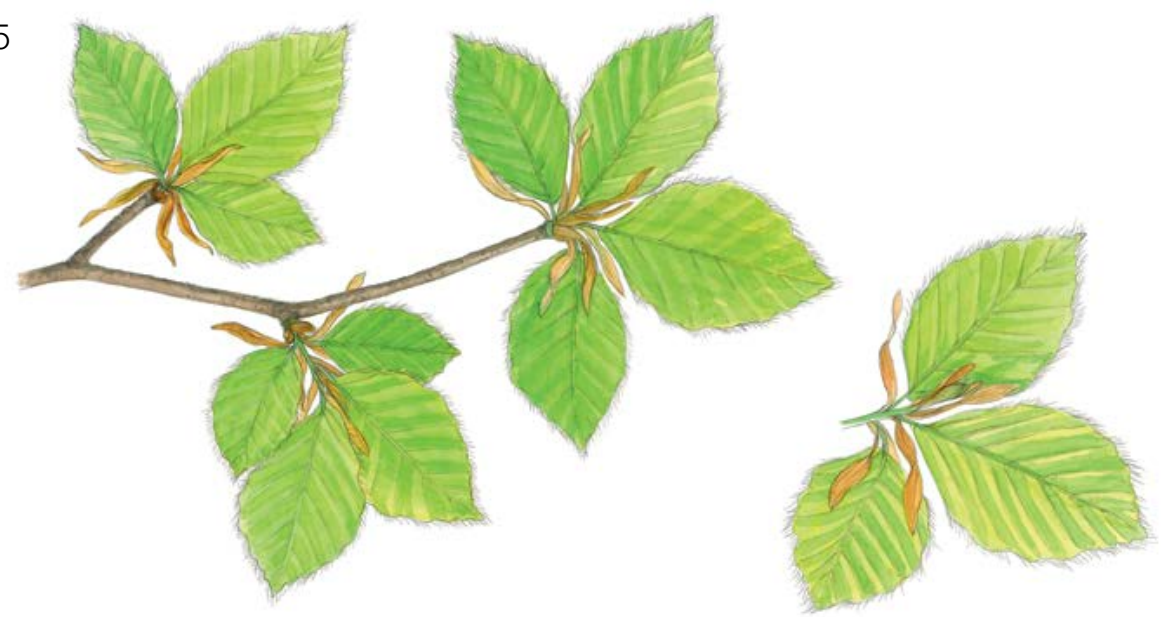

Abbildung 5: Illustration zur Beschreibung der Hintergrundinformation „Austrieb“ auf Standard- und Intensivniveau.

\subsubsection{Seneszenz}

Die Seneszenz beschreibt den Prozess der Blattalterung. Die Erfassung dieser Hintergrundinformation erfolgt nur auf dem Standard- und Intensivniveau.

\subsubsection{Standardniveau}

Auf Standardniveau wird die Seneszenz alle 5 Jahre für alle 50 Beobachtungsbäume auf Einzelbaumebene beobachtet. Gesucht wird das Stadium 3, wenn die Blätter gelb sind und keine Photosynthese mehr betreiben. Die Beobachtungen enden, wenn alle Bäume das Stadium 3 erreicht haben. Normalerweise sind dafür zwei Begehungen der Monitoringfläche erforderlich. Für jeden Baum werden zwei Werte erfasst: das Stadium der Seneszenz und der entsprechende Kronenanteil. Die Stadien der Seneszenz sind in Abbildung 6 dargestellt. 


\begin{tabular}{|c|c|c|}
\hline \\
\hline \multicolumn{3}{|c|}{$\begin{array}{cl}\text { Code } & \text { Stadium der Seneszenz } \\
1 & \text { Blätter sind grün }\end{array}$} \\
\hline 2 & Blattfarbe wechselt von grün zu gelb (grünlich-gelb) & \\
\hline 3 & Blattfarbe wechselt von gelb zu braun (bräunlich) & \\
\hline 4 & Blätter sind braun / abgefallen & \\
\hline \multicolumn{2}{|l|}{ Code } & Anteil der Krone mit dem entsprechenden Seneszenzstadium (\%) \\
\hline \multicolumn{2}{|l|}{1} & $>0-33$ \\
\hline \multicolumn{2}{|l|}{2} & $>33-66$ \\
\hline \multicolumn{2}{|l|}{3} & $>66-99$ \\
\hline \multicolumn{2}{|l|}{4} & 100 \\
\hline
\end{tabular}

\subsubsection{Intensivniveau}

Auf Intensivniveau wird die Seneszenz jährlich für alle 50 Beobachtungsbäume auf Einzelbaumebene erfasst, mit derselben Verfahrensweise wie auf Standardniveau. Details dazu sind im Kapitel 7.2.4.1 Standardniveau zu finden.
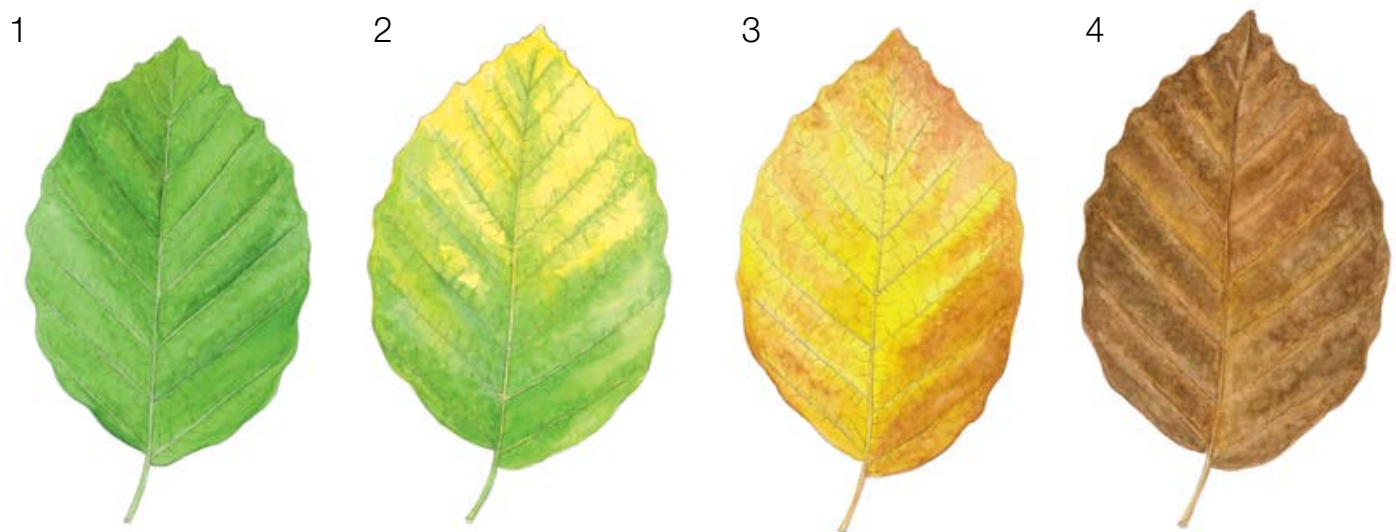

Abbildung 6: Illustration zur Beschreibung der Seneszenz für die Hintergrundinformation „Seneszenz" auf Standardund Intensivniveau.

\subsubsection{Blühsynchronisation}

\subsubsection{Intensivniveau}

Die Hintergrundinformation „Blühsynchronisation“ wird nur auf Intensivniveau erfasst und basiert auf den für den Verifikator „Blüte“ erhobenen Daten. Sie wird verwendet, um festzustellen, ob die männliche und weibliche Blüte innerhalb des untersuchten Bestandes gleichzeitig stattfindet.

\section{Formular für die Beschreibung der Monitoringfläche: 'FGM Plot description'}

Formular für die Erfassung der Verifikatoren: 'Form for recording field level verifiers within FGM'

Formular für die Aufzeichnung von Hintergrundinformationen: 'Form for recording field level background information within FGM' 


\section{Quellen}

1. Houston Durrant T, de Rigo D, Caudullo G (2016) Fagus sylvatica and other beeches in Europe: distribution, habitat, usage and threats. In: San-Miguel-Ayanz J, de Rigo D, Caudullo G, Houston Durrant T, Mauri A (Eds.) European Atlas of Forest Tree Species. Publ. Off. EU, Luxembourg, pp 94-97. DOI: 10.2788/4251

2. von Wuehlisch $\mathrm{G}$ (2008) EUFORGEN Technical Guidelines for genetic conservation and use for European beech (Fagus sylvatica). Bioversity International, Rome

3. Kraigher H, Westergren M (2011) Gozdno semenarstvo in drevesničarstvo. In: Gospodarjenje z gozdom za lastnike gozdov. Kmečki glas, Ljubljana

4. Johnson O \& More D (2010) Collins Tree guide. Slovenian edition, Narava d.o.o., Kranj

5. Ogris N (2020) Varstvo gozdov Slovenije - portal. https://www.zdravgozd.si/meni_index.aspx. Accessed 15 September 2020

Die folgenden Ressourcen wurden für die derzeit akzeptierten (Dezember 2020) wissenschaftlichen Namen der in diesem Dokument erfassten oder erwähnten Arten konsultiert:

a. CABI (2020) Invasive Species Compendium. CAB International, Wallingford, UK. www.cabi.org/isc. Accessed 15 December 2020

b. EPPO (2020) EPPO Global Database (available online). https://gd.eppo.int. Accessed 15 December 2020

c. GBIF (2020) Global Biodiversity Information Facility. https://www.gbif.org Accessed 15 December 2020

d. IPNI (2020) International Plant Names Index. The Royal Botanic Gardens, Kew, Harvard University Herbaria \& Libraries \& Australian National Botanic Gardens. http://www.ipni.org, Accessed 10 December 2020

e. National Center for Biotechnology Information (NCBI) (1998) National Library of Medicine (US), National Center for Biotechnology Information, Bethesda (MD). https://www.ncbi.nlm.nih.gov/. Accessed 15 December 2020

f. Stevens PF (2001) Angiosperm Phylogeny Website, Version 14. http://www.mobot.org/MOBOT/research/APweb/. Accessed 15 December 2020

g. The Plant List (2013) Version 1.1. http://www.theplantlist.org/. Accessed 12 December 2020

h. Tropicos.org (2020) Missouri Botanical Garden. http://www.tropicos.org. Accessed 15 December 2020

i. WFO (2020) World Flora Online. http://www.worldfloraonline.org. Accessed 15 December 2020 



\section{Leitfaden für das genetische Monitoring der}

\subsubsection{Gemeinen Esche (Fraxinus excelsior L.)}

Marjana WESTERGREN ${ }^{1}$, Marko BAJC'1, Rok DAMJANIĆ ${ }^{1}$, Barbara FUSSI ${ }^{2}$,

Dalibor BALLIAN ${ }^{1,3}$, Andrej BREZNIKAR ${ }^{4}$, Darius KAVALIAUSKAS ${ }^{2}$,

Peter ŽELEZNII'1', Hojka KRAIGHER'

Botanische lllustrationen von Metka KLADNIK

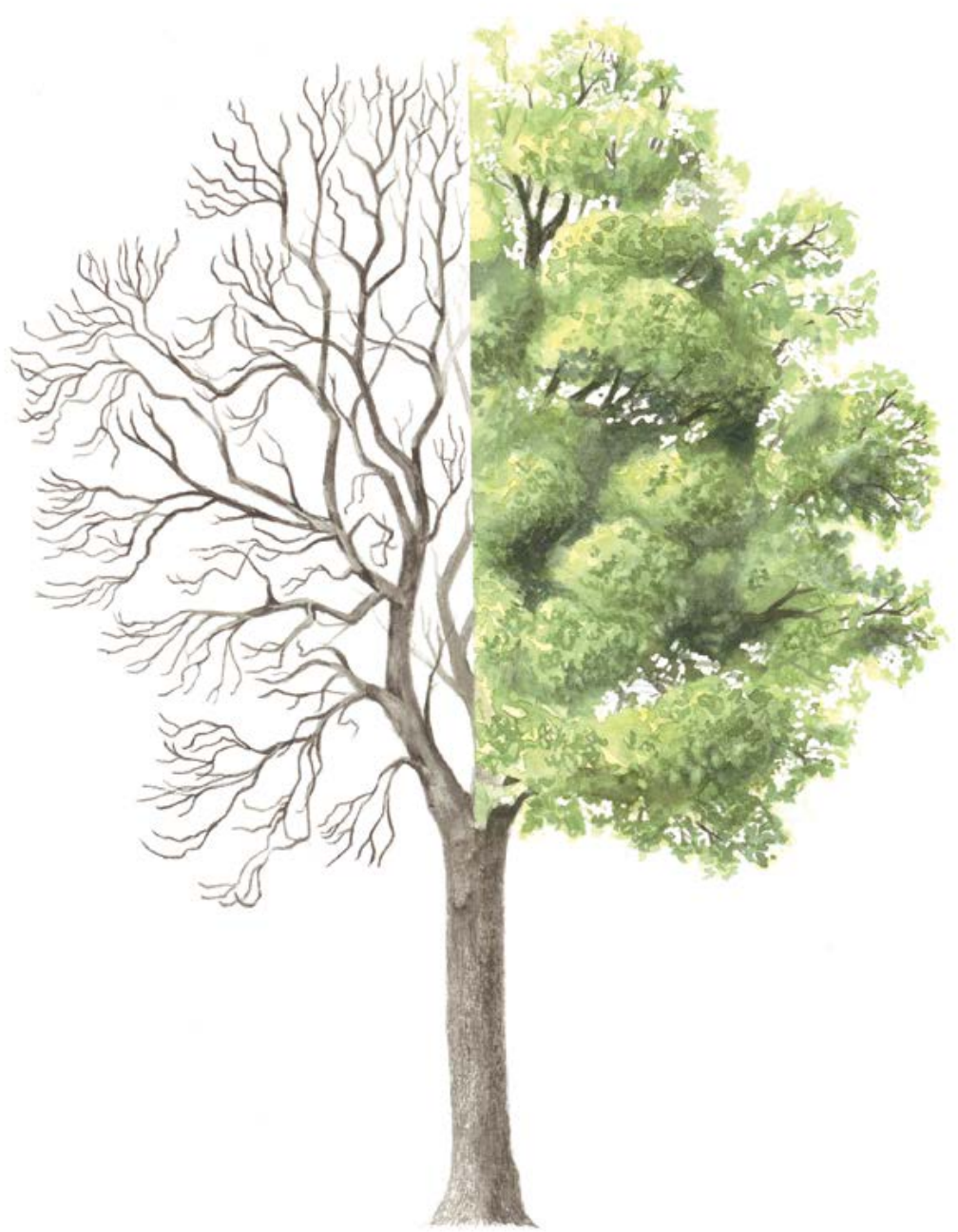

Zitat: Westergren et al. (2020) Leitfaden für das genetische Monitoring der Gemeinen Esche (Fraxinus excelsior L.). In: Bajc et al. (Ed.) Handbuch zum Forstgenetischen Monitoring. Slowenisches Forstinstitut: Verlag Silva Slovenica, Ljubljana, S. 209-228. http://dx.doi.org/10.20315/SFS.176

1. Slowenisches Forstinstitut (SFI), Slowenien

2. Bayerisches Amt für Waldgenetik (AWG), Deutschland

3. Forstliche Fakultät, Universität von Sarajevo, Bosnien und Herzegowina

4. Slowenische Staatsforsten (ZGS), Slowenien 


\section{ZUSAMMENFASSUNG}

Die Gemeine Esche (Fraxinus excelsior L.) ist eine polygame, Laubbaumart, die - mit Ausnahme der trockensten Mittelmeergebiete - in ganz Europa vorkommt. Die Esche kann in Reinbeständen vorkommen, ist aber häufiger als Kleingruppen in Mischbeständen zu finden und damit besser vergleichbar mit nicht-bestandesbildenden Baumarten. Sie ist eng mit der Schmalblättrigen Esche ( $F$. angustifolia Vahl.) verwandt, mit der sie hybridisiert. Aufgrund ihrer großen ökologischen Bedeutung und ihrem Nutzen für die Holzindustrie ist diese vom Eschensterben stark bedrohte Art für das forstgenetische Monitoring prädestiniert.

Dieser Leitfaden beschreibt die Gemeine Esche sowie ihre Reproduktion, Umwelt und Gefährdung. Er enthält außerdem eine Anleitung zur Einrichtung forstgenetischer Monitoringflächen und zur Erfassung aller vor Ort im Bestand zu erhebenden Verifikatoren.

\section{BESCHREIBUNG DER BAUMART}

Die Gemeine Esche (Abbildung 1) ist ein Laubbaum, der im Alter von 90-120 Jahren eine Höhe von bis zu 40 m erreicht [1]. Die starkastige Krone ist unregelmäßig; in Waldbeständen ist sie eher langgestreckt [1]. Die Rinde ist blassbraun bis grau, und wird mit zunehmendem Alter des Baumes rissig [2]. Im Winter lässt sich die Gemeine Esche leicht an den glatten Zweigen mit deutlich schwarzen, samtigen Blattknospen erkennen, die gegenständig angeordnet sind. Die Blätter sind unpaarig gefiedert und bestehen typischerweise aus 7-13 ovalen Fiederblättchen mit langen Spitzen, inklusive eines einzelnen endständigen Fiederblättchens [2, 3] (Abbildung 2a). Die insgesamt bis zu $35 \mathrm{~cm}$ langen Blätter [2] sind auf der Unterseite hellgrün und auf der Oberseite grün-grau.

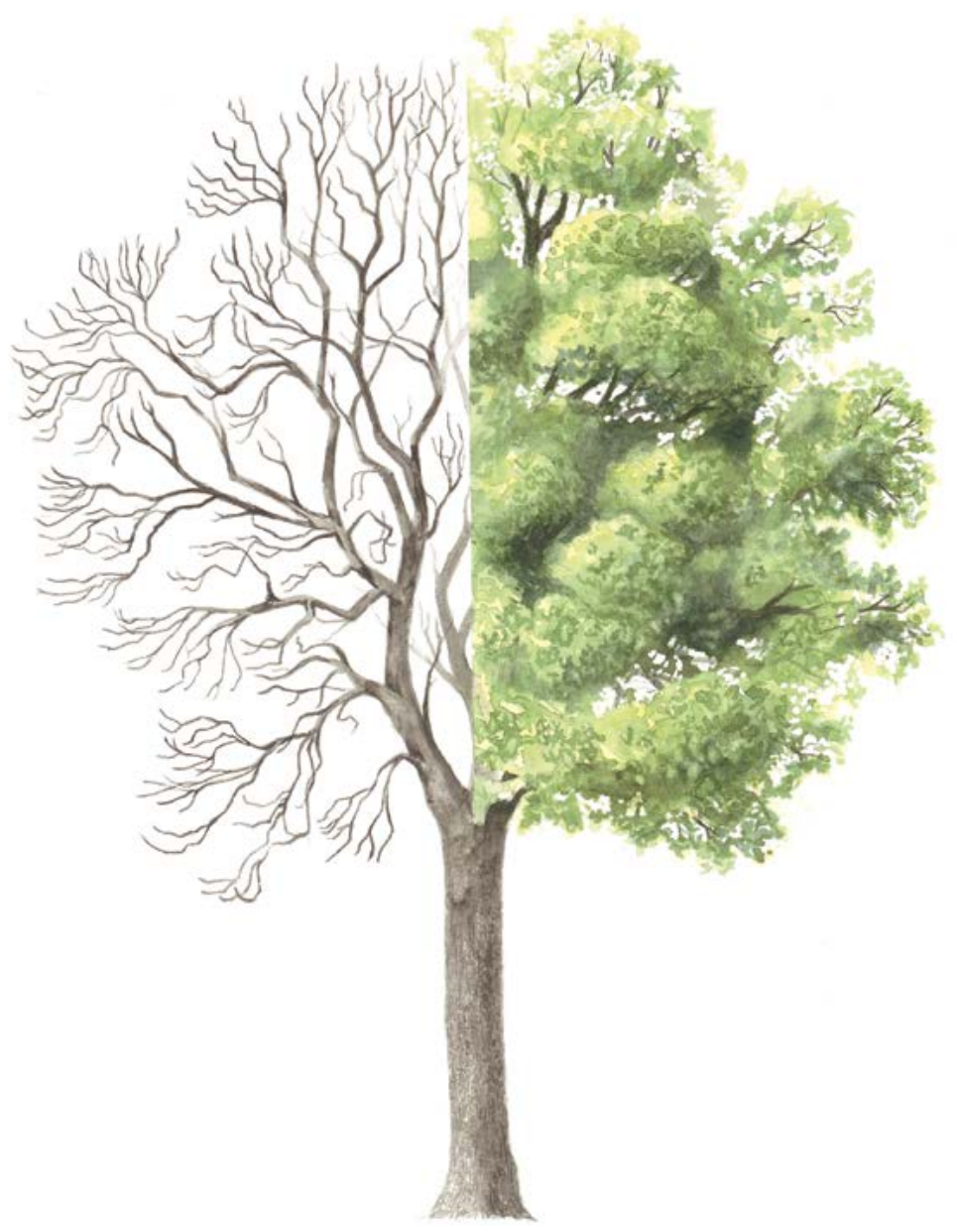

Abbildung 1: Habitus der Gemeinen Esche (Fraxinus excelsior). 
(a)

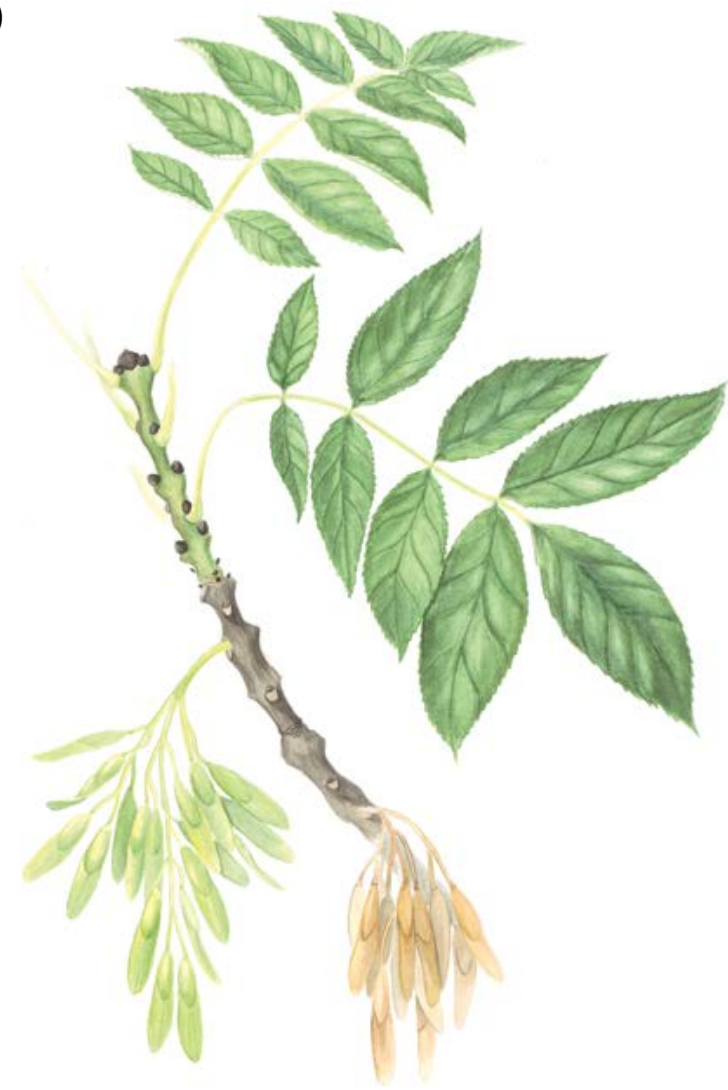

(b)

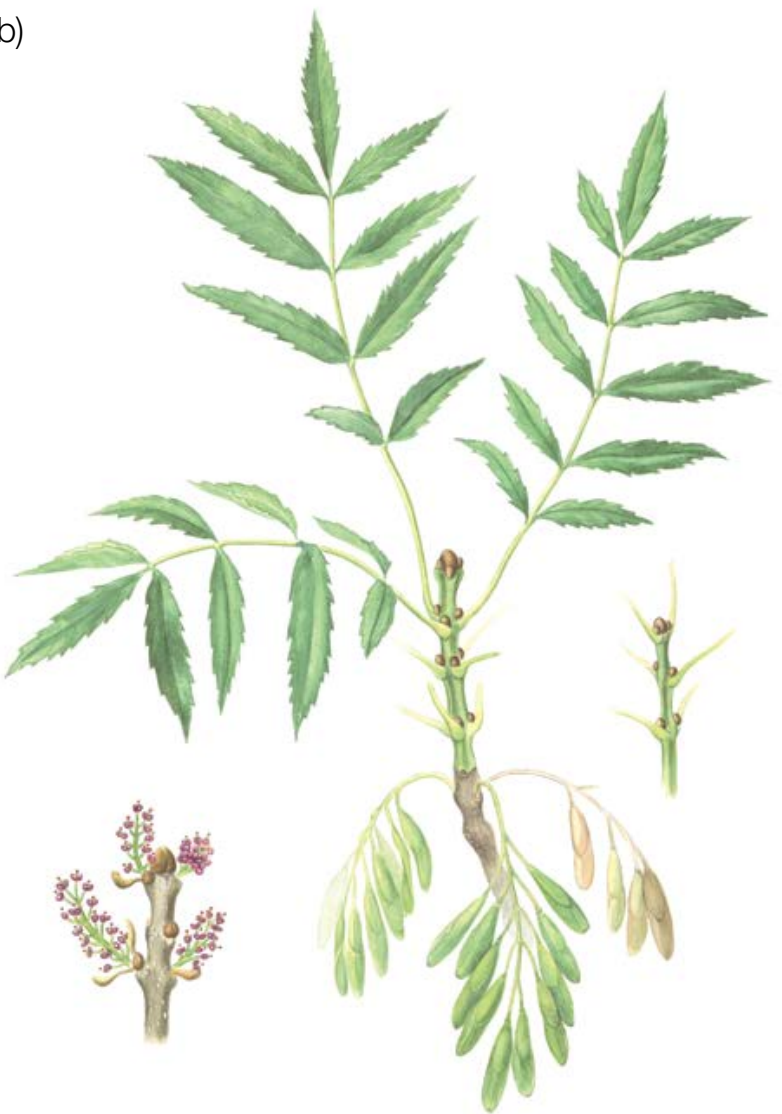

Abbildung 2: Morphologische Merkmale zur Unterscheidung von F. excelsior (a) und F. angustifolia (b).

Die Gemeine Esche ist eng mit $F$. angustifolia verwandt. Die beiden Arten sind am besten an ihren Blüten und Fruchtständen zu unterscheiden (Abbildung 2): Die Gemeine Esche hat einen verzweigten Blütenstand (Rispe), während $F$. angustifolia eine einfache, unverzweigte Blütentraube ausbildet [3]. Eine Ausnahme bilden die gemischten Blütenstände einzelner F. excelsior-Bäume, die nur auf dem Haupttrieb zwittrige Blütenstände und auf Seitenzweigen ausschließlich männliche Blütenstände ausbilden. Nach dem Abfallen der männlichen Blüten kann so der Anschein der für F. angustifolia typischen unverzweigten Blütentrauben erweckt werden [3]. In Gebieten, in denen die beiden Arten zusammenwachsen, wurden Hybriden beobachtet [2, 3].

\section{REPRODUKTION}

Die Gemeine Esche ist polygam. Sie kann ausschließlich männliche oder weibliche Blütenstände an einem einzigen Baum entwickeln, oder eingeschlechtliche Blütenstände mit ausschließlich männlichen oder weiblichen Blüten, die getrennt am selben Baum getragen werden, oder sogar zwittrige Blütenstände [1,2, 3]. Sie ist selbstbefruchtend [3]. Allerdings können selbstbefruchtete Samen aufgrund einer Inzuchtdepression nicht überleben, was die Art möglicherweise funktionell zweihäusig macht [3]. Sowohl die männlichen als auch die weiblichen Blütenstände sind violett und wachsen in ährenförmigen Büscheln an den Spitzen der Zweige. Die Blütenstände erscheinen noch vor den Blättern, in Mitteleuropa in den Monaten März bis April. Die Blätter erscheinen erst nach Ende der Blüte an den aus den Terminalknospen entstehenden Jahrestrieben. Der Beginn der Blüte variiert von Population zu Population und von Jahr zu Jahr. Nach warmen Wintern erfolgen sowohl Blüte als auch Blattaustrieb zeitiger [3].

Nachdem die weiblichen Blütenstände durch den Wind bestäubt wurden, entwickeln sie sich im Spätsommer und Herbst zu gut sichtbaren Flügelnüssen (Samaras). Sie fallen im Winter und im zeitigen Frühjahr von den Bäumen und werden hauptsächlich vom Wind verbreitet [1, 2, 3]. Die in unregelmäßigen Abständen auftretende 
Blüte beginnt bei einzeln stehenden Eschen im Alter von 15-20 Jahren, in Waldbeständen mit etwa 30 Jahren [1]. Die Samenruhe dauert üblicherweise zwei Winter; auf trockenen oder höher gelegenen Standorten manchmal auch bis zu sechs Jahre [2, 3].

Die Gemeine Esche weist Eigenschaften auf, die zwischen denen einer Pionier- und einer Klimaxbaumart liegen. Ihre Ausbreitung und natürliche Verjüngung sind effizient; inre Konkurrenzfähigkeit ist jedoch nur dann stark, wenn ihre ökologischen Anforderungen erfüllt sind [2, 3]. Die vegetative Verjüngung der Esche ist vor allem ausgeprägt, wenn sie auf den Stock gesetzt wird (Niederwaldbewirtschaftung) [3].

\subsection{Identifikation des Geschlechts}

Männliche Bäume sind Bäume, bei denen die meisten Blütenstände männlich sind. Diese Kategorie lässt sich unterteilen in rein männliche Bäume (mit ausschließlich männlichen Blütenständen) und Bäume mit einer Mischung aus männlichen und zwittrigen Blütenständen. Diese männlich-hermaphroditen Bäume können einige wenige Samen produzieren [3].

Weibliche Bäume sind Bäume mit überwiegend weiblichen Blütenständen. Sie produzieren Samen [3].

Zwitterbäume sind Bäume mit überwiegend zwittrigen Blütenständen. Sie produzieren hauptsächlich Samen. Da sie auch Pollen produzieren, können sie jedoch auch einige Samen an anderen Bäumen zeugen. Zwitterbäume können in ihrem Geschlecht variieren und im jeweiligen Mastjahr die Tendenz zu mehr weiblich oder mehr männlich zeigen [3].

\section{UMWELT}

Die Gemeine Esche wächst in ganz Europa. Da sie keine ausgedehnte Sommertrockenheit verträgt und ihre Jungpflanzen anfällig für Spätfröste im Frühjahr sind, fehlt sie jedoch sowohl in den trockensten Mittelmeergebieten als auch in den nördlichen borealen Regionen [1, 2, 3]. Sie wächst am besten auf nährstoffreichen Böden mit pH-Werten über 5,5, so dass die lokale Verbreitung der Esche stark durch Bodeneigenschaften bestimmt wird. Die Esche verträgt saisonale Staunässe, aber keine lang anhaltenden Überschwemmungen [2]. Sie ist eine Baumart, die nur selten Reinbestände bildet und meist in kleinen Gruppen innerhalb von Mischbeständen zu finden ist [2].

\section{GEFÄHRDUNG}

Die größte Bedrohung für die Gemeine Esche ist derzeit das Eschentriebsterben, das durch einen Pilz namens Hymenoscyphus fraxineus (T. Kowalski) Baral, Queloz \& Hosoya (früher Chalara fraxinea) verursacht wird. Die Krankheit wurde erstmals 1992 in Polen entdeckt und ist heute in ganz Europa weit verbreitet, wobei in vielen Ländern bis zu 80-90\% der Bäume befallen sind. Zu den Symptomen gehören erhebliche Blattverluste, Welke, Rindennekrosen an den Stämmen und Verfärbungen des Holzes. Es sind Eschen allen Alters (Altbäume, Jungpflanzen und Sämlinge) betroffen. Beobachtungen zeigen, dass sich das Eschentriebsterben mit bis zu 20-30 km/Jahr ausbreitet. Zusätzlich zu den Pilzsporen kann sich die Krankheit auch über kontaminiertes Pflanzenmaterial ausbreiten. Weitere Gefahren für die Gesundheit der Esche sind u.a. Eschenkrebs (Neonectria ditissima (Tul. \& C. Tul.) Samuels \& Rossman und Pseudomonas savastanoi (Janse) Gardan, et al.), Phyllactinia fraxini (DC.) Fuss und Armillaria gallica Marxm. \& Romagn [2, 4] (Abbildung 3b).

Eine potentiell große Bedrohung stellt der Asiatische Eschenprachtkäfer (Agrilus planipennis Fairmaire) dar, ein in Asien und Ostrussland beheimateter Käfer (Abbildung 3a). Während die adulten Tiere Eschenblätter fressen, ernähren sich die Larven vom Phloem und töten somit den Baum. Der Eschenprachtkäfer wurde 2007 in Westrussland und Schweden beobachtet, und es besteht die starke Befürchtung, dass er sich auf ganz Europa ausbreiten und wie in den USA verheerende Schäden anrichten könnte [2, 4]. 
(a)

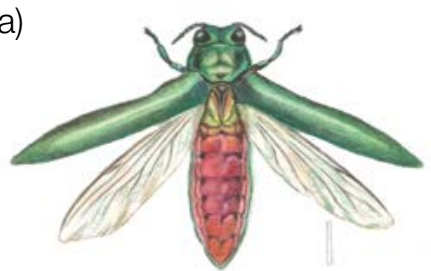

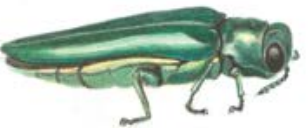
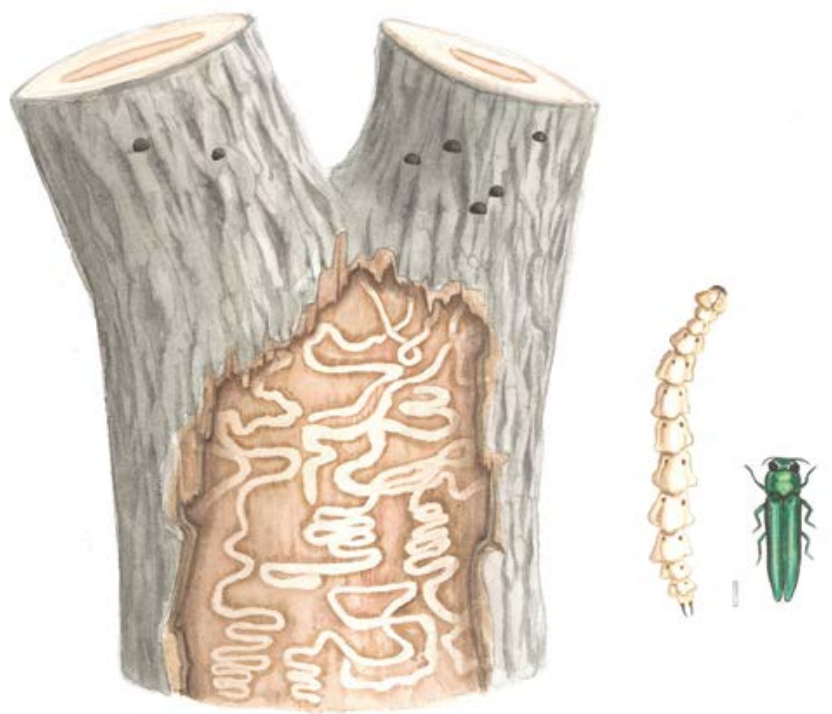

(b)

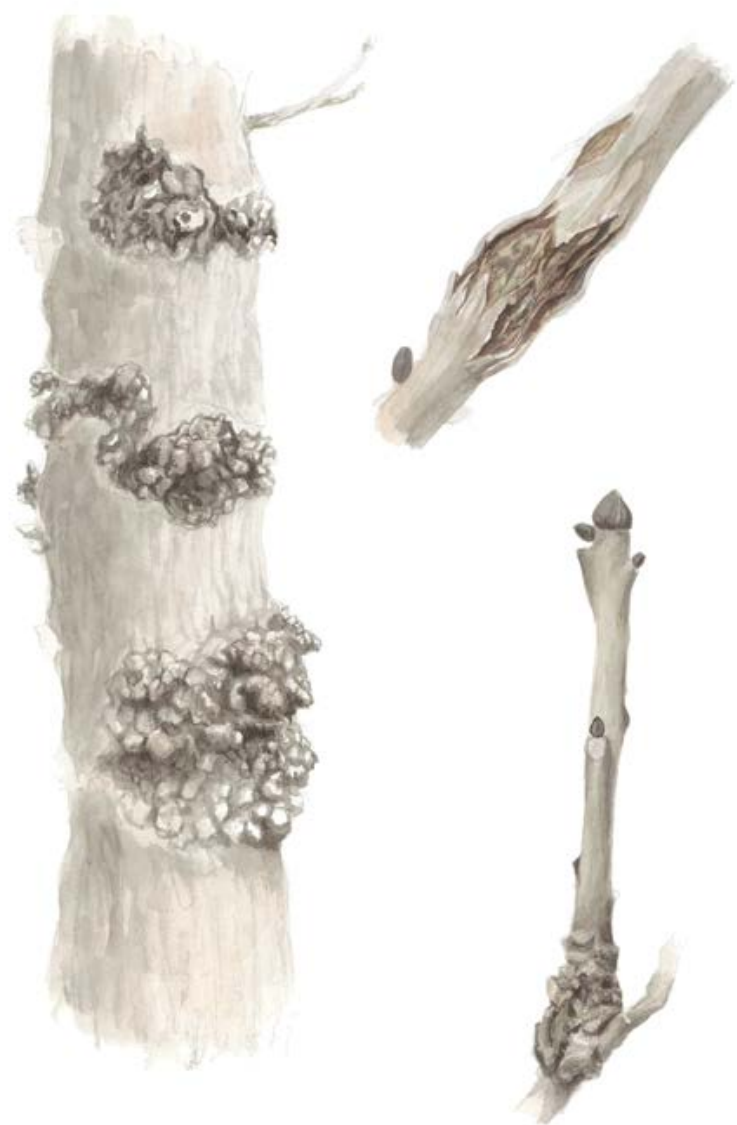

Abbildung 3: Der Asiatische Eschenprachtkäfer, eine neue Bedrohung für die Gemeine Esche (a), und der Eschenkrebs (b).

\section{EINRICHTUNG UND INSTANDHALTUNG VON MONITORINGFLÄCHEN}

EineforstgenetischeMonitoringflächeumfasst50fortpflanzungsfähigeAltbäumemiteinemBrusthöhendurchmesser $(B H D)$ von mehr als $15 \mathrm{~cm}$ und einem Mindestabstand von $30 \mathrm{~m}$ zwischen je zwei beliebigen Bäumen. Ein Baum gilt als fortpflanzungsfähig, wenn er blüht. Der BHD und die soziale Stellung eines Baumes können als Anhaltspunkte für die Identifizierung fortpflanzungsfähiger Bäume verwendet werden, wenn die Monitoringfläche außerhalb der Blütezeit angelegt wird. Dabei sollte auf das Fachwissen des zuständigen Försters zurückgegriffen werden. Bei der Neueinrichtung einer Monitoringfläche sollten alle Bäume beschriftet und ihre Koordinaten erfasst werden. Gleichzeitig können die jeweiligen BHD gemessen und Proben für die DNA-Extraktion gesammelt werden.

Da die Gemeine Esche meist in Mischbeständen vorkommt ${ }^{1}$, ist eine Pilotstudie erforderlich, um die Größe und Form der forstgenetischen Monitoringfläche so anzupassen, dass sie 50 fortpflanzungsfähige Altbäume enthält. Von diesen sollten je 25 funktionell weiblich bzw. männlich sein. Zwitterbäume sind oft funktionell weiblich, da sie beträchtliche Samenmengen produzieren. Da diese Zwitterbäume in ihrem Geschlecht variieren und im Mastjahr weiblicher oder männlicher werden können, kann sich der tatsächliche Anteil funktionell weiblicher und männlicher Bäume im Verlauf der Jahre ändern.

Erforderliche Ausrüstung:

- ein Gerät zur Entfernungsmessung (empfehlenswert ist ein Fernglas mit Entfernungsmesser)

- ein Kompass

- Farbe und Pinsel oder Farbspray zum Kennzeichnen der Bäume

1 Die Gemeine Esche kommt im Großteil ihres natürlichen Verbreitungsgebiets als nicht-bestandesbildende Baumart vor. An Standorten, an denen sie Reinbestände bildet, muss die FGM-Fläche gemäß den Richtlinien für bestandesbildende Arten wie die Rotbuche (Fagus sylvatica L.) eingerichtet werden. 
- eine Kluppe für BHD-Messungen und

- ein ausreichend präzises GPS-Gerät, welches das Speichern von Baumkoordinaten ermöglicht

\subsection{Einrichtung der Monitoringfläche}

\subsubsection{Auswahl der Monitoringfläche}

Um eine Monitoringfläche für F. excelsior anzulegen, sollten die ersten Aktivitäten idealerweise im Frühjahr während der Blütezeit durchgeführt werden. Zu diesem Zeitpunkt sollten alle Eschen im Bestand mit einem GPS-Gerät kartiert und ihr Geschlecht erfasst werden. Im Sommer, wenn die Bäume Früchte tragen, sollte bei den Zwitterbäumen zusätzlich das funktionelle Geschlecht festgestellt werden.

Nachdem das Geschlecht (und bei Zwitterbäumen zusätzlich das funktionelle Geschlecht) erfasst wurde, sollten die GPS-Standorte aller Bäume mit GIS-Software in einem Punkt-Layer dargestellt werden. Nach dem Zufallsprinzip sollten dann 50 dieser Punkte ausgewählt werden, die jeweils einen Mindestabstand von 30 m untereinander haben, wobei das Verhältnis von je 50\% funktionell männlichen und weiblichen Bäumen (einschließlich männlicher, weiblicher und zwittriger Bäume) eingehalten werden sollte. Um GPS-Messfehler zu berücksichtigen, wird empfohlen, nach Bäumen zu suchen, die mehr als $35 \mathrm{~m}$ voneinander entfernt sind (Anpassung des Mindestabstandes auf 35 m). Während der Einrichtung der Monitoringfläche müssen diese vorausgewählten Bäume vor Ort identifiziert und gekennzeichnet werden.

Falls es nicht möglich ist, zur Feststellung des Baumgeschlechts zwei Begehungen durchzuführen, sollte die Einrichtung der Monitoringfläche im Sommer erfolgen; wobei nach dem Zufallsprinzip je 25 funktionell männliche (ohne Früchte) und weibliche (mit Früchten) Altbäume ausgewählt werden müssen.

\subsubsection{Einrichtung der Monitoringfläche}

Mit Hilfe des GPS werden alle im Büro vorausgewählten Bäume vor Ort lokalisiert und gekennzeichnet. Der Mindestabstand von 30 m zwischen den Bäumen muss nochmals überprüft werden.
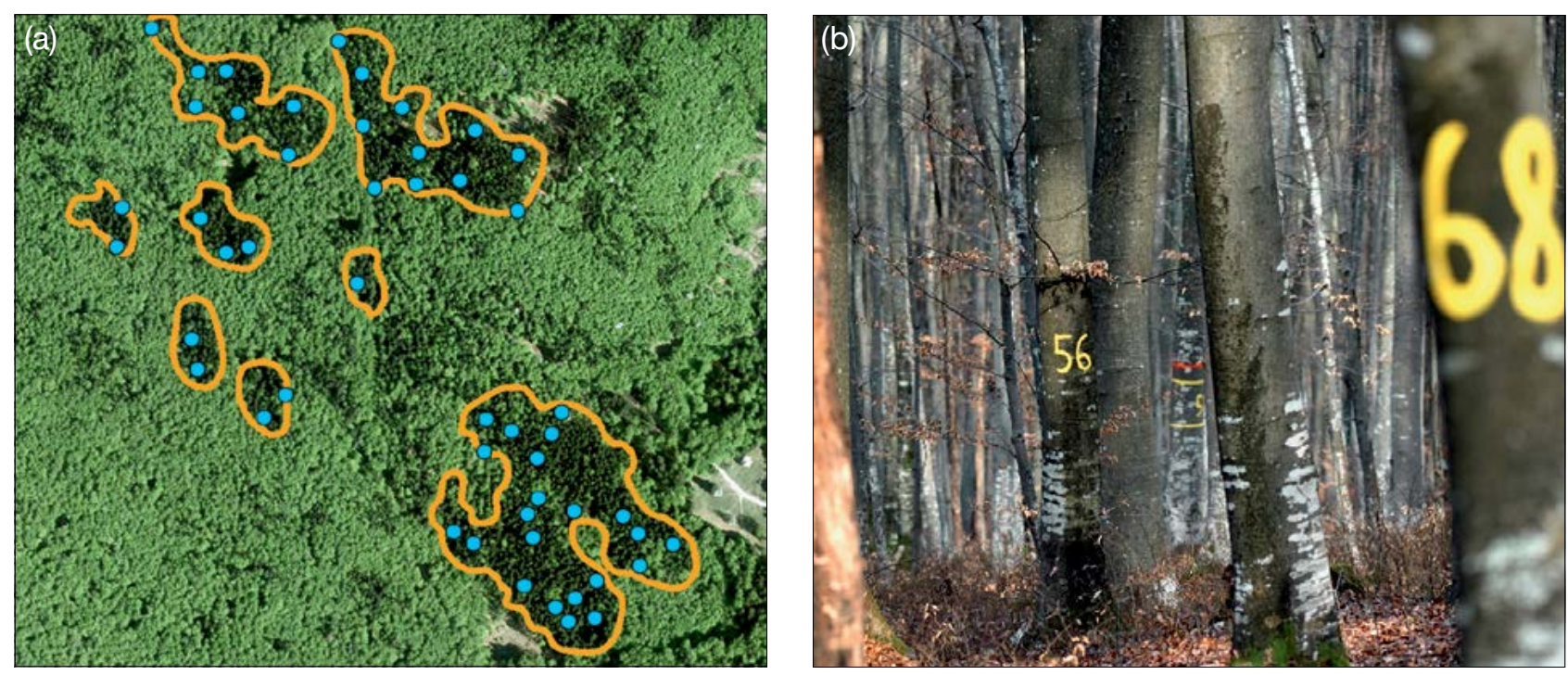

Abbildung 4: Grafische Darstellung der Standorte von zufällig ausgewählten Bäumen, die in mehreren Clustern wachsen (a); jeder für das genetische Monitoring ausgewählte Baum muss mit einer entsprechenden Nummer gekennzeichnet werden (das Bild zeigt die FGM-Fläche von Fagus sylvatica in Slowenien). Um die Sichtbarkeit der Beobachtungsbäume aus allen Richtungen zu verbessern, können ihre Stämme mit einem um den Stamm herum laufenden Streifen gekennzeichnet werden (b). 


\subsubsection{Kennzeichnung der Bäume}

Jeder ausgewählte Beobachtungsbaum muss mit einer entsprechenden Nummer (1-50) (Abbildung 4b) und idealerweise mit einem um den Stamm herum laufenden Streifen gekennzeichnet werden, um die Sichtbarkeit der Bäume aus allen Richtungen zu erhöhen.

\subsection{Einrichtung von Naturverjüngungs-Plots}

Die Einrichtung von Plots zur Erfassung der Naturverjüngung (NV) sollte während der Keimungsperiode zwei oder mehr Jahre nach einem starken oder extremen Fruktifikationsereignis erfolgen; das Intervall hängt dabei von der Dauer der Samenruhe in der entsprechenden Population ab.

Bereiche mit aufgelaufener Naturverjüngung aus dem letzten Mastjahr (sogenannte Verjüngungscluster) sollten vor Ort vermessen und ihre Position erfasst werden (GPS-Koordinaten, Nummer des Beobachtungsbaumes neben dem Verjüngungscluster). Von allen erfassten Verjüngungsclustern sollten nach dem Zufallsprinzip 20 für die Einrichtung von NV-Plots ausgewählt werden. Wenn 20 oder weniger natürliche Verjüngungscluster vorhanden sind, sollten alle verwendet werden.

Innerhalb jedes ausgewählten Verjüngungsclusters ist ein $1 \mathrm{~m}^{2}$ großer Plot einzurichten und mit Metallstäben zu markieren. Die Metallstäbe sollten an jeder Ecke der Teilfläche so tief wie möglich in den Boden getrieben werden, damit sie nicht von Tieren entfernt werden können. Die oberen Spitzen der Metallstäbe sollten farbig markiert werden, um ihre Sichtbarkeit zu verbessern.

\subsection{Instandhaltung der Monitoringfläche}

\subsubsection{Allgemeine Instandhaltung}

Die Kennzeichnung der Bäume und NV-Plots muss periodisch (alle 2 Jahre) überprüft und bei Bedarf erneuert werden.

\subsubsection{Ersatz von Bäumen}

Wenn ein ausgewählter Beobachtungsbaum stirbt oder im Zuge der forstlichen Bewirtschaftung gefällt wird, muss er ersetzt werden. Dabei sollte der dem abgestorbenen/gefälten Baum nächstgelegene geeignete Baum ausgewählt werden, wobei der Mindestabstand von $30 \mathrm{~m}$ zum nächsten Beobachtungsbaum erfüllt sein muss. Der Ersatzbaum wird mit der nächsten verfügbaren Zahl über 50 gekennzeichnet, d.h. 51, 52, 53, usw., um ihn eindeutig von den ursprünglich 50 ausgewählten Beobachtungsbäumen zu unterscheiden.

Wenn die Baumkronez.B. durch Wind-, Eis- oder Schneebruch geschädigt ist, der Baum aber weiterhin fruktifiziert, wird der Baum im Monitoringprogramm belassen. Ist der Schaden zu schwerwiegend und eine Fruktifikation nicht mehr zu erwarten, muss der Baum ersetzt werden. Bei Auftreten von Eschentriebsterben im Bestand werden die Bäume solange beobachtet, bis sie das Stadium 6 der Hintergrundinformation „Kronensterben“ erreicht haben. Danach werden sie ersetzt.

\section{ERFASSUNG VON VERIFIKATOREN UND HINTERGRUNDINFORMATIONEN}

Auf der Monitoringfläche werden periodisch Verifikatoren und Hintergrundinformationen erfasst. Verifikatoren werden genutzt, um die genetischen Eigenschaften der Population und ihre Anpassung an Umweltveränderungen und/oder Bewirtschaftung zu verfolgen, während Hintergrundinformationen aufgezeichnet werden, um die Interpretation der Verifikatoren zu unterstützen. Verifikatoren können auf drei verschiedenen Intensitätsniveaus erfasst werden: Basis, Standard und Intensiv. 
Höherrangigere Niveaus (Standard, Intensiv) müssen stets auch die Erfassung der Verifikatoren auf allen niedrigeren Niveaus (Basis, Standard) einschließen. Dies ist für die Aufzeichnung von Hintergrundinformationen nicht erforderlich.

Tabelle 2: Liste der Verifikatoren und Hintergrundinformationen, die während der Außenaufnahmen auf den EschenMonitoringflächen zu erfassen sind; jeweils mit Kurzbeschreibung und Beobachtungshäufigkeit.

\begin{tabular}{|c|c|c|c|c|}
\hline & Bezeichnung & Basisniveau & Standardniveau & Intensivniveau \\
\hline \multirow{5}{*}{ 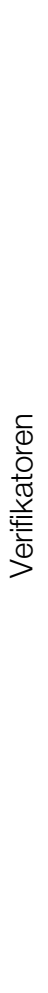 } & $\begin{array}{l}\text { Mortalität / } \\
\text { Überlebensrate }\end{array}$ & $\begin{array}{l}\text { Altbäume: Zählung der } \\
\text { verbleibenden markierten Bäume } \\
\text { alle } 10 \text { Jahre und nach jedem } \\
\text { extremen Witterungsereignis/ } \\
\text { jeder Störung }\end{array}$ & wie Basisniveau & wie Basisniveau \\
\hline & & Naturverjüngung: / & $\begin{array}{l}\text { Zählung der verbleibenden } \\
\text { Sämlinge auf den NV-Plots, } \\
\text { zweimal pro Jahrzehnt }\end{array}$ & wie Standardniveau \\
\hline & Blüte & $\begin{array}{c}\text { bestandesweise Schätzung; } \\
\text { jährlich }\end{array}$ & $\begin{array}{l}\text { Erfassung auf Einzelbaumebene, } \\
\text { während zwei bedeutenden } \\
\text { Blühereignissen pro Jahrzehnt, } \\
\text { idealerweise in gleichen } \\
\text { Abständen * }\end{array}$ & $\begin{array}{l}\text { Erfassung auf Einzelbaumebene, } \\
\text { während zwei bedeutenden } \\
\text { Blühereignissen pro Jahrzehnt, } \\
\text { idealerweise in gleichen } \\
\text { Abständen * }\end{array}$ \\
\hline & Fruktifikation & $\begin{array}{c}\text { bestandesweise Schätzung; } \\
\text { jährlich }\end{array}$ & $\begin{array}{l}\text { Erfassung auf Einzelbaum- } \\
\text { ebene im selben Jahr, in dem } \\
\text { die Erfassung der Blüte auf } \\
\text { Basisniveau erfolgt (unabhängig } \\
\text { von der Fruchtbildungsintensität) } \\
\text { * }\end{array}$ & $\begin{array}{c}\text { Zählung der Früchte in den } \\
\text { gleichen Jahren, in denen } \\
\text { die Bewertung der Blüte } \\
\text { auf Intensivniveau erfolgt, } \\
\text { unabhängig von der Frucht- } \\
\text { bildungsintensität* Bei jedem } \\
\text { auf Intensivniveau erfassten } \\
\text { Fruktifikationsereignis wird auch } \\
\text { Saatgut für Laboranalysen } \\
\text { gesammelt }\end{array}$ \\
\hline & $\begin{array}{l}\text { Abundanz der } \\
\text { Naturverjüngung }\end{array}$ & $\begin{array}{l}\text { bestandesweise Schätzung; } \\
\text { jährlich }\end{array}$ & $\begin{array}{l}\text { Zählung der Sämlinge im 2. und } \\
\text { 7. Jahr nach jedem erfassten } \\
\text { Fruktifikationsereignis }{ }^{\star \star}\end{array}$ & $\begin{array}{l}\text { Zählung der Sämlinge im 2., 7., } \\
\text { 12. und 17. Jahr nach jedem } \\
\text { erfassten Fruktifikationsereignis }\end{array}$ \\
\hline \multirow{7}{*}{ 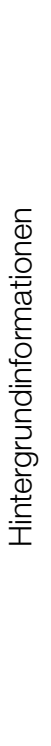 } & $\begin{array}{l}\text { Durchmesser- } \\
\text { klassen-vertei- } \\
\text { lung }\end{array}$ & / & Messung alle 10 Jahre & wie Standardniveau \\
\hline & $\begin{array}{l}\text { Höhenklassen- } \\
\text { verteilung }\end{array}$ & / & Messung alle 10 Jahre & wie Standardniveau \\
\hline & $\begin{array}{l}\text { Geschlechter- } \\
\text { verhältnis }\end{array}$ & / & $\begin{array}{l}\text { Erfassung auf Einzelbaumebene; } \\
\text { zeitgleich zum Verifikator „Blüte“ }\end{array}$ & $\begin{array}{l}\text { Erfassung des Anteils der } \\
\text { verschiedenen Blütentypen auf } \\
\text { Einzelbaumebene; zeitgleich } \\
\text { zum Verifikator „Blüte“ }\end{array}$ \\
\hline & Kronensterben & $\begin{array}{c}\text { Schätzung auf Einzelbaumebe- } \\
\text { ne; jährlich }\end{array}$ & wie Basisniveau & wie Basisniveau \\
\hline & Austrieb & / & $\begin{array}{l}\text { Erfassung auf Einzelbaumebene; } \\
\text { alle } 5 \text { Jahre }\end{array}$ & $\begin{array}{l}\text { Erfassung auf Einzelbaumebene; } \\
\text { jährlich }\end{array}$ \\
\hline & Seneszenz & / & $\begin{array}{l}\text { Erfassung auf Einzelbaumebene; } \\
\text { alle } 5 \text { Jahre }\end{array}$ & $\begin{array}{l}\text { Erfassung auf Einzelbaumebene; } \\
\text { jährlich }\end{array}$ \\
\hline & $\begin{array}{l}\text { Blühsynchroni- } \\
\text { sation }\end{array}$ & / & / & $\begin{array}{l}\text { Erfassung auf Einzelbaum- } \\
\text { ebene; während jedes erfassten } \\
\text { bedeutenden Blühereignisses }\end{array}$ \\
\hline
\end{tabular}

Idealerweise sollte mindestens ein größeres Fruktifikationsereignis pro Jahrzehnt bewertet werden. Ein bedeutendes Blühereignis führt jedoch nicht unbedingt zu einem bedeutenden Fruktifikationsereignis. Wenn auf das bewertete Blühereignis kein wesentliches Fruktifikationsereignis folgt, muss die Bewertung sowohl der Blüte als auch der Fruchtbildung beim nächsten bedeutenden Blühereignis wiederholt werden, unabhängig von der Zeit, die zwischen aufeinanderfolgenden bedeutenden Blühereignissen liegt. Erhebungen auf Basisniveau werden zur Identifizierung bedeutender Blüh- und Fruktifikationsereignisse verwendet.

" Die Samenruhe der Gemeinen Esche dauert in der Regel zwei Winter. Deshalb wird die Abundanz der Naturverjüngung erst zwei Jahre nach einem bedeutenden Fruktifikationsereignis erfasst. Sollte die Samenruhe in einem beobachteten Bestand länger oder kürzer dauern, müssen die Monitoringzeitpunkte entsprechend angepasst werden. 


\subsection{Verfahren zur Erfassung der Verifikatoren}

\subsubsection{Mortalität / Überlebensrate}

Die Mortalität beschreibt die Sterblichkeit von Altbäumen und Naturverjüngung. Ihr Pendant - die Überlebensratesteht für Bäume, die seit der letzten Datenerhebung noch am Leben sind. Die Überlebensrate wird berechnet als 1 - Mortalität.

\subsubsection{Altbäume: Basis-, Standard- und Intensivniveau}

Verifikator für die Mortalität von Altbäumen. Die Mortalität wird geschätzt, indem die verbleibenden lebenden Beobachtungsbäume alle 10 Jahre sowie nach jedem extremen Witterungsereignis bzw. jeder Störung gezählt werden. Die Mortalität ist die Differenz zwischen der ursprünglichen Anzahl markierter Beobachtungsbäume und den davon verbleibenden lebenden Bäumen der ursprünglichen 50 Beobachtungsbäume.

\subsubsection{Naturverjüngung: Standard- und Intensivniveau}

Die Mortalität der Naturverjüngung wird auf Grundlage des Verifikators „Abundanz der Naturverjüngung“ berechnet. Die Mortalität ist der Unterschied zwischen der anfänglichen Anzahl der Jungpflanzen und den Pflanzen, die zum Zeitpunkt der nächsten Zählung noch am Leben sind. Für jede Bewertungsrunde werden die Jungpflanzen zuerst im Jahr der Keimung und dann wieder nach 5 Jahren auf Standardniveau gezählt, während auf dem Intensivniveau die Zählung zusätzlich nach 10 und 15 Jahren durchgeführt wird. Die Bewertung der „Abundanz der Naturverjüngung“ erfolgt zweimal pro Jahrzehnt, idealerweise etwa alle fünf Jahre.

\subsubsection{Blüte}

Dieser Verifikator beschreibt das Auftreten der Blüte (Anteil der Bäume) und die Blühintensität. Er kann in Mitteleuropa von März bis April zeitgleich mit der Hintergrundinformation 7.2.3 „Geschlechterverhältnis“ erfasst werden. Nach warmen Wintern erfolgt die Blüte früher.

\subsubsection{Basisniveau}

Der Verifikator wird jährlich auf Bestandesebene erfasst. Die Erfassung erfolgt zum Zeitpunkt der Hauptblüte. Die Schätzung des durchschnittlichen Zustands erfolgt nach einer Begehung der gesamten Monitoringfläche. Es werden zwei Werte erfasst: einer für die Blühintensität und einer für den Anteil der blühenden Bäume im Bestand.

\begin{tabular}{llr}
\hline 1 & Keine Blüte: Keine oder nur gelegentlich auftretende Blüten & $0-10$ \\
\hline 2 & Schwache Blüte: Einige Blüten erscheinen an den Bäumen & $>10-30$ \\
\hline 3 & Mäßige Blüte: Mäßig viele Blüten an den Bäumen & $>30-60$ \\
\hline 4 & Starke Blüte: Reichlich Blüten an den Bäumen & $>60-90$ \\
\hline 5 & Extreme Blüte: Enorme Anzahl von Blüten an den Bäumen & $>90$ \\
\hline
\end{tabular}

\begin{tabular}{lr} 
Code & Anteil der Bäume im Bestand mit dem entsprechenden Stadium der Blühintensität (\%) \\
\hline 1 & $0-10$ \\
\hline 2 & $>10-30$ \\
\hline 3 & $>30-60$ \\
\hline 4 & $>60-90$ \\
\hline 5 & $>90$ \\
\hline
\end{tabular}




\subsubsection{Standardniveau}

Der Verifikator wird während zweier bedeutender Blühereignisse pro Jahrzehnt aufgezeichnet, idealerweise mit einem ähnlichen zeitlichen Abstand. Er wird für alle 50 Beobachtungsbäume auf Einzelbaumebene erfasst. Ein bedeutendes Blühereignis liegt vor, wenn die Blühintensität auf Basisniveau als stark oder extrem eingeschätzt wird (Code 4 oder 5) und der Anteil der Bäume mit der angegebenen Blühintensität über 60\% liegt (Code 4 oder 5). Die Erfassung erfolgt zum Zeitpunkt der Hauptblüte. Für jeden Beobachtungsbaum wird ein Wert erfasst.

\begin{tabular}{clr}
\multicolumn{2}{l}{ Code Blühintensität auf Bestandesebene } & Mittlerer Anteil der Kronen in Blüte (\%) \\
\hline 1 & Keine Blüte: Keine oder nur gelegentlich auftretende Blüten & $0-10$ \\
\hline 2 & Schwache Blüte: Einige Blüten erscheinen an den Bäumen & $>10-30$ \\
\hline 3 & Mäßige Blüte: Mäßig viele Blüten an den Bäumen & $>30-60$ \\
\hline 4 & Starke Blüte: Reichlich Blüten an den Bäumen & $>60-90$ \\
\hline 5 & Extreme Blüte: Enorme Anzahl von Blüten an den Bäumen & $>90$ \\
\hline
\end{tabular}

\subsubsection{Intensivniveau}

Der Verifikator wird während zweier bedeutender Blühereignisse pro Jahrzehnt aufgezeichnet, idealerweise mit einem ähnlichen zeitlichen Abstand. Er wird für alle 50 Beobachtungsbäume auf Einzelbaumebene erfasst. Ein bedeutendes Blühereignis liegt vor, wenn die Blühintensität auf Basisniveau als stark oder extrem eingeschätzt wird (Code 4 oder 5) und der Anteil der Bäume mit der angegebenen Blühintensität über 60\% liegt (Code 4 oder 5). Im Durchschnitt sind zwei Begehungen der Monitoringfläche erforderlich: der erste früh genug, um das Frühstadium der Blüte zu beobachten, der zweite zum Zeitpunkt der Hauptblüte.

Für jeden Baum werden drei Werte angegeben: weibliches Blühstadium, männliches Blühstadium und der blühende Kronenanteil. Letzterer bezieht sich auf die Gesamtmenge der Blüten (männlich + weiblich + zwittrig) am Baum (Abbildung 5).

Hintergrundinformationen zur Blühsynchronisation können anhand der für diesen Verifikator erfassten Werte zum Blühstadium sowie aus der Hintergrundinformation 7.2.3 „Geschlechterverhältnis“ abgeschätzt werden.

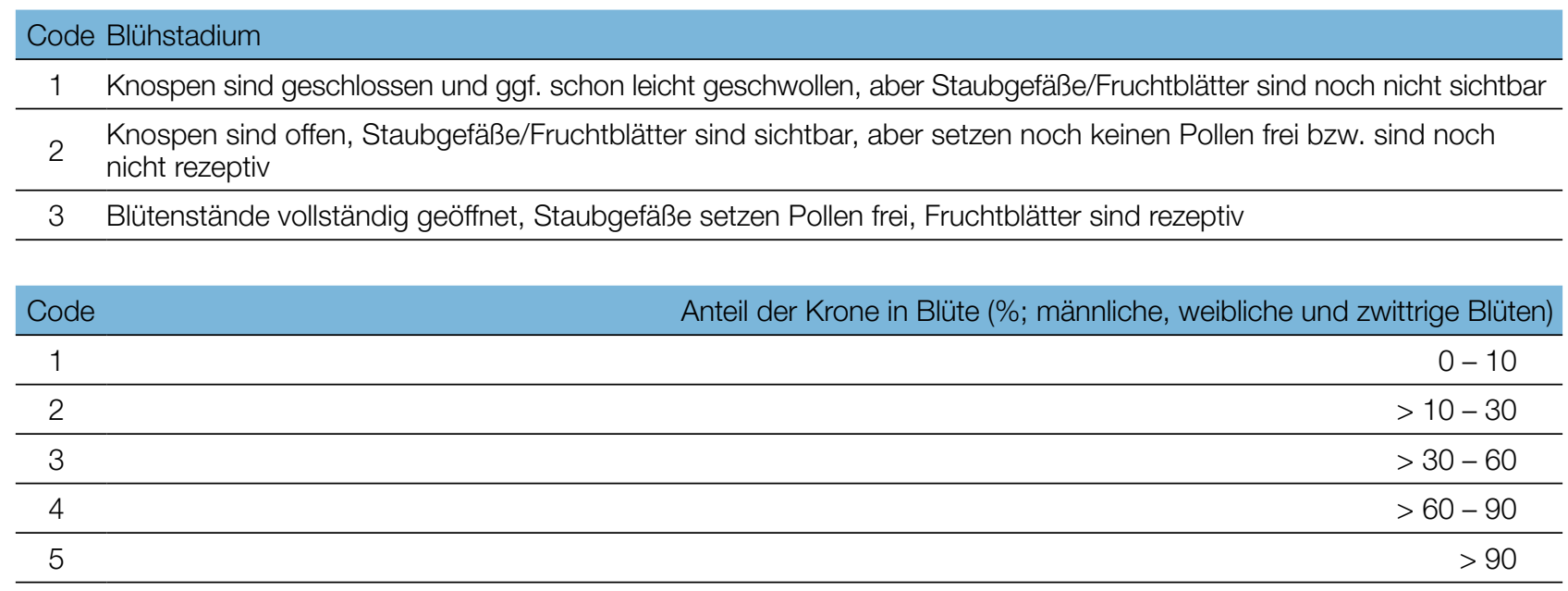




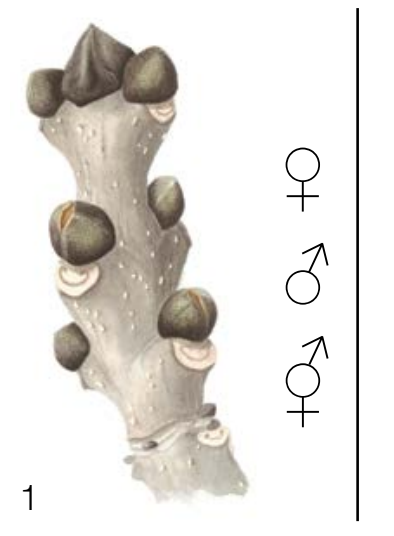

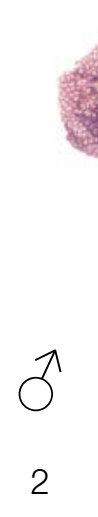

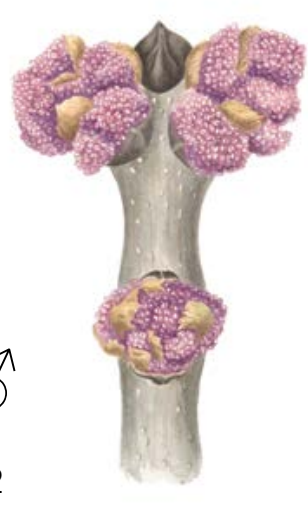

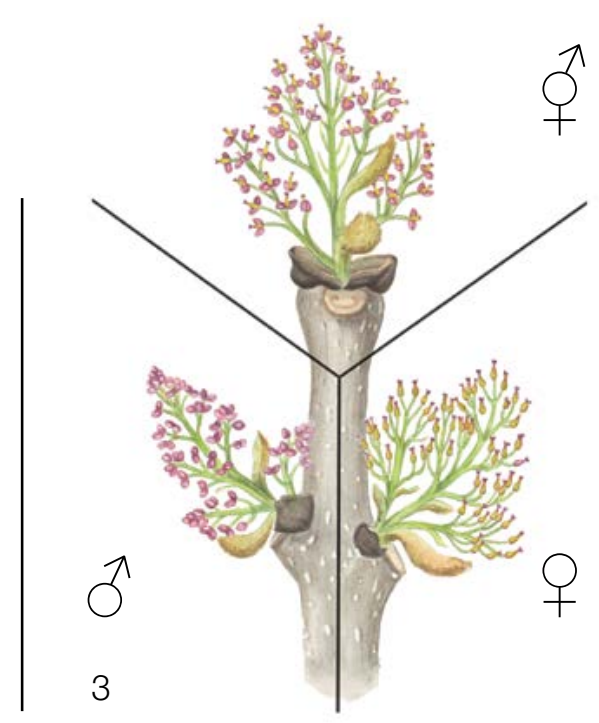

Abbildung 5: Illustration zur Beschreibung der Blühstadien für den Verifikator „Blüte" auf Intensivniveau. Beim Stadium 3 dient der aus der Endknospe entstehende Blütenstand nur zur Veranschaulichung; in Wirklichkeit entwickeln sich aus der Endknospe die Blätter.

\subsubsection{Fruktifikation}

Dieser Verifikator beschreibt das Auftreten und die Häufigkeit der Fruchtbildung. Die Daten für diesen Verifikator sollten während der Fruktifikationszeit erhoben werden, d.h. in Mitteleuropa von August bis Oktober.

\subsubsection{Basisniveau}

Der Verifikator wird jährlich auf Bestandesebene erfasst. Die Schätzung des durchschnittlichen Zustands erfolgt nach einer Begehung der gesamten Monitoringfläche. Es werden zwei Werte erfasst: einer für die Intensität der Fruktifikation und einer für den Anteil fruchttragender Bäume im Bestand.

\begin{tabular}{rlr}
\hline 1 & $\begin{array}{l}\text { Keine Fruchtbildung: Keine oder nur gelegentlich auftretende Früchte } \\
\text { an den Bäumen }\end{array}$ & $0-10$ \\
\hline 2 & Schwache Fruchtbildung: Einige Früchte an den Bäumen & $>10-30$ \\
\hline 3 & Mäßige Fruchtbildung: Mäßig viele Früchte an den Bäumen & $>30-60$ \\
\hline 4 & Starke Fruchtbildung: Reichlich Früchte an den Bäumen & $>60-90$ \\
\hline 5 & Extreme Fruchtbildung: Enorme Anzahl von Früchten an den Bäumen & $>90$ \\
\hline
\end{tabular}

\begin{tabular}{lr} 
Code & Anteil der Bäume im Bestand mit dem entsprechenden Stadium der Fruktifikationsintensität (\%) \\
\hline 1 & $0-10$ \\
\hline 2 & $>10-30$ \\
\hline 3 & $>30-60$ \\
\hline 4 & $>60-90$ \\
\hline 5 & $>90$ \\
\hline
\end{tabular}




\subsubsection{Standardniveau}

Die Erfassung des Verifikators erfolgt in denselben Jahren wie die Bewertung der Blüte auf Standardniveau (unabhängig von der Fruktifikationsintensität). Sie wird für alle 50 Beobachtungsbäume auf Einzelbaumebene durchgeführt - und zwar bevor die Früchte beginnen zu fallen. Für jeden Beobachtungsbaum wird ein Wert erfasst.

Im Idealfall sollte pro Jahrzehnt ein auf ein bedeutendes Blühereignis folgendes größeres Fruktifikationsereignis erfasst werden. Ein bedeutendes Blühereignis führt jedoch nicht unbedingt zu einem bedeutenden Fruktifikationsereignis. Wenn auf das bewertete Blühereignis kein wesentliches Fruktifikationsereignis folgt, muss die Bewertung sowohl der Blüte als auch der Fruchtbildung beim nächsten bedeutenden Blühereignis wiederholt werden, unabhängig von der Zeit, die zwischen aufeinanderfolgenden bedeutenden Blühereignissen liegt. Erhebungen auf Basisniveau werden genutzt, um bedeutende Fruktifikationsereignisse zu identifizieren. Ein bedeutendes Fruktifikationsereignis liegt vor, wenn die Fruktifikationsintensität auf Basisniveau als stark oder extrem eingeschätzt wird (Code 4 oder 5) und der Anteil der Bäume mit der angegebenen Fruktifikationsintensität über 60\% liegt (Code 4 oder 5).

\begin{tabular}{llr}
\multicolumn{2}{l}{ Code Intensität der Fruktifikation auf Bestandesebene } & Mittlerer Anteil der Krone mit Fruchtbehang (\%) \\
\hline 1 & $\begin{array}{l}\text { Keine Fruchtbildung: Keine oder nur gelegentlich auftretende Früchte } \\
\text { an den Bäumen }\end{array}$ & $0-10$ \\
\hline 2 & Schwache Fruchtbildung: Einige Früchte an den Bäumen & $>10-30$ \\
\hline 3 & Mäßige Fruchtbildung: Mäßig viele Früchte an den Bäumen & $>30-60$ \\
\hline 4 & Starke Fruchtbildung: Reichlich Früchte an den Bäumen & $>60-90$ \\
\hline 5 & Extreme Fruchtbildung: Enorme Anzahl von Früchten an den Bäumen & $>90$ \\
\hline
\end{tabular}

Die Aufzeichnung dieses Verifikators liefert indirekt auch Informationen darüber, ob ein Baum funktionell weiblich oder männlich ist, und ermöglicht bei Zwitterbäumen die Beobachtung von Schwankungen des funktionellen Geschlechts im Laufe der Zeit.

\subsubsection{Intensivniveau}

Die Erfassung des Verifikators erfolgt für alle 50 Beobachtungsbäume auf Einzelbaumebene in denselben Jahren wie die Bewertung der Blüte auf Intensivniveau (unabhängig von der Fruktifikationsintensität). Sie wird durchgeführt, bevor die Früchte beginnen zu fallen. Für jeden Beobachtungsbaum wird ein Wert erfasst. Zeitgleich wird Saatgut für die Saatgut- und Genanalysen gesammelt (für die Verifikatoren und Hintergrundinformationen auf Intensivniveau).

Im Idealfall sollte pro Jahrzehnt ein auf ein bedeutendes Blühereignis folgendes größeres Fruktifikationsereignis erfasst werden. Ein bedeutendes Blühereignis führt jedoch nicht unbedingt zu einem bedeutenden Fruktifikationsereignis. Wenn auf das bewertete Blühereignis kein wesentliches Fruktifikationsereignis folgt, muss die Bewertung sowohl der Blüte als auch der Fruchtbildung beim nächsten bedeutenden Blühereignis wiederholt werden, unabhängig von der Zeit, die zwischen aufeinanderfolgenden bedeutenden Blühereignissen liegt. Erhebungen auf Basisniveau werden genutzt, um bedeutende Fruktifikationsereignisse zu identifizieren. Ein bedeutendes Fruktifikationsereignis liegt vor, wenn die Fruktifikationsintensität auf Basisniveau als stark oder extrem eingeschätzt wird (Code 4 oder 5) und der Anteil der Bäume mit der angegebenen Fruktifikationsintensität über 60\% liegt (Code 4 oder 5).

Der Verifikator wird durch das Zählen von Früchten unter Nutzung eines Fernglases erfasst (als Durchschnitt von drei Zählrunden). Jede Zählrunde besteht aus der Anzahl der Früchte, die der Beobachter in 30 Sekunden zählt. Bei allen Bäumen sollte das gleiche Kronendrittel untersucht werden. Sobald ein Kronendrittel für die Beobachtung ausgewählt wurde, sollte dieses für jede weitere Erhebung dieses Verifikators ausgewählt werden. Für die Zählung wird das obere Kronendrittel dem unteren und mittleren Drittel vorgezogen. 
Es werden zwei Werte erfasst: die Anzahl der Früchte und das untersuchte Kronendrittel.

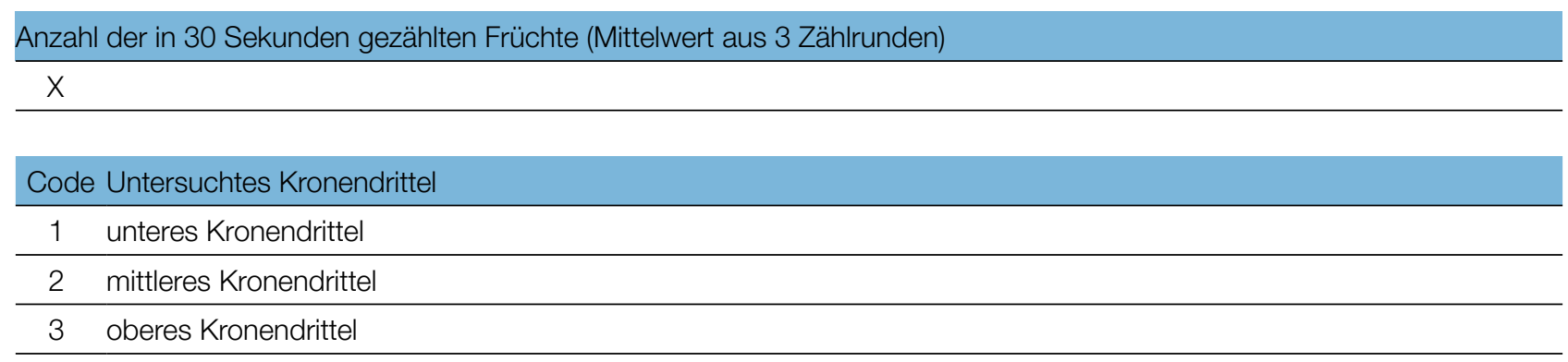

\subsubsection{Abundanz der Naturverjüngung}

Dieser Verifikator beschreibt das Vorhandensein und die Häufigkeit von Naturverjüngung auf der Monitoringfläche.

\subsubsection{Basisniveau}

Der Verifikator wird jährlich im Herbst auf Bestandesebene erfasst. Für die Schätzung der Situation auf der gesamten Monitoringfläche werden Expertenmeinungen herangezogen. Es sollten zwei Werte erfasst werden: einer für neue aufgelaufene Naturverjüngung (diesjährige Keimlinge) und einer für etablierte Naturverjüngung (ein- und mehrjährige Jungpflanzen).

Code Beschreibung: neue aufgelaufene Naturverjüngung (diesjährige Keimlinge)
\begin{tabular}{cl} 
1a & Auf der Monitoringfläche gibt es keine oder nur sehr wenig neue Naturverjüngung \\
\hline 2a & Auf der Monitoringfläche ist in ausreichender Anzahl neue Naturverjüngung vorhanden
\end{tabular}

\begin{tabular}{|c|c|}
\hline Code & Beschreibung: etablierte Naturverjüngung (Sämlinge) \\
\hline $1 b$ & Auf der Monitoringfläche gibt es keine oder nur sehr wenig etablierte Naturverjüngung \\
\hline $2 b$ & Auf der Monitoringfläche ist in ausreichender Anzahl etablierte Naturverjüngung vorhanden \\
\hline
\end{tabular}

\subsubsection{Standardniveau}

Der Verifikator wird durch Zählung der Sämlinge im 2. und 7. Herbst nach jedem bewerteten Fruktifikationsereignis erfasst (das Jahr des Fruktifikationsereignisses wird als Jahr 0 betrachtet), da die Eschensamen in der Regel zwei Jahre im Boden ruhen.

Zählung der Naturverjüngung:

Nach der Einrichtung der NV-Plots werden alle Eschensämlinge in den NV-Plots gezählt. Ältere Eschenjungpflanzen, die in den NV-Plots vorhanden sind, dürfen nicht mitgezählt werden. Bei der nächsten Zählung sind nur die Eschenjungpflanzen im entsprechenden Alter zu zählen; d.h. im 8. Jahr alle 5 Jahre alten Eschen.

\section{Anzahl der Jungpflanzen auf einem NV-Plot}

$$
\mathrm{X}
$$

Die Mortalität/Überlebensrate der Naturverjüngung wird anhand der für diesen Verifikator erfassten Werte berechnet.

Sollte die Samenruhe in einem beobachteten Bestand länger dauern, müssen die Monitoringzeitpunkte entsprechend angepasst werden.

Zur Einrichtung von NV-Plots siehe Kapitel 6.2 Einrichtung von Naturverjüngungs-Plots. 


\subsubsection{Intensivniveau}

Der Verifikator wird durch das Zählen der Sämlinge im 2., 7., 12. und 17. Herbst nach jedem bewerteten Fruktifikationsereignis auf allen 20 NV-Plots erfasst (das Jahr des Fruktifikationsereignisses wird als Jahr 0 betrachtet), da die Eschensamen in der Regel zwei Jahre im Boden ruhen.

Sollte die Samenruhe in einem beobachteten Bestand länger dauern, müssen die Monitoringzeitpunkte entsprechend angepasst werden.

Tabelle 3: Zeitstrahl zur Erfassung der Abundanz der Naturverjüngung (NV). In diesem Beispiel findet das erste Fruktifikationsereignis im 2. Jahr des Beobachtungsjahrzehnts statt; und angesichts der zwei Winter andauernden Samenruhe von Esche werden im 4. Jahr des Jahrzehnts 20 NV-Plots angelegt. Die nächste Einschätzung der Fruktifikation erfolgt im 8. Jahr des Jahrzehnts. Angesichts der Samenruhe von Esche werden im 10. Jahr der Dekade 20 neue NV-Plots angelegt. Nach jedem bewerteten Fruktifikationsereignis werden 20 neue NV-Plots etabliert. Die Erfassung der NV-Abundanz auf jedem Set von 20 NV-Plots erfolgt alle fünf Jahre. Die zur jeweils erfassten NV gehörigen Fruktifikationsereignisse und der Verlauf der Monitoringaktivitäten sind in derselben Farbe schattiert. Nach der letzten Runde der NV-Zählung wird die Erfassung der NV-Abundanz auf dem entsprechenden Set von NV-Plots eingestellt und die jeweiligen NV-Plots werden aufgelöst. S - Standardniveau; I - Intensivniveau.

\begin{tabular}{|c|c|c|c|c|c|c|c|c|c|c|c|c|c|c|c|c|c|c|c|}
\hline Monitoringjahr & 1 & 2 & 3 & 4 & 5 & 6 & 7 & 8 & 9 & 10 & 11 & 1213 & 14 & 1516 & 17 & 1819 & 2021 & 2223 & 2425 \\
\hline Fruktifikationsereignis & & $\bullet$ & & & $\bullet$ & $\bullet$ & & $\bullet$ & & $\bullet$ & & - & $\bullet$ & & - & - & $\bullet$ & $\bullet$ & $\bullet$ \\
\hline $\begin{array}{l}\text { Erfassung von NV aus dem } \\
\text { ersten bewerteten Fruktifika- } \\
\text { tionsereignis [Jahre] }\end{array}$ & & 0 & 1 & 2 & 3 & 4 & 5 & 6 & 7 & 8 & 9 & 1011 & 12 & 1314 & 15 & 1617 & 1819 & 2021 & 2223 \\
\hline Einrichtung von NV-Plots & & & & $\mathrm{SI}$ & & & & & & & & & & & & & & & \\
\hline Zählung der NV & & & & $\mathrm{SI}$ & & & & & SI & & & & I & & & । & & & \\
\hline $\begin{array}{l}\text { Erfassung von NV aus dem } \\
\text { zweiten bewerteten Frukti- } \\
\text { fikationsereignis [Jahre] }\end{array}$ & & & & & & & & 0 & 1 & 2 & 3 & 45 & 6 & 78 & 91 & 1011 & 1213 & 1415 & 1617 \\
\hline Einrichtung von NV-Plots & & & & & & & & & & SI & & & & & & & & & \\
\hline Zählung der NV & & & & & & & & & & SI & & & & SI & & & I & & I \\
\hline
\end{tabular}

Die Mortalität/Überlebensrate der Naturverjüngung wird anhand der für diesen Verifikator erfassten Werte berechnet.

Zur Einrichtung von NV-Plots siehe Kapitel 6.2 Einrichtung von Naturverjüngungs-Plots; zur Zählung der NV siehe Kapitel 7.1.4.2 Standardniveau.

\subsection{Verfahren zur Erfassung von Hintergrundinformationen}

\subsubsection{Durchmesserklassenverteilung}

\subsubsection{Standard- und Intensivniveau}

Der BHD wird alle 10 Jahre für alle 50 Beobachtungsbäume auf Einzelbaumebene erfasst. Der BHD ist der Stammdurchmesser in 1,30 m Höhe, d.h. ungefähr auf Brusthöhe eines Erwachsenen. Hat der Baum mehr als einen Stamm, messen Sie bitte alle Stämme und erfassen Sie den Durchschnitt (versuchen Sie jedoch, Bäume mit vielen kleinen Stämmen zu vermeiden). Notieren Sie in den Anmerkungen, dass der Baum mehrstämmig ist, und geben Sie die Anzahl der gemessenen Stämme an. Ist der Baum geneigt, messen Sie den BHD senkrecht zum Baumstamm. Der BHD kann auf zwei Arten gemessen werden:

1) mit einer Kluppe; in diesem Fall messen Sie senkrecht zueinander zwei Durchmesser und berechnen den Mittelwert 
2) Messen Sie den Umfang des Baumes und berechnen Sie daraus den Durchmesser (d.h. dividieren Sie durch $\pi ; \sim 3,14)$

Der BHD wird in cm angegeben. Für nachfolgende Messungen ist stets dieselbe Methode anzuwenden.

\subsubsection{Höhenklassenverteilung}

\subsubsection{Standard- und Intensivniveau}

Die Baumhöhe wird alle 10 Jahre für alle 50 Beobachtungsbäume auf Einzelbaumebene erfasst. Die Höhe wird vom Boden bis zum höchsten Punkt der Krone gemessen, idealerweise mit einem Klinometer oder Hypsometer (z.B. Vertex). Die Höhe wird in Metern auf eine Dezimalstelle angegeben. Ist die Krone beschädigt, muss dies in den Anmerkungen zusammen mit dem mutmaßlichen Grund für den Schaden notiert werden.

\subsubsection{Geschlechterverhältnis}

Diese Hintergrundinformation beschreibt das Geschlecht der einzelnen Eschen. Das Geschlecht kann zeitgleich mit dem Verifikator 7.1 .3 „Blüte“ während der Blütezeit erfasst werden, d. h. in Mitteleuropa von März bis April.

\subsubsection{Standardniveau}

Auf Standardniveau wird diese Hintergrundinformation auf Einzelbaumebene bei allen 50 Beobachtungsbäumen zeitgleich mit dem Verifikator „Blüte“ erfasst. Die männlichen, weiblichen und zwittrigen Blütenstände sind in Abbildung 6 dargestellt.

\begin{tabular}{lll} 
Code & Geschlecht & Beschreibung \\
\hline 1 & Männlich & Mehr als die Hälfte der Blütenstände am Baum sind männlich. \\
\hline 2 & Weiblich & Mehr als die Hälfte der Blütenstände am Baum sind weiblich. \\
\hline 3 & Zwittrig & Mehr als die Hälfte der Blütenstände am Baum sind zwittrig. \\
\hline
\end{tabular}

\subsubsection{Intensivniveau}

Auf Intensivniveau wird diese Hintergrundinformation auf Einzelbaumebene bei allen 50 Beobachtungsbäumen zeitgleich mit dem Verifikator „Blüte“ erfasst. Der Prozentsatz der männlichen, weiblichen und zwittrigen Blütenstände wird für jeden Beobachtungsbaum mit einer Genauigkeit von $10 \%$ angegeben. Die männlichen, weiblichen und zwittrigen Blütenstände sind in Abbildung 6 dargestellt.

\begin{tabular}{ll} 
Code & Geschlecht \\
\hline 1 & $\%$ männliche Blütenstände \\
\hline 2 & $\%$ weibliche Blütenstände \\
\hline 3 & $\%$ zwittrige Blütenstände \\
\hline
\end{tabular}




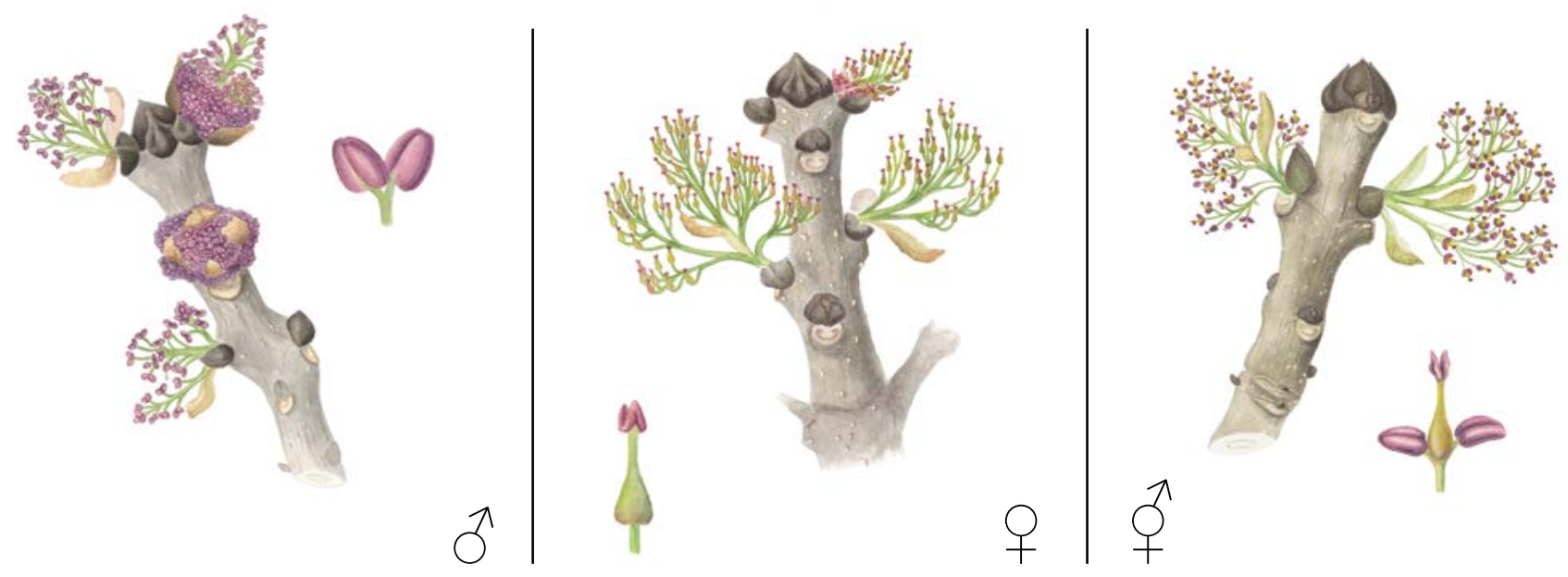

Abbildung 6: Illustration der Blütenstände von F. excelsior zur Bestimmung des Geschlechterverhältnisses

Bäume mit Blütenständen, die weder klar weiblich noch zwittrig sind, und kleine Staubgefäße aufweisen, die Pollen freisetzen können oder auch nicht, sind schwer zu charakterisieren. Sind mehr Blütenstände weiblich, kann der Baum als weiblich klassifiziert werden; sind mehr Blütenstände zwittrig, kann der Baum als Zwitter klassifiziert werden.

\subsubsection{Eschentriebsterben}

Diese Hintergrundinformation beschreibt den Zustand der Krone aufgrund des Eschentriebsterbens. Sie wird jährlich durch Experteneinschätzung aller 50 Beobachtungsbäume erfasst. Die Daten sollten idealerweise zu einer Zeit erhoben werden, in der die Blätter voll entwickelt sind, d.h. in Mitteleuropa z.B. im Juli. Die Stadien des Eschentriebsterbens sind in Abbildung 7 dargestellt.

\subsubsection{Basis-, Standard- und Intensivniveau}

\begin{tabular}{|c|c|}
\hline Cod & Beschreibung \\
\hline 1 & gesunde Krone (0-10\% Blattverlust) \\
\hline 2 & tote Zweigspitzen am Kronenrand sichtbar, Krone ansonsten in gutem Zustand (11-30\% Blattverlust) \\
\hline 3 & tote Äste am Rand der Krone sichtbar, die Krone ist licht und man kann durch sie hindurchsehen (31-50\% Blattverlust) \\
\hline 4 & Bildung einer Sekundärkrone am Stamm, dicke Äste ohne Blätter sichtbar, Krone ist sehr licht (51-80\% Blattverlust) \\
\hline 5 & nur ein kleiner Teil der Krone ist noch erhalten (81-99\% Blattverlust) \\
\hline 6 & Baum ist abgestorben (100\% Blattverlust) \\
\hline
\end{tabular}

\subsubsection{Austrieb}

Diese Hintergrundinformation beschreibt die Stadien des Blattaustriebs. Bei der Esche erfolgt der Blattaustrieb nach der Blüte. Die Aufzeichnung dieser Hintergrundinformation erfolgt nur auf Standard- und Intensivniveau. Die Daten für diese Hintergrundinformation sollten in Mitteleuropa im April erhoben werden, bis alle Beobachtungsbäume voll entwickelte Blätter haben. Nach warmen Wintern erfolgt der Austrieb früher.

\subsubsection{Standardniveau}

Auf Standardniveau wird der Austrieb alle 5 Jahre für alle 50 Beobachtungsbäume auf Einzelbaumebene beobachtet. Gesucht werden der Beginn (Stadium 3) und das Ende der Knospenöffnung (Stadium 5). Die Beobachtungen werden beendet, wenn alle Bäume das Stadium 5 erreicht haben. In der Regel sind dafür 
1

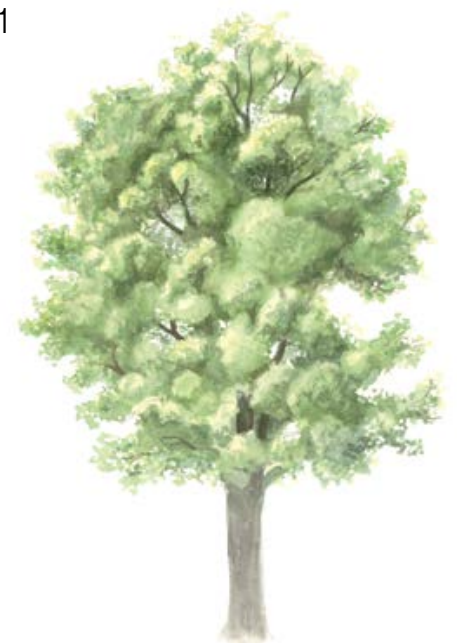

4

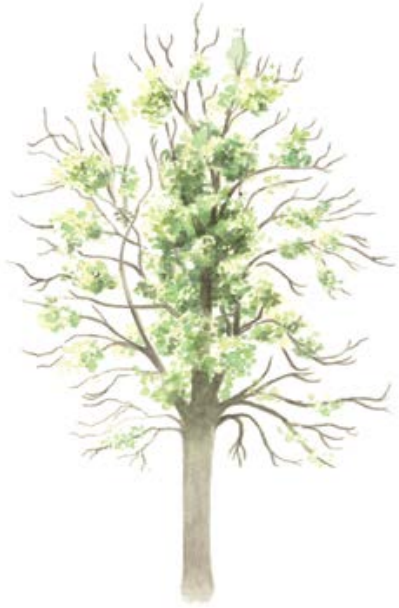

2

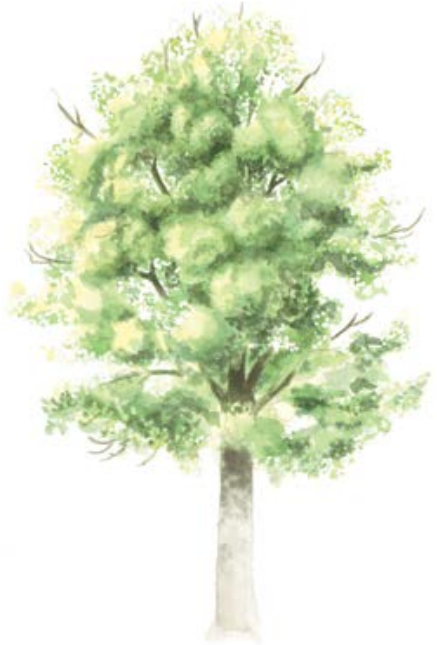

5

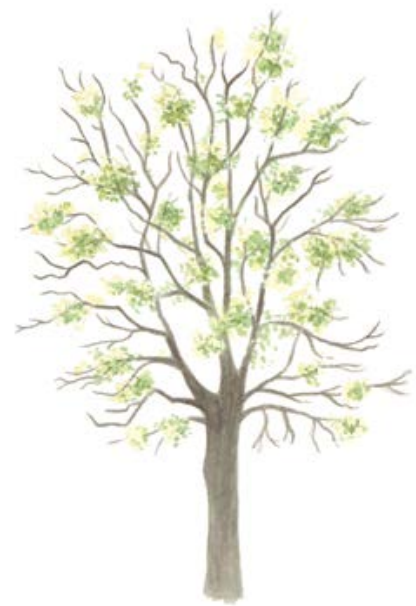

3

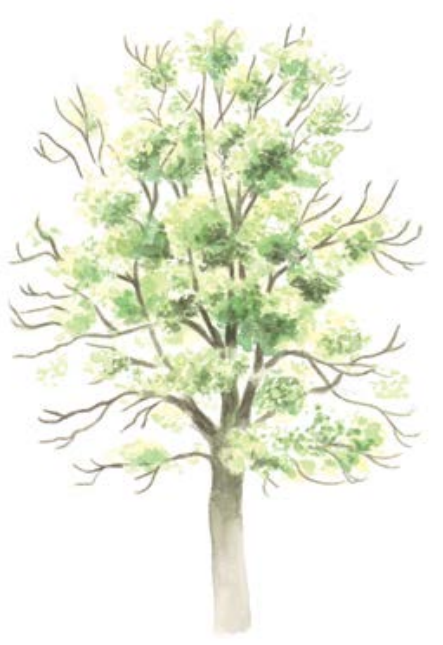

6

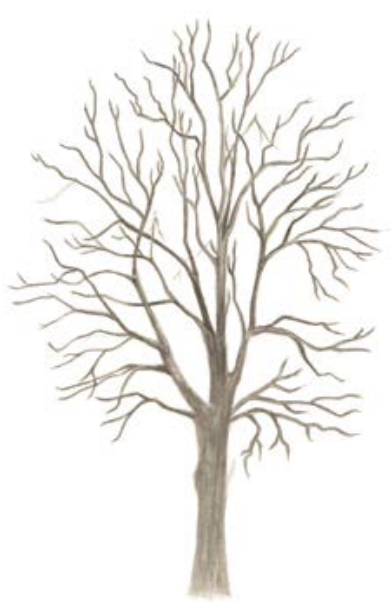

Abbildung 7: Illustration zur Abschätzung des Eschentriebsterbens

6 Begehungen erforderlich. Für jeden Baum werden zwei Werte erfasst: das Austriebsstadium und der entsprechende Kronenanteil. Die Austriebsstadien sind in Abbildung 8 dargestellt.

\begin{tabular}{|c|c|}
\hline Code & Austriebsstadium \\
\hline 1 & schlafende Winterknospe \\
\hline 2 & geschwollene aber noch geschlossene Knospen \\
\hline 3 & beginnende Knospenöffnung \\
\hline 4 & verlängerte Knospen \\
\hline 5 & Die Fiederblätter sind getrennt und beginnen aufrecht zu wachsen \\
\hline
\end{tabular}

\begin{tabular}{lr} 
Code & Anteil der Krone mit dem entsprechenden Austriebsstadium (\%) \\
\hline 1 & $>0-33$ \\
\hline 2 & $>33-66$ \\
\hline 3 & $>66-99$ \\
\hline 4 & 100 \\
\hline
\end{tabular}




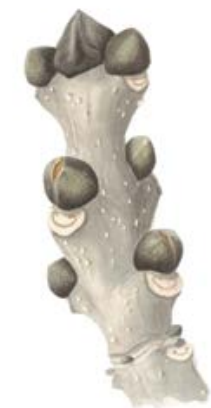

1

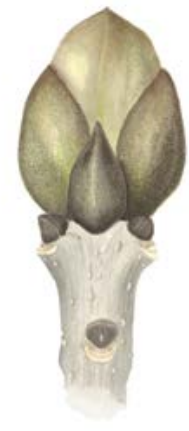

2

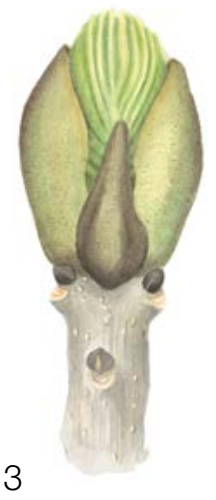

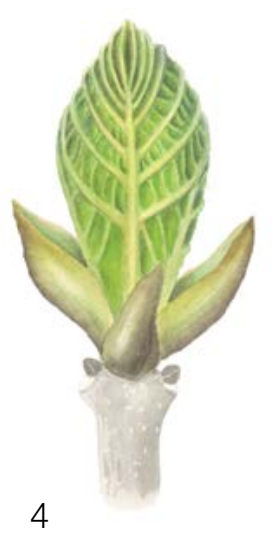

5

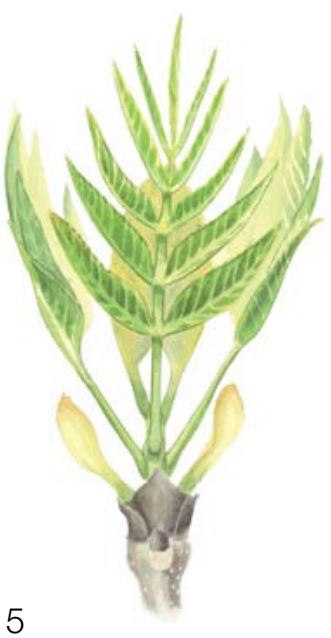

Abbildung 8: Illustration zur Beschreibung der Knospenöffnung (Hintergrundinformation „Austrieb“) auf Standard- und Intensivniveau.

\subsubsection{Intensivniveau}

Auf Intensivniveau wird der Austrieb jährlich für alle 50 Beobachtungsbäume auf Einzelbaumebene erhoben, mit derselben Verfahrensweise wie auf Standardniveau. Details dazu sind im Kapitel 7.2.5.1 Standardniveau zu finden.

\subsubsection{Seneszenz}

Die Seneszenz beschreibt den Prozess der Blattalterung. Die Erfassung dieser Hintergrundinformation erfolgt nur auf Standard- und Intensivniveau.

\subsubsection{Standardniveau}

Auf Standardniveau wird die Seneszenz alle 5 Jahre für alle 50 Beobachtungsbäume auf Einzelbaumebene beobachtet. Gesucht wird das Stadium 3, wenn die Blätter gelb sind und keine Photosynthese mehr betreiben. Die Beobachtungen enden, wenn alle Bäume das Stadium 3 erreicht haben. Normalerweise sind dafür zwei Begehungen der Monitoringfläche erforderlich. Für jeden Baum werden drei Werte erfasst: das Stadium der Seneszenz (Blattfarbe), entsprechender Kronenanteil und Anteil der abgeworfenen Blätter. 


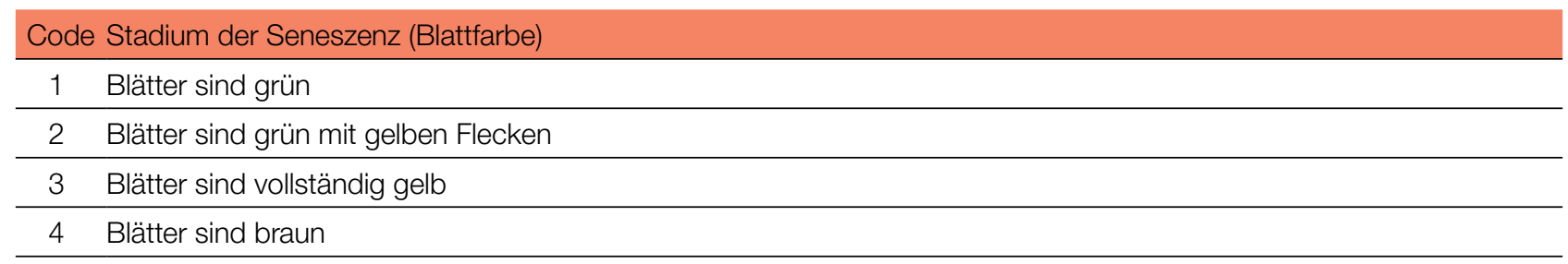

\begin{tabular}{lr} 
Code & Anteil der Krone mit dem entsprechenden Seneszenzstadium (\%) \\
\hline 1 & $>0-33$ \\
\hline 2 & $>33-66$ \\
\hline 3 & $>66-99$ \\
\hline 4 & 100
\end{tabular}

\begin{tabular}{lr} 
Code & Anteil der Blätter die aufgrund der Blattalterung abgeworfen wurden (\%) \\
\hline 1 & $>0-33$ \\
\hline 2 & $>33-66$ \\
\hline 3 & $>66-99$ \\
\hline 4 & 100 \\
\hline
\end{tabular}

\subsubsection{Intensivniveau}

Auf Intensivniveau wird die Seneszenz jährlich für alle 50 Beobachtungsbäume auf Einzelbaumebene erfasst, mit derselben Verfahrensweise wie auf Standardniveau. Details dazu sind im Kapitel 7.2.6.1 Standardniveau zu finden.

\subsubsection{Blühsynchronisation}

\subsubsection{Intensivniveau}

Die Hintergrundinformation „Blühsynchronisation“ wird nur auf Intensivniveau erfasst und basiert auf den für den Verifikator „Blüte“ erhobenen Daten. Sie wird verwendet, um festzustellen, ob die männliche und weibliche Blüte innerhalb des untersuchten Bestandes gleichzeitig stattfindet.

\section{Formular für die Beschreibung der Monitoringfläche: 'FGM Plot description'}

Formular für die Erfassung der Verifikatoren: 'Form for recording field level verifiers within FGM'

Formular für die Aufzeichnung von Hintergrundinformationen: 'Form for recording field level background information within FGM' 


\section{Quellen}

1. Pliūra A, Heuertz M (2003) EUFORGEN Technical Guidelines for genetic conservation and use for common ash (Fraxinus exce/sior). International Plant Genetic Resources Institute, Rome

2. Beck P, Caudullo G, Tinner W, de Rigo D (2016) Fraxinus excelsior in Europe: distribution, habitat, usage and threats. In: San-Miguel-Ayanz J, de Rigo D, Caudullo G, Houston Durrant T, Mauri A (ed) European Atlas of Forest Tree Species. Publ. Off. EU, Luxembourg, pp 98-99. DOI: 10.2788/4251

3. FRAXIGEN (2005) Ash species in Europe: biological characteristics and practical guidelines for sustainable use. Oxford Forestry Institute, University of Oxford, UK

4. Ogris N (2020) Varstvo gozdov Slovenije - portal. https://www.zdravgozd.si/meni_index.aspx. Accessed 16 September 2020

Die folgenden Ressourcen wurden für die derzeit akzeptierten (Dezember 2020) wissenschaftlichen Namen der in diesem Dokument erfassten oder erwähnten Arten konsultiert:

a. CABI (2020) Invasive Species Compendium. CAB International, Wallingford, UK. www.cabi.org/isc. Accessed 15 December 2020

b. EPPO (2020) EPPO Global Database (available online). https://gd.eppo.int. Accessed 15 December 2020

c. GBIF (2020) Global Biodiversity Information Facility. https://www.gbif.org Accessed 15 December 2020

d. IPNI (2020) International Plant Names Index. The Royal Botanic Gardens, Kew, Harvard University Herbaria \& Libraries \& Australian National Botanic Gardens. http://www.ipni.org, Accessed 10 December 2020

e. National Center for Biotechnology Information (NCBI) (1998) National Library of Medicine (US), National Center for Biotechnology Information, Bethesda (MD). https://www.ncbi.nlm.nih.gov/. Accessed 15 December 2020

f. Stevens PF (2001) Angiosperm Phylogeny Website, Version 14. http://www.mobot.org/MOBOT/research/APweb/. Accessed 15 December 2020

g. The Plant List (2013) Version 1.1. http://www.theplantlist.org/. Accessed 12 December 2020

h. Tropicos.org (2020) Missouri Botanical Garden. http://www.tropicos.org. Accessed 15 December 2020

i. WFO (2020) World Flora Online. http://www.worldfloraonline.org. Accessed 15 December 2020 


\section{Leitfaden für das genetische Monitoring der}

\subsubsection{Europäischen Schwarzkiefer (Pinus nigra J. F. Arnold)}

Paraskevi ALIZOTI', Darius KAVALIAUSKAS², Barbara FUSSI², Marjana WESTERGREN ${ }^{3}$, Marko BAJC ${ }^{3}$, Phil ARAVANOPOULOS', Rok DAMJANIĆ ${ }^{3}$, Hojka KRAIGHER ${ }^{3}$

Botanische Illustrationen von Klara JAGER

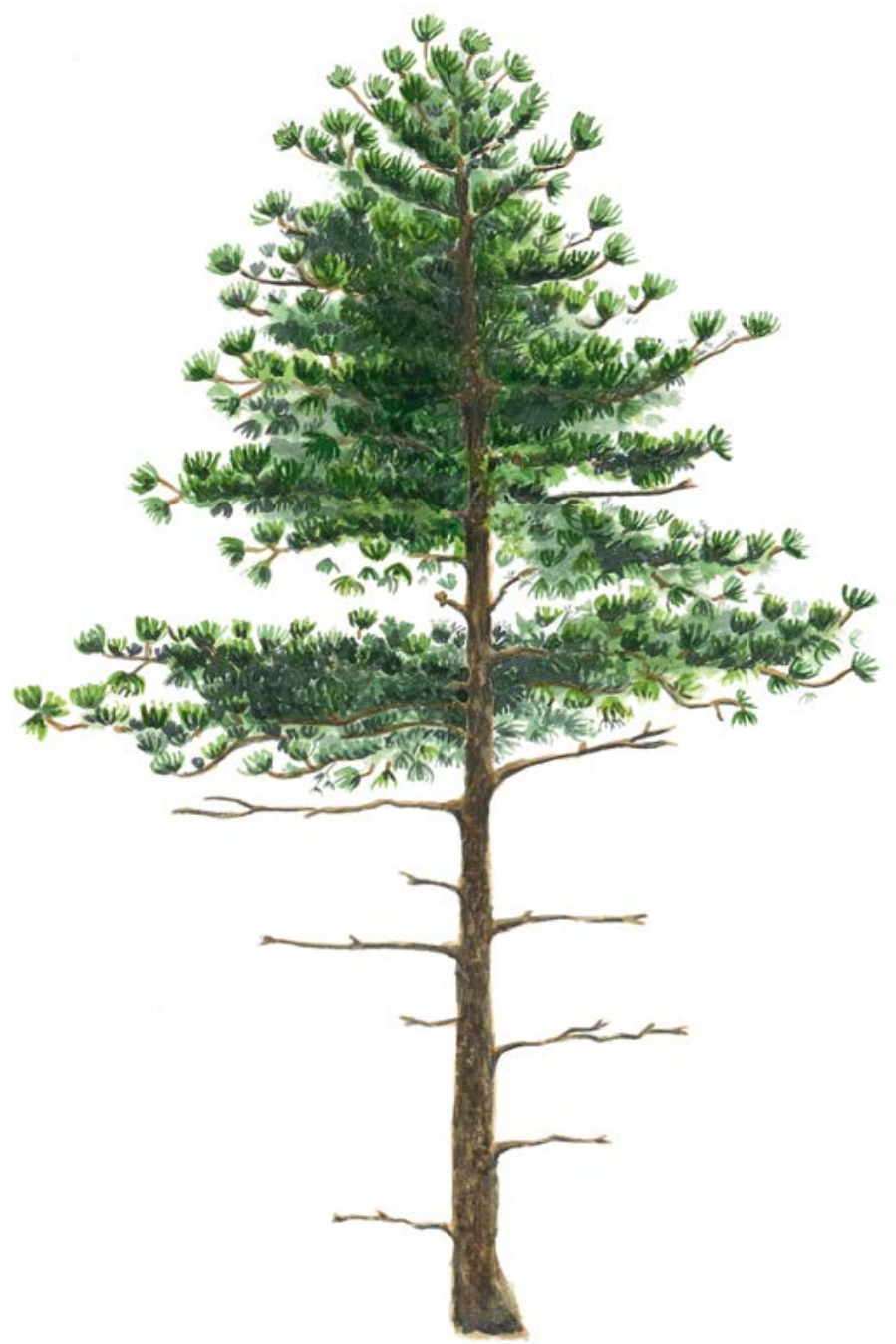

Zitat: Alizoti et al. (2020) Leitfaden für das genetische Monitoring der Europäischen Schwarzkiefer (Pinus nigra J. F. Arnold). In: Bajc et al. (Ed.) Handbuch zum Forstgenetischen Monitoring. Slowenisches Forstinstitut: Verlag Silva Slovenica, Ljubljana, S. 229-247. http://dx.doi.org/10.20315/ SFS.176 


\section{ZUSAMMENFASSUNG}

Die Europäische Schwarzkiefer (Pinus nigra J. F. Arnold) ist eine windbestäubte, einhäusige, meist auskreuzende zirkummediterrane Nadelbaumart der Hochlagen, die auch in Österreich, auf der Krim und am Schwarzen Meer wächst. Aufgrund der ausgedehnten Verbreitung der Art in einem breiten Spektrum verschiedener Umweltbedingungen, die zu ihrer morphologischen und genetischen Differenzierung führten, lassen sich innerhalb ihres natürlichen Verbreitungsgebietes fünf interfertile Unterarten unterscheiden. Schwarzkiefer ist eine wertvolle Schlüsselart von großer wirtschaftlicher und ökologischer Bedeutung, die Holz von hoher Qualität und natürlicher Dauerhaftigkeit produziert. Sie zeichnet sich durch ihre Toleranz gegenüber abiotischen Belastungen wie armen oder salzhaltigen Böden, Frost, Eisbehang, starkem Wind oder Dürre aus. Die Art verjüngt sich auf natürliche Weise in Waldökosystemen, hat aber keine Mechanismen zur Regeneration nach einem Waldbrand, was sie anfällig gegenüber den im gesamten Mittelmeerraum verbreiteten Waldbränden macht. Angesichts der hohen wirtschaftlichen und ökologischen Bedeutung dieser Baumart, ihrer ausgedehnten natürlichen Verbreitung in einer Vielzahl von Lebensräumen und der Existenz isolierter und marginaler Populationen, die angesichts des Klimawandels gefährdet sein könnten, kann sie als eine gute Kandidatin für das forstgenetische Monitoring eingestuft werden.

Der vorliegende Leitfaden enthält eine Beschreibung der Schwarzkiefer, ihrer Verbreitung, Ökologie, Fortpflanzung und der die Art bedrohenden Gefährdungsfaktoren. Er enthält außerdem eine Anleitung zur Einrichtung einer Monitoringfläche und zur Erfassung aller Verifikatoren, die zur Erfüllung der Ziele des FGM erforderlich sind.

\section{BESCHREIBUNG DER BAUMART}

Die Europäische Schwarzkiefer ist eine zirkummediterrane Nadelbaumart, die auch in Österreich, auf der Krim und am Schwarzen Meer vorkommt. Die folgenden [1] fünf Unterarten lassen sich vor allem anhand morphologischanatomischer Merkmale unterscheiden: a) P. nigra J. F., Arnold subsp. nigra, verbreitet im Südosten Österreichs, in Norditalien, auf der Balkanhalbinsel, in Bulgarien, Rumänien, im Europäischen Teil der Türkei; b) P. nigra subsp. dalmatica (Vis.) Franco, verbreitet in Kroatien; c) P. nigra subsp. laricio (Poir.) Palib. ex Maire, verbreitet in Frankreich (Korsika) und Italien (Apennin, Sizilien); d) P. nigra subsp. pallasiana (Lamb.) Holmboe verbreitet in Griechenland, Zypern, Südwestbulgarien, Südost-Nordmazedonien, Südalbanien und von der Krim entlang der Schwarzmeerküste bis zur Türkei; und e) P. nigra subsp. salzmannii (Dunal) Franco, verbreitet in Südwesteuropa,

(a)

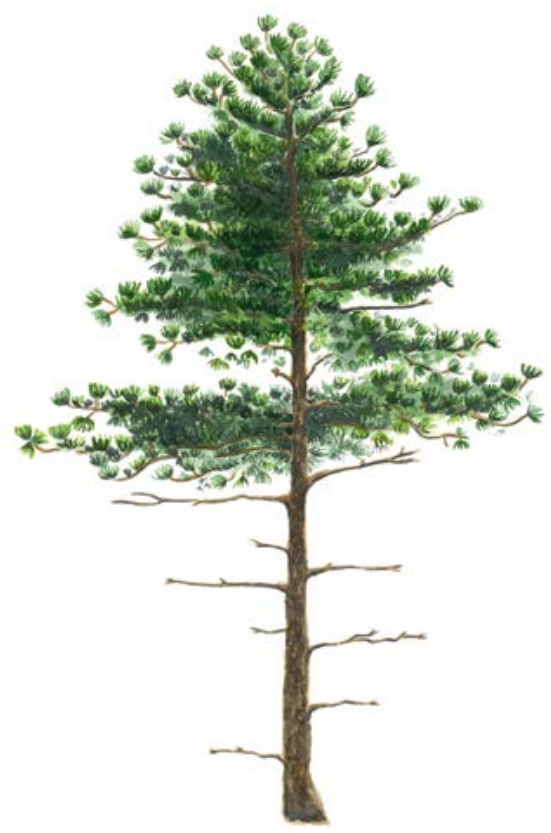

(b)

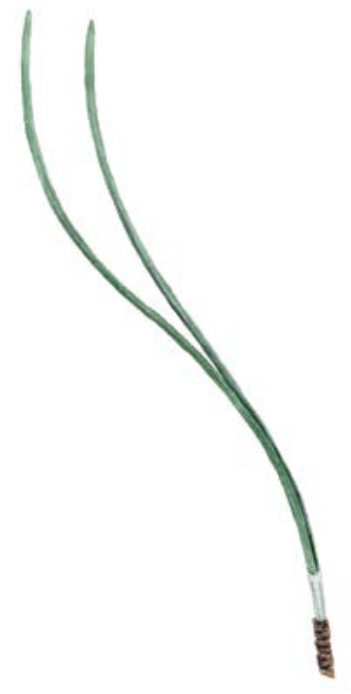

Abbildung 1: Pinus nigra Habitus (a) und Nadeln (b). 
Frankreich (Hérault, Pyrenäen), Spanien, Algerien und Marokko. Die Art wächst in Vergesellschaftung mit Pinus sylvestris L., Pinus mugo Turrra, Pinus halepensis Mill., Pinus pinea L. und Pinus heldreichii Christ [2]. In den meisten Fällen bildet die Art Reinbestände, wobei sie in Mischbeständen zusammen mit anderen Kiefernarten, insbesondere Pinus sylvestris zu finden ist [12].

Es gibt Belege für natürliche interspezifische Kreuzungen zwischen Pinus nigra und anderen Kiefernarten, z.B. $P$. sylvestris, P. heldreichii, P. densiflora Siebold \& Zucc., P. resinosa Aiton, P. tabulaeformis Carrière, P. taiwanensis Hayata, P. mugo, P. thunbergii Parl. [3,4,5,6,7], wo diese Arten natürlich koexistieren oder künstlich eingeführt wurden. Eine intraspezifische Hybridisierung zwischen Unterarten ist möglich, da die Reproduktionshindernisse für genetischen Austausch zwischen diesen Unterarten schwach sind, was zu Übergangsformen führt, die sich durch erheblichen Genfluss aufgrund von Pollenverbreitung über weite Distanzen entwickeln [8].

Die Europäische Schwarzkiefer (Abbildung 1) ist eine mittelgroße, zweinadelige Kiefer, die im hiebsreifen Alter (80 Jahre) eine Höhe von 30-50 m erreicht und sich durch eine gerade Stammform auszeichnet. Die Farbe der Rinde variiert von hellgrau zu dunkelbraun, Altbäume haben eine von breiten Rissen durchzogene Schuppenborke [9]. Mit zunehmendem Alter wird die Rinde zunehmend zerfurcht [10]. Die Krone hat im jungen Alter eine pyramidale Form, wird mit zunehmendem Alter rund und bildet eine sich ausbreitende flache oder leicht gewölbte Krone. Die Nadeln sind steif, 8-16 cm lang und 1-2 mm breit, gerade oder gebogen und fein gesägt, mit einer Nadelscheide von 10-12 mm Länge [11,12].

\section{REPRODUKTION}

Die Europäische Schwarzkiefer ist eine einhäusige, windbestäubte Nadelbaumart mit geflügelten Samen, die durch den Wind verbreitet werden. Im Alter von 15-20 Jahren wird die Europäische Schwarzkiefer fortpflanzungsfähig. Die männlichen Blütenstände und die weiblichen Blüten (Zäpfchen) (Abbildung 2a) erscheinen jedes Jahr im Mai. Die weiblichen Blüten (Zäpfchen) sind rot bis violett und die männlichen Blütenstände im unreifen Zustand zunächst grün und färben sich allmählich gelb, wenn sie reif werden und Pollen abgeben. Die Pollenausbreitung und die Bestäubung der weiblichen Blütenzäpfchen erfolgt von Mai bis Anfang Juni, wobei das Fruchtbarkeitsfenster der Zäpfchen in der Regel drei Tage beträgt [8]. Die Befruchtung erfolgt 13 Monate nach der Bestäubung. Die reifen Zapfen (Abbildung 2b) sind sitzend und zu einer Manschette gruppiert, 4-8 cm lang und 2-4 cm breit, mit einer zwischen braun und gelb-braun oder sogar hellgelb variierenden Färbung. Die Zapfen reifen

(a)

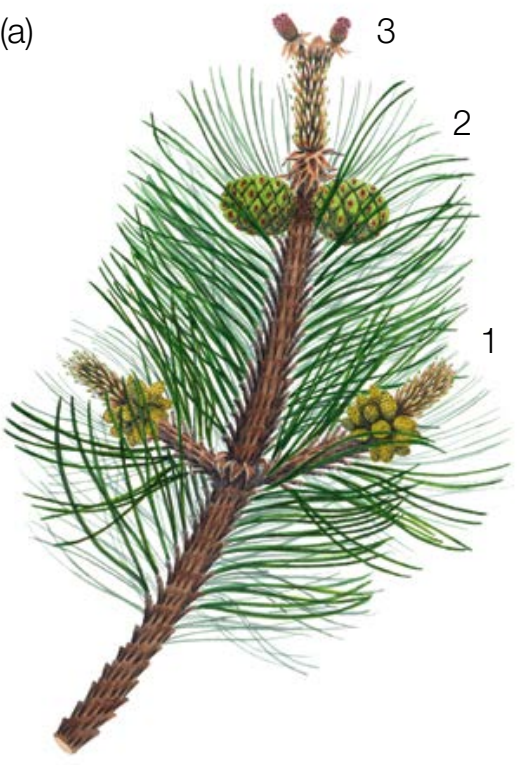

(b)

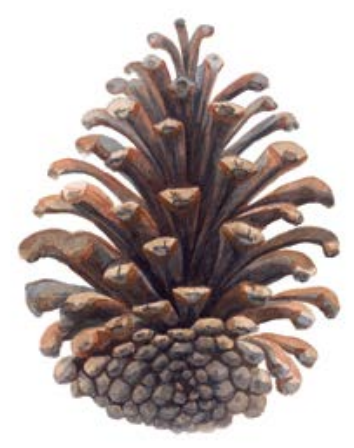

(c)

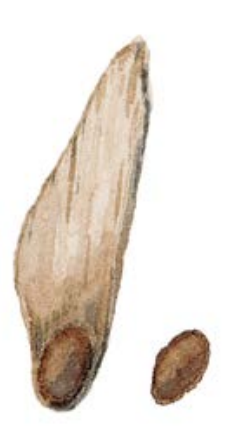

Abbildung 2: Pinus nigra -Zweig mit männlichen Blütenständen (a-1), den weiblichen, noch unreifen Zäpfchen des ersten Jahres (a-2) und diesjährige Zäpfchen (a-3), reifer offener Zapfen (b) und Samenkorn mit und ohne Flügel (c). 
von September bis November des zweiten Jahres und öffnen sich im dritten Jahr nach der Bestäubung [12]. In der Regel produziert jede fruchtbare Zapfenschuppe zwei geflügelte Samen (Abbildung 2c) und die Zapfen tragen gewöhnlich 30-40 Samen, von denen fast die Hälfte keimt. Die Samenausbreitung erfolgt von Oktober bis November der darauffolgenden Vegetationsperiode. Die Farbe der Samen reicht von grau bis hellgelb. Die Länge der Samen beträgt 5-7mm, die Flügellänge zwischen 19-26 mm. Ein Mastjahr erfolgt alle zwei bis fünf Jahre [13].

\section{UMWELT}

Pinus nigra zeichnet sich durch ihre ausgedehnte natürliche Verbreitung (d.h. zirkummediterrane Verbreitung mit Vorkommen in Österreich, auf der Krim und am Schwarzen Meer) aus, die ein breites Spektrum an Lebensräumen umfasst. Sie wächst in Höhenlagen zwischen 350 m und 2200 m (Taurusgebirge, Türkei), aber ihr Optimum liegt zwischen 800 m und 1500 m. Die Art kann in trockenen Umgebungen mit schlechten Böden und auf einer Vielzahl von Substraten wachsen, von Kalkstein über Dolomit bis hin zu sauren oder vulkanischen Böden [8]. Der Großteil des Verbreitungsgebiets der Art liegt im mediterranen Klimatyp, wobei die bioklimatischen Bedingungen von humid zu sub-humid und semi-arid reichen. In Teilen ihres natürlichen Verbreitungsgebiets wächst die Schwarzkiefer in kühlen bis kalten Klimaten; während die nördlichen Populationen frostresistent sind und Temperaturen von $-30^{\circ} \mathrm{C}$ aushalten, tolerieren die südlichen Populationen bis $z u-7^{\circ} \mathrm{C}$ [2]. Es gibt sogar Aufzeichnungen, dass um Temperaturen bis $z u-5^{\circ} \mathrm{C}$ Photosynthese stattfindet, bei $-19^{\circ} \mathrm{C}$ konnte noch Atmungsaktivität nachgewiesen werden [2,14]. Die Art kann auch Eisbehang gut vertragen und gilt allgemein als widerstandsfähig. Die Art ist lichtliebend, schattenunverträglich und verträgt Wind, Dürre und salzhaltige Böden gut.

\section{GEFÄHRDUNG}

Die Europäische Schwarzkiefer kann gefährdet sein, insbesondere dort, wo sie in isolierten Populationen wächst, und zwar aufgrund mehrerer Faktoren, die zum Aussterben führen können, wie Waldbrände, Insekten und Krankheiten, illegaler Holzeinschlag und die übergeordnete Bedrohung durch den Klimawandel. Insekten wie Rhyacionia buoliana Denis \& Schiffermüller, Thaumetopoea pityocampa Denis \& Schiffermüller, Acantholyda hieroglyphica Christ, Diprion pini L., Pissodes validirostis L., Marchalina hellenica (Monophlebus hellenicus) Gen., Ips pini Say, Bursaphelenchus xylophilus können die Art befallen [8,15]. Pilze wie Mycosphaerella pini Rostr. (Dothistroma pini Hulbary), Lophodermella spp., Sphaeropsis sapinea (Fr.) Dyko \& B. Sutton (Diplodia pinea (Desm.) J. Kickx f.) können auch die Nadeln der Schwarzkiefer befallen [16,17,18].

In den letzten zwei Jahrhunderten wurden mit genetischem Material unbekannter Herkunft, das für die lokalen Bedingungen ungeeignet sein kann, in ganz Europa ausgedehnte künstliche Bestände angelegt. Die damit einhergehende Vermischung des Genpools kann eine Bedrohung für die autochthonen Populationen [8] sowie für deren Anpassungs- und Evolutionspotential darstellen.

\section{EINRICHTUNG UND INSTANDHALTUNG VON MONITORINGFLÄCHEN}

Die Europäische Schwarzkiefer ist eine bestandesbildende Baumart, die in den meisten Fällen Reinbestände bildet, aber auch Mischbestände mit $P$. sylvestris bzw. anderen Nadel- oder Laubbaumarten bilden kann [2]. Daher kann bei Schwarzkiefer das reguläre FGM-Verfahren für bestandesbildende Baumarten angewendet werden.

Eine forstgenetische Monitoringfläche umfasst 50 fortpflanzungsfähige (d.h. blühende) Altbäume mit einem Brusthöhendurchmesser (BHD) von mehr als $15 \mathrm{~cm}$ und einem Mindestabstand von $30 \mathrm{~m}$ zwischen je zwei beliebigen Bäumen. In ihrem natürlichen Verbreitungsgebiet werden die Bäume im Alter von 15-20 Jahren fortpflanzungsfähig [8]. Der BHD ( $\geq 15 \mathrm{~cm})$ und die KRAFT'sche Klasse eines Baumes können als Anhaltspunkte für die Identifizierung fortpflanzungsfähiger Bäume verwendet werden, wenn die Monitoringfläche außerhalb der 
Blütezeit angelegt wird. Dabei sollte auf das Fachwissen des zuständigen Försters zurückgegriffen werden. Wird die Monitoringfläche während der Blütezeit angelegt, wird die Blüte mit erfasst. Darüber hinaus muss vor der Einrichtung einer FGM-Fläche das Vorhandensein von ausreichend Naturverjüngung (NV) geprüft werden, falls NV-Plots eingerichtet werden müssen, um die Muster der Paarungssysteme, den Genfluss und das Ausmaß der Änderung möglicher genetischer Variation zwischen verschiedenen Generationen zu untersuchen. Bei der Neueinrichtung einer Monitoringfläche sollten alle Bäume beschriftet und ihre Koordinaten erfasst werden. Gleichzeitig können die jeweiligen BHD gemessen und Proben für die DNA-Extraktion gesammelt werden. Zusätzlich müssen bis zu 20 NV-Plots ausgewählt und markiert werden.

Erforderliche Ausrüstung:

- ein Gerät zur Entfernungsmessung (empfehlenswert ist ein Fernglas mit Entfernungsmesser)

- ein Kompass

- Farbe und Pinsel oder Farbspray zum Kennzeichnen der Bäume

- eine Maske oder Schutzbrille sowie Handschuhe zum Eigenschutz bei der Kennzeichnung der Bäume

- eine Kluppe für BHD-Messungen und

- ein ausreichend präzises GPS-Gerät, welches das Speichern von Baumkoordinaten ermöglicht

- ein Fotoapparat, falls die Monitoringfläche während der Blütezeit angelegt wird

Für isolierte, marginale oder bedrohte Populationen dieser Art können die Flächen für das genetische Monitoring größer sein als regulär. In diesen Fällen sollten Größe und Form der FGM-Fläche flexibel gehandhabt werden, aus praktischen Gründen aber nicht größer als 10 ha.

\subsection{Einrichtung der Monitoringfläche}

\subsubsection{Auswahl des Mittelpunkts}

Das allgemeine Verfahren für eine Zufallsauswahl der Monitoringfläche besteht aus den folgenden Schritten (Abbildung 3):

- zufällige Auswahl eines Punktes (grüner Punkt) entlang einer an der Bestandesgrenze verlaufenden Forststraße oder eines Waldweges auf einer Karte;

- Einzeichnen einer annähernd senkrecht zur Straße verlaufenden Linie an diesem zufällig entlang der Straße ausgewählten Punkt;

- zufällige Auswahl eines Punktes auf der Linie (roter Punkt) - dieser Punkt stellt den Mittelpunkt der forstgenetischen Monitoringfläche dar.

Der Mindestabstand zwischen dem ausgewählten Mittelpunkt und der Bestandesgrenze beträgt ca. $150 \mathrm{~m}$. Wenn der ausgewählte Mittelpunkt diese Anforderung nicht erfüllt, muss nach dem oben beschriebenen Verfahren ein neuer Punkt ausgewählt werden.

Anstelle des oben beschriebenen Verfahrens können auch entsprechende Werkzeuge zur Erstellung von Zufallspunkten in GIS-Software verwendet werden.

Für die Nutzung im Gelände sollten die Koordinaten des ausgewählten Punktes in einem GPS-Gerät gespeichert werden. 
(a)

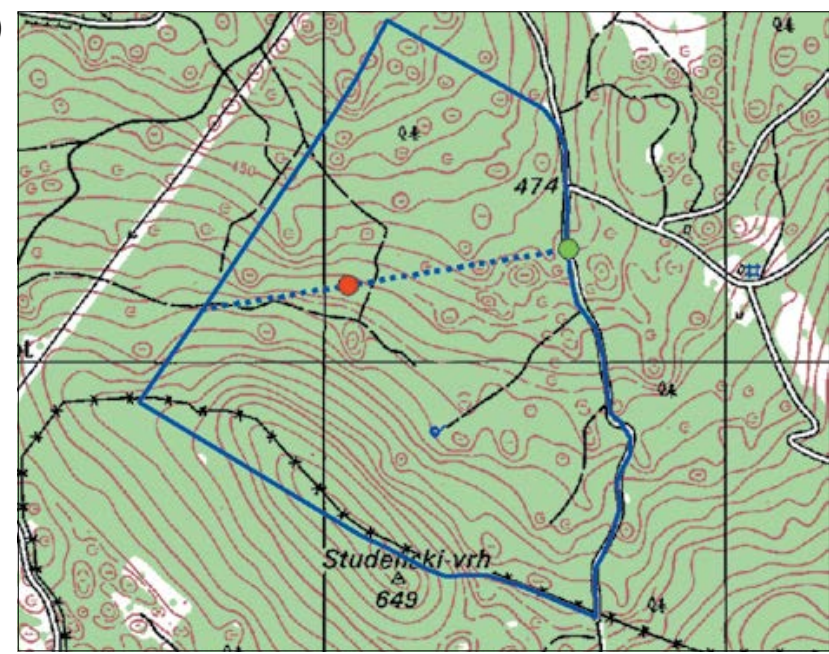

(b)

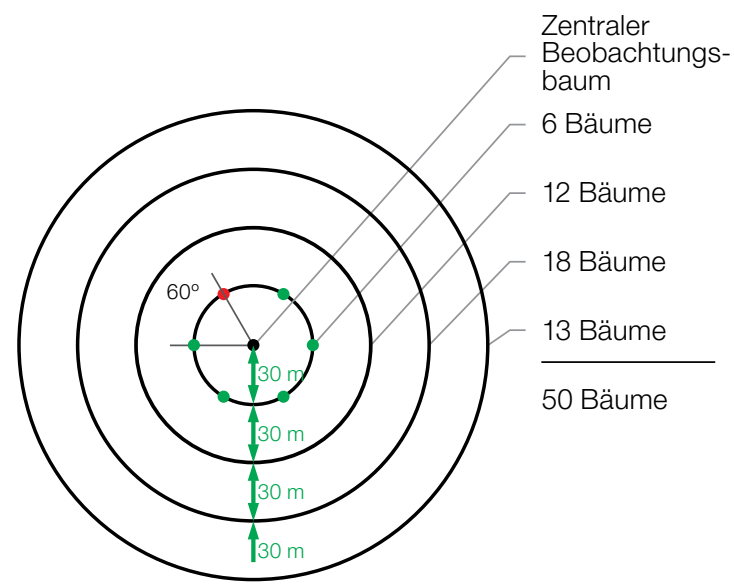

Abbildung 3: Zufallsauswahl des Mittelpunkts der forstgenetischen Monitoringfläche (a); Auswahl von Bäumen in konzentrischen Kreisen mit einem zunehmenden Radius von $30 \mathrm{~m}$ um den zuvor ausgewählten zentralen Beobachtungsbaum (b).

\subsubsection{Einrichtung der Monitoringfläche}

Vor Ort im Bestand wird ein zentraler Beobachtungsbaum der Monitoringfläche bestimmt und mit der Nummer 1 gekennzeichnet. Dieser Baum entspricht dem der gespeicherten GPS-Koordinate am nächsten stehende, fortpflanzungsfähige Baum.

In konzentrischen Kreisen mit einem zunehmenden Radius von 30 m um den zentralen Beobachtungsbaum werden weitere Altbäume ausgewählt (Abbildung 2b). Der erste Baum in jedem Kreis sollte nach dem Zufallsprinzip ausgewählt werden, was auf verschiedene Weise geschehen kann: durch Verwendung eines zufälligen Azimuts, der vom zentralen Beobachtungsbaum aus eingemessen wird (Tabelle 1), durch Folgen der Richtung des Sekundenzeigers auf einer analogen Uhr oder durch eine andere Vorgehensweise, die eine objektive Auswahl ermöglicht. Die verbleibenden Bäume in jedem Kreis werden mit einem entsprechend größeren Azimut ausgewählt, um einen Mindestabstand von 30 m zwischen je zwei beliebigen Bäumen zu gewährleisten:

$\cdot+60^{\circ}$ im ersten Kreis

- $+30^{\circ}$ im zweiten Kreis

$\cdot+20^{\circ}$ im dritten Kreis

$\cdot+15^{\circ}$ im vierten Kreis

Sollte es nicht möglich sein, 6, 12 bzw. 18 Bäume in den inneren 3 Kreisen zu finden (Abbildung 3b), werden im äußersten Kreis zusätzliche Bäume ausgewählt.

Tabelle 1: Zufällig generierte Azimute, die für die Auswahl des ersten Baumes in jedem Kreis verwendet werden können.

\begin{tabular}{rrrrrrrrrrr}
\hline 108 & 15 & 186 & 35 & 178 & 29 & 305 & 351 & 44 & 150 \\
\hline 232 & 23 & 160 & 141 & 112 & 292 & 216 & 83 & 245 & 214 \\
\hline 63 & 65 & 345 & 234 & 95 & 78 & 279 & 323 & 40 & 236 \\
\hline 201 & 313 & 275 & 144 & 182 & 68 & 268 & 289 & 185 & 92 \\
\hline 356 & 177 & 93 & 1 & 145 & 198 & 287 & 251 & 224 & 142 \\
\hline
\end{tabular}


Falls der zentrale Beobachtungsbaum aufgrund vorhandener Hindernisse (d.h. andere Bäume, die diesen verdecken) oder der Topografie nicht sichtbar ist, kann die Auswahl der Bäume hauptsächlich auf der Grundlage ihres Mindestabstands zu den anderen ausgewählten Bäumen $(\geq 30 \mathrm{~m})$ erfolgen, während die ungefähre Position des zentralen Beobachtungsbaums unter Berücksichtigung der Position der ausgewählten Bäume aus den inneren Kreisen oder durch Einzeichnen der Koordinaten auf Open Earth-Plattformen (z.B. Google Maps/Earth) angenommen werden kann.

\subsubsection{Kennzeichnung der Bäume}

Alle 50 ausgewählten Beobachtungsbäume müssen mit einer entsprechenden Nummer und idealerweise mit einem um den Stamm herum laufenden Ring gekennzeichnet werden, um die Sichtbarkeit der Bäume aus allen Richtungen zu erhöhen. Markieren Sie den zentralen Beobachtungsbaum (Nummer 1) mit zwei oder mehr Streifen, um inn von anderen Bäumen zu unterscheiden (Abbildung 4a). Es wird empfohlen, die Baumnummer stets auf der vom zentralen Beobachtungsbaum abgewandten Seite der Bäume anzubringen, da dies die Lokalisierung des zentralen Beobachtungsbaum v.a. von den äußeren Kreisen der Monitoringfläche aus erleichtert (Abbildung 4b).

\subsection{Einrichtung von Naturverjüngungs-Plots}

Die Einrichtung von Plots für das Monitoring der Naturverjüngung (NV) sollte während der Keimungsperiode nach einem starken oder extremen Fruktifikationsereignis erfolgen.

Bereiche mit aufgelaufener Naturverjüngung aus dem letzten Mastjahr (sogenannte Verjüngungscluster) sollten vor Ort vermessen und ihre Position erfasst werden (GPS-Koordinaten, Nummer des Beobachtungsbaumes neben dem Verjüngungscluster). Von allen erfassten Verjüngungsclustern sollten nach dem Zufallsprinzip 20 für die Einrichtung von NV-Plots ausgewählt werden. Wenn 20 oder weniger natürliche Verjüngungscluster vorhanden sind, sollten alle verwendet werden.

Innerhalb jedes ausgewählten Verjüngungsclusters ist ein $1 \mathrm{~m}^{2}$ großer Plot einzurichten und mit Metallstäben zu markieren. Die Metallstäbe sollten an jeder Ecke der Teilfläche so tief wie möglich in den Boden getrieben werden, damit sie nicht von Tieren entfernt werden können. Die oberen Spitzen der Metallstäbe sollten farbig markiert werden, um ihre Sichtbarkeit zu verbessern.
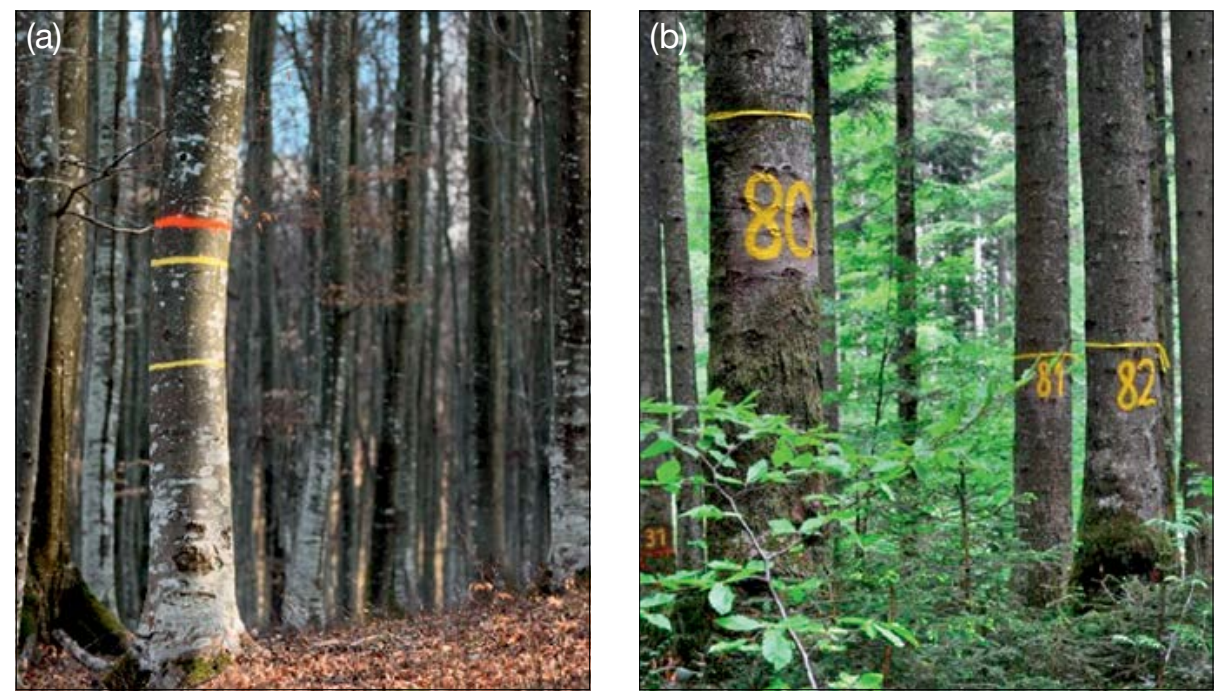

Abbildung 4: a) Der zentrale Beobachtungsbaum der forstgenetischen Monitoringfläche ist mit mehreren Streifen markiert, um inn von anderen Bäumen zu unterscheiden (links; das Foto zeigt beispielhaft die Kennzeichnung einer Buchen-FGM-Fläche); b) die Nummerierung der ausgewählten Bäume erfolgt auf der vom zentralen Beobachtungsbaum abgewandten Seite (rechts; das Foto zeigt beispielhaft die Markierungen auf einer Weißtannen (Abies alba Mill.)-FGMFläche in Bayern). 


\subsection{Instandhaltung der Monitoringfläche}

\subsubsection{Allgemeine Instandhaltung}

Die Kennzeichnung der Bäume und NV-Plots muss periodisch (alle 2 Jahre) überprüft und bei Bedarf erneuert werden.

\subsubsection{Ersatz von Bäumen}

Wenn ein ausgewählter Beobachtungsbaum stirbt oder im Zuge der forstlichen Bewirtschaftung gefällt wird, muss er ersetzt werden. Dabei sollte der dem abgestorbenen/gefällten Baum nächstgelegene geeignete Baum ausgewählt werden, wobei der Mindestabstand von $30 \mathrm{~m}$ zum nächsten Beobachtungsbaum erfüllt sein muss. Andernfalls ist ein Baum aus der Peripherie (vorzugsweise im äußeren Kreis) der Monitoringfläche zu wählen. Der Ersatzbaum wird mit der nächsten verfügbaren Zahl über 50 gekennzeichnet, d.h. 51, 52, 53, usw., um ihn eindeutig von den ursprünglich 50 ausgewählten Beobachtungsbäumen zu unterscheiden.

Wenn die Baumkronez.B. durch Wind-, Eis- oder Schneebruch geschädigt ist, der Baum aber weiterhin fruktifiziert, wird der Baum im Monitoringprogramm belassen. Ist der Schaden zu schwerwiegend und eine Fruktifikation nicht mehr zu erwarten, muss der Baum ersetzt werden. Die Schadensursache muss aufgenommen werden, da der Schaden die Werte für Verifikatoren im Gelände und Hintergrundinformationen beeinträchtigen kann.

\section{ERFASSUNG VON VERIFIKATOREN UND HINTERGRUNDINFORMATION}

Auf der Monitoringfläche werden periodisch Verifikatoren und Hintergrundinformationen erfasst. Verifikatoren werden genutzt, um die genetischen Eigenschaften der Population und ihre Anpassung an Umweltveränderungen und/oder Bewirtschaftung zu verfolgen, während Hintergrundinformationen aufgezeichnet werden, um die Interpretation der Verifikatoren zu unterstützen. Verifikatoren können auf drei verschiedenen Intensitätsniveaus erfasst werden: Basis, Standard und Intensiv.

Höherrangigere Niveaus (Standard, Intensiv) müssen stets auch die Erfassung der Verifikatoren auf allen niedrigeren Niveaus (Basis, Standard) einschließen. Dies ist für die Aufzeichnung von Hintergrundinformationen nicht erforderlich. 
Tabelle 2: Liste der Verifikatoren und Hintergrundinformationen, die während der Außenaufnahmen auf den AbiesMonitoringflächen zu erfassen sind; jeweils mit Kurzbeschreibung und Beobachtungshäufigkeit.

\begin{tabular}{|c|c|c|c|c|}
\hline & Bezeichnung & Basisniveau & Standardniveau & Intensivniveau \\
\hline \multirow{5}{*}{ 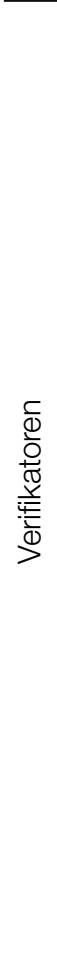 } & \multirow[t]{2}{*}{$\begin{array}{l}\text { Mortalität/ } \\
\text { Überlebensrate }\end{array}$} & $\begin{array}{c}\text { Altbäume: Zählung der } \\
\text { verbleibenden markierten Bäume } \\
\text { alle } 10 \text { Jahre und nach jedem } \\
\text { extremen Witterungsereignis/ } \\
\text { jeder Störung }\end{array}$ & wie Basisniveau & wie Basisniveau \\
\hline & & Naturverjüngung: / & $\begin{array}{l}\text { Zählung der verbleibenden } \\
\text { Sämlinge auf den NV-Plots, } \\
\text { zweimal pro Jahrzehnt }\end{array}$ & wie Standardniveau \\
\hline & \multirow{2}{*}{ Dlüte } & $\begin{array}{l}\text { bestandesweise Schätzung; } \\
\text { jährlich }\end{array}$ & $\begin{array}{l}\text { Erfassung auf Einzelbaumebene, } \\
\text { während zwei bedeutenden } \\
\text { Blühereignissen pro Jahrzehnt, } \\
\text { idealerweise in gleichen } \\
\text { Abständen * }\end{array}$ & $\begin{array}{c}\text { Erfassung auf Einzelbaumebene, } \\
\text { während zwei bedeutenden } \\
\text { Blühereignissen pro Jahrzehnt, } \\
\text { idealerweise in gleichen } \\
\text { Abständen * }\end{array}$ \\
\hline & & $\begin{array}{c}\text { bestandesweise Schätzung; } \\
\text { jährlich }\end{array}$ & $\begin{array}{l}\text { Erfassung auf Einzelbaum- } \\
\text { ebene im selben Jahr, in dem } \\
\text { die Erfassung der Blüte auf } \\
\text { Basisniveau erfolgt (unabhängig } \\
\text { von der Fruktifikationsintensität) * }\end{array}$ & $\begin{array}{l}\text { Zählung der Früchte in } \\
\text { den gleichen Jahren, in } \\
\text { denen die Bewertung der } \\
\text { Blüte auf Intensivniveau } \\
\text { erfolgt, unabhängig von der } \\
\text { Fruktifikationsintensität* } \\
\text { Bei jedem erfassten Fruktifika- } \\
\text { tionsereignis wird auch Saatgut } \\
\text { für Laboranalysen gesammelt }\end{array}$ \\
\hline & $\begin{array}{l}\text { Abundanz von } \\
\text { Naturverjüngung }\end{array}$ & $\begin{array}{l}\text { bestandesweise Schätzung; } \\
\text { jährlich }\end{array}$ & $\begin{array}{l}\text { Zählung der Sämlinge im 1. und } \\
\text { 6. Jahr nach jedem erfassten } \\
\text { Fruktifikationsereignis }\end{array}$ & $\begin{array}{l}\text { Zählung der Sämlinge im 1., } 6 ., \\
\text { 11. und 16. Jahr nach jedem } \\
\text { erfassten Fruktifikationsereignis }\end{array}$ \\
\hline \multirow{4}{*}{ 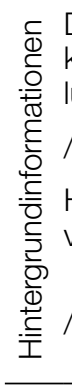 } & $\begin{array}{l}\text { Durchmesser- } \\
\text { klassenvertei- } \\
\text { lung }\end{array}$ & / & Measurement every 10 years & Same as standard level \\
\hline & & Messung alle 10 Jahre & wie Standardniveau & Same as standard level \\
\hline & $\begin{array}{l}\text { Höhenklassen- } \\
\text { verteilung }\end{array}$ & / & $\begin{array}{c}\text { Individual tree level observation, } \\
\text { every } 5 \text { years }\end{array}$ & $\begin{array}{l}\text { Individual tree level observation, } \\
\text { every year }\end{array}$ \\
\hline & & Messung alle 10 Jahre & wie Standardniveau & $\begin{array}{l}\text { Individual tree level observation, } \\
\text { during each assessed major } \\
\text { flowering event }\end{array}$ \\
\hline & Austrieb & / & $\begin{array}{l}\text { Erfassung auf Einzelbaumebene; } \\
\text { alle } 5 \text { Jahre }\end{array}$ & $\begin{array}{l}\text { Erfassung auf Einzelbaumebene; } \\
\text { jährlich }\end{array}$ \\
\hline & $\begin{array}{l}\text { Blühsynchroni- } \\
\text { sation }\end{array}$ & / & / & $\begin{array}{l}\text { Erfassung auf Einzel- } \\
\text { baumebene; während } \\
\text { jedes erfassten größeren } \\
\text { Fruktifikationsereignisses }\end{array}$ \\
\hline
\end{tabular}

\footnotetext{
* Idealerweise sollte mindestens ein größeres Fruktifikationsereignis pro Jahrzehnt bewertet werden. Ein bedeutendes Blühereignis führt jedoch nicht unbedingt zu einem bedeutenden Fruktifikationsereignis. Wenn auf das bewertete Blühereignis kein wesentliches Fruktifikationsereignis folgt, muss die Bewertung sowohl der Blüte als auch der Fruchtbildung beim nächsten bedeutenden Blühereignis wiederholt werden, unabhängig von der Zeit, die zwischen aufeinanderfolgenden bedeutenden Blühereignissen liegt. Erhebungen auf Basisniveau werden zur Identifizierung bedeutender Blüh- und Fruktifikationsereignisse verwendet.
}

\subsection{Verfahren zur Erfassung der Verifikatoren}

\subsubsection{Mortalität / Überlebensrate}

Die Mortalität beschreibt die Sterblichkeit von Altbäumen und Naturverjüngung. Ihr Pendant - die Überlebensratesteht für Bäume, die seit der letzten Datenerhebung noch am Leben sind. Die Überlebensrate wird berechnet als 1 - Mortalität. 


\subsubsection{Altbäume: Basis- Standard- und Intensivniveau}

Der Verifikator für die Mortalität von Altbäumen wird geschätzt, indem die verbleibenden lebenden Beobachtungsbäume alle 10 Jahre sowie nach jedem extremen Witterungsereignis bzw. jeder Störung gezählt werden. Die Mortalität ist die Differenz zwischen der ursprünglichen Anzahl markierter Beobachtungsbäume und den davon verbleibenden lebenden Bäumen der ursprünglichen 50 Beobachtungsbäume.

\subsubsection{Naturverjüngung: Standard- und Intensivniveau}

Die Mortalität der Naturverjüngung wird auf Grundlage des Verifikators „Abundanz der Naturverjüngung“ berechnet. Die Mortalität ist der Unterschied zwischen der anfänglichen Anzahl der Jungpflanzen und den Pflanzen, die zum Zeitpunkt der nächsten Zählung noch am Leben sind. Für jede Bewertungsrunde werden die Jungpflanzen zuerst im Jahr der Keimung und dann wieder nach 5 Jahren auf Standardniveau gezählt, während auf dem Intensivniveau die Zählung zusätzlich nach 10 und 15 Jahren durchgeführt wird. Die Bewertung der „Abundanz der Naturverjüngung“ erfolgt zweimal pro Jahrzehnt, idealerweise etwa alle fünf Jahre.

\subsubsection{Blüte}

Dieser Verifikator beschreibt das Auftreten der Blüte (Anteil der Bäume) und die Blühintensität. Er kann in Mitteleuropa üblicherweise von April bis Anfang Juni erfasst werden.

\subsubsection{Basisniveau}

Der Verifikator wird jährlich auf Bestandesebene erfasst. Die Erfassung erfolgt zum Zeitpunkt der Hauptblüte. Die Schätzung des durchschnittlichen Zustands erfolgt nach einer Begehung der gesamten Monitoringfläche. Es werden zwei Werte erfasst: einer für die Blühintensität, ausgedrückt als mittlerer Kronenanteil in Blüte; und einer für den Anteil der blühenden Bäume im Bestand.

\begin{tabular}{clc} 
Code Blühintensität auf Bestandesebene & Mittlerer Anteil der Kronen in Blüte [\%] \\
\hline 1 & Keine Blüte: Keine oder nur gelegentlich auftretende Blüten & $0-10$ \\
\hline 2 & Schwache Blüte: Einige Blüten erscheinen an den Bäumen & $>10-30$ \\
\hline 3 & Mäßige Blüte: Mäßig viele Blüten an den Bäumen & $>30-60$ \\
\hline 4 & Starke Blüte: Reichlich Blüten an den Bäumen & $>60-90$ \\
\hline 5 & Extreme Blüte: Enorme Anzahl von Blüten an den Bäumen & $>90$ \\
\hline
\end{tabular}

\begin{tabular}{lr} 
Code Anteil der Bäume im Bestand mit dem entsprechenden Stadium der Blühintensität [\%] \\
\hline 1 & $0-10$ \\
\hline 2 & $>10-30$ \\
\hline 3 & $>30-60$ \\
\hline 4 & $>60-90$ \\
\hline 5 & $>90$ \\
\hline
\end{tabular}

\subsubsection{Standardniveau}

Der Verifikator wird während zweier bedeutender Blüteereignisse pro Jahrzehnt aufgezeichnet, idealerweise mit einem ähnlichen zeitlichen Abstand. Er wird für alle 50 Beobachtungsbäume auf Einzelbaumebene erfasst. Ein bedeutendes Blühereignis liegt vor, wenn die Blühintensität auf Basisniveau als stark oder extrem eingeschätzt wird (Code 4 oder 5) und der Anteil der Bäume mit der angegebenen Blühintensität über 60\% liegt (Code 4 oder 5). Die Erfassung erfolgt zum Zeitpunkt der Hauptblüte. Für jeden Beobachtungsbaum wird ein Wert erfasst. 


\begin{tabular}{clr} 
Code Blühintensität auf Bestandesebene & Mittlerer Anteil der Kronen in Blüte [\%] \\
\hline 1 & Keine Blüte: Keine oder nur gelegentlich auftretende Blüten & $0-10$ \\
\hline 2 & Schwache Blüte: Einige Blüten erscheinen an den Bäumen & $>10-30$ \\
\hline 3 & Mäßige Blüte: Mäßig viele Blüten an den Bäumen & $>30-60$ \\
\hline 4 & Starke Blüte: Reichlich Blüten an den Bäumen & $>60-90$ \\
\hline 5 & Extreme Blüte: Enorme Anzahl von Blüten an den Bäumen & $>90$ \\
\hline
\end{tabular}

\subsubsection{Intensivniveau}

Der Verifikator wird während zweier bedeutender Blüteereignisse pro Jahrzehnt aufgezeichnet, idealerweise mit einem ähnlichen zeitlichen Abstand. Er wird für alle 50 Beobachtungsbäume auf Einzelbaumebene erfasst. Ein bedeutendes Blühereignis liegt vor, wenn die Blühintensität auf Basisniveau als stark oder extrem eingeschätzt wird (Code 4 oder 5) und der Anteil der Bäume mit der angegebenen Blühintensität über 60\% liegt (Code 4 oder 5). Im Durchschnitt sind zwei Begehungen auf der Monitoringfläche erforderlich: der erste früh genug, um das Frühstadium der Blüte zu beobachten, der zweite zum Zeitpunkt der Hauptblüte.

Für jeden Baum werden drei Werte angegeben: weibliches Blühstadium, männliches Blühstadium [5] und der blühende Kronenanteil. Letzterer bezieht sich auf die Gesamtmenge der Blüten (männlich + weiblich) am Baum. Die Blühstadien sind in Abbildung 5 dargestellt.

Ein bedeutendes Blühereignis führt nicht unbedingt zu einem bedeutenden Fruktifikationsereignis. Wenn auf das bewertete Blühereignis kein wesentliches Fruktifikationsereignis folgt, muss die Bewertung sowohl der Blüte als auch der Fruchtbildung beim nächsten bedeutenden Blühereignis wiederholt werden. Erhebungen auf Basisniveau werden genutzt, um bedeutende Fruktifikationsereignisse zu identifizieren

\begin{tabular}{ll}
\multicolumn{2}{l}{ Code Weibliches Blühstadium } \\
\hline 1 & $\begin{array}{l}\text { Weibliche Blütenknospen (Zäpfchen) an der Triebspitze deutlich erkennbar, jedoch noch geschlossen und vollständig } \\
\text { von Knospenschuppen bedeckt. }\end{array}$ \\
\hline 2 & Die Spitze des zylindrischen Zäpfchens ist geöffnet und die ersten Samenschuppen erscheinen. \\
\hline 3 & $\begin{array}{l}\text { Die Zäpfchenschuppen sind gespreizt und bilden mit der Achse des Zäpfchens beinahe einen rechten Winkel } \\
\text { (Rezeptivität 100\%). }\end{array}$ \\
\hline 4 & Die Samenschuppen sind geschlossen. \\
\hline
\end{tabular}

\section{Code Männliches Blühstadium}

1 Die männlichen Blütenstände (Pollensäcke) beginnen sich zu entwickeln, sind jedoch noch geschlossen und vollständig bedeckt.

2 Die Mikrosporangien sind nicht mehr kompakt, bei Druck tritt eine grün-gelbe Flüssigkeit aus den Pollensäcken aus.

3 Die Pollensäcke sind gelb und setzen ihren Pollen frei.

\begin{tabular}{lr} 
Code Anteil der Krone in Blüte [\%, männliche und weibliche Blüten] & \\
\hline 1 & $0-10$ \\
\hline 2 & $>10-30$ \\
\hline 3 & $>30-60$ \\
\hline 4 & $>60-90$ \\
\hline 5 & $>90$ \\
\hline
\end{tabular}

Hintergrundinformationen zur Blühsynchronisation können anhand der für diesen Verifikator erfassten Werte für die weibliche und männliche Blüte abgeleitet werden. 
(a)

1

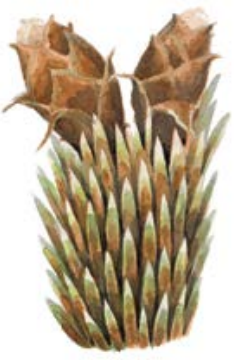

2

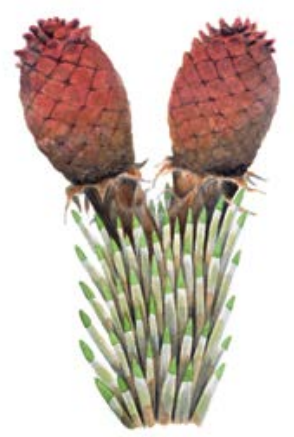

3

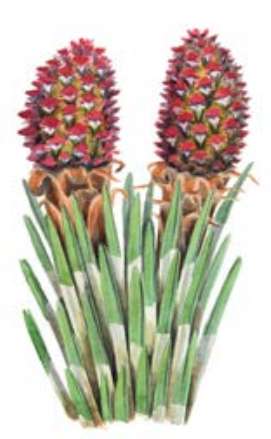

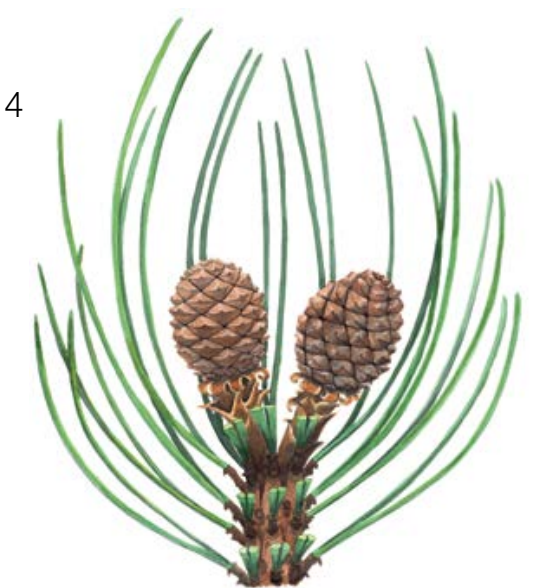

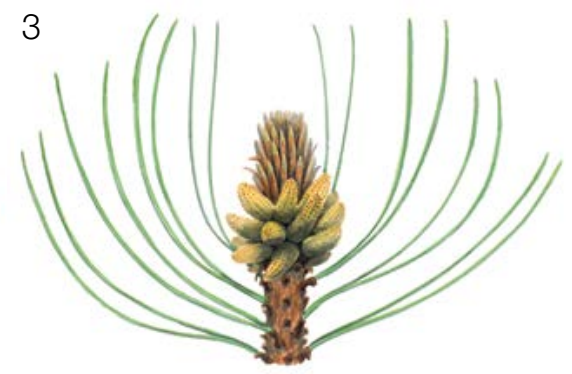

(b)
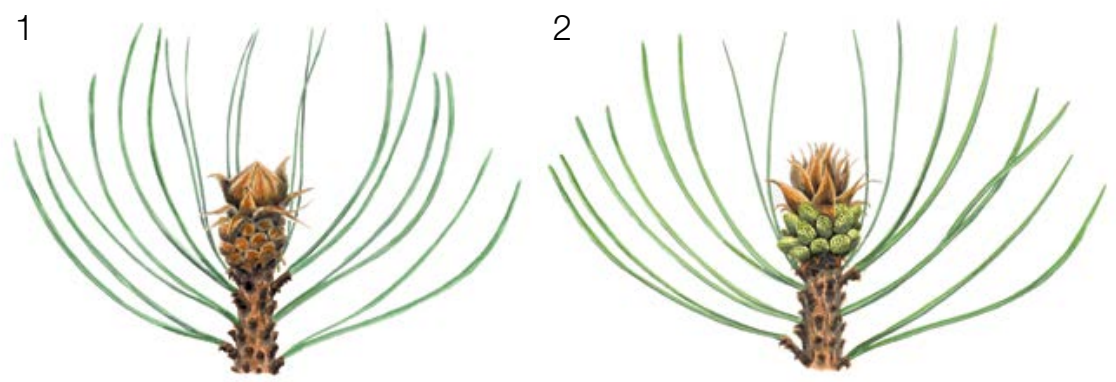

Abbildung 5: Illustrationen zur Beschreibung der weiblichen (a) und männlichen (b) Blühstadien für den Verifikator „Blüte“ auf Intensivniveau.

\subsubsection{Fruktifikation}

Dieser Verifikator beschreibt das Auftreten und die Häufigkeit der Fruchtbildung für Pinus nigra. Die Daten für diesen Verifikator sollten während der Fruktifikationszeit von Pinus nigra erhoben werden, d.h. von September bis November. Die Zapfen der Schwarzkiefer reifen im zweiten Herbst nach der Blüte.

\subsubsection{Basisniveau}

Der Verifikator wird jährlich auf Bestandesebene erfasst. Die Schätzung des durchschnittlichen Zustands erfolgt nach einer Begehung der gesamten Monitoringfläche. Es werden zwei Werte erfasst: einer für die Intensität der Fruktifikation und einer für den Anteil fruchttragender Bäume im Bestand.

\begin{tabular}{llr}
\hline \multicolumn{2}{l}{ Code Intensität der Fruktifikation auf Bestandesebene } & Mittlerer Anteil der Krone mit Fruchtbehang (\%) \\
\hline 1 & $\begin{array}{l}\text { Keine Fruchtbildung: Keine oder nur gelegentlich auftretende Früchte } \\
\text { an den Bäumen }\end{array}$ & $0-10$ \\
\hline 2 & Schwache Fruchtbildung: Einige Früchte an den Bäumen & $>10-30$ \\
\hline 3 & Mäßige Fruchtbildung: Mäßig viele Früchte an den Bäumen & $>30-60$ \\
\hline 4 & Starke Fruchtbildung: Reichlich Früchte an den Bäumen & $>60-90$ \\
\hline 5 & Extreme Fruchtbildung: Enorme Anzahl von Früchten an den Bäumen & $>90$ \\
\hline
\end{tabular}




\begin{tabular}{lr} 
Code & Anteil der Bäume im Bestand mit dem entsprechenden Stadium der Fruktifikationsintensität [\%] \\
\hline 1 & $0-10$ \\
\hline 2 & $>10-30$ \\
\hline 3 & $>30-60$ \\
\hline 4 & $>60-90$ \\
\hline 5 & $>90$ \\
\hline
\end{tabular}

\subsubsection{Standardniveau}

Die Erfassung des Verifikators erfolgt in denselben Jahren wie die Bewertung der Blüte auf Standardniveau (unabhängig von der Fruktifikationsintensität). Sie wird für alle 50 Beobachtungsbäume auf Einzelbaumebene durchgeführt - und zwar bevor die reifen Zapfen ihre Samen verteilen und zu fallen beginnen. Für jeden Beobachtungsbaum wird ein Wert erfasst.

Im Idealfall sollte pro Jahrzehnt ein auf ein bedeutendes Blühereignis folgendes größeres Fruktifikationsereignis erfasst werden. Ein bedeutendes Blühereignis führt jedoch nicht unbedingt $z u$ einem bedeutenden Fruktifikationsereignis. Wenn auf das bewertete Blühereignis kein wesentliches Fruktifikationsereignis folgt, muss die Bewertung sowohl der Blüte als auch der Fruchtbildung beim nächsten bedeutenden Blühereignis wiederholt werden, unabhängig von der Zeit, die zwischen aufeinanderfolgenden bedeutenden Blühereignissen liegt. Erhebungen auf Basisniveau werden genutzt, um bedeutende Fruktifikationsereignisse zu identifizieren. Ein bedeutendes Fruktifikationsereignis liegt vor, wenn die Fruktifikationsintensität auf Basisniveau als stark oder extrem eingeschätzt wird (Code 4 oder 5) und der Anteil der Bäume mit der angegebenen Fruktifikationsintensität über 60\% liegt (Code 4 oder 5).

\begin{tabular}{llr} 
Code Intensität der Fruktifikation auf Bestandesebene & $\begin{array}{r}\text { Mittlerer Anteil der Krone mit Fruchtbehang } \\
\text { (\%) }\end{array}$ \\
\hline 1 & $\begin{array}{l}\text { Keine Fruchtbildung: Keine oder nur gelegentlich auftretende Früchte } \\
\text { an den Bäumen }\end{array}$ & $0-10$ \\
\hline 2 & Schwache Fruchtbildung: Einige Früchte an den Bäumen & $>10-30$ \\
\hline 3 & Mäßige Fruchtbildung: Mäßig viele Früchte an den Bäumen & $>30-60$ \\
\hline 4 & Starke Fruchtbildung: Reichlich Früchte an den Bäumen & $>60-90$ \\
\hline 5 & Extreme Fruchtbildung: Enorme Anzahl von Früchten an den Bäumen & $>90$ \\
\hline
\end{tabular}

\subsubsection{Intensivniveau}

Die Erfassung des Verifikators erfolgt für alle 50 Beobachtungsbäume auf Einzelbaumebene in denselben Jahren wie die Bewertung der Blüte auf Intensivniveau (unabhängig von der Fruktifikationsintensität). Sie wird durchgeführt, bevor die Zapfen beginnen zu zerfallen. Für jeden Beobachtungsbaum wird ein Wert erfasst. Zeitgleich wird Saatgut für die Saatgut- und Genanalysen gesammelt (für die Verifikatoren und Hintergrundinformationen auf Intensivniveau).

Im Idealfall sollte pro Jahrzehnt ein auf ein bedeutendes Blühereignis folgendes größeres Fruktifikationsereignis erfasst werden. Ein bedeutendes Blühereignis führt jedoch nicht unbedingt zu einem bedeutenden Fruktifikationsereignis. Wenn auf das bewertete Blühereignis kein wesentliches Fruktifikationsereignis folgt, muss die Bewertung sowohl der Blüte als auch der Fruchtbildung beim nächsten bedeutenden Blühereignis wiederholt werden, unabhängig von der Zeit, die zwischen aufeinanderfolgenden bedeutenden Blühereignissen liegt. Erhebungen auf Basisniveau werden genutzt, um bedeutende Fruktifikationsereignisse zu identifizieren. Ein bedeutendes Fruktifikationsereignis liegt vor, wenn die Fruktifikationsintensität auf Basisniveau als stark oder extrem eingeschätzt wird (Code 4 oder 5) und der Anteil der Bäume mit der angegebenen Fruktifikationsintensität über 60\% liegt (Code 4 oder 5). 
Der Verifikator wird durch das Zählen von Zapfen unter Nutzung eines Fernglases erfasst (als Durchschnitt von drei Zählrunden). Jede Zählrunde besteht aus der Anzahl der Zapfen, die der Beobachter in 30 Sekunden zählt. Bei allen Bäumen sollte das gleiche Kronendrittel untersucht werden. Sobald ein Kronendrittel für die Beobachtung ausgewählt wurde, sollte dieses für jede weitere Erhebung dieses Verifikators ausgewählt werden. Für die Zählung wird das obere Kronendrittel dem unteren und mittleren Drittel vorgezogen.

Es werden zwei Werte erfasst: die Anzahl der Zapfen und das untersuchte Kronendrittel.

\section{Anzahl der in 30 Sekunden gezählten Zapfen (Mittelwert aus 3 Zählrunden)}

$$
\mathrm{X}
$$

\begin{tabular}{|c|c|}
\hline \multicolumn{2}{|c|}{ Code Untersuchtes Kronen } \\
\hline 1 & unteres Kronendrittel \\
\hline 2 & mittleres Kronendrittel \\
\hline 3 & oberes Kronendrittel \\
\hline
\end{tabular}

\subsubsection{Abundanz von Naturverjüngung}

Dieser Verifikator beschreibt das Vorhandensein und die Häufigkeit von Naturverjüngung auf der Monitoringfläche.

\subsubsection{Basisniveau}

Der Verifikator wird jährlich im Herbst auf Bestandesebene erfasst. Für die Schätzung der Situation auf der gesamten Monitoringfläche werden Expertenmeinungen herangezogen. Es sollten zwei Werte erfasst werden: einer für neue aufgelaufene Naturverjüngung (diesjährige Keimlinge) und einer für etablierte Naturverjüngung (ein- und mehrjährige Jungpflanzen). Da Pinus nigra alle 3-5 Jahre fruktifiziert, sollte die Etablierung neuer NV im dem auf ein Mastjahr folgenden Sommer/Herbst erfasst werden.

\begin{tabular}{|c|c|}
\hline Code & Beschreibung: neue aufgelaufene Naturverjüngung (diesjährige Keimlinge) \\
\hline $1 \mathrm{a}$ & Auf der Monitoringfläche gibt es keine oder nur sehr wenig neue Naturverjüngung \\
\hline $2 a$ & Auf der Monitoringfläche ist in ausreichender Anzahl neue Naturverjüngung vorhanden \\
\hline Code & Beschreibung: etablierte Naturverjüngung (Sämlinge) \\
\hline $1 b$ & Auf der Monitoringfläche gibt es keine oder nur sehr wenig etablierte Naturverjüngung \\
\hline $2 b$ & Auf der Monitoringfläche ist in ausreichender Anzahl etablierte Naturverjüngung vorhanden \\
\hline
\end{tabular}

\subsubsection{Standardniveau}

DieserVerifikator wird durchZählung der Sämlinge im 1. und 6. Herbstnach jedem bewerteten Fruktifikationsereignis erfasst (das Jahr des Fruktifikationsereignisses wird als Jahr 0 betrachtet).

Zählung der Naturverjüngung:

Nach der Anlage der NV-Plots werden alle Pinus nigra-Sämlinge in den NV-Plots gezählt. Ältere Kiefernjungpflanzen, die in den NV-Plots vorhanden sind, dürfen nicht mitgezählt werden. Bei der nächsten Zählung sind nur die Kiefernjungpflanzen im entsprechenden Alter zu zählen; d.h. im 6. Jahr alle 5 Jahre alten Kiefern.

\section{Anzahl der Jungpflanzen auf einem NV-Plot}


Die Mortalität/Überlebensrate der Naturverjüngung wird anhand der für diesen Verifikator erfassten Werte berechnet.

Zur Anlage von NV-Plots siehe Kapitel 6.2 Anlage von Naturverjüngungs-Plots.

\subsubsection{Intensivniveau}

Der Verifikator wird durch Zählung der Sämlinge im 1., 6., 11. und 16. Herbst nach jedem bewerteten Fruktifikationsereignis erfasst (das Jahr des Fruktifikationsereignisses wird als Jahr 0 betrachtet). Die nächste Runde des NV-Monitorings (Einrichtung neuer 20 NV-Plots und Schätzung der NV-Abundanz) wird mindestens 5 Jahre nach dem ersten Fruktifikationsereignis nach einem weiteren bedeutenden Fruktifikationsereignis durchgeführt (siehe Tabelle 3 für eine grafische Darstellung der Zeitachse zur Schätzung der NV-Abundanz). Es wird erwartet, dass die NV-Abundanz für ein oder zwei bedeutende Fruktifikationsereignisse pro Monitoringintervall beurteilt wird.

Tabelle 3: Zeitstrahl zur Erfassung der Abundanz von Naturverjüngung (NV). In diesem Beispiel findet das erste Fruktifikationsereignis im 2. Jahr des Beobachtungsjahrzehnts statt; das zweite erfasste Fruktifikationsereignis fünf Jahre später, d.h. im 7. Jahr des Monitorings. Da bei Pinus nigra größere Fruktifikationsereignisse alle 3 - 5 Jahre auftreten, kann das Intervall zwischen zwei aufeinander folgenden größeren Fruktifikationsereignissen entsprechend variieren. Nach jedem bewerteten Fruktifikationsereignis werden 20 neue NV-Plots angelegt. Die Erfassung der NV-Abundanz auf jedem Set von 20 NV-Plots erfolgt alle fünf Jahre. Die zur jeweils erfassten NV gehörigen Fruktifikationsereignisse und der Verlauf der Monitoringaktivitäten sind in derselben Farbe schattiert. Nach der letzten Runde der NV-Zählung wird das Monitoring der NV-Abundanz auf dem entsprechenden Set von NV-Plots eingestellt und die jeweiligen NV-Plots werden aufgelöst. S - Standardniveau; I - Intensivniveau.

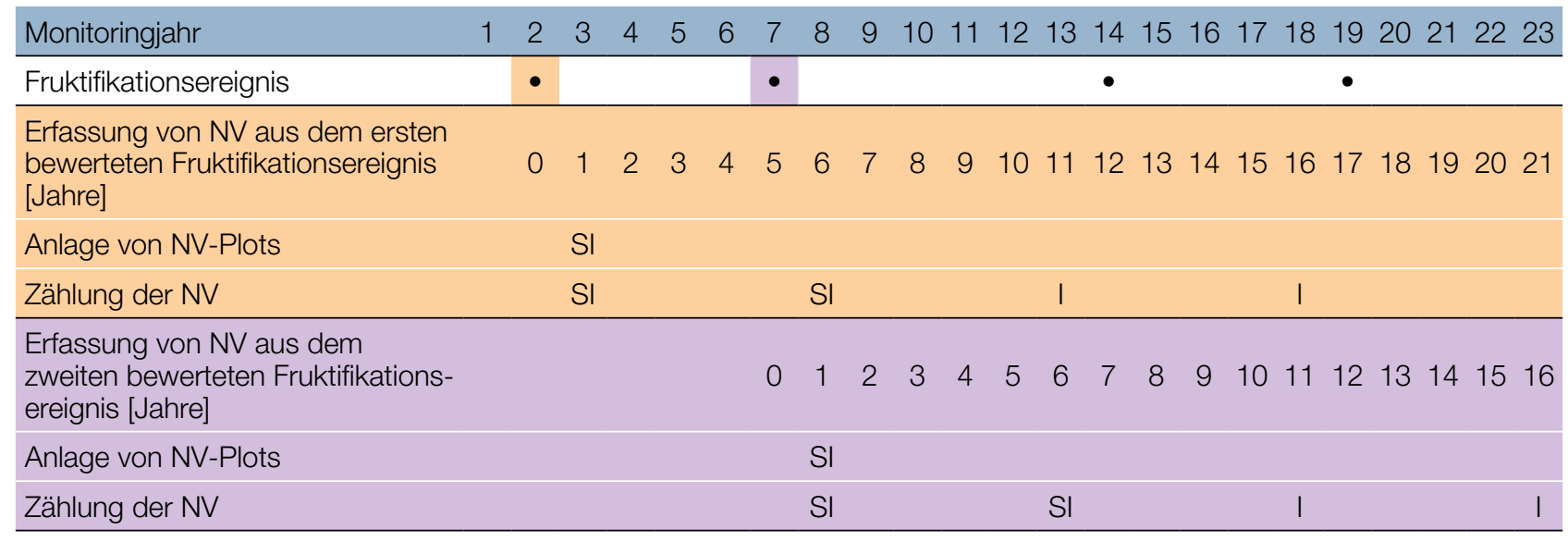

Die Mortalität/Überlebensrate der Naturverjüngung wird anhand der für diesen Verifikator erfassten Werte berechnet.

Zur Anlage von NV-Plots siehe Kapitel 6.2 Anlage von Naturverjüngungs-Plots; zur Zählung der NV siehe Kapitel 7.1.4.2 Standardniveau.

\subsection{Verfahren zur Erfassung von Hintergrundinformationen}

\subsubsection{Durchmesserklassenverteilung}

\subsubsection{Standard- und Intensivniveau}

Der BHD wird alle 10 Jahre für alle 50 Beobachtungsbäume auf Einzelbaumebene erfasst. Der BHD ist der Stammdurchmesser in 1,30 m Höhe, d.h. ungefähr auf Brusthöhe eines Erwachsenen. Hat der Baum mehr als einen Stamm, messen Sie bitte alle Stämme und erfassen Sie den Durchschnitt (versuchen Sie jedoch, Bäume mit vielen kleinen Stämmen zu vermeiden). Notieren Sie in den Anmerkungen, dass der Baum mehrstämmig ist, und geben Sie die Anzahl der gemessenen Stämme an. Ist der Baum geneigt, messen Sie den BHD senkrecht zum Baumstamm. Der BHD kann auf zwei Arten gemessen werden: 
1) mit einer Kluppe; in diesem Fall messen Sie senkrecht zueinander zwei Durchmesser und berechnen den Mittelwert

2) Messen Sie den Umfang des Baumes und berechnen Sie daraus den Durchmesser (d.h. dividieren Sie durch $\pi ; \sim 3,14)$

Der BHD wird in cm angegeben. Für nachfolgende Messungen ist stets dieselbe Methode anzuwenden.

\subsubsection{Höhenklassenverteilung}

\subsubsection{Standard- und Intensivniveau}

Die Baumhöhe wird alle 10 Jahre für alle 50 Beobachtungsbäume auf Einzelbaumebene erfasst. Die Höhe wird vom Boden bis zum höchsten Punkt der Krone gemessen, idealerweise mit einem Klinometer oder Hypsometer (z.B. Vertex). Die Höhe wird in Metern auf eine Dezimalstelle angegeben. Ist die Krone beschädigt, muss dies in den Anmerkungen zusammen mit dem mutmaßlichen Grund für den Schaden notiert werden.

\subsubsection{Austrieb}

Diese Hintergrundinformation beschreibt die Austriebsstadien. Bei der Schwarzkiefer beginnt der Austrieb etwas später als die Blüte. Die Aufzeichnung erfolgt nur auf Standard- und Intensivniveau. Die Daten für diese Hintergrundinformation sollten in Mitteleuropa von April bis Mai erhoben werden, bis alle Beobachtungsbäume voll entwickelte Nadeln haben.

\subsubsection{Standardniveau}

Auf Standardniveau wird der Austrieb alle 5 Jahre für alle 50 Beobachtungsbäume auf Einzelbaumebene beobachtet. Untersucht werden der Beginn der Knospenöffnung (Stadium 2) und das Ende des Austriebs (Stadium 5). Die Beobachtungen werden beendet, wenn alle Bäume das Stadium 5 erreicht haben. In der Regel sind dafür 6 Begehungen erforderlich. Für jeden Baum werden zwei Werte erfasst: das Austriebsstadium und der entsprechende Kronenanteil. Die Austriebsstadien sind in Abbildung 6 dargestellt.

\begin{tabular}{|c|c|}
\hline \multicolumn{2}{|c|}{ Code Austriebsstadium (vereinfachte Stadien [5]) } \\
\hline 1 & Ruhende Knospen \\
\hline 2 & Beginnende Verlängerung der Knospen \\
\hline 3 & Deutliche Verlängerung der Terminalknospe \\
\hline 4 & Nadeln erscheinen aus transparenter Hülle (Nadelscheide) \\
\hline 5 & Die zwei Nadeln derselben Nadelscheide sind voll entwickelt \\
\hline
\end{tabular}

\begin{tabular}{lr} 
Code Anteil der Krone mit dem entsprechenden Austriebsstadium [\%] & $>0-33$ \\
\hline 1 & $>33-66$ \\
\hline 2 & $>66-99$ \\
\hline 3 & 100 \\
\hline 4 & \\
\hline
\end{tabular}

\subsubsection{Intensivniveau}

Auf Intensivniveau wird der Austrieb jährlich für alle 50 Beobachtungsbäume auf Einzelbaumebene erhoben, mit derselben Verfahrensweise wie auf Standardniveau. Details dazu sind im Kapitel 7.2.3.1 Standardniveau zu finden. 


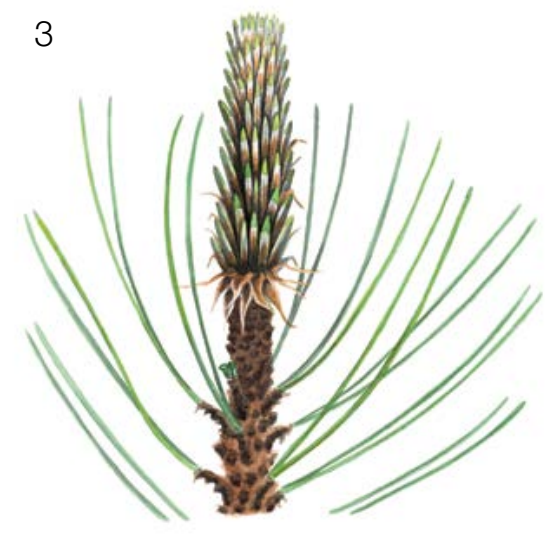

4
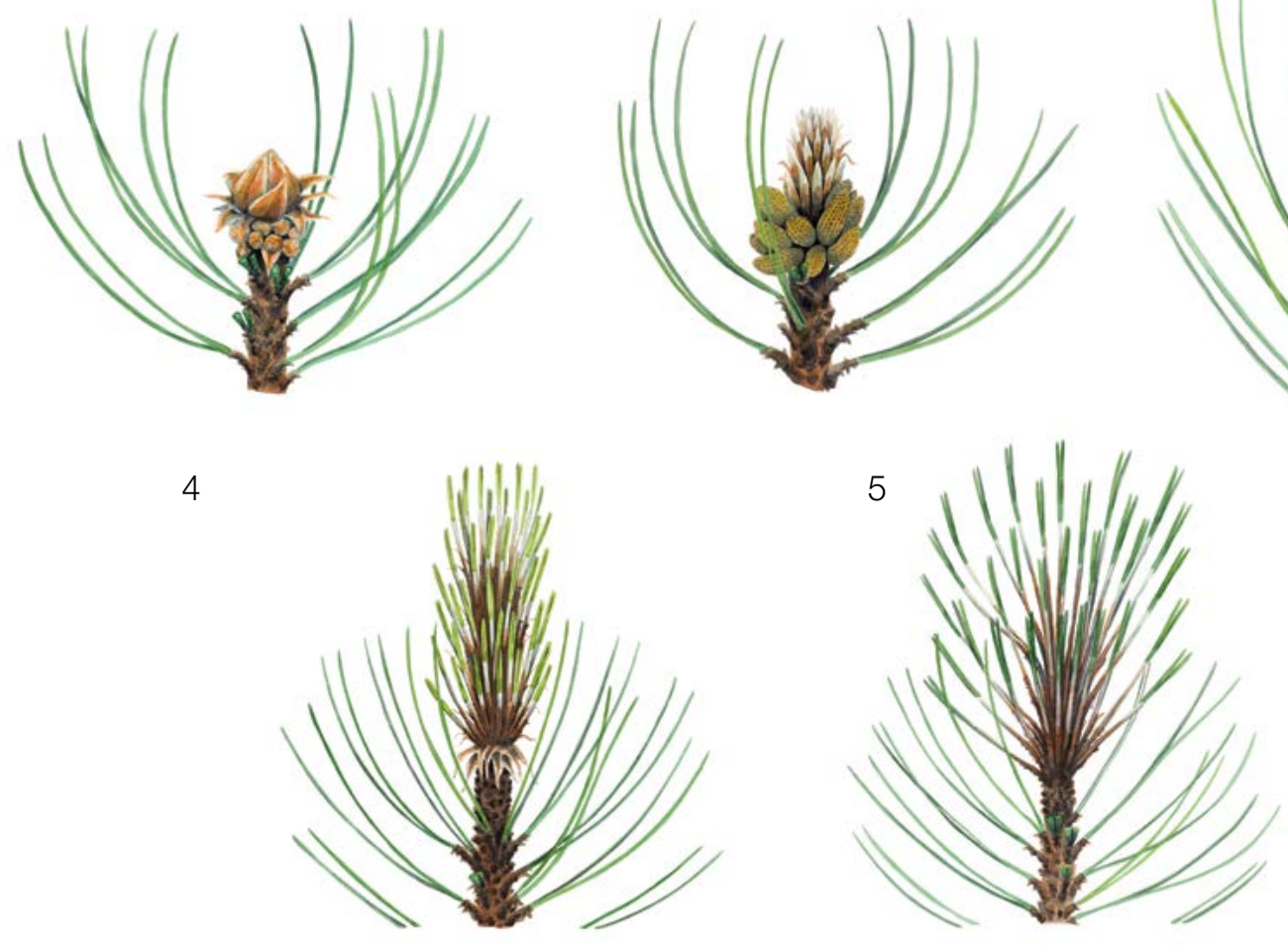

Abbildung 6: Illustration zur Beschreibung der Hintergrundinformation „Austrieb“ auf Standard- und Intensivniveau.

\subsubsection{Blühsynchronisation}

Die Hintergrundinformation „Blühsynchronisation“ wird nur auf Intensivniveau erfasst und basiert auf den für den Verifikator „Blüte“ erhobenen Daten. Sie wird verwendet, um festzustellen, ob die männliche und weibliche Blüte innerhalb des untersuchten Bestandes gleichzeitig stattfindet bzw. inwieweit sie sich zeitlich überschneidet [19].

\subsubsection{Intensivniveau}

Die Blühsynchronisation wird jährlich für alle 50 Beobachtungsbäume auf Einzelbaumebene erfasst; und zwar für jedes erfasste bedeutende Blühereignis und im selben Jahr, in dem auch Samen beprobt werden (wie für den Verifikator „Blüte“ auf Intensivniveau).

\section{Formular für die Beschreibung der Monitoringfläche: 'FGM Plot description'}

Formular für die Erfassung der Verifikatoren: 'Form for recording field level verifiers within FGM'

Formular für die Aufzeichnung von Hintergrundinformationen: 'Form for recording field level background information within FGM' 


\section{Quellen}

1. 1. Farjon A (2017) A Handbook of the World's Conifers. 2nd revised Edition, Volume 1. Brill Leiden - Boston. Brill Acad. Publ. https://doi.org/10.1163/9789047430629

2. Burns RM, Honkala BH (1990) Silvics of North America. Volume 1. Conifers. Agriculture Handbook 654, USDA Forest service, Washington

3. Vidaković M (1958) Investigation on the intermediate type between the Austrian and Scots pine. Silv Gen 7:12-19.

4. Fukarek P (1958) Die Standortstrassen per Shwarzföhre (Pinus nigra Arn.). Centralblatt fuer das gesamte Forstwesen 75:203-207

5. McWilliam JR (1959) Interspecific incompatibility in Pinus. Am J Bot 46:425-433. https://doi. org/10.1002/j.1537-2197.1959.tb07033.x

6. Righter Fl, Duffield JW (1951) Interspecific hybrids in pines. J Hered 42:75-80. https://doi.org/10.1093/oxfordjournals. jhered.a106169

7. Juranović-Cindrić I, Zeiner M, Starčević A, Liber Z, Rusak G, Idžojtić M, Stingeder G (2018) Influence of F1 hybridization on the metal uptake behaviour of pine trees (Pinus nigra $x$ Pinus thunbergiana; Pinus thunbergiana $x$ Pinus nigra). J. Trace Elem Med Biol 48:190-195. https://doi.org/10.1016/j.jtemb.2018.04.009

8. Vidaković M (1974) Genetics of European black pine (Pinus nigra Arn.). Annales Forestales (6/3):57-86.

9. Mitchell AF (1972) Conifers in the British Isles: A descriptive handbook. Forestry Commission Booklet No. 33. London: Her Majesty's Stationery Office

10. Rose $\mathrm{Cl}$ (1979) Observations on the ecology and conservation value of native and introduced tree species. Q J Forest 73(4):219-229

11. Athanasiadis NH (1986) Forest Botany (Trees and Shrubs of the Hellenic Forests). Part II. Publ. Giahoudi Thessaloniki

12. Isajev V, Fady B, Semerci H, Andonovski V (2004) EUFORGEN technical guidelines for genetic conservation and use of European black pine (Pinus nigra). International Plant Genetic Resources Institute, Rome

13. Van Haverbeke DF (1990) Pinus nigra Arnold - European black pine. In: Burns RM; Honkala BH (eds). Silvics of North America. Volume 1. Conifers. Agric. Handb. U.S. Department of Agriculture, Forest Service, Washington, DC

14. Freeland RO (1944) Apparent photosynthesis in some conifers during the winter. PI Physiol 19:179-185

15. Boutheina A, El Aouni MH, Balandier $P$ (2013) Influence of stand and tree attributes and silviculture on cone and seed productions in forests of Pinus pinea L. in northern Tunisia. Options Méditerranéennes Series A: Mediterranean Seminars, No. 105. CIHEAM, FAO, INIA, IRTA, CESEFOR, CTFC, Zaragoza

16. Nicholls TH, Hudler GW (1971) Dothistroma pini on Pinus nigra in Minnesota. Plant Disease Reporter 55: 1040.

17. Millar CS (1970) Role of Lophodermella species in premature death of Pine needles in Scotland. Report on Forest Research, London, pp 176-178

18. Blodgett JT, Eyles A, Bonello P (2007) Organ-dependent induction of systemic resistance and systemic susceptibility in Pinus nigra inoculated with Sphaeropsis sapinea and Diplodia scrobiculata. Tree Physiol 27: 511-517. https://doi. org/10.1093/treephys/27.4.511

19. Alizoti PG, Kilimis K, Gallios P (2010). Temporal and spatial variation of flowering among Pinus nigra Arn. clones under changing climatic conditions. For Ecol Manag 259:768-797. http://dx.doi.org/10.1016/j.foreco.2009.06.029 
Die folgenden Ressourcen wurden für die derzeit akzeptierten (Dezember 2020) wissenschaftlichen Namen der in diesem Dokument erfassten oder erwähnten Arten konsultiert:

a. Avtzis N (1985) Marchalina hellenica (Monophlebus hellenicus) Gen. An important honey producing insect of Greece. Dasiki Erevna VI(1):51-63

b. Bußkamp J, Langer GJ \& Langer EJ (2020) Sphaeropsis sapinea and fungal endophyte diversity in twigs of Scots pine (Pinus sy/vestris) in Germany. Mycol Progress 19:985-999. https://doi.org/10.1007/s11557-020-01617-0

c. CABI (2020) Invasive Species Compendium. CAB International, Wallingford, UK. www.cabi.org/isc. Accessed 15 December 2020

d. EPPO (2020) EPPO Global Database (available online). https://gd.eppo.int. Accessed 15 December 2020

e. GBIF (2020) Global Biodiversity Information Facility. https://www.gbif.org Accessed 15 December 2020

f. IPNI (2020) International Plant Names Index. The Royal Botanic Gardens, Kew, Harvard University Herbaria \& Libraries \& Australian National Botanic Gardens. http://www.ipni.org, Accessed 10 December 2020

g. National Center for Biotechnology Information (NCBI) (1998) National Library of Medicine (US), National Center for Biotechnology Information, Bethesda (MD). https://www.ncbi.nlm.nih.gov/. Accessed 15 December 2020

h. The Plant List (2013) Version 1.1. http://www.theplantlist.org/. Accessed 12 December 2020

i. Tropicos.org (2020) Missouri Botanical Garden. http://www.tropicos.org. Accessed 15 December 2020

j. $\quad$ WFO (2020) World Flora Online. http://www.worldfloraonline.org. Accessed 15 December 2020 



\section{Leitfaden für das genetische Monitoring der}

\subsubsection{Schwarz-Pappel (Populus nigra L.)}

Gregor BOŽIČ' ${ }^{1}$, Sándor BORDÁCS², Berthold HEINZE³, Marko BAJC'1, Filippos A. ARAVANOPOULOS ${ }^{4}$, Dalibor BALLIAN ${ }^{1,5}$, Rok DAMJANIĆ', Barbara FUSSI', Darius KAVALIAUSKAS ${ }^{6}$, Zvonimir VUJNOVIĆ7 Marjana WESTERGREN', Hojka KRAIGHER ${ }^{1}$

Botanische Illustrationen von Marina Gabor

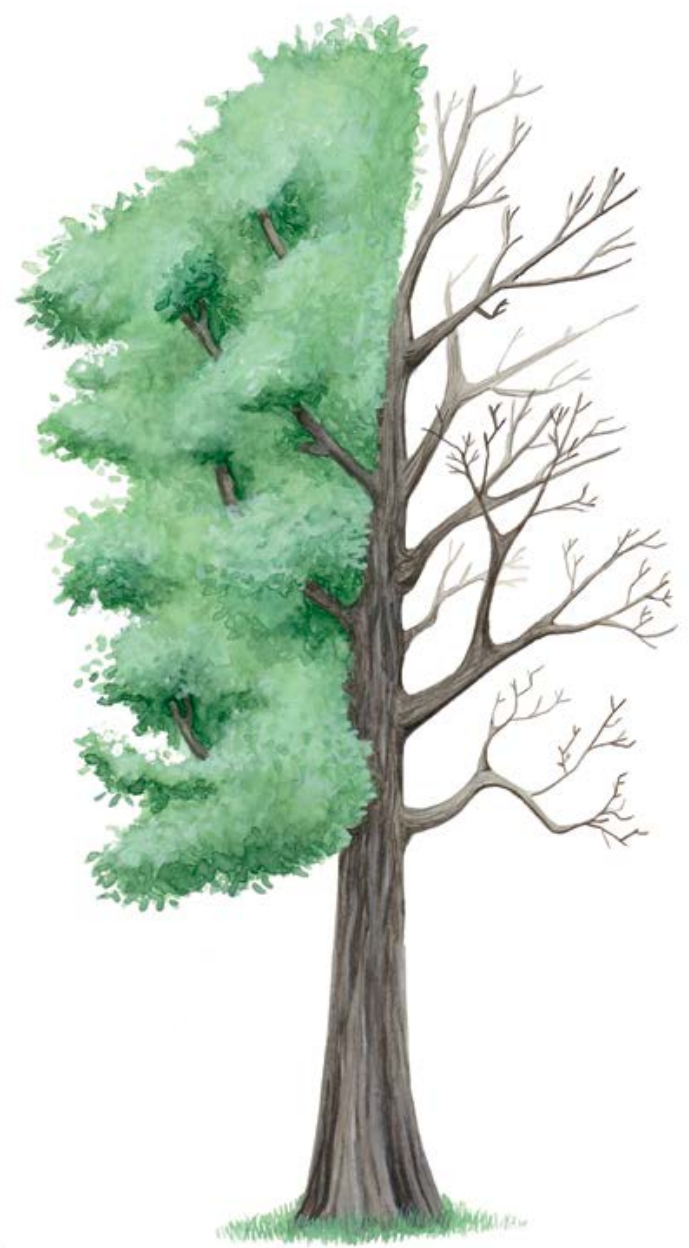

Zitat: Božič et al. (2020) Leitfaden für das genetische Monitoring der Europäischen Schwarz-Pappel (Populus nigra L.). In: Bajc et al. (Ed.) Handbuch zum Forstgenetischen Monitoring. Slowenisches Forstinstitut: Verlag Silva Slovenica, Ljubljana, S. 249-269. http://dx.doi.org/10.20315/SFS.176

Institut:

1. Slowenisches Forstinstitut (SFI), Slowenien

2. Szent-István-Universität, Budapest, Ungarn

3. B̈undesforschungs- und Ausbildungszentrum für Wald, Naturgefahren und Landschaft (BFW), Osterreich

4. Aristoteles Universität von Thessaloniki (AUTH), Griechenland

5. Forstliche Fakultät, Universität von Sarajevo, Bosnien und Herzegowina

6. Bayerisches Amt für Waldgenetik (AWG), Deutschland

7. Kroatisches Forstliches Forschungsinstitut (CFRI), Jastrebarsko, Kroatien 


\section{ZUSAMMENFASSUNG}

Die Schwarz-Pappel (Populus nigra L.) ist eine ökologisch bedeutsame, schnell wachsende und kurzlebige Laubbaumart gemischter Auwälder. Sie ist physiologisch an die Besiedlung offener Flächen nach Störungsereignissen angepasst und kann drastische Veränderungen im Zusammenhang mit dynamischen Flusssystemen überleben. Als Schlüsselart für den dynamischen Schutz und die Renaturierung von Auenwäldern trägt die Baumart zu einer natürlichen Hochwasserregulierung bei und gilt als Indikatorart für den Gesundheitszustand und die Artenvielfalt von Auwald-Ökosystemen [1]. Die Schwarz-Pappel ist auch für ihre Fähigkeit bekannt, während ihrem schnellen Wachstum große Mengen an Wasser und Nährstoffen aus dem Boden aufzunehmen. Diese Fähigkeit macht sie wichtig für die Phytosanierung, Renaturierung und Umweltschutzmaßnahmen in verschmutzten Industriegebieten, für die Regulierung des Mikroklimas und für die Erhöhung der Biodiversität in offenen Agrarlandschaften [2]. Sie wird als Elternpool für mehrere Pappelzuchtprogramme auf derganzen Welt verwendet. DieSchwarz-Pappel lässt sich gut im Niederwaldbetrieb bewirtschaften, was die langfristige Ex situ-Erhaltung der besten Genotypen von reinem Schwarz-PappelPflanzenmaterial ermöglicht. Im Rahmen von EUFORGEN wurde eine breite Palette von Empfehlungen für In situ-Erhaltungseinheiten und Ex situ-Erhaltungsmethoden vorgeschlagen [3] und später von mehreren regionalen Projekten aufgegriffen [4].

Die Schwarz-Pappel bildet von Natur aus eher Metapopulationen aus miteinander verbundenen lokalen Populationen anstelle kleiner, isolierter Populationen [6]. Um eine repräsentative Probenahme der gesamten Metapopulation zu gewährleisten, ist es daher wichtig, ein genetisches Monitoringsystem zu konzipieren, das aus einem vollständigen Netzwerk miteinander verbundener zufällig ausgewählter Monitoringflächen mit Altbäumen und Flächen mit natürlichen Verjüngungszentren entlang eines Flusssystems besteht. Die genetische Identifizierung der Schwarz-Pappel erfolgt durch den Einsatz artdiagnostischer DNA-Marker. Das größte Hindernis für das forstgenetische Monitoring (FGM) der Schwarz-Pappel ist das Auffinden von Habitaten, in denen sich die Art effektiv fortpflanzt und die Bedingungen das langfristige Überleben der Nachkommenschaft ermöglichen.

Dieser Leitfaden beschreibt die Schwarz-Pappel sowie ihre Reproduktion, Umwelt und Gefährdung. Er enthält außerdem eine Anleitung zur Einrichtung genetischer In situ-Monitoringflächen und zur Erfassung aller vor Ort im Bestand zu erhebenden Verifikatoren.

\section{BESCHREIBUNG DER BAUMART}

Die Schwarz-Pappel (Abbildung 1) ist eine heimische, heliophile und nährstoffbedürftige Laubbaumart der gemäßigten Klimazonen Eurasiens. Sie gehört zur Sektion Aigeros der Gattung Populus, Familie Salicaceae [5]. Die Art besiedelt durch Störungsereignisse entstandene offene Flächen, insbesondere in dynamischen Flusssystemen, und ist in den frühen Sukzessionsstadien von Auwald-Ökosystemen zu finden. SchwarzPappel-Populationen umfassen eine breite Spanne an Populationstypen, die von isolierten Einzelbäumen bis hin zu großen Rein- oder Mischbeständen reichen. Die Schwarz-Pappel bildet natürlicherweise Metapopulationen, die aus kleineren lokalen Populationen bestehen [6, 7].

Die Schwarz-Pappel ist ein mittelgroßer bis großer Baum, der meist eine Höhe von bis zu $40 \mathrm{~m}$ und einen Durchmesser von bis zu 3 m erreicht und 100-200 Jahre alt wird. In seltenen Fällen können Individuen ein Alter von 400 Jahren erreichen [8, 9]. Die Baumart bildet häufig eine unregelmäßige, stark verzweigte Krone aus. Der oft gekrümmte oder gebogene, spannrückige Stamm kann massiv sein und bringt häufig große Wasserreiser-Knollen hervor. In geschlossenen Beständen können Schwarz-Pappeln jedoch auch gerade und gut geformt sein [10]. Die Rinde ausgewachsener Bäume ist dunkelbraun oder schwarz (Abbildung 2a) und tief gefurcht [11]. Die Blätter sind rautenförmig bis dreieckig, 5-12 cm lang und 4-10 cm breit, mit einem 2-6 cm langen Blattstiel [12, 13], haben gezackte Ränder und sind beidseitig grün (Abbildung 2b). Schwarz-Pappeln erreichen die Geschlechtsreife innerhalb von 10 bis 15 Jahren [14]. 

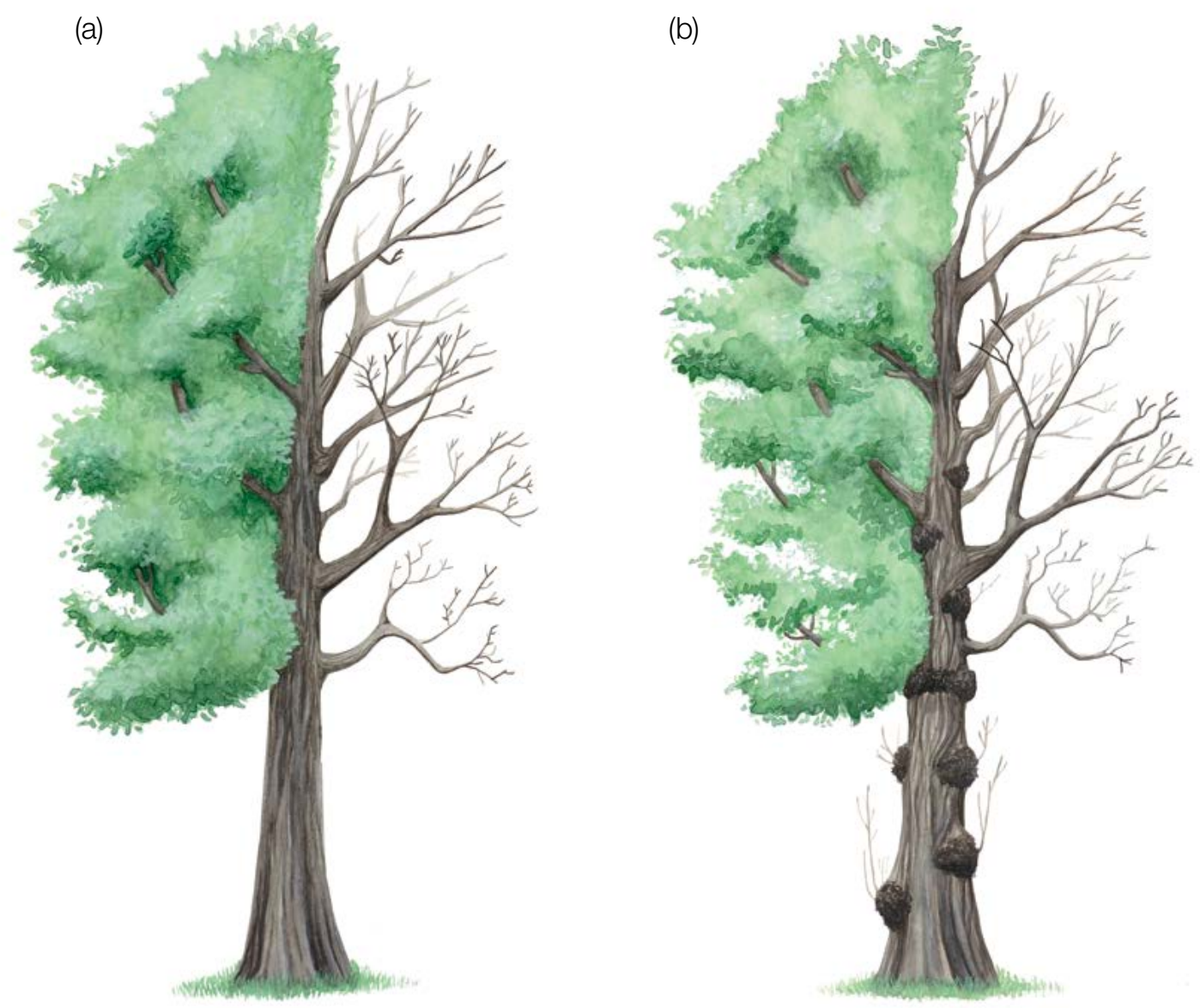

Abbildung 1: Habitus der Schwarz-Pappel (Populus nigra) ohne (a) und mit den häufig auftretenden WasserreiserKnollen (b).

(a)

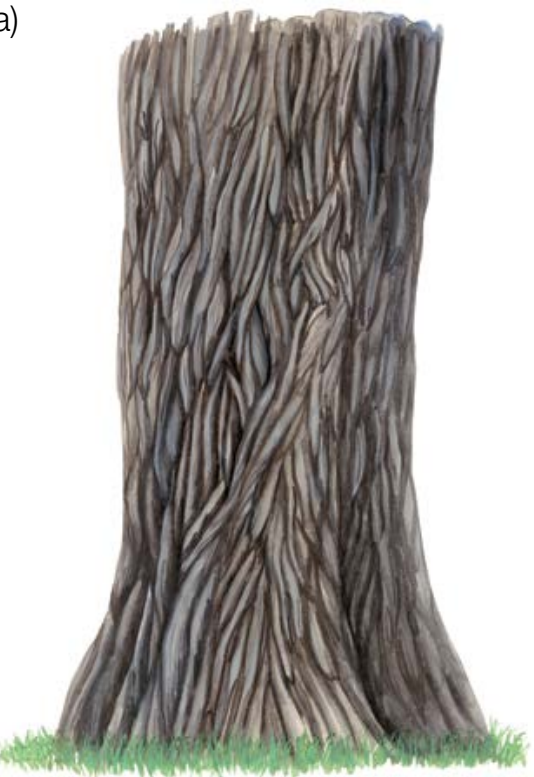

(b)

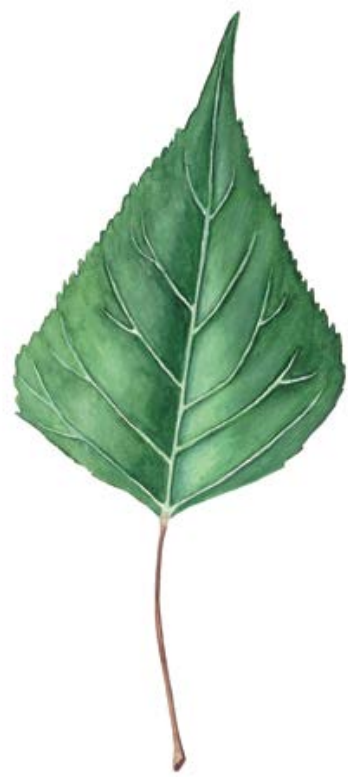

Abbildung 2: Die Rinde ausgewachsener Bäume ist dunkel-graubraun oder schwarz mit zahlreichen tiefen, sich kreuzenden Rissen (a). Charakteristisches rautenförmiges (rhomboides) bis dreieckiges Blatt der Schwarz-Pappel (b). 
Die morphologischen und phänologischen Merkmale von Populus nigra können als erster Ansatz für die Charakterisierung reiner (d.h. nicht hybridisierter) Schwarz-Pappel-Bäume dienen, zumindest bei erwachsenen und mittelalten Individuen. Die stabilsten artspezifischen Merkmale und Charakteristika sind im EUFORGENBestimmungsblatt von Populus nigra [24] detailliert aufgeführt:

- Wuchsform der Bäume,

- Wasserreiser und schlafende Knospen am Stamm

- sich kreuzende Rindenrisse am unteren Teil des Stammes,

- Blattformen (rautenförmig, rhomboid oder dreieckig),

- Fehlen der Europäischen Mistel (Viscum album L.) innerhalb der Krone,

- Auftreten von gallenverursachenden Blattlausarten der Gattung Pemphigus auf den Blattstielen.

Basierend auf den Erfahrungen europäischer Projekte (EUROPOP, DANUBEPARKS, etc.) wurden die Bäume, die anhand der oben aufgeführten morphologischen Merkmale charakterisiert und für die Generhaltung ausgewählt wurden, in den meisten Fällen auch durch diagnostische molekulare Marker als artreine Populus nigra bestätigt.

Die Schwarz-Pappel ist eine zweihäusige Art. Eingeschlechtliche männliche oder weibliche Blüten (Abbildung 3) entwickeln sich aus speziell dafür angelegten Knospen, die vorgeformte Blütenstände enthalten [11]. Die Blüten sind in hängenden Kätzchen auf unterschiedlichen Bäumen zu finden, was eine strenge Auskreuzung ermöglicht. Die männlichen Kätzchen haben rötlich-violette Staubgefäße, während die Narben der weiblichen Kätzchen gelb-grün sind.

(a)

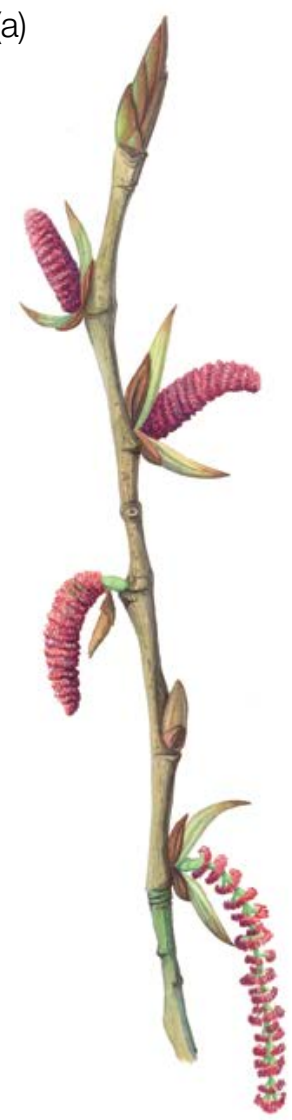

(b)

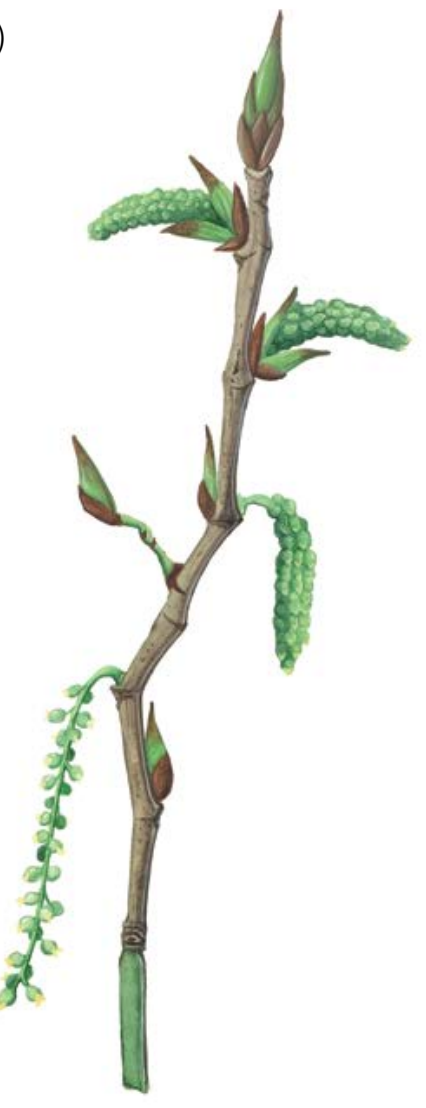

Abbildung 3: Geschlechtsbestimmung bei der Schwarz-Pappel - schematische Darstellung männlicher (a) und weiblicher Blüten (b) in verschiedenen Entwicklungsphasen. 


\section{REPRODUKTION}

Männliche Bäume sind Bäume mit ausschließlich männlichen Blüten und produzieren Pollen; weibliche Bäume sind Bäume mit ausschließlich weiblichen Blüten und produzieren Samen. In niedrigeren Höhenlagen und Breitengraden erscheinen die Blüten im zeitigen Frühjahr (März-April) aus speziell dafür angelegten Knospen, etwa 1-2 Wochen vor dem Blattaustrieb. In höheren Breiten und Höhenlagen verzögert sich die Blüte bis in den Mai [15]. Der Zeitpunkt und die Dauer der Blüte sowie die Dauer des Samenreifungsprozesses hängen sowohl von der Tageslänge als auch von den lokalen Temperaturen ab und variieren daher je nach Standort, was sich auf den Zeitpunkt der Samenfreisetzung auswirkt [16]. Möglicherweise spielt dabei auch eine genetische Komponente eine Rolle, die zu ,frühen“ und „späten“ Genotypen führt. Der Pollen wird durch den Wind verbreitet. Sobald die weiblichen Blüten befruchtet sind, reifen an jedem Kätzchen innerhalb von 4-6 Wochen etwa 20-50 kahle, runde, grün-braune Fruchtkapseln (Abbildung 4a), die bis zu 250 kleine hellbraune Samen pro Kätzchen produzieren [17]. Aus den weiblichen Kätzchen entwickeln sich flauschige, baumwollartige Flugsamen mit langen, weißen, seidigen Haaren (Abbildung 4b), die im Frühsommer abfallen [17].

Die Schwarz-Pappel produziert fast jedes Jahr Samen. Die Samen haben eine kurze (1-3 Tage) Lebensfähigkeit und benötigen für die Keimung über einen Zeitraum von 4 Wochen spezielle Feuchte- und Bodenbedingungen (kontinuierlich feuchtes Substrat) [18].

Die Schwarz-Pappel kann sich, wie oben beschrieben, generativ oder vegetativ (klonal) vermehren. Die natürliche klonale Vermehrung erfolgt durch Ablegerbildung via Wurzelbrut, aus Stockaustrieb, von umgestürzten Bäumen und im Jugendstadium von abgebrochenen Äste [17]. Eine natürliche vegetative Vermehrung ist auch dann möglich, wenn sich keine Sämlinge etablieren und kann daher zur Fortpflanzung der Art beitragen. Populus nigra wächst häufig in Gruppen klonaler Pflanzen (sog. Polykormen) [2].

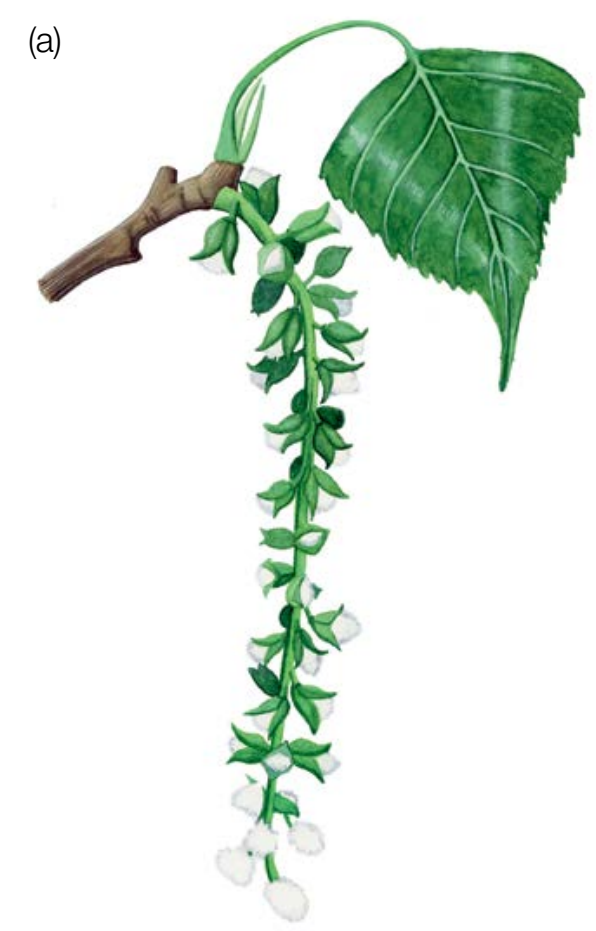

(b)

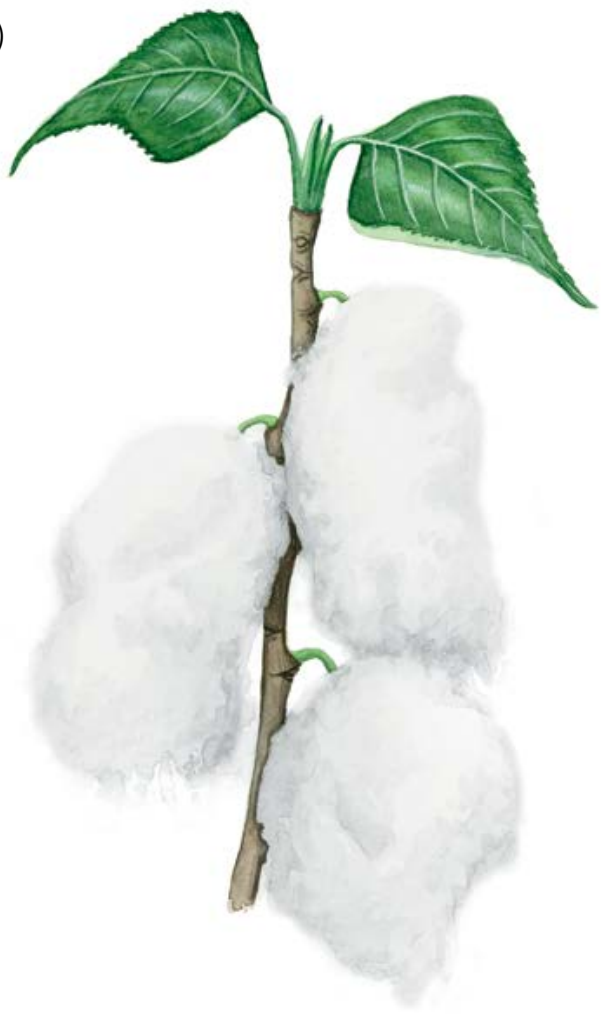

Abbildung 4: Weibliches Kätzchen mit reifenden Samenkapseln (a); die reifen Samen von Populus nigra haben lange, weiße, seidige Haare, die innen ein flauschiges, baumwollartiges Aussehen verleihen (b). 


\section{Identifikation von Verjüngungsflächen}

Von Natur aus verjüngt sich die Schwarz-Pappel nur auf ruderalen, feuchten Sand- und Lehmböden an Flussufern, die durch saisonale Überschwemmungen exponiert werden [14], nicht jedoch im Unterstand älterer Auenwaldbestände aus fortpflanzungsfähigen Bäumen. Die Rekrutierung von Sämlingen erfolgt entlang mäandrierender Flüsse in bogenförmigen Bändern aufeinanderfolgender Altersstufen, während sie in verzweigten Flusssystemen an spezifischen Mikrostandorten auftritt (z. B. auf Sandflecken hinter Vegetationsbüscheln oder in schlammgefüllten Vertiefungen der Aue inmitten von Totholzansammlungen) [17]. Erfolgreiche Naturverjüngung ist meist lückenhaft und sporadisch. Aufgrund sich verändernder Standortbedingungen kann die Populationsgröße der Art im Laufe der Zeit erheblich variieren (sich ausdehnen oder schrumpfen) [7].

\section{UMWELT}

Die Schwarz-Pappel hat ein großes natürliches Verbreitungsgebiet in Europa (mit Ausnahme der nordischen Länder) und von Nordafrika bis Zentralasien, einschließlich des Kaukasus und großer Teile des Nahen Ostens, bis nach Kasachstan und China [11]. Sie ist in allen Höhenlagen zu finden, vom Meeresspiegel bis in $4.000 \mathrm{~m}$ Höhe [19]. In ihrem gesamten Verbreitungsgebiet verdrängen oft Kulturformen oder Hybriden die natürlichen Bestände von Populus nigra [20]. Die Schwarz-Pappel ist vor allem auf Auenstandorten entlang großer Flüsse und ihrer Nebenflüsse angewiesen. Sie bildet von Natur aus eher Metapopulationen als kleine, isolierte Populationen (Abbildung 5) [6, 7]. In Beständen sind oft viele Einzelbäume (Solitäre) oder kleinere Gruppen überalterter Bäume zu finden. Die Schwarz-Pappel wächst zusammen mit Weißpappel (Populus alba L.), Weide (Salix sp.), Erle (Alnus pp.), Ahorn (Acer sp.), Ulme (Ulmus sp.) und manchmal Eiche (Quercus sp.) [21]. Das beste Wachstum zeigt die Schwarz-Pappel auf tiefgründigen Böden mittlerer Textur mit einem pH-Wert zwischen 5,5 und 7,5 und hohem Nährstoffgehalt. Aufgrund ihres sporadischen Vorkommens in gemischten Auwaldbeständen wird die Art in den regulären Waldinventuren meist nicht erfasst.

\section{GEFÄHRDUNG}

Trotz ihres großen Verbreitungsgebiets ist die Schwarz-Pappel eine gefährdete und seltene Baumart. Sie ist derzeit in mehreren Teilen ihres Verbreitungsgebiets aufgrund folgender menschlicher Einflüsse vom Aussterben bedroht: i) Übernutzung ihrer natürlichen Standorte; ii) Veränderung von Auwald-Ökosystemen durch menschliche Aktivitäten; iii) Anbau überlegener Hybriden von P. $\times$ canadensis Moench (Hybriden zwischen Populus deltoides W. Bartram ex Marshall und Populus nigra), der Kanadischen Schwarz-Pappel (Populus deltoides) sowie Balsam-Pappeln (P. trichocarpa Torr. \& A. Gray ex. Hook, P. maximowiczii Henry) innerhalb ihres natürlichen Verbreitungsgebiets; und iv) Gen-Introgression von den eingeführten weiblichen Hybridklonen, wenn deren Blüte synchron zur Blüte der männlichen Schwarz-Pappel erfolgt [22, 14, 11].

Ein an der Schwarz-Pappel oft beobachteter Schädling ist der Pappelblattkäfer (Chrysomela populi L.), während die häufigsten Krankheiten der Pappelrost (Melampsora larici-populina Kleb.) und die MarssoninaBlattfleckenkrankheit der Pappel (Drepanopeziza punctiformis Gremmen, auch bekannt als Marssonina brunnea (Ellis \& Everh.) Magnus) sind. Auch an ihren natürlichen Standorten wird häufig ein Absterben alter Schwarz-Pappeln aufgrund veränderter Standortbedingungen und Trockenheit (rascher Rückgang des Grundwasserspiegels) beobachtet. Alte Bäume werden schließlich durch die von Plagiostoma populinum (Fuckel) L. C. Mejía (früher Cryptodiaporthe populea (Saccardo) Butin, auch bekannt als Dothichiza populea Saccardo) verursachte Dothichiza-Rindennekrose sowie durch Windbruch zerstört, so dass im Zuge der natürlichen Sukzession des gemischten Auwaldes zunehmend Hartlaubhölzer dominieren. 


\section{EINRICHTUNG UND INSTANDHALTUNG VON MONITORINGFLÄCHEN}

Die Schwarz-Pappel ist eine Pionierbaumart der Auenmischwälder. Sie zeichnet sich durch eine ganze Auensysteme umfassende Metapopulationsstruktur aus. Das FGM der Schwarz-Pappel darf deshalb nicht auf einem einzelnen, lokal isolierten Standort angewendet werden, sondern sollte auf der Skala einer Metapopulation durchgeführt werden, die ein ganzes Netzwerk miteinander verbundener lokaler Teilpopulationen repräsentiert, zwischen denen ein Pollen- und Samenaustausch stattfindet.

(a)

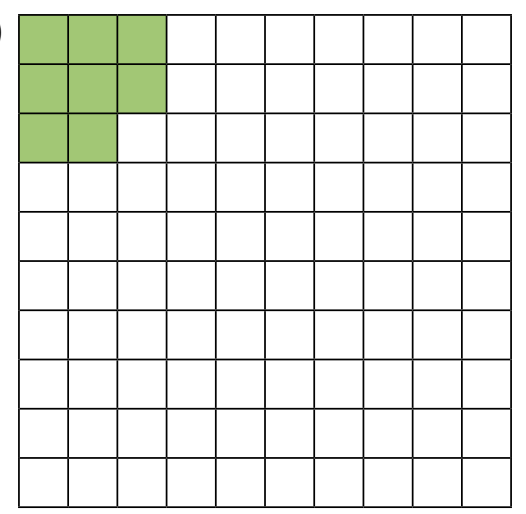

(b)

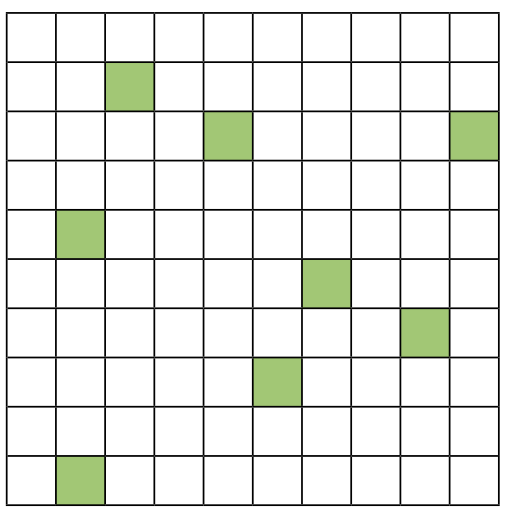

Abbildung 5: Schematische Darstellung miteinander verbundener lokaler Schwarz-Pappel-Populationen entlang eines Flusssystems (a) im Vergleich zu einer isolierten lokalen Schwarz-Pappel-Population (b).

Um eine repräsentative Beprobung der gesamten Metapopulation zu gewährleisten, sollte das genetische Monitoringsystem aus zufällig ausgewählten Monitoringflächen mit Altbäumen und Flächen mit natürlichen Verjüngungszentren entlang eines Flusssystems bestehen. Eine Schwarz-Pappel-FGM-Fläche besteht aus so vielen Teilflächen, wie es lokale Populationen innerhalb der überwachten Metapopulation gibt. Die Anzahl der Bäume in jeder Teilfläche sollte proportional zur Größe der lokalen Population sein, mit einer Gesamtsumme von 50 fortpflanzungsfähigen, genetisch unterschiedlichen, artreinen Populus nigra - Altbäumen, vorzugsweise mit gleichen Anteilen männlicher und weiblicher Individuen (Geschlechterverhältnis 1:1). Die FGM-Teilfläche in jeder lokalen Population sollte mindestens 20 Altbäume umfassen, die über eine maximale Entfernung von $5 \mathrm{~km}$ verteilt sind.

Es ist empfehlenswert, die Bäume vor Ort anhand der in der Artbeschreibung detailliert aufgeführten morphologischen Merkmale vorauszuwählen. Basierend auf den Ergebnissen langfristiger Generhaltungsprojekte in Ungarn [23], bei denen ein Komplex stabiler morphologischer Merkmale verwendet wurde und die vorselektierten Bäume zusätzlich durch diagnostische DNA-Marker getestet wurden, konnte die Vorauswahl in den meisten Fällen hybride und introgressive Genotypen ausschließen. In jedem Fall sollten jedoch diagnostische molekulargenetische Marker verwendet werden, um die taxonomische Identität und die Nicht-Hybridität der getesteten Bäume als artreine Populus nigra -Individuen zu bestätigen [7, 23]. Der Einsatz genetischer Tests bezüglich molekulardiagnostischer Marker ist somit auf allen Monitoringniveaus ein wesentliches Element des forstgenetischen Monitorings von Populus nigra. Zusätzlich müssen die Bäume durch Genotypisierung auf Klonalität getestet werden (nur ein Individuum des gleichen Genotyps kann in das Monitoring aufgenommen werden). Ein Baum gilt als fortpflanzungsfähig, wenn er blüht. Um die Geschlechter zu differenzieren, sollte die Einrichtung der FGM-Fläche idealerweise während der Blütezeit erfolgen. Bei der Neueinrichtung einer Monitoringfläche sollten alle Bäume beschriftet und ihre Koordinaten erfasst werden. Gleichzeitig kann der BHD gemessen und Proben für die DNA-Extraktion gesammelt werden. 


\subsection{Einrichtung der Monitoringfläche}

\subsubsection{Definition der Grundgesamtheit für die Stichproben}

Vor der Einrichtung einer FGM-Fläche sollte mithilfe einer GIS-Software eine Karte der Schwarz-PappelMetapopulation erstellt werden. Zu diesem Zweck sollten die lokalen Populationen, an denen die Art in ausreichender Dichte für eine Monitoring-Teilfläche auftritt, vor Ort genauer untersucht werden. Es wird empfohlen, bei dieser ersten Begehung mit einer Handy-App (z. B. Locus map) oder einem GPS-Gerät einen Track aufzuzeichnen, um die weitere Planung zu erleichtern.

Die Standorte der lokalen Populationen werden auf der Karte in Form von Polygonen eingezeichnet, die insgesamt die Grundgesamtheit für die Stichprobennahme darstellen. Die Bäume innerhalb jeder lokalen Population sollten nach dem Zufallsprinzip ausgewählt werden. Eine zufällige Auswahl kann beispielsweise durch die Erstellung einer angemessenen Anzahl (proportional zur Größe der lokalen Population) zufälliger GPS-Koordinaten mit einem Mindestabstand von je $35 \mathrm{~m}$ erfolgen. Der etwas größere Mindestabstand zwischen den Zufallspunkten beinhaltet eine Sicherheitsmarge für die geringere Genauigkeit von GPS-Geräten in Wäldern und die Entfernung des nächstgelegenen Baums vom jeweiligen GPS-Zufallspunkt. Die Koordinaten der Zufallspunkte werden in einem geländetauglichen GPS-Gerät gespeichert.

Ist die beschriebene Vorgehensweise aufgrund der Komplexität der Flussläufe in Auenwäldern nicht durchführbar, kann ein vereinfachter "Suche-und-Finde-Ansatz" innerhalb der lokalen Populationen verwendet werden: Dabei wird vorzugsweise mit Hilfe lokaler Försterlnnen das entsprechende Gebiet mit einem GPS-Gerät oder einer Handy-App mit Track-Aufzeichnung systematisch durchkämmt, wodurch sichergestellt ist, dass dasselbe Gebiet nicht wiederholt untersucht oder ein Teil dessen übersehen wird. Die Koordinaten aller fortpflanzungsfähigen Altbäume werden aufgezeichnet und ihr Geschlecht bestimmt. Für jede lokale Population wird aus dem Pool geeigneter Bäume eine angemessene Anzahl von Bäumen zufällig ausgewählt.

Alle Altbäume müssen auf allen Monitoringniveaus genotypisiert werden, um Hybriden und Klone auszuschließen.

\subsubsection{Einrichtung der Monitoringfläche}

Da die Koordinaten der ungefähren Baumstandorte bekannt sind, ist das Verfahren für die Einrichtung der FGM-Fläche in ausgewählten lokalen Beständen wie folgt:

- Auffinden der gespeicherten GPS-Koordinaten vor Ort,

- Auswahl und Kennzeichnung des fortpflanzungsfähigen Altbaums, der der gespeicherten GPS-Koordinate am nächsten steht.

\subsubsection{Kennzeichnung der Bäume}

Jeder ausgewählte Beobachtungsbaum muss mit einer entsprechenden Nummer und idealerweise mit einem um den Stamm herum laufenden Streifen gekennzeichnet werden, um die Sichtbarkeit der Bäume aus allen Richtungen zu erhöhen.

\subsubsection{Beprobung für genetische Analysen}

Zur Beurteilung der Hybridisierung und des Vorhandenseins von Klonen müssen von allen ausgewählten Beobachtungsbäumen Proben für die DNA-Extraktion gesammelt werden. Hybriden und Klone müssen ausgeschlossen und durch artreine Individuen mit einzigartigen Genotypen (keine Klone) ersetzt werden. Es kann somit notwendig sein, eine größere Anzahl von Bäumen auszuwählen und zu beproben, um 50 artreine Schwarz-Pappel-Bäume zu finden, die keine Klone sind. 


\subsection{Einrichtung von Naturverjüngungs-Plots}

Das Stichprobendesign für die Naturverjüngung (NV) folgt dem Metapopulationskonzept mit mehreren NV-Clustern, um die gesamte genetische Vielfalt der Schwarz-Pappel abzubilden und das Risiko der GenIntrogression und Hybridisierung durch exotische Pappelarten und Lombardei-Pappeln im entsprechenden Gebiet zu bewerten. Bei der Auswahl der NV-Cluster müssen Überschwemmungen und die sich dadurch ständig ändernden Umweltbedingungen, Mikrostandorte oder möglicherweise sogar deren Verschwinden berücksichtigt werden.

Die Mikrostandorte möglicher NV sollten am Ende der Fruktifikationsphase im Frühsommer (hauptsächlich von April bis Juni) häufig kontrolliert werden (mindestens einmal pro Woche). Dort wo neu gekeimte NV-Cluster entdeckt werden, sollten die Schwarz-Pappel-Nachkommen, sobald sie Keimblätter oder erste Laubblätter zeigen, sofort beprobt werden. Die GPS-Koordinaten der beprobten NV-Cluster sollten erfasst werden. Idealerweise sollten 20 NV-Cluster mit einer Größe von je $1 \mathrm{~m}^{2}$ über die gesamte FGM-Fläche verteilt werden, mit bis zu 0,5 km Entfernung in beiden Richtungen entlang des Flusssystems.

Die Schwarz-Pappel in den NV-Clustern muss beprobt werden, da die Nachkommenschaft an jedem Standort sehr divers sein kann. Idealerweise sollten aus jedem der 20 NV-Cluster Proben von 5 zufällig ausgewählten Pflanzen gesammelt werden, so dass insgesamt 100 Proben vorliegen. Werden weniger als $20 \mathrm{NV}$-Cluster gefunden, ist eine proportional höhere Anzahl von Proben je NV-Cluster zu erfassen. Alle Proben werden auf Hybridisierung getestet, und unter innen werden nach dem Zufallsprinzip 50 artreine Schwarz-Pappeln für weitere FGM-Analysen ausgewählt. Ist es nicht möglich, innerhalb der beprobten 100 Pflanzen 50 artreine Pflanzen zu identifizieren, muss eine weitere Charge von 100 Proben beprobt und getestet werden; solange bis die für die FGM-Analyse erforderliche Mindestanzahl von 50 Genotypen artreiner Populus nigra -Individuen in den NV-Cluster erreicht ist.

\subsection{Instandhaltung der Monitoringfläche}

\subsubsection{Allgemeine Instandhaltung}

Die Kennzeichnung der Bäume muss periodisch (alle 2 Jahre) überprüft und bei Bedarf erneuert werden.

\subsubsection{Ersatz von Bäumen}

Wenn ein ausgewählter Beobachtungsbaum stirbt oder im Zuge der forstlichen Bewirtschaftung gefällt wird, muss er ersetzt werden. Dabei sollte der dem abgestorbenen/gefällten Baum nächstgelegene geeignete Baum ausgewählt werden, wobei der Mindestabstand von 30 m zum nächsten Beobachtungsbaum erfüllt sein muss. Andernfalls ist ein Baum aus der Peripherie der Monitoringfläche (Metapopulation) zu wählen.

Wenn die Baumkrone z.B. durch Wind-, Eis- oder Schneebruch geschädigt ist, der Baum aber weiterhin fruktifiziert, wird der Baum im Monitoringprogramm belassen. Ist der Schaden zu schwerwiegend und eine Fruktifikation nicht mehr zu erwarten, muss der Baum ersetzt werden. Die Schadensursache ist zu erfassen, da der Schaden Auswirkungen auf die erfassten Werte der Verifikatoren und Hintergrundinformationen haben kann.

\section{ERFASSUNG VON VERIFIKATOREN UND HINTERGRUNDINFORMATIONEN}

Die molekulargenetische Identifizierung von Schwarz-Pappeln sollte mithilfe artdiagnostischer genetischer Marker erfolgen. Auch die Prüfung auf Klonalität sowohl in der Metapopulation der Altbäume als auch in den NV-Clustern sollte als Teil der molekulargenetischen Analysen mit genetischen Markern erfolgen. Ein Satz verifizierter Referenzproben der beiden (oder sogar mehrerer) hybridisierenden Arten ist erforderlich, um zwischen artreinen Individuen und Hybriden zu unterscheiden. 
Generell sollte Folgendes beachtet werden:

- Die Population der Schwarz-Pappel hat eine Metapopulationsstruktur.

- Die FGM-Teilflächen bilden „lokale Populationen“ der Metapopulation.

- Die in einer Metapopulation ausgewählten FGM-Teilflächen entlang des Flusssystems bilden eine FGM-Fläche mit insgesamt 50 Schwarz-Pappel-Altbäumen.

- Alle ausgewählten FGM-Altbäume werden für Beobachtungen und Messungen berücksichtigt.

- Die molekulargenetischen Analysen müssen auf allen Monitoringniveaus durchgeführt werden, um ausschließlich „artreine“ Individuen in das Monitoring einzubeziehen. Daher ist das FGM dieser Art im Vergleich zu dem FGM bestandsbildender Baumarten zu Beginn deutlich teurer.

Auf der Monitoringfläche werden periodisch Verifikatoren und Hintergrundinformationen erfasst. Verifikatoren werden genutzt, um die genetischen Eigenschaften der Population und ihre Anpassung an Umweltveränderungen und/oder Bewirtschaftung zu verfolgen, während Hintergrundinformationen aufgezeichnet werden, um die Interpretation der Verifikatoren zu unterstützen. Verifikatoren können auf drei verschiedenen Intensitätsniveaus erfasst werden: Basis, Standard und Intensiv.

Höherrangigere Niveaus (Standard, Intensiv) müssen stets auch die Erfassung der Verifikatoren auf allen niedrigeren Niveaus (Basis, Standard) einschließen. Dies ist für die Aufzeichnung von Hintergrundinformationen nicht erforderlich. 
Tabelle 1: Liste der Verifikatoren und Hintergrundinformationen, die während der Außenaufnahmen auf den FGMMonitoringflächen zu erfassen sind; jeweils mit Kurzbeschreibung und Beobachtungshäufigkeit.

\begin{tabular}{|c|c|c|c|c|}
\hline & Bezeichnung & Basisniveau & Standardniveau & Intensivniveau \\
\hline \multirow{5}{*}{ 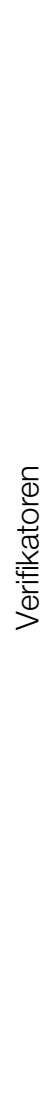 } & \multirow[t]{2}{*}{$\begin{array}{l}\text { Mortalität / } \\
\text { Überlebensrate }\end{array}$} & $\begin{array}{l}\text { Altbäume: Zählung der } \\
\text { verbleibenden markierten Bäume } \\
\text { alle } 10 \text { Jahre und nach jedem } \\
\text { extremen Witterungsereignis/ } \\
\text { jeder Störung }\end{array}$ & wie Basisniveau & wie Basisniveau \\
\hline & & $\begin{array}{c}\text { Naturverjüngung: Mortalität / } \\
\text { Überlebensrate wird für diese Art } \\
\text { nicht erfasst }\end{array}$ & / & / \\
\hline & Blüte & $\begin{array}{l}\text { Expertenbasierte Schätzung für } \\
\text { die FGM-Teilfläche; jährlich }\end{array}$ & $\begin{array}{l}\text { Erfassung auf Einzelbaumebene, } \\
\text { während zwei bedeutenden } \\
\text { Blühereignissen pro Jahrzehnt, } \\
\text { idealerweise in gleichen } \\
\text { Abständen * }\end{array}$ & $\begin{array}{l}\text { wie Standardniveau, aber } \\
\text { zusätzlich Erfassung des } \\
\text { Blühstadiums. * }\end{array}$ \\
\hline & Fruktifikation & $\begin{array}{l}\text { Erfassung auf Einzelbaum- } \\
\text { ebene im selben Jahr, in dem } \\
\text { die Erfassung der Blüte auf } \\
\text { Basisniveau erfolgt (unabhängig } \\
\text { von der Fruktifikationsintensität) * }\end{array}$ & $\begin{array}{l}\text { Erfassung auf Einzelbaum- } \\
\text { ebene im selben Jahr, in dem } \\
\text { die Erfassung der Blüte auf } \\
\text { Basisniveau erfolgt (unabhängig } \\
\text { von der Fruktifikationsintensität) * }\end{array}$ & $\begin{array}{l}\text { Zählung der Früchte (baumwoll- } \\
\text { ähnliche Kätzchen mit reifen } \\
\text { Samenkapseln) in den gleichen } \\
\text { Jahren, in denen die Bewertung } \\
\text { der Blüte auf Intensivniveau } \\
\text { erfolgt, unabhängig von der } \\
\text { Fruktifikationsintensität* Bei } \\
\text { jedem erfassten Fruktifikations- } \\
\text { ereignis wird auch Saatgut für } \\
\text { Laboranalysen gesammelt }\end{array}$ \\
\hline & $\begin{array}{l}\text { Abundanz der } \\
\text { Naturverjüngung }\end{array}$ & $\begin{array}{l}\text { Expertenbasierte Schätzung für } \\
\text { die FGM-Teilfläche. }{ }^{* *}\end{array}$ & $\begin{array}{l}\text { Zählung neuer (!) Sämlinge in bis } \\
\text { zu } 20 \text { NV-Clustern nach jedem } \\
\text { erfassten Fruktifikationsereignis. } \\
\text { Zeitgleich werden Proben für } \\
\text { genetische Analysen gesammelt. } \\
\underset{* \star}{*}\end{array}$ & wie Standardniveau ** \\
\hline \multirow{5}{*}{ 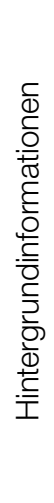 } & $\begin{array}{l}\text { Durchmesser- } \\
\text { klassen-vertei- } \\
\text { lung }\end{array}$ & / & Messung alle 10 Jahre & wie Standardniveau \\
\hline & $\begin{array}{l}\text { Höhenklassen- } \\
\text { verteilung }\end{array}$ & / & Messung alle 10 Jahre & wie Standardniveau \\
\hline & Austrieb & / & $\begin{array}{l}\text { Erfassung auf Einzelbaumebene; } \\
\text { alle } 5 \text { Jahre }\end{array}$ & $\begin{array}{l}\text { Erfassung auf Einzelbaumebene; } \\
\text { jährlich }\end{array}$ \\
\hline & Seneszenz & / & $\begin{array}{l}\text { Erfassung auf Einzelbaumebene; } \\
\text { alle } 5 \text { Jahre }\end{array}$ & $\begin{array}{l}\text { Erfassung auf Einzelbaumebene; } \\
\text { jährlich }\end{array}$ \\
\hline & $\begin{array}{l}\text { Blühsynchroni- } \\
\text { sation }\end{array}$ & / & / & $\begin{array}{l}\text { Erfassung auf Einzelbaum- } \\
\text { ebene, während jedes erfassten } \\
\text { bedeutenden Blühereignisses }\end{array}$ \\
\hline
\end{tabular}

Idealerweise sollte mindestens ein größeres Fruktifikationsereignis pro Jahrzehnt bewertet werden. Ein bedeutendes Blühereignis führt jedoch nicht unbedingt zu einem bedeutenden Fruktifikationsereignis. Wenn auf das bewertete Blühereignis kein wesentliches Fruktifikationsereignis folgt, muss die Bewertung sowohl der Blüte als auch der Fruchtbildung beim nächsten bedeutenden Blühereignis wiederholt werden, unabhängig von der Zeit, die zwischen aufeinanderfolgenden bedeutenden Blühereignissen liegt. Erhebungen auf Basisniveau werden zur Identifizierung bedeutender Blüh- und Fruktifikationsereignisse verwendet.

" Sind nach einem erfassten bedeutenden Blüh- und Fruktifikationsereignis keine neuen NV-Cluster zu finden (da z.B. Sämlinge durch Hochwasser weggeschwemmt wurden), muss die Bewertung der drei Verifikatoren (Blüte, Fruktifikation und NV-Abundanz) beim nächsten bedeutenden Blühereignis wiederholt werden, unabhängig von der Zeit, die zwischen aufeinanderfolgenden bedeutenden Blühereignissen liegt. Erhebungen auf Basisniveau werden zur Identifizierung bedeutender Blüh- und Fruktifikationsereignisse verwendet. 


\subsection{VERFAHREN ZUR ERFASSUNG DER VERIFIKATOREN}

\subsubsection{Mortalität / Überlebensrate}

Die Mortalität beschreibt die Sterblichkeit von Altbäumen und Naturverjüngung. Ihr Pendant - die Überlebensrate steht für Bäume, die seit der letzten Datenerhebung noch am Leben sind. Die Überlebensrate wird berechnet als 1 - Mortalität.

\subsubsection{Altbäume: Basis-, Standard- und Intensivniveau}

Verifikator für die Mortalität von Altbäumen. Die Mortalität wird geschätzt, indem die verbleibenden lebenden Beobachtungsbäume alle 10 Jahre sowie nach jedem extremen Witterungsereignis bzw. jeder Störung gezählt werden. Die Mortalität ist die Differenz zwischen der ursprünglichen Anzahl markierter Beobachtungsbäume und den davon verbleibenden lebenden Bäumen der ursprünglichen 50 Beobachtungsbäume.

\subsubsection{Blüte}

Dieser Verifikator beschreibt das Auftreten der Blüte (Anteil der Bäume) und die Blühintensität. Er kann in Mitteleuropa im April erfasst werden. Nach warmen Wintern erfolgt die Blüte früher.

\subsubsection{Basisniveau}

Der Verifikator wird jährlich auf Bestandesebene erfasst. Die Erfassung erfolgt zum Zeitpunkt der Hauptblüte. Die Schätzung des durchschnittlichen Zustands erfolgt nach einer Begehung der gesamten Monitoringfläche. Es werden zwei Werte erfasst: einer für die Blühintensität, ausgedrückt als mittlerer Kronenanteil in Blüte; und einer für den Anteil der blühenden Bäume im Bestand.

\begin{tabular}{llr}
\hline 1 & Keine Blüte: Keine oder nur gelegentlich auftretende Blüten & $0-10$ \\
\hline 2 & Schwache Blüte: Einige Blüten erscheinen an den Bäumen & $>10-30$ \\
\hline 3 & Mäßige Blüte: Mäßig viele Blüten an den Bäumen & $>30-60$ \\
\hline 4 & Starke Blüte: Reichlich Blüten an den Bäumen & $>60-90$ \\
\hline 5 & Extreme Blüte: Enorme Anzahl von Blüten an den Bäumen & $>90$ \\
\hline
\end{tabular}

\begin{tabular}{lr} 
Code Anteil der Bäume im Bestand mit dem entsprechenden Stadium der Blühintensität (\%) \\
\hline 1 & $0-10$ \\
\hline 2 & $>10-30$ \\
\hline 3 & $>30-60$ \\
\hline 4 & $>60-90$ \\
\hline 5 & $>90$ \\
\hline
\end{tabular}

\subsubsection{Standardniveau}

Der Verifikator wird während zweier bedeutender Blühereignisse pro Jahrzehnt aufgezeichnet, idealerweise mit einem ähnlichen zeitlichen Abstand. Er wird für alle 50 Beobachtungsbäume auf Einzelbaumebene erfasst. Ein bedeutendes Blühereignis liegt vor, wenn die Blühintensität auf Basisniveau als stark oder extrem eingeschätzt wird (Code 4 oder 5) und der Anteil der Bäume mit der angegebenen Blühintensität über 60\% liegt (Code 4 oder 5). Die Erfassung erfolgt zum Zeitpunkt der Hauptblüte. Für jeden Beobachtungsbaum wird ein Wert erfasst. 


\begin{tabular}{clc}
\multicolumn{2}{l}{ Code Blühintensität auf Bestandesebene } & Mittlerer Anteil der Kronen in Blüte (\%) \\
\hline 1 & Keine Blüte: Keine oder nur gelegentlich auftretende Blüten & $0-10$ \\
\hline 2 & Schwache Blüte: Einige Blüten erscheinen an den Bäumen & $>10-30$ \\
\hline 3 & Mäßige Blüte: Mäßig viele Blüten an den Bäumen & $>30-60$ \\
\hline 4 & Starke Blüte: Reichlich Blüten an den Bäumen & $>60-90$ \\
\hline 5 & Extreme Blüte: Enorme Anzahl von Blüten an den Bäumen & $>90$ \\
\hline
\end{tabular}

\subsubsection{Intensivniveau}

Der Verifikator wird während zweier bedeutender Blühereignisse pro Jahrzehnt aufgezeichnet, idealerweise mit einem ähnlichen zeitlichen Abstand. Er wird für alle 50 Beobachtungsbäume auf Einzelbaumebene erfasst. Ein bedeutendes Blühereignis liegt vor, wenn die Blühintensität auf Basisniveau als stark oder extrem eingeschätzt wird (Code 4 oder 5) und der Anteil der Bäume mit der angegebenen Blühintensität über 60\% liegt (Code 4 oder 5).

Für jeden Baum werden zwei Werte angegeben: das Blühstadium männlicher und weiblicher Bäume sowie der blühende Kronenanteil. Im Durchschnitt sind zwei Begehungen auf der Monitoringfläche erforderlich: der erste früh genug, um das Frühstadium der Blüte zu beobachten, der zweite zum Zeitpunkt der Hauptblüte. Hintergrundinformationen zur Blühsynchronisation können anhand der für diesen Verifikator erfassten Werte abgeschätzt werden. Die männlichen und weiblichen Blühstadien sind in Abbildung 6 und 7 dargestellt.

\begin{tabular}{ll}
\multicolumn{2}{l}{ Code Weibliches Blühstadium } \\
\hline 1 & Inaktive weibliche Blühknospen (braune Färbung) \\
\hline 2 & Vergrößerte weibliche Blühknospen mit beginnender Knospenöffnung (hellgrüne Färbung) \\
\hline 3 & Längenwachstum der Blüte (kurze, hellgrüne Blüten) \\
\hline 4 & Offene Blüten (grün-gefärbte Kätzchen) \\
\hline 5 & Offene Blüten (Kätzchen mit voll entwickelten gelb-grünen Blüten) \\
\hline
\end{tabular}

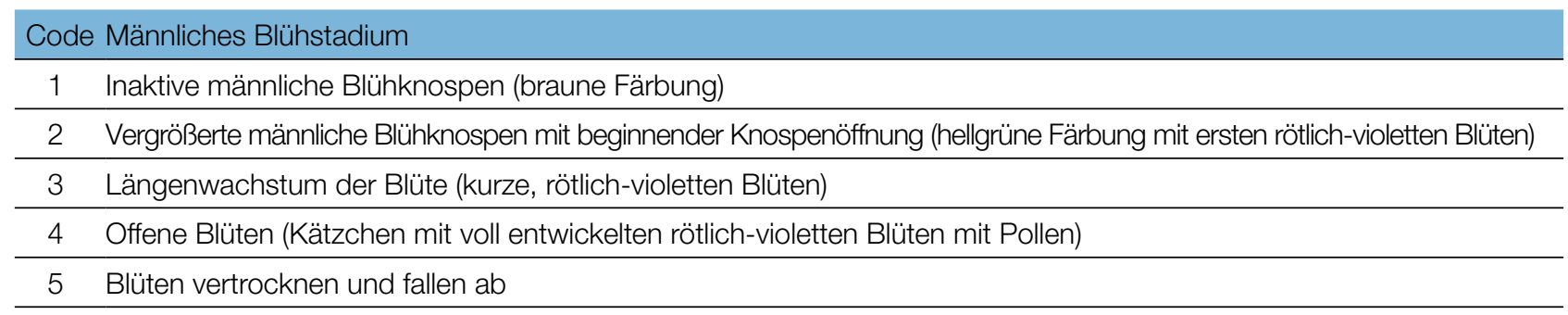

\begin{tabular}{clr}
\multicolumn{2}{c}{ Code Blühintensität des Einzelbaums (beide Geschlechter) } & Mittlerer Anteil der Kronen in Blüte (\%) \\
\hline 1 & Keine Blüte: Keine oder nur gelegentlich auftretende Blüten & $0-10$ \\
\hline 2 & Schwache Blüte: Einige Blüten erscheinen an den Bäumen & $>10-30$ \\
\hline 3 & Mäßige Blüte: Mäßig viele Blüten an den Bäumen & $>30-60$ \\
\hline 4 & Starke Blüte: Reichlich Blüten an den Bäumen & $>60-90$ \\
\hline 5 & Extreme Blüte: Enorme Anzahl von Blüten an den Bäumen & $>90$ \\
\hline
\end{tabular}


1

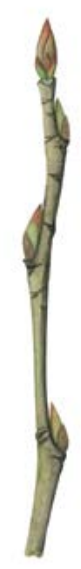

2

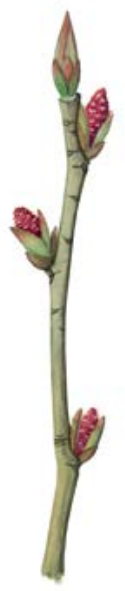

3

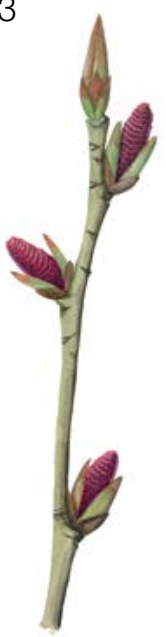

4

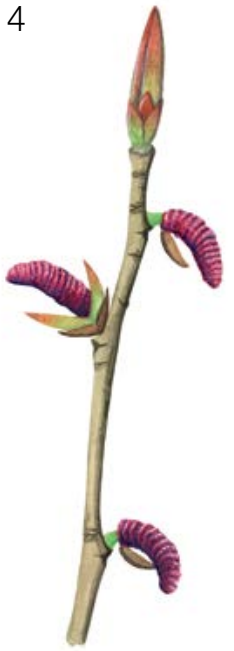

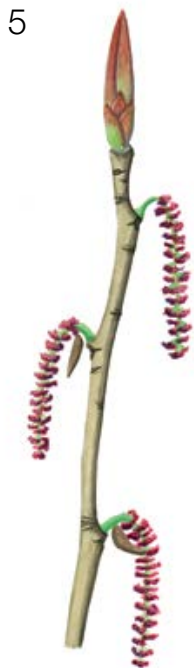

Abbildung 6: Illustration zur Beschreibung der männlichen Blühstadien (rötliche Kätzchen) für den Veritikator „Blüte“ auf Intensivniveau.

1

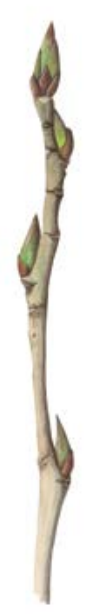

2

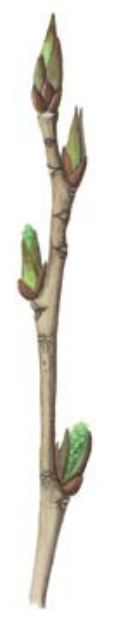

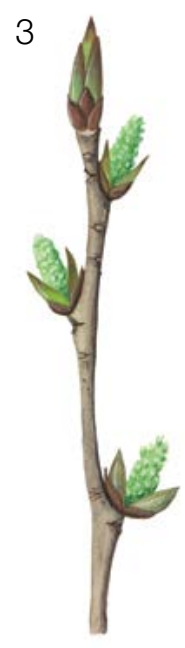

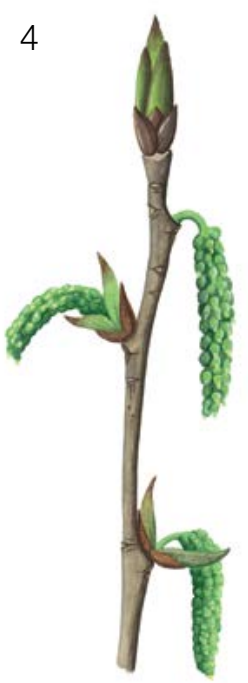

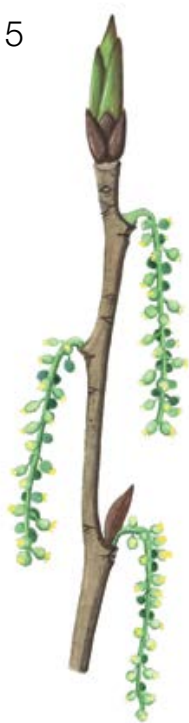

Abbildung 7: llustration zur Beschreibung der weiblichen Blühstadien (gelb-grüne Kätzchen) für den Verifikator „Blüte“ auf Intensivniveau.

\subsubsection{Fruktifikation}

Dieser Verifikator beschreibt das Auftreten und die Häufigkeit der Fruchtbildung. Die Daten für diesen Verifikator sollten während der Fruktifikationszeit erhoben werden, d.h. in Mitteleuropa von Ende April bis Juni.

\subsubsection{Basis- und Standardniveau}

Die Erfassung des Verifikators erfolgt in denselben Jahren wie die Bewertung der Blüte auf Standard- und Intensivniveau (unabhängig von der Fruktifikationsintensität). Sie wird für alle weiblichen Beobachtungsbäume (idealerweise 25) auf Einzelbaumebene durchgeführt - und zwar bevor die Früchte beginnen zu fallen. Für jeden Beobachtungsbaum wird ein Wert erfasst.

Im Idealfall sollte pro Jahrzehnt ein auf ein bedeutendes Blühereignis folgendes größeres Fruktifikationsereignis erfasst werden. Ein bedeutendes Blühereignis führt jedoch nicht unbedingt zu einem bedeutenden 
Fruktifikationsereignis. Wenn auf das bewertete Blühereignis kein wesentliches Fruktifikationsereignis folgt, muss die Bewertung sowohl der Blüte als auch der Fruchtbildung beim nächsten bedeutenden Blühereignis wiederholt werden, unabhängig von der Zeit, die zwischen aufeinanderfolgenden bedeutenden Blühereignissen liegt. Erhebungen auf Basisniveau werden genutzt, um bedeutende Fruktifikationsereignisse zu identifizieren. Ein bedeutendes Fruktifikationsereignis liegt vor, wenn die Fruktifikationsintensität auf Basisniveau als stark oder extrem eingeschätzt wird (Code 4 oder 5) und der Anteil der Bäume mit der angegebenen Fruktifikationsintensität über 60\% liegt (Code 4 oder 5).

\begin{tabular}{llr}
\hline \multicolumn{2}{l}{ Code Intensität der Fruktifikation auf Bestandesebene } & Mittlerer Anteil der Krone mit Fruchtbehang (\%) \\
\hline 1 & $\begin{array}{l}\text { Keine Fruchtbildung: Keine oder nur gelegentlich auftretende Früchte } \\
\text { an den Bäumen }\end{array}$ & $0-10$ \\
\hline 2 & Schwache Fruchtbildung: Einige Früchte an den Bäumen & $>10-30$ \\
\hline 3 & Mäßige Fruchtbildung: Mäßig viele Früchte an den Bäumen & $>30-60$ \\
\hline 4 & Starke Fruchtbildung: Reichlich Früchte an den Bäumen & $>60-90$ \\
\hline 5 & Extreme Fruchtbildung: Enorme Anzahl von Früchten an den Bäumen & $>90$ \\
\hline
\end{tabular}

\subsubsection{Intensivniveau}

Die Erfassung des Verifikators erfolgt in denselben Jahren wie die Bewertung der Blüte auf Basis-, Standard- und Intensivniveau (unabhängig von der Fruktifikationsintensität). Sie wird für alle weiblichen Beobachtungsbäume (idealerweise 25) auf Einzelbaumebene durchgeführt - und zwar bevor die Früchte beginnen zu fallen. Für jeden Beobachtungsbaum wird ein Wert erfasst. Zeitgleich wird von 20 weiblichen Bäumen Saatgut für die Saatgutund Genanalysen gesammelt (für die Verifikatoren und Hintergrundinformationen auf Intensivniveau).

Im Idealfall sollte pro Jahrzehnt ein auf ein bedeutendes Blühereignis folgendes größeres Fruktifikationsereignis erfasst werden. Ein bedeutendes Blühereignis führt jedoch nicht unbedingt zu einem bedeutenden Fruktifikationsereignis. Wenn auf das bewertete Blühereignis kein wesentliches Fruktifikationsereignis folgt, muss die Bewertung sowohl der Blüte als auch der Fruchtbildung beim nächsten bedeutenden Blühereignis wiederholt werden, unabhängig von der Zeit, die zwischen aufeinanderfolgenden bedeutenden Blühereignissen liegt. Erhebungen auf Basisniveau werden genutzt, um bedeutende Fruktifikationsereignisse zu identifizieren. Ein bedeutendes Fruktifikationsereignis liegt vor, wenn die Fruktifikationsintensität auf Basisniveau als stark oder extrem eingeschätzt wird (Code 4 oder 5) und der Anteil der Bäume mit der angegebenen Fruktifikationsintensität über 60\% liegt (Code 4 oder 5).

Der Verifikator wird durch das Zählen von Früchten (baumwollähnliche Kätzchen mit reifen Samenkapseln) unter Nutzung eines Fernglases erfasst (als Durchschnitt von drei Zählrunden). Jede Zählrunde besteht aus der Anzahl der Früchte, die der Beobachter in 30 Sekunden zählt. Bei allen Bäumen sollte das gleiche Kronendrittel untersucht werden. Sobald ein Kronendrittel für die Beobachtung ausgewählt wurde, sollte dieses für jede weitere Erhebung dieses Verifikators ausgewählt werden. Für die Zählung wird das obere Kronendrittel dem unteren und mittleren Drittel vorgezogen.

Es werden zwei Werte erfasst: die Anzahl der Früchte und das untersuchte Kronendrittel.

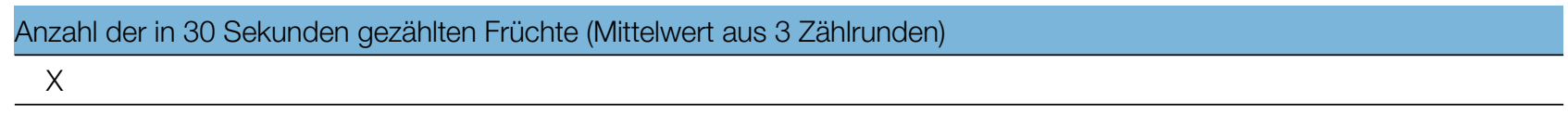

\begin{tabular}{|c|c|}
\hline Cod & Untersuchtes Kronendr \\
\hline 1 & unteres Kronendrittel \\
\hline 2 & mittleres Kronendrittel \\
\hline 3 & oberes Kronendrittel \\
\hline
\end{tabular}




\subsubsection{Auftreten und Abundanz der Naturverjüngung}

Dieser Verifikator beschreibt das Vorhandensein und die Häufigkeit von Naturverjüngung auf der Monitoringfläche.

\subsubsection{Basisniveau}

Der Verifikator wird jährlich im späten Frühjahr/Frühsommer auf Ebene der FGM-Teilflächen erfasst. Für die Schätzung der Situation auf der gesamten Monitoringfläche werden Expertenmeinungen herangezogen.

Code Beschreibung: neue aufgelaufene Naturverjüngung (diesjährige Keimlinge)

1a Auf der Monitoringfläche gibt es keine oder nur sehr wenig neue Naturverjüngung

$2 a$ Auf der Monitoringfläche ist in ausreichender Anzahl neue Naturverjüngung vorhanden

Code Beschreibung: etablierte Naturverjüngung (Sämlinge)

1b Auf der Monitoringfläche gibt es keine oder nur sehr wenig etablierte Naturverjüngung

2b Auf der Monitoringfläche ist in ausreichender Anzahl etablierte Naturverjüngung vorhanden

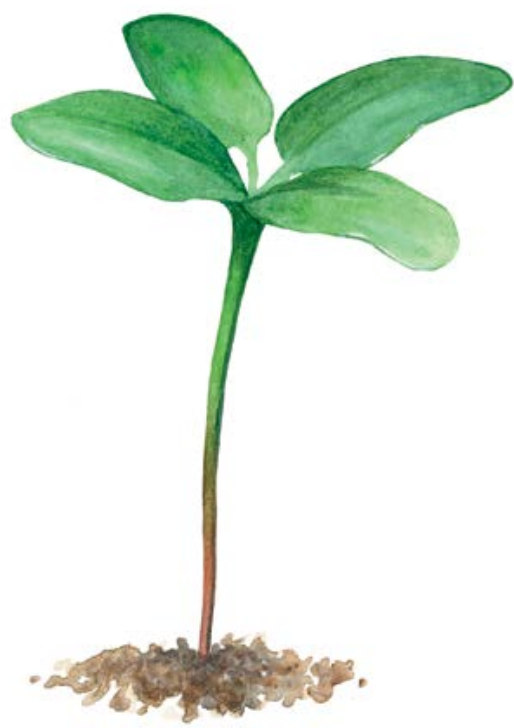

Abbildung 8: Neu gekeimter Keimling der Schwarz-Pappel mit charakteristischen Keimblättern und den ersten entwickelten Blättern.

\subsubsection{Standard- und Intensivniveau}

Der Verifikator wird durch Zählung der neu gekeimten Sämlinge (Abbildung 8) in bis zu 20 NV-Clustern nach jedem bewerteten Fruktifikationsereignis erfasst (das Jahr des Fruktifikationsereignisses wird als Jahr 0 betrachtet). Für die Schwarz-Pappel werden keine regulären NV-Plots angelegt, da aufgrund regelmäßiger Überschwemmungsereignisse ein hoher Verlust von NV zu erwarten ist. Folglich wird die Zählung nur einmal durchgeführt - unmittelbar nach der Keimung - und das Überleben bzw. die Mortalität der NV wird für diese Art nicht bewertet. Gleichzeitig werden NV-Proben für genetische Analysen gesammelt.

Zählung der Naturverjüngung:

In den 20 NV-Clustern werden alle neu gekeimten Schwarz-Pappel-Sämlinge gezählt. Ältere Schwarz-PappelJungpflanzen, die in den NV-Clustern vorhanden sind, dürfen nicht mitgezählt werden. 
Sind nach einem erfassten bedeutenden Blüh- und Fruktifikationsereignis keine neuen NV-Cluster zu finden (da z.B. Sämlinge durch Hochwasser weggeschwemmt wurden), muss die Bewertung der drei Verifikatoren (Blüte, Fruktifikation und NV-Abundanz) beim nächsten bedeutenden Blühereignis wiederholt werden, unabhängig von der Zeit, die zwischen aufeinanderfolgenden bedeutenden Blühereignissen liegt. Erhebungen auf Basisniveau werden zur Identifizierung bedeutender Blüh- und Fruktifikationsereignisse verwendet.

Sind in 5 aufeinanderfolgenden Monitoringjahren (nach zwei großen Fruktifikationsereignissen in einer Dekade) keine neuen NV-Cluster zu finden, sollte die NV an bereits erfolgreich etablierten NV-Standorten einmal pro Dekade geschätzt werden. In solchen Fällen ist das ungefähre Alter der NV zu schätzen und zu erfassen.

Anzahl der Sämlinge in einem NV-Cluster

$\mathrm{X}$

\subsection{Verfahren zur Erfassung von Hintergrundinformationen}

\subsubsection{Durchmesserklassenverteilung}

\subsubsection{Standard- und Intensivniveau}

Der BHD wird alle 10 Jahre für alle 50 Beobachtungsbäume auf Einzelbaumebene erfasst. Der BHD ist der Stammdurchmesser in 1,30 m Höhe, d.h. ungefähr auf Brusthöhe eines Erwachsenen. Hat der Baum mehr als einen Stamm, messen Sie bitte alle Stämme und erfassen Sie den Durchschnitt (versuchen Sie jedoch, Bäume mit vielen kleinen Stämmen zu vermeiden). Notieren Sie in den Anmerkungen, dass der Baum mehrstämmig ist, und geben Sie die Anzahl der gemessenen Stämme an. Ist der Baum geneigt, messen Sie den BHD senkrecht zum Baumstamm. Der BHD kann auf zwei Arten gemessen werden:

1) mit einer Kluppe; in diesem Fall messen Sie senkrecht zueinander zwei Durchmesser und berechnen den Mittelwert

2) Messen Sie den Umfang des Baumes und berechnen Sie daraus den Durchmesser (d.h. dividieren Sie durch $\pi ; \sim 3,14)$

Der BHD wird in cm angegeben. Für nachfolgende Messungen ist stets dieselbe Methode anzuwenden.

\subsubsection{Höhenklassenverteilung}

\subsubsection{Standard- und Intensivniveau}

Die Baumhöhe wird alle 10 Jahre für alle 50 Beobachtungsbäume auf Einzelbaumebene erfasst. Die Höhe wird vom Boden bis zum höchsten Punkt der Krone gemessen, idealerweise mit einem Klinometer oder Hypsometer (z.B. Vertex). Die Höhe wird in Metern auf eine Dezimalstelle angegeben. Ist die Krone beschädigt, muss dies in den Anmerkungen zusammen mit dem mutmaßlichen Grund für den Schaden notiert werden.

\subsubsection{Austrieb}

Diese Hintergrundinformation beschreibt die Austriebsstadien. Die Aufzeichnung erfolgt nur auf Standard- und Intensivniveau. Bei der Schwarz-Pappel beginnt der Blattaustrieb später als die Blüte. Die Daten für diese Hintergrundinformation sollten in Mitteleuropa von März bis Mai erhoben werden, bis alle Beobachtungsbäume voll entwickelte Blätter haben. Nach warmen Wintern erfolgt der Austrieb früher.

\subsubsection{Standardniveau}

Auf Standardniveau wird der Austrieb alle 5 Jahre für alle 50 Beobachtungsbäume auf Einzelbaumebene beobachtet. Gesucht werden der Beginn der Knospenöffnung (Stadium 3) und das Ende der Blattentfaltung 
(Stadium 6). Die Beobachtungen werden beendet, wenn alle Bäume das Stadium 5 erreicht haben. In der Regel sind dafür 2 Begehungen erforderlich. Für jeden Baum werden zwei Werte erfasst: das Austriebsstadium und der entsprechende Kronenanteil. Die Austriebsstadien sind in Abbildung 9 dargestellt.

\begin{tabular}{lll} 
Code & Stadium & Beschreibung \\
\hline 1 & $\begin{array}{l}\text { Schlafende } \\
\text { Winterknospe }\end{array}$ & $\begin{array}{l}\text { Knospen vollständig von Knospenschuppen umhüllt (vor dem ersten Anzeichen des } \\
\text { Anschwellens) }\end{array}$ \\
\hline 2 & Anschwellen & Geschwollene Knospe mit leicht geöffneten Knospenschuppen \\
\hline 3 & Knospenöffnung & Beginnende Knospenöffnung \\
\hline 4 & Blattentfaltung & Vollständig geöffnete Knospen, aber die Blätter sind noch eng beieinander \\
\hline 5 & Blattverlängerung & Blätter entfalten sich \\
\hline 6 & Vertikales Wachstum & Blätter vollständig entfaltet und voll entwickelt \\
\hline
\end{tabular}

\begin{tabular}{lr} 
Code Anteil der Krone mit dem entsprechenden Austriebsstadium (\%) & $>0-33 \%$ \\
\hline 1 & $>33-66 \%$ \\
\hline 2 & $>66-99 \%$ \\
\hline 3 & $100 \%$ \\
\hline 4 & \\
\hline
\end{tabular}

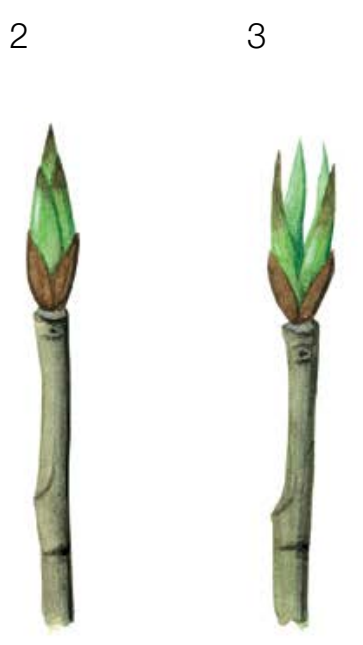

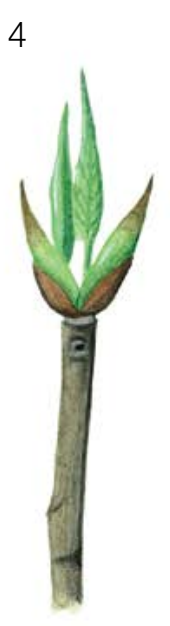

6

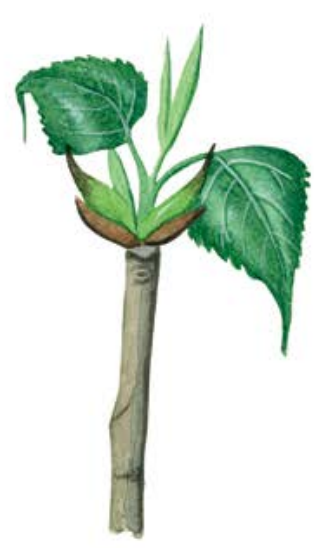

Abbildung 9: Illustration zur Beschreibung der Hintergrundinformation „Austrieb“ auf Standard- und Intensivniveau.

\subsubsection{Intensivniveau}

Auf Intensivniveau wird der Austrieb jährlich für alle 50 Beobachtungsbäume auf Einzelbaumebene erhoben, mit derselben Verfahrensweise wie auf Standardniveau. Gesucht werden der Beginn der Knospenöffnung (Stadium 3) und das Ende der Blattentfaltung (Stadium 5). Die Beobachtungen werden beendet, wenn alle Bäume das Stadium 6 erreicht haben. In der Regel sind dafür 2 Begehungen erforderlich. Details zu den Stadien sind im Kapitel 7.2.3.1 Standardniveau zu finden.

\subsubsection{Seneszenz}

Die Seneszenz beschreibt den Prozess der Blattalterung. Die Erfassung dieser Hintergrundinformation erfolgt nur auf dem Standard- und Intensivniveau. 


\subsubsection{Standardniveau}

Auf Standardniveau wird die Seneszenz alle 5 Jahre für alle 50 Beobachtungsbäume auf Einzelbaumebene beobachtet. Gesucht wird das Stadium 3, wenn die Blätter gelb sind und keine Photosynthese mehr betreiben. Die Beobachtungen enden, wenn alle Bäume das Stadium 3 erreicht haben. Normalerweise sind dafür zwei Begehungen der Monitoringfläche erforderlich. Für jeden Baum werden zwei Werte erfasst: das Stadium der Seneszenz und der entsprechende Kronenanteil. Die Stadien der Seneszenz sind in Abbildung 10 dargestellt.

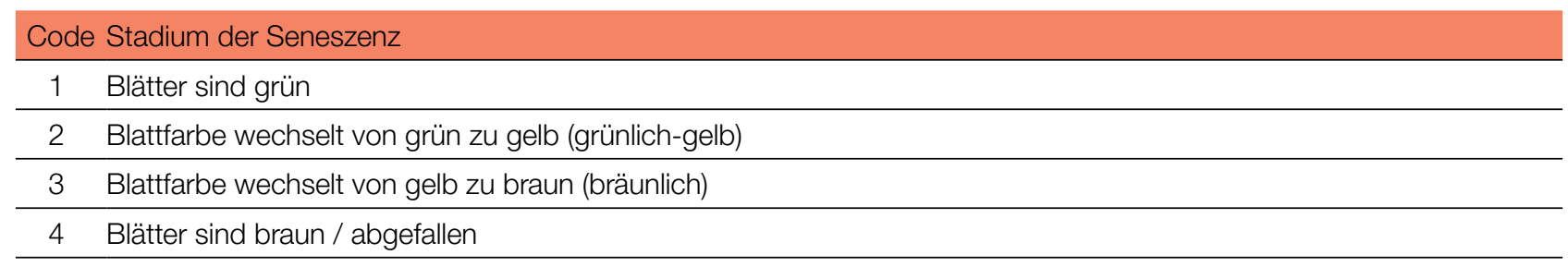

\begin{tabular}{lr}
\hline Code Anteil der Krone mit dem entsprechenden Seneszenzstadium (\%) & $>0-33 \%$ \\
\hline 1 & $>33-66 \%$ \\
\hline 2 & $>66-99 \%$ \\
\hline 3 & $100 \%$ \\
\hline 4 & \\
\hline
\end{tabular}

\subsubsection{Intensivniveau}

Auf Intensivniveau wird die Seneszenz jährlich für alle 50 Beobachtungsbäume auf Einzelbaumebene erfasst, mit derselben Verfahrensweise wie auf Standardniveau. Gesucht wird das Stadium 3, wenn die Blätter gelb sind und keine Photosynthese mehr betreiben. Die Beobachtungen enden, wenn alle Bäume das Stadium 3 erreicht haben. Normalerweise sind dafür zwei Begehungen der Monitoringfläche erforderlich. Details dazu sind im Kapitel 7.2.4.1 Standardniveau zu finden.
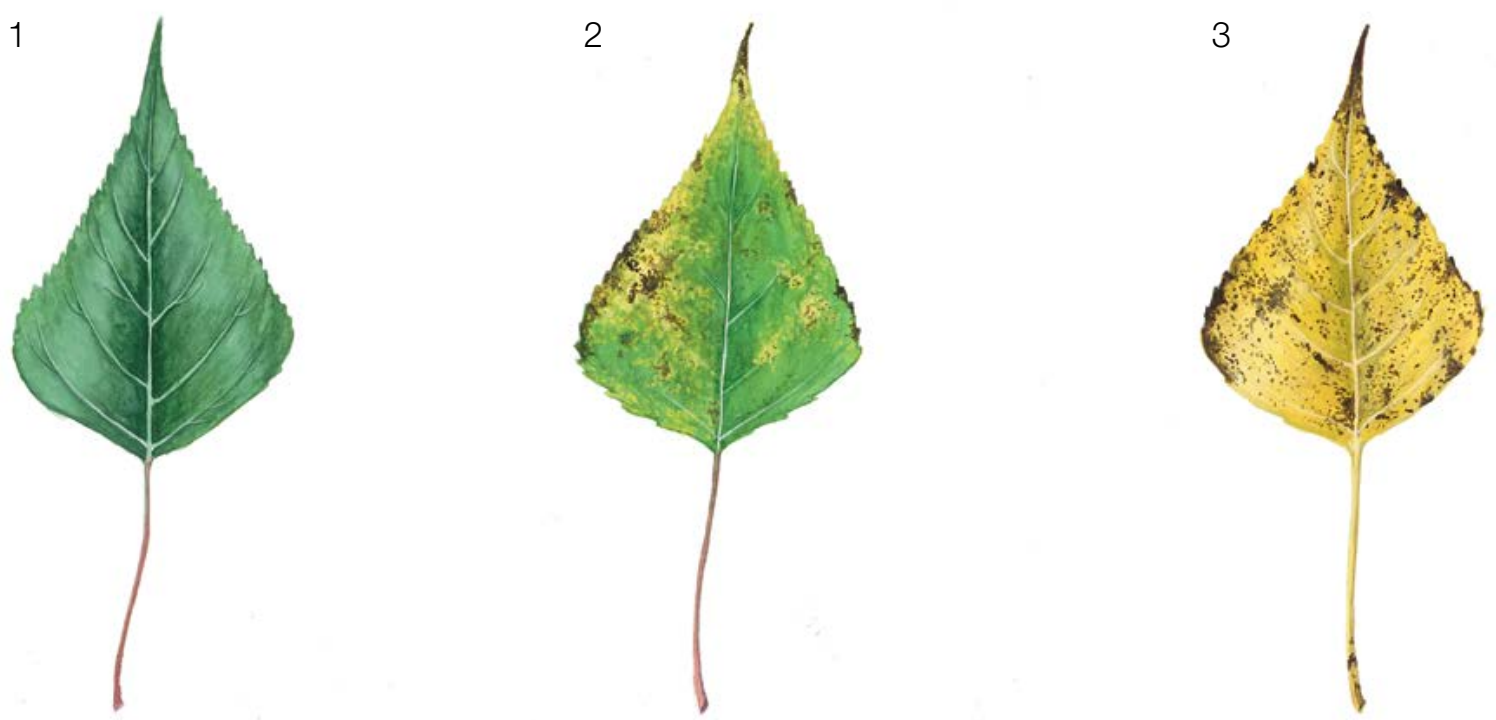

Abbildung 10: Illustration zur Beschreibung der Seneszenz für die Hintergrundinformation „Seneszenz" auf Standardund Intensivniveau (Phase 4 ist nicht dargestellt). 


\subsubsection{Blühsynchronisation}

\subsubsection{Intensivniveau}

Die Hintergrundinformation „Blühsynchronisation“ wird nur auf Intensivniveau erfasst und basiert auf den für den Verifikator „Blüte“ erhobenen Daten (siehe Kapitel 7.1.2.3). Sie wird verwendet, um festzustellen, ob die männliche und weibliche Blüte innerhalb des untersuchten Bestandes gleichzeitig stattfindet.

\section{Formular für die Beschreibung der Monitoringfläche: 'FGM Plot description'}

Formular für die Erfassung der Verifikatoren: 'Form for recording field level verifiers within FGM'

Formular für die Aufzeichnung von Hintergrundinformationen: 'Form for recording field level background information within FGM'

\section{Quellen}

1. Smulders MJM, Cottrell JE, Lefèvre F, van der Schoot J, Arens P, Vosman B, Tabbener HE, Grassi F, Fossati T, Castiglione S, Krystufek V, Fluch S, Burg K, Vornam B, Pohl A, Gebhardt K, Alba N, Agúndez D, Maestro C, Notivol E, Volosyanchuk R, Pospíšková M, Bordács S, Bovenschen J, van Dam BC, Koelewijn HP, Halfmaerten D, Ivens B, van Slycken J, Vanden Broeck A, Storme V, Boerjan W (2008) Structure of the genetic diversity in black poplar (Populus nigra L.) populations across European river systems: Consequences for conservation and restoration. Forest Ecol Manag 255(5-6):1388-1399. DOI:10.1016/j.foreco.2007.10.063

2. Lefèvre F, Barsoum N, Heinze B, Kajba D, Rotach P, de Vries S, Turok J (2001). EUFORGEN Technical Bulletin: In situ conservation of Populus nigra. International Plant Genetic Resources Institute, Rome

3. Lefèvre F, Bordács S, Cottrell JE, Gebhardt K, Smulders MJM, Vanden Broeck A, Vornam B, van Dam BC (2002) Recommendation for riparian ecosystem management based on the general frame defined in EUFORGEN and results from EUROPOP. In: van Dam BC, Bordács S (eds) Genetic diversity in river populations of European Black Poplar. (Implications for riparian eco-system management), Csiszár Nyomda, Budapest, pp 157-161

4. Jelić M, Patenković A, Skorić M, Mišić D, Kurbalija Novičić Z, Bordács S, Varhidi F, Vasić I, Benke A, Frank G, Šiler B (2015) Indigenous forests of European black poplar along the Danube River: genetic structure and reliable detection of introgression. Tree Genet Genomes 11:89 https://doi.org/10.1007/s11295-015-0915-5

5. Eckenwalder JE (1996) Systematics and evolution of Populus. In: Stettler RF, Bradshaw HD. Jr, Heilman PE, Hinckley TM (eds) Biology of Populus and Its Implications for Management and Conservation. NRC Research Press, Ottawa, pp. 7-32. https://doi.org/10.1139/9780660165066

6. Rotach P (2001) General consideration and basic strategies. In: Lefevre F, Barsoum N, Heinze B, Kajba D, Rotach P, de Vries SMG, Turok J (eds) EUFORGEN technical bulletin: in situ conservation of Populus nigra. International Plant Genetic Resources Institute, Rome, pp 8-15

7. Heinze B, Lefevre F (2001) Genetic considerations for the restoration of riparian populations. In: Lefevre F, Barsoum N, Heinze B, Kajba D, Rotach P, de Vries SMG, Turok J (eds) EUFORGEN technical bulletin: in situ conservation of Populus nigra. International Plant Genetic Resources Institute, Rome, pp 25-35

8. Allegri E (1971) Identification of species and varieties of poplar indigenous in Italy. Annali dell Istituto Sperimentale per la Selvicoltura 2:1-62

9. Popivshchy II; Prokazin AE; Routkovsky LV (1997) Black poplar in the Russian Federation. In: Turok J, Lefévre F, de Vries S, Toth B (eds) Populus nigra Network. Report of the third meeting, Sarvar, Hungary, 5-7 October 1996, IPGRI, Rome, pp 46-52.

10. Dickmann D, Kuzovkina J (2014) Poplars and Willows in the World, With Emphasis on Silviculturally Important Species. In: Isebrands JG, Richardson J (eds) Poplars and Willows: Trees for Society and the Environment. FAO UN, CABI, Rome, pp 8-91. http://dx.doi.org/10.1079/9781780641089.0008

11. de Rigo D, Enescu CM, Houston Durrant T, Caudullo G (2016) Populus nigra in Europe: distribution, habitat, usage and threats. In: San-Miguel-Ayanz J, de Rigo D, Caudullo G, Houston Durrant T, Mauri A (eds) European Atlas of Forest Tree Species. Publ. Off. EU, Luxembourg, pp 136-137. DOI: 10.2788/4251

12. Fitschen JB (2002) Gehölzflora. Quelle \& Meyer Verlag, Wiebelsheim, pp 45-1; 45-7

13. Roloff A, Bärtels A (2006) Flora der Gehölze. Eugen UlmerKG, Stuttgart, pp 457-464 
14. Vanden Broeck A (2003) Technical guidelines for genetic conservation and use of European Black Poplar (Populus nigra L.). International Plant Genetic Resources Institute,Rome

15. Braatne JH, Rood SB, Heilman PE (1996) Life history, ecology, and conservation of riparian cottonwoods in North America. In: Stettler RF, Bradshaw HD, Heiman PE, Hinckley TM (eds.) Biology of Populus and its Implications for Management and Conservation. NRC Research Press, Ottawa, pp 57-80. https://doi.org/10.1139/9780660165066

16. Mahoney JM, Rood SB (1998) Streamflow requirements for cottonwood seedling recruitment-an integrative model. Wetlands 18:634-645. https://doi.org/10.1007/BF03161678

17. Barsoum N (2001) Regeneration requirements and promotion measures. In: Lefevre F, Barsoum N, Heinze B, Kajba D, Rotach P, de Vries SMG, Turok J (eds) EUFORGEN technical bulletin: insitu conservation of Populus nigra. International Plant GeneticResources Institute, Rome, pp 16-24

18. Guilloy-Froget H, Muller E, Barsoum N, Hughes FMR (2002) Dispersal, germination, and survival of Populus nigra L. (Salicaceae) in changing hydrologic conditions. Wetlands 22:478-488. https://doi. org/10.1672/0277-5212(2002)022[0478:DGASOP]2.0.CO;2

19. Rihardson J, Isebrands JG, Ball JB (2014) Ecology and Physiology of Populus and Willows. In: Isebrands JG, Richardson J (eds) Poplars and Willows: Trees for Society and the Environment. CAB International, Food and Agriculture Organization of the United Nations (FAO), pp 92-123. http://dx.doi.org/10.1079/9781780641089.0008

20. Zsuffa L (1974) The genetics of Populus nigra L. Annales Forestales 6:29-53

21. Ballian D (2017) Varijabilnost crne topole (Populus nigra L.) i njeno očuvanje u Bosni i Hercegovini. (Variability of Black poplar (Populus nigra L.) and its preservation in Bosnia and Herzegovina). Forestry Faculty of the University of Sarajevo/Silva Slovenica - Slovenian Forestry Institute Publishing Centre, Sarajevo/Ljubljana.

22. Lefèvre F, Légionnet A, de Vries S, Turok J (1998) Strategies for the conservation of a pioneer tree species, Populus nigra L., in Europe. Genet Sel Evol 30:S181 https://doi.org/10.1186/1297-9686-30-S1-S181

23. Bordács S, Bach I (2014) Restoration and afforestation with Populus nigra in Hungary. In: Bozzano M, Jalonen R, Thomas E, Boshier D, Gallo L, Cavers S, Bordács S, Smith P, Loo J (eds) Genetic considerations in ecosystem restoration using native tree species: State of the World's Forest Genetic Resources. Thematic study, Rome: Food and Agriculture Organization of the United Nations (FAO), pp 233-235. http://www.fao.org/3/a-i3938e.pdf. Accessed 10 August 2020

24. EUFORGEN Identification Sheet of Populus nigra L. http://www.euforgen.org/fileadmin/templates/euforgen.org/ upload/Publications/Other_PDFs/Pop_nigra_IdSheets/English.pdf. Accessed 10 August 2020

Die folgenden Ressourcen wurden für die derzeit akzeptierten (Dezember 2020) wissenschaftlichen Namen der in diesem Dokument erfassten oder erwähnten Arten konsultiert:

a. CABI (2020) Invasive Species Compendium. CAB International, Wallingford, UK. www.cabi.org/isc. Accessed 15 December 2020

b. EPPO (2020) EPPO Global Database (available online). https://gd.eppo.int. Accessed 15 December 2020

c. GBIF (2020) Global Biodiversity Information Facility. https://www.gbif.org Accessed 15 December 2020

d. IPNI (2020) International Plant Names Index. The Royal Botanic Gardens, Kew, Harvard University Herbaria \& Libraries \& Australian National Botanic Gardens. http://www.ipni.org, Accessed 10 December 2020

e. National Center for Biotechnology Information (NCBI) (1998) National Library of Medicine (US), National Center for Biotechnology Information, Bethesda (MD). https://www.ncbi.nlm.nih.gov/. Accessed 15 December 2020

f. Stevens PF (2001) Angiosperm Phylogeny Website, Version 14. http://www.mobot.org/MOBOT/research/APweb/. Accessed 15 December 2020

g. The Plant List (2013) Version 1.1. http://www.theplantlist.org/. Accessed 12 December 2020

h. Tropicos.org (2020) Missouri Botanical Garden. http://www.tropicos.org. Accessed 15 December 2020

i. WFO (2020) World Flora Online. http://www.worldfloraonline.org. Accessed 15 December 2020 



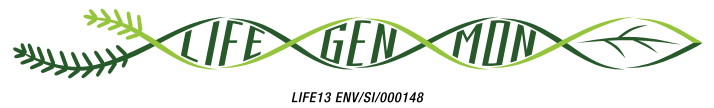

\section{Leitfaden für das genetische Monitoring der}

\subsubsection{Vogelkirsche (Prunus avium (L.) L.)}

Darius KAVALIAUSKAS ${ }^{1}$, Barbara FUSSI', Filippos ARAVANOPOULOS², Paraskevi ALIZOTI², Dalibor BALLIAN³,4, Nikos TOURVAS², Gregor BOŽIČ³, Evangelos BARBAS ${ }^{2}$, Marjana WESTERGREN ${ }^{3}$, Marko BAJC ${ }^{3}$, Rok DAMJANIĆ ${ }^{3}$, Hojka KRAIGHER ${ }^{3}$

Botanische Illustrationen von Teja MILAVEC

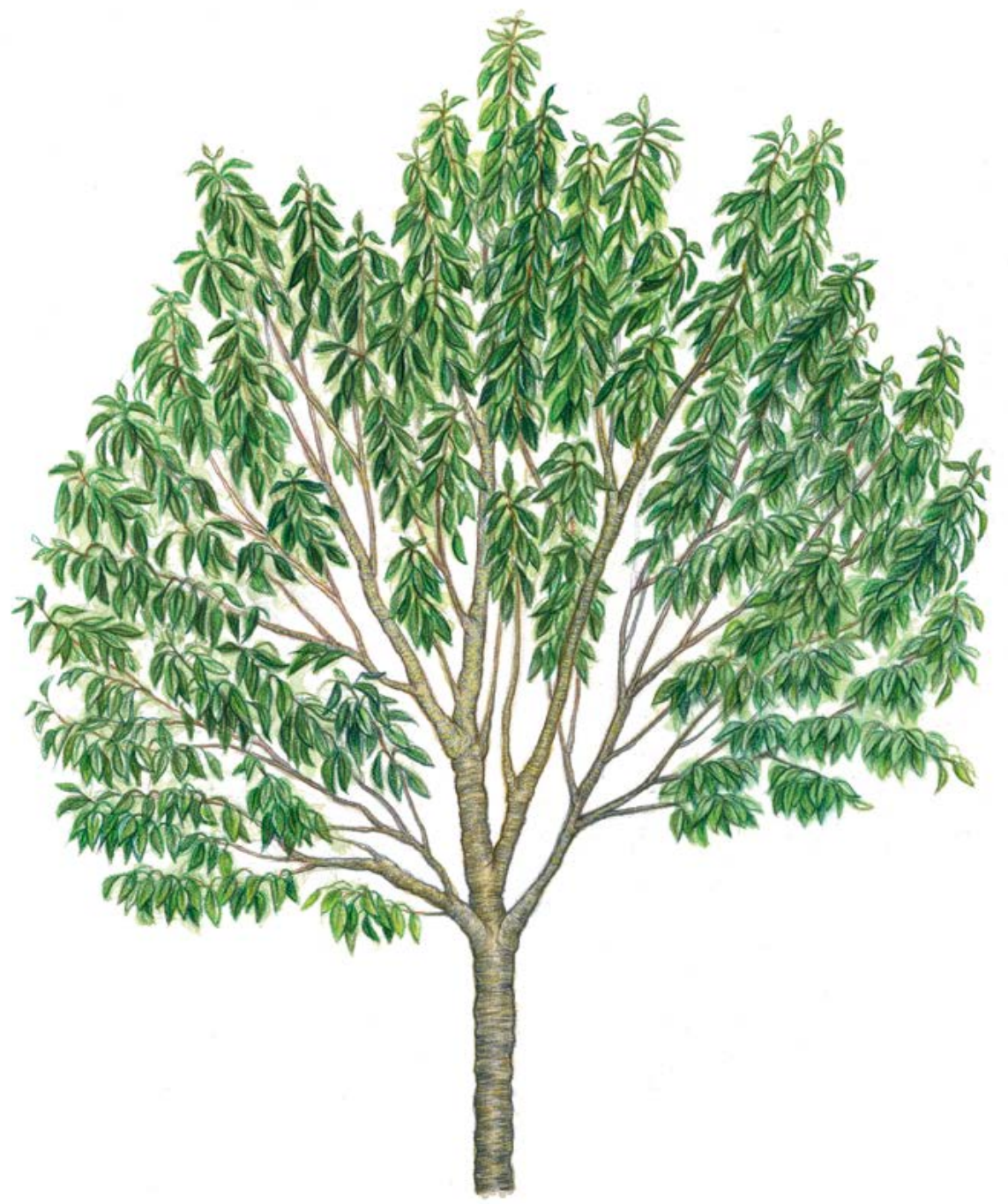

Zitat: Kavaliauskas et al. (2020) Leitfaden für das genetische Monitoring der Vogelkirsche (Prunus avium (L.) L.). In: Bajc et al. (Ed.) Handbuch zum Forstgenetischen Monitoring. Slowenisches Forstinstitut: Verlag Silva Slovenica, Ljubljana, S. 271-287. http://dx.doi.org/10.20315/SFS.176 


\section{ZUSAMMENFASSUNG}

Die Vogelkirsche (Prunus avium (L.) L.) ist ein mittelgroßer, schnell wachsender und eher kurzlebiger Laubbaum mit einem großen natürlichen Verbreitungsgebiet, das den Westen Eurasiens und den nördlichen Teil Afrikas umfasst [1]. Sie ist eine nicht-bestandesbildende Pionierbaumart, die in einer Vielzahl von Lebensräumen überleben kann. Die Art wächst in ihrem Verbreitungsgebiet jedoch extrem verstreut, da sie sehr lichtbedürftig und konkurrenzschwach ist. Die natürlichen Populationen der Vogelkirsche zeichnen sich durch ihre geringe Größe aus; sie bestehen meist aus kleinen Gruppen und Einzelbäumen, die an Waldrändern und auf Waldlichtungen wachsen. Die Vogelkirsche ist aus ökologischer (sie ist eine lebenswichtige Nahrungsquelle für viele Vogelund Insektenarten) und wirtschaftlicher Sicht (das qualitativ hochwertige und leicht zu bearbeitende Holz der Vogelkirsche ist wertvoll und wird oft für die Furnier- und Möbelherstellung, für Schreinerarbeiten usw. verwendet) eine wichtige Waldbaumart.

Dieser Leitfaden beschreibt die Vogelkirsche sowie ihre Reproduktion, Umweltansprüche und Gefährdung. Er enthält außerdem eine Anleitung zur Einrichtung genetischer Monitoringflächen und zur Erfassung aller vor Ort im Bestand zu erhebenden Verifikatoren.

\section{BESCHREIBUNG DER BAUMART}

Die Vogelkirsche ist ein mittelgroßer, schnell wachsender und ziemlich kurzlebiger Laubbaum, der eine Höhe von 15-30 m (bis max. $35 \mathrm{~m}$ ) und einen Stammdurchmesser (BHD) von bis zu 90-120 cm erreichen kann [3, 4, 5, 16, 19 und darin enthaltene Quellen] (Abbildung 1). Die Vogelkirsche hat eine ausgeprägte Apikaldominanz und die meisten ihrer jährlichen Seitentriebe sind in Quirlen angeordnet. Die Krone ist breit-kegelförmig; der Stamm meist gerade. Die Rinde ist glänzend, mit auffälligen Lentizellen, und schält sich horizontal $[16,19]$. Die Blätter sind im Frühjahr hellgrün, im Sommer dunkelgrün und im Herbst gelb, orange oder rotbraun. Sie sind wechselständig

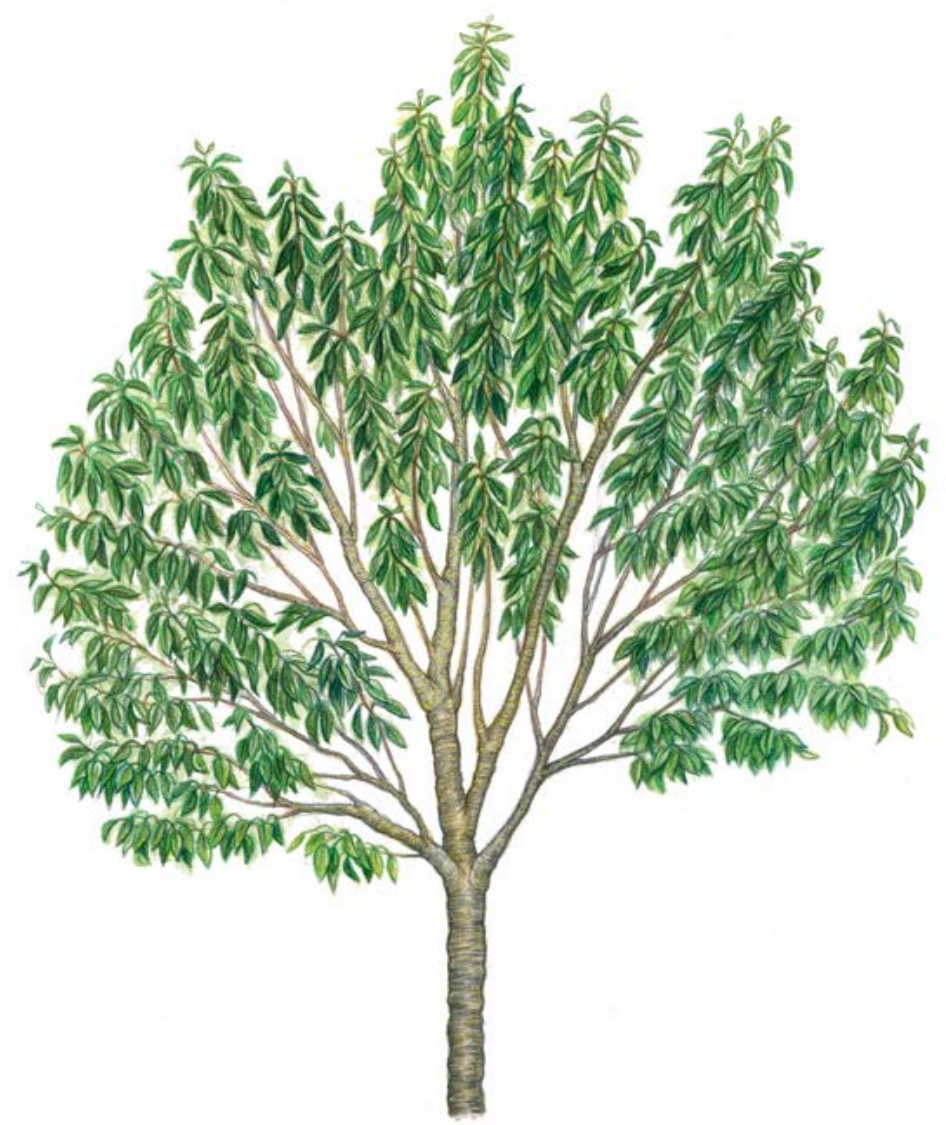

Abbildung 1. Habitus der Vogelkirsche (Prunus avium) 
angeordnet, hängend, ungeteilt, und elliptisch-eiförmig bis verkehrt-eiförmig, mit leicht abgerundeten Zähnen am Blattrand. An dem 2 bis 3,5 cm langen Blattstiel befinden sich unterhalb der Blattspreite paarweise auffällige, dunkelrot gefärbte Nektardrüsen [19].

\section{REPRODUKTION}

Die Vogelkirsche gehört zu den Baumarten mit einem gemischten Paarungssystem, das sowohl ungeschlechtliche Fortpflanzung über Wurzelbrut als auch sexuelle Fortpflanzung umfasst. Die Art ist einhäusig, zwittrig, mit typischen fünfzähligen, gestielten Blüten mit weißen Blütenblättern, die in Gruppen von drei bis zehn oder mehr auf Kurztrieben stehen [3, 9]. Die Blüten werden von Insekten bestäubt, hauptsächlich von Honigbienen, Wildbienen und Hummeln [2, 3, 5, 16, 19]. Die Blüte und Samenproduktion von Vogelkirschen beginnt unter optimalen Bedingungen im Alter von 4-6 Jahren. Sie gehört zu den Baumarten, die im Frühjahr als erstes blühen, und produziert Unmengen weißer Blüten. Die kleinen roten oder schwarzen Früchte sind essbar (Abbildung 2) [2, 6]. Die Samen werden von Vögeln und kleinen Säugetieren verbreitet [5, 16, 19]. Die Samenruhe dauert ein bis zwei Winter. Die Keimung gelagerter Samen erfordert eine Kombination aus warmer und kalter Stratifikation [16].
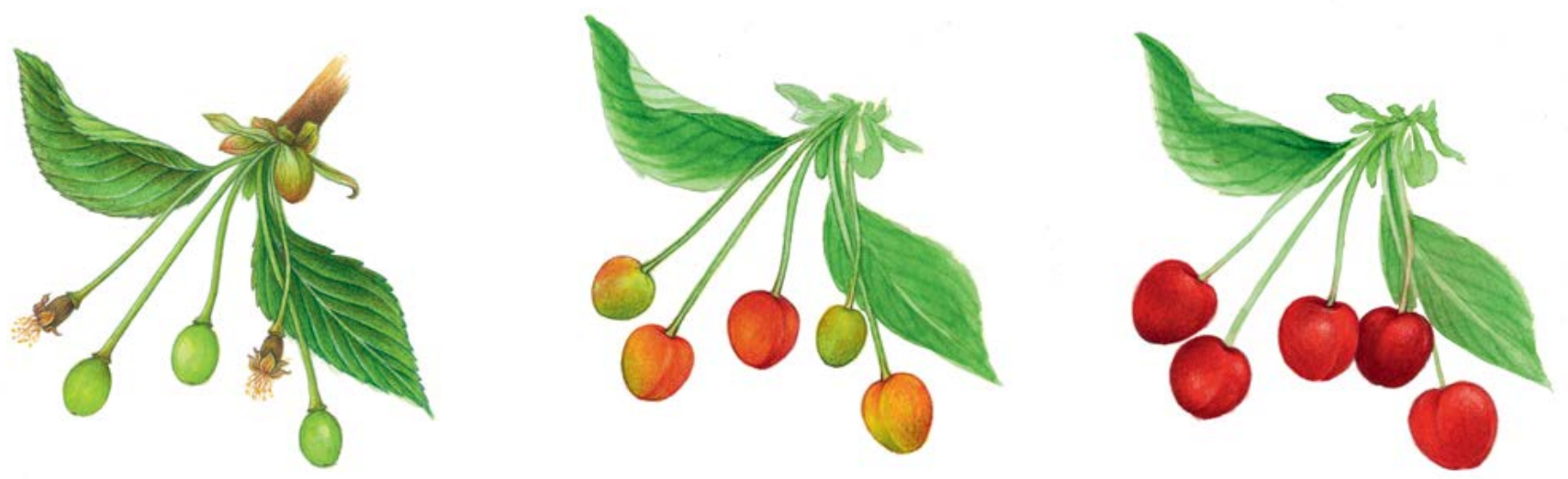

Abbildung 2. Fruchtentwicklung der Vogelkirsche (Prunus avium).

Die sexuelle Fortpflanzung der Baumart zeichnet sich durch gametophytische Selbstinkompatibilität aus (die durch das 'S"'-Allel reguliert wird), was Auskreuzung begünstigt und Selbstbefruchtung verhindert [7, 11, 12, 15, 16, 17, 9 und darin enthaltene Quellen]. Die Vogelkirsche kann sich mit anderen Kirscharten kreuzen (Hybridisierung), insbesondere dort wo sich die natürlichen Verbreitungsgebiete überschneiden (z.B. mit Süßkirsche, Sauerkirsche (Prunus cerasus L.) oder Europäischer Zwergkirsche (Prunus fruticosa Pall.) [7, 14, 16, 18]), sowie in der Nähe von Kirschanbaugebieten.

Bezüglich der räumlichen Ausbreitungsstrategie der Art wird angesichts ihres gemischten Paarungssystems davon ausgegangen, dass die erfolgreiche Etablierung in einer neuen ökosystemaren Nische dann gelingt, wenn auf die initiale Ansiedlung von Sämlingen die ungeschlechtliche Fortpflanzung über Wurzelbrut folgt [13].

\section{UMWELT}

Die Vogelkirsche ist eine Pionierbaumart, die in einer Vielzahl von Lebensräumen wächst. Aufgrund ihrer geringen Konkurrenzstärke und ihres hohen Lichtbedarfs gehört sie jedoch zu den nicht-bestandesbildenden Arten mit einem verstreuten Verbreitungsgebiet. Die natürlichen Populationen der Vogelkirsche sind oft relativ klein und bestehen aus Baumgruppen oder Einzelbäumen, die an Waldrändern und auf Waldlichtungen wachsen, die z.B. infolge von Störungsereignissen entstanden sind [16]. In den frühen Stadien der Waldsukzession kann die Baumart offene Flächen (Lücken) schnell durch Samen oder Wurzelbrut besiedeln, wird aber während der 
fortschreitenden Sukzession oft durch andere Laubholzarten (Klimaxbaumarten) ersetzt [16, 19]. Die Vogelkirsche bevorzugt tiefgründige, leichte, schluffige Böden ( $\mathrm{pH} 5,5-8,5)$, die nährstoffreich und gut wasserversorgt sind (Jahresniederschlag von 580-1800 mm). Sie ist grundsätzlich eine sehr kälteresistente Baumart, aber die Blüten können durch Spätfröste im Frühjahr beschädigt werden. Im Kern ihres Verbreitungsgebietes kommt die Art in Laubmischwald-Gesellschaften der Klasse Querco-Fagetea vor, wie z.B. in Schluchtwäldern (Tilio-Acerion), Eichen-Hainbuchenwäldern (Carpinion betuli), Tiefland-Buchenwäldern (Fagion) und Auenwäldern (Alno-Ulmion) [19 und darin enthaltene Quellen].

\section{GEFÄHRDUNG}

Die in der Forstwirtschaft vorherrschende Hochwaldbewirtschaftung und die langen Umtriebszeiten führten in den letzten Jahrzehnten zu suboptimalen Bedingungen für die Vogelkirsche. Gegenwärtig wird die Rolle der Vogelkirsche für eine Erhöhung der Biodiversität von Waldökosystemen stärker gewürdigt, und sie wird durch Waldbesitzer aktiv gefördert [9]. Die Baumart ist relativ empfindlich gegenüber Umwelteinflüssen (z.B. Dürreperioden) und kann unter ungünstigen Bedingungen leicht von Krankheiten und Schädlingen befallen werden. Darüber hinaus zeichnet sich ihr Wurzelsystem durch weitreichende Seitenwurzeln in den oberen Bodenhorizonten aus, was sie sturmanfällig macht [9, 19 und darin enthaltene Quellen]. Die Wurzeln können von Mäusen und Wühlmäusen geschädigt werden. Vogelkirschenverjüngung ist besonders anfällig für Verbiss. Die Blätter können z.B. durch Raupen des Kleinen Frostspanners (Operophtera brumata L.) oder des Schwammspinners (Lymantria dispar L.) geschädigt werden; die Früchte können von der Europäischen Kirschfruchtfliege (Rhagoletis cerasi L.) und dem Kirschkernstecher (Anthonomus rectirostris L.) befallen werden. Die Vogelkirsche kann auch durch bakterielle Erreger wie Pseudomonas syringae Van Hall oder Erwinia amylovora (Burrill), das Kirschblattrollvirus (CLRV), und pilzliche Pathogene (Apiognomonia erythrostoma Höhnel, Blumeriella jaapi (Rehm) Arx) geschädigt werden [19 und darin enthaltene Quellen].

\section{EINRICHTUNG UND INSTANDHALTUNG VON MONITORINGFLÄCHEN}

EineforstgenetischeMonitoringflächeumfasst50fortpflanzungsfähigeAltbäumemiteinemBrusthöhendurchmesser $(\mathrm{BHD})$ von mehr als $15 \mathrm{~cm}$ und einem Mindestabstand von $30 \mathrm{~m}$ zwischen je zwei beliebigen Bäumen. Ein Baum gilt als fortpflanzungsfähig, wenn er blüht. Der BHD und die soziale Stellung eines Baumes können als Anhaltspunkte für die Identifizierung fortpflanzungsfähiger Bäume verwendet werden, wenn die Monitoringfläche außerhalb der Blütezeit angelegt wird. Dabei sollte auf das Fachwissen des zuständigen Försters zurückgegriffen werden. Bei der Neueinrichtung einer Monitoringfläche sollten alle Bäume beschriftet und ihre Koordinaten erfasst werden. Gleichzeitig können die jeweiligen BHD gemessen und Proben für die DNA-Extraktion gesammelt werden.

Aufgrund der Hybridisierung von Prunus avium mit Kulturkirschen wird empfohlen, FGM-Flächen in einer sicheren Entfernung (8-10 km) von Anbauflächen domestizierter Kirschsorten auszuwählen und anzulegen.

Für nicht-bestandesbildende Baumarten wie die Vogelkirsche, die in natürlichen Waldbeständen mit geringer Dichte vorkommen, ist eine Pilotstudie erforderlich, um die Größe und Form der forstgenetischen Monitoringfläche so anzupassen, dass sie 50 fortpflanzungsfähige Altbäume enthält. Darüber hinaus muss in der Monitoringfläche auch Naturverjüngung vorhanden sein (in Gruppen oder einzelne Jungpflanzen). Es wird jedoch empfohlen, die Größe der Monitoringfläche auf 10 ha zu begrenzen, da andernfalls die Durchführung des FGM-Verfahrens (Beprobung, phänologische Beobachtungen, usw.) zu kompliziert wird. Es ist wichtig, bei der Auswahl von Vogelkirschen potentielle Klone zu vermeiden. Wenn Vogelkirschengruppen aus einem einzelnen Genotyp bestehen, sollte deshalb nur ein Baum der Gruppe für das FGM ausgewählt werden.

Erforderliche Ausrüstung:

- ein Gerät zur Entfernungsmessung (empfehlenswert ist ein Fernglas mit Entfernungsmesser)

- ein Kompass 
- Farbe und Pinsel oder Farbspray zum Kennzeichnen der Bäume

- eine Kluppe für BHD-Messungen und

- ein ausreichend präzises GPS-Gerät, welches das Speichern von Baumkoordinaten ermöglicht

\subsection{Einrichtung der Monitoringfläche}

\subsubsection{Auswahl der Monitoringfläche}

Um eine Monitoringfläche für Prunus avium einzurichten, sollten die ersten Aktivitäten idealerweise im Frühjahr während der Blütezeit durchgeführt werden. Die Vogelkirsche ist im Frühjahr weithin sichtbar und unterscheidet sich durch ihre weißen Blüten von anderen Arten. Zusätzlich zu einer Begehung können auch Luftbilder visuell ausgewertet werden, um die ungefähre Anzahl, Dichte und Verteilung fortpflanzungsfähiger Vogelkirschen in einem ausgewählten Gebiet zu beurteilen. Sollten im Gebiet möglicherweise auch andere weißblühende Baumarten vorkommen, ist einer Vor-Ort-Begehung der Vorrang zu geben.

Zu diesem Zeitpunkt sollten alle vorhandenen Vogelkirschen im Bestand bzw. Gebiet mit einem GPS-Gerät kartiert und mit GIS-Software in einem Punkt-Layer dargestellt werden. Nach dem Zufallsprinzip sollten dann 50 dieser Punkte ausgewählt werden, die jeweils einen Mindestabstand von 30 m untereinander haben (Abbildung 3a). Während der Einrichtung der Monitoringfläche müssen diese vorausgewählten Bäume vor Ort identifiziert und gekennzeichnet werden.

\subsubsection{Einrichtung der Monitoringfläche}

Mit Hilfe des GPS werden alle im Büro vorausgewählten Bäume vor Ort lokalisiert und gekennzeichnet. Der Mindestabstand von 30 m zwischen den Bäumen muss nochmals überprüft werden.

\subsubsection{Kennzeichnung der Bäume}

Jeder ausgewählte Beobachtungsbaum muss mit einer entsprechenden Nummer (1-50) und idealerweise mit einem um den Stamm herum laufenden Streifen gekennzeichnet werden, um die Sichtbarkeit der Bäume aus allen Richtungen zu erhöhen (Abbildung 3b).
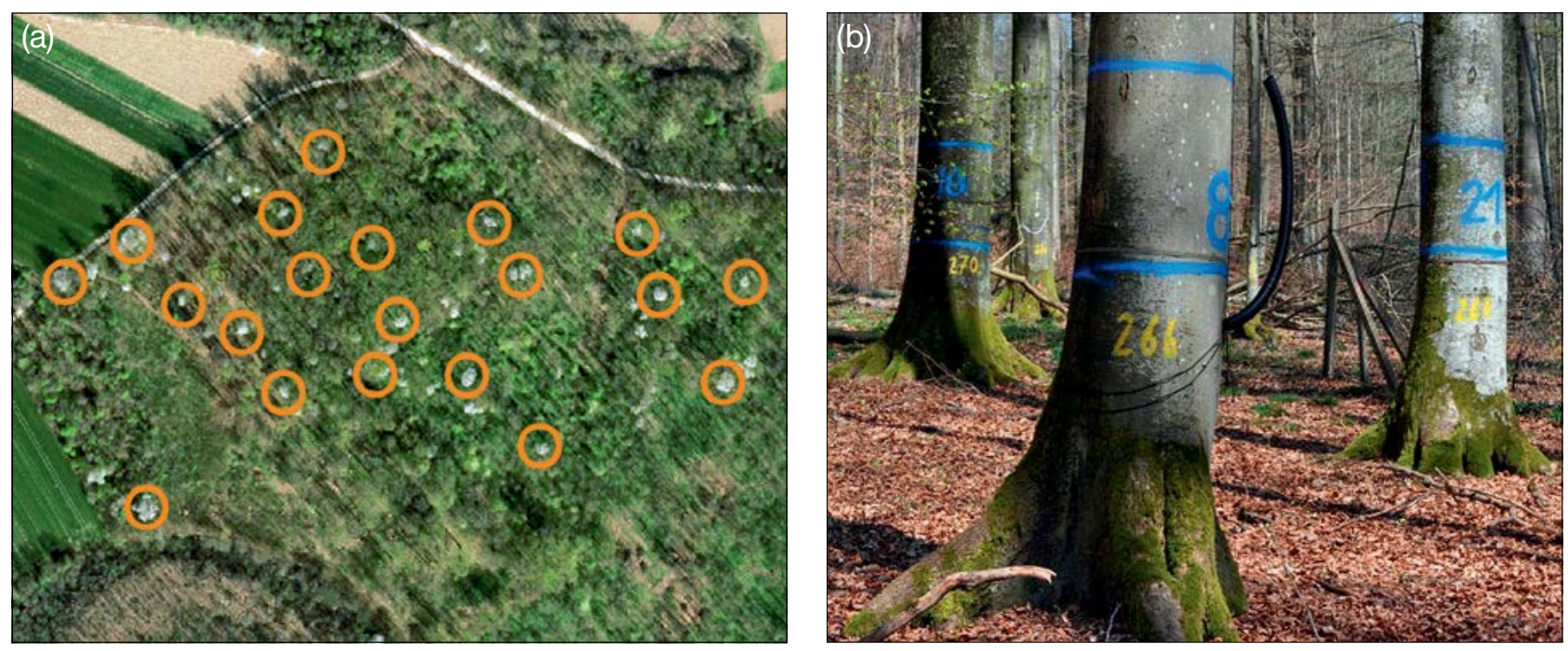

Abbildung 3: a) Alle fortpflanzungsfähigen Vogelkirschen im ausgewählten Bestand werden zuerst mit einem GPS-Gerät kartiert. Fünfzig Bäume mit einem Mindestabstand von 30 m voneinander werden dann zufällig für das FGM ausgewählt; b) die ausgewählten Bäume werden mit Zahlen und Streifen gekennzeichnet, um die Sichtbarkeit der Bäume aus allen Richtungen zu verbessern (die Fotos zeigen beispielhaft die Kennzeichnung auf einer Buchen-FGM-Fläche). 


\subsection{Einrichtung von Naturverjüngungs-Plots}

Bereiche mit aufgelaufener Naturverjüngung aus dem letzten Mastjahr (sogenannte Verjüngungscluster) sollten vor Ort vermessen und ihre Position erfasst werden (GPS-Koordinaten, Nummer des Beobachtungsbaumes neben dem Verjüngungscluster). Aufgrund der Samenruhe der Vogelkirsche kann die aus einem Mastjahr (Jahr mit ausgeprägter Frucht-/Samenproduktion) stammende Naturverjüngung ein oder zwei Jahre später auftreten, so dass unterschiedlich alte Sämlinge auf dasselbe Mastjahr zurückzuführen sein können. Von allen erfassten Verjüngungsclustern sollten nach dem Zufallsprinzip 20 für die Einrichtung von NV-Plots ausgewählt werden. Wenn 20 oder weniger natürliche Verjüngungscluster vorhanden sind, sollten alle verwendet werden.

Innerhalb jedes ausgewählten Verjüngungsclusters ist ein $1 \mathrm{~m}^{2}$ großer Plot einzurichten und mit Metallstäben zu markieren. Die Metallstäbe sollten an jeder Ecke der Teilfläche so tief wie möglich in den Boden getrieben werden, damit sie nicht von Tieren entfernt werden können. Die oberen Spitzen der Metallstäbe sollten farbig markiert werden, um ihre Sichtbarkeit zu verbessern.

\subsection{Instandhaltung}

\subsubsection{Allgemeine Instandhaltung}

Die Kennzeichnung der Bäume und NV-Plots muss periodisch (alle 2 Jahre) überprüft und bei Bedarf erneuert werden.

\subsubsection{Ersatz von Bäumen}

Wenn ein ausgewählter Beobachtungsbaum stirbt oder im Zuge der forstlichen Bewirtschaftung gefällt wird, muss er ersetzt werden. Dabei sollte der dem abgestorbenen/gefällten Baum nächstgelegene geeignete Baum ausgewählt werden, wobei der Mindestabstand von 30 m zum nächsten Beobachtungsbaum erfüllt sein muss. Der Ersatzbaum wird mit der nächsten verfügbaren Zahl über 50 gekennzeichnet, d.h. 51, 52, 53, usw., um inn eindeutig von den ursprünglich 50 ausgewählten Beobachtungsbäumen zu unterscheiden.

Wenn die Baumkrone z.B. durch Wind-, Eis- oder Schneebruch geschädigt ist, der Baum aber weiterhin fruktifiziert, wird der Baum im Monitoringprogramm belassen. Ist der Schaden zu schwerwiegend und eine Fruktifikation nicht mehr zu erwarten, muss der Baum ersetzt werden.

\section{ERFASSUNG VON VERIFIKATOREN UND HINTERGRUNDINFORMATIONEN}

Verifikatoren werden genutzt, um die genetischen Eigenschaften der Population und ihre Anpassung an Umweltveränderungen und/oder Bewirtschaftung zu verfolgen, während Hintergrundinformationen aufgezeichnet werden, um die Interpretation der Verifikatoren zu unterstützen. Verifikatoren können auf drei verschiedenen Intensitätsniveaus erfasst werden: Basis, Standard und Intensiv.

Höherrangigere Niveaus (Standard, Intensiv) müssen stets auch die Erfassung der Verifikatoren auf allen niedrigeren Niveaus (Basis, Standard) einschließen. Dies ist für die Aufzeichnung von Hintergrundinformationen nicht erforderlich. 
Tabelle 1: Liste der Verifikatoren und Hintergrundinformationen, die während der Außenaufnahmen auf den Vogelkirschen-Monitoringflächen zu erfassen sind; jeweils mit Kurzbeschreibung und Beobachtungshäufigkeit.

\begin{tabular}{|c|c|c|c|c|}
\hline & Bezeichnung & Basisniveau & Standardniveau & Intensivniveau \\
\hline \multirow{5}{*}{ 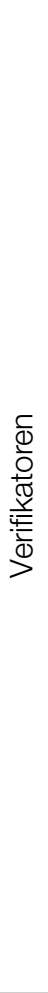 } & $\begin{array}{l}\text { Mortalität / } \\
\text { Überlebensrate }\end{array}$ & $\begin{array}{l}\text { Altbäume: Zählung der } \\
\text { verbleibenden markierten } \\
\text { Bäume; alle } 10 \text { Jahre und nach } \\
\text { jedem extremen Witterungs- } \\
\text { ereignis/ jeder Störung }\end{array}$ & wie Basisniveau & wie Basisniveau \\
\hline & & Naturverjüngung: / & $\begin{array}{l}\text { Zählung der verbleibenden } \\
\text { Sämlinge auf den NV-Plots, } \\
\text { zweimal pro Jahrzehnt }\end{array}$ & wie Standardniveau \\
\hline & Blüte & $\begin{array}{l}\text { bestandesweise Schätzung; } \\
\text { jährlich }\end{array}$ & $\begin{array}{l}\text { Erfassung auf Einzelbaumebene, } \\
\text { während zwei bedeutenden } \\
\text { Blühereignissen pro Jahrzehnt, } \\
\text { idealerweise in gleichen } \\
\text { Abständen* }\end{array}$ & $\begin{array}{l}\text { Erfassung auf Einzelbaumebene, } \\
\text { während zwei bedeutenden } \\
\text { Blühereignissen pro Jahrzehnt, } \\
\text { idealerweise in gleichen } \\
\text { Abständen* }\end{array}$ \\
\hline & Fruktifikation & $\begin{array}{l}\text { bestandesweise Schätzung; } \\
\text { jährlich }\end{array}$ & $\begin{array}{l}\text { Erfassung auf Einzelbaum- } \\
\text { ebene im selben Jahr, in dem } \\
\text { die Erfassung der Blüte auf } \\
\text { Basisniveau erfolgt (unabhängig } \\
\text { von der Fruktifikationsintensität)* }\end{array}$ & $\begin{array}{l}\text { Zählung der Früchte in den } \\
\text { gleichen Jahren, in denen } \\
\text { die Bewertung der Blüte } \\
\text { auf Intensivniveau erfolgt, } \\
\text { unabhängig von der Fruktifika- } \\
\text { tionsintensität * } \\
\text { Bei jedem auf Intensivniveau } \\
\text { erfassten Fruktifikations- } \\
\text { ereignis wird auch Saatgut für } \\
\text { Laboranalysen gesammelt }\end{array}$ \\
\hline & $\begin{array}{l}\text { Abundanz der } \\
\text { Naturverjüngung }\end{array}$ & $\begin{array}{l}\text { bestandesweise Schätzung; } \\
\text { jährlich }\end{array}$ & $\begin{array}{l}\text { Zählung der Sämlinge im 2. und } \\
\text { 7. Jahr nach einem Mastjahr ** }\end{array}$ & $\begin{array}{c}\text { Zählung der Sämlinge im 2., 7., } \\
\text { 12. und 17. Jahr nach einem } \\
\text { Mastjahr }{ }^{* \star}\end{array}$ \\
\hline \multirow{7}{*}{ 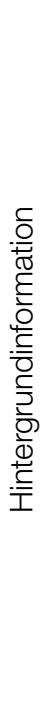 } & $\begin{array}{l}\text { Durchmesser- } \\
\text { klassen-vertei- } \\
\text { lung }\end{array}$ & / & Messung alle 10 Jahre & wie Standardniveau \\
\hline & $\begin{array}{l}\text { Höhenklassen- } \\
\text { verteilung }\end{array}$ & / & Messung alle 10 Jahre & wie Standardniveau \\
\hline & Austrieb & / & $\begin{array}{l}\text { Erfassung auf Einzelbaumebene; } \\
\text { alle } 5 \text { Jahre }\end{array}$ & $\begin{array}{l}\text { Erfassung auf Einzelbaumebene; } \\
\text { jährlich }\end{array}$ \\
\hline & Seneszenz & / & $\begin{array}{l}\text { Erfassung auf Einzelbaumebene; } \\
\text { alle } 5 \text { Jahre }\end{array}$ & $\begin{array}{l}\text { Erfassung auf Einzelbaumebene; } \\
\text { jährlich }\end{array}$ \\
\hline & $\begin{array}{l}\text { Blühsynchroni- } \\
\text { sation }\end{array}$ & / & / & $\begin{array}{l}\text { Erfassung auf Einzelbaumebene; } \\
\text { während }\end{array}$ \\
\hline & $\begin{array}{l}\text { jedes erfassten } \\
\text { bedeutenden } \\
\text { Blühereignisses }\end{array}$ & / & $\begin{array}{c}\text { Individual tree level observation, } \\
\text { every } 5 \text { years }\end{array}$ & $\begin{array}{c}\text { Individual tree level observation, } \\
\text { every year }\end{array}$ \\
\hline & $\begin{array}{l}\text { Flowering } \\
\text { synchronisation }\end{array}$ & / & / & $\begin{array}{l}\text { Individual tree level observation, } \\
\text { during each assessed major } \\
\text { flowering event }\end{array}$ \\
\hline
\end{tabular}

Idealerweise sollte mindestens ein größeres Fruktifikationsereignis pro Jahrzehnt bewertet werden. Ein bedeutendes Blühereignis führt jedoch nicht unbedingt zu einem bedeutenden Fruktifikationsereignis. Wenn auf das bewertete Blühereignis kein wesentliches Fruktifikationsereignis folgt, muss die Bewertung sowohl der Blüte als auch der Fruchtbildung beim nächsten bedeutenden Blühereignis wiederholt werden, unabhängig von der Zeit, die zwischen aufeinanderfolgenden bedeutenden Blühereignissen liegt. Erhebungen auf Basisniveau werden zur Identifizierung bedeutender Blüh- und Fruktifikationsereignisse verwendet.

* Aufgrund der Samenruhe der Vogelkirsche kann die aus einem Mastjahr (Jahr mit ausgeprägter Frucht-/Samenproduktion) stammende Naturverjüngung ein oder zwei Jahre später auftreten, so dass unterschiedlich alte Sämlinge auf dasselbe Mastjahr zurückzuführen sein können. 


\subsection{Verfahren zur Erfassung der Verifikatoren}

Da es sich bei der Vogelkirsche um eine nicht-bestandesbildende Baumart handelt und die Verteilung innerhalb der FGM-Fläche ungleichmäßig ist, müssen alle Verifikatoren und Hintergrundinformationen (z.B. Mortalität, Blüte, Fruktifikation, usw.) auf Einzelbaumebene durchgeführt werden.

\subsubsection{Mortalität / Überlebensrate}

Die Mortalität beschreibt die Sterblichkeit von Altbäumen und Naturverjüngung. Ihr Pendant - die Überlebensratesteht für Bäume, die seit der letzten Datenerhebung noch am Leben sind. Die Überlebensrate wird berechnet als 1 - Mortalität.

\subsubsection{Altbäume: Basis-, Standard- und Intensivniveau}

Verifikator für die Mortalität von Altbäumen. Die Mortalität wird geschätzt, indem die verbleibenden lebenden Beobachtungsbäume alle 10 Jahre sowie nach jedem extremen Witterungsereignis bzw. jeder Störung gezählt werden. Die Mortalität ist die Differenz zwischen der ursprünglichen Anzahl markierter Beobachtungsbäume und den verbleibenden lebenden Bäumen der ursprünglichen 50 Beobachtungsbäume.

\subsubsection{Naturverjüngung: Standard- und Intensivniveau}

Die Mortalität der Naturverjüngung wird auf Grundlage des Verifikators „Abundanz der Naturverjüngung“ berechnet. Die Mortalität ist der Unterschied zwischen der anfänglichen Anzahl der Jungpflanzen und den Pflanzen, die zum Zeitpunkt der nächsten Zählung noch am Leben sind. Für jede Bewertungsrunde werden die Jungpflanzen zuerst im Jahr der Keimung und dann wieder nach 5 Jahren auf Standardniveau gezählt, während auf dem Intensivniveau die Zählung zusätzlich nach 10 und 15 Jahren durchgeführt wird. Die Bewertung der „Abundanz der Naturverjüngung" erfolgt zweimal pro Jahrzehnt, idealerweise etwa alle fünf Jahre.

\subsubsection{Blüte}

Dieser Verifikator beschreibt für die Vogelkirsche das Auftreten der Blüte und die Blühintensität. Normalerweise können die Blüten der Vogelkirsche in Mitteleuropa von März bis Mai beobachtet werden. Die Blüte erfolgt früher, wenn ihr ein warmer Winter vorausgeht. Die Vogelkirsche blüht üblicherweise alle zwei Jahre.

\subsubsection{Basisniveau}

Der Verifikator wird jährlich auf Bestandesebene erfasst; jedoch müssen wegen der verstreuten Verteilung der Vogelkirsche alle 50 Beobachtungsbäume aufgesucht werden, um eine gute Einschätzung des durchschnittlichen Zustands zu erhalten. Die Erfassung erfolgt zum Zeitpunkt der Hauptblüte. Die Schätzung des durchschnittlichen Zustands erfolgt nach der Begehung der gesamten Monitoringfläche. Es werden zwei Werte erfasst: einer für die Blühintensität, und einer für den Anteil der blühenden Bäume im Bestand.

\begin{tabular}{clr} 
Code Blühintensität auf Bestandesebene & Mittlerer Anteil der Kronen in Blüte (\%) \\
\hline 1 & Keine Blüte: Keine oder nur gelegentlich auftretende Blüten & $0-10$ \\
\hline 2 & Schwache Blüte: Einige Blüten erscheinen an den Bäumen & $>10-30$ \\
\hline 3 & Mäßige Blüte: Mäßig viele Blüten an den Bäumen & $>30-60$ \\
\hline 4 & Starke Blüte: Reichlich Blüten an den Bäumen & $>60-90$ \\
\hline 5 & Extreme Blüte: Enorme Anzahl von Blüten an den Bäumen & $>90$ \\
\hline
\end{tabular}




\begin{tabular}{lr} 
Code & Anteil der Bäume im Bestand mit dem entsprechenden Stadium der Blühintensität (\%) \\
\hline 1 & $0-10$ \\
\hline 2 & $>10-30$ \\
\hline 3 & $>30-60$ \\
\hline 4 & $>60-90$ \\
\hline 5 & $>90$ \\
\hline
\end{tabular}

\subsubsection{Standardniveau}

Der Verifikator wird während zweier bedeutender Blühereignisse pro Jahrzehnt aufgezeichnet, idealerweise mit einem ähnlichen zeitlichen Abstand. Er wird für alle 50 Beobachtungsbäume auf Einzelbaumebene erfasst. Ein bedeutendes Blühereignis liegt vor, wenn die Blühintensität auf Basisniveau als stark oder extrem eingeschätzt wird (Code 4 oder 5) und der Anteil der Bäume mit der angegebenen Blühintensität über 60\% liegt (Code 4 oder 5). Die Erfassung erfolgt zum Zeitpunkt der Hauptblüte. Für jeden Beobachtungsbaum wird ein Wert erfasst.

\begin{tabular}{clr}
\multicolumn{2}{l}{ Code Blühintensität auf Bestandesebene } & Mittlerer Anteil der Kronen in Blüte (\%) \\
\hline 1 & Keine Blüte: Keine oder nur gelegentlich auftretende Blüten & $0-10$ \\
\hline 2 & Schwache Blüte: Einige Blüten erscheinen an den Bäumen & $>10-30$ \\
\hline 3 & Mäßige Blüte: Mäßig viele Blüten an den Bäumen & $>30-60$ \\
\hline 4 & Starke Blüte: Reichlich Blüten an den Bäumen & $>60-90$ \\
\hline 5 & Extreme Blüte: Enorme Anzahl von Blüten an den Bäumen & $>90$ \\
\hline
\end{tabular}

\subsubsection{Intensivniveau}

Der Verifikator wird während zweier bedeutender Blühereignisse pro Jahrzehnt aufgezeichnet, idealerweise mit einem ähnlichen zeitlichen Abstand. Er wird für alle 50 Beobachtungsbäume auf Einzelbaumebene erfasst. Ein bedeutendes Blühereignis liegt vor, wenn die Blühintensität auf Basisniveau als stark oder extrem eingeschätzt wird (Code 4 oder 5) und der Anteil der Bäume mit der angegebenen Blühintensität über 60\% liegt (Code 4 oder 5). Im Durchschnitt sind zwei Begehungen der Monitoringfläche erforderlich: der erste früh genug, um das Frühstadium der Blüte zu beobachten, der zweite zum Zeitpunkt der Hauptblüte [8]. Die Blühstadien sind in Abbildung 4 zu finden.

\begin{tabular}{|c|c|}
\hline \multicolumn{2}{|c|}{ Code Stadien der Blütenphänologie } \\
\hline 1 & Knospen inaktiv, Knospenschuppen braun und geschlossen \\
\hline 2 & Knospen vergrößert, Knospenschuppen beginnen sich zu öffnen, so dass die Ränder der ersten Blätter sichtbar sind \\
\hline 3 & Blütenknopsen offen, Blütenblätter noch geschlossen, Blütenstiel verlängert \\
\hline 4 & Blütenblätter vollständig geöffnet, Narbe ist aufnahmefähig, Staubgefäße setzen Pollen frei \\
\hline
\end{tabular}

\begin{tabular}{clr} 
Code Blühintensität auf Bestandesebene & Mittlerer Anteil der Kronen in Blüte (\%) \\
\hline 1 & Keine Blüte: Keine oder nur gelegentlich auftretende Blüten & $0-10$ \\
\hline 2 & Schwache Blüte: Einige Blüten erscheinen an den Bäumen & $>10-30$ \\
\hline 3 & Mäßige Blüte: Mäßig viele Blüten an den Bäumen & $>30-60$ \\
\hline 4 & Starke Blüte: Reichlich Blüten an den Bäumen & $>60-90$ \\
\hline 5 & Extreme Blüte: Enorme Anzahl von Blüten an den Bäumen & $>90$ \\
\hline
\end{tabular}


1

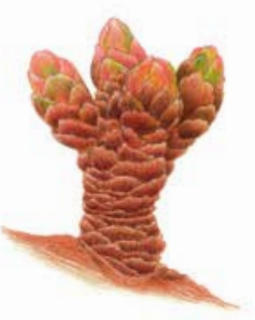

2

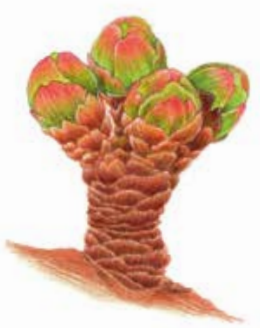

3

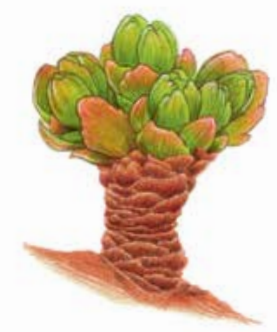

4

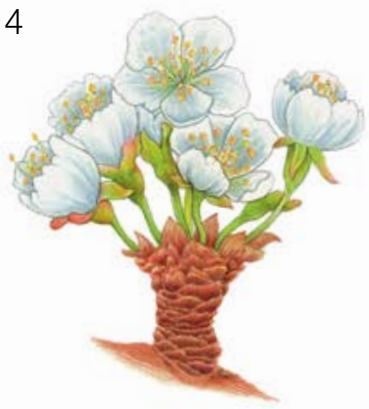

Abbildung 4: Illustration zur Beschreibung der Blüte für den Verifikator „Blüte“ auf Intensivniveau.

\subsubsection{Fruktifikation}

Dieser Verifikator beschreibt das Auftreten und die Häufigkeit der Fruchtbildung. Die Daten für diesen Verifikator sollten während der Fruktifikationszeit erhoben werden, d.h. in Mitteleuropa vom späten Frühjahr bis zum Hochoder Spätsommer. In der Regel fruktifizieren Vogelkirschen alle zwei Jahre.

\subsubsection{Basisniveau}

Dieser Verifikator wird jährlich auf Bestandesebene erfasst. Aufgrund des eingestreuten Vorkommens der Vogelkirsche im Bestand werden alle 50 ausgewählten und gekennzeichneten Vogelkirschen aufgesucht und bewertet.

Es werden zwei Werte erfasst: einer für die Intensität der Fruktifikation und einer für den Anteil fruchttragender Bäume.

\begin{tabular}{clr}
\hline \multicolumn{2}{l}{ Code Intensität der Fruktifikation auf Bestandesebene } & Mittlerer Anteil der Krone mit Fruchtbehang (\%) \\
\hline 1 & $\begin{array}{l}\text { Keine Fruchtbildung: Keine oder nur gelegentlich auftretende Früchte } \\
\text { an den Bäumen }\end{array}$ & $0-10$ \\
\hline 2 & Schwache Fruchtbildung: Einige Früchte an den Bäumen & $>10-30$ \\
\hline 3 & Mäßige Fruchtbildung: Mäßig viele Früchte an den Bäumen & $>30-60$ \\
\hline 4 & Starke Fruchtbildung: Reichlich Früchte an den Bäumen & $>60-90$ \\
\hline 5 & Extreme Fruchtbildung: Enorme Anzahl von Früchten an den Bäumen & $>90$ \\
\hline
\end{tabular}

\begin{tabular}{lr} 
Code Anteil der Bäume mit dem entsprechenden Stadium der Fruktifikationsintensität (\%) & $0-10$ \\
\hline 1 & $>10-30$ \\
\hline 2 & $>30-60$ \\
\hline 3 & $>60-90$ \\
\hline 4 & $>90$ \\
\hline 5 & \\
\hline
\end{tabular}

\subsubsection{Standardniveau}

Die Erfassung des Verifikators erfolgt in denselben Jahren wie die Bewertung der Blüte auf Standardniveau (unabhängig von der Fruktifikationsintensität). Sie wird für alle 50 Beobachtungsbäume auf Einzelbaumebene durchgeführt - und zwar bevor die Früchte beginnen zu fallen oder von Vögeln gefressen werden. Für jeden Beobachtungsbaum wird ein Wert erfasst. 
Im Idealfall sollte pro Jahrzehnt ein auf ein bedeutendes Blühereignis folgendes größeres Fruktifikationsereignis erfasst werden. Ein bedeutendes Blühereignis führt jedoch nicht unbedingt zu einem bedeutenden Fruktifikationsereignis. Wenn auf das bewertete Blühereignis kein wesentliches Fruktifikationsereignis folgt, muss die Bewertung sowohl der Blüte als auch der Fruchtbildung beim nächsten bedeutenden Blühereignis wiederholt werden, unabhängig von der Zeit, die zwischen aufeinanderfolgenden bedeutenden Blühereignissen liegt. Erhebungen auf Basisniveau werden genutzt, um bedeutende Fruktifikationsereignisse zu identifizieren. Ein bedeutendes Fruktifikationsereignis liegt vor, wenn die Fruktifikationsintensität auf Basisniveau als stark oder extrem eingeschätzt wird (Code 4 oder 5) und der Anteil der Bäume mit der angegebenen Fruktifikationsintensität über 60\% liegt (Code 4 oder 5).

\begin{tabular}{llr} 
Code Intensität der Fruktifikation auf Bestandesebene & $\begin{array}{r}\text { Mittlerer Anteil der Krone mit Fruchtbehang } \\
\text { (\%) }\end{array}$ \\
\hline $\begin{array}{llr}\text { Keine Fruchtbildung: Keine oder nur gelegentlich auftretende Früchte } \\
\text { an den Bäumen }\end{array}$ & $>10-30$ \\
\hline 2 & Schwache Fruchtbildung: Einige Früchte an den Bäumen & $>30-60$ \\
\hline 3 & Mäßige Fruchtbildung: Mäßig viele Früchte an den Bäumen & $>60-90$ \\
\hline 4 & Starke Fruchtbildung: Reichlich Früchte an den Bäumen & $>90$ \\
\hline 5 & Extreme Fruchtbildung: Enorme Anzahl von Früchten an den Bäumen & $\begin{array}{r}0 \\
\end{array}$
\end{tabular}

\subsubsection{Intensivniveau}

Die Erfassung des Verifikators erfolgt für alle 50 Beobachtungsbäume auf Einzelbaumebene in denselben Jahren wie die Bewertung der Blüte auf Intensivniveau (unabhängig von der Fruktifikationsintensität). Sie wird durchgeführt, bevor die Früchte beginnen zu fallen oder von Vögeln gefressen werden. Für jeden Beobachtungsbaum wird ein Wert erfasst. Zeitgleich wird Saatgut für die Saatgut- und Genanalysen gesammelt (für die Verifikatoren und Hintergrundinformationen auf Intensivniveau).

Im Idealfall sollte pro Jahrzehnt ein auf ein bedeutendes Blühereignis folgendes größeres Fruktifikationsereignis erfasst werden. Ein bedeutendes Blühereignis führt jedoch nicht unbedingt zu einem bedeutenden Fruktifikationsereignis. Wenn auf das bewertete Blühereignis kein wesentliches Fruktifikationsereignis folgt, muss die Bewertung sowohl der Blüte als auch der Fruchtbildung beim nächsten bedeutenden Blühereignis wiederholt werden, unabhängig von der Zeit, die zwischen aufeinanderfolgenden bedeutenden Blühereignissen liegt. Erhebungen auf Basisniveau werden genutzt, um bedeutende Fruktifikationsereignisse zu identifizieren. Ein bedeutendes Fruktifikationsereignis liegt vor, wenn die Fruktifikationsintensität auf Basisniveau als stark oder extrem eingeschätzt wird (Code 4 oder 5) und der Anteil der Bäume mit der angegebenen Fruktifikationsintensität über 60\% liegt (Code 4 oder 5).

Der Verifikator wird durch das Zählen von Früchten unter Nutzung eines Fernglases erfasst (als Durchschnitt von drei Zählrunden). Jede Zählrunde besteht aus der Anzahl der Früchte, die der Beobachter in 30 Sekunden zählt. Bei allen Bäumen sollte das gleiche Kronendrittel untersucht werden. Sobald ein Kronendrittel für die Beobachtung ausgewählt wurde, sollte dieses für jede weitere Erhebung dieses Verifikators ausgewählt werden. Für die Zählung wird das obere Kronendrittel dem unteren und mittleren Drittel vorgezogen.

Es werden zwei Werte erfasst: die Anzahl der Früchte und das untersuchte Kronendrittel.

Anzahl der in 30 Sekunden gezählten Früchte (Mittelwert aus 3 Zählrunden)

$x$

Code Untersuchtes Kronendrittel

1 unteres Kronendrittel

2 mittleres Kronendrittel

3 oberes Kronendrittel 


\subsubsection{Abundanz der Naturverjüngung}

Dieser Verifikator beschreibt das Vorhandensein und die Häufigkeit von Naturverjüngung (NV) auf der Monitoringfläche. Auf Basisniveau wird sie jährlich anhand von Experteneinschätzungen erfasst. Die Samenruhe der Vogelkirsche kann 1-2 Winter dauern, so dass die ersten Sämlinge erst 1,5-2,5 Jahre nach der Fruktifikation auftreten können.

\subsubsection{Basisniveau}

Der Verifikator wird jährlich im Herbst auf Bestandesebene erfasst (überprüfen Sie Flächen mit existierenden und blühenden Vogelkirschen sowie offene, für die Etablierung von NV geeignete Flächen). Für die Einschätzung werden Expertenmeinungen herangezogen. Es sollten zwei Werte erfasst werden: einer für neue aufgelaufene Naturverjüngung (einjährige Sämlinge) und einer für etablierte Naturverjüngung (ein- und mehrjährige Jungpflanzen). Da die Lichtverfügbarkeit ein entscheidender Faktor für die Etablierung neuer VogelkirschenNV ist, sollten Waldlichtungen und offene Flächen sowie Waldränder im Fokus stehen. Weil die Abundanz von Vogelkirschen-NV in der Regel gering ist, werden nur zwei Abundanzstufen angewendet.

\begin{tabular}{ll} 
Code Beschreibung: neue aufgelaufene Naturverjüngung (einjährige Keimlinge) \\
\hline 1a $\quad$ Auf der Monitoringfläche gibt es keine oder nur sehr wenig neue Naturverjüngung \\
\hline 2a $\quad$ Auf der Monitoringfläche ist in ausreichender Anzahl neue Naturverjüngung vorhanden \\
\hline
\end{tabular}

\begin{tabular}{ll} 
Code & Beschreibung: etablierte Naturverjüngung (Sämlinge) \\
\hline 1b & Auf der Monitoringfläche gibt es keine oder nur sehr wenig etablierte Naturverjüngung \\
\hline 2b & Auf der Monitoringfläche ist in ausreichender Anzahl etablierte Naturverjüngung vorhanden
\end{tabular}

\subsubsection{Standardniveau}

Die Samenruhe der Vogelkirsche kann 1-2 Winter dauern, so dass die ersten Sämlinge erst 1,5 - 2,5 Jahre nach der Fruktifikation auftreten können. Die Einrichtung der NV-Plots und die Erhebungszeitpunkte müssen entsprechend der Samenruhe angepasst werden. Der Verifikator wird im 2. und 7. Jahr nach dem Mastjahr erfasst. Für Vogelkirsche müssen nach dem nächsten Mastjahr 20 neue NV-Plots angelegt werden, idealerweise 5 Jahre nach dem ersten Mastjahr.

Idealerweise müssen nach dem nächsten bewerteten großen Fruktifikationsereignis, das etwa fünf Jahre nach dem vorherigen erfolgen sollte, zwanzig (20) neue NR-Subplots für Wildkirschen eingerichtet werden.

\section{Anzahl der Jungpflanzen auf einem NV-Plot}

\section{$\mathrm{X}$}

Zur Einrichtung von NV-Plots siehe Kapitel 6.2 Einrichtung von Naturverjüngungs-Plots.

\subsubsection{Intensivniveau}

Die Samenruhe der Vogelkirsche kann 1-2 Winter dauern, so dass die ersten Sämlinge erst 1,5 - 2,5 Jahre nach der Fruktifikation auftreten können. Die Einrichtung der NV-Plots und die Erhebungszeitpunkte müssen entsprechend der Samenruhe angepasst werden. Der Verifikator wird im 2., 7., 12., und 17. Jahr nach dem Mastjahr erfasst. Für Vogelkirsche müssen nach dem nächsten Mastjahr 20 neue NV-Plots angelegt werden, idealerweise 5 Jahre nach dem ersten Mastjahr. 
Tabelle 2: Zeitstrahl zur Erfassung der Abundanz der Naturverjüngung (NV). In diesem Beispiel findet das erste Fruktifikationsereignis im 2. Jahr des Beobachtungsjahrzehnts statt; und angesichts der 1-2 Winter andauernden Samenruhe von Vogelkirsche werden im 4. Jahr des Jahrzehnts 20 NV-Plots angelegt. Die nächste Einschätzung der Fruktifikation erfolgt im 8. Jahr des Jahrzehnts. Angesichts der Samenruhe von Vogelkirsche werden 10. Jahr der Dekade 20 neue NV-Plots angelegt. Nach jedem bewerteten Fruktifikationsereignis werden 20 neue NV-Plots etabliert. Die Erfassung der NV-Abundanz auf jedem Set von 20 NV-Plots erfolgt alle fünf Jahre. Die zur jeweils erfassten NV gehörigen Fruktifikationsereignisse und der Verlauf der Monitoringaktivitäten sind in derselben Farbe schattiert. Nach der letzten Runde der NV-Zählung wird das Monitoring der NV-Abundanz auf dem entsprechenden Set von NV-Plots eingestellt und die jeweiligen NV-Plots werden aufgelöst. S - Standardniveau; I - Intensivniveau.

\begin{tabular}{|c|c|c|c|c|c|c|c|c|c|c|c|c|c|c|c|c|c|c|c|}
\hline Monitoringjahr & 1 & 2 & 3 & 4 & 5 & 6 & 7 & 8 & 9 & 10 & 11 & 1213 & 14 & 1516 & 17 & 1819 & 2021 & 22232 & 2425 \\
\hline Fruktifikationsereignis & & $\bullet$ & & & $\bullet$ & $\bullet$ & & $\bullet$ & & $\bullet$ & & $\bullet$ & $\bullet$ & & $\bullet$ & $\bullet$ & $\bullet$ & $\bullet$ & $\bullet$ \\
\hline $\begin{array}{l}\text { Erfassung von NV aus dem } \\
\text { ersten bewerteten Fruktifika- } \\
\text { tionsereignis [Jahre] }\end{array}$ & & 0 & 1 & 2 & 3 & 4 & 5 & 6 & 7 & 8 & 9 & 1011 & 12 & 1314 & 15 & 1617 & 1819 & 20212 & 2223 \\
\hline Einrichtung von NV-Plots & & & & $\mathrm{SI}$ & & & & & & & & & & & & & & & \\
\hline Zählung der NV & & & & SI & & & & & $\mathrm{SI}$ & & & & I & & & I & & & \\
\hline $\begin{array}{l}\text { Erfassung von NV aus dem } \\
\text { zweiten bewerteten Fruktifika- } \\
\text { tionsereignis [Jahre] }\end{array}$ & & & & & & & & 0 & 1 & 2 & 3 & 45 & 6 & 78 & 9 & 1011 & 1213 & 1415 & 1617 \\
\hline Einrichtung von NV-Plots & & & & & & & & & & $\mathrm{SI}$ & & & & & & & & & \\
\hline Zählung der NV & & & & & & & & & & $\mathrm{SI}$ & & & & $\mathrm{SI}$ & & & I & & I \\
\hline
\end{tabular}

Zur Einrichtung von NV-Plots siehe Kapitel 6.2 Einrichtung von Naturverjüngungs-Plots; zur Zählung der NV siehe Kapitel 7.1.4.2 Standardniveau.

\subsection{Verfahren zur Erfassung von Hintergrundinformationen}

\subsubsection{Durchmesserklassenverteilung}

\subsubsection{Standard- und Intensivniveau}

Der BHD wird alle 10 Jahre für alle 50 Beobachtungsbäume auf Einzelbaumebene erfasst. Der BHD ist der Stammdurchmesser in 1,30 m Höhe, d.h. ungefähr auf Brusthöhe eines Erwachsenen. Hat der Baum mehr als einen Stamm, messen Sie bitte alle Stämme und erfassen Sie den Durchschnitt (versuchen Sie jedoch, Bäume mit vielen kleinen Stämmen zu vermeiden). Notieren Sie in den Anmerkungen, dass der Baum mehrstämmig ist, und geben Sie die Anzahl der gemessenen Stämme an. Ist der Baum geneigt, messen Sie den BHD senkrecht zum Baumstamm. Der BHD kann auf zwei Arten gemessen werden:

1) mit einer Kluppe; in diesem Fall messen Sie senkrecht zueinander zwei Durchmesser und berechnen den Mittelwert

2) Messen Sie den Umfang des Baumes und berechnen Sie daraus den Durchmesser (d.h. dividieren Sie durch $\pi ; \sim 3,14)$

Der BHD wird in cm angegeben. Für nachfolgende Messungen ist stets dieselbe Methode anzuwenden.

\subsubsection{Höhenklassenverteilung}

\subsubsection{Standard- und Intensivniveau}

Die Baumhöhe wird alle 10 Jahre für alle 50 Beobachtungsbäume auf Einzelbaumebene erfasst. Die Höhe wird vom Boden bis zum höchsten Punkt der Krone gemessen, idealerweise mit einem Klinometer oder Hypsometer (z.B. Vertex). Die Höhe wird in Metern auf eine Dezimalstelle angegeben. 


\subsubsection{Austrieb}

Diese Hintergrundinformation beschreibt die Austriebsstadien. Bei der Vogelkirsche erfolgt der Blattaustrieb zusammen mit der Blüte. Die Erfassung erfolgt nur auf Standard- und Intensivniveau. Die Daten für diese Hintergrundinformation sollten in Mitteleuropa von März bis Mai erhoben werden. Nach warmen Wintern erfolgt der Austrieb früher.

\subsubsection{Standardniveau}

Auf Standardniveau wird der Austrieb alle 5 Jahre für alle 50 Beobachtungsbäume auf Einzelbaumebene beobachtet. Gesucht werden der Beginn der Knospenöffnung (Stadium 2) und das Ende der Blattentfaltung (Stadium 4). Die Beobachtungen werden beendet, wenn alle Bäume das Stadium 4 erreicht haben. In der Regel sind dafür 6 Begehungen erforderlich. Für jeden Baum werden zwei Werte erfasst: das Austriebsstadium und der entsprechende Kronenanteil. Die Austriebsstadien sind in Abbildung 5 dargestellt.

\begin{tabular}{|c|c|}
\hline \multicolumn{2}{|c|}{ Code Austriebsstadium } \\
\hline 1 & $\begin{array}{l}\text { Knospen sind geschwollen, einige Knospenschuppen leicht geöffnet so dass die Ränder der ersten Blätter sichtbar } \\
\text { sind }\end{array}$ \\
\hline 2 & Die Blättchen erreichen die gleiche Größe wie die vorherigen Knospen und beginnen sich zu trennen \\
\hline 3 & Blätter sind länger, aber noch gefaltet \\
\hline 4 & $\begin{array}{l}\text { Die Blätter sind voll entfaltet; die Blattfläche ist deutlich vergrößert; Blattstiele vorhanden; die Blätter drehen sich und } \\
\text { hängen herab }\end{array}$ \\
\hline
\end{tabular}

\begin{tabular}{lr} 
Code Anteil der Krone mit dem entsprechenden Austriebsstadium (\%) & $>0-33$ \\
\hline 1 & $>33-66$ \\
\hline 2 & $>66-99$ \\
\hline 3 & 100 \\
\hline 4 & \\
\hline
\end{tabular}

1

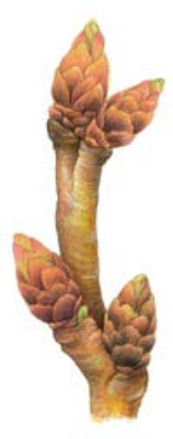

2

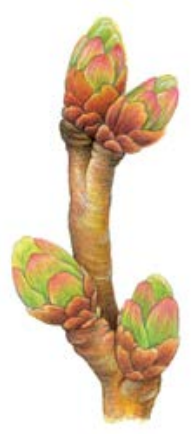

3

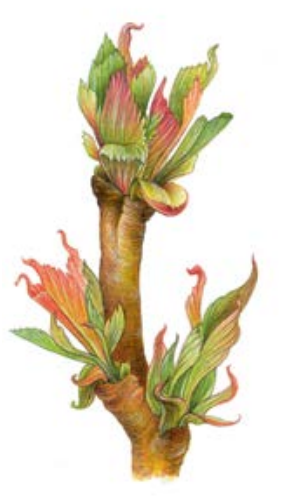

4

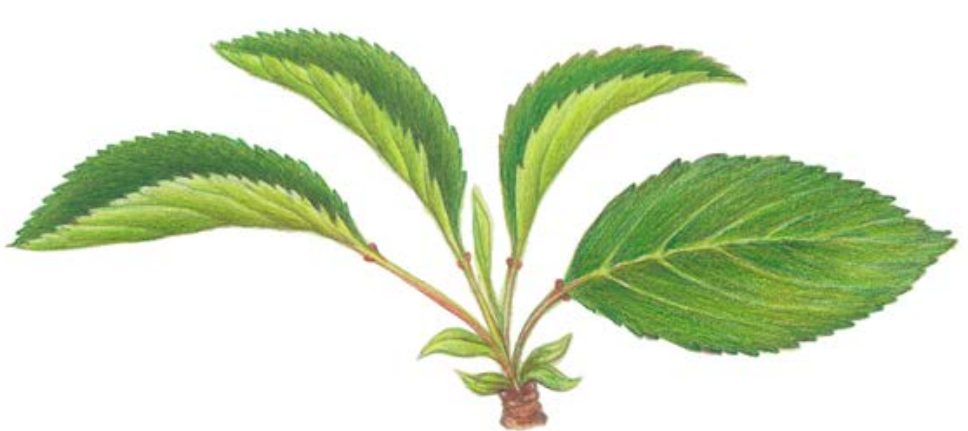

Abbildung 5: Illustration zur Beschreibung der Hintergrundinformation „Austrieb“ auf Basis-, Standard- und Intensivniveau. 


\subsubsection{Intensivniveau}

Auf Intensivniveau wird der Austrieb jährlich für alle 50 Beobachtungsbäume auf Einzelbaumebene erhoben. Details zur Verfahrensweise und den Werten (Austriebsstadien, Kronenanteil) sind im Kapitel 7.2.3.1 Standardniveau zu finden.

\subsubsection{Seneszenz}

Die Seneszenz beschreibt den Prozess der Blattalterung. Die Erfassung dieser Hintergrundinformation erfolgt nur auf Standard- und Intensivniveau.

\subsubsection{Standardniveau}

Auf Standardniveau wird die Seneszenz alle 5 Jahre für alle 50 Beobachtungsbäume auf Einzelbaumebene beobachtet. Gesucht wird das Stadium 3, wenn die Blätter gelb sind und keine Photosynthese mehr betreiben. Die Beobachtungen enden, wenn alle Bäume das Stadium 3 erreicht haben. Normalerweise sind dafür zwei Begehungen der Monitoringfläche erforderlich. Für jeden Baum werden zwei Werte erfasst: das Stadium der Seneszenz und der entsprechende Kronenanteil. Die Stadien der Seneszenz sind in Abbildung 6 dargestellt.

\begin{tabular}{|c|c|c|}
\hline \multicolumn{3}{|c|}{ Code Stadium der Seneszenz } \\
\hline 1 & Blätter sind grün & \\
\hline 2 & Blattfarbe wechselt von grün zu gelb (grünlich-gelb) & \\
\hline 3 & Blattfarbe wechselt von gelb zu braun (bräunlich) & \\
\hline 4 & Blätter sind braun / abgefallen & \\
\hline \multicolumn{3}{|c|}{ Code Anteil der Krone mit dem entsprechenden Seneszenzstadium (\%) } \\
\hline 1 & & $>0-33$ \\
\hline 2 & & $>33-66$ \\
\hline 3 & & $>66-99$ \\
\hline 4 & & 100 \\
\hline
\end{tabular}

Abbildung 6: Illustration zur Beschreibung der Hintergrundinformation „Seneszenz" auf Standard- und Intensivniveau.

\subsubsection{Intensivniveau}

Auf Intensivniveau wird die Seneszenz jährlich für alle 50 Beobachtungsbäume auf Einzelbaumebene erfasst. Details zur Verfahrensweise und den Werten (Seneszenzstadien, Kronenanteil) sind im Kapitel 7.2.4.1 Standardniveau zu finden.

\subsubsection{Blühsynchronisation}

Die Hintergrundinformation „Blühsynchronisation“ wird nur auf Intensivniveau erfasst und basiert auf den für den Verifikator „Blüte“ erhobenen Daten. Sie wird verwendet, um festzustellen, ob die Blüte innerhalb des untersuchten Bestandes gleichzeitig stattfindet.

\subsubsection{Intensivniveau}

Die Blühsynchronisation wird jährlich für alle 50 Beobachtungsbäume auf Einzelbaumebene erfasst; und zwar für jedes erfasste bedeutende Blühereignis und im selben Jahr, in dem auch Samen beprobt werden (wie für den Verifikator „Blüte“ auf Intensivniveau). 


\section{Formular für die Beschreibung der Monitoringfläche: 'FGM Plot description'}

\section{Formular für die Erfassung der Verifikatoren: 'Form for recording field level verifiers within FGM' \\ Formular für die Aufzeichnung von Hintergrundinformationen: 'Form for recording field level background information within FGM'}

\section{QUELLEN}

1. EUFORGEN (2009) Distribution map of Wild cherry (Prunus avium L.). http://www.euforgen.org/species/prunus-avium/. Accessed 25 August 2020

2. Ballian D (2000) Početna istraživanja varijabilnosti morfoloških svojstava sjemena divlje trešnje (Prunus avium L.). Šum list 5-6:271-278

3. Ballian D (2002) Variability of characteristics of the wild cherry blossom (Prunus avium L.) in the region of central Bosnia, Annales forestales 25/2:1-19

4. Ballian D, Bogunić F (2006) Preliminary results of investigation of morphological traits variation of wild cherry (Prunus avium L.) in Bosnia and Herzegovina. International Scientific Conferrence In occasion of 60 year of operation of Institute of Forestry, Belgrade, Serbia, Donji Milanovac 08.-10.11. 2006. PROCEEDINGS pp. 47-51

5. Ballian D, Bogunić F, Čabaravdić A, Pekeč S, Franjić J (2012) Population differentiation in the wild cherry (Prunus avium L.) in Bosnia and Herzegovina. Period Biol 114(1):43-54

6. Ballian D, Mujagić-Pašić A (2013) Morphological variability of the fruit and seed of wild cherry (Prunus avium L.) in a part of its natural distribution in Bosnia and Herzegovina. Biologica Nyssana 4(1-2):15-17

7. Buiteveld J (2012) Prunus avium L. In: Fussi B, Belle C, Konnert M, Blanc-Jolivet C, Liesebach M, Buiteveld J, Piotti A, Vendramin GG, Wagner S, Petit RJ, Jahn D, Heinze B (ed) Project: Designing Trees for the Future. D7.1 - Report on review of available and tested methods for identification and on new marker development. http://www.trees4future.eu/ publications/deliverables-2.html\#wp2 Accessed 09 September 2020

8. Ducci F, De Cuyper B, Pâques LE, Proietti R, Wolf H (2012) Reference protocols for assessment of trait and reference genotypes to be used as standards in international research projects. Ed. CRA SEL - Arezzo, p 82.

9. Ducci F, De Cuyper B, De Rogatis A, Dufour J, Santi F (2013) Wild cherry breeding (Prunus avium L.). In: Pâques LE (ed) Forest Tree Breeding in Europe. Springer, Dordrecht, pp 463-511. DOI: 10.1007/978-94-007-6146-9

10. FUTMON project. (2009) FUTMON FIELD PROTOCOL PHENOLOGY (D1). http://www.futmon.org/futmon-fieldprotocols.html. Accessed 12 September 2016

11. Ganopoulos I, Aravanopoulos FA, Argiriou A, Kalivas A \& A Tsaftaris (2012) Genome and population dynamics under selection and neutrality: an example of S-allele diversity in wild cherry (Prunus avium L.). Tree Genet. Genomes 8(6):1181-1190. https://doi.org/10.1007/s11295-012-0504-9

12. Hedhly A, Wünsch A, Kartar Ö, Herrero M, Hormaza Jl (2016) Paternal-specific S-allele transmission in sweet cherry (Prunus avium L.): the potential for sexual selection. J Evol Biol 29(3):490-501. https://doi.org/10.1111/jeb.12790

13. Höltken AM, Gregorious HR (2006) Detecting local establishment strategies of wild cherry (Prunus avium L.). BMC Ecol 6(1):13. https://doi.org/10.1186/1472-6785-6-13

14. Olden EJ, Nybom N (1968) On the origin of Prunus cerasus L. Hereditas 59(2-3):327-345. https://doi. org/10.1111/j.1601-5223.1968.tb02181.x

15. Radičević S, Marić S, Cerović R (2015) S-allele Constitution and Flowering Time Synchronization - Preconditions for Effective Fertilization in Sweet Cherry (Prunus avium L.) Orchards. Romanian Biotechnological Letters 20(6):10997-11006

16. Russell K (2003) EUFORGEN Technical Guidelines for genetic conservation and use for wild cherry (Prunus avium). International Plant Genetic Resources Institute, Rome

17. Schuster M, Früh S (2005) Bestimmung der S-Allele in Brennkirschensorten (Prunus avium L.). Erwerbs-Obstbau 47:40-45. DOI: 10.1007/s10341-004-0051-0

18. Tavaud M, Zanetto A, David JL, Laigret F, Dirlewanger E (2004) Genetic relationships between diploid and allotetraploid cherry species (Prunus avium, Prunus $\times$ gondouinii and Prunus cerasus). Heredity 93(6):631-638. DOI: 10.1038/ sj.hdy.6800589

19. Welk E, de Rigo D, Caudullo G (2016) Prunus avium in Europe: distribution, habitat, usage and threats. In: San-MiguelAyanz J, de Rigo D, Caudullo G, Houston Durrant T, Mauri A (Eds.) European Atlas of Forest Tree Species. Publ. Off. EU, Luxembourg, pp e01491d+. https://ies-ows.jrc.ec.europa.eu/efdac/download/Atlas/pdf/Prunus_avium.pdf. Accessed 25 August 2020 
Die folgenden Ressourcen wurden für die derzeit akzeptierten (Dezember 2020) wissenschaftlichen Namen der in diesem Dokument erfassten oder erwähnten Arten konsultiert:

a. CABI (2020) Invasive Species Compendium. CAB International, Wallingford, UK. www.cabi.org/isc. Accessed 15 December 2020

b. EPPO (2020) EPPO Global Database (available online). https://gd.eppo.int. Accessed 15 December 2020

c. GBIF (2020) Global Biodiversity Information Facility. https://www.gbif.org Accessed 15 December 2020

d. IPNI (2020) International Plant Names Index. The Royal Botanic Gardens, Kew, Harvard University Herbaria \& Libraries \& Australian National Botanic Gardens. http://www.ipni.org, Accessed 10 December 2020

e. National Center for Biotechnology Information (NCBI) (1998) National Library of Medicine (US), National Center for Biotechnology Information, Bethesda (MD). https://www.ncbi.nlm.nih.gov/. Accessed 15 December 2020

f. Stevens PF (2001) Angiosperm Phylogeny Website, Version 14. http://www.mobot.org/MOBOT/research/APweb/. Accessed 15 December 2020

g. The Plant List (2013) Version 1.1. http://www.theplantlist.org/. Accessed 12 December 2020

h. Tropicos.org (2020) Missouri Botanical Garden. http://www.tropicos.org. Accessed 15 December 2020

i. WFO (2020) World Flora Online. http://www.worldfloraonline.org. Accessed 15 December 2020 



\section{Leitfaden für das genetische Monitoring der}

\subsubsection{Stie
(Que
und}

\section{Traubeneiche (Quercus petraea (Matt.) Liebl.)}

Kristina SEVER ${ }^{1}$, Andrej BREZNIKAR ${ }^{1}$, Marko BAJC², Phil ARAVANOPOULOS ${ }^{3}$,

Rok DAMJANIĆ2 ${ }^{2}$ Barbara FUSSI ${ }^{4}$, Darius KAVALIAUSKAS ${ }^{4}$,

Marjana WESTERGREN², Hojka KRAIGHER²

Botanische lllustrationen von Eva MARGON
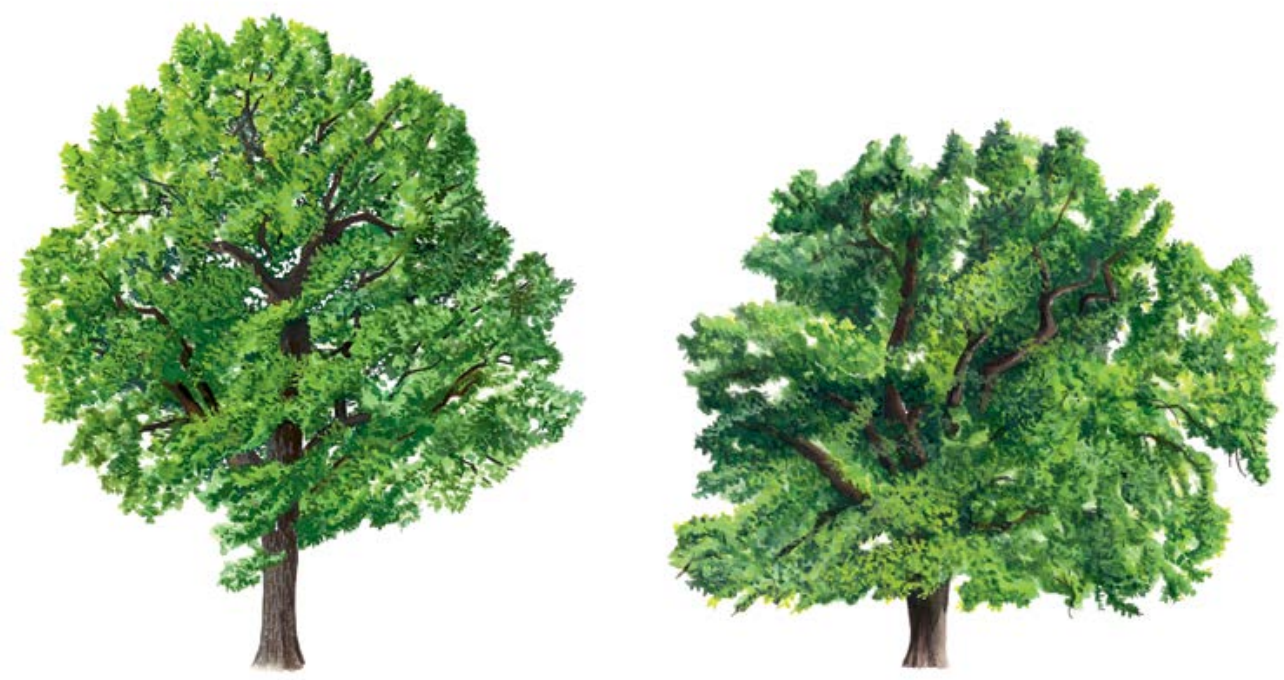

Zitat: Sever et al. (2020) Leitfaden für das genetische Monitoring der Stieleiche (Quercus robur L.) und Traubeneiche (Quercus petraea (Matt.) Liebl.). In: Bajc et al. (Ed.) Handbuch zum Forstgenetischen Monitoring. Slowenisches Forstinstitut: Verlag Silva Slovenica, Ljubljana, S. 289-309. http://dx.doi.org/10.20315/SFS.176

2. Slowenisches Forstinstitut (SFI), Slowenien

3. Aristoteles Universität von Thessaloniki (AUTh), Griechenland

4. Bayerisches Amt für Waldgenetik (AWG), Deutschland 


\section{ZUSAMMENFASSUNG}

Unter den 13 europäischen Weißeichenarten sind die Stiel- (Quercus robur L.) und die Traubeneiche (Q. petraea (Matt.) Liebl.) die wirtschaftlich und ökologisch wichtigsten europäischen Laubbaumarten. Beide Eichenarten sind in Europa weit verbreitet: von Nordspanien bis Südskandinavien und von Irland bis Osteuropa. Außerdem sind beide eng miteinander verwandt. Sie können sich untereinander und mit anderen Eichen mischen, konkurrieren und natürlich hybridisieren [2, 3, 5, 8].

Eichen gehören zu den vielfältigsten Waldbaumarten. Die hohe Diversität ist höchstwahrscheinlich auf die Aufrechterhaltung großer Populationen, die Überlappung ökologischer Nischen, den Genfluss über große Entfernungen und die Interfertilitätzurückzuführen. DerEinfluss des Menschen aufEichenpopulationen istsehrgroß. Die meisten Eichenwälder werden bewirtschaftet, während Urwälder wie Bialowieza in Polen und Weißrussland sehr selten sind. Die genetischen Ressourcen der Eiche sind durch den Verlust natürlicher Ökosysteme, limitierter Saatguterntebestände und durch die Auswirkungen der jahrzehntelangen Luftverschmutzung und durch langfristige Klimaveränderungen gefährdet [3].

Dieser Leitfaden beschreibt die Stiel- und Traubeneiche sowie ihre Reproduktion, Ökologie, Bedeutung und Gefährdung. Er enthält außerdem eine Anleitung zur Einrichtung genetischer Monitoringflächen und zur Erfassung aller vor Ort im Bestand zu erhebenden Verifikatoren.

\section{BESCHREIBUNG DER BAUMART}

Die Stieleiche (Quercus robur) und die Traubeneiche (Q. petraea) sind große Laubbäume, die Baumhöhen von 30-40 m erreichen und bis zu 800 Jahre oder mehr alt werden können. Beide Baumarten, wie auch andere Eichen, sind morphologisch sehr variabel und können auf natürliche Weise hybridisieren. Dadurch entstehen Individuen, die intermediäre Merkmale aufweisen oder bei denen ein Merkmal vorherrscht, so dass es schwierig sein kann, sie allein durch Beobachtungen eindeutig zu charakterisieren [1, 2, 3, 5].

Die Stiel- und Traubeneiche haben ein ausgedehntes und großflächig überlappendes Verbreitungsgebiet über fast ganz Europa. Ihre natürliche Verbreitung erstreckt sich im Westen von Irland und den nordwestlichen Teilen der Pyrenäenhalbinsel bis nach Osteuropa; im Norden bis zu den südlichen Teilen Skandinaviens. Die südlichen Verbreitungsgrenzen hingegen sind schwieriger zu definieren, da sich diese Eichen mit anderen mediterranen Eichenarten, wie z. B. Quercus pubescens Willd. und Quercus frainetto Ten., mischen, konkurrieren und natürlich hybridisieren können, wenn auch in relativ geringem Umfang $[3,5]$. Im Osten hat die Stieleiche ein größeres Verbreitungsgebiet, das bis zum Ural reicht, während das der Traubeneiche bis in die Ukraine reicht.

Stiel- und Traubeneiche sind hauptsächlich anhand von Blatt-, Frucht- und Stammmerkmalen zu unterscheiden.

Der Hauptstamm von Q. robur neigt dazu, sich in der Krone ,aufzulösen“ und unregelmäßige Äste mit gewundenen Zweigen zu entwickeln (Abbildung 1), während Q. petraea gewöhnlich einen Hauptstamm mit allmählich kleiner werdenden Ästen entwickelt (Abbildung 2) [1, 2, 3, 5]. Die Rinde beider Arten ist grau, zerklüftet und bildet rechteckige, längliche Blöcke, die bei $Q$. robur etwas dicker sind, während die von Q. petraea oft abblättern.

Die Blätter sind einfach, verkehrt-eiförmig, länglich und unregelmäßig tief gelappt, mit einem kurzen Stiel (2-7 $\mathrm{mm}$ ) bei $\mathrm{Q}$. robur und einem langen Stiel (13-25 mm) bei Q. petraea (Abb. 3) [1, 2, 3, 5].

Die Eicheln hängen oft paarweise in schuppigen Bechern an den Enden langer Stiele (Q. robur) oder sitzen an kurzen Stielen bzw. direkt am Zweig (Q. petraea). Die Eicheln sind generell sehr variabel in Größe und Form, aber die von $Q$. robur sind normalerweise kleiner und rundlich mit olivgrünen Längsstreifen, die im frischen Zustand gut sichtbar sind $[1,2,3,5]$.

Es kann manchmal schwierig sein, die beiden Arten nur durch visuelle Beobachtungen zu differenzieren, so dass molekulare Methoden das zuverlässigste Werkzeug zur Artbestimmung sind. Vor Ort im Bestand sind Blätter und Eicheln die wichtigsten Merkmale zur Bestimmung der Art und zur Definition des Hybridisierungsgrades zwischen 

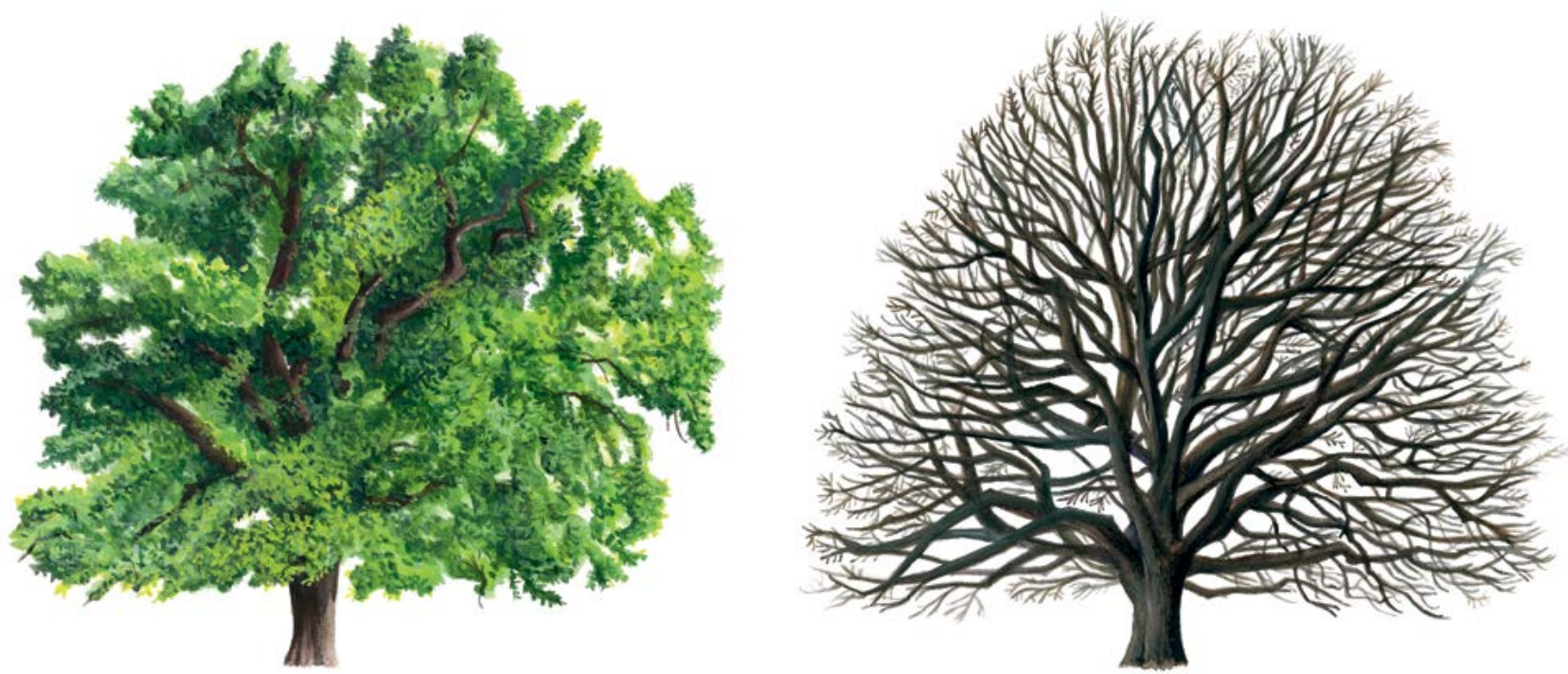

Abbildung 1: Habitus der Stieleiche (Quercus robur) im Sommer und Winter.
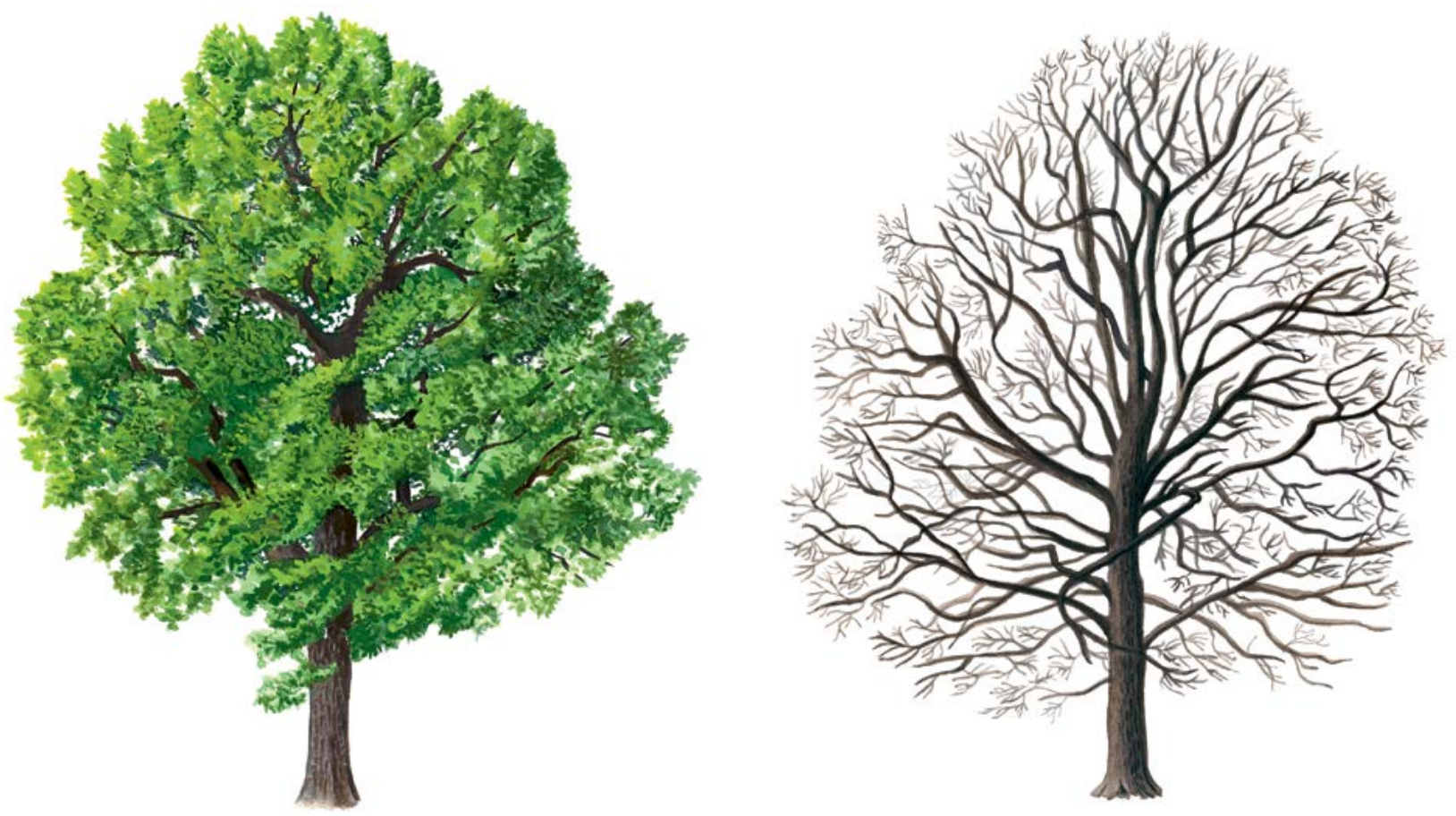

Abbildung 2: Habitus der Traubeneiche (Quercus petraea) im Sommer und Winter.

Stiel- und Traubeneiche in Mischpopulationen. Das Hauptkriterium für die taxonomische Bestimmung von Stielund Traubeneichen-Hybriden ist der Intermediärwert mehrerer morphologischer Merkmale unter Berücksichtigung der für jede Art typischen Werte. Die beste Grundlage für die Unterscheidung bieten die Länge des Blattstiels (Traubeneiche - lang, Stieleiche - kurz ), die Stiellänge der Eichel (Traubeneiche - kurz, Stieleiche - lang), die Lappung der Blätter (Traubeneiche - nicht tief, Stieleiche - eher tiefer), das Vorhandensein von Blattnerven in den Blatteinbuchtungen (Traubeneiche - nicht vorhanden, Stieleiche - sehr häufig), die Form der Blattbasis (Traubeneiche-klinale odernicht ausgeprägte Lappen, Stieleiche-sehr ausgeprägte Lappen), sowie Blattbehaarung (Traubeneiche - flach anliegende, sternförmige Haare auf der Blattunterseite, Stieleiche - ohne Haare) [1, 2, 3, 5]. 

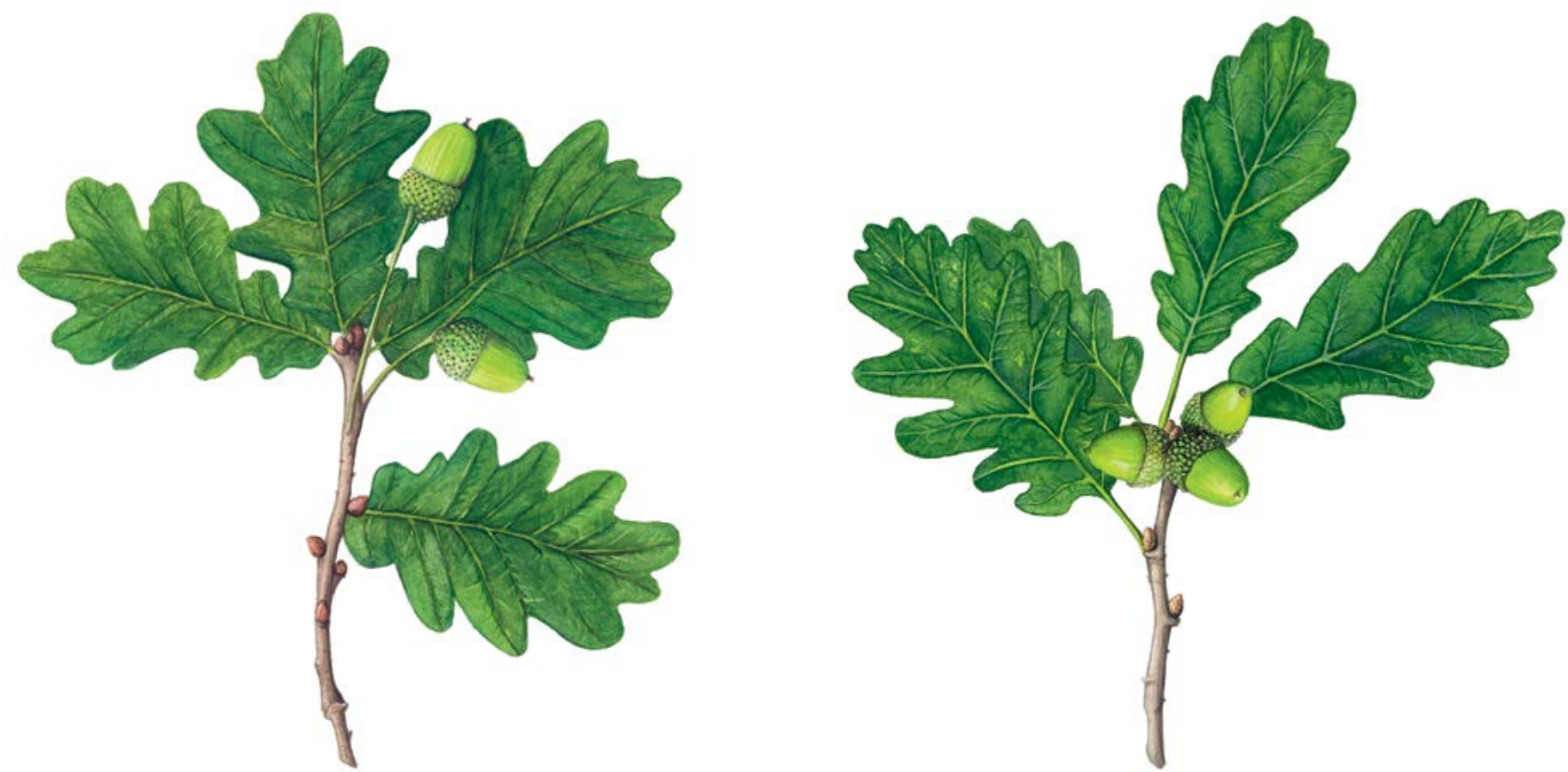

Abbildung 3: Blätter und Früchte der Stiel- (Quercus robur) (links) und Traubeneiche (Q. petraea) (rechts)

\section{REPRODUKTION}

Die beiden Eichenarten sind einhäusig, werden vom Wind bestäubt, und haben unterschiedliche männliche und weibliche Blüten, die auf zwei Arten von Blütenständen getragen werden [1, 2, 3, 5].

Die männlichen Blüten sind in Kätzchen gruppiert, die etwa $5 \mathrm{~cm}$ lang sind; sie entwickeln sich entweder in den Achseln der inneren Knospenschuppen oder der ersten Blätter. Beide Arten blühen im späten Frühjahr (Ende April und Mai), zusammen mit dem Blattaustrieb (Q. robur zwei Wochen vor Q. petraea). Bei geeigneten Witterungsbedingungen ist das Wachstum der Kätzchen ca. 1-2 Wochen nach Öffnung der Knospen abgeschlossen und die Bestäubung erfolgt in 2-4 Tagen [1, 2, 3, 5, 6].

Die weiblichen Blüten erscheinen an den Terminaltrieben, kurz nach dem Erscheinen der ersten Blätter (und der männlichen Kätzchen). Sie sind kugelförmig und nur $1 \mathrm{~mm}$ groß, d.h. sehr unauffällig und schwer zu sehen. Wenn die weiblichen Blüten empfänglich sind, werden sie klebrig und rötlich. Bei Q. robur erscheinen sie einzeln oder in kleinen Gruppen an langen Stielen, während sie bei Q. petraea in Gruppen von 2-5 am Zweig sitzen [1, $2,3,5,6]$.

Die Allogamie wird durch verschiedene Mechanismen unterstützt, wie z. B. durch eine unterschiedliche Blütezeit der männlichen und weiblichen Blüten eines Individuums, physiologische Vorteile von Fremdpollen, es blühen und fruktifizieren nicht jedes Jahr dieselben Bäume im Bestand, usw. [3, 6].

Nach der Befruchtung reifen die Eicheln innerhalb von ca. 3 Monaten und fallen dann vom Baum. Die Eicheln von $Q$. robur reifen Ende September oder Anfang Oktober, etwas früher als die im Oktober reifenden Eicheln von Q. petraea [1, 2, 3, 5]. Die Bäume beginnen in der Regel im Alter von 40 bis 100 Jahren zu fruktifizieren, in Niederwaldbeständen bereits mit etwa 20 Jahren. Mastjahre treten in der Regel alle 5 bis 7 Jahre auf und variieren je nach Individuum, Bestand, Region, Jahr und Baumdichte (eine geringe Dichte begünstigt eine frühere Fortpflanzungsfähigkeit) [3].

Die Vermehrung der Eiche erfolgt hauptsächlich durch Samen. Säugetiere und Vögel sind besonders wichtig für die Verbreitung der Samen. Dabei ist insbesondere der Eichelhäher (Garrulus glandarius L.) zu nennen, der als primärer Ausbreitungsvektor angesehen wird, da er die Eicheln bis zu $5 \mathrm{~km}$ weit verbringen kann. Bei jungen 
Eichen kann die Befähigung zum Stockausschlag bei fehlender Samenproduktion eine Möglichkeit zum Erhalt von Populationen sein, wenngleich diese Fähigkeit mit zunehmendem Baumalter abnimmt. Im Gegensatz zur Ausbreitung von Pollen und Eicheln ist die vegetative Vermehrung keine wichtige Genfluss-Komponente, kann jedoch an der Erhaltung der genetischen Variabilität innerhalb einer Population beteiligt sein $[2,3,4,5,6]$.

\section{UMWELT}

An vielen Standorten bilden Q. robur und Q. petraea gemeinsam den Hauptbestandteil von Laubmischwäldern der gemäßigten Zone, und beide weisen mehrere identische Eigenschaften auf. Die zwei Eichenarten sind wüchsige Baumarten mit einer großen ökologischen Amplitude, obwohl sie nährstoffreiche und feuchte Böden bevorzugen. Sie sind in der Lage, Wälder in niedrigen bis mittleren Höhenlagen in Anzahl und Größe zu dominieren. Beide Arten weisen Eigenschaften von Pionierarten auf; sie werden kaum durch Spätfrost beeinträchtigt und haben eine gute Stockausschlagsfähigkeit, so dass sie mit Niederwaldbewirtschaftung und einer Kappung des Haupttriebs gut umgehen können. Ihre tiefreichenden Pfahlwurzeln (bei Q. petraea stärker entwickelt) geben innen im Hinblick auf Windwurf eine hohe strukturelle Stabilität und ermöglichen ihnen durch den Zugang zu tiefer liegendem Boden- bzw. Grundwasser das Überstehen moderater Dürreperioden.

Unter Bedingungen, die weit von ihrem Optimum entfernt sind, zeigen die beiden Eichenarten jedoch ökologische Unterschiede. Q. robur wächst tendenziell auf schwereren Böden in kontinentaleren Klimazonen, in feuchten Niederungen und Auen entlang von Bächen und Flüssen und toleriert periodische Überschwemmungen. Q. petraea hingegen ist gegenüber Trockenheit und schlechten Böden toleranter als die Stieleiche, aber empfindlicher gegenüber schweren Böden. Sie wächst bevorzugt in atlantischerem Klima auf leichten und gut durchlässigen, oft felsigen Böden, oft an Hängen und auf Hügeln, und bevorzugt eher saure Böden.

Beide Arten sind lichtbedürttig (Q. robur mehr als Q. petraea), und ihr Kronendach lässt viel Licht in den Unterstand, was die Verjüngung vieler Baumarten begünstigt und förderlich für die Biodiversität ist. Beide Eichenarten bilden unter natürlichen Bedingungen nur selten Reinbestände. Auf Ebenen, Hochebenen und Hügeln ist die Stieleiche eine Pionierbaumart; die Traubeneiche eher eine Art der späten Sukzession. In Klimaten mit trockenen Sommern kann die Traubeneiche die Schlusswaldgesellschaft bilden. In Tälern und Auen ist die Stieleiche eine Art der späten Sukzession, die zusammen mit Bergahorn, Platane, Ahorn, Esche und Ulme die Schlusswaldgesellschaft bildet $[2,3,5]$.

\section{GEFÄHRDUNG}

Eichenpopulationen sind aufgrund des Klimawandels und der Fragmentierung ihrer Lebensräume (vor allem Q. robur im Tiefland), Veränderungen des Grundwasserregimes und der Übernutzung von Altbäumen gefährdet [2].

Eine große Bedrohung für die genetische Vielfalt der Eiche ist die Einführung exotischer Genotypen durch künstlich begründete Bestände. Besonders stark vom Verschwinden bedroht sind Populationen, die extremere Lebensräume besetzen, da die Anzahl ihrer Individuen gering ist, die Habitate instabil sind und der menschliche Einfluss oft erheblich ist [3].

Aufgrund des unausgewogenen Verhältnisses der Entwicklungsphasen, einem überhöhten Wildbestand oder Veränderungen des Grundwasserregimes kann die Naturverjüngung von Eichen stark limitiert sein. Oft sterben die Sämlinge innerhalb weniger Jahre nach der Keimung ab [1, 2].

Auch Schädlinge und Krankheitserreger stellen eine ernsthafte Bedrohung dar. Der Eichenmehltau (Erysiphe alphitoides (Griffon \& Maubl.) U. Braun \& S. Takam) ist Berichten zufolge der häufigste Schaderreger an Eichen. Das Eichensterben ist ein neues, komplexes Krankheitsbild, das hauptsächlich an Stiel- und Traubeneichen auftritt und durch eine Kronenverlichtung, dunkle, nässende Wunden („Schleimfluss“) am Stamm, und meist mit einem Befall durch den Zweipunktigen Eichenprachtkäfer Agrilus biguttatus Fabricius einhergeht [3]. 
Nach dem ersten Blattaustrieb kommt es häufig zu einer teilweisen oder vollständigen Entlaubung durch Raupen verschiedener Schmetterlingsarten, z. B. Tortrix viridana L., Lymantria dispar L., Operophtera brumata L. und Thaumetopoea processionea L.. Auch Knopperngallwespen (Andricus quercuscalicis Burgsdorf) können Schäden an Eichenkulturen verursachen [3].

\section{EINRICHTUNG UND INSTANDHALTUNG VON MONITORINGFLÄCHEN}

Da Eichen mit vielen Waldbaumarten des Tieflandes fast reine oder gemischte Bestände bilden, sollte wie bei anderen bestandsbildenden Arten eine reguläre forstgenetische Monitoringfläche mit 50 fortpflanzungsfähigen Altbäumen eingerichtet werden. Dabei handelt es sich um herrschende oder mitherrschende Bäume, die phänotypisch geeignet scheinen, einen Abstand von mindestens $30 \mathrm{~m}$ zueinander aufweisen und zu nachfolgenden Generationen beitragen werden. Ein Baum gilt als fortpflanzungsfähig, wenn er blüht.

Die beste Zeit für die Einrichtung einer FGM-Fläche und die Auswahl der Beobachtungsbäume ist das Frühjahr, wenn die fortpflanzungsfähigen Bäume blühen und für die Artbestimmung (Hybridisierung) Blätter und Eicheln vom Boden gesammelt werden können. Der BHD und die soziale Stellung eines Baumes können als Anhaltspunkte für die Identifizierung fortpflanzungsfähiger Bäume verwendet werden, wenn die Monitoringfläche außerhalb der Blütezeit eingerichtet wird. Dabei sollte auf das Fachwissen der zuständigen Försterlnnen zurückgegriffen werden. Bei der Neueinrichtung einer Monitoringfläche sollten alle Bäume gekennzeichnet und ihre Koordinaten erfasst werden. Gleichzeitig können die jeweiligen BHD gemessen und Proben für die DNA-Extraktion gesammelt werden.

Aufgrund der natürlichen Hybridisierung zwischen Eichenarten ist es ratsam, morphometrische Analysen von Falllaub und Eicheln durchzuführen, um die jeweiligen Arten und die Populationstaxonomie eines Bestandes zu bestimmen, bevor eine forstgenetische Monitoringfläche eingerichtet wird. Die Hauptkriterien für die taxonomische Bestimmung von Eichenhybriden sind in der Artenbeschreibung erläutert.

Erforderliche Ausrüstung:

- ein Gerät zur Entfernungsmessung (empfehlenswert ist ein Fernglas mit Entfernungsmesser)

- ein Kompass

- Farbe und Pinsel oder Farbspray zum dauerhaften Kennzeichnen der Bäume

- eine Kluppe für BHD-Messungen und

- ein ausreichend präzises GPS-Gerät, welches das Speichern von Baumkoordinaten ermöglicht

\subsection{Einrichtung der Monitoringfläche}

\subsubsection{Auswahl des Mittelpunkts}

Das allgemeine Verfahren für eine Zufallsauswahl der Monitoringfläche besteht aus den folgenden Schritten (Abbildung 4a):

- zufällige Auswahl eines Punktes (grüner Punkt) entlang einer an der Bestandesgrenze verlaufenden Forststraße oder eines Waldweges auf einer Karte;

- Einzeichnen einer annähernd senkrecht zur Straße verlaufenden Linie an diesem zufällig entlang der Straße ausgewählten Punkt;

- zufällige Auswahl eines Punktes auf der Linie (roter Punkt) - dieser Punkt stellt den Mittelpunkt der forstgenetischen Monitoringfläche dar.

Der Mindestabstand zwischen dem ausgewählten Mittelpunkt und der Bestandesgrenze beträgt ca. $150 \mathrm{~m}$. Wenn der ausgewählte Mittelpunkt diese Anforderung nicht erfüllt, muss nach dem oben beschriebenen Verfahren ein neuer Punkt ausgewählt werden. 
(a)

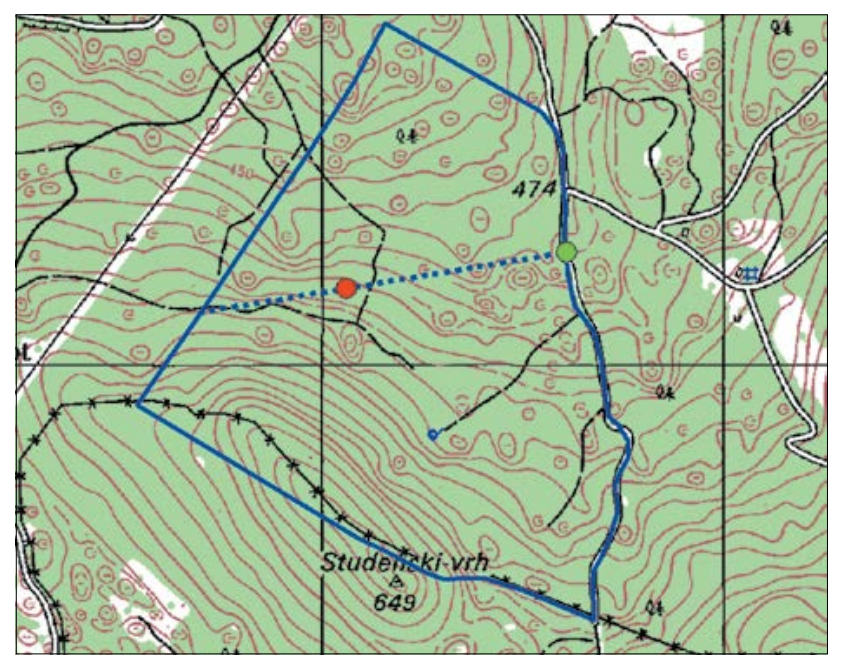

(b)

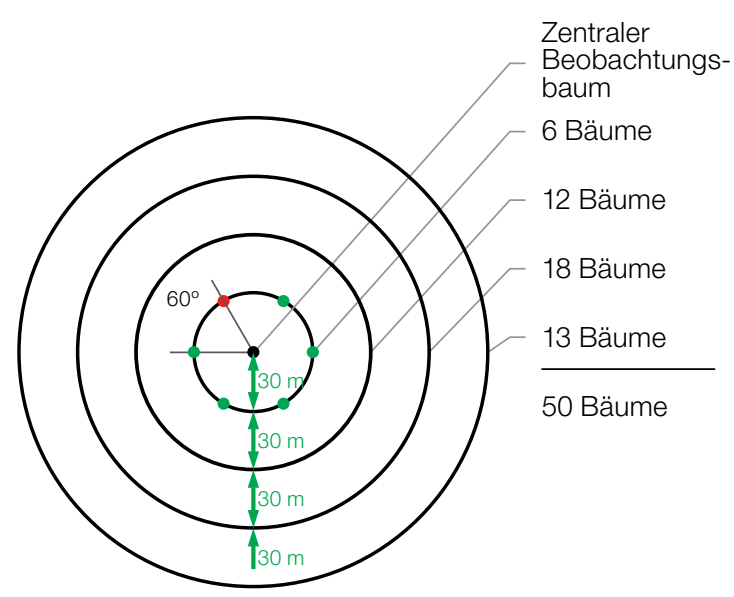

Abbildung 4: Zufällige Auswahl des Mittelpunkts der forstgenetischen Monitoringfläche (a); Auswahl von Bäumen in konzentrischen Kreisen mit einem zunehmenden Radius von 30 m um den zuvor ausgewählten zentralen Beobachtungsbaum (b).

Anstelle des oben beschriebenen Verfahrens können auch entsprechende Werkzeuge zur Erstellung von Zufallspunkten in GIS-Software verwendet werden.

Für die Nutzung im Gelände sollten die Koordinaten des ausgewählten Punktes in einem GPS-Gerät gespeichert werden.

\subsubsection{Einrichtung der Monitoringfläche}

Vor Ort im Bestand wird ein zentraler Beobachtungsbaum der Monitoringfläche bestimmt und mit der Nummer 1 gekennzeichnet. Dieser Baum entspricht dem der gespeicherten GPS-Koordinate am nächsten stehenden, fortpflanzungsfähigen Baum.

In konzentrischen Kreisen mit einem zunehmenden Radius von $30 \mathrm{~m}$ um den zentralen Beobachtungsbaum werden weitere Altbäume ausgewählt (Abbildung 4b). Der erste Baum in jedem Kreis sollte nach dem Zufallsprinzip ausgewählt werden, was auf verschiedene Weise geschehen kann: durch Verwendung eines zufälligen Azimuts, der vom zentralen Beobachtungsbaum aus eingemessen wird (Tabelle 1), durch Folgen der Richtung des Sekundenzeigers auf einer analogen Uhr oder durch eine andere Vorgehensweise, die eine objektive Auswahl ermöglicht. Die verbleibenden Bäume in jedem Kreis werden mit einem entsprechend größeren Azimut ausgewählt, um einen Mindestabstand von 30 m zwischen je zwei beliebigen Bäumen zu gewährleisten:

$\cdot+60^{\circ}$ im ersten Kreis

- $+30^{\circ}$ im zweiten Kreis

$\cdot+20^{\circ}$ im dritten Kreis

$\cdot+15^{\circ}$ im vierten Kreis

Sollte es nicht möglich sein, 6, 12 bzw. 18 Bäume in den inneren 3 Kreisen zu finden (Abbildung 4b), werden im äußersten Kreis zusätzliche Bäume ausgewählt. 
Tabelle 1: Zufällig generierte Azimute, die für die Auswahl des ersten Baumes in jedem Kreis verwendet werden können.

\begin{tabular}{rrrrrrrrrr}
\hline 108 & 15 & 186 & 35 & 178 & 29 & 305 & 351 & 44 & 150 \\
\hline 232 & 23 & 160 & 141 & 112 & 292 & 216 & 83 & 245 & 214 \\
\hline 63 & 65 & 345 & 234 & 95 & 78 & 279 & 323 & 40 & 236 \\
\hline 201 & 313 & 275 & 144 & 182 & 68 & 268 & 289 & 185 & 92 \\
\hline 356 & 177 & 93 & 1 & 145 & 198 & 287 & 251 & 224 & 142 \\
\hline
\end{tabular}

\subsubsection{Kennzeichnung der Bäume}

Jeder ausgewählte Beobachtungsbaum muss mit einer entsprechenden Nummer und idealerweise mit einem um den Stamm herum laufenden Streifen gekennzeichnet werden, um die Sichtbarkeit der Bäume aus allen Richtungen zu erhöhen. Markieren Sie den zentralen Beobachtungsbaum (Nummer 1) mit zwei oder mehr Streifen, um ihn von anderen Bäumen zu unterscheiden (Abbildung 5a). Es wird empfohlen, die Baumnummer stets auf der vom zentralen Beobachtungsbaum abgewandten Seite der Bäume anzubringen, da dies die Lokalisierung des zentralen Beobachtungsbaums v.a. von den äußeren Kreisen der Monitoringfläche aus erleichtert (Abbildung 5b).
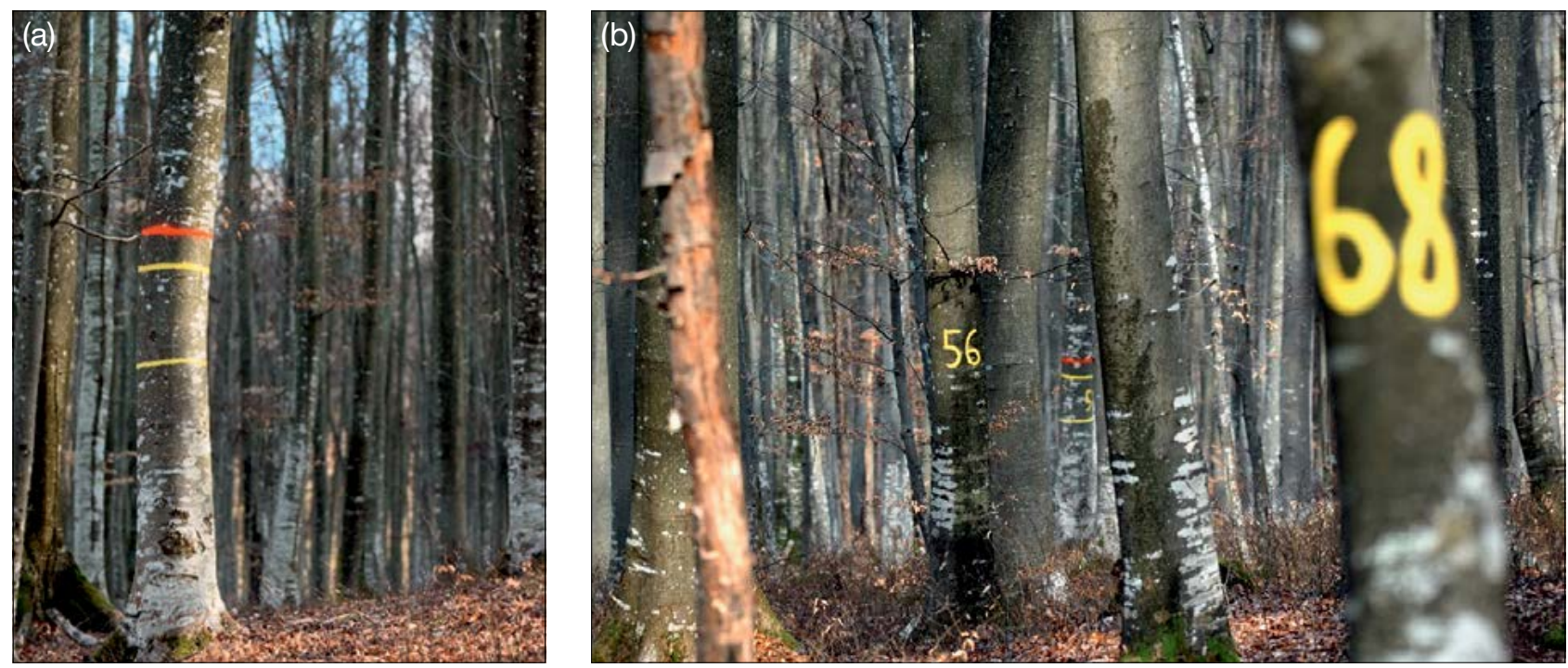

Abbildung 5: a) Der zentrale Beobachtungsbaum der forstgenetischen Monitoringfläche ist mit mehreren Streifen markiert, um inn von anderen Bäumen zu unterscheiden; b) die Nummerierung der ausgewählten Bäume erfolgt auf der vom zentralen Beobachtungsbaum abgewandten Seite (die Fotos zeigen beispielhaft die Kennzeichnung einer Buchen-FGM-Fläche).

\subsection{Einrichtung von Naturverjüngungs-Plots}

Die Einrichtung von Plots für das Monitoring der Naturverjüngung (NV) sollte während der Keimungsperiode nach einem Halb- oder Vollmastjahr erfolgen.

Bereiche mit aufgelaufener Naturverjüngung aus dem letzten Mastjahr (sogenannte Verjüngungscluster) sollten vor Ort vermessen und ihre Position erfasst werden (GPS-Koordinaten, Nummer des Beobachtungsbaumes neben dem Verjüngungscluster). Von allen erfassten Verjüngungsclustern sollten nach dem Zufallsprinzip 20 für die Einrichtung von NV-Plots ausgewählt werden. Wenn 20 oder weniger natürliche Verjüngungscluster vorhanden sind, sollten alle verwendet werden.

Innerhalb jedes ausgewählten Verjüngungsclusters ist ein $1 \mathrm{~m}^{2}$ großer Plot einzurichten und mit Metallstäben zu markieren. Die Metallstäbe sollten an jeder Ecke der Teilfläche so tief wie möglich in den Boden getrieben werden, damit sie nicht von Tieren entfernt werden können. Die oberen Spitzen der Metallstäbe sollten farbig markiert werden, um ihre Sichtbarkeit zu verbessern. 


\subsection{Instandhaltung der Monitoringfläche}

\subsubsection{Allgemeine Instandhaltung}

Die Kennzeichnung der Bäume und NV-Plots muss periodisch (alle 2 Jahre) überprüft und bei Bedarf erneuert werden.

\subsubsection{Ersatz von Bäumen}

Wenn ein ausgewählter Beobachtungsbaum stirbt oder im Zuge der forstlichen Bewirtschaftung gefällt wird, muss er ersetzt werden. Dabei sollte der dem abgestorbenen/gefällten Baum nächstgelegene geeignete Baum ausgewählt werden, wobei der Mindestabstand von 30 m zum nächsten Beobachtungsbaum erfüllt sein muss. Andernfalls ist ein Baum aus der Peripherie (vorzugsweise im äußeren Kreis) der Monitoringfläche zu wählen. Der Ersatzbaum wird mit der nächsten verfügbaren Zahl über 50 gekennzeichnet, d.h. 51, 52, 53, usw., um ihn eindeutig von den ursprünglich 50 ausgewählten Beobachtungsbäumen zu unterscheiden.

Wenn die Baumkrone z.B. durch Wind-, Eis- oder Schneebruch geschädigt ist, der Baum aber weiterhin fruktifiziert, wird der Baum im Monitoringprogramm belassen. Ist der Schaden zu schwerwiegend und eine Fruktifikation nicht mehr zu erwarten, muss der Baum ersetzt werden. Die Schadensursache ist zu erfassen, da der Schaden Auswirkungen auf die erfassten Werte der Verifikatoren und Hintergrundinformationen haben kann.

\section{ERFASSUNG VON VERIFIKATOREN UND HINTERGRUNDINFORMATIONEN}

Auf der Monitoringfläche werden periodisch Verifikatoren und Hintergrundinformationen erfasst. Verifikatoren werden genutzt, um die genetischen Eigenschaften der Population und ihre Anpassung an Umweltveränderungen und/oder Bewirtschaftung zu verfolgen, während Hintergrundinformationen aufgezeichnet werden, um die Interpretation der Verifikatoren zu unterstützen. Verifikatoren können auf drei verschiedenen Intensitätsniveaus erfasst werden: Basis, Standard und Intensiv.

Höherrangigere Niveaus (Standard, Intensiv) müssen stets auch die Erfassung der Verifikatoren auf allen niedrigeren Niveaus (Basis, Standard) einschließen. Dies ist für die Aufzeichnung von Hintergrundinformationen nicht erforderlich. 
Tabelle 2: Liste der Verifikatoren und Hintergrundinformationen, die während der Außenaufnahmen auf den Eichen-

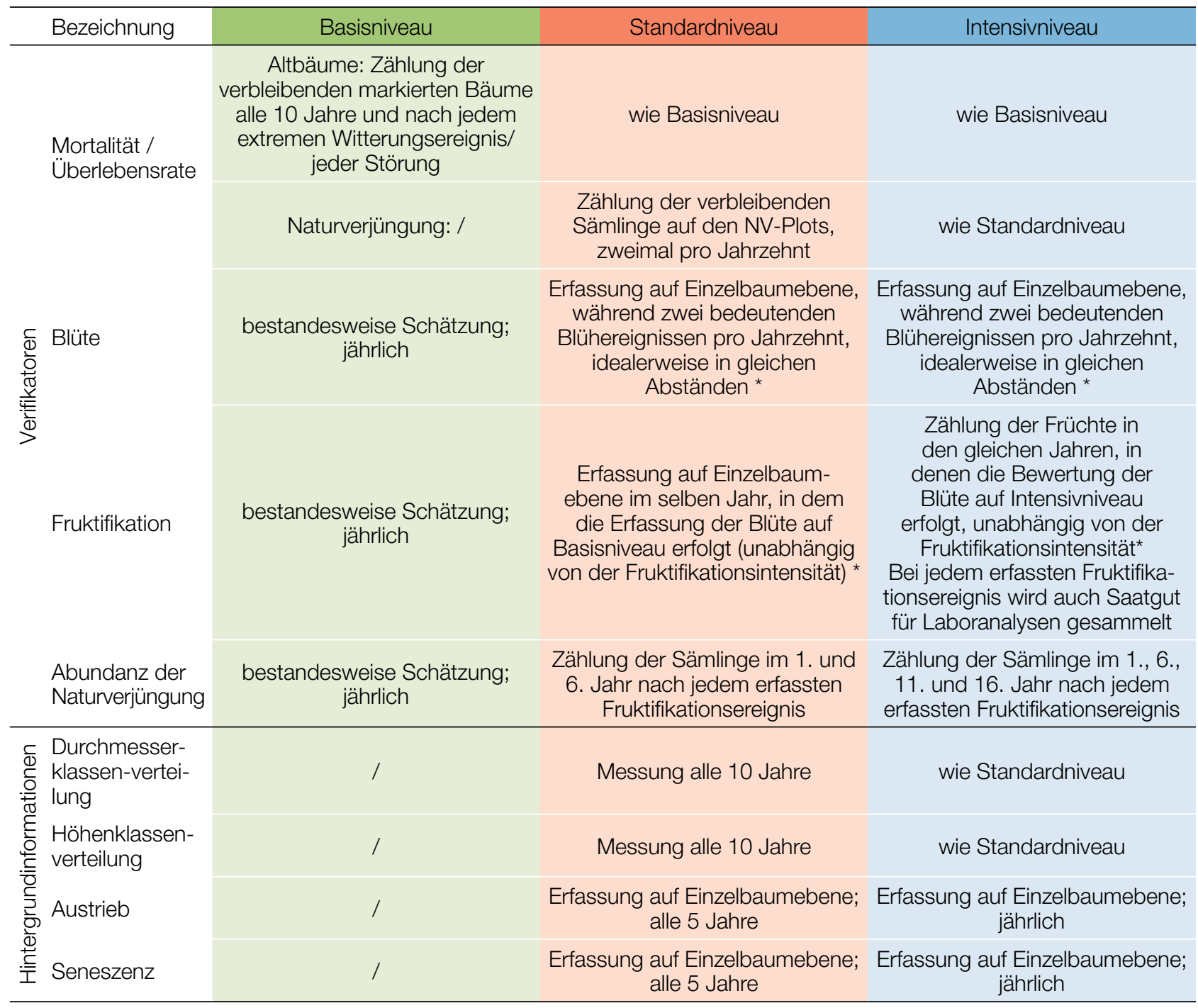

Idealerweise sollte mindestens ein größeres Fruktifikationsereignis pro Jahrzehnt bewertet werden. Ein bedeutendes Blühereignis führt jedoch nicht unbedingt zu einem bedeutenden Fruktifikationsereignis. Wenn auf das bewertete Blühereignis kein wesentliches Fruktifikationsereignis folgt, muss die Bewertung sowohl der Blüte als auch der Fruchtbildung beim nächsten bedeutenden Blühereignis wiederholt werden, unabhängig von der Zeit, die zwischen aufeinanderfolgenden bedeutenden Blühereignissen liegt. Erhebungen auf Basisniveau werden zur Identifizierung bedeutender Blüh- und Fruktifikationsereignisse verwendet.

\subsection{Verfahren zur Erfassung der Verifikatoren}

\subsubsection{Mortalität / Überlebensrate}

Die Mortalität beschreibt die Sterblichkeit von Altbäumen und Naturverjüngung. Ihr Pendant - die Überlebensratesteht für Bäume, die seit der letzten Datenerhebung noch am Leben sind. Die Überlebensrate wird berechnet als 1 - Mortalität.

\subsubsection{Altbäume: Basis-, Standard- und Intensivniveau}

Der Verifikator für die Mortalität von Altbäumen wird geschätzt, indem die verbleibenden lebenden Beobachtungsbäume alle 10 Jahre sowie nach jedem extremen Witterungsereignis bzw. jeder Störung gezählt werden. Die Mortalität ist die Differenz zwischen der ursprünglichen Anzahl markierter Beobachtungsbäume und den davon verbleibenden lebenden Bäumen der ursprünglichen 50 Beobachtungsbäume. 


\subsubsection{Naturverjüngung: Standard- und Intensivniveau}

Die Mortalität der Naturverjüngung wird auf Grundlage des Verifikators „Abundanz der Naturverjüngung“ berechnet. Die Mortalität ist der Unterschied zwischen der anfänglichen Anzahl der Jungpflanzen und den Pflanzen, die zum Zeitpunkt der nächsten Zählung noch am Leben sind. Für jede Bewertungsrunde werden die Jungpflanzen zuerst im Jahr der Keimung und dann wieder nach 5 Jahren auf Standardniveau gezählt, während auf dem Intensivniveau die Zählung zusätzlich nach 10 und 15 Jahren durchgeführt wird. Die Bewertung der „Abundanz der Naturverjüngung“ erfolgt zweimal pro Jahrzehnt, idealerweise etwa alle fünf Jahre.

\subsubsection{Blüte}

Dieser Verifikator beschreibt das Auftreten der Blüte (Anteil der Bäume) und die Blühintensität. Er kann in Mitteleuropa von April bis Mai erfasst werden. Nach warmen Wintern erfolgt die Blüte früher.

Männliche Blüten (Abbildung 7): Das Kriterium zur Bestimmung des Beginns der Blüte wird durch die Entwicklung der Kätzchen definiert. Die männlichen Blüten (Kätzchen) entwickeln sich unmittelbar nach dem Erscheinen der ersten Blätter; die Freisetzung von Pollen beginnt, wenn sich die Kätzchen verlängern und verdicken. Die Blütezeit der männlichen Blüten endet, wenn keine männlichen Blüten in der Krone mehr Pollen freisetzen. Die Farbe der Kätzchen ändert sich zu dunkelbraun; ihre Konsistenz wird spinnwebenartig.

Weibliche Blüten (Abbildung 6): Die weiblichen Blüten der Eiche sind sehr klein und kaum sichtbar; daher konzentrieren sich alle Beurteilungen der Blütezeit ausschließlich auf die männlichen Blüten. Im Gegensatz zu den meisten anderen Arten wird deshalb die Hintergrundinformation Blühsynchronisation bei der Stiel- und Traubeneiche nicht überwacht.

\subsubsection{Basisniveau}

Der Verifikator wird jährlich auf Bestandesebene erfasst. Die Erfassung erfolgt zum Zeitpunkt der Hauptblüte. Die Schätzung des durchschnittlichen Zustands erfolgt nach einer Begehung der gesamten Monitoringfläche. Es werden zwei Werte erfasst: einer für die Blühintensität, ausgedrückt als mittlerer Kronenanteil in Blüte; und einer für den Anteil der blühenden Bäume im Bestand.

\begin{tabular}{llr} 
Code Blühintensität auf Bestandesebene & Mittlerer Anteil der Kronen in Blüte (\%) \\
\hline 1 & Keine Blüte: Keine oder nur gelegentlich auftretende Blüten & $0-10$ \\
\hline 2 & Schwache Blüte: Einige Blüten erscheinen an den Bäumen & $>10-30$ \\
\hline 3 & Mäßige Blüte: Mäßig viele Blüten an den Bäumen & $>30-60$ \\
\hline 4 & Starke Blüte: Reichlich Blüten an den Bäumen & $>60-90$ \\
\hline 5 & Extreme Blüte: Enorme Anzahl von Blüten an den Bäumen & $>90$ \\
\hline
\end{tabular}

\begin{tabular}{lr}
\hline Code Anteil der Bäume im Bestand mit dem entsprechenden Stadium der Blühintensität (\%) \\
\hline 1 & $0-10$ \\
\hline 2 & $>10-30$ \\
\hline 3 & $>30-60$ \\
\hline 4 & $>60-90$ \\
\hline 5 & $>90$ \\
\hline
\end{tabular}




\subsubsection{Standardniveau}

Der Verifikator wird während zweier bedeutender Blühereignisse pro Jahrzehnt aufgezeichnet, idealerweise mit einem ähnlichen zeitlichen Abstand. Er wird für alle 50 Beobachtungsbäume auf Einzelbaumebene erfasst. Ein bedeutendes Blühereignis liegt vor, wenn die Blühintensität auf Basisniveau als stark oder extrem eingeschätzt wird (Code 4 oder 5) und der Anteil der Bäume mit der angegebenen Blühintensität über 60\% liegt (Code 4 oder 5). Die Erfassung erfolgt zum Zeitpunkt der Hauptblüte. Für jeden Beobachtungsbaum wird ein Wert erfasst.

\begin{tabular}{clc}
\multicolumn{2}{l}{ Code Blühintensität auf Bestandesebene } & Mittlerer Anteil der Kronen in Blüte (\%) \\
\hline 1 & Keine Blüte: Keine oder nur gelegentlich auftretende Blüten & $0-10$ \\
\hline 2 & Schwache Blüte: Einige Blüten erscheinen an den Bäumen & $>10-30$ \\
\hline 3 & Mäßige Blüte: Mäßig viele Blüten an den Bäumen & $>30-60$ \\
\hline 4 & Starke Blüte: Reichlich Blüten an den Bäumen & $>60-90$ \\
\hline 5 & Extreme Blüte: Enorme Anzahl von Blüten an den Bäumen & $>90$ \\
\hline
\end{tabular}

\subsubsection{Intensivniveau}

Der Verifikator wird während zweier bedeutender Blühereignisse pro Jahrzehnt aufgezeichnet, idealerweise mit einem ähnlichen zeitlichen Abstand. Er wird für alle 50 Beobachtungsbäume auf Einzelbaumebene erfasst. Ein bedeutendes Blühereignis liegt vor, wenn die Blühintensität auf Basisniveau als stark oder extrem eingeschätzt wird (Code 4 oder 5) und der Anteil der Bäume mit der angegebenen Blühintensität über 60\% liegt (Code 4 oder 5). Im Durchschnitt sind zwei Begehungen auf der Monitoringfläche erforderlich: der erste früh genug, um das Frühstadium der Blüte zu beobachten, der zweite zum Zeitpunkt der Hauptblüte.

Für jeden Baum werden zwei Werte angegeben: das männliche Blühstadium und der blühende Kronenanteil. Da die weiblichen Blüten bei Stiel- und Traubeneiche sehr klein und eher unscheinbar sind, kann die Beurteilung des weiblichen Blühstadiums im Bestand nicht zuverlässig erfolgen. Der blühende Kronenanteil bezieht sich auf die Menge der männlichen Blüten am Baum. Die Blühstadien sind in Abbildungen 6 und 7 dargestellt.

Code Männliches Blühstadium
\begin{tabular}{ll}
\hline 1 & verlängerter Blütenstiel - geschlossene Blüte (grün) \\
\hline 2 & Pollen abgebende Staubgefäße (gelb) \\
\hline 3 & leere Staubgefäße (Pollen freigesetzt) (braun) \\
\hline
\end{tabular}

\begin{tabular}{lr}
\hline Code Anteil der Krone in Blüte (\%; männliche Blüten) & $0-10$ \\
\hline 1 & $>10-30$ \\
\hline 2 & $>30-60$ \\
\hline 3 & $>60-90$ \\
\hline 4 & $>90$ \\
\hline 5 &
\end{tabular}


(a)

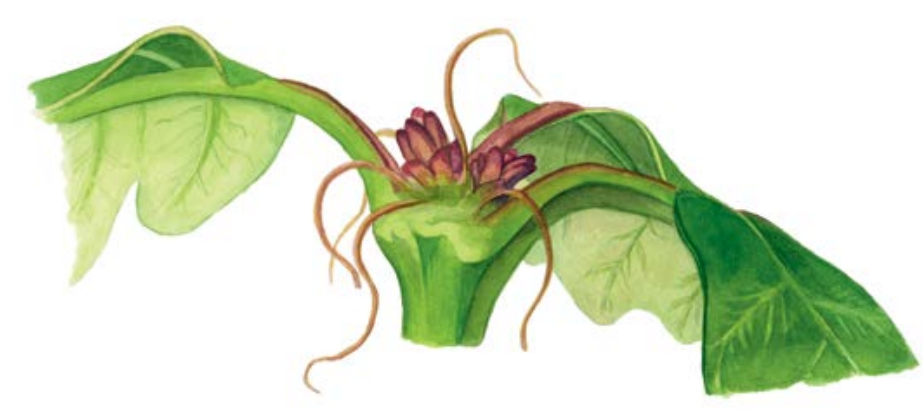

(b)

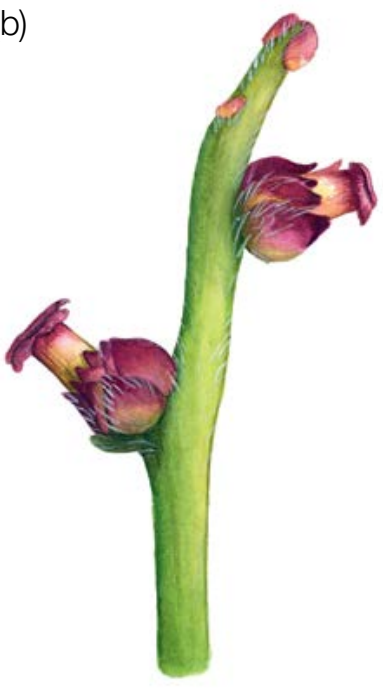

Abbildung 6: Die weiblichen Blüten der Stieleiche (Quercus robur) (a), und Traubeneiche (Q. petraea) (b). Die weibliche Blüte wird nicht bewertet, da die weiblichen Blüten beider Arten zu unauffällig sind, um sie im Bestand zuverlässig zu beobachten.

1

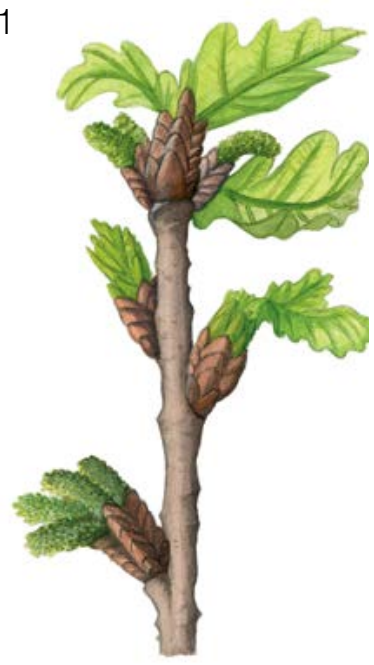

2

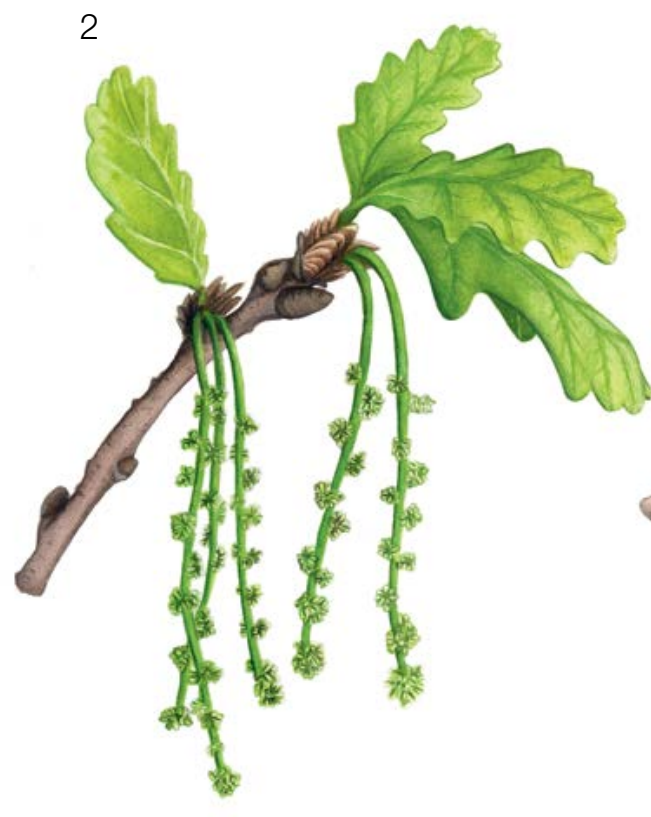

3

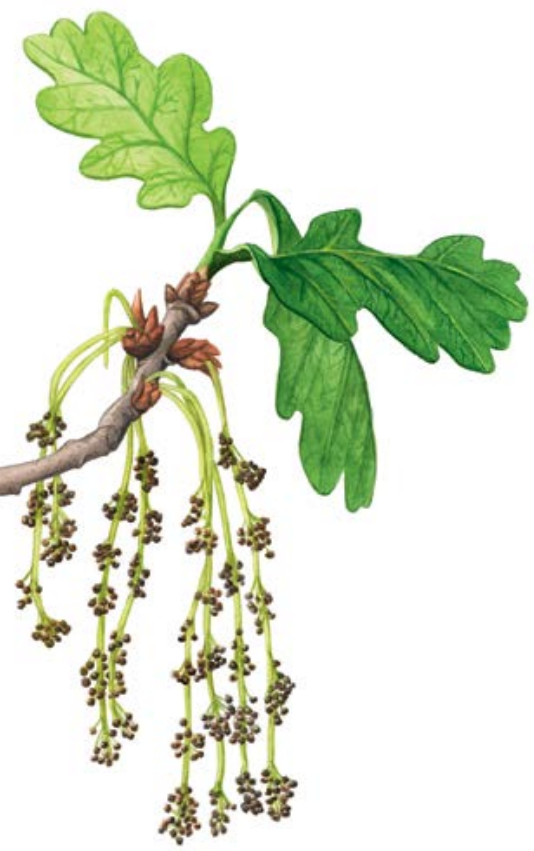

Abbildung 7: Illustrationen zur Beschreibung der männlichen Blühstadien von Stiel- und Traubeneiche für den Verifikator „Blüte" auf Intensivniveau.

\subsubsection{Fruktifikation}

Dieser Verifikator beschreibt das Auftreten und die Häufigkeit der Fruchtbildung. Die Daten für diesen Verifikator sollten während der Fruktifikationszeit erhoben werden, d.h. in Mitteleuropa von September bis Oktober. Die Eicheln von Q. robur reifen Ende September oder Anfang Oktober, etwas früher als die Eicheln von Q. petraea, die im Oktober reifen. 


\subsubsection{Basisniveau}

Der Verifikator wird jährlich auf Bestandesebene erfasst. Die Schätzung des durchschnittlichen Zustands erfolgt nach einer Begehung der gesamten Monitoringfläche. Es werden zwei Werte erfasst: einer für die Intensität der Fruktifikation und einer für den Anteil fruchttragender Bäume im Bestand.

\begin{tabular}{llr}
\hline \multicolumn{2}{l}{ Code Intensität der Fruktifikation auf Bestandesebene } & Mittlerer Anteil der Krone mit Fruchtbehang (\%) \\
\hline $\begin{array}{l}\text { Keine Fruchtbildung: Keine oder nur gelegentlich auftretende Früchte } \\
\text { an den Bäumen }\end{array}$ & $0-10$ \\
\hline 2 & Schwache Fruchtbildung: Einige Früchte an den Bäumen & $>10-30$ \\
\hline 3 & Mäßige Fruchtbildung: Mäßig viele Früchte an den Bäumen & $>30-60$ \\
\hline 4 & Starke Fruchtbildung: Reichlich Früchte an den Bäumen & $>60-90$ \\
\hline 5 & Extreme Fruchtbildung: Enorme Anzahl von Früchten an den Bäumen & $>90$ \\
\hline & & $0-10$ \\
\hline Code Anteil der Bäume im Bestand mit dem entsprechenden Stadium der Fruktifikationsintensität (\%) & $>10-30$ \\
\hline 1 & & $>30-60$ \\
\hline 2 & & $>60-90$ \\
\hline 3 & & $>90$ \\
\hline 4 & & $>$ \\
\hline
\end{tabular}

\subsubsection{Standardniveau}

Die Erfassung des Verifikators erfolgt in denselben Jahren wie die Bewertung der Blüte auf Standardniveau (unabhängig von der Fruktifikationsintensität). Sie wird für alle 50 Beobachtungsbäume auf Einzelbaumebene durchgeführt - und zwar bevor die Früchte (Eicheln) beginnen zu fallen. Für jeden Beobachtungsbaum wird ein Wert erfasst.

Im Idealfall sollte pro Jahrzehnt ein auf ein bedeutendes Blühereignis folgendes größeres Fruktifikationsereignis erfasst werden. Ein bedeutendes Blühereignis führt jedoch nicht unbedingt zu einem bedeutenden Fruktifikationsereignis. Wenn auf das bewertete Blühereignis kein wesentliches Fruktifikationsereignis folgt, muss die Bewertung sowohl der Blüte als auch der Fruchtbildung beim nächsten bedeutenden Blühereignis wiederholt werden, unabhängig von der Zeit, die zwischen aufeinanderfolgenden bedeutenden Blühereignissen liegt. Erhebungen auf Basisniveau werden genutzt, um bedeutende Fruktifikationsereignisse zu identifizieren. Ein bedeutendes Fruktifikationsereignis liegt vor, wenn die Fruktifikationsintensität auf Basisniveau als stark oder extrem eingeschätzt wird (Code 4 oder 5) und der Anteil der Bäume mit der angegebenen Fruktifikationsintensität über 60\% liegt (Code 4 oder 5).

\begin{tabular}{clr}
\multicolumn{2}{l}{ Code Intensität der Fruktifikation auf Bestandesebene } & Mittlerer Anteil der Krone mit Fruchtbehang (\%) \\
\hline 1 & $\begin{array}{l}\text { Keine Fruchtbildung: Keine oder nur gelegentlich auftretende Früchte } \\
\text { an den Bäumen }\end{array}$ & $0-10$ \\
\hline 2 & Schwache Fruchtbildung: Einige Früchte an den Bäumen & $>10-30$ \\
\hline 3 & Mäßige Fruchtbildung: Mäßig viele Früchte an den Bäumen & $>30-60$ \\
\hline 4 & Starke Fruchtbildung: Reichlich Früchte an den Bäumen & $>60-90$ \\
\hline 5 & Extreme Fruchtbildung: Enorme Anzahl von Früchten an den Bäumen & $>90$ \\
\hline
\end{tabular}

\subsubsection{Intensivniveau}

Die Erfassung des Verifikators erfolgt für alle 50 Beobachtungsbäume auf Einzelbaumebene in denselben Jahren wie die Bewertung der Blüte auf Intensivniveau (unabhängig von der Fruktifikationsintensität). Sie wird durchgeführt, 
bevor die Früchte (Eicheln) beginnen zu fallen. Für jeden Beobachtungsbaum wird ein Wert erfasst. Zeitgleich werden Eicheln für die Saatgut- und Genanalysen gesammelt (für die Verifikatoren und Hintergrundinformationen auf Intensivniveau).

Im Idealfall sollte pro Jahrzehnt ein auf ein bedeutendes Blühereignis folgendes größeres Fruktifikationsereignis erfasst werden. Ein bedeutendes Blühereignis führt jedoch nicht unbedingt $z u$ einem bedeutenden Fruktifikationsereignis. Wenn auf das bewertete Blühereignis kein wesentliches Fruktifikationsereignis folgt, muss die Bewertung sowohl der Blüte als auch der Fruchtbildung beim nächsten bedeutenden Blühereignis wiederholt werden, unabhängig von der Zeit, die zwischen aufeinanderfolgenden bedeutenden Blühereignissen liegt. Erhebungen auf Basisniveau werden genutzt, um bedeutende Fruktifikationsereignisse zu identifizieren. Ein bedeutendes Fruktifikationsereignis liegt vor, wenn die Fruktifikationsintensität auf Basisniveau als stark oder extrem eingeschätzt wird (Code 4 oder 5) und der Anteil der Bäume mit der angegebenen Fruktifikationsintensität über 60\% liegt (Code 4 oder 5).

Der Verifikator wird durch das Zählen von Früchten unter Nutzung eines Fernglases erfasst (als Durchschnitt von drei Zählrunden). Jede Zählrunde besteht aus der Anzahl der Früchte, die der Beobachter in 30 Sekunden zählt. Bei allen Bäumen sollte das gleiche Kronendrittel untersucht werden. Sobald ein Kronendrittel für die Beobachtung ausgewählt wurde, sollte dieses für jede weitere Erhebung dieses Verifikators ausgewählt werden. Für die Zählung wird das obere Kronendrittel dem unteren und mittleren Drittel vorgezogen.

Es werden zwei Werte erfasst: die Anzahl der Früchte und das untersuchte Kronendrittel.

\begin{tabular}{l} 
Anzahl der in 30 Sekunden gezählten Früchte (Mittelwert aus 3 Zählrunden) \\
\hline
\end{tabular}

\section{Code Untersuchtes Kronendrittel}

\begin{tabular}{ll}
\hline 1 & unteres Kronendrittel \\
\hline 2 & mittleres Kronendrittel \\
\hline 3 & oberes Kronendrittel \\
\hline
\end{tabular}

\subsubsection{Abundanz der Naturverjüngung}

Dieser Verifikator beschreibt das Vorhandensein und die Häufigkeit von Naturverjüngung auf der Monitoringfläche.

\subsubsection{Basisniveau}

Der Verifikator wird jährlich im Herbst auf Bestandesebene erfasst. Für die Schätzung der Situation auf der gesamten Monitoringfläche werden Expertenmeinungen herangezogen. Es sollten zwei Werte erfasst werden: einer für neue aufgelaufene Naturverjüngung (diesjährige Keimlinge) und einer für etablierte Naturverjüngung (Sämlinge und junge Bäume, die den neuen Bestand bilden werden).

\begin{tabular}{ll} 
Code Beschreibung: neue aufgelaufene Naturverjüngung (diesjährige Keimlinge) \\
\hline $1 a \quad$ Auf der Monitoringfläche gibt es keine oder nur sehr wenig neue Naturverjüngung \\
\hline 2a $\quad$ Auf der Monitoringfläche ist in ausreichender Anzahl neue Naturverjüngung vorhanden \\
\hline
\end{tabular}

Code Beschreibung: etablierte Naturverjüngung (Sämlinge)

1b Auf der Monitoringfläche gibt es keine oder nur sehr wenig etablierte Naturverjüngung

2b Auf der Monitoringfläche ist in ausreichender Anzahl etablierte Naturverjüngung vorhanden 


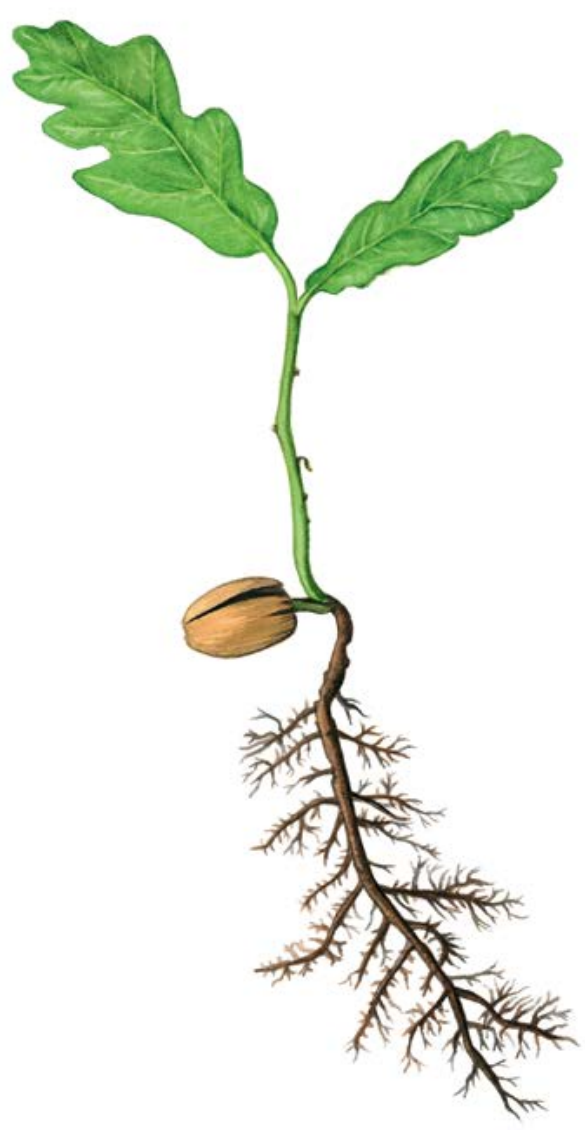

Abbildung 8: Ein einjähriger Eichensämling.

\subsubsection{Standardniveau}

Der Verifikator wird durch Zählung der Sämlinge im 1. und 6. Herbst nach jedem bewerteten Fruktifikationsereignis erfasst (das Jahr des Fruktifikationsereignisses wird als Jahr 0 betrachtet).

Eichen haben keine Samenruhe und können bereits im folgenden Jahr keimen. Da Mastjahre von Stiel- und Traubeneiche etwa alle 5 bis 7 Jahre auftreten, erfolgt das nächste Monitoring der Naturverjüngung nach dem nächsten Mastjahr (etwa 5 bis 7 Jahre nach Einrichtung der vorherigen NV-Plots).

Zählung der Naturverjüngung:

Nach der Einrichtung der NV-Plots werden alle Eichensämlinge in den NV-Plots gezählt. Ältere Eichenjungpflanzen, die in den NV-Plots vorhanden sind, dürfen nicht mitgezählt werden. Bei der nächsten Zählung sind nur die Eichenjungpflanzen im entsprechenden Alter zu zählen; d.h. im 6. Jahr alle 5 Jahre alten Eichen.

\section{Anzahl der Jungpflanzen auf einem NV-Plot}

\section{$\mathrm{x}$}

Die Mortalität/Überlebensrate der Naturverjüngung wird anhand der für diesen Verifikator erfassten Werte berechnet.

Zur Einrichtung von NV-Plots siehe Kapitel 6.2 Einrichtung von Naturverjüngungs-Plots.

\subsubsection{Intensivniveau}

Der Verifikator wird durch das Zählen der Sämlinge im 1., 6., 11. und 16. Herbst nach jedem bewerteten Fruktifikationsereignis erfasst (das Jahr des Fruktifikationsereignisses wird als Jahr 0 betrachtet). 
Tabelle 3: Zeitstrahl zur Erfassung der Abundanz der Naturverjüngung (NV). In diesem Beispiel findet das erste Fruktifikationsereignis im 2. Jahr des Beobachtungsjahrzehnts statt; das zweite erfasste Fruktifikationsereignis fünf Jahre später, d.h. im 7. Jahr des Monitorings. Nach jedem bewerteten Fruktifikationsereignis werden 20 neue NV-Plots angelegt. Die Erfassung der NV-Abundanz auf jedem Set von 20 NV-Plots erfolgt alle fünf Jahre. Die zur jeweils erfassten NV gehörigen Fruktifikationsereignisse und der Verlauf der Monitoringaktivitäten sind in derselben Farbe schattiert. Nach der letzten Runde der NV-Zählung wird das Monitoring der NV-Abundanz auf dem entsprechenden Set von NV-Plots eingestellt und die jeweiligen NV-Plots werden aufgelöst. S - Standardniveau; I - Intensivniveau.

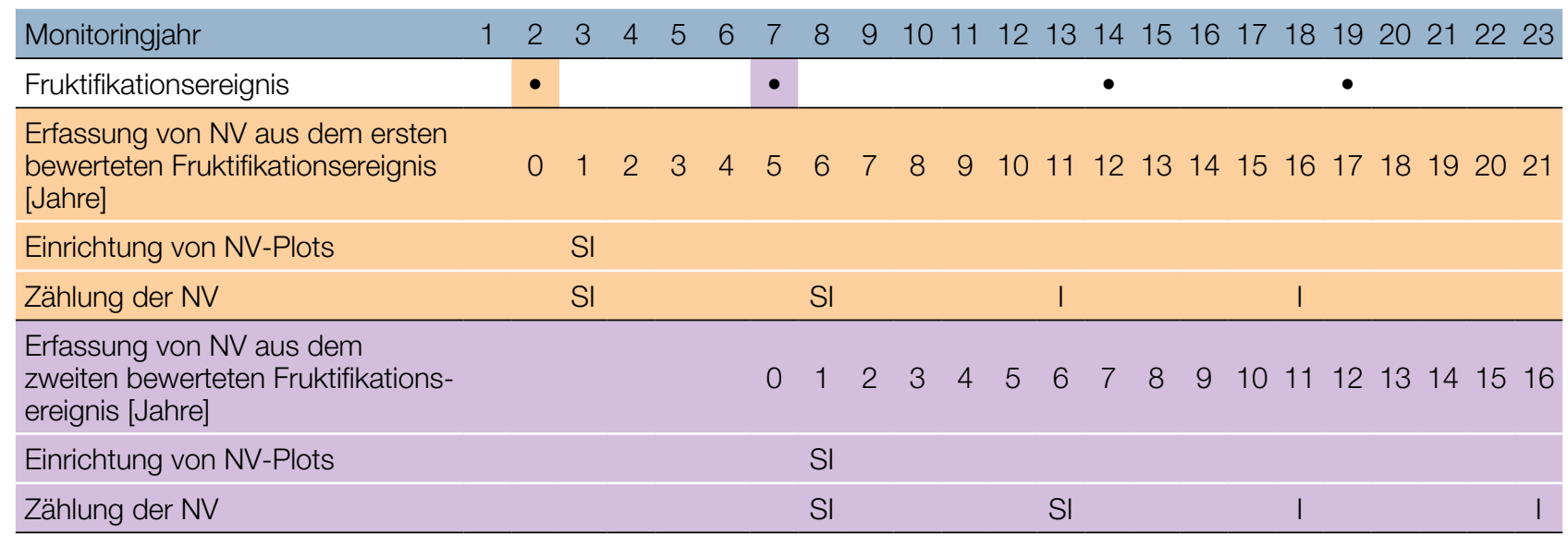

Die Mortalität/Überlebensrate der Naturverjüngung wird anhand der für diesen Verifikator erfassten Werte berechnet.

Zur Einrichtung von NV-Plots siehe Kapitel 6.2 Einrichtung von Naturverjüngungs-Plots; zur Zählung der NV siehe Kapitel 7.1.4.2 Standardniveau.

\subsection{Verfahren zur Erfassung von Hintergrundinformationen}

\subsubsection{Durchmesserklassenverteilung}

\subsubsection{Standard- und Intensivniveau}

Der BHD wird alle 10 Jahre für alle 50 Beobachtungsbäume auf Einzelbaumebene erfasst. Der BHD ist der Stammdurchmesser in 1,30 m Höhe, d.h. ungefähr auf Brusthöhe eines Erwachsenen. Hat der Baum mehr als einen Stamm, messen Sie bitte alle Stämme und erfassen Sie den Durchschnitt (versuchen Sie jedoch, Bäume mit vielen kleinen Stämmen zu vermeiden). Notieren Sie in den Anmerkungen, dass der Baum mehrstämmig ist, und geben Sie die Anzahl der gemessenen Stämme an. Ist der Baum geneigt, messen Sie den BHD senkrecht zum Baumstamm. Der BHD kann auf zwei Arten gemessen werden:

1) mit einer Kluppe; in diesem Fall messen Sie senkrecht zueinander zwei Durchmesser und berechnen den Mittelwert

2) Messen Sie den Umfang des Baumes und berechnen Sie daraus den Durchmesser (d.h. dividieren Sie durch $\pi ; \sim 3,14)$

Der BHD wird in cm angegeben. Für nachfolgende Messungen ist stets dieselbe Methode anzuwenden.

\subsubsection{Höhenklassenverteilung}

\subsubsection{Standard- und Intensivniveau}

Die Baumhöhe wird alle 10 Jahre für alle 50 Beobachtungsbäume auf Einzelbaumebene erfasst. Die Höhe wird vom Boden bis zum höchsten Punkt der Krone gemessen, idealerweise mit einem Klinometer oder Hypsometer (z.B. Vertex). Die Höhe wird in Metern auf eine Dezimalstelle angegeben. Ist die Krone beschädigt, muss dies in den Anmerkungen zusammen mit dem mutmaßlichen Grund für den Schaden notiert werden. 


\subsubsection{Austrieb}

Diese Hintergrundinformation beschreibt die Austriebsstadien. Die Aufzeichnung erfolgt nur auf Standard- und Intensivniveau. Bei Stiel- und Traubeneiche beginnt der Austrieb zusammen mit der Blüte (Q. robur ca. zwei Wochen vor $Q$. petraea). Die Daten für diese Hintergrundinformation sollten in Mitteleuropa im April und Mai erhoben werden, bis alle Beobachtungsbäume voll entwickelte Blätter haben. Nach warmen Wintern erfolgt der Austrieb früher.

\subsubsection{Standardniveau}

Auf Standardniveau wird der Austrieb alle 5 Jahre für alle 50 Beobachtungsbäume auf Einzelbaumebene beobachtet. Gesucht werden der Beginn der Knospenöffnung (Stadium 3) und das Ende der Blattentfaltung (Stadium 5). Die Beobachtungen werden beendet, wenn alle Bäume das Stadium 5 erreicht haben. In der Regel sind dafür 6 Begehungen erforderlich. Für jeden Baum werden zwei Werte erfasst: das Austriebsstadium und der entsprechende Kronenanteil. Die Austriebsstadien sind in Abbildung 9 dargestellt.

\begin{tabular}{|c|c|}
\hline \multicolumn{2}{|c|}{ Code Austriebsstadium } \\
\hline 1 & Knospen noch vollständig geschlossen (kein Grün sichtbar) \\
\hline 2 & beginnende Knospenöffnung (erstes Grün ist sichtbar) \\
\hline 3 & gefaltete und behaarte Blätter erscheinen; einzeln sichtbare gefaltete und behaarte Blätter \\
\hline 4 & Blätter vollständig entfaltet, glatt und hellgrün \\
\hline
\end{tabular}

\begin{tabular}{lr} 
Code Anteil der Krone mit dem entsprechenden Austriebsstadium (\%) & $>0-33$ \\
\hline 1 & $>33-66$ \\
\hline 2 & $>66-99$ \\
\hline 3 & 100 \\
\hline 4 & \\
\hline
\end{tabular}

\subsubsection{Intensivniveau}

Auf Intensivniveau wird der Austrieb jährlich für alle 50 Beobachtungsbäume auf Einzelbaumebene erhoben, mit derselben Verfahrensweise wie auf Standardniveau. Details dazu sind im Kapitel 7.2.3.1 Standardniveau zu finden.

\subsubsection{Seneszenz}

Die Seneszenz beschreibt den Prozess der Blattalterung. Die Erfassung dieser Hintergrundinformation erfolgt nur auf dem Standard- und Intensivniveau. 
1

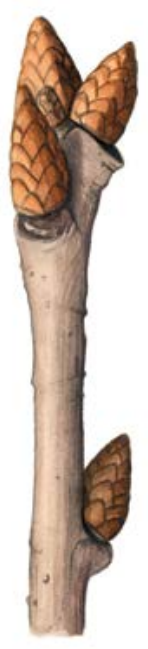

2

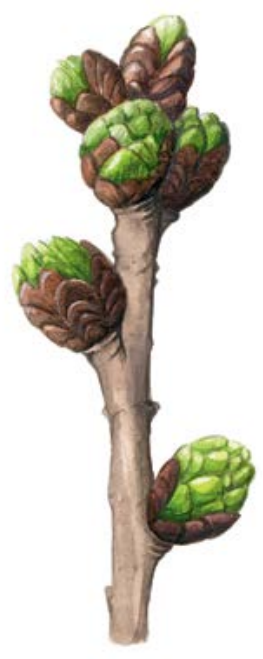

3

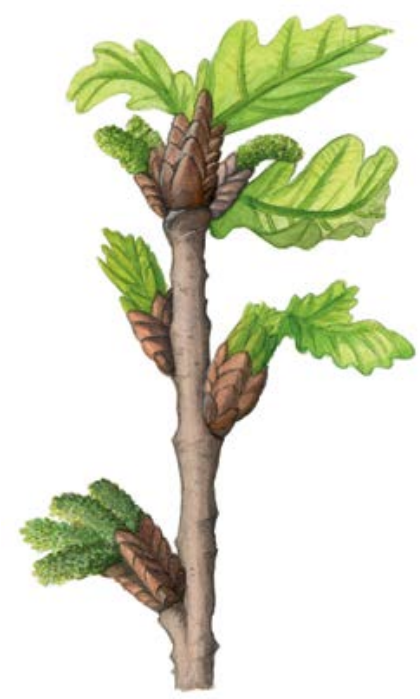

4

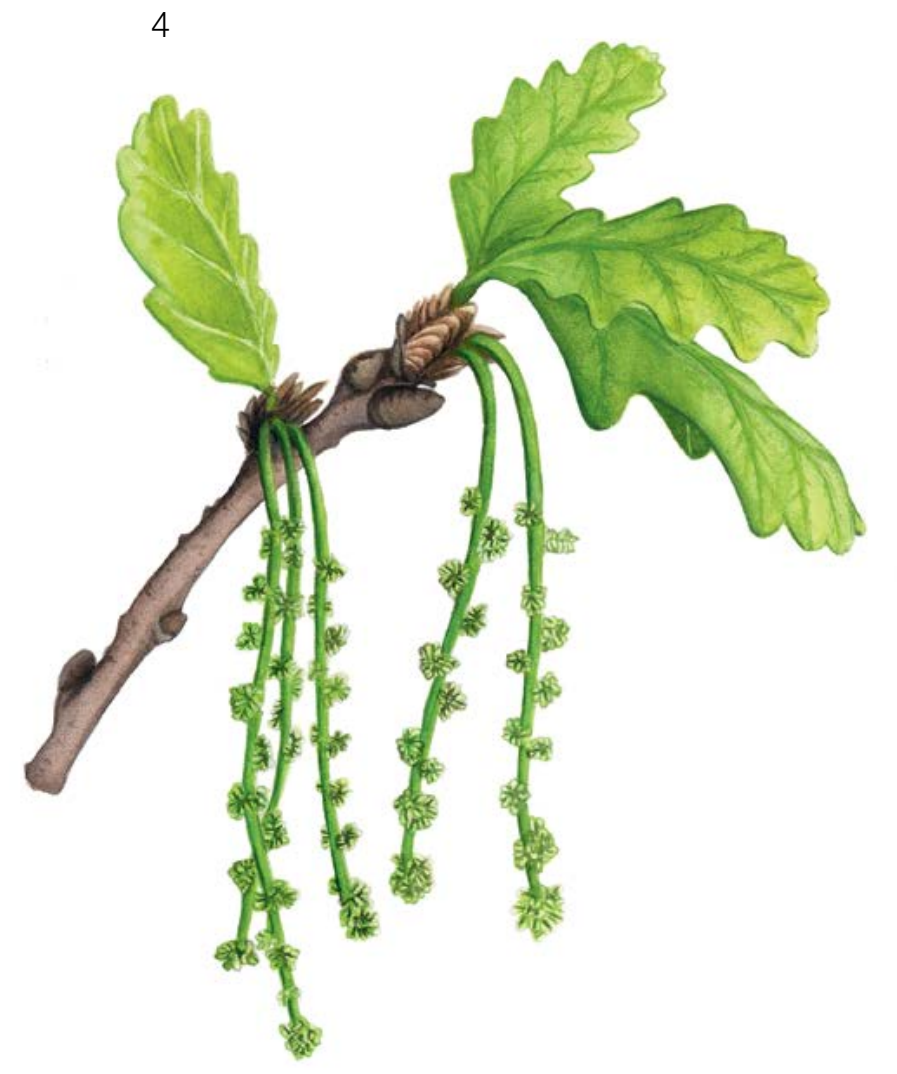

Abbildung 9: Illustration zur Beschreibung der Hintergrundinformation „Austrieb“ auf Standard- und Intensivniveau. 


\subsubsection{Standardniveau}

Auf Standardniveau wird die Seneszenz alle 5 Jahre für alle 50 Beobachtungsbäume auf Einzelbaumebene beobachtet. Gesucht wird das Stadium 3, wenn die Blätter gelb sind und keine Photosynthese mehr betreiben. Die Beobachtungen enden, wenn alle Bäume das Stadium 3 erreicht haben. Normalerweise sind dafür zwei Begehungen der Monitoringfläche erforderlich. Für jeden Baum werden zwei Werte erfasst: das Stadium der Seneszenz und der entsprechende Kronenanteil. Die Stadien der Seneszenz sind in Abbildung 6 dargestellt.

\begin{tabular}{|c|c|}
\hline Cod & Stadium der Seneszenz \\
\hline 1 & Blätter sind grün \\
\hline 2 & Blattfarbe wechselt von grün zu gelb (grünlich-gelb) \\
\hline 3 & Blattfarbe wechselt von gelb zu braun (bräunlich) \\
\hline 4 & Blätter sind braun / abgefallen \\
\hline
\end{tabular}

\begin{tabular}{lr} 
Code Anteil der Krone mit dem entsprechenden Seneszenzstadium (\%) & $>0-33$ \\
\hline 1 & $>33-66$ \\
\hline 2 & $>66-99$ \\
\hline 3 & 100 \\
\hline 4 & \\
\hline
\end{tabular}

\subsubsection{Intensivniveau}

Auf Intensivniveau wird die Seneszenz jährlich für alle 50 Beobachtungsbäume auf Einzelbaumebene erfasst, mit derselben Verfahrensweise wie auf Standardniveau. Details dazu sind im Kapitel 7.2.4.1 Standardniveau zu finden.

Formular für die Beschreibung der Monitoringfläche: 'FGM Plot description'

Formular für die Erfassung der Verifikatoren: 'Form for recording field level verifiers within FGM'

Formular für die Aufzeichnung von Hintergrundinformationen: 'Form for recording field level background information within FGM' 


\section{Quellen}

1. Breznikar A (1997) Morfološka in fenološka variabilnost doba (Quercus robur L.) in gradna (Quercus petraea (Matt.) Liebl.) na robnih območjih njunih naravnih habitatov v severovzhodni Sloveniji/Morphological and phenological variability of pedunculate oak (Quercus robur L.) and sessile oak (Quercus petraea (Matt.) Liebl.) at the edge of their natural habitats in northeastern Slovenia. Master Thesis, Biotechnical Faculty, University of Ljubljana. http://eprints. gozdis.si/800/1/Breznikar,Horvat-Marlot_1998.pdf. Accessed 10 September 2020

2. Brus R. (2005) Dendrologija za gozdarje/Dendrology for foresters. Biotehniška fakulteta, University of Ljubljana, Ljubljana

3. Ballian D, Memišević-Hodžić M (2016) Varijabilnost hrasta lužnjaka (Quercus robur L.) u Bosni i Hercegovini/Variability of the pedunculate oak (Quercus robur L.) in Bosnia and Herzegovina. Silva Slovenica - Slovenian Forestry Institute, Ljubljana

4. Eriksson G (2015) Quercus petraea and Quercus robur - Recent Genetic Research. Silva Slovenica - Slovenian Forestry Institute, Ljubljana

5. Ducousso A, Bordacs S (2004) EUFORGEN Technical Guidelines for genetic conservation and use for pedunculate and sessile oaks (Quercus robur and Q. petraea). International Plant Genetic Resources Institute, Rome

6. Ducousso A, Michaud H, Lumaret R (1993) Reproduction and gene flow in the genus Quercus L. Ann Sci For 50(1):91 - 106. https://doi.org/10.1051/forest:19930708

7. Eaton E, Caudullo G, Oliveira S, de Rigo D (2016) Quercus robur and Quercus petraea in Europe: distribution, habitat, usage and threats. In: San-Miguel-Ayanz J, de Rigo D, Caudullo G, Houston Durrant T, Mauri A (eds.) European Atlas of Forest Tree Species. Publ. Off. EU, Luxembourg, pp e01c6df+. https://ies-ows.jrc.ec.europa.eu/efdac/download/ Atlas/pdf/Quercus_robur_petraea.pdf. Accessed 15 October 2020

8. Kraigher H (2001) Semenarski praktikum. Skripta za strokovni seminar o gozdnem semenarstvu in predmet podiplomskega študija fiziologija gozdnega drevja/Seed technology practicum. A script for seminar on seed technology in forestry and for the course in postgraduate studies program on physiology of forest tree species. Slovenian Forestry Institute. Ljubljana

9. Kraigher H, Bogovič M, Westergren M (2010) Tehnične smernice za ohranjanje in rabo genskih virov : hrasti = Quercus spp. : Slovenija/Technical guidelines for conservation and use of forest genetic resources: Oak = Quercus spp.: Slovenia. Gozdarski vestnik 68(3):167-174

Die folgenden Ressourcen wurden für die derzeit akzeptierten (Dezember 2020) wissenschaftlichen Namen der in diesem Dokument erfassten oder erwähnten Arten konsultiert:

a. CABI (2020) Invasive Species Compendium. CAB International, Wallingford, UK. www.cabi.org/isc. Accessed 15 December 2020

b. EPPO (2020) EPPO Global Database (available online). https://gd.eppo.int. Accessed 15 December 2020

c. GBIF (2020) Global Biodiversity Information Facility. https://www.gbif.org Accessed 15 December 2020

d. IPNI (2020) International Plant Names Index. The Royal Botanic Gardens, Kew, Harvard University Herbaria \& Libraries \& Australian National Botanic Gardens. http://www.ipni.org, Accessed 10 December 2020

e. National Center for Biotechnology Information (NCBI) (1998) National Library of Medicine (US), National Center for Biotechnology Information, Bethesda (MD). https://www.ncbi.nlm.nih.gov/. Accessed 15 December 2020

f. Stevens PF (2001) Angiosperm Phylogeny Website, Version 14. http://www.mobot.org/MOBOT/research/APweb/. Accessed 15 December 2020

g. The Plant List (2013) Version 1.1. http://www.theplantlist.org/. Accessed 12 December 2020

h. Tropicos.org (2020) Missouri Botanical Garden. http://www.tropicos.org. Accessed 15 December 2020

i. WFO (2020) World Flora Online. http://www.worldfloraonline.org. Accessed 15 December 2020 



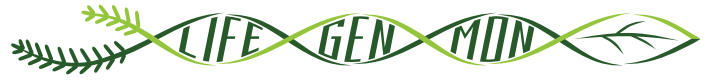

Handbuch zum Forstgenetisches Monitoring

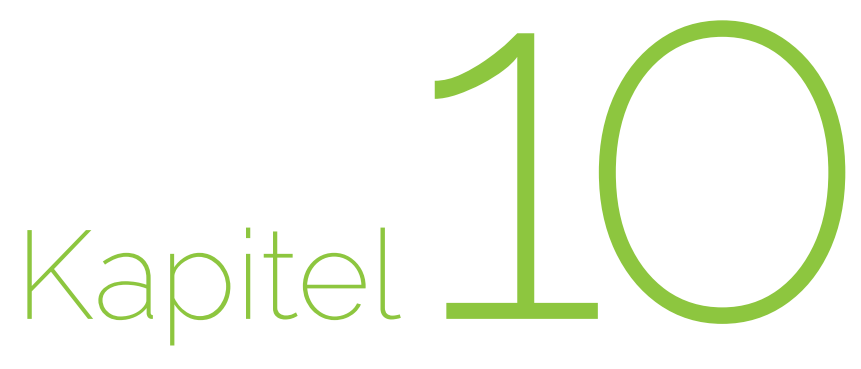

ANHANG 


\subsection{DESCRIPTION OF DESIGNATION AND MAPS OF MONITORING REGIONS (SUPPLEMENTARY MATERIALS FOR CHAPTER 2: PLOT SELECTION)}

In the cascade of the FGM implementation process, the identification of FGM regions is a priority. Within LIFEGENMON, the delineation of FGM regions has been carried out by a joint data-driven and expert-based approach, in a NW to SE transect spanning from Bavaria to Greece.

This approach is founded upon the representative coverage of environmental zones, the coverage of characterised races or ecotypes, the inclusion of marginal and peripheral populations, the presence of already assigned GCUs, the levels of standing genetic variation (if known), the coverage of standing genetic structure/recolonisation routes, the relevant results of provenance trials (if available), and expert knowledge.

Seven priority species with contrasting biology, ecology and distributional properties were employed: Abies alba/A. borisii-regis complex, Fagus sylvatica, Fraxinus excelsior, Pinus nigra, Populus nigra, Prunus avium, and Quercus robur/Q. petraea complex. Six to nine monitoring regions per species/species complex were recognised and are presented below.

The monitoring regions as delineated within the LIFEGENMON project are valid for the transect from Bavaria to mainland Greece. If a wider, pan-European, area was assessed, the monitoring regions might be delineated differently. 


\section{Monitoring regions for firs (Abies alba Mill./ Abies borisii-regis Mafft.)}

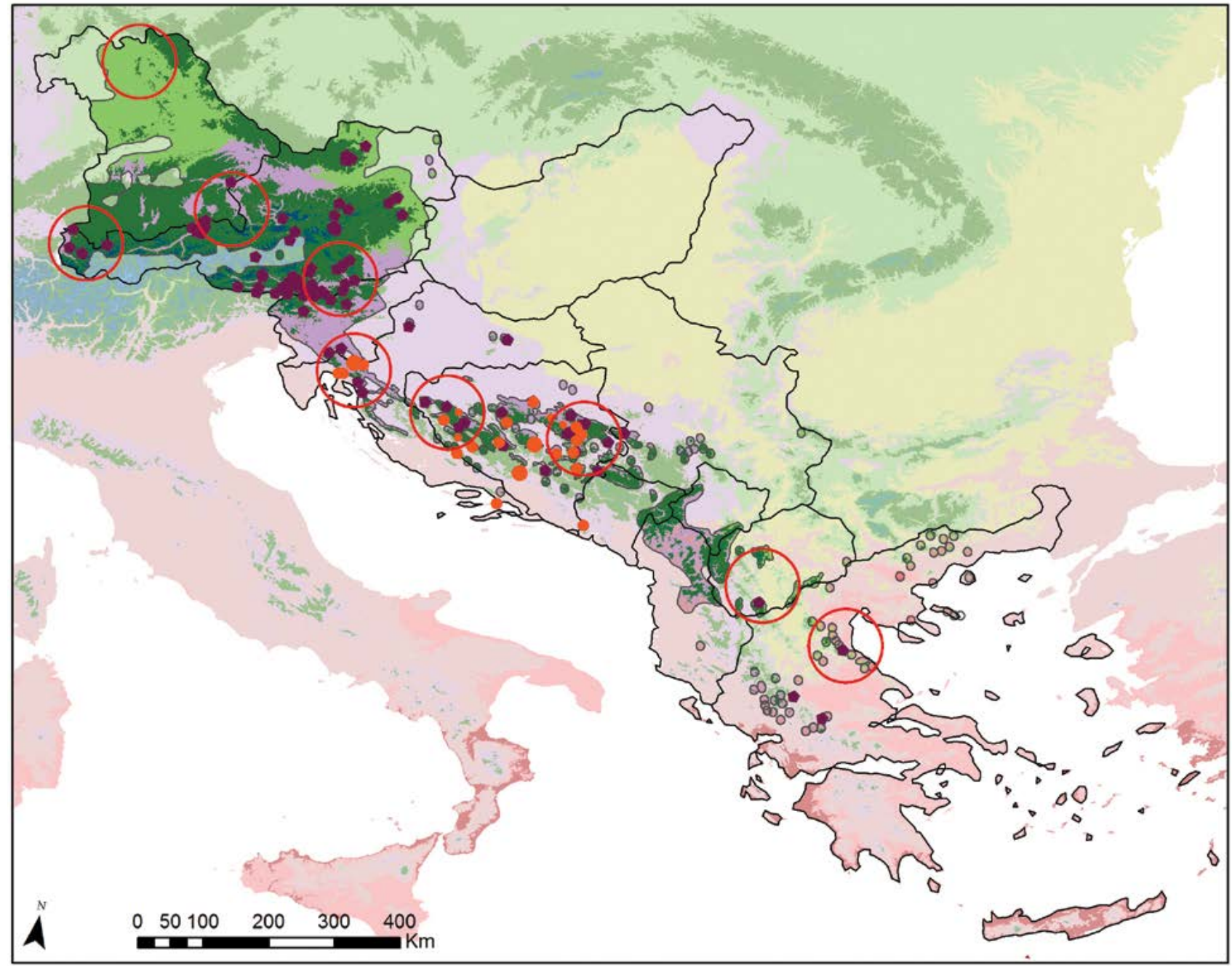

\section{Legend}

\section{Global Environmental Zone}

B. Arctic

C. Extremely cold and wet

D. Extremely cold and wet

E. Cold and wet

F. Extremely cold and mesic

G. Cold and mesic

H. Cool temperate and dry

J. Cool temperate and moist

I. Cool temperate and xeric

K. Warm temperate and mesic

L. Warm temperate and xeric

N. Hot and dry

\section{Monitoring Region}

- EUFGIS GCU

\section{He (isoenzymes)}

- $0.12-0.14$

- $0.14-0.16$

$0.16-0.18$

This map was created within the LIFEGENMON project to show the forest genetic monitoring regions for the transect spanning from Bavaria to Greece. We acknowledge the data sources: Global Environmental Zones (Metzger et al. 2012, Global Ecol. Biogeogr); Species distribution range (www.euforgen.org); EUFGIS Dynamic Gene Conservation Units (EUFORGEN, the EUFGIS project and National Focal Points) and genetic data (published studies available from the LIFEGENMOM project by request). Although a part of the transect, Albania was excluded from monitoring regions delineation as no data was available for this country. 


\section{Monitoring regions for European beech (Fagus sylvatica)}

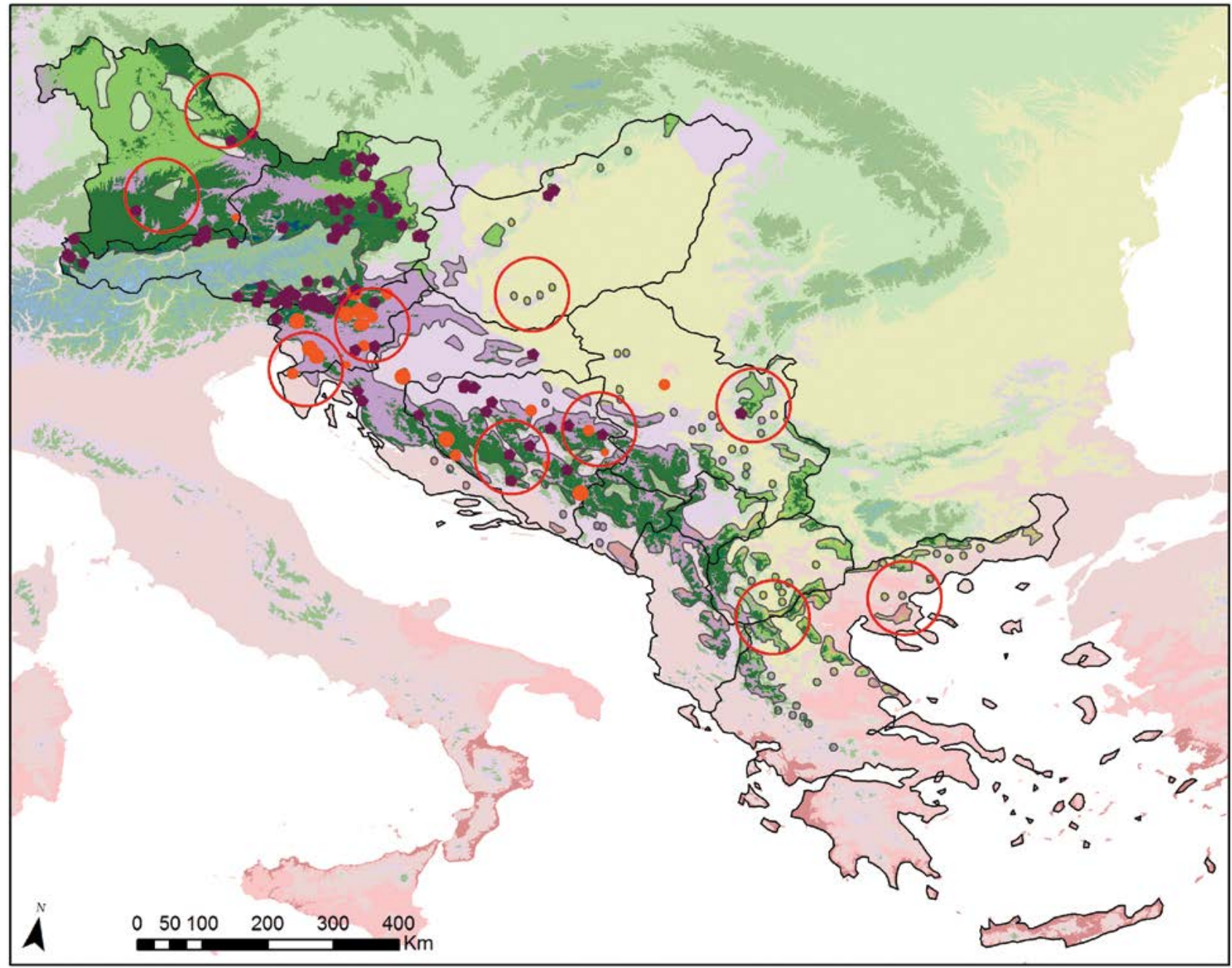

\section{Legend}

\section{Global Environmental Zone}
B. Arctic
C. Extremely cold and wet
D. Extremely cold and wet
E. Cold and wet
F. Extremely cold and mesic
G. Cold and mesic
H. Cool temperate and dry
J. Cool temperate and moist
I. Cool temperate and xeric
K. Warm temperate and mesic
L. Warm temperate and xeric
N. Hot and dry

Monitoring Region

- EUFGIS GCU

\section{He (isoenzymes)}

- $0.21-0.23$

- $0.23-0.25$

$0.25-0.28$

This map was created within the LIFEGENMON project to show the forest genetic monitoring regions for the transect spanning from Bavaria to Greece. We acknowledge the data sources: Global Environmental Zones (Metzger et al. 2012, Global Ecol. Biogeogr); Species distribution range (www.euforgen.org); EUFGIS Dynamic Gene Conservation Units (EUFORGEN, the EUFGIS project and National Focal Points) and genetic data (published studies available from the LIFEGENMOM project by request). Although a part of the transect, Albania was excluded from monitoring regions delineation as no data was available for this country. 


\section{Monitoring regions for common ash (Fraxinus excelsior)}

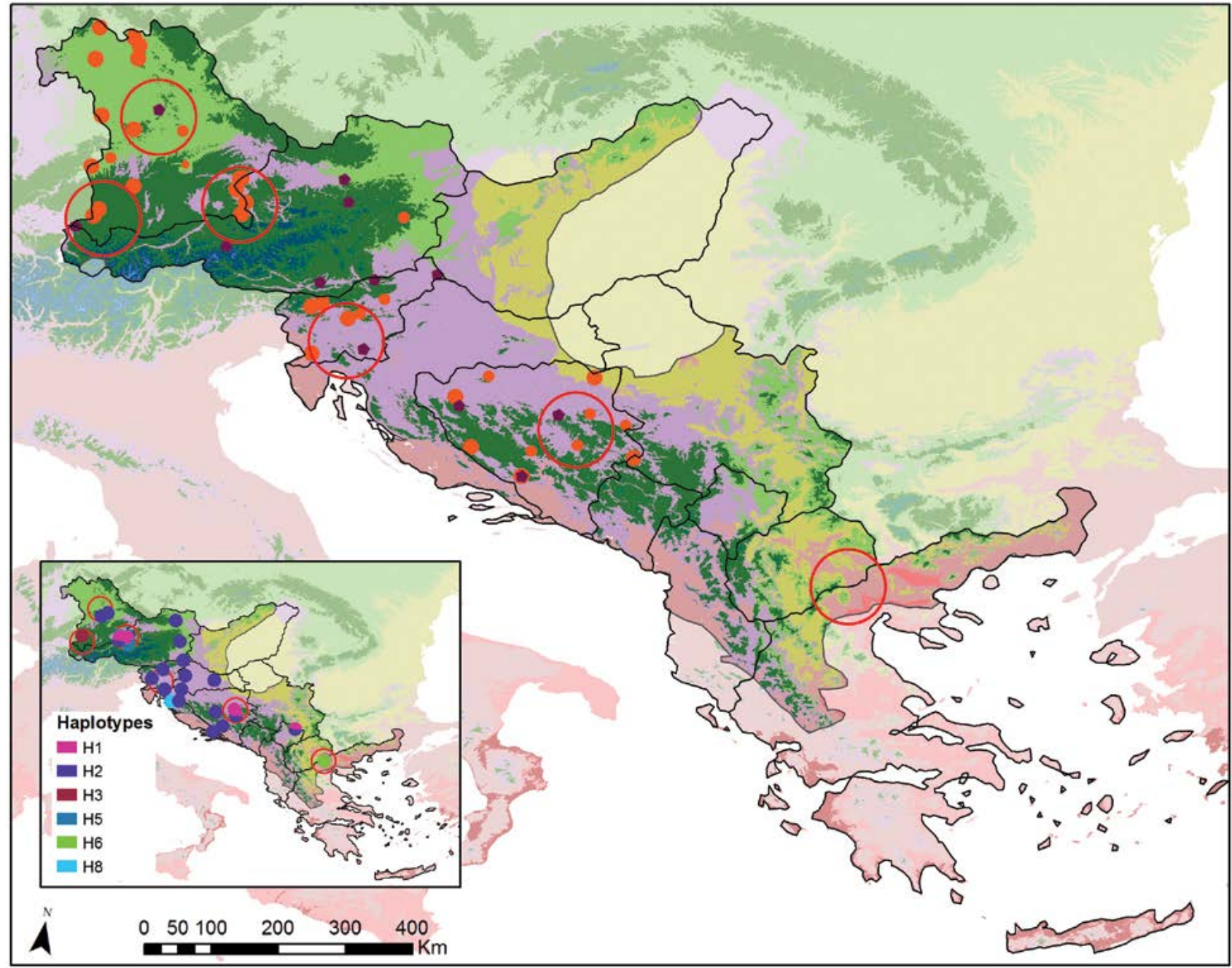

\section{Legend}

\section{Global Environmental Zone}

B. Arctic

C. Extremely cold and wet

D. Extremely cold and wet

E. Cold and wet

F. Extremely cold and mesic

G. Cold and mesic

H. Cool temperate and dry

J. Cool temperate and moist

I. Cool temperate and xeric

K. Warm temperate and mesic

L. Warm temperate and xeric

N. Hot and dry
Monitoring Region

- EUFGIS GCU

\section{He (isoenzymes)}

- $0.85-0.72$

$0.72-0.79$

$0.79-0.88$

This map was created within the LIFEGENMON project to show the forest genetic monitoring regions for the transect spanning from Bavaria to Greece. We acknowledge the data sources: Global Environmental Zones (Metzger et al. 2012, Global Ecol. Biogeogr); Species distribution range (www.euforgen.org); EUFGIS Dynamic Gene Conservation Units (EUFORGEN, the EUFGIS project and National Focal Points) and genetic data (published studies available from the LIFEGENMOM project by request). Although a part of the transect, Albania was excluded from monitoring regions delineation as no data was available for this country. 


\section{Monitoring regions for black pine (Pinus nigra)}

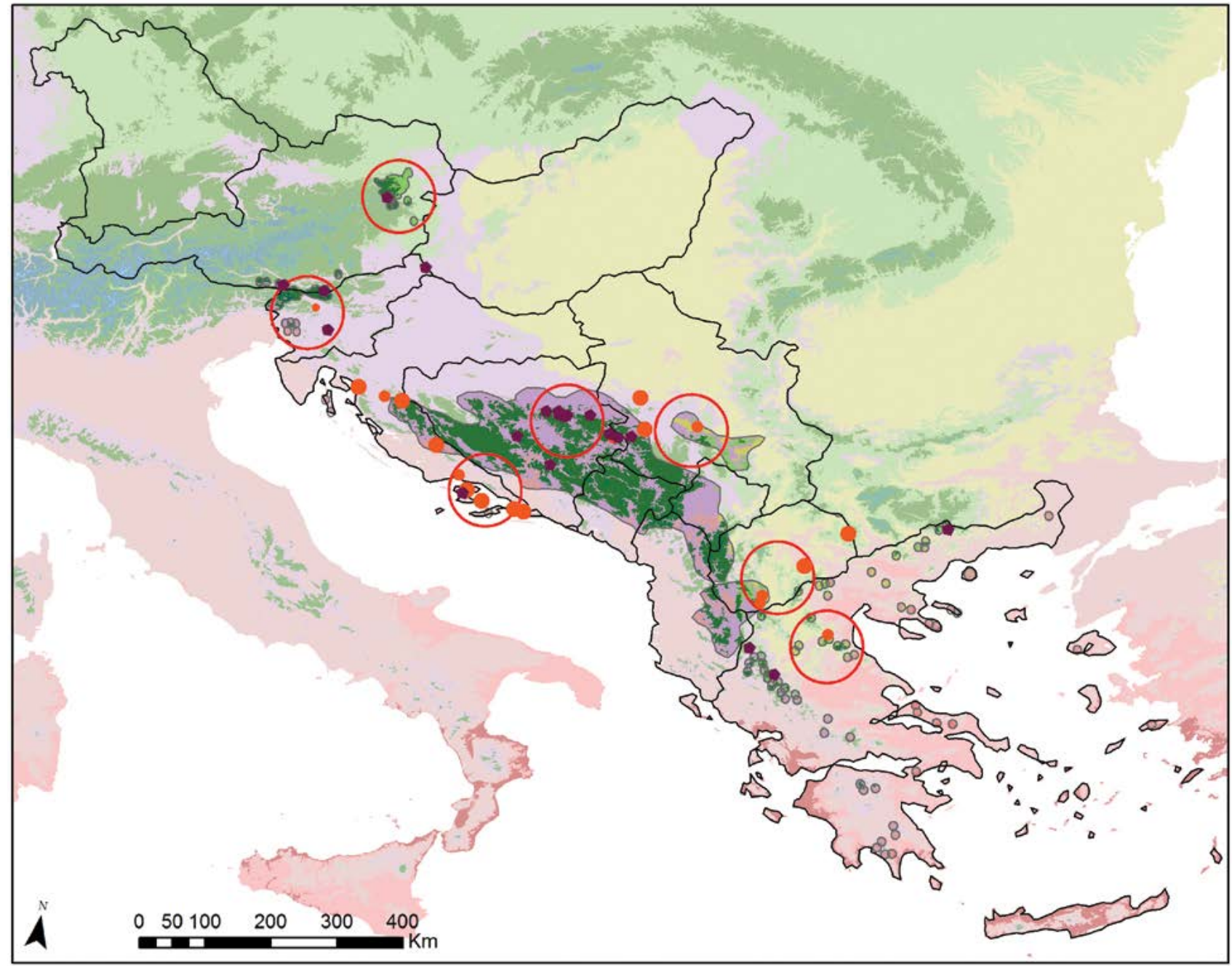

\section{Legend}

\section{Global Environmental Zone}

B. Arctic

C. Extremely cold and wet

D. Extremely cold and wet

E. Cold and wet

F. Extremely cold and mesic

G. Cold and mesic

$\mathrm{H}$. Cool temperate and dry

J. Cool temperate and moist

I. Cool temperate and xeric

K. Warm temperate and mesic

L. Warm temperate and xeric

N. Hot and dry
Monitoring Region

- EUFGIS GCU

\section{He (isoenzymes)}

- $0.00-0.12$

- $0.12-0.24$

$0.24-0.36$

This map was created within the LIFEGENMON project to show the forest genetic monitoring regions for the transect spanning from Bavaria to Greece. We acknowledge the data sources: Global Environmental Zones (Metzger et al. 2012, Global Ecol. Biogeogr); Species distribution range (www.euforgen.org); EUFGIS Dynamic Gene Conservation Units (EUFORGEN, the EUFGIS project and National Focal Points) and genetic data (published studies available from the LIFEGENMOM project by request). Although a part of the transect, Albania was excluded from monitoring regions delineation as no data was available for this country. 


\section{Monitoring regions for black poplar (Populus nigra)}

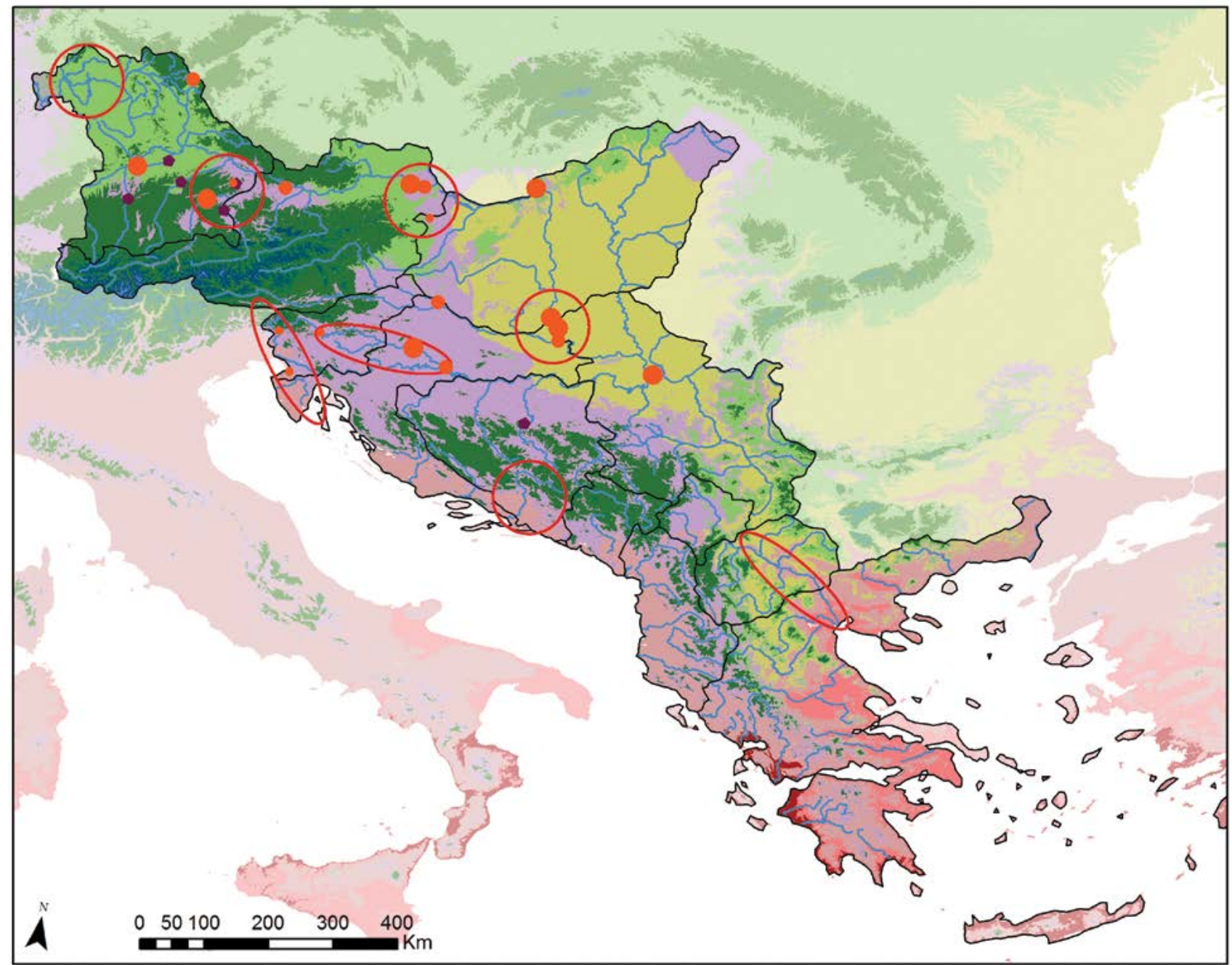

\section{Legend}

\section{Global Environmental Zone}
B. Arctic
C. Extremely cold and wet
D. Extremely cold and wet
E. Cold and wet
F. Extremely cold and mesic
G. Cold and mesic
$\mathrm{H}$. Cool temperate and dry
J. Cool temperate and moist
I. Cool temperate and xeric
K. Warm temperate and mesic
L. Warm temperate and xeric
N. Hot and dry

\section{Monitoring Region}

- EUFGIS GCU

\section{He (isoenzymes)}

- $0.74-0.77$

$0.77-0.80$

$0.80-0.83$

This map was created within the LIFEGENMON project to show the forest genetic monitoring regions for the transect spanning from Bavaria to Greece. We acknowledge the data sources: Global Environmental Zones (Metzger et al. 2012, Global Ecol. Biogeogr); Species distribution range (www.euforgen.org); EUFGIS Dynamic Gene Conservation Units (EUFORGEN, the EUFGIS project and National Focal Points) and genetic data (published studies available from the LIFEGENMOM project by request). Although a part of the transect, Albania was excluded from monitoring regions delineation as no data was available for this country. 


\section{Monitoring regions for wild cherry (Prunus avium)}

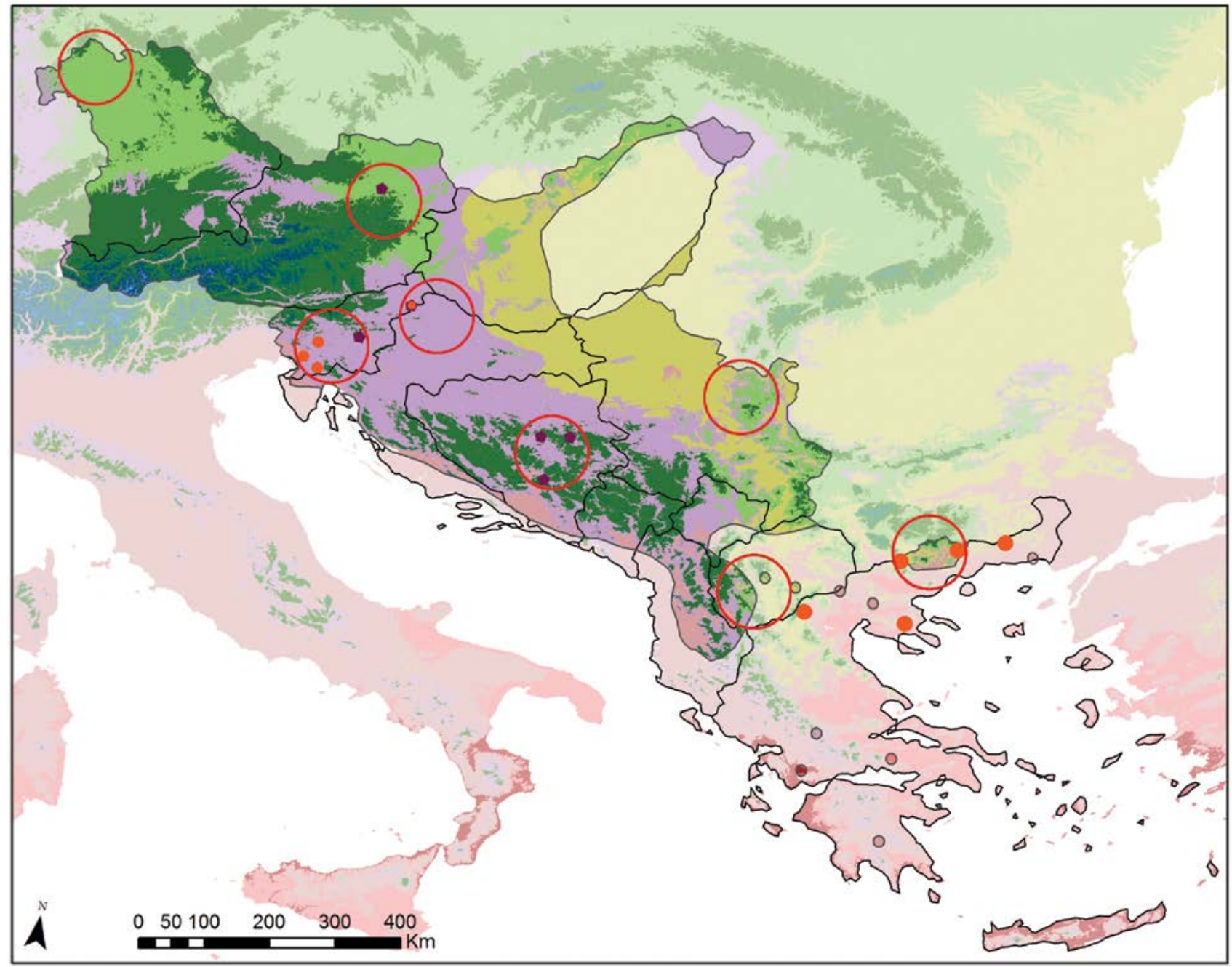

\section{Legend}

\section{Global Environmental Zone}
B. Arctic
C. Extremely cold and wet
D. Extremely cold and wet
E. Cold and wet
F. Extremely cold and mesic
G. Cold and mesic
H. Cool temperate and dry
J. Cool temperate and moist
I. Cool temperate and xeric
K. Warm temperate and mesic
L. Warm temperate and xeric
N. Hot and dry

\section{Monitoring Region}

- EUFGIS GCU

\section{He (isoenzymes)}

- $0.57-0.63$

- $0.63-0.70$

$0.70-0.77$

This map was created within the LIFEGENMON project to show the forest genetic monitoring regions for the transect spanning from Bavaria to Greece. We acknowledge the data sources: Global Environmental Zones (Metzger et al. 2012, Global Ecol. Biogeogr); Species distribution range (www.euforgen.org); EUFGIS Dynamic Gene Conservation Units (EUFORGEN, the EUFGIS project and National Focal Points) and genetic data (published studies available from the LIFEGENMOM project by request). Although a part of the transect, Albania was excluded from monitoring regions delineation as no data was available for this country. 


\section{Monitoring regions for oaks (Quercus robur, Quercus petraea)}

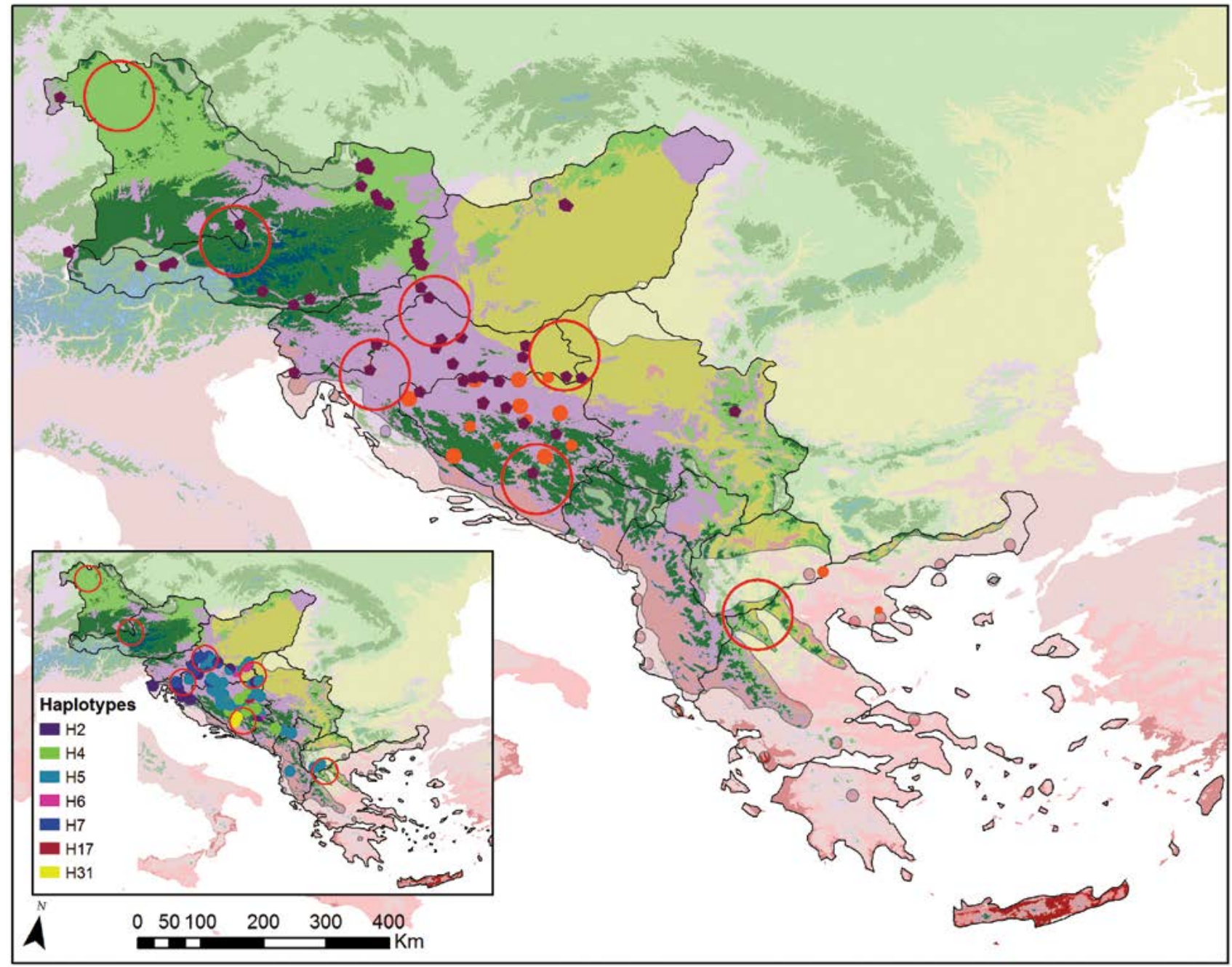

\section{Legend}

\section{Global Environmental Zone}
B. Arctic
C. Extremely cold and wet
D. Extremely cold and wet
E. Cold and wet
F. Extremely cold and mesic
G. Cold and mesic
H. Cool temperate and dry
J. Cool temperate and moist
I. Cool temperate and xeric
K. Warm temperate and mesic
L. Warm temperate and xeric
N. Hot and dry

\section{$\bigcirc$ Monitoring Region}

- EUFGIS GCU

\section{He (isoenzymes)}

- $0.78-0.82$

$0.82-0.85$

$0.85-0.89$

This map was created within the LIFEGENMON project to show the forest genetic monitoring regions for the transect spanning from Bavaria to Greece. We acknowledge the data sources: Global Environmental Zones (Metzger et al. 2012, Global Ecol. Biogeogr); Species distribution range (www.euforgen.org); EUFGIS Dynamic Gene Conservation Units (EUFORGEN, the EUFGIS project and National Focal Points) and genetic data (published studies available from the LIFEGENMOM project by request). Although a part of the transect, Albania was excluded from monitoring regions delineation as no data was available for this country. 


\section{Additional data contributors}

Vlatko ANDONOVSKI ${ }^{1}$, Evangelia V. AVRAMIDOU ${ }^{2,3}$, Roland BAIER ${ }^{4}$, Sandor BORDAC ${ }^{5}$, Andrej BREZNIKAR ${ }^{6}$, Ioannis V. GANOPOULOS², Mladen IVANKOVIĆ 7 , Davorin KAJBA ${ }^{8}$, Heino KONRAD ${ }^{9}$, Ermioni MALLIAROU², Saša ORLOVIĆ ${ }^{10}$, Srđan STOJNIĆ ${ }^{10}$

\footnotetext{
Affiliations:

1. Faculty of Forestry, Ss. Cyril and Methodius University in Skopje, North Macedonia

2. Aristotle University of Thessaloniki (AUTh), Greece

3. Institute of Mediterranean Forest Ecosystems, DEMETER, Greece

4. Bavarian Office for Forest Genetics (AWG), Germany

5. Szent István University, Budapest, Hungary

6. Slovenia Forest Service (ZGS), Slovenia

7. Croatian Forest Research Institute, Jastrebarsko, Croatia

8. Faculty of Forestry, University of Zagreb, Croatia

9. Federal Research and Training Centre for Forests, Natural Hazards and Landscape (BFW), Austria

10. Institute of Lowland Forestry and Environment (ILFE), Novi Sad, Serbia
} 


\subsection{FIELD OBSERVATION FORMS}

10.2.1 Plot description form

10.2.2 Form for recording field verifiers

10.2.3 Form for recording field background information 


\subsubsection{Plot description form}

\section{FGM PLOT DESCRIPTION FORM}

\section{PLOT DESCRIPTION DATA}

Monitored tree species

Plot size

ha

\section{Exact position *}

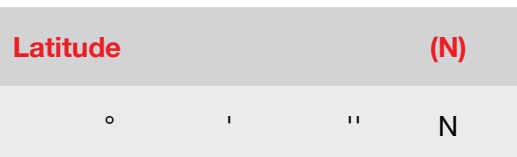

\begin{tabular}{l} 
Ownership \\
\hline $\begin{array}{l}\text { Information about owner (restricted information: the parcel } \\
\text { numbers, cadastral number, etc.) }\end{array}$ \\
\hline State Forest Office / District \\
\hline Forest division \\
\hline Forest compartment \\
\hline Forest sub-compartment \\
\hline FGM plot code
\end{tabular}

\begin{tabular}{l}
\hline $\begin{array}{l}\text { Monitored tree species and its } \\
\text { proportion in the stand }\end{array}$ \\
\hline $\begin{array}{l}\text { Non-target species and its proportion } \\
\text { in the stand }\end{array}$ \\
\hline $\begin{array}{l}\text { Non-target species and its proportion } \\
\text { in the stand }\end{array}$ \\
\hline $\begin{array}{l}\text { Non-target species and its proportion } \\
\text { in the stand }\end{array}$
\end{tabular}

Regional classification into growth areas (growth districts)

\section{Bedrock}

Phytocoenological association (according to Braun-Blanquet)

Soil type (according to FAO, 1971-1981) ${ }^{\star *}$

\section{Soil humidity (dry/mesic/wet)}

\section{Proportion, \%}

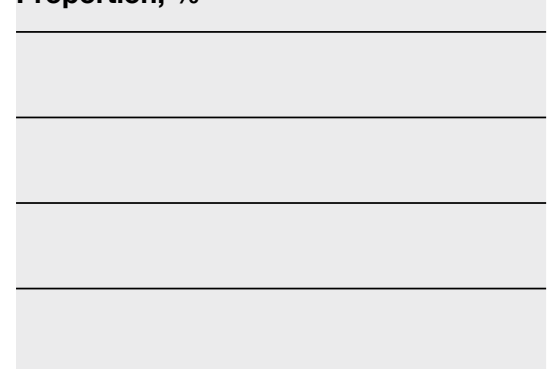

Stand age (range, from - to)

yrs

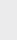

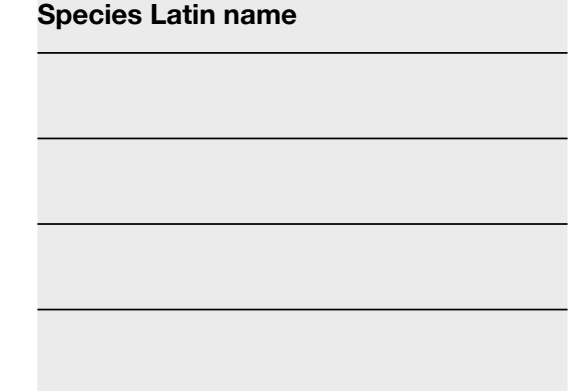


Nutrient supply (rich/medium/poor)

Regional forest site classification

Climograph

Mean annual temperature $\left(C^{\circ}\right)$

Mean annual temperature during vegetation period $\left(C^{\circ}\right)$

\section{Mean temperature of the warmest} month (July) (C')

Mean precipitation during vegetation period $(\mathrm{mm})$

Ellenberg's climate quotient (EQ)

FOREST MANAGEMENT OBJECTIVES:

1. Wood production

2. Habitat-focused

3. Recreation/aesthetics-focused

4. Multiple use focused

5. Other - specify

SILVICULTURAL SYSTEM:

1. Shelter wood

2. Coppice

3. Continuous cover

4. Selective logging

5. Other - specify

\section{DESIGNATED STATUS:}
1. Forest reserve
2. Gene conservation area
3. Protected area

4. Other - specify

\section{If taken out of management, since} when

* Exact position is confidential information for LIFEGENMON project use only

** FAO/UNESCO $(1971$ - 1981) the FAO-UNESCO Soil Map of the World. 


\section{STAND QUALITY AND DESCRIPTION}

\section{Forest health condition}

Describe causes of poor or medium health in remarks

\begin{tabular}{|l|l|l|}
\hline Good & Medium & Poor \\
\hline & & \\
\hline
\end{tabular}

\section{Source}

\begin{tabular}{|c|c|c|}
\hline $\begin{array}{c}\text { Autochth- } \\
\text { onous }\end{array}$ & $\begin{array}{l}\text { Non-Auto- } \\
\text { chthonous }\end{array}$ & Unknown \\
\hline & & \\
\hline
\end{tabular}

\section{Isolation}

Isolated from the nearest stand of the same species by a min. of $400 \mathrm{~m}$

\begin{tabular}{|l|l|l|}
\hline & Yes & No \\
\hline Isolated & & \\
\hline
\end{tabular}

\section{Horizontal structure of stand}

Openness and spacing of canopy

\begin{tabular}{|c|c|c|}
\hline Even & $\begin{array}{c}\text { Even with } \\
\text { openings }\end{array}$ & $\begin{array}{c}\text { Uneven } \\
\text { with } \\
\text { openings }\end{array}$ \\
\hline & & \\
\hline
\end{tabular}

Slope exposition

\begin{tabular}{|c|c|c|c|}
\hline N & NE & E & SE \\
\hline & & & \\
\hline S & SW & W & NW \\
\hline & & & \\
\hline
\end{tabular}

\section{Crown form}

\begin{tabular}{|l|l|l|}
\hline Good & Medium & Poor \\
\hline & & \\
\hline
\end{tabular}

Forest management

\begin{tabular}{|c|c|c|}
\hline & Yes & No \\
\hline Managed & & \\
\hline
\end{tabular}

Natural regeneration

\begin{tabular}{|l|l|l|}
\hline Rare & Modest & Frequent \\
\hline & & \\
\hline
\end{tabular}

\section{Fragmentation}

Species scattered within FGM plot (some grouping is visible)

\begin{tabular}{|l|l|l|}
\hline & Yes & No \\
\hline Fragmented & & \\
\hline
\end{tabular}

\section{Distance between trees /} groups of trees

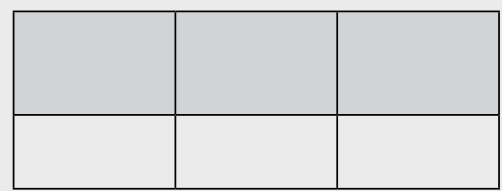

Slope

\begin{tabular}{|l|l|l|}
\hline$<5 \%$ & $5-15 \%$ & $15-40 \%$ \\
\hline & & \\
\hline & & \\
\hline
\end{tabular}

Quality of tree stems in general

Top straightness, forking, etc.

\begin{tabular}{|l|l|l|}
\hline Good & Medium & Poor \\
\hline & & \\
\hline
\end{tabular}

Stand history (origin)

If planted, provide the origin of FRM (if known)

\begin{tabular}{|c|c|}
\hline $\begin{array}{c}\text { Naturally } \\
\text { regenerated }\end{array}$ & Planted \\
\hline & \\
\hline
\end{tabular}

\section{Structure of natural regeneration}

\begin{tabular}{|c|c|}
\hline In Groups & $\begin{array}{c}\text { Evenly } \\
\text { distributed }\end{array}$ \\
\hline & \\
\hline
\end{tabular}

\section{Vertical structure of stands}

\begin{tabular}{|c|c|c|}
\hline $\begin{array}{c}\text { Single } \\
\text { Canopy }\end{array}$ & $\begin{array}{c}\text { Two } \\
\text { storied }\end{array}$ & $\begin{array}{c}\text { Multi } \\
\text { layered }\end{array}$ \\
\hline & & \\
\hline
\end{tabular}

\section{Genetic data}

\begin{tabular}{|l|l|l|}
\hline & Yes & No \\
\hline Available & & \\
\hline
\end{tabular}

Past records of flowering, fructification (mast years) and seed collection

\begin{tabular}{|l|l|l|}
\hline & Year & $\begin{array}{c}\text { Amount of } \\
\text { seed }\end{array}$ \\
\hline Flowering & & \\
\hline $\begin{array}{l}\text { Fructifica- } \\
\text { tion }\end{array}$ & & \\
\hline $\begin{array}{l}\text { Seed } \\
\text { collection }\end{array}$ & & \\
\hline
\end{tabular}

\section{Accessibility}

Accessibility for seed collection/climbing

\begin{tabular}{|l|l|l|}
\hline Good & Medium & Poor \\
\hline & & \\
\hline
\end{tabular}


Remarks:

Date: Name / Surname / Signature: 
10.2.2 Form for recording field verifiers

\begin{tabular}{|l|l|l|}
\hline Plot: & Signature: \\
\hline Tree species: & \\
\hline Date: & \\
\hline Evaluator: & \\
\hline
\end{tabular}

VERIFIER: MORTALITY

\section{BASIC, STANDARD, ADVANCED LEVELS}

Please mark with an $x$.

\begin{tabular}{|l|l|l|l|l|l|l|l|l|l|l|l|l|l|}
\hline $\begin{array}{c}\text { Tree } \\
\text { No. }\end{array}$ & Alive & Dead & $\begin{array}{c}\text { Tree } \\
\text { No. }\end{array}$ & Alive & Dead & $\begin{array}{c}\text { Tree } \\
\text { No. }\end{array}$ & Alive & Dead & $\begin{array}{c}\text { Tree } \\
\text { No. }\end{array}$ & Alive & Dead & $\begin{array}{c}\text { Tree } \\
\text { No. }\end{array}$ & Alive \\
\hline 1
\end{tabular}

Notes: 


\begin{tabular}{|l|l|l|}
\hline Plot: & Signature: \\
\hline Tree species: & & \\
\hline Date: & & \\
\hline Evaluator: & & \\
\hline
\end{tabular}

VERIFIER: FLOWERING

\section{BASIC LEVEL}

Please circle the relevant code.

\begin{tabular}{|c|c|}
\hline \multicolumn{3}{|c|}{ Flowering intensity of the stand } \\
\hline Code & $\begin{array}{c}\text { Percentage of crown } \\
\text { with flowers on an average tree }\end{array}$ \\
\hline 1 & $0-10$ \\
\hline 2 & $>10-30$ \\
\hline 3 & $>30-60$ \\
\hline 4 & $>60-90$ \\
\hline 5 & $>90$ \\
\hline
\end{tabular}

\begin{tabular}{|c|c|}
\hline \multicolumn{2}{|c|}{$\begin{array}{c}\text { Proportion of trees in the stand } \\
\text { with the given flowering intensity stage (\%) }\end{array}$} \\
\hline Code & \% of trees \\
\hline 1 & $0-10$ \\
\hline 2 & $>10-30$ \\
\hline 3 & $>30-60$ \\
\hline 4 & $>60-90$ \\
\hline 5 & $>90$ \\
\hline
\end{tabular}

\section{STANDARD LEVEL}

Please fill in the code. Consult guidelines for the code values.

Proportion of the crown flowering per tree

\begin{tabular}{|c|c|c|c|c|c|c|c|c|c|}
\hline $\begin{array}{c}\text { Tree } \\
\text { No. }\end{array}$ & Code & $\begin{array}{c}\text { Tree } \\
\text { No. }\end{array}$ & Code & $\begin{array}{c}\text { Tree } \\
\text { No. }\end{array}$ & Code & $\begin{array}{c}\text { Tree } \\
\text { No. }\end{array} \quad$ Code & $\begin{array}{c}\text { Tree } \\
\text { No. }\end{array}$ & Code \\
\hline 1 & 11 & & 21 & & 31 & & 41 & \\
\hline 2 & 12 & & 22 & & 32 & & 42 & \\
\hline 3 & 13 & & 23 & & 33 & & 43 & \\
\hline 4 & 14 & & 24 & & 34 & & 44 & \\
\hline 5 & 15 & & 25 & & 35 & & 45 & \\
\hline 6 & 16 & & 26 & & 36 & & 46 & \\
\hline 7 & 17 & & 27 & & 37 & & 47 & \\
\hline 8 & 18 & & 28 & & 38 & & 48 & \\
\hline 9 & 19 & 20 & & 29 & & 39 & & 49 & \\
\hline 10 & & & & & & & & & \\
\hline
\end{tabular}




\begin{tabular}{|l|l|l|}
\hline Plot: & Signature: \\
\hline Tree species: & & \\
\hline Date: & & \\
\hline Evaluator: & & \\
\hline
\end{tabular}

\section{ADVANCED LEVEL}

Please fill in the code. Consult guidelines for the code values.

Female and male flowering stage, and proportion of the crown flowering (male and female flowering together) per tree

\begin{tabular}{|c|c|c|c|c|c|c|c|}
\hline $\begin{array}{l}\text { Tree } \\
\text { No. }\end{array}$ & $\begin{array}{c}\text { Female } \\
\text { flowering code }\end{array}$ & $\begin{array}{c}\text { Male } \\
\text { flowering code }\end{array}$ & $\begin{array}{l}\% \text { of crown } \\
\text { flowering code }\end{array}$ & $\begin{array}{l}\text { Tree } \\
\text { No. }\end{array}$ & $\begin{array}{c}\text { Female } \\
\text { flowering code }\end{array}$ & $\begin{array}{c}\text { Male } \\
\text { flowering code }\end{array}$ & $\begin{array}{l}\% \text { of crown } \\
\text { flowering code }\end{array}$ \\
\hline 1 & & & & 26 & & & \\
\hline 2 & & & & 27 & & & \\
\hline 3 & & & & 28 & & & \\
\hline 4 & & & & 29 & & & \\
\hline 5 & & & & 30 & & & \\
\hline 6 & & & & 31 & & & \\
\hline 7 & & & & 32 & & & \\
\hline 8 & & & & 33 & & & \\
\hline 9 & & & & 34 & & & \\
\hline 10 & & & & 35 & & & \\
\hline 11 & & & & 36 & & & \\
\hline 12 & & & & 37 & & & \\
\hline 13 & & & & 38 & & & \\
\hline 14 & & & & 39 & & & \\
\hline 15 & & & & 40 & & & \\
\hline 16 & & & & 41 & & & \\
\hline 17 & & & & 42 & & & \\
\hline 18 & & & & 43 & & & \\
\hline 19 & & & & 44 & & & \\
\hline 20 & & & & 45 & & & \\
\hline 21 & & & & 46 & & & \\
\hline 22 & & & & 47 & & & \\
\hline 23 & & & & 48 & & & \\
\hline 24 & & & & 49 & & & \\
\hline 25 & & & & 50 & & & \\
\hline
\end{tabular}




\begin{tabular}{|l|l|l|}
\hline Plot: & Signature: \\
\hline Tree species: & & \\
\hline Date: & & \\
\hline Evaluator: & & \\
\hline
\end{tabular}

VERIFIER: FRUCTIFICATION

\section{BASIC LEVEL}

Please circle the relevant code.

\begin{tabular}{|c|r|}
\hline \multicolumn{2}{|c|}{ Fructification intensity of the stand } \\
\hline Code & Average \% of crowns flowering \\
\hline 1 & $0-10$ \\
\hline 2 & $>10-30$ \\
\hline 3 & $>30-60$ \\
\hline 4 & $>60-90$ \\
\hline 5 & $>90$ \\
\hline
\end{tabular}

\begin{tabular}{|c|c|}
\hline \multicolumn{2}{|c|}{$\begin{array}{c}\text { Proportion of trees in the stand with the given } \\
\text { fructification intensity stage (\%) }\end{array}$} \\
\hline Code & \% of trees \\
\hline 1 & $0-10$ \\
\hline 2 & $>10-30$ \\
\hline 3 & $>30-60$ \\
\hline 4 & $>60-90$ \\
\hline 5 & $>90$ \\
\hline
\end{tabular}

\section{STANDARD LEVEL}

Please fill in the code. Consult guidelines for the code values.

Fructification intensity per tree

\begin{tabular}{|c|c|c|c|c|c|c|c|c|c|}
\hline $\begin{array}{l}\text { Tree } \\
\text { No. }\end{array}$ & Code & $\begin{array}{l}\text { Tree } \\
\text { No. }\end{array}$ & Code & $\begin{array}{l}\text { Tree } \\
\text { No. }\end{array}$ & Code & $\begin{array}{l}\text { Tree } \\
\text { No. }\end{array}$ & Code & $\begin{array}{l}\text { Tree } \\
\text { No. }\end{array}$ & Code \\
\hline 1 & & 11 & & 21 & & 31 & & 41 & \\
\hline 2 & & 12 & & 22 & & 32 & & 42 & \\
\hline 3 & & 13 & & 23 & & 33 & & 43 & \\
\hline 4 & & 14 & & 24 & & 34 & & 44 & \\
\hline 5 & & 15 & & 25 & & 35 & & 45 & \\
\hline 6 & & 16 & & 26 & & 36 & & 46 & \\
\hline 7 & & 17 & & 27 & & 37 & & 47 & \\
\hline 8 & & 18 & & 28 & & 38 & & 48 & \\
\hline 9 & & 19 & & 29 & & 39 & & 49 & \\
\hline 10 & & 20 & & 30 & & 40 & & 50 & \\
\hline
\end{tabular}




\begin{tabular}{|l|l|l|}
\hline Plot: & Signature: \\
\hline Tree species: & & \\
\hline Date: & & \\
\hline Evaluator: & & \\
\hline
\end{tabular}

\section{ADVANCED LEVEL}

Please fill in the code. Consult guidelines for the code values.

Fructification abundance at a given part of crown

\begin{tabular}{|c|c|c|c|c|c|c|c|}
\hline $\begin{array}{l}\text { Tree } \\
\text { No. }\end{array}$ & $\begin{array}{c}\text { Female } \\
\text { flowering code }\end{array}$ & $\begin{array}{c}\text { Male } \\
\text { flowering code }\end{array}$ & $\begin{array}{l}\% \text { of crown } \\
\text { flowering code }\end{array}$ & $\begin{array}{l}\text { Tree } \\
\text { No. }\end{array}$ & $\begin{array}{c}\text { Female } \\
\text { flowering code }\end{array}$ & $\begin{array}{c}\text { Male } \\
\text { flowering code }\end{array}$ & $\begin{array}{l}\% \text { of crown } \\
\text { flowering code }\end{array}$ \\
\hline 1 & & & & 26 & & & \\
\hline 2 & & & & 27 & & & \\
\hline 3 & & & & 28 & & & \\
\hline 4 & & & & 29 & & & \\
\hline 5 & & & & 30 & & & \\
\hline 6 & & & & 31 & & & \\
\hline 7 & & & & 32 & & & \\
\hline 8 & & & & 33 & & & \\
\hline 9 & & & & 34 & & & \\
\hline 10 & & & & 35 & & & \\
\hline 11 & & & & 36 & & & \\
\hline 12 & & & & 37 & & & \\
\hline 13 & & & & 38 & & & \\
\hline 14 & & & & 39 & & & \\
\hline 15 & & & & 40 & & & \\
\hline 16 & & & & 41 & & & \\
\hline 17 & & & & 42 & & & \\
\hline 18 & & & & 43 & & & \\
\hline 19 & & & & 44 & & & \\
\hline 20 & & & & 45 & & & \\
\hline 21 & & & & 46 & & & \\
\hline 22 & & & & 47 & & & \\
\hline 23 & & & & 48 & & & \\
\hline 24 & & & & 49 & & & \\
\hline 25 & & & & 50 & & & \\
\hline
\end{tabular}




\begin{tabular}{|l|l|l|}
\hline Plot: & Signature: \\
\hline Tree species: & & \\
\hline Date: & & \\
\hline Evaluator: & & \\
\hline
\end{tabular}

\section{VERIFIER: NATURAL REGENERATION ABUNDANCE}

\section{BASIC LEVEL}

Please circle the relevant code.

\begin{tabular}{|c|c|}
\hline Code & Description: new regeneration (current-year seedlings) \\
\hline $1 a$ & There is no or very little new natural regeneration on the monitoring plot \\
\hline $2 a$ & New regeneration is present in sufficient numbers on the monitoring plot \\
\hline
\end{tabular}

\begin{tabular}{|c|c|}
\hline Code & Description: established natural regeneration (saplings) \\
\hline $1 \mathrm{~b}$ & There is no or very little established natural regeneration on the monitoring plot \\
\hline $2 \mathrm{~b}$ & Established regeneration is present in sufficient quantity on the monitoring plot \\
\hline
\end{tabular}

\section{STANDARD LEVEL}

Please fill in the number after counting

Age of seedlings:

\begin{tabular}{|c|l|c|l|}
\hline $\begin{array}{c}\text { Subplot } \\
\text { No. }\end{array}$ & No. of seedlings & $\begin{array}{c}\text { Subplot } \\
\text { No. }\end{array}$ & No. of seedlings \\
\hline 1 & & 11 & \\
\hline 2 & & 12 & \\
\hline 3 & & 13 & \\
\hline 4 & & 14 & \\
\hline 5 & & 15 & \\
\hline 6 & & 16 & \\
\hline 7 & & 17 & \\
\hline 8 & & 18 & \\
\hline 9 & & 19 & \\
\hline 10 & & 20 & \\
\hline
\end{tabular}

Age of seedlings:

\begin{tabular}{|c|l|c|l|}
\hline $\begin{array}{c}\text { Subplot } \\
\text { No. }\end{array}$ & No. of seedlings & $\begin{array}{c}\text { Subplot } \\
\text { No. }\end{array}$ & No. of seedlings \\
\hline 1 & & 11 & \\
\hline 2 & & 12 & \\
\hline 3 & & 13 & \\
\hline 4 & & 14 & \\
\hline 5 & & 15 & \\
\hline 6 & & 16 & \\
\hline 7 & & 17 & \\
\hline 8 & & 18 & \\
\hline 9 & & 19 & \\
\hline 10 & & 20 & \\
\hline
\end{tabular}




\begin{tabular}{|l|l|l|}
\hline Plot: & Signature: \\
\hline Tree species: & & \\
\hline Date: & & \\
\hline Evaluator: & & \\
\hline
\end{tabular}

\section{ADVANCED LEVEL}

Please fill in the number after counting.

Age of seedlings:

\begin{tabular}{|c|c|c|c|}
\hline $\begin{array}{c}\text { Subplot } \\
\text { No. }\end{array}$ & No. of seedlings & $\begin{array}{c}\text { Subplot } \\
\text { No. }\end{array}$ & No. of seedlings \\
\hline 1 & & 11 & \\
\hline 2 & & 12 & \\
\hline 3 & & 13 & \\
\hline 4 & & 14 & \\
\hline 5 & & 15 & \\
\hline 6 & & 16 & \\
\hline 7 & & 17 & \\
\hline 8 & & 18 & \\
\hline 9 & & 19 & \\
\hline 10 & & 20 & \\
\hline
\end{tabular}

Age of seedlings:

\begin{tabular}{|c|c|c|c|}
\hline $\begin{array}{c}\text { Subplot } \\
\text { No. }\end{array}$ & No. of seedlings & $\begin{array}{c}\text { Subplot } \\
\text { No. }\end{array}$ & No. of seedlings \\
\hline 1 & & 11 & \\
\hline 2 & & 12 & \\
\hline 3 & & 13 & \\
\hline 4 & & 14 & \\
\hline 5 & & 15 & \\
\hline 6 & & 16 & \\
\hline 7 & & 17 & \\
\hline 8 & & 18 & \\
\hline 9 & & 19 & \\
\hline 10 & & 20 & \\
\hline
\end{tabular}

Age of seedlings:

\begin{tabular}{|c|c|c|c|}
\hline $\begin{array}{c}\text { Subplot } \\
\text { No. }\end{array}$ & No. of seedlings & $\begin{array}{c}\text { Subplot } \\
\text { No. }\end{array}$ & No. of seedlings \\
\hline 1 & & 11 & \\
\hline 2 & & 12 & \\
\hline 3 & & 13 & \\
\hline 4 & & 14 & \\
\hline 5 & & 15 & \\
\hline 6 & & 16 & \\
\hline 7 & & 17 & \\
\hline 8 & & 18 & \\
\hline 9 & & 19 & \\
\hline 10 & & 20 & \\
\hline
\end{tabular}


10.2.3 Form for recording field background information

\begin{tabular}{|l|l|l|}
\hline Plot: & Signature: \\
\hline Tree species: & \\
\hline Date: & & \\
\hline Evaluator: & & \\
\hline
\end{tabular}

\section{BACKGROUND INFORMATION: DBH CLASS DISTRIBUTION}

\section{STANDARD, ADVANCED LEVELS}

Please fill in the number after measuring.

\begin{tabular}{|c|c|c|c|c|c|c|c|c|c|}
\hline Tree No. & $\mathrm{DBH}[\mathrm{cm}]$ & Tree No. & $\mathrm{DBH}[\mathrm{cm}]$ & Tree No. & $\mathrm{DBH}[\mathrm{cm}]$ & Tree No. & $\mathrm{DBH}[\mathrm{cm}]$ & Tree No. & $\mathrm{DBH}[\mathrm{cm}]$ \\
\hline 1 & & 11 & & 21 & & 31 & & 41 & \\
\hline 2 & & 12 & & 22 & & 32 & & 42 & \\
\hline 3 & & 13 & & 23 & & 33 & & 43 & \\
\hline 4 & & 14 & & 24 & & 34 & & 44 & \\
\hline 5 & & 15 & & 25 & & 35 & & 45 & \\
\hline 6 & & 16 & & 26 & & 36 & & 46 & \\
\hline 7 & & 17 & & 27 & & 37 & & 47 & \\
\hline 8 & & 18 & & 28 & & 38 & & 48 & \\
\hline 9 & & 19 & & 29 & & 39 & & 49 & \\
\hline 10 & & 20 & & 30 & & 40 & & 50 & \\
\hline
\end{tabular}

\section{BACKGROUND INFORMATION: HEIGHT CLASS DISTRIBUTION}

\section{STANDARD, ADVANCED LEVELS}

Please fill in the number after measuring.

\begin{tabular}{|c|c|c|c|c|c|c|c|c|c|}
\hline Tree No. & Height [m] & Tree No. & Height [m] & Tree No. & Height [m] & Tree No. & Height [m] & Tree No. & Height [m] \\
\hline 1 & & 11 & & 21 & & 31 & & 41 & \\
\hline 2 & & 12 & & 22 & & 32 & & 42 & \\
\hline 3 & & 13 & & 23 & & 33 & & 43 & \\
\hline 4 & & 14 & & 24 & & 34 & & 44 & \\
\hline 5 & & 15 & & 25 & & 35 & & 45 & \\
\hline 6 & & 16 & & 26 & & 36 & & 46 & \\
\hline 7 & & 17 & & 27 & & 37 & & 47 & \\
\hline 8 & & 18 & & 28 & & 38 & & 48 & \\
\hline 9 & & 19 & & 29 & & 39 & & 49 & \\
\hline 10 & & 20 & & 30 & & 40 & & 50 & \\
\hline
\end{tabular}




\begin{tabular}{|l|l|l|}
\hline Plot: & Signature: \\
\hline Tree species: & \\
\hline Date: & & \\
\hline Evaluator: & \\
\hline
\end{tabular}

\section{BACKGROUND INFORMATION: BUD BREAK}

\section{STANDARD, ADVANCED LEVELS}

Please fill in the code. Consult guidelines for the code values.

\begin{tabular}{|c|c|c|c|c|c|c|c|c|c|c|c|c|c|c|}
\hline $\begin{array}{c}\text { Tree } \\
\text { No. }\end{array}$ & Stage & $\begin{array}{c}\text { \% of } \\
\text { crown }\end{array}$ & $\begin{array}{c}\text { Tree } \\
\text { No. }\end{array}$ & Stage & $\begin{array}{c}\text { \% of } \\
\text { crown }\end{array}$ & $\begin{array}{c}\text { Tree } \\
\text { No. }\end{array}$ & Stage & $\begin{array}{c}\text { \% of } \\
\text { crown }\end{array}$ & $\begin{array}{c}\text { Tree } \\
\text { No. }\end{array}$ & Stage & $\begin{array}{c}\% \text { of } \\
\text { crown }\end{array}$ & $\begin{array}{c}\text { Tree } \\
\text { No. }\end{array}$ & Stage & $\begin{array}{c}\% \text { of } \\
\text { crown }\end{array}$ \\
\hline 1 & & & 11 & & & 21 & & & 31 & & & 41 & & \\
\hline 2 & & & 12 & & & 22 & & & 32 & & & 42 & & \\
\hline 3 & & & 13 & & & 23 & & & 33 & & & 43 & & \\
\hline 4 & & & 14 & & & 24 & & & 34 & & & 44 & & \\
\hline 5 & & & 15 & & & 25 & & & 35 & & & 45 & & \\
\hline 6 & & & 16 & & & 26 & & & 36 & & & 46 & & \\
\hline 7 & & & 17 & & & 27 & & & 37 & & & 47 & & \\
\hline 8 & & & 18 & & & 28 & & & 38 & & & 48 & & \\
\hline 9 & & & 19 & & & 29 & & & 39 & & & 49 & & \\
\hline 10 & & & 20 & & & 30 & & & 40 & & & 50 & & \\
\hline
\end{tabular}

\section{BACKGROUND INFORMATION: SENESCENCE}

\section{STANDARD, ADVANCED LEVELS}

Please fill in the code. Consult guidelines for the code values. Only relevant for tree species shedding leaves.

\begin{tabular}{|c|c|c|c|c|c|c|c|c|c|c|c|c|c|c|}
\hline $\begin{array}{l}\text { Tree } \\
\text { No. }\end{array}$ & Stage & $\begin{array}{c}\% \text { of } \\
\text { crown }\end{array}$ & $\begin{array}{l}\text { Tree } \\
\text { No. }\end{array}$ & Stage & $\begin{array}{c}\% \text { of } \\
\text { crown }\end{array}$ & $\begin{array}{l}\text { Tree } \\
\text { No. }\end{array}$ & Stage & $\begin{array}{c}\% \text { of } \\
\text { crown }\end{array}$ & $\begin{array}{l}\text { Tree } \\
\text { No. }\end{array}$ & Stage & $\begin{array}{c}\% \text { of } \\
\text { crown }\end{array}$ & $\begin{array}{l}\text { Tree } \\
\text { No. }\end{array}$ & Stage & $\begin{array}{c}\% \text { of } \\
\text { crown }\end{array}$ \\
\hline 1 & & & 11 & & & 21 & & & 31 & & & 41 & & \\
\hline 2 & & & 12 & & & 22 & & & 32 & & & 42 & & \\
\hline 3 & & & 13 & & & 23 & & & 33 & & & 43 & & \\
\hline 4 & & & 14 & & & 24 & & & 34 & & & 44 & & \\
\hline 5 & & & 15 & & & 25 & & & 35 & & & 45 & & \\
\hline 6 & & & 16 & & & 26 & & & 36 & & & 46 & & \\
\hline 7 & & & 17 & & & 27 & & & 37 & & & 47 & & \\
\hline 8 & & & 18 & & & 28 & & & 38 & & & 48 & & \\
\hline 9 & & & 19 & & & 29 & & & 39 & & & 49 & & \\
\hline 10 & & & 20 & & & 30 & & & 40 & & & 50 & & \\
\hline
\end{tabular}




\begin{tabular}{|l|l|l|}
\hline Plot: & & Signature: \\
\hline Tree species: & & \\
\hline Date: & & \\
\hline Evaluator: & & \\
\hline
\end{tabular}

\section{BACKGROUND INFORMATION: SEX RATIO}

\section{STANDARD LEVEL}

Please fill in the code. Consult guidelines for the code values. Only relevant for diecious/polygamous species such as ash, cherry, poplar...

\begin{tabular}{|c|c|c|c|c|c|c|c|c|c|}
\hline Tree No. & Sex & Tree No. & Sex & Tree No. & Sex & Tree No. & Sex & Tree No. & Sex \\
\hline 1 & & 11 & & 21 & & 31 & & 41 & \\
\hline 2 & & 12 & & 22 & & 32 & & 42 & \\
\hline 3 & & 13 & & 23 & & 33 & & 43 & \\
\hline 4 & & 14 & & 24 & & 34 & & 44 & \\
\hline 5 & & 15 & & 25 & & 35 & & 45 & \\
\hline 6 & & 16 & & 26 & & 36 & & 46 & \\
\hline 7 & & 17 & & 27 & & 37 & & 47 & \\
\hline 8 & & 18 & & 28 & & 38 & & 48 & \\
\hline 9 & & 19 & & 29 & & 39 & & 49 & \\
\hline 10 & & 20 & & 30 & & 40 & & 50 & \\
\hline
\end{tabular}




\begin{tabular}{|l|l|l|}
\hline Plot: & Signature: \\
\hline Tree species: & & \\
\hline Date: & & \\
\hline Evaluator: & & \\
\hline
\end{tabular}

\section{ADVANCED LEVEL}

Please fill in the percentage of male/female/hermaphrodite inflorescences. Only relevant for polygamous species such as ash...

\begin{tabular}{|c|c|c|c|c|c|c|c|}
\hline $\begin{array}{l}\text { Tree } \\
\text { No. }\end{array}$ & $\begin{array}{c}\% \text { male } \\
\text { inflorescences }\end{array}$ & $\begin{array}{c}\% \text { female } \\
\text { inflorescences }\end{array}$ & $\begin{array}{c}\% \text { hermaphrodite } \\
\text { inflorescences }\end{array}$ & $\begin{array}{l}\text { Tree } \\
\text { No. }\end{array}$ & $\begin{array}{c}\% \text { male } \\
\text { inflorescences }\end{array}$ & $\begin{array}{c}\% \text { female } \\
\text { inflorescences }\end{array}$ & $\begin{array}{c}\% \text { hermaphrodite } \\
\text { inflorescences }\end{array}$ \\
\hline 1 & & & & 26 & & & \\
\hline 2 & & & & 27 & & & \\
\hline 3 & & & & 28 & & & \\
\hline 4 & & & & 29 & & & \\
\hline 5 & & & & 30 & & & \\
\hline 6 & & & & 31 & & & \\
\hline 7 & & & & 32 & & & \\
\hline 8 & & & & 33 & & & \\
\hline 9 & & & & 34 & & & \\
\hline 10 & & & & 35 & & & \\
\hline 11 & & & & 36 & & & \\
\hline 12 & & & & 37 & & & \\
\hline 13 & & & & 38 & & & \\
\hline 14 & & & & 39 & & & \\
\hline 15 & & & & 40 & & & \\
\hline 16 & & & & 41 & & & \\
\hline 17 & & & & 42 & & & \\
\hline 18 & & & & 43 & & & \\
\hline 19 & & & & 44 & & & \\
\hline 20 & & & & 45 & & & \\
\hline 21 & & & & 46 & & & \\
\hline 22 & & & & 47 & & & \\
\hline 23 & & & & 48 & & & \\
\hline 24 & & & & 49 & & & \\
\hline 25 & & & & 50 & & & \\
\hline
\end{tabular}




\begin{tabular}{|l|l|l|}
\hline Plot: & & Signature: \\
\hline Tree species: & & \\
\hline Date: & & \\
\hline Evaluator: & & \\
\hline
\end{tabular}

BACKGROUND INFORMATION: CROWN DIEBACK

\section{BASIC, STANDARD, ADVANCED LEVELS}

Please fill in the code. Consult guidelines for the code values. Only relevant for species with severe dieback such as ash...

\begin{tabular}{|c|c|c|c|c|c|c|c|c|c|}
\hline Tree No. & Code & Tree No. & Code & Tree No. & Code & Tree No. & Code & Tree No. & Code \\
\hline 1 & & 11 & & 21 & & 31 & & 41 & \\
\hline 2 & & 12 & & 22 & & 32 & & 42 & \\
\hline 3 & & 13 & & 23 & & 33 & & 43 & \\
\hline 4 & & 14 & & 24 & & 34 & & 44 & \\
\hline 5 & & 15 & & 25 & & 35 & & 45 & \\
\hline 6 & & 16 & & 26 & & 36 & & 46 & \\
\hline 7 & & 17 & & 27 & & 37 & & 47 & \\
\hline 8 & & 18 & & 28 & & 38 & & 48 & \\
\hline 9 & & 19 & & 29 & & 39 & & 49 & \\
\hline 10 & & 20 & & 30 & & 40 & & 50 & \\
\hline
\end{tabular}




\subsection{Supplementary tables for Chapter 7: Cost assessment}

Table S7.1: Cost assessment of forest genetic monitoring of European beech (Fagus sylvatica L.) in Germany. The first Forest genetic monitoring interval (Interval $1^{\text {st) }}$ is distinguished from subsequent intervals (Interval $\left.1+\mathrm{N}^{\mathrm{Nh}}\right)$. C - consumables; $\mathrm{O}$ - outsourcing; $\mathrm{F}$ - forester; $\mathrm{T}$ - technician; $\mathrm{R}$ - researcher; $\mathrm{M}-\mathrm{S}$ - mileage and subsistence; $\mathrm{t}$ - time travelling

\begin{tabular}{|c|c|c|c|c|c|c|c|c|c|c|c|c|}
\hline \multirow[b]{3}{*}{ Activity } & \multirow[b]{3}{*}{ Interval } & \multirow[b]{3}{*}{ Level } & \multicolumn{2}{|c|}{ Materials } & \multicolumn{4}{|c|}{ Labour } & \multicolumn{3}{|c|}{ Travelling } & \multirow[b]{2}{*}{ Total } \\
\hline & & & $C$ & 0 & $\mathrm{~F}$ & $\mathrm{~T}$ & $\mathrm{R}$ & Cost & M-S & t & t & \\
\hline & & & {$[€]$} & {$[€]$} & [prs h] & [prs h] & [prs h] & {$[€]$} & {$[€]$} & [prs h] & {$[€]$} & {$[€]$} \\
\hline \multirow{6}{*}{ Plot selection } & \multirow{3}{*}{$1^{\text {st }}$} & Basic & 0 & 0 & 40 & 0 & 40 & 2,791 & 395 & 28 & 972 & 4,158 \\
\hline & & Standard & 0 & 0 & 40 & 0 & 40 & 2,791 & 395 & 28 & 972 & 4,158 \\
\hline & & Advanced & 0 & 0 & 40 & 0 & 40 & 2,791 & 395 & 28 & 972 & 4,158 \\
\hline & \multirow{3}{*}{$1+\mathrm{N}^{\text {th }}$} & Basic & 0 & 0 & 0 & 0 & 0 & 0 & 0 & 0 & 0 & 0 \\
\hline & & Standard & 0 & 0 & 0 & 0 & 0 & 0 & 0 & 0 & 0 & 0 \\
\hline & & Advanced & 0 & 0 & 0 & 0 & 0 & 0 & 0 & 0 & 0 & 0 \\
\hline \multirow{6}{*}{$\begin{array}{l}\text { Plot } \\
\text { establishment }\end{array}$} & \multirow{3}{*}{$1^{\text {st }}$} & Basic & 525 & 0 & 0 & 12 & 15 & 854 & 395 & 11 & 357 & 2,130 \\
\hline & & Standard & 845 & 0 & 0 & 23 & 28 & 1,614 & 553 & 22 & 710 & 3,722 \\
\hline & & Advanced & 845 & 0 & 0 & 23 & 28 & 1,614 & 553 & 22 & 710 & 3,722 \\
\hline & \multirow{3}{*}{$1+\mathrm{N}^{\text {th }}$} & Basic & 0 & 0 & 0 & 0 & 0 & 0 & 0 & 0 & 0 & 0 \\
\hline & & Standard & 320 & 0 & 0 & 13 & 15 & 884 & 184 & 13 & 411 & 1,799 \\
\hline & & Advanced & 320 & 0 & 0 & 13 & 15 & 884 & 184 & 13 & 411 & 1,799 \\
\hline \multirow{6}{*}{$\begin{array}{l}\text { Field } \\
\text { observations }\end{array}$} & \multirow{3}{*}{$1^{\text {st }}$} & Basic & 0 & 0 & 0 & 0 & 121 & 4,554 & 1,753 & 74 & 2,809 & 9,116 \\
\hline & & Standard & 0 & 0 & 0 & 46 & 421 & 17,033 & 3,559 & 152 & 5,558 & 26,150 \\
\hline & & Advanced & 0 & 0 & 0 & 43 & 830 & 32,407 & 8,139 & 322 & 11,972 & 52,518 \\
\hline & \multirow{3}{*}{$1+\mathrm{N}^{\text {th }}$} & Basic & 0 & 0 & 0 & 1 & 130 & 4,906 & 1,780 & 76 & 2,875 & 9,561 \\
\hline & & Standard & 0 & 0 & 0 & 47 & 398 & 16,176 & 3,586 & 154 & 5,613 & 25,375 \\
\hline & & Advanced & 0 & 0 & 0 & 87 & 823 & 33,214 & 8,442 & 344 & 12,555 & 54,210 \\
\hline \multirow{6}{*}{ Sampling } & \multirow{3}{*}{$1^{\text {st }}$} & Basic & 0 & 0 & 0 & 0 & 0 & 0 & 0 & 0 & 0 & 0 \\
\hline & & Standard & 10 & 0 & 0 & 7 & 7 & 417 & 158 & 11 & 347 & 932 \\
\hline & & Advanced & 10 & 3,616 & 0 & 7 & 43 & 1,778 & 704 & 22 & 802 & 6,910 \\
\hline & \multirow{3}{*}{$1+\mathrm{N}^{\mathrm{th}}$} & Basic & 0 & 0 & 0 & 0 & 0 & 0 & 0 & 0 & 0 & 0 \\
\hline & & Standard & 7 & 0 & 0 & 1 & 1 & 83 & 79 & 6 & 173 & 342 \\
\hline & & Advanced & 7 & 3,616 & 0 & 1 & 37 & 1,443 & 625 & 17 & 624 & 6,315 \\
\hline \multirow{6}{*}{ Lab. analyses } & \multirow{3}{*}{$1^{\text {st }}$} & Basic & 0 & 0 & 0 & 0 & 0 & 0 & 0 & 0 & 0 & 0 \\
\hline & & Standard & 2,100 & 0 & 0 & 33 & 80 & 3,836 & 0 & 0 & 0 & 5,936 \\
\hline & & Advanced & 13,340 & 0 & 0 & 224 & 80 & 8,485 & 0 & 0 & 0 & 21,825 \\
\hline & \multirow{3}{*}{$1+\mathrm{N}^{\text {th }}$} & Basic & 0 & 0 & 0 & 0 & 0 & 0 & 0 & 0 & 0 & 0 \\
\hline & & Standard & 1,400 & 0 & 0 & 24 & 80 & 3,614 & 0 & 0 & 0 & 5,014 \\
\hline & & Advanced & 12,640 & 0 & 0 & 215 & 80 & 8,263 & 0 & 0 & 0 & 20,903 \\
\hline \multirow{6}{*}{ Total } & & Basic & 525 & 0 & 40 & 12 & 176 & 8,198 & 2,543 & 113 & 4,138 & 15,405 \\
\hline & $1^{\text {st }}$ & Standard & 2,955 & 0 & 40 & 109 & 576 & 25,690 & 4,665 & 214 & 7,587 & 40,898 \\
\hline & & Advanced & 14,195 & 3,616 & 40 & 296 & 1,021 & 47,074 & 9,791 & 395 & 14,456 & 89,132 \\
\hline & & Basic & 0 & 0 & 0 & 1 & 130 & 4,906 & 1,780 & 76 & 2,875 & 9,561 \\
\hline & $1+\mathrm{N}^{\text {th }}$ & Standard & 1,727 & 0 & 0 & 85 & 494 & 20,757 & 3,849 & 173 & 6,197 & 32,530 \\
\hline & & Advanced & 12,967 & 3,616 & 0 & 315 & 955 & 43,805 & 9,251 & 374 & 13,590 & 83,228 \\
\hline
\end{tabular}


Table S7.2: Cost assessment of forest genetic monitoring of Silver fir (Abies alba Mill.) in Germany. The first Forest genetic monitoring interval (Interval $1^{\text {st }}$ ) is distinguished from subsequent intervals (Interval $1+\mathrm{N}^{\text {th }}$ ). $\mathrm{C}-$ consumables; $\mathrm{O}$ - outsourcing; F - forester; $\mathrm{T}$ - technician; $\mathrm{R}$ - researcher; $\mathrm{M}-\mathrm{S}$ - mileage and subsistence; $\mathrm{t}$ - time travelling.

\begin{tabular}{|c|c|c|c|c|c|c|c|c|c|c|c|c|}
\hline \multirow[b]{3}{*}{ Activity } & \multirow[b]{3}{*}{ Interval } & \multirow[b]{3}{*}{ Level } & \multicolumn{2}{|c|}{ Materials } & \multicolumn{4}{|c|}{ Labour } & \multicolumn{3}{|c|}{ Travelling } & \multirow[b]{2}{*}{ Total } \\
\hline & & & C & O & $\mathrm{F}$ & $\mathrm{T}$ & $\mathrm{R}$ & Cost & M-S & $\mathrm{t}$ & $\mathrm{t}$ & \\
\hline & & & {$[€]$} & {$[€]$} & [prs h] & [prs h] & [prs h] & {$[€]$} & {$[€]$} & [prs h] & {$[€]$} & {$[€]$} \\
\hline \multirow{6}{*}{ Plot selection } & \multirow{3}{*}{$1^{s t}$} & Basic & 0 & 0 & 40 & 0 & 40 & 2,791 & 395 & 28 & 972 & 4,158 \\
\hline & & Standard & 0 & 0 & 40 & 0 & 40 & 2,791 & 395 & 28 & 972 & 4,158 \\
\hline & & Advanced & 0 & 0 & 40 & 0 & 40 & 2,791 & 395 & 28 & 972 & 4,158 \\
\hline & \multirow{3}{*}{$1+\mathrm{N}^{\text {th }}$} & Basic & 0 & 0 & 0 & 0 & 0 & 0 & 0 & 0 & 0 & 0 \\
\hline & & Standard & 0 & 0 & 0 & 0 & 0 & 0 & 0 & 0 & 0 & 0 \\
\hline & & Advanced & 0 & 0 & 0 & 0 & 0 & 0 & 0 & 0 & 0 & 0 \\
\hline \multirow{6}{*}{$\begin{array}{l}\text { Plot } \\
\text { establishment }\end{array}$} & \multirow{3}{*}{$1^{\text {st }}$} & Basic & 525 & 0 & 0 & 12 & 15 & 854 & 395 & 11 & 357 & 2,130 \\
\hline & & Standard & 845 & 0 & 0 & 23 & 28 & 1,614 & 553 & 22 & 710 & 3,722 \\
\hline & & Advanced & 845 & 0 & 0 & 23 & 28 & 1,614 & 553 & 22 & 710 & 3,722 \\
\hline & \multirow{3}{*}{$1+\mathrm{N}^{\text {th }}$} & Basic & 0 & 0 & 0 & 0 & 0 & 0 & 0 & 0 & 0 & 0 \\
\hline & & Standard & 320 & 0 & 0 & 13 & 15 & 884 & 184 & 13 & 411 & 1,799 \\
\hline & & Advanced & 320 & 0 & 0 & 13 & 15 & 884 & 184 & 13 & 411 & 1,799 \\
\hline \multirow{6}{*}{$\begin{array}{l}\text { Field } \\
\text { observations }\end{array}$} & \multirow{3}{*}{$1^{\text {st }}$} & Basic & 0 & 0 & 0 & 0 & 121 & 4,554 & 1,753 & 74 & 2,809 & 9,116 \\
\hline & & Standard & 0 & 0 & 0 & 46 & 396 & 16,088 & 3,261 & 141 & 5,141 & 24,490 \\
\hline & & Advanced & 97 & 0 & 0 & 43 & 748 & 29,299 & 6,649 & 267 & 9,884 & 45,928 \\
\hline & \multirow{3}{*}{$1+\mathrm{N}^{\text {th }}$} & Basic & 0 & 0 & 0 & 1 & 130 & 4,906 & 1,780 & 76 & 2,875 & 9,561 \\
\hline & & Standard & 0 & 0 & 0 & 47 & 354 & 14,494 & 3,288 & 143 & 5,185 & 22,967 \\
\hline & & Advanced & 5 & 0 & 0 & 87 & 746 & 30,285 & 6,952 & 288 & 10,485 & 47,727 \\
\hline \multirow{6}{*}{ Sampling } & \multirow{3}{*}{$1^{\text {st }}$} & Basic & 0 & 0 & 0 & 0 & 0 & 0 & 0 & 0 & 0 & 0 \\
\hline & & Standard & 10 & 0 & 0 & 3 & 3 & 192 & 158 & 11 & 347 & 707 \\
\hline & & Advanced & 10 & 3,616 & 0 & 15 & 15 & 938 & 704 & 22 & 694 & 5,962 \\
\hline & \multirow{3}{*}{$1+\mathrm{N}^{\text {th }}$} & Basic & 0 & 0 & 0 & 0 & 0 & 0 & 0 & 0 & 0 & 0 \\
\hline & & Standard & 7 & 0 & 0 & 1 & 1 & 83 & 79 & 6 & 173 & 342 \\
\hline & & Advanced & 7 & 3,616 & 0 & 13 & 13 & 829 & 625 & 17 & 520 & 5,597 \\
\hline \multirow{6}{*}{ Lab. analyses } & \multirow{3}{*}{$1^{\text {st }}$} & Basic & 0 & 0 & 0 & 0 & 0 & 0 & 0 & 0 & 0 & 0 \\
\hline & & Standard & 2,100 & 0 & 0 & 33 & 80 & 3,836 & 0 & 0 & 0 & 5,936 \\
\hline & & Advanced & 13,340 & 0 & 0 & 216 & 80 & 8,290 & 0 & 0 & 0 & 21,630 \\
\hline & \multirow{3}{*}{$1+\mathrm{N}^{\text {th }}$} & Basic & 0 & 0 & 0 & 0 & 0 & 0 & 0 & 0 & 0 & 0 \\
\hline & & Standard & 1,400 & 0 & 0 & 24 & 80 & 3,614 & 0 & 0 & 0 & 5,014 \\
\hline & & Advanced & 12,640 & 0 & 0 & 207 & 80 & 8,068 & 0 & 0 & 0 & 20,708 \\
\hline \multirow{6}{*}{ Total } & & Basic & 525 & 0 & 40 & 12 & 176 & 8,198 & 2,543 & 113 & 4,138 & 15,405 \\
\hline & $1^{\text {st }}$ & Standard & 2,955 & 0 & 40 & 105 & 547 & 24,520 & 4,367 & 203 & 7,170 & 39,012 \\
\hline & & Advanced & 14,292 & 3,616 & 40 & 296 & 911 & 42,931 & 8,301 & 339 & 12,259 & 81,399 \\
\hline & & Basic & 0 & 0 & 0 & 1 & 130 & 4,906 & 1,780 & 76 & 2,875 & 9,561 \\
\hline & $1+\mathrm{N}^{\text {th }}$ & Standard & 1,727 & 0 & 0 & 85 & 450 & 19,075 & 3,551 & 162 & 5,769 & 30,122 \\
\hline & & Advanced & 12,972 & 3,616 & 0 & 319 & 854 & 40,067 & 7,761 & 318 & 11,416 & 75,831 \\
\hline
\end{tabular}


Table S7.3: Cost assessment of forest genetic monitoring of European beech (Fagus sylvatica L.) in Greece. The first Forest genetic monitoring interval (Interval $1^{\text {st }}$ ) is distinguished from subsequent intervals (Interval $1+\mathrm{N}^{\text {th }}$ ). $\mathrm{C}-$ consumables; $\mathrm{O}$ - outsourcing; F - forester; $\mathrm{T}$ - technician; $\mathrm{R}$ - researcher; $\mathrm{M}-\mathrm{S}$ - mileage and subsistence; $\mathrm{t}$ - time travelling.

\begin{tabular}{|c|c|c|c|c|c|c|c|c|c|c|c|c|}
\hline \multirow[b]{3}{*}{ Activity } & \multirow[b]{3}{*}{ Interval } & \multirow[b]{3}{*}{ Level } & \multicolumn{2}{|c|}{ Material } & \multicolumn{4}{|c|}{ Labour } & \multicolumn{3}{|c|}{ Travel } & \multirow[b]{2}{*}{ Total } \\
\hline & & & C & O & $\mathrm{F}$ & $\mathrm{T}$ & $\mathrm{R}$ & Cost & M-S & $\mathrm{t}$ & $\mathrm{t}$ & \\
\hline & & & {$[€]$} & {$[€]$} & [prs h] & [prs h] & [prs h] & {$[€]$} & {$[€]$} & [prs h] & {$[€]$} & {$[€]$} \\
\hline \multirow{6}{*}{ Plot selection } & \multirow{3}{*}{$1^{\mathrm{st}}$} & Basic & 0 & 0 & 40 & 0 & 40 & 1,076 & 424 & 33 & 440 & 1,939 \\
\hline & & Standard & 0 & 0 & 40 & 0 & 40 & 1,076 & 424 & 33 & 440 & 1,939 \\
\hline & & Advanced & 0 & 0 & 40 & 0 & 40 & 1,076 & 424 & 33 & 440 & 1,939 \\
\hline & \multirow{3}{*}{$1+\mathrm{N}^{\text {th }}$} & Basic & 0 & 0 & 0 & 0 & 0 & 0 & 0 & 0 & 0 & 0 \\
\hline & & Standard & 0 & 0 & 0 & 0 & 0 & 0 & 0 & 0 & 0 & 0 \\
\hline & & Advanced & 0 & 0 & 0 & 0 & 0 & 0 & 0 & 0 & 0 & 0 \\
\hline \multirow{6}{*}{$\begin{array}{l}\text { Plot } \\
\text { establishment }\end{array}$} & \multirow{3}{*}{$1^{\text {st }}$} & Basic & 434 & 0 & 21 & 0 & 23 & 582 & 254 & 20 & 266 & 1,536 \\
\hline & & Standard & 754 & 0 & 32 & 0 & 36 & 909 & 424 & 33 & 444 & 2,530 \\
\hline & & Advanced & 754 & 0 & 32 & 0 & 36 & 909 & 424 & 33 & 444 & 2,530 \\
\hline & \multirow{3}{*}{$1+\mathrm{N}^{\text {th }}$} & Basic & 0 & 0 & 0 & 0 & 0 & 0 & 0 & 0 & 0 & 0 \\
\hline & & Standard & 320 & 0 & 16 & 0 & 18 & 461 & 198 & 15 & 207 & 1,186 \\
\hline & & Advanced & 320 & 0 & 16 & 0 & 18 & 461 & 198 & 15 & 207 & 1,186 \\
\hline \multirow{6}{*}{$\begin{array}{l}\text { Field } \\
\text { observations* }\end{array}$} & \multirow{3}{*}{$1^{\text {st }}$} & Basic & 0 & 0 & 40 & 0 & 81 & 1,700 & 1,282 & 87 & 1,232 & 4,214 \\
\hline & & Standard & 0 & 0 & 1,276 & 40 & 308 & 19,911 & 2,621 & 244 & 2,998 & 25,530 \\
\hline & & Advanced & 0 & 0 & 5,042 & 40 & 458 & 65,428 & 5,679 & 647 & 7,642 & 78,749 \\
\hline & \multirow{3}{*}{$1+\mathrm{N}^{\text {th }}$} & Basic & 0 & 0 & 42 & 0 & 91 & 1,896 & 1,311 & 89 & 1,268 & 4,474 \\
\hline & & Standard & 0 & 0 & 1,278 & 40 & 286 & 19,614 & 2,650 & 247 & 3,014 & 25,277 \\
\hline & & Advanced & 0 & 0 & 5,050 & 80 & 456 & 66,034 & 6,004 & 672 & 7,945 & 79,982 \\
\hline \multirow{6}{*}{ Sampling } & \multirow{3}{*}{$1^{\text {st }}$} & Basic & 0 & 0 & 0 & 0 & 0 & 0 & 0 & 0 & 0 & 0 \\
\hline & & Standard & 16 & 0 & 11 & 0 & 11 & 287 & 169 & 13 & 176 & 648 \\
\hline & & Advanced & 16 & 10,000 & 47 & 0 & 47 & 1,255 & 508 & 39 & 528 & 12,307 \\
\hline & \multirow{3}{*}{$1+\mathrm{N}^{\text {th }}$} & Basic & 0 & 0 & 0 & 0 & 0 & 0 & 0 & 0 & 0 & 0 \\
\hline & & Standard & 11 & 0 & 5 & 0 & 5 & 125 & 85 & 7 & 88 & 309 \\
\hline & & Advanced & 11 & 10,000 & 41 & 0 & 41 & 1,094 & 424 & 33 & 440 & 11,968 \\
\hline \multirow{6}{*}{ Lab. analyses } & \multirow{3}{*}{$1^{\text {st }}$} & Basic & 0 & 0 & 0 & 0 & 0 & 0 & 0 & 0 & 0 & 0 \\
\hline & & Standard & 862 & 1,235 & 0 & 38 & 80 & 1,744 & 0 & 0 & 0 & 3,842 \\
\hline & & Advanced & 6,919 & 7,824 & 0 & 246 & 80 & 4,523 & 0 & 0 & 0 & 19,266 \\
\hline & \multirow{3}{*}{$1+\mathrm{N}^{\text {th }}$} & Basic & 0 & 0 & 0 & 0 & 0 & 0 & 0 & 0 & 0 & 0 \\
\hline & & Standard & 575 & 824 & 0 & 29 & 80 & 1,618 & 0 & 0 & 0 & 3,016 \\
\hline & & Advanced & 6,631 & 7,412 & 0 & 237 & 80 & 4,397 & 0 & 0 & 0 & 18,440 \\
\hline \multirow{6}{*}{ Total } & & Basic & 434 & 0 & 101 & 0 & 143 & 3,358 & 1,960 & 140 & 1,938 & 7,690 \\
\hline & $1^{\text {st }}$ & Standard & 1,632 & 1,235 & 1,358 & 78 & 474 & 23,927 & 3,638 & 323 & 4,058 & 34,490 \\
\hline & & Advanced & 7,689 & 17,824 & 5,160 & 286 & 660 & 73,191 & 7,035 & 752 & 9,054 & 114,791 \\
\hline & & Basic & 0 & 0 & 42 & 0 & 91 & 1,896 & 1,311 & 89 & 1,268 & 4,474 \\
\hline & $1+\mathrm{N}^{\text {th }}$ & Standard & 905 & 824 & 1,299 & 69 & 389 & 21,818 & 2,932 & 268 & 3,309 & 29,788 \\
\hline & & Advanced & 6,962 & 17,412 & 5,107 & 317 & 595 & 71,986 & 6,625 & 720 & 8,592 & 111,576 \\
\hline
\end{tabular}

* phenological observations (Field observations) were performed through digital photography and image analysis. 
Table S7.4: Cost assessment of forest genetic monitoring of King Boris' fir (Abies borisii-regis Mafft.) in Greece. The first Forest genetic monitoring interval (Interval $1^{\text {st }}$ ) is distinguished from subsequent intervals (Interval $1+\mathrm{N}^{\text {th }}$ ). $\mathrm{C}-$ consumables; O - outsourcing; F - forester; T - technician; R - researcher; M-S - mileage and subsistence; $t$ - time travelling.

\begin{tabular}{|c|c|c|c|c|c|c|c|c|c|c|c|c|}
\hline \multirow[b]{3}{*}{ Activity } & \multirow[b]{3}{*}{ Interval } & \multirow[b]{3}{*}{ Level } & \multicolumn{2}{|c|}{ Materials } & \multicolumn{4}{|c|}{ Labour } & \multicolumn{3}{|c|}{ Travel } & \multirow[b]{2}{*}{ Cost } \\
\hline & & & C & $\mathrm{O}$ & $\mathrm{F}$ & $\mathrm{T}$ & $\mathrm{R}$ & Cost & M-S & $\mathrm{t}$ & $\mathrm{t}$ & \\
\hline & & & {$[€]$} & {$[€]$} & [prs h] & [prs h] & [prs h] & {$[€]$} & {$[€]$} & [prs h] & {$[€]$} & {$[€]$} \\
\hline \multirow{6}{*}{ Plot selection } & \multirow{3}{*}{$1^{\text {st }}$} & Basic & 0 & 0 & 40 & 0 & 40 & 1,076 & 424 & 33 & 440 & 1,939 \\
\hline & & Standard & 0 & 0 & 40 & 0 & 40 & 1,076 & 424 & 33 & 440 & 1,939 \\
\hline & & Advanced & 0 & 0 & 40 & 0 & 40 & 1,076 & 424 & 33 & 440 & 1,939 \\
\hline & \multirow{3}{*}{$1+\mathrm{N}^{\text {th }}$} & Basic & 0 & 0 & 0 & 0 & 0 & 0 & 0 & 0 & 0 & 0 \\
\hline & & Standard & 0 & 0 & 0 & 0 & 0 & 0 & 0 & 0 & 0 & 0 \\
\hline & & Advanced & 0 & 0 & 0 & 0 & 0 & 0 & 0 & 0 & 0 & 0 \\
\hline \multirow{6}{*}{$\begin{array}{l}\text { Plot } \\
\text { establishment }\end{array}$} & \multirow{3}{*}{$1^{\text {st }}$} & Basic & 434 & 0 & 21 & 0 & 23 & 582 & 254 & 20 & 266 & 1,536 \\
\hline & & Standard & 754 & 0 & 32 & 0 & 36 & 909 & 424 & 33 & 444 & 2,530 \\
\hline & & Advanced & 754 & 0 & 32 & 0 & 36 & 909 & 424 & 33 & 444 & 2,530 \\
\hline & \multirow{3}{*}{$1+\mathrm{N}^{\text {th }}$} & Basic & 0 & 0 & 0 & 0 & 0 & 0 & 0 & 0 & 0 & 0 \\
\hline & & Standard & 320 & 0 & 16 & 0 & 18 & 461 & 198 & 15 & 207 & 1,186 \\
\hline & & Advanced & 320 & 0 & 16 & 0 & 18 & 461 & 198 & 15 & 207 & 1,186 \\
\hline \multirow{6}{*}{$\begin{array}{l}\text { Field } \\
\text { observations* }\end{array}$} & \multirow{3}{*}{$1^{\text {st }}$} & Basic & 0 & 0 & 40 & 0 & 81 & 1,700 & 1,282 & 87 & 1,232 & 4,214 \\
\hline & & Standard & 0 & 0 & 1,048 & 40 & 304 & 17,235 & 2,421 & 218 & 2,703 & 22,359 \\
\hline & & Advanced & 0 & 0 & 3,902 & 40 & 438 & 52,044 & 4,679 & 516 & 6,133 & 62,855 \\
\hline & \multirow{3}{*}{$1+\mathrm{N}^{\text {th }}$} & Basic & 0 & 0 & 42 & 0 & 91 & 1,896 & 1,311 & 89 & 1,268 & 4,474 \\
\hline & & Standard & 0 & 0 & 1,050 & 40 & 282 & 16,937 & 2,450 & 220 & 2,719 & 22,106 \\
\hline & & Advanced & 0 & 0 & 3,910 & 80 & 436 & 52,650 & 5,004 & 541 & 6,437 & 64,090 \\
\hline \multirow{6}{*}{ Sampling } & \multirow{3}{*}{$1^{\text {st }}$} & Basic & 0 & 0 & 0 & 0 & 0 & 0 & 0 & 0 & 0 & 0 \\
\hline & & Standard & 16 & 0 & 11 & 0 & 11 & 287 & 169 & 13 & 176 & 648 \\
\hline & & Advanced & 16 & 5,008 & 47 & 0 & 47 & 1,255 & 508 & 39 & 528 & 7,315 \\
\hline & \multirow{3}{*}{$1+\mathrm{N}^{\text {th }}$} & Basic & 0 & 0 & 0 & 0 & 0 & 0 & 0 & 0 & 0 & 0 \\
\hline & & Standard & 11 & 0 & 5 & 0 & 5 & 125 & 85 & 7 & 88 & 309 \\
\hline & & Advanced & 11 & 5,008 & 41 & 0 & 41 & 1,094 & 424 & 33 & 440 & 6,976 \\
\hline \multirow{6}{*}{ Lab. analyses } & \multirow{3}{*}{$1^{\text {st }}$} & Basic & 0 & 0 & 0 & 0 & 0 & 0 & 0 & 0 & 0 & 0 \\
\hline & & Standard & 809 & 882 & 0 & 36 & 80 & 1,714 & 0 & 0 & 0 & 3,405 \\
\hline & & Advanced & 6,583 & 5,588 & 0 & 236 & 80 & 4,384 & 0 & 0 & 0 & 16,556 \\
\hline & \multirow{3}{*}{$1+\mathrm{N}^{\text {th }}$} & Basic & 0 & 0 & 0 & 0 & 0 & 0 & 0 & 0 & 0 & 0 \\
\hline & & Standard & 540 & 588 & 0 & 27 & 80 & 1,591 & 0 & 0 & 0 & 2,719 \\
\hline & & Advanced & 6,314 & 5,294 & 0 & 227 & 80 & 4,262 & 0 & 0 & 0 & 15,870 \\
\hline \multirow{6}{*}{ Total } & & Basic & 434 & 0 & 101 & 0 & 143 & 3,358 & 1,960 & 140 & 1,938 & 7,690 \\
\hline & $1^{\text {st }}$ & Standard & 1,579 & 882 & 1,130 & 76 & 470 & 21,219 & 3,438 & 297 & 3,763 & 30,882 \\
\hline & & Advanced & 7,353 & 10,596 & 4,020 & 276 & 640 & 59,668 & 6,035 & 621 & 7,545 & 91,196 \\
\hline & & Basic & 0 & 0 & 42 & 0 & 91 & 1,896 & 1,311 & 89 & 1,268 & 4,474 \\
\hline & $1+\mathrm{N}^{\text {th }}$ & Standard & 870 & 588 & 1,071 & 67 & 385 & 19,115 & 2,732 & 242 & 3,015 & 26,319 \\
\hline & & Advanced & 6,644 & 10,302 & 3,967 & 307 & 575 & 58,466 & 5,625 & 589 & 7,084 & 88,122 \\
\hline
\end{tabular}

phenological observations (Field observations) were performed through digital photography and image analysis. 
Table S7.5: Cost assessment of forest genetic monitoring of European beech (Fagus sylvatica L.) in Slovenia. The first Forest genetic monitoring interval (FGM Interval $1^{\text {st }}$ ) is distinguished from subsequent intervals (FGM Interval $\left.1+\mathrm{N}^{\text {th }}\right)$. $\mathrm{C}$ - consumables; $\mathrm{O}$ - outsourcing; $\mathrm{F}$ - forester; $\mathrm{T}$ - technician; $\mathrm{R}$ - researcher; $\mathrm{M}$ - $\mathrm{S}$ - mileage and subsistence; $\mathrm{t}$ - time travelling.

\begin{tabular}{|c|c|c|c|c|c|c|c|c|c|c|c|c|}
\hline \multirow[b]{3}{*}{ Activity } & \multirow[b]{3}{*}{ Interval } & \multirow[b]{3}{*}{ Level } & \multicolumn{2}{|c|}{ Materials } & \multicolumn{4}{|c|}{ Labour } & \multicolumn{3}{|c|}{ Travel } & \multirow[b]{2}{*}{ Total } \\
\hline & & & C & $\mathrm{O}$ & $\mathrm{F}$ & $\mathrm{T}$ & $\mathrm{R}$ & Cost & M-S & $\mathrm{t}$ & $\mathrm{t}$ & \\
\hline & & & {$[€]$} & {$[€]$} & [prs h] & [prs h] & [prs h] & {$[€]$} & {$[€]$} & [prs h] & {$[€]$} & {$[€]$} \\
\hline \multirow{6}{*}{ Plot selection } & \multirow{3}{*}{$1^{\text {st }}$} & Basic & 0 & 0 & 40 & 0 & 40 & 1,318 & 240 & 32 & 520 & 2,077 \\
\hline & & Standard & 0 & 0 & 40 & 0 & 40 & 1,318 & 240 & 32 & 520 & 2,077 \\
\hline & & Advanced & 0 & 0 & 40 & 0 & 40 & 1,318 & 240 & 32 & 520 & 2,077 \\
\hline & \multirow{3}{*}{$1+\mathrm{N}^{\text {th }}$} & Basic & 0 & 0 & 0 & 0 & 0 & 0 & 0 & 0 & 0 & 0 \\
\hline & & Standard & 0 & 0 & 0 & 0 & 0 & 0 & 0 & 0 & 0 & 0 \\
\hline & & Advanced & 0 & 0 & 0 & 0 & 0 & 0 & 0 & 0 & 0 & 0 \\
\hline \multirow{6}{*}{$\begin{array}{l}\text { Plot } \\
\text { establishment }\end{array}$} & \multirow{3}{*}{$1^{\text {st }}$} & Basic & 65 & 0 & 0 & 27 & 2 & 434 & 144 & 19 & 288 & 931 \\
\hline & & Standard & 385 & 0 & 0 & 48 & 4 & 798 & 240 & 32 & 481 & 1,904 \\
\hline & & Advanced & 385 & 0 & 0 & 48 & 4 & 798 & 240 & 32 & 481 & 1,904 \\
\hline & \multirow{3}{*}{$1+\mathrm{N}^{\text {th }}$} & Basic & 0 & 0 & 0 & 0 & 0 & 0 & 0 & 0 & 0 & 0 \\
\hline & & Standard & 320 & 0 & 0 & 25 & 2 & 412 & 112 & 15 & 224 & 1,068 \\
\hline & & Advanced & 320 & 0 & 0 & 25 & 2 & 412 & 112 & 15 & 224 & 1,068 \\
\hline \multirow{6}{*}{$\begin{array}{l}\text { Field } \\
\text { observations }\end{array}$} & \multirow{3}{*}{$1^{\text {st }}$} & Basic & 0 & 0 & 20 & 20 & 81 & 2,105 & 1,120 & 84 & 1,469 & 4,694 \\
\hline & & Standard & 0 & 0 & 20 & 157 & 296 & 8,232 & 2,272 & 235 & 4,101 & 14,605 \\
\hline & & Advanced & 0 & 0 & 20 & 428 & 454 & 15,281 & 5,224 & 623 & 10,564 & 31,069 \\
\hline & \multirow{3}{*}{$1+\mathrm{N}^{\text {th }}$} & Basic & 0 & 0 & 20 & 21 & 89 & 2,281 & 1,136 & 86 & 1,513 & 4,930 \\
\hline & & Standard & 0 & 0 & 20 & 158 & 272 & 7,801 & 2,288 & 238 & 4,117 & 14,206 \\
\hline & & Advanced & 0 & 0 & 20 & 474 & 444 & 15,779 & 5,408 & 648 & 10,896 & 32,083 \\
\hline \multirow{6}{*}{ Sampling } & \multirow{3}{*}{$1^{\text {st }}$} & Basic & 0 & 0 & 0 & 0 & 0 & 0 & 0 & 0 & 0 & 0 \\
\hline & & Standard & 4 & 0 & 0 & 18 & 0 & 262 & 96 & 13 & 189 & 551 \\
\hline & & Advanced & 4 & 3,758 & 0 & 90 & 0 & 1,337 & 288 & 38 & 566 & 5,953 \\
\hline & \multirow{3}{*}{$1+\mathrm{N}^{\text {th }}$} & Basic & 0 & 0 & 0 & 0 & 0 & 0 & 0 & 0 & 0 & 0 \\
\hline & & Standard & 3 & 0 & 0 & 10 & 0 & 149 & 48 & 6 & 94 & 295 \\
\hline & & Advanced & 3 & 3,758 & 0 & 82 & 0 & 1,225 & 240 & 32 & 471 & 5,697 \\
\hline \multirow{6}{*}{ Lab. analyses } & \multirow{3}{*}{$1^{\text {st }}$} & Basic & 0 & 0 & 0 & 0 & 0 & 0 & 0 & 0 & 0 & 0 \\
\hline & & Standard & 2,239 & 0 & 0 & 26 & 84 & 1,984 & 0 & 0 & 0 & 4,222 \\
\hline & & Advanced & 14,238 & 0 & 0 & 189 & 107 & 4,857 & 0 & 0 & 0 & 19,094 \\
\hline & \multirow{3}{*}{$1+\mathrm{N}^{\text {th }}$} & Basic & 0 & 0 & 0 & 0 & 0 & 0 & 0 & 0 & 0 & 0 \\
\hline & & Standard & 1,492 & 0 & 0 & 17 & 84 & 1,855 & 0 & 0 & 0 & 3,347 \\
\hline & & Advanced & 13,491 & 0 & 0 & 181 & 107 & 4,728 & 0 & 0 & 0 & 18,219 \\
\hline \multirow{6}{*}{ Total } & & Basic & 65 & 0 & 60 & 47 & 123 & 3,857 & 1,504 & 135 & 2,277 & 7,703 \\
\hline & $1^{\text {st }}$ & Standard & 2,628 & 0 & 60 & 249 & 424 & 12,593 & 2,848 & 311 & 5,290 & 23,359 \\
\hline & & Advanced & 14,627 & 3,758 & 60 & 755 & 605 & 23,591 & 5,992 & 724 & 12,130 & 60,098 \\
\hline & & Basic & 0 & 0 & 20 & 21 & 89 & 2,281 & 1,136 & 86 & 1,513 & 4,930 \\
\hline & $1+\mathrm{N}^{\text {th }}$ & Standard & 1,815 & 0 & 20 & 210 & 358 & 10,217 & 2,448 & 259 & 4,436 & 18,916 \\
\hline & & Advanced & 13,814 & 3,758 & 20 & 762 & 553 & 22,144 & 5,760 & 694 & 11,591 & 57,068 \\
\hline
\end{tabular}


Table S7.6: Cost assessment of forest genetic monitoring of Silver fir (Abies alba Mill.) in Slovenia. The first Forest genetic monitoring interval (FGM Interval $1^{\text {st }}$ ) is distinguished from subsequent intervals (FGM Interval $1+\mathrm{N}^{\text {th }}$ ). $\mathrm{C}-$ consumables; $\mathrm{O}$ - outsourcing; F - forester; $\mathrm{T}$ - technician; $\mathrm{R}$ - researcher; $\mathrm{M}-\mathrm{S}$ - mileage and subsistence; $\mathrm{t}$ - time travelling.

\begin{tabular}{|c|c|c|c|c|c|c|c|c|c|c|c|c|}
\hline \multirow[b]{3}{*}{ Activity } & \multirow[b]{3}{*}{ Interval } & \multirow[b]{3}{*}{ Level } & \multicolumn{2}{|c|}{ Materials } & \multicolumn{4}{|c|}{ Labour } & \multicolumn{3}{|c|}{ Travelling } & \multirow[b]{2}{*}{ Cost } \\
\hline & & & C & $\mathrm{O}$ & $\mathrm{F}$ & $\mathrm{T}$ & $\mathrm{R}$ & Cost & M-S & $\mathrm{t}$ & $\mathrm{t}$ & \\
\hline & & & {$[€]$} & {$[€]$} & [prs h] & [prs h] & [prs h] & {$[€]$} & {$[€]$} & [prs h] & {$[€]$} & {$[€]$} \\
\hline \multirow{6}{*}{ Plot selection } & \multirow{3}{*}{$1^{s t}$} & Basic & 0 & 0 & 40 & 0 & 40 & 1,318 & 240 & 32 & 520 & 2,077 \\
\hline & & Standard & 0 & 0 & 40 & 0 & 40 & 1,318 & 240 & 32 & 520 & 2,077 \\
\hline & & Advanced & 0 & 0 & 40 & 0 & 40 & 1,318 & 240 & 32 & 520 & 2,077 \\
\hline & \multirow{3}{*}{$1+\mathrm{N}^{\text {th }}$} & Basic & 0 & 0 & 0 & 0 & 0 & 0 & 0 & 0 & 0 & 0 \\
\hline & & Standard & 0 & 0 & 0 & 0 & 0 & 0 & 0 & 0 & 0 & 0 \\
\hline & & Advanced & 0 & 0 & 0 & 0 & 0 & 0 & 0 & 0 & 0 & 0 \\
\hline \multirow{6}{*}{$\begin{array}{l}\text { Plot } \\
\text { establishment }\end{array}$} & \multirow{3}{*}{$1^{\text {st }}$} & Basic & 65 & 0 & 0 & 27 & 2 & 434 & 144 & 19 & 288 & 931 \\
\hline & & Standard & 385 & 0 & 0 & 48 & 4 & 798 & 240 & 32 & 481 & 1,904 \\
\hline & & Advanced & 385 & 0 & 0 & 48 & 4 & 798 & 240 & 32 & 481 & 1,904 \\
\hline & \multirow{3}{*}{$1+\mathrm{N}^{\text {th }}$} & Basic & 0 & 0 & 0 & 0 & 0 & 0 & 0 & 0 & 0 & 0 \\
\hline & & Standard & 320 & 0 & 0 & 25 & 2 & 412 & 112 & 15 & 224 & 1,068 \\
\hline & & Advanced & 320 & 0 & 0 & 25 & 2 & 412 & 112 & 15 & 224 & 1,068 \\
\hline \multirow{6}{*}{$\begin{array}{l}\text { Field } \\
\text { observations }\end{array}$} & \multirow{3}{*}{$1^{\text {st }}$} & Basic & 0 & 0 & 20 & 20 & 81 & 2,105 & 1,120 & 84 & 1,469 & 4,694 \\
\hline & & Standard & 0 & 0 & 20 & 146 & 292 & 7,986 & 2,080 & 210 & 3,672 & 13,738 \\
\hline & & Advanced & 97 & 0 & 23 & 397 & 471 & 15,178 & 4,408 & 516 & 8,797 & 28,480 \\
\hline & \multirow{3}{*}{$1+\mathrm{N}^{\text {th }}$} & Basic & 0 & 0 & 20 & 21 & 89 & 2,281 & 1,136 & 86 & 1,513 & 4,930 \\
\hline & & Standard & 0 & 0 & 20 & 147 & 268 & 7,555 & 2,096 & 212 & 3,690 & 13,341 \\
\hline & & Advanced & 5 & 0 & 20 & 421 & 426 & 14,646 & 4,496 & 528 & 8,917 & 28,064 \\
\hline \multirow{6}{*}{ Sampling } & \multirow{3}{*}{$1^{\text {st }}$} & Basic & 0 & 0 & 0 & 0 & 0 & 0 & 0 & 0 & 0 & 0 \\
\hline & & Standard & 4 & 0 & 0 & 18 & 0 & 262 & 96 & 13 & 189 & 551 \\
\hline & & Advanced & 4 & 2,074 & 0 & 98 & 0 & 1,457 & 288 & 38 & 566 & 4,389 \\
\hline & \multirow{3}{*}{$1+\mathrm{N}^{\text {th }}$} & Basic & 0 & 0 & 0 & 0 & 0 & 0 & 0 & 0 & 0 & 0 \\
\hline & & Standard & 3 & 0 & 0 & 10 & 0 & 149 & 48 & 6 & 94 & 295 \\
\hline & & Advanced & 3 & 2,074 & 0 & 90 & 0 & 1,345 & 240 & 32 & 471 & 4,133 \\
\hline \multirow{6}{*}{ Lab. analyses } & \multirow{3}{*}{$1^{\text {st }}$} & Basic & 0 & 0 & 0 & 0 & 0 & 0 & 0 & 0 & 0 & 0 \\
\hline & & Standard & 1,910 & 0 & 0 & 24 & 87 & 2,003 & 0 & 0 & 0 & 3,912 \\
\hline & & Advanced & 12,154 & 0 & 0 & 178 & 125 & 5,026 & 0 & 0 & 0 & 17,180 \\
\hline & \multirow{3}{*}{$1+\mathrm{N}^{\text {th }}$} & Basic & 0 & 0 & 0 & 0 & 0 & 0 & 0 & 0 & 0 & 0 \\
\hline & & Standard & 1,273 & 0 & 0 & 16 & 87 & 1,885 & 0 & 0 & 0 & 3,158 \\
\hline & & Advanced & 11,517 & 0 & 0 & 170 & 125 & 4,909 & 0 & 0 & 0 & 16,426 \\
\hline \multirow{6}{*}{ Total } & & Basic & 65 & 0 & 60 & 47 & 123 & 3,857 & 1,504 & 135 & 2,277 & 7,703 \\
\hline & $1^{\text {st }}$ & Standard & 2,299 & 0 & 60 & 235 & 423 & 12,365 & 2,656 & 286 & 4,861 & 22,181 \\
\hline & & Advanced & 12,640 & 2,074 & 63 & 721 & 639 & 23,777 & 5,176 & 617 & 10,363 & 54,030 \\
\hline & & Basic & 0 & 0 & 20 & 21 & 89 & 2,281 & 1,136 & 86 & 1,513 & 4,930 \\
\hline & $1+\mathrm{N}^{\text {th }}$ & Standard & 1,596 & 0 & 20 & 197 & 357 & 10,002 & 2,256 & 233 & 4,008 & 17,862 \\
\hline & & Advanced & 11,845 & 2,074 & 20 & 706 & 553 & 21,311 & 4,848 & 574 & 9,612 & 49,691 \\
\hline
\end{tabular}





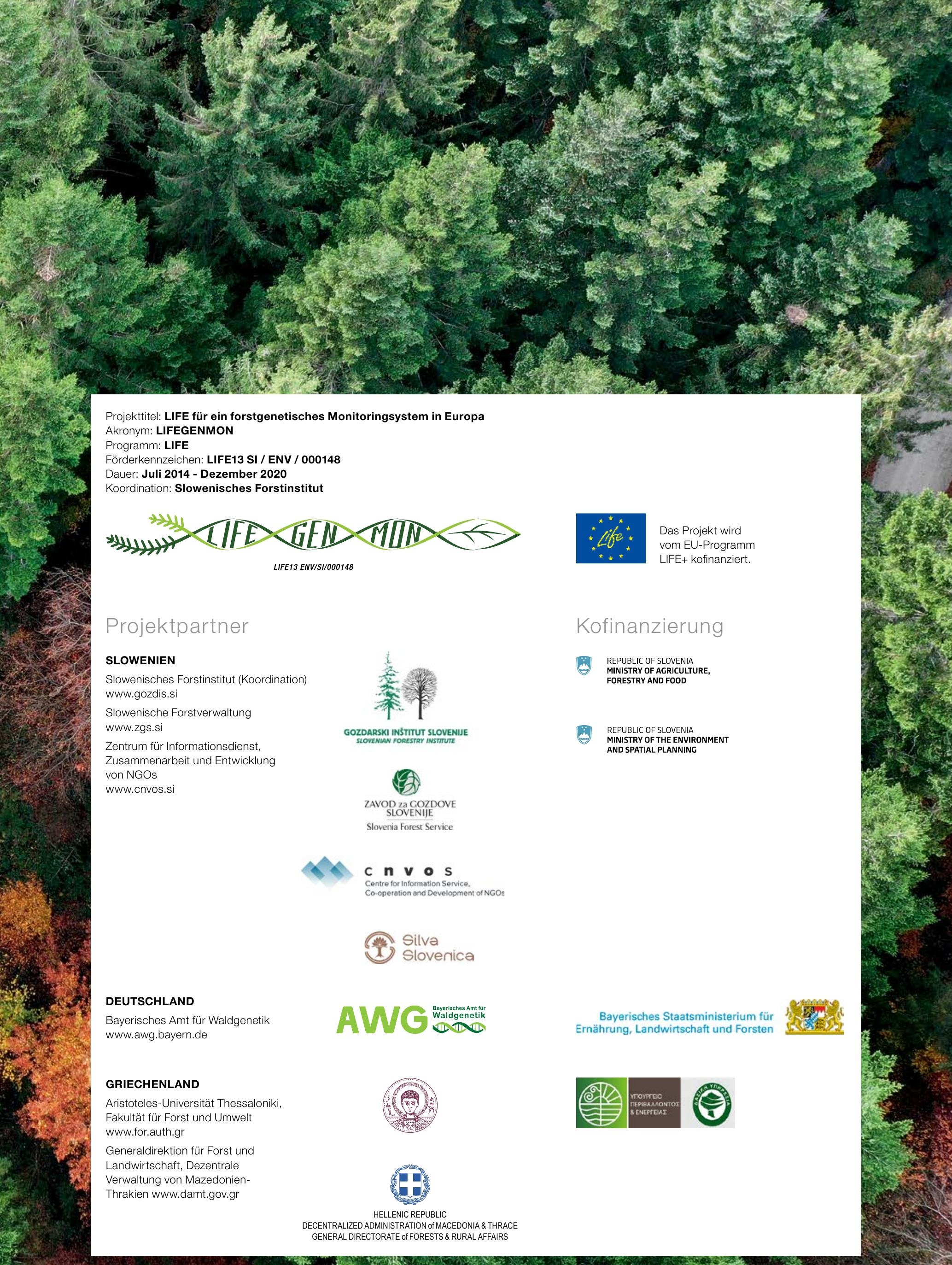

Projekttitel: LIFE für ein forstgenetisches Monitoringsystem in Europa

Förderkennzeichen: LIFE13 SI / ENV / 000148

Dauer: Juli 2014 - Dezember 2020

Kofinanzierung

SLOWENIEN

Slowenisches Forstinstitut (Koordination)

www.zgs.si

Zentrum für Informationsdienst,

narbeit und Entwicklung

$$
\begin{aligned}
& \text { ZAVOD za GOZDOVE } \\
& \text { SLOVENIJE } \\
& \text { Slovenia Forest Service }
\end{aligned}
$$

$\mathbf{Y} \mathbf{s}$

Silva

Slovenica

\section{DEUTSCHLAND}

Bayerisches Amt für Waldgenetik

\section{GRIECHENLAND}

Aristoteles-Universität Thessaloniki

und Umwelt

Generaldirektion für Forst und

andwirtschaft, Dezentrale

Verwaltung von Mazedonien-

Thrakien www.damt.gov.gr

\section{AWG}

